\title{
ANÁLISE TEÓRICA E EXPERIMENTAL DA EBULIÇÃO NUCLEADA DE REFRIGERANTES \\ HALOGENADOS
}

Gherhardt Ribatski

Tese apresentada à Escola de Engenharia de São Carlos, da Universidade de São Paulo, como parte dos requisitos para obtenção do título de Doutor em Engenharia Mecânica

ORIENTADOR: Prof. Dr. José M. Saiz Jabardo 
Dedico este trabalho aos meus pais Geraldo e Marli, sempre participando da minha vida e presenteando-me com amor, dedicação, compreensão e permanente incentivo. 


\section{Agradecimentos}

Ao Prof. José M. Saiz Jabardo não apenas pela excelente orientação proporcionada durante a elaboração deste trabalho, mas também pela amizade, dedicação e principalmente pelos exemplos de conduta pessoal e profissional.

À Fundação de Amparo a Pesquisa do Estado de São Paulo (FAPESP) pela bolsa concedida.

À Aline pelo carinho, atenção, dedicação e permanente incentivo.

Aos meus irmãos João Vitor e Daniele pela amizade e companheirismo.

A José Roberto Bogni pela amizade, animadas conversas, momentos de descontração e imprescindível ajuda na construção do aparato experimental e das superfícies de transferência de calor, sem o qual este trabalho não alcançaria os objetivos pretendidos.

Ao Prof. Benedito Di Giácomo e a todo pessoal do Laboratório de Metrologia pelo equipamento cedido e auxílio na determinação do acabamento das superfícies de ensaio.

Aos companheiros do grupo de ebulição nucleada Samuel Freire de Barros, Evandro Fockink da Silva e Elvio Bugança Stelute, não somente pela ajuda na aquisição e análise de resultados experimentais, mas principalmente pela amizade.

A todos os colegas que tive o prazer de conviver no Laboratório de Refrigeração da EESC-USP: Artur Augusto Morais Jarhmann, Carlos Umberto da Silva Lima, Elton Fereira Higino de Cuba, Enio Pedone Bandarra Filho, João Zoghbi Filho, Leonardo Serafim, Luben Cabezas Gomes, Marcelo Rogério Ianella, Paulo Eduardo L. Barbieri, Ricardo Masini, Richard Garcia Alves de Mello, Sidney José de Oliveira e Willians Gonzales Mamani

A todos que me brindaram com amizade e apoio desinteressado durante estes onze anos em São Carlos, proporcionando, durante minha graduação, mestrado e doutorado, momentos que serão guardados como boas recordações.

Aos demais professores e funcionários da EESC-USP, pela formação e colaboração. 


\section{Sumário}

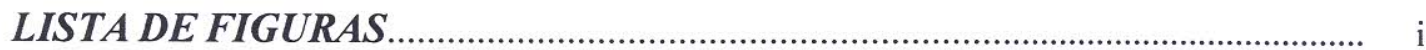

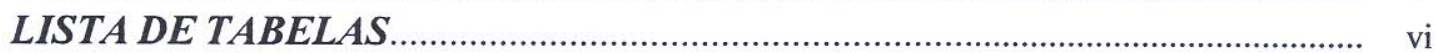

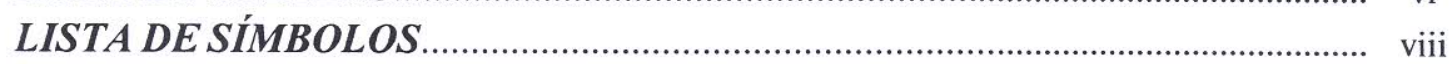

RESUMO

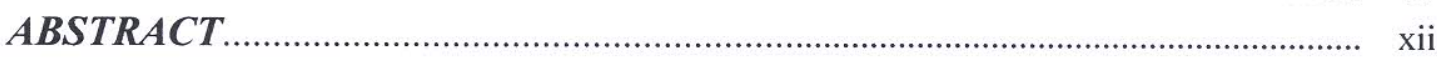

I INTRODUÇÃO

1.1 Introdução.

1.2 O coeficiente de transferência de calor e a eficiência do ciclo de compressão a

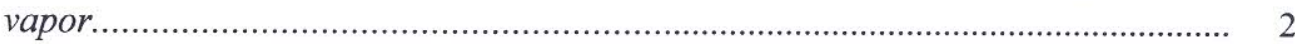

1.3 Ebulição nucleada........................................................................................... 4

1.4 As pesquisas em transferência de calor através de ebulição nucleada................ 6

1.4.1 Fundamentos.............................................................................................. 7

1.4.2 Correlações e modelos físicos...................................................................... 7

1.4.3 Métodos de intensificação da transferência de calor em ebulição nucleada............ 9

1.4.4 Ebulição nucleada de misturas de refrigerante e óleo de lubrificação..................... 17

1.4.5 Estudo da ebulição em banco de tubos................................................................ 21

1.4 .6 Conclusões......................................................................................... 24

1.5 Escopo da tese .............................................................................................. 24

1.5.1 Objetivos do trabalho....................................................................................... 24

1.5.2 Análise da literatura........................................................................................... 24

1.5.3 Condições experimentais................................................................................... 25

1.5.3.1 Refrigerantes........................................................................................ 25

1.5.3.2 Pressões de saturação...................................................................................... 25

1.5.3.3 Características superficiais........................................................................... 25

2 FUNDAMENTOS DA EBULIÇÃO NUCLEADA .......................................... 27

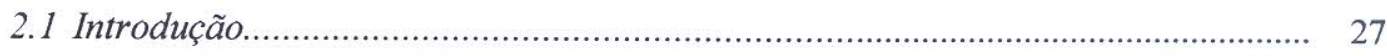

2.2 Curva de ebulição............................................................................................ 27

2.3 Mecanismos fisicos responsáveis pela transferência de calor............................... 30

2.4 Formação e crescimento de bolhas...................................................................... 32

2.4.1 Critério de nucleação....................................................................................... 33

2.4.2 Crescimento da bolha junto a uma parede aquecida............................................ 37

2.4.3 Diâmetro e freqüência de desprendimento de bolhas............................................ 41

2.5 Fatores que influenciam a taxa de transferência de calor em ebulição nucleada. 44 
2.5.1 Geometria, material e espessura da superfície................................................ 45

2.5.2 Acabamento superficial............................................................................ 48

2.5.3 Ângulo de contato....................................................................................... 52

2.5.4 Contaminação da superfície.......................................................................... 54

2.5.5 Pressão do sistema.................................................................................... 55

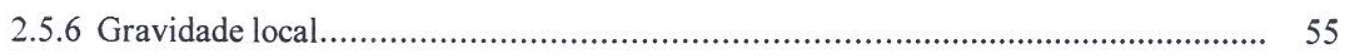

2.5.7 Subresfriamento do líquido........................................................................ 56

2.5.8 Gases não condensáveis............................................................................. 58

3 CORRELAÇÕES DA LITERATURA ............................................................. 60

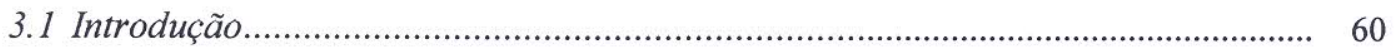

3.2 Correlações estritamente empíricas................................................................... 61

3.2.1 Correlação de Stephan e Abdelsalam (1980).......................................................... 61

3.3 Correlações baseadas em propriedades reduzidas................................................. 62

3.3.1 Correlação de Cooper (1984) .............................................................................. 62

, 3.3.2 Correlação do VDI-Wärmeatlas.......................................................................... 63

3.3.3 Correlação de Leiner (1994) ................................................................................ 65

3.3.4 Análise comparativa das correlações empíricas baseadas em propriedades

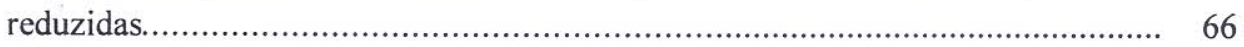

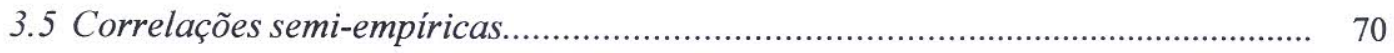

3.5.1 Modelo de Rohsenow (1952) ................................................................. 71

3.5.2 Modelo de Foster e Zuber (1955) .................................................................... 73

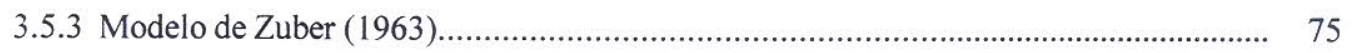

3.5.4 Modelo de Han e Griffith (1965b)....................................................................... 78

3.5.5 Modelo de Mikic e Rohsenow (1969) ................................................................ 81

3.5.6 Modelo de Nishikawa e Fujita (1977) .................................................................. 83

3.5.7 Modelo de Benjamin e Balakrishnan (1996) .............................................................. 85

3.5.8 Modelo de Haider e Webb (1997) ............................................................... 89

3.5.9 Comparação dos resultados proporcionados pelas correlações semi-empíricas......... 93

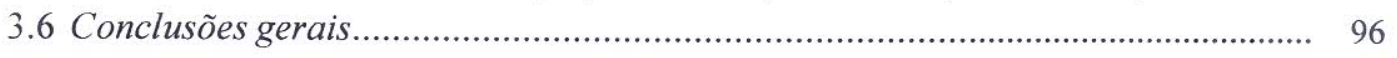

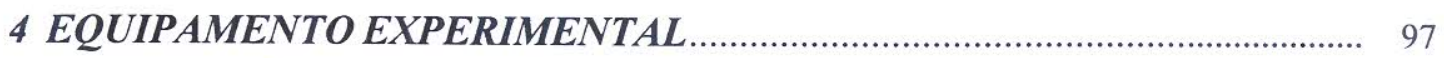

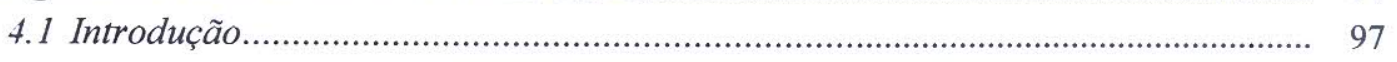

4.2 Detalhamento do aparato experimental .......................................................... 97

4.2.1 Seção de testes................................................................................................... 100

4.2.2 Superfície de transferência de calor............................................................ 100

4.2.3 Circuito etileno/glicol................................................................................ 104

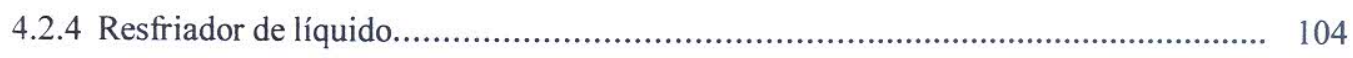

4.2.5 Sistema de alimentação da resistência elétrica.................................................... 105

4.2.6 Sistema de aquisição de dados.............................................................................. 105

5 PROCEDIMENTO EXPERIMENTAL _....................................................... 107

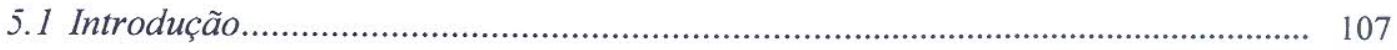

5.2 Procedimento experimental na bancada ........................................................ 107 
5.2.1 Carregamento do sistema................................................................................ 107

5.2.2 Levantamento dos resultados experimentais..................................................... 109

5.3 Preparação e caracterização do acabamento da superficie de testes................... 110

5.4 Descrição dos procedimentos envolvendo a determinação dos parâmetros medidos, dos erros experimentais e das incertezas............................................ 113

5.4.1 Procedimento utilizado na determinação de $\phi$....................................................... 117

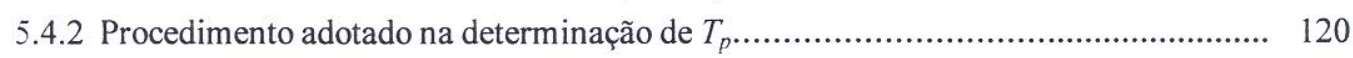

5.4.2.1 Análise dos efeitos de resistência térmica............................................... 120

5.4.2.2 Análise de variações de $T_{p}$ ao longo da circunferência da superfície de testes.. 124

5.4.2.2.1 Procedimentos adotados e resultados verificados na literatura............... 125

5.4.2.2.2 Procedimento adotado na determinação da variação de $T_{p}$ ao longo do perímetro da superfície............................................................. 126

5.4.2.2.3 Resultados verificados............................................................. 129

5.4.2.2.4 Conclusões............................................................................... 132

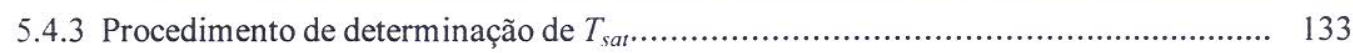

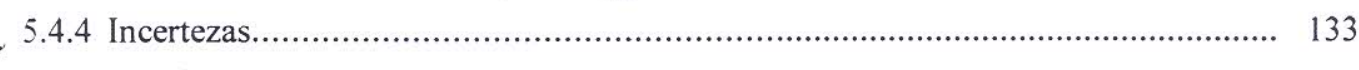

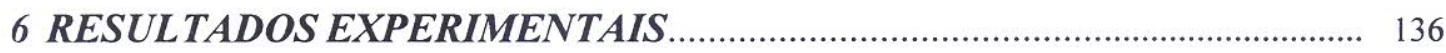

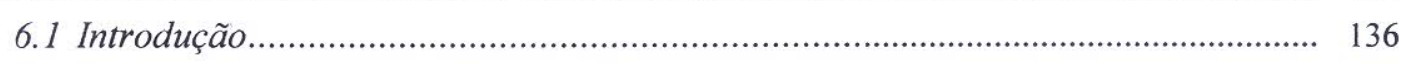

6.2 Resultados para convecção natural ................................................................. 137

6.3 Resultados para ebulição nucleada ................................................................ 143

6.3.1 Comparação com resultados experimentais e correlações da literatura.................... 143

6.3.1.1 Comparação com resultados experimentais de outros autores....................... 143

6.3.1.2 Comparação com as correlações............................................................. 146

6.3.2 Análise paramétrica dos fatores que afetam a ebulição nucleada.......................... 157

6.3.2.1 Efeitos de $\phi$ em $h$ e o fluxo crítico de calor.......................................... 157

6.3.2.2 Refrigerante................................................................................. 158

6.3.2.3 Efeito da pressão.......................................................................... 160

6.3.2.4 Efeito do acabamento superficial.............................................................. 162

6.3.2.5 Efeito do material da superfície......................................................... 167

6.3.2.6 Anomalias na curva de ebulição.............................................................. 172

7 DESENVOLVIMENTO DE UMA CORRELAÇÃO GENERALIZADA....... 174

7.1 Introdução ........................................................................................................ 174

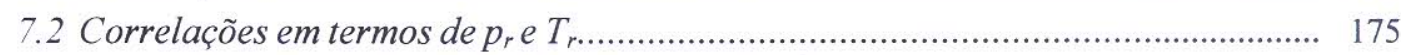

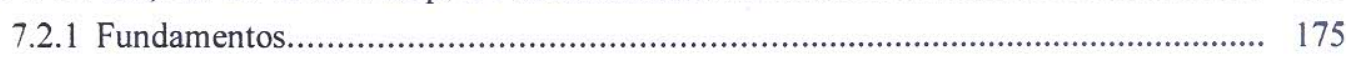

7.2.1.1 Lei dos Estados Correspondentes........................................................ 175

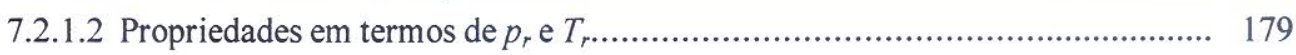

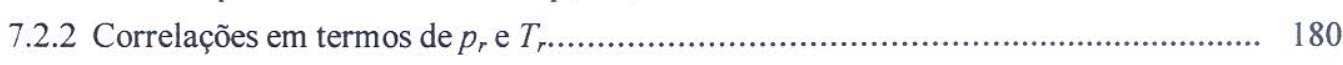

7.2.3 Incorporação de um parâmetro característico do fluido........................................ 183

7.3 Efeitos do fluxo especifico de calor .................................................................... 185

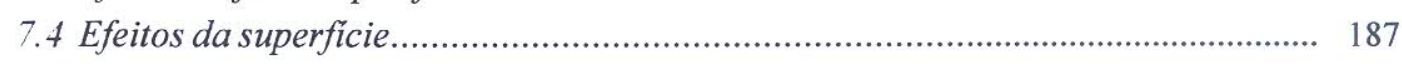

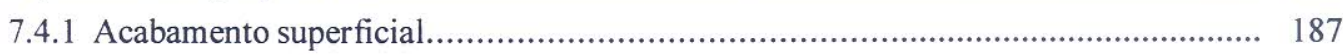



7.5 Procedimento utilizado .............................................................................. 190 


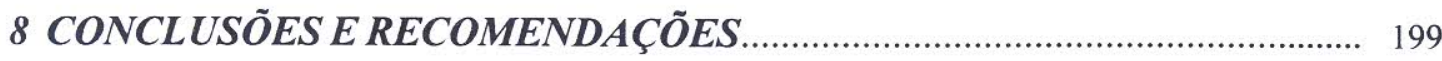

8.1 Considerações gerais................................................................................. 199

8.2 Conclusões........................................................................................................... 200

8.3 Recomendações para trabalhos futuros.............................................................. 202

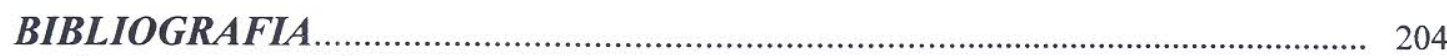

APÊEDICE I - PARÂMETROS DE RUGOSIDADE .................................................... 215

APÊEDICE II - INCERTEZAS E CALIBRAÇÃO ..................................................... 218

APE NDICE III - RESULTADOS EXPERIMENTAIS .................................................... 224

APÊENDICE IV - CORRELAÇÕES LEVANTADAS..................................................... 253 


\section{Lista de Figuras}

Figura 1.1 Ciclo de refrigeração de Carnot

Figura 1.2 Análise da influência da variação de $T_{e v}$ no COP para o ciclo da Fig. 1.1 .

Figura 1.3

Evaporador Inundado.

Figura 1.4

Análise relativa do número de publicações em ebulição nucleada........ 6

Figurq 1.5

Evolução do número de publicações sobre ebulição nucleada.

Figura 1.6 Comparação de algumas correlações da literatura; $R-113, R a=1 \mu m e$ $T_{\text {sat }}=45^{\circ} \mathrm{C}$

Figura 1.7 Ilustração esquemática de algumas superficies intensificadoras........... 11

Figura 1.8 Variação do coeficiente de transferência de calor com a concentração de óleo, para fluxo de calor constante, utilizando a correlação de Hahne e Noworyta (1984).

Figura 2.2 Transição entre os regimes de convecção natural e ebulição nucleada. a) fluxo de calor controlado; b) superaquecimento controlado.....

Figura 2.3 Ilustração da transferência de calor através do mecanismo de termocapilaridade, Saiz Jabardo (1978).

Figura 2.4 Ilustração do critério para início do crescimento de bolhas. Han e Griffith (1965a)......

Figura 2.5 Condições iniciais e de contorno no modelo de Han e Griffth (1965a) para o crescimento de bolhas.

Figura 2.6 Evaporação na linha tripla, Mitrovic (1997)....................................... 40

Figura 2.7 Desprendimento da bolha segundo Mitrovic (1997)............................. 41

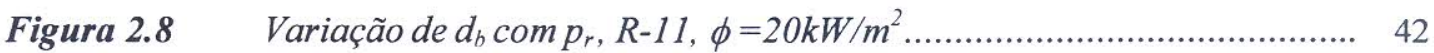

Figura 2.9 Influência do material da parede e do acabamento superficial na taxa de transferência de calor, Berenson (1962).

Figura 2.10 Efeito do sentido de lixamento na transferência de calor, n-pentano, $p_{\text {sat }}=100 \mathrm{kPa}$. Resultados experimentais de Berenson (1962)

Figura 2.11 Ilustração esquemática da influência do ângulo de contato.

Figura 2.12 Efeito do ângulo de contato na curva de ebulição, n-pentano, $p_{\text {sat }}=100 \mathrm{kPa}$. Resultados experimentais de Berenson (1962)...

Figura 2.13 Efeito de $p_{\text {sat }}$ em $h$, segundo os resultados experimentais de Silva (1989).

Figura 2.14 Influência do subresfriamento do fluido na curva de ebulição............... 57 
Figura 2.15 Núcleo de vapor. 58

Figura 3.1 Efeito do expoente de $\phi$ na taxa de transferência de calor.

Figura 3.2 Efeito da pressão reduzida na taxa de transferência de calor para o $R-11, R a=R p=1 \mu$ m e $\phi=30 \mathrm{~kW} / \mathrm{m}^{2}$.

Figura 3.3 Variação da relação entre coeficiente de transferência de calor com Ra......

Figura 3.4

Camada limite térmica no momento do desprendimento da bolha. 79

Figura 3.5 Relação entre o número de Nusselt e a espessura da camada limite térmica em ebulição nucleada para a água.....

Figura 3.6 Mecanismos de transferência de calor no modelo de Benjamin e Balakrishnan (1996).

Figura 3.7 Acompanhamento do escoamento após o desprendimento de uma bolha segundo o modelo de Haider e Webb (1994)...

Figura 3.8 Crescimento da camada limite térmica durante o ciclo de uma bolha...

Figura 3.9 Comparação de algumas correlações da literatura; $R-22, R a=1 \mu m$ e

$T_{\text {sat }}=320 \mathrm{~K}$.......

Figurá 3.10 Comparação de algumas correlações da literatura; $R-123, R a=1 \mu m$ e $T_{\text {sat }}=260 \mathrm{~K}$.

Figura 4.1

Bancada experimental para o estudo da ebulição nucleada.

Figura 5.2 Ilustração esquemática das condições experimentais simuladas numericamente. a) corte longitudinal, efeitos de condução axial; b) corte transversal. efeitos de resistência térmica radial.......

Figura 5.3 Perfil de temperaturas externo para a superficie de cobre.R-11, $p_{r}=0,011$.

Figura 5.4 Perfil de temperaturas externo para a superficie de aço inoxidável. $R$ $11, R a=0,16 \mu m$.

Figura 5.5 Relação entre o fluxo de calor longitudinal e o radial para a superficie de aço inoxidável, $R-11$.

Figura 5.6 Relação entre o fluxo de calor longitudinal e o radial para a superficie de cobre, R-11.

Figura 5.7 Ilustração esquemática das possiveis localizações da junta "quente" do termopar..

$\begin{aligned} \text { Figura 5.8 Simulação numérica dos perfis de temperaturas para o corte radial da } & \text { superficie ilustrado na Fig.5.2, R-11, Superficie de aço inoxidável a), }\end{aligned}$

$\begin{aligned} \text { Figura 5.8 } & \text { Simulação numérica dos perfis de temperaturas para o corte radial da } \\ & \text { superficie ilustrado na Fig.5.2, R-11, Superficie de aço inoxidável a), }\end{aligned}$ $R a=0,16 \mu m, \phi=70 \mathrm{~kW} / \mathrm{m}^{2}$; b) $R a=0,16 \mu \mathrm{m}, \phi=20 \mathrm{~kW} / \mathrm{m}^{2} \ldots \ldots \ldots \ldots \ldots \ldots \ldots . . . . . . . .$.
Curvas de ebulição para o $R-11, p_{r}=0,011$, na superficie de aço Figura 5.9 Curvas de ebulição para o $R-11, p_{r}=0,011$, na superfície de aço
inoxidável e $R a=0,17 \mu m$, com diferentes posicionamentos para o termopar; a) simulação numérica; b) resultados experimentais.. 
Figura 5.10 Curvas de ebulição para o R-11, $p_{r}=0,011$, na superficie de cobre $e$ $R a=0,17 \mu m$, com diferentes posicionamentos para o termopar; a) simulação numérica; b) resultados experimentais.

Figura 5.11 Curvas de ebulição ilustrando a variação de $T_{p}$ ao longo da circunferência da superficie de cobre, para o $R-11, R a=0,17 \mu m e$ $p_{r}=0,011$

Figura 5.12 Comparação ilustrativa da variação de $T_{p}$ ao longo do perímetro da

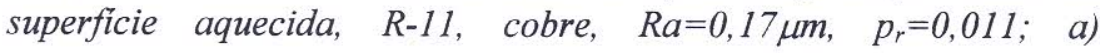
convecção natural; b) ebulição nucleada; c) ebulição nucleada.

Figura 5.13 Comparação ilustrativa da variação de $T_{p}$ ao longo da perímetro da superficie aquecida. $R-11$, cobre, $R a=0,17 \mu \mathrm{m}$ e $p_{r}=0,011$.

Figura 5.14

Incertezas experimentais na determinação de $h$

Figura 6.1

Curva de ebulição para o $R-11$ para $T_{\text {sat }}=5,5^{\circ} \mathrm{C}$ sobre uma superficie cilindrica de cobre com $D_{\text {ext }}=19 \mathrm{~mm}$.

Figura 6.2 Comparação de resultados para convecção natural, $R-11, T_{\text {sat }} \cong 5,5^{\circ} \mathrm{C}$ a) análise efeito rugosidade; cobre b) análise efeito material; $R a \cong 0,16 \mu \mathrm{m}$.

Figura 6.3 Comparação dos resultados experimentais para convecção natural com correlações da literatura. a) Churchill e Chu (1975); b) Morgan (1975).

Figura 6.4 Comparação entre os resultados levantados neste estudo com os de Silva (1989)

Figura 6.5 Comparação entre os resultados levantados neste estudo e os de Webb e Pais (1992) para o $R-12$.

Figura 6.6 Ilustração para algumas correlações do efeito de $\phi$ nos seus resíduos em relação aos resultados experimentais. $R-12$, cobre, $R a=0,06$ e $0,51 \mu \mathrm{m}, 0,05 \leq p_{r} \leq 0,260$.

Figura 6.7 Variação do parâmetro adimensional $h / h\left(\phi=10 \mathrm{~kW} / \mathrm{m}^{2}\right)$ para o $R$ 134 a com $R a=0,07 \mu m$ e a superficie de cobre.

Figura 6.8 Variação do parâmetro adimensional $h / h\left(\phi=10 \mathrm{~kW} / \mathrm{m}^{2}\right)$ para o $R$ 22 com $R a=0,07 \mu m$ e a superficie de cobre.

Figura 6.9 Variação do adimensional $h / h\left(p_{r}=0,011\right)$ com $p_{r}$ para o $R-11 \mathrm{com}$ $\phi=30 \mathrm{~kW} / \mathrm{m}^{2}, R a=0,17 \mu \mathrm{m}$, quando não especificado considerar a superficie de cobre......

Figura 6.10 Variação do adimensional $h / h(R a=0,08 \mu \mathrm{m})$ com Ra para o $R-134 a$ com $\phi=30 \mathrm{~kW} / \mathrm{m}^{2}$, superficie de cobre...

Figura 6.11 Curva de ebulição ilustrando a transição entre ebulição nucleada e em película com o $R-11$, superficie de aço inoxidável, $R a=0,02 \mu m$, e $T_{\text {sat }}=24^{\circ} \mathrm{C}$.

Figura 6.12 Comparação de desempenho dos refrigerantes para $p_{r}=0,064 \mathrm{na}$ superficie de cobre.

Figura 6.13 Efeito da pressão na curva de ebulição, $R-11, R a=0,02 \mu m$, superficie de aço inoxidável.

Figura 6.14 Variação com $p_{r}$ de $P r_{l}$, da $\sigma$ e do $\left(r_{c}\right)_{\text {min }}$ segundo Han e Griffith (1965a), R-11

Figura 6.15 Ilustração do efeito da rugosidade para o R-11, superficie de cobre..... 
Figura 6.16 Análise comparativa do efeito da rugosidade para os refrigerantes de baixa pressão, $p_{r}=0,011$, superficie de cobre

Figura 6.17 Análise comparativa do efeito da rugosidade para os refrigerantes de média pressão, $p_{r}=0,120$, superficie de cobre

Figura 6.18 Comparação entre o $R-11$ e o $R-123$ para valores de $R a$ respectivamente iguais a 0,17 e 0,16 4 m para a superficie de cobre...... 165

Figura 6.19 Comparação entre o $R-11$ e o $R-123$ para valores de $R a$ respectivamente iguais a 2,3 e 3,3 $\mu$ m para a superficie de cobre.

Figura 6.20 Comparação entre o $R-12$ e o $R-22$ e $R-134$ a para valores de $R a$ respectivamente iguais a 0,06, 0,07 e 0,07 um para a superficie de cobre.

Figura 6.21 Comparação entre $o$ respectivamente iguais a 2,6 e 2,5 $\mu$ m para a superficie de cobre.

Figura 6.22 Comparação entre as curva de ebulição do R-11 para as superficies de cobre, latão e aço inoxidável, cujos símbolos são de cores, respectivamente, preta, azul e vermelha.

Figura 6.23 Comparação entre as curva de ebulição do R-123 para as superficies de cobre, latão e aço inoxidável, cujos símbolos são de cores, respectivamente, preta, azul e vermelha.

Figura 6.24 Comparação entre as curva de ebulição do R-134a para as superficies de cobre, latão e aço inoxidável, cujos símbolos são de cores, respectivamente, preta, azul e vermelha

Figura 6.25 Comparação entre as curva de ebulição do R-22 para as superficies de cobre e latão, cujos símbolos são de cores, respectivamente, preta e azul......

Figura 6.26 Comparação entre as curva de ebulição do R-12 para as superficies de cobre e latão, cujos símbolos são de cores, respectivamente, preta e azul......

Figura 7.1 Isotérmicas baseadas na equação de estado de van der Waals.....

Figura 7.2 Comparação de tendências do coeficiente de transferência de calor com $p_{r}$ para distintas correlações; $R-22, \phi=35 \mathrm{~kW} / \mathrm{m}^{2}$, superficie lisa..

Figura 7.3 Comparação entre os valores de $M, \omega e c^{*}$ para refrigerantes halogenados.

Figura 7.4 Comparação entre os valores de $\omega, z_{\text {crit }}$ e $K$ para refrigerantes halogenados.

Figura 7.5 Variação de $h$ com $M$ segundo distintas correlações, para $p_{r}=0,1$.

Figura 7.6 Variação de $h$ com $\omega$ segundo distintas correlações com $p_{r}=0,1 \ldots \ldots \ldots .$.

Figura 7.7 Variação do expoente $m$ com $p_{r}$ para distintos refrigerantes. superficie de cobre e $R a \approx 0,5$. .

Figura 7.8 Variação de $h /\left[\left(\right.\right.$ efeitos de $\left.p_{r}\right)$ (efeitos de $\left.\phi\right)$ (efeitos de Ra)] com $M$ baseada na correlação proposta.

Figura 7.9 Variação de $h /\left[\left(\right.\right.$ efeitos de $\left.p_{r}\right)($ (efeitos de $\phi)$ (efeitos de Ra)] com $\omega$ baseada na correlação proposta.

Figura 7.10 Curva comparativa dos resultados experimentais com os proporcionados pela Eq. (7.23) 
Figura 7.11 Curva de resíduos para os resultados apresentados pela Eq. (7.23) em relação ao banco de dados experimentais............................................ 196

Figura 7.12 Variação com $p_{r}$ do desvio médio dos resultados fornecidos pela Eq. (7.23) em relação aos experimentais....................................................... 197

Figura 7.13 Variação com Ra do desvio médio dos resultados fornecidos pela Eq. (7.23) em relação aos experimentais, com a superficie de cobre........... 197 


\section{Lista de Tabelas}

Tabela 1.1 Valores aproximados do coeficiente de transferência de calor.............. 5

Tabela 1.2 Literatura sobre superficies intensificadoras...................................... 12

Tabela 1.3 Literatura referente a ebulição de misturas compostas por 18 refrigerante e óleo de lubrificação.

Tabela 1.4 Literatura referente a ebulição em banco de tubos................................ 22

Tabela 2.1 Efeito da temperatura na taxa de formação de núcleos de vapor........... 33

Tabela 2.2 Correlações para a determinação de $d_{b}$, Carey (1992).......................... 43

Tabela 2.3 Correlações para a determinação de $f$..................................................... 45

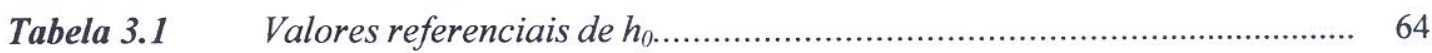

Tabela $3.2 \quad$ Valores de $F_{p m}$ para diferentes materiais.............................................. 69

Tabela 3.3 Resumo das características dos modelos analisadas............................ 95

Tabela 4.1 Características das superficies de testes................................................. 103

Tabela 5.1 Descrição esquemática da preparação das superficies de testes............ 111

Tabela 5.2 Descrição do procedimento adotado por diferentes autores na determinação de $T_{p}$ e a variação do superaquecimento ao longo da circunferência.

Tabela 5.3 Literatura envolvendo a análise da variação de $T_{p}$ com o ângulo de inclinação de uma superficie plana.......................................................... 126

Tabela 5.4 Incerteza dos parâmetros medidos e calculados...................................... 134

Tabela 5.5 Resumo ilustrativo das incertezas de h para o mecanismo de ebulição

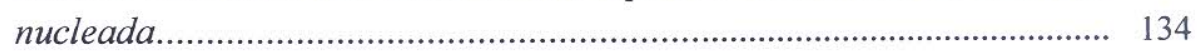

Tabela 6.1 Condições experimentais do banco de dados levantado......................... 137

Tabela 6.2 Características dos resultados experimentais levantados para convecção natural.............................................................................. 139

Tabela 6.3 Valores de B e m, Eq. (6.2), de acordo com Morgan (1975)................ 141

Tabela 6.4 Relação entre valores de $h$ do presente estudo e de Webb e Pais (1992)................................................................................................. 146

Tabela 6.5 Desvios médios entre os resultados experimentais e os das correlações............................................................................................. 150

Tabela 6.6 Comparação entre os resultados das correlações e os experimentais da relação $h / h_{\text {cobre }}$ para diferentes materiais da superficie; $R-123$, $p_{r}=0,011, \phi=30 \mathrm{~kW} / \mathrm{m}^{2}, R a \approx 0,16 \mu \mathrm{m}$.

Tabela 6.7 Comparação relativa do $\mathrm{Pr}_{l}$ e da $\sigma$ para distintos refrigerantes com $p_{r}=0,12$. 
Tabela 6.8 Comparação entre o $\left(r_{c}\right)_{\min }$ dado por Han e Griffith (1965a) e a variação de h com Ra.....

Tabela 6.9 Comparação da relação entre h para os distintos materiais com $\sigma e$ parâmetros utilizados na literatura para caracterizar a superficie. $\phi=50 \mathrm{~kW} / \mathrm{m}^{2}, p_{r}=0,064$ e $R a \approx 0,5 \mu \mathrm{m}$.

Tabela 6.10 Variações de h para as distintas superficies e da tensão superficial $\operatorname{comp}_{r} \phi=50 \mathrm{~kW} / \mathrm{m}^{2}, R a \approx 0,5 \mu \mathrm{m}$.

Tabela 7.1 Correlações da literatura escritas conforme Eq. (7.12).

Tabela 7.2 Correlações para h escritas em termos de $T_{r}$ e desvio médio relativo as correlações originais.....

Tabela 7.3 Parâmetros que afetam he as formas como foram correlacionados.....

Tabela 7.4 Desvios médios da Eq. (7.23) em relação aos resultados experimentais. 


\section{Lista de Símbolos}

\section{Letras Latinas}

a - difusividade térmica

A - área

c - calor específico

$C_{s f} \quad$ - coeficiente de superfície/líquido, Rohsenow (1952)

COP - coeficiente de eficácia

d - diâmetro instantâneo da bolha

$D \quad$ - diâmetro

$d_{b} \quad$ - diâmetro de desprendimento de bolha

$f \quad$ - freqüência de bolhas

$f_{\zeta} \quad$ - fator de nucleação Nishikawa e Fujita (1977)

$F \quad$ - força

$F_{p} \quad$ - fator associado à efeitos da superfície

$F_{\text {psat }}$ - fator associado à efeitos de pressão

$F_{R a} \quad$ - fator associado à efeitos de rugosidade

$F_{\phi} \quad$ - fator associado à efeitos de $\phi$

$g \quad$ - aceleração da gravidade

G $\quad$ - velocidade mássica

$h$ - coeficiente de transferência de calor

$h_{l v} \quad$ - calor latente de vaporização

$J \quad$ - taxa de formação de núcleos de vapor

$k \quad$ - condutividade térmica

$k_{B} \quad$ - constante de Boltzmann $=1,3805 \cdot 10^{-23}$

$L \quad$ - dimensão característica

$L \quad$ - comprimento da superfície de testes

$L_{\text {Res }} \quad$ - comprimento resistência elétrica do tipo cartucho

$M \quad$ - massa molecular

$n / A \quad$ - número de cavidades ativas

$N \quad$ - constante de Avogadro $\quad=6,02 \cdot 10^{26}$

p $\quad$ - pressão

$q \quad$ - potência

$\mathrm{Ra} \quad$ - rugosidade aritmética média descrita no Apêndice I

$R p \quad$ - parâmetro de rugosidade descrito no Apêndice I

$s \quad$ - entropia específica

$s \quad$ - fator relativo ao material da superfície $=\left(k_{p} \rho_{p} c_{p}\right)^{0,5}$

$r, R \quad$ - raio

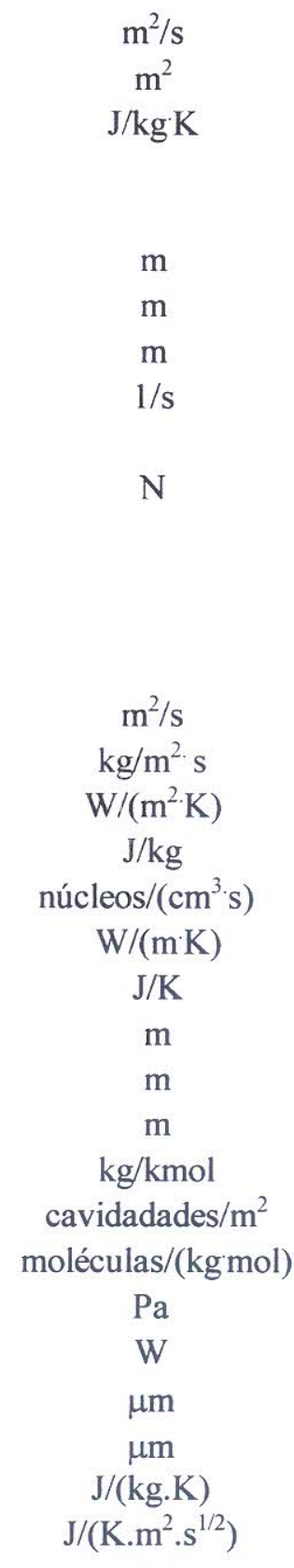

$\mathrm{m}$ 

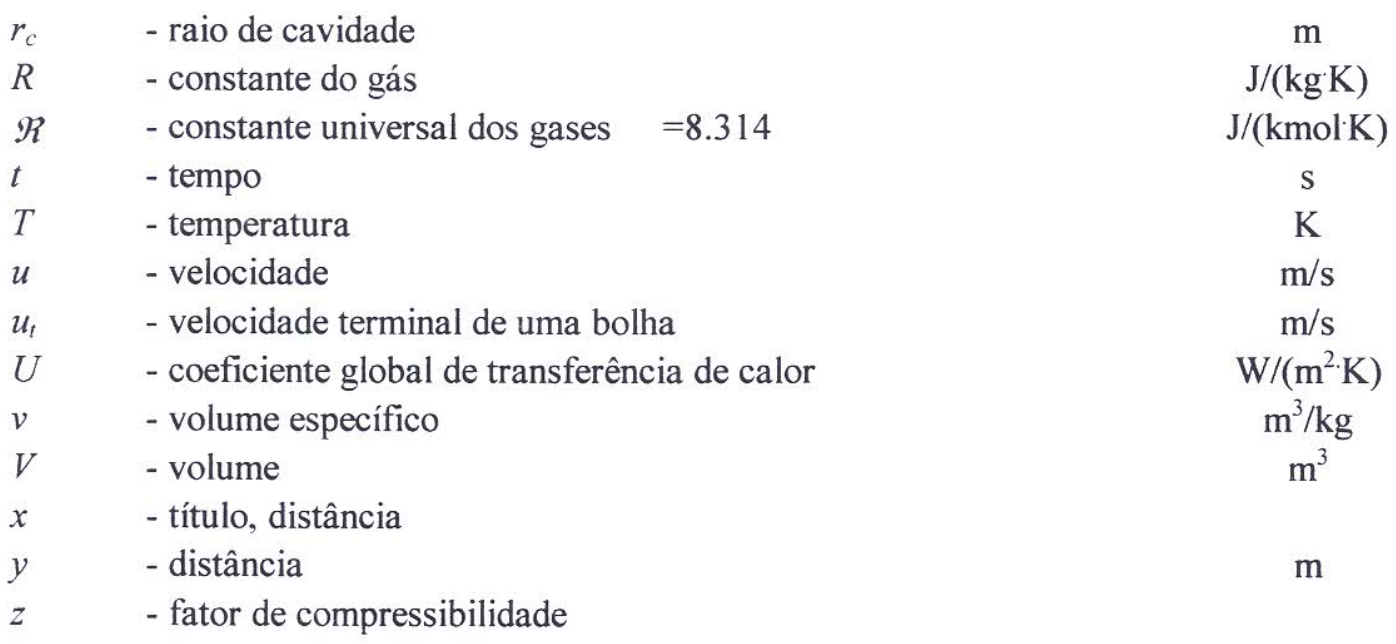

\section{Letras gregas}
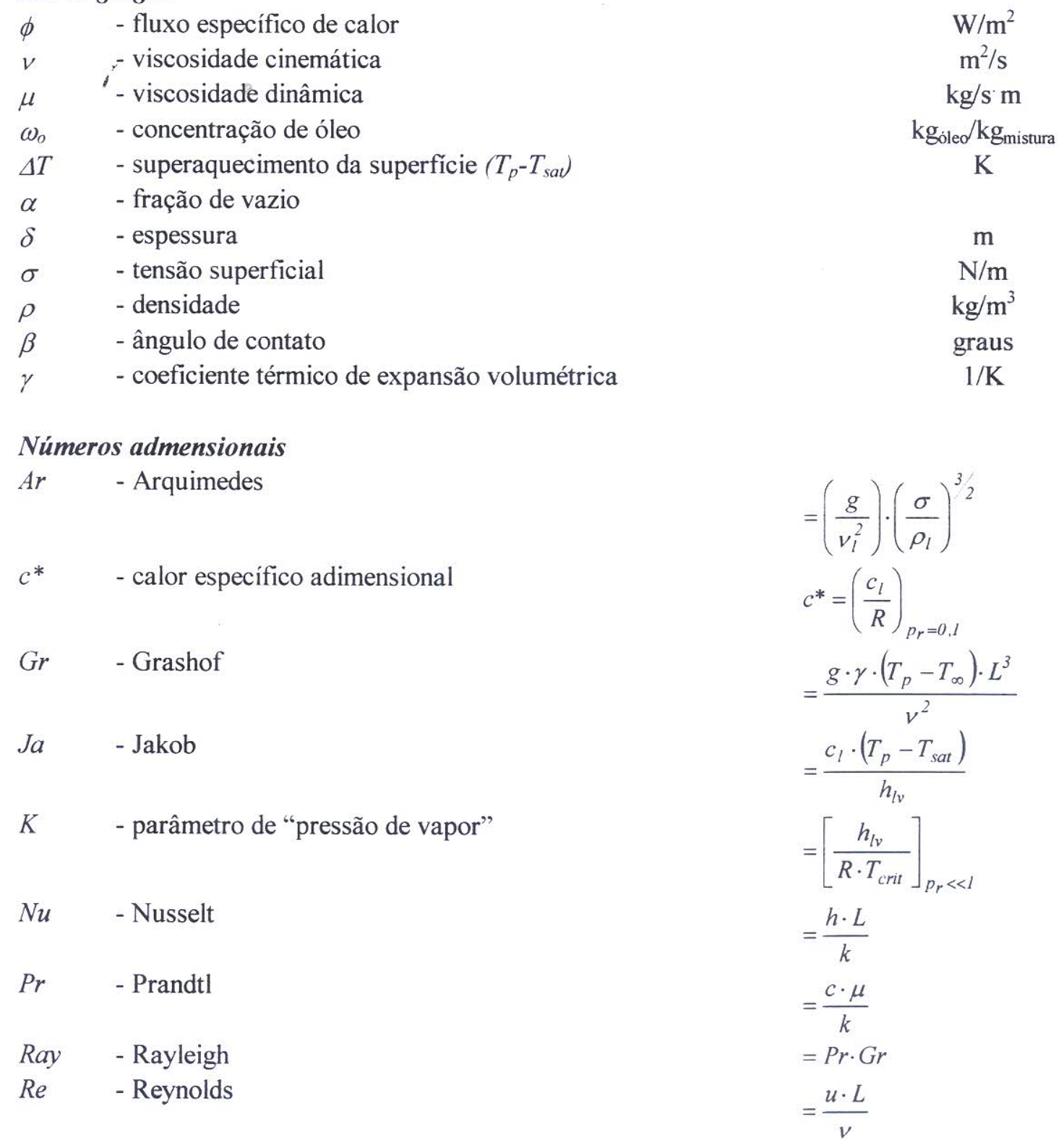


\section{Subscritos}

$\begin{array}{ll}\text { atm } & \text { - pressão atmosférica normal } \\ b & \text { - bolha } \\ c & \text { - crescimento } \\ C N & \text { - convecção natural } \\ \text { con } & \text { - condução transitória } \\ \text { cond } & \text { - condensação } \\ c r i t & \text { - estado crítico } \\ e & \text { - espera } \\ e b & \text { - ebulição nucleada } \\ e m & \text { - evaporação da microcamada } \\ e v & \text { - evaporação } \\ e x t & \text { - dimensão externa } \\ l & \text { - líquido } \\ m c & \text { - micro convecção } \\ p & \text { - superfície } \\ r & \text { - propriedades reduzidas } \\ s a t & \text { - estado saturado } \\ t & \text { - transição entre regimes } \\ v & \text { - vapor } \\ \infty & \text { - relativo ao seio do líquido } \\ 0 & \text { - condição de referência }\end{array}$




\section{Resumo}

Ribatski, G. (2001). Análise teórica e experimental da ebulição nucleada de refrigerantes halogenados, São Carlos, 2002, 257p. Tese (Doutorado) - Escola de Engenharia de São Carlos, Universidade de São Paulo.

O estudo consistiu em uma análise teórica experimental, com o desenvolvimento de uma correlação, dos parâmetros que afetam a ebulição nucleada de refrigerantes halogenados em superfícies cilíndricas lisas. Uma ampla análise da literatura permitiu levantar os distintos tópicos envolvendo este tema destacando entre eles o presente estudo. A análise da literatura envolveu, ainda, um estudo detalhado dos fundamentos da ebulição e das correlações para a previsão do coeficiente de transferência de calor. Foi projetado e construído um aparato experimental no qual foram realizados ensaios envolvendo superfícies de aço inoxidável, cobre e latão, os refrigerantes R-11, R-123, R-12, R-22 e R-134a, fluxos específicos de calor entre 0,8 e $120 \mathrm{~kW} / \mathrm{m}^{2}$, pressões reduzidas de 0,008 a 0,26 e rugosidade aritmética média variando entre 0,02 e $3,3 \mu \mathrm{m}$. A análise destes resultados possibilitou a verificação de comportamentos físicos inéditos segundo a literatura consultada. Destaca-se a análise de efeitos da condução longitudinal e da resistência térmica de contato entre a superfície de transferência de calor e os termopares. Esta análise foi incorporada ao procedimento de determinação da temperatura superficial, e permitiu estabelecer a distribuição de temperaturas ao longo do perímetro da superfície. Finalmente, com base no banco de dados levantado, foi desenvolvida uma correlação para o coeficiente de transferência de calor em ebulição nucleada plenamente desenvolvida de refrigerantes halogenados.

Palavras-chave: ebulição nucleada, refrigerantes halogenados, transferência de calor, mudança de fase 


\section{Abstract}

Ribatski, G. (2002). Theoretical and experimental analysis of pool boiling of halocarbon refrigerants. São Carlos, 2002, 257p. Tese (Doutorado) - Escola de Engenharia de São Carlos, Universidade de São Paulo.

The present research has been focused in a theoretical and experimental analysis of the parameters that affect the pool boiling of halocarbon refrigerants in smooth cylindrical surfaces with the development of a correlation. A wide survey of the literature allowed to list the distinct topics related to this subject and to highlight among them the theme of this study. The literature analysis still involved a detailed study of the pool boiling fundamentals and of the correlations for the pool boiling heat transfer coefficient. An experimental set up has been developed and constructed in which were raise data involving surfaces of stainless steel, copper and brass, the refrigerants R-11, R-123, R-12, R-22 and R-134a, specific heat flux range of 0.8 to $120 \mathrm{~kW} / \mathrm{m}^{2}$, reduced pressures from 0.008 to 0.26 and arithmetic mean roughness varying between 0.02 and $3.3 \mu \mathrm{m}$. The analysis of these results revealed, according to the consulted literature, unpublished physical behaviors. In this work the effects of the longitudinal conduction and of the thermal contact resistance between the heat transfer surface and the thermocouple were analyzed carefully. This analysis was incorporated to the superficial temperature determination procedure and allowed to establish the temperature distribution along the surface perimeter. Finally, using the data base raised in this research, a simple and accurate correlation for the fully developed pool boiling heat transfer coefficient for halocarbon refrigerants applications has been developed.

keywords : pool boiling, halocarbon refrigerants, heat transfer, change of phase 


\section{Capítulo 1 - Introdução}

\section{$1.1 \quad$ Introdução}

A indústria de refrigeração e aquecimento, através das bombas de calor, passa por uma reformulação devido a três importantes aspectos: a mudança dos refrigerantes convencionais, a necessidade de se adequar a padrões mais razoáveis de consumo de energia e a introdução de controladores microprocessados, otimizando o funcionamento do sistema.

Embora existam algumas exceções, entre elas o ciclo de absorção e algumas tecnologias recentes ainda em desenvolvimento, como a termoacústica para "geração de frio", a maioria dos sistemas baseia-se no ciclo de compressão a vapor, que deverá permanecer, com aplicações em larga escala, pelo menos num horizonte de médio prazo.

O protocolo de Montreal, firmado em 1986, estabeleceu as bases para a retirada do mercado de hidrocarbonetos halogenados à base de cloro e flúor, conhecidos como CFCs. Nesse documento foram estabelecidos programas de redução progressiva na produção destes compostos. Embora alguns países, como U.S.A, Japão e Europa Ocidental, já tenham, teoricamente, retirado os CFCs do mercado, o impulso dado às pesquisas na década de $80 \mathrm{e}$ parte da década de 90, tanto em nível industrial como acadêmico, permanece em virtude da contínua introdução de novos refrigerantes, o que exige o desenvolvimento e a adequação das tecnologias existentes.

A redução dos custos de produção de equipamentos e a otimização energética, visando a manutenção da competitividade em um mercado cada vez mais aberto e tecnologicamente dinâmico, aliadas à disseminação de uma nova "mentalidade energética" englobando aspectos ambientais, são também, fatores propulsores de novas pesquisas. 
Destacando que, no caso da refrigeração, a questão da conservação de energia confunde-se com a do meio ambiente através de dois aspectos: um direto, relacionado à mudança de refrigerantes e seu efeito na camada de ozônio estratosférico e no aquecimento terrestre (efeito estufa). Outro, indireto, relacionado ao consumo de energia elétrica, a qual, no caso de geração através da queima de combustíveis fosseis, libera $\mathrm{CO}_{2}$, um dos agentes responsáveis pelo efeito estufa.

Por outro lado, a utilização de controladores microprocessados permite uma melhor adequação do sistema à carga térmica instantânea, proporcionando que este opere sempre em seu ponto ótimo. Desta forma, avanços tecnológicos nos trocadores de calor e no compressor tornam-se, relativamente, importantes. Especificamente, no que diz respeito aos trocadores de calor, pesquisas relativas aos mecanismos de transferência de calor em aplicações frigoríficas, envolvendo a mudança de fase associada a evaporação e à condensação de gases refrigerantes, tem-se mostrado promissoras.

Dentro deste contexto, o presente trabalho trata, de maneira geral, do estudo da transferência de calor através do mecanismo de ebulição nucleada, que encontra aplicações em evaporadores inundados e aqueles com recirculação de líquido, comumentemente encontrados em instalações frigoríficas.

\subsection{O Coeficiente de Transferência de Calor e a Eficiência do Ciclo de Compressão a Vapor}

A eficiência de um ciclo de refrigeração, esta intimamente relacionada ao desempenho dos trocadores de calor. Variações nas temperaturas de evaporação ou condensação alteram significantemente seu desempenho. A eficiência deste ciclo, geralmente, é expressa através do coeficiente de eficácia, COP "coefficient of performance", definido como a razão entre a energia pretendida e a energia consumida. Na refrigeração, este coeficiente é dado pela razão entre a refrigeração útil e o trabalho líquido. Para o ciclo reversível da Fig. 1.1, popularmente conhecido como de Carnot, o COP é determinado da seguinte forma:

$$
\begin{aligned}
& C O P=\frac{\text { calor cedido do reservatório de menor temperatura }}{\text { trabalho requerido na compressão }} \\
& C O P=\frac{T_{e v} \cdot \Delta s}{\left(T_{\text {cond }}-T_{e v}\right) \cdot \Delta s}=\frac{T_{e v}}{T_{\text {cond }}-T_{e v}}
\end{aligned}
$$



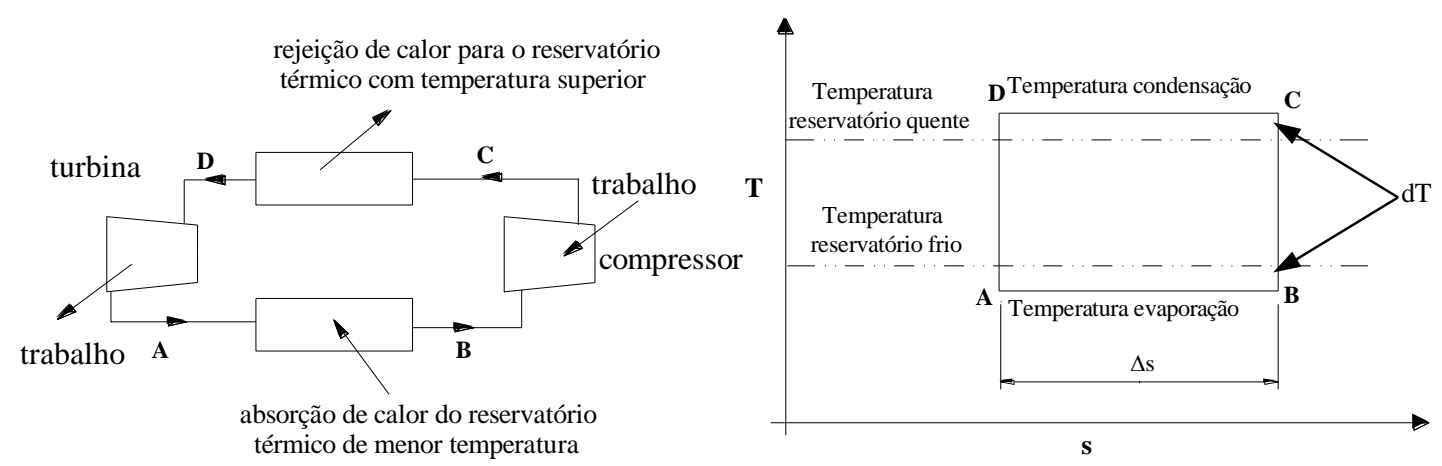

Figura 1.1 Ciclo de refrigeração de Carnot

Assim, com base na Eq. (1.2) concluímos que a eficiência do ciclo depende das temperaturas limites. Um valor reduzido de $T_{\text {cond }}$ produzirá um coeficiente de eficácia elevado. Um valor alto de $T_{e v}$ eleva o valor do numerador e diminui o denominador, incrementando o coeficiente de eficácia. Consequentemente conclui-se que ambas alterações proporcionam reduções no consumo de energia. Este comportamento pode ser observado na Fig. 1.2, elaborada com base na Eq.(1.2), fixando-se $T_{\text {cond }}$ em $40^{\circ} \mathrm{C}$ e variando-se $T_{e v}$.



Figura 1.2 Análise da influência da variação de $T_{e v}$ no COP para o ciclo da Fig 1.1

Desta forma, conclui-se que, o incremento do produto $U \cdot A$, permitindo diferenças de temperaturas reduzidas nos trocadores de calor, resulta em um desempenho superior do ciclo. Variações apenas na área de transferência de calor podem resultar na elevação dos custos de matéria prima ou, até mesmo, na construção de trocadores com tamanhos inviáveis. Já, o incremento no coeficiente global, considerando custos e processos de fabricação, proporciona trocadores mais eficientes e compactos. Estes resultados 
ressaltam, a importância dos estudos sobre mecanismos de transferência de calor, visando a otimização do ciclo de compressão a vapor. No presente trabalho o mecanismo em estudo é o da ebulição nucleada.

\subsection{Ebulição Nucleada}

Estudos da transferência de calor em ebulição nucleada, desde a primeira curva de ebulição obtida por Nukiyama (1934), continuam a representar uma parte significante das publicações em periódicos, conferências e simpósios. Este mecanismo pode ser encontrado em aplicações frigoríficas associadas a evaporadores inundados, conforme o descrito na Fig. 1.3, onde o refrigerante muda de fase do lado externo do tubo, resfriando o fluido que escoa em seu interior. Por outro lado, nas regiões de baixo título da ebulição convectiva, a ebulição nucleada apresenta-se como um dos mecanismos importantes na transferência de calor. As razões para o contínuo interesse neste mecanismo de transferência de calor podem ser, incluindo as anteriormente mencionadas, as seguintes:

Constitui-se num modo eficiente de transferência de calor e, como tal, é utilizado em resfriamento de vários sistemas, fato ilustrado na Tabela 1.1, através da comparação entre o coeficiente de transferência de calor em ebulição nucleada e o obtido por intermédio de outros mecanismos físicos de transferência de calor.

Desenvolvimento de novos refrigerantes em substituição aos CFCs (R-11, R-12, R114, R-115 e R-502 ), apontados como responsáveis pela redução na camada de ozônio. A indústria de ar condicionado, refrigeração e de bombas de calor vem substituindo-os por HCFCs (R-22 e R-123), HFCs (R-134a, R-152a) e refrigerantes naturais (hidrocarbonetos e amônia). Estas mudanças envolvem, além do desenvolvimento de novos equipamentos, a readequação dos que já se encontram em uso.

$>\quad$ Vai ao encontro à necessidade de otimização dos componentes e do próprio sistema que compõe o ciclo frigorífico, tendo como objetivo significativas reduções no custo do produto e incremento da eficiência, com implicações importantes tanto na racionalização do consumo energético como no meio ambiente.

> É um fenômeno complexo e, como tal, continua a desafiar grande número de pesquisadores. 
Carcaça do

evaporador

Tubos

inundados

Refrigerante

em ebulição

Fluido sendo

refrigerado

Figura 1.3 Evaporador Inundado.

Tabela 1.1 Valores aproximados do coeficiente de transferência de calor

\begin{tabular}{|c|c|c|}
\hline Mecanismo & Condições & $h\left(k W / m^{2} . K\right)$ \\
\hline Convecção Natural & ar, Churchill e Chu (1975) & $5 \cdot 10^{-3}$ \\
\hline Convecção Natural & $\mathrm{H}_{2} \mathrm{O}$, Churchill e Chu (1975) & 0,6 \\
\hline Convecção Forçada & $\begin{array}{l}\text { interior de um cilindro } \mathrm{p} / \mathrm{H}_{2} \mathrm{O} u=3 \mathrm{~m} / \mathrm{s} \text {, Dittus e Boelter } \\
\text { (1930), para aquecimento }\end{array}$ & 10 \\
\hline Convecção Forçada & $\begin{array}{l}\text { interior de um cilindro } \mathrm{p} / \text { ar } u=7 \mathrm{~m} / \mathrm{s} \text {, Dittus e Boelter } \\
\text { (1930), para aquecimento }\end{array}$ & $40 \cdot 10^{-3}$ \\
\hline Condensação em Película & p/ R-11, Dhir e Lienhard (1971) & 1,5 \\
\hline Condensação em Película & $\mathrm{p} / \mathrm{H}_{2} \mathrm{O}$, Dhir e Lienhard (1971) & 9 \\
\hline Ebulição Nucleada & superfície Lisa com R-11, Cooper (1984) & 3 \\
\hline Ebulição Nucleada & superfície Lisa com $\mathrm{H}_{2} \mathrm{O}$, Cooper (1984) & 10 \\
\hline Ebulição Nucleada & $\begin{array}{l}\text { superfície intensificadora (Turbo-B) com R-11, Webb e } \\
\text { Pais (1992) para } \Delta T=2^{\circ} \mathrm{C}\end{array}$ & 22 \\
\hline Ebulição Convectiva & $\begin{array}{l}\text { R-134a, interior de um tubo, } d=10,9 \mathrm{~mm}, G=300 \mathrm{~kg} / \mathrm{m}^{2} . \mathrm{s}, \\
x=0,6 \text {, Saiz Jabardo, Bandarra e Lima (1999) }\end{array}$ & 2,2 \\
\hline
\end{tabular}

\footnotetext{
* É interessante ressaltar, que a elaboração desta tabela é apenas com fim comparativo, ressaltando que, a escolha de um mecanismo não é resultado apenas do seu potencial de transferência de calor.

** Com exceção de Webb e Pais (1992), o superaquecimento da parede adotado nos cálculos foi de $9^{\circ} \mathrm{C}$.

*** Com exceção das condições especificadas na tabela, todos os coeficientes foram levantados para o lado externo de uma superfície cilíndrica com diâmetro igual à $25,4 \mathrm{~mm}$. No caso de transferência de calor sem mudança de fase adotou-se uma temperatura do fluido igual à $26,7^{\circ} \mathrm{C}$ e pressão igual à 1 bar. Já, para transferência de calor com mudança de fase adotou-se o fluido como saturado e temperatura igual à $26,7^{\circ} \mathrm{C}$.
} 


\subsection{As Pesquisas em Transferência de Calor Através de Ebulição Nucleada}

As pesquisas relativas a ebulição nucleada visam aplicações em diferentes áreas, entre elas os setores nuclear e aeroespacial, a refrigeração e a indústria de processos (destilação). No presente trabalho, devido à ampla abrangência do assunto, apenas os estudos relacionados à aplicações frigoríficas serão considerados.

Com o objetivo de destacar a importância deste tema, foram realizadas análises quantitativas da literatura, ilustradas nas Fig. 1.4 e 1.5. A primeira, cujos dados foram levantados em revistas de destaque na área de transferência de calor (International Journal of Heat and Mass Transfer, Journal of Heat Transfer), apresenta um gráfico comparativo, relacionando as publicações que envolvem o estudo da ebulição nucleada com o número total de artigos. Na figura constata-se um declínio no índice de publicações a partir do início da década de 70, seguido de um incremento nos últimos anos. Já, para a elaboração da Fig. 1.5 foram levantados 1330 trabalhos referentes, apenas, à ebulição nucleada, incluindo teses e artigos de congressos e revistas. Foi verificado um número relevante de estudos publicados, que se acentuou no decorrer das décadas. Desta forma, conclui-se, de maneira geral, que embora a importância relativa das pesquisas em ebulição nucleada tenha diminuído, como resultado da contínua descoberta de novos horizontes de pesquisas, este, ainda, continua sendo um tema de reconhecido interesse, haja vista o contínuo incremento no número absoluto de publicações.

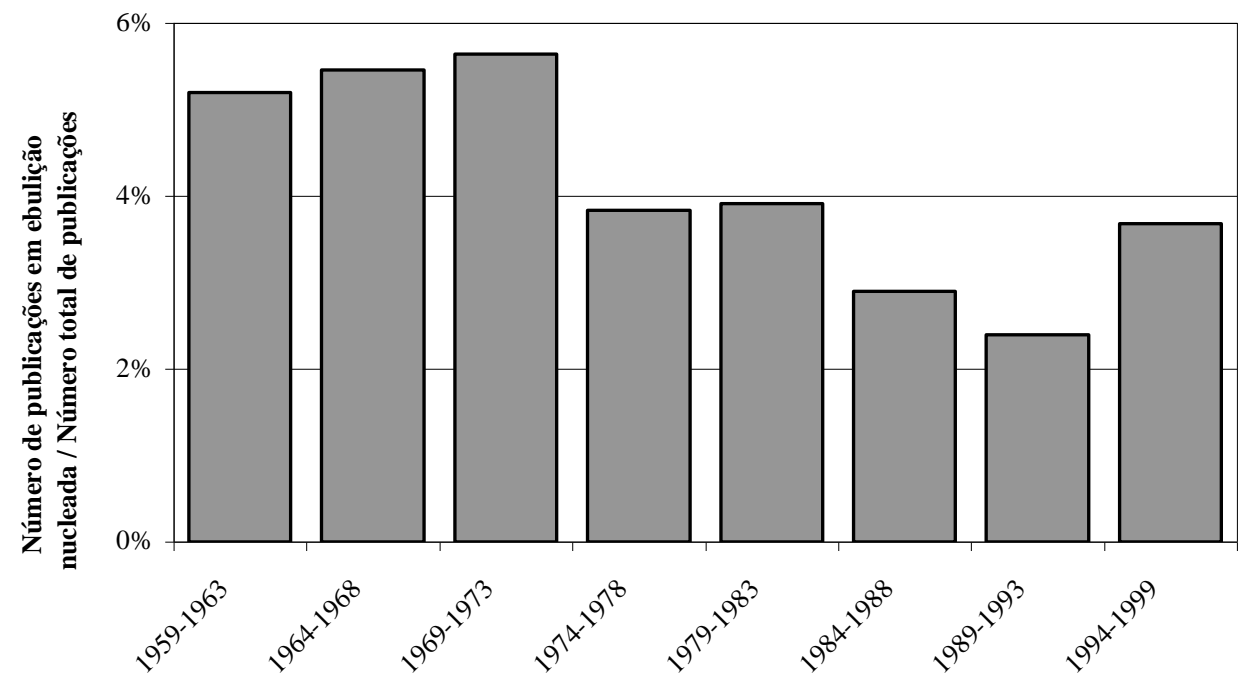

Figura 1.4 Análise relativa do número de publicações em ebulição nucleada 


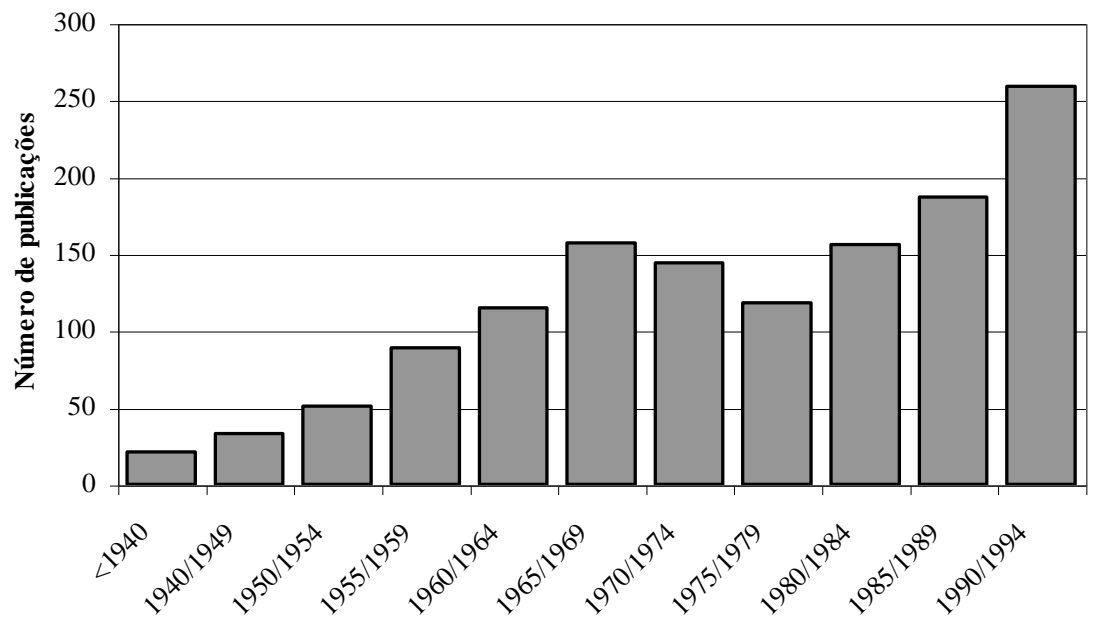

Figura 1.5 Evolução do número de publicações sobre ebulição nucleada

O estudo da ebulição nucleada, devido a sua abrangência, foi dividido em diferentes tópicos, para os quais será feita uma breve análise do estado da arte localizando, ao final, o presente trabalho.

\subsubsection{Fundamentos}

As publicações referentes a este tema analisam a ebulição através de uma abordagem local. São estudados os critérios de nucleação, mecanismos físicos de transferência de calor, a taxa de crescimento da bolha, a frequiência de bolhas e o número de cavidades ativas, bem como a influência de parâmetros físicos tais como características da superfície, fluido em ebulição, a presença de gases não condensáveis, pressão do sistema, aceleração gravitacional e superaquecimento da parede nestas variáveis. Estes itens são extensivamente discutidos no Capítulo 2.

\subsubsection{Correlações e Modelos Físicos}

Grande parte dos trabalhos dedicados a este assunto objetiva a determinação de correlações para o coeficiente de transferência de calor. Como resultado destas pesquisas, foram elaboradas inúmeras correlações. Estas, devido à complexidade fenomenológica da 
ebulição nucleada, são baseadas em bancos de dados específicos, objetivando, consequentemente, aplicações particulares. Os trabalhos desenvolvidos entre o final da década de 40 e o início dos anos 70, visando, geralmente, o setor nuclear, tentaram interpretar o processo físico da ebulição, aspirando aplicações genéricas. Evidentemente, o mecanismo físico que efetivamente ocorre na superfície aquecida envolve o efeito simultâneo de dois ou mais mecanismos. São raros os modelos que tentaram uma combinação de mecanismos, o que se justifica pela complexidade que tal modelagem introduziria. Já, na maioria dos trabalhos publicados a partir da década de 80 , os esforços se concentraram na busca de correlações para uso industrial imediato, não se constatando grande preocupação com a investigação do fenômeno físico. Estas correlações geralmente proporcionam bons resultados e são de aplicação relativamente fácil. No entanto, sua aplicabilidade é limitada à faixa de parâmetros para a qual foram desenvolvidas. A Fig. 1.6 apresenta uma comparação, inicial, entre algumas correlações, onde se constata uma grande discrepância entre elas. Mais recentemente, alguns estudos tem tentado modelar numericamente a ebulição nucleada, simulando o ciclo de vida das bolhas e seu efeito na taxa de transferência de calor da parede para o fluido.

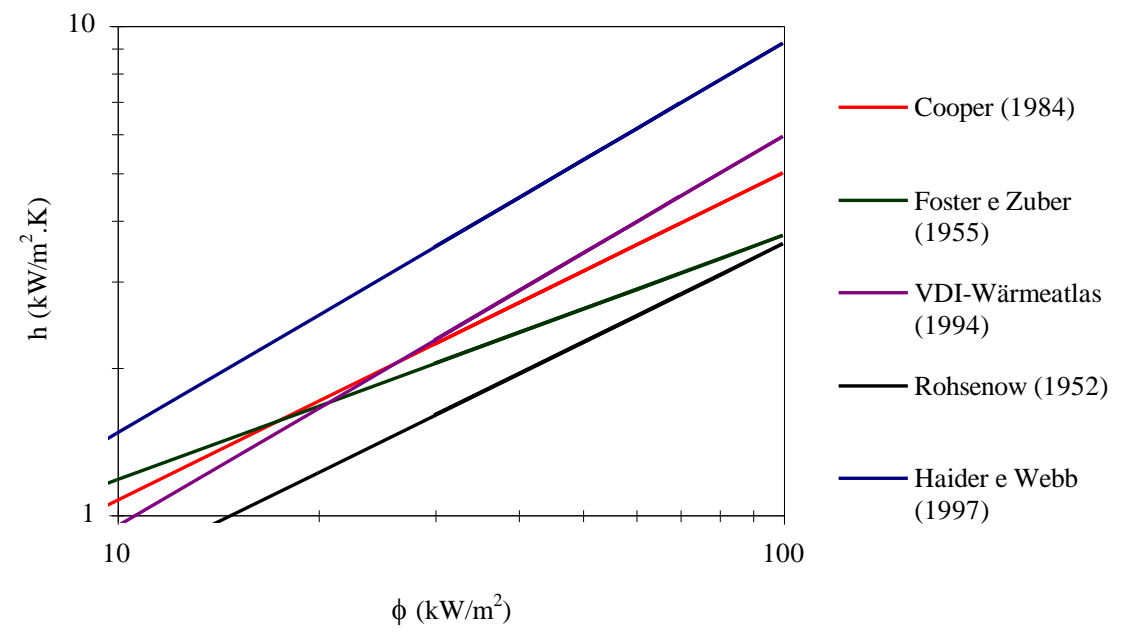

Figura 1.6 Comparação de algumas correlações da literatura; R-113, $R a=1 \mu \mathrm{m}$ e $T_{\text {sal }}=45^{\circ} \mathrm{C}$

Devido à maneira como foram formuladas, para efeitos de análise, as correlações podem ser divididas nos seguintes grupos:

i. Correlações semi-empíricas consistem em modelos físicos ajustados a resultados experimentais através de coeficientes numéricos. Entre os mecanismos físicos considerados pelos autores encontram-se os seguintes: a agitação de líquido junto a

* Embora a correlação do VDI-Wärmeatlas (1994) levantada não tenha sido obtida em sua publicação original, mas em Ribeiro (1998) e em Collier e Thome (1996), será adotado no decorrer deste trabalho apenas a indicação original. 
parede, resultante do desprendimento das bolhas; evaporação de uma microcamada de líquido superaquecido na base das bolhas; efeitos de termocapilaridade, resultantes de gradientes de temperatura ao longo da interface das bolhas; efeitos de microconvecção, resultantes do deslocamento de líquido causado pelo crescimento das bolhas, ou devido à micro vórtices gerados no seu desprendimento; substituição da camada aquecida junto a parede por líquido frio que se desloca para a região da parede em virtude do desprendimento das bolhas, sendo posteriormente aquecido por um mecanismo de condução transitória; evaporação na linha de contato triplo, localizada na base da bolha, correspondendo à região de contato das três fases: sólido, líquido e vapor. A evaporação nesta região tem sido objeto de estudos recentes, com seus mecanismos sendo ainda pouco conhecidos.

ii. Correlações estritamente empíricas. Nestas, os autores tentaram a introdução de grupos adimensionais, que apresentam alguma relação com fenômenos de transferência de calor, como os números de Prandtl e Reynolds, referido ao diâmetro de desprendimento de bolhas.

iii. Correlações baseadas em propriedades reduzidas. Tomam por base uma extensão da Lei dos Estados Correspondentes, aplicada às propriedades do fluido no estado de saturação. Neste tipo de correlação, o coeficiente de transferência de calor é função apenas de propriedades reduzidas primitivas: pressão, $p_{r}$ e temperatura, $T_{r}$. Embora não incorporem qualquer mecanismo físico, tais correlações caracterizam-se pela simplicidade e relativa precisão.

No desenvolvimento de modelos (empíricos ou não), alguns parâmetros físicos foram incorporados, tais como geometria da superfície aquecida, rugosidade da mesma, efeito de mistura de componente volátil ou não (neste caso o óleo de lubrificação), orientação da superfície, dispositivos intensificadores e a gravidade, em trabalhos envolvendo aplicações espaciais.

\subsubsection{Métodos de Intensificação da Transferência de Calor em Ebulição Nucleada}

Durante os últimos 20 anos, uma das áreas que mais avançou na intensificação da transferência de calor foi a de superfícies especiais, que proporcionam uma elevada taxa de transferência de calor através do mecanismo da ebulição nucleada. Embora o fato de superfícies rugosas intensificarem a transferência de calor seja conhecido há mais de 60 anos, durante aproximadamente 35 anos este assunto não despertou interesse comercial. 
Acreditava-se que as superfícies rugosas apresentariam desempenho superior apenas durante poucas horas, com seu desempenho aproximando-se ao de uma superfície lisa com o decorrer do tempo. No período de 1955 a 1965, com o maior conhecimento do mecanismo físico, foram desenvolvidos os fundamentos básicos para as pesquisas relacionadas ao desenvolvimento de superfícies intensificadoras comercialmente viáveis. A primeira superfície de alto desempenho, segundo Webb (1994), foi patenteada em 1968. Estas superfícies de elevado desempenho foram denominadas de superfícies intensificadoras e encontram-se atualmente em um número elevado de equipamentos. A partir daí, vários métodos de intensificação da transferência de calor em ebulição nucleada, através da alteração de características de superfície, foram e ainda são desenvolvidos, tornando este um tema responsável por um significativo número de pesquisas. Segundo Bergles (1997), devido ao preço do petróleo, um importante componente na matriz energética de diversos países, assumir valores reduzidos durante este período, o número de pesquisas relativas a intensificação da transferência de calor permanecia estável, com o número de publicações em torno de 400 artigos anuais. Mas, atualmente, com a expectativa da elevação nos preços de energia tornando-se real, é provável que as pesquisas nesta área assumam uma relevância ainda maior.

$\mathrm{Na}$ literatura, as técnicas de intensificação da transferência de calor são comumentemente divididas em dois grupos: passivas e ativas. A primeira consiste na utilização de superfícies intensificadoras ou aditivos que incrementem a taxa de transferência de calor. Já as técnicas ativas requerem energia externa, tais como: campo elétrico, campo acústico e vibração da superfície. Estas técnicas, embora promissoras, são limitadas, ainda, à aplicações científicas. As diferentes técnicas, tanto passivas quanto ativas, apresentam características muito específicas, sendo, assim, controladas por fatores particulares. A Fig. 1.7 ilustra algumas superfícies intensificadoras.

É interessante destacar a especificidade de cada publicação relativa a esta área, isto é, dificilmente dois trabalhos abrangem o mesmo par superfície e fluido refrigerante, como pode ser verificado na Tabela 1.2, que apresenta um resumo das publicações sobre técnicas passivas de intensificação da transferência de calor em ebulição nucleada. Resultado que, apesar da concorrência dos trocadores de placa, permite manter elevadas as perspectivas relativas a esta área. A interação entre as duas fases para estas superfícies, tem sua complexidade incrementada, dependendo da interação da configuração superficial com a seguintes variáveis: pressão de saturação; fluxo de calor e propriedades de transporte do refrigerante. Isto faz com que as correlações existentes para previsão do coeficiente de transferência de calor possam ser classificadas como especulações sobre os mecanismos 
físicos responsáveis pela intensificação, caracterizadas para situações especificas. Assim, embora exista um considerável número de publicações, verifica-se um grande empirismo, onde, a análise do melhor desempenho depende quase que exclusivamente de dados experimentais, caracterizados pelas condições de operação do equipamento. Logo, para o melhor entendimento do fenômeno e, caso possível, formulação de um modelamento apropriado, torna-se necessária a ampliação dos bancos de dados experimentais existentes de forma a abranger um elevado número de fluidos, superfícies intensificadoras e níveis de fluxos de calor. Isto é particularmente importante na indústria de refrigeração, onde novos refrigerantes, óleos de lubrificação do compressor e superfícies de troca de calor tem sido constantemente introduzidos.

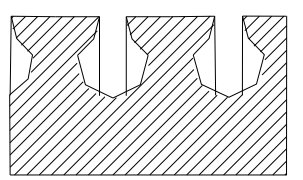

GEWA-TX

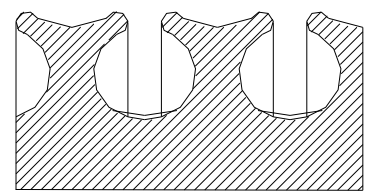

GEWA-YX

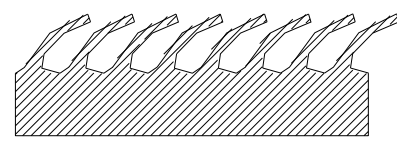

aletas curvadas ( Trane )

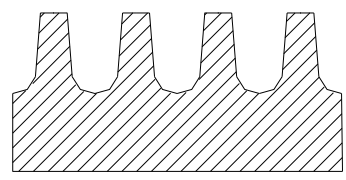

Aletas simples

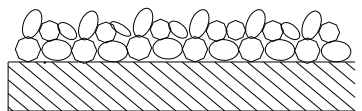

Poroso

High-Flux

(Hitachi)

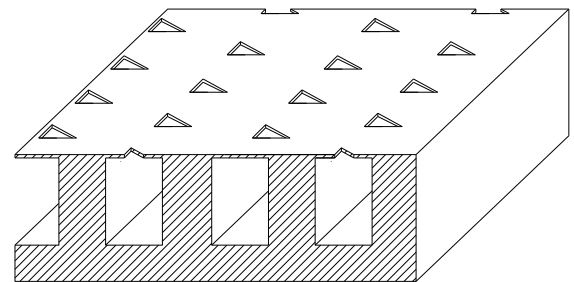

Nakayama (1980a)
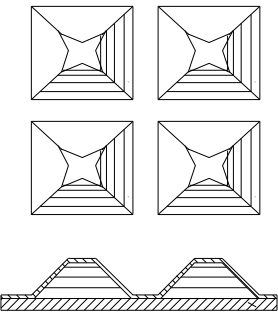

Ragi apud Webb (1994)

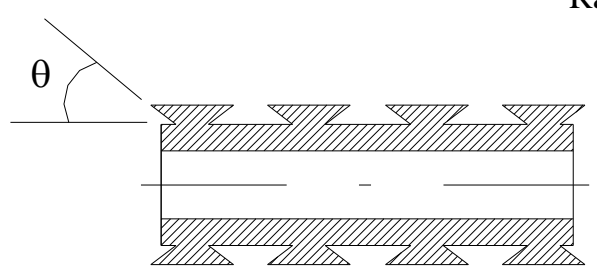

Hsieh e Weng (1997a)

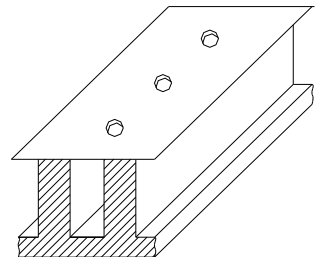

Chien (1996)

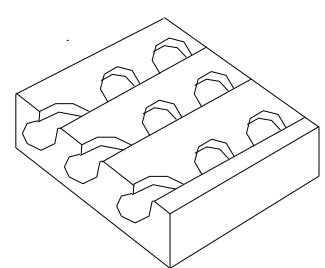

Termohexcel-HE

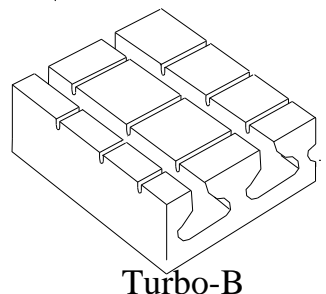

Turbo-B

Figura 1.7 Ilustração esquemática de algumas superfícies intensificadoras. 
A chave para o elevado desempenho destas superfícies é decorrente de três fatores básicos: (1) quando as cavidades se comunicam entre si, verificam-se efeitos mútuos de ativação. (2) a evaporação ocorre numa fina camada de líquido (3) a estrutura das superfícies (porosas e estruturadas) providencia o aprisionamento de vapor de forma estável, proporcionando um elemento de ativação para superaquecimentos reduzidos.

Uma vantagem relativa das superfícies porosas é que podem ser construídas com diferentes materiais. Deste modo, na superfície interna pode ser utilizado um material de custo inferior àquele em contato com o líquido em ebulição. Isto é extremamente importante em ambientes corrosivos.

Tabela 1.2 Literatura sobre superfícies intensificadoras.

\begin{tabular}{|c|c|c|c|c|}
\hline Autor & Ano & "Geometria da Superfície & Fluido & $\begin{array}{l}p_{\text {sat }} \text { ou } T_{\text {sat }} \\
\text { s. }\end{array}$ \\
\hline Furse & 1965 & - placa horizontal lisa & $\mathrm{R}-11$ e R-12 & $\begin{array}{l}10,-3,9, \\
-17,8 \mathrm{e} \\
-31,7^{\circ} \mathrm{C}\end{array}$ \\
\hline Vachon et al. & 1968 & $\begin{array}{l}\text { - superfícies de aço, cobre, níquel e inconel } \\
\text { com os seguintes acabamentos: retificada; } \\
\text { quimicamente tratada; artificialmente riscada; } \\
\text { polida; revestida. }\end{array}$ & $\mathrm{H}_{2} \mathrm{O}$, n-pentano, $\mathrm{CCl}_{4}$ & $1 \mathrm{~atm}$ \\
\hline Czikk et al. & 1970 & $\begin{array}{l}\text { - superfícies de cobre, planas e posicionadas } \\
\text { horizontalmente possuindo os seguintes } \\
\text { acabamentos superficiais: lisa, porosa e uma } \\
\text { superfície lisa recoberta com material poroso }\end{array}$ & $\mathrm{R}-11$ & $1,1^{\circ} \mathrm{C}$ \\
\hline Kartsounes & 1975 & $\begin{array}{l}\text { - superfície de cobre plana posicionada } \\
\text { verticalmente com dois diferentes acabamentos } \\
\text { superficiais } \\
\text { - superfícies recobertas com spray de plasma de } \\
\text { cobre } \\
\text { - superfícies recobertas com Koro-Tex } \\
\text { produzido pela Union Carbide }\end{array}$ & $\mathrm{R}-11$ & $\begin{array}{l}-17,7,-12,2 \text { e } \\
-6,6^{\circ} \mathrm{C}\end{array}$ \\
\hline Sauer. et al & 1975 & $\begin{array}{l}\text { - } \quad \text { superfícies de inconel com } 5 \text { diferentes } \\
\text { acabamentos }\end{array}$ & $\mathrm{R}-11$ & $\begin{array}{l}\text { não } \\
\text { especificada }\end{array}$ \\
\hline $\begin{array}{l}\text { Corman e } \\
\text { McLaughlin }\end{array}$ & 1976 & $\begin{array}{l}\text { - } \quad \text { superfície tubular recoberta com telas de níquel } \\
\text { - } \quad \text { superfície tubular recoberta com feltro de } \\
\text { níquel e cobre } \\
\text { - } \quad \text { superfície tubular de cobre com aletas cúbicas } \\
\text { de níquel } \\
\text { - } \quad \text { superfície lisa }\end{array}$ & $\mathrm{R}-22, \mathrm{H}_{2} \mathrm{O}$ & $\begin{array}{l}110,138 \\
207 \mathrm{kPa}\end{array}$ \\
\hline $\begin{array}{l}\text { Asakavicius } \\
\text { et al. }\end{array}$ & 1979 & - tubo de cobre recoberto com mechas de cobre & $\begin{array}{l}\mathrm{R}-113, \mathrm{H}_{2} \mathrm{O} \text { e álcool } \\
\text { etílico }\end{array}$ & $1 \mathrm{~atm}$ \\
\hline
\end{tabular}


Tabela 1.2 (continuação) Literatura sobre superfícies intensificadoras

\begin{tabular}{|c|c|c|c|c|}
\hline Autor & Ano & Geometria da Superfície & Fluido & $p_{\text {sat }}$ ou $T_{\text {sat }}$ \\
\hline $\begin{array}{l}\text { Nakayama et. } \\
\text { al. }\end{array}$ & $\begin{array}{l}1980 \mathrm{a} \\
1980 \mathrm{~b}\end{array}$ & $\begin{array}{l}\text { - superfície horizontal aletada recoberta com } \\
\text { folha metálica perfurada }\end{array}$ & $\mathrm{R}-11, \mathrm{H}_{2} \mathrm{O}, \mathrm{N}_{2}$ & $1 \mathrm{~atm}$ \\
\hline Petukov et al. & 1981 & - diferentes formatos de aletas & R-113 & $47^{\circ} \mathrm{C}$ \\
\hline $\begin{array}{l}\text { Marto e } \\
\text { Lepere }\end{array}$ & 1982 & $\begin{array}{l}\text { - } \text { superfícies comerciais } \\
\text { Thermoexcel-E e GEWA-T }\end{array}$ & R-113, FC-72 & $1 \mathrm{~atm}$ \\
\hline $\begin{array}{l}\text { Nakayama et. } \\
\text { al. }\end{array}$ & 1982 & $\begin{array}{l}\text { - superfície horizontal aletada recoberta com } \\
\text { folha metálica perfurada. }\end{array}$ & $\mathrm{R}-11$ & $\begin{array}{l}0,04,0,1 \mathrm{e} \\
0,23 \mathrm{Mpa}\end{array}$ \\
\hline $\begin{array}{l}\text { Arshad e } \\
\text { Thome }\end{array}$ & 1983 & $\begin{array}{l}\text { - superfície plana composta por canais com } \\
\text { formatos retangulares, triangulares e circulares } \\
\text { recoberta com folha metálica perfurada. }\end{array}$ & $\mathrm{H}_{2} \mathrm{O}$ & $1 \mathrm{~atm}$ \\
\hline $\begin{array}{l}\text { Nishikawa et } \\
\text { al. }\end{array}$ & 1984 & $\begin{array}{l}\text { - disco com superfície plana e lisa com } \\
\text { inclinação variável entre } 0 \text { e } 175^{\circ}\end{array}$ & $\mathrm{H}_{2} \mathrm{O}$ & $1 \mathrm{~atm}$ \\
\hline Ma et al & 1986 & $\begin{array}{l}\text { - superfície ranhurada de cobre recoberta com } \\
\text { tela fina } \\
\text { - superfície ranhurada de cobre recoberta com } \\
40 \text { camadas de tela fina } \\
\text { - superfície ranhurada de cobre recoberta com } \\
\text { folha metálica perfurada }\end{array}$ & $\mathrm{H}_{2} \mathrm{O}$ e metanol & $1 \mathrm{~atm}$ \\
\hline Tewari. et al. & 1986 & $\begin{array}{l}\text { - } \quad \text { tubo liso de alumínio } \\
\text { - } \quad \text { tubo de alumínio com diferentes acabamentos }\end{array}$ & $\begin{array}{l}\mathrm{H}_{2} \mathrm{O} \text { e mistura de } \mathrm{H}_{2} \mathrm{O} \\
\text { com HEC (aditivo) }\end{array}$ & 8 a $100 \mathrm{kPa}$ \\
\hline Chuah e Carey & 1987 & $\begin{array}{l}\text { - superfície tubular contaminada com partículas } \\
\text { de vidro e cobre. }\end{array}$ & $\mathrm{H}_{2} \mathrm{O}$ & $1 \mathrm{~atm}$ \\
\hline $\begin{array}{l}\text { Wanniarachchi } \\
\text { et al. }\end{array}$ & 1987 & $\begin{array}{l}\text { - } \quad \text { tubo liso } \\
\text { - } \quad \text { tubo com superfície porosa de cobre e níquel }\end{array}$ & $\begin{array}{l}\text { R-114 e mistura R-114 e } \\
\text { óleo }\end{array}$ & $-2,2$ e $6,7^{\circ} \mathrm{C}$ \\
\hline $\begin{array}{l}\text { Anderson e } \\
\text { Mudawar }\end{array}$ & 1989 & $\begin{array}{l}\text { - } 3 \text { diferentes tipos de superficies verticais: } \\
\text { - } 3 \text { superficies planas com diferentes } \\
\text { acabamentos } \\
\text { - } 3 \text { superficies com diferentes cavidades } \\
\text { - } 3 \text { superficies com diferentes aletas }\end{array}$ & FC-72 & $1 \mathrm{~atm}$ \\
\hline Thome & 1989 & - GEWA-TX & $\begin{array}{l}\text { mistura de } \\
\text { hidrocarbonetos }\end{array}$ & $\begin{array}{l}2,07 \text { e } 6,90 \\
\text { bar }\end{array}$ \\
\hline Sokol et al. & 1990 & $\begin{array}{ll}\text { - } & \text { tubos lisos com } R p=1,0 \text { e } 0,8 \mu \mathrm{m} \\
\text { - } & \text { GEWA-TX }\end{array}$ & propano e propileno & $0,05 \leq p_{r} \leq 0,5$ \\
\hline Hahne. et al. & 1991 & $\begin{array}{l}\text { - tubos integralmente aletados com } 1024 \text { e } 748 \\
\text { aletas por metro. }\end{array}$ & $\mathrm{R}-11$ & $1 \mathrm{bar}$ \\
\hline
\end{tabular}


Tabela 1.2 (continuação) Literatura sobre superfícies intensificadoras

\begin{tabular}{|c|c|c|c|c|}
\hline Autor & Ano & Geometria da Superfície & Fluido & $p_{\text {sat }}$ ou $T_{\text {sat }}$ \\
\hline Palm, B. & 1991 & $\begin{array}{l}\text { - } \text { superfícies de cobre tubulares com três } \\
\text { diferentes acabamentos } \\
\text { - } \quad \text { superfícies de cobre tubulares com } 433,748 \text {, } \\
1024 \text { aletas/m } \\
\text { - } 5 \text { superfícies de cobre tubulares com diferentes } \\
\text { ranhuras elaboradas com laser } \\
\text { - } \quad \text { superfície de cobre tubular com aletas } \\
\text { curvadas, } 1024 \text { aletas/m } \\
\text { - } \quad \text { superfícies de cobre tubulares e estriadas } \\
\text { - } \text { GEWA-T, } 748 \text { aletas/m } \\
\text { - } \quad \text { superfícies porosas de cobre tubulares } \\
\text { comercialmente denominadas de Sumitomo EVR } \\
\text { 40, Sumitomo EV 26D e Sumitomo SEVAC } \\
\text { - superfícies tubulares lisas recobertas com } \\
\text { folhas metálicas constituídas de poros com } \\
\text { diferentes diâmetros. }\end{array}$ & R-11, R-22, R-134a & $\begin{array}{l}1, \quad 2, \quad 5, \quad 8 \\
1,3,3 \text { e } 5 \text { bar }\end{array}$ \\
\hline Webb e Pais & 1991 & $\begin{array}{ll}\text { - } & \text { tubo de cobre com } 1024 \text { aletas/m } \\
\text { - } & \text { Turbo-B } \\
\text { - } & \text { GEWA-SE }\end{array}$ & $\begin{array}{c}\mathrm{R}-11, \mathrm{R}-12, \mathrm{R}-22 \\
\mathrm{R}-113, \mathrm{R}-123, \mathrm{R}-134 \mathrm{a}\end{array}$ & $27,0^{\circ} \mathrm{C}$ \\
\hline $\begin{array}{l}\text { Matijevic et } \\
\text { al. }\end{array}$ & 1992 & $\begin{array}{l}\text { - } \quad \text { superfície plana contaminada com esferas de } \\
\text { chumbo de diferentes diâmetros }\end{array}$ & $\mathrm{H}_{2} \mathrm{O}$ & $1 \mathrm{~atm}$ \\
\hline Webb e Pais & 1992 & $\begin{array}{l}\text { - } \text { tubo liso } \\
\text { - } \quad \text { tubo integralmente aletados com } 1024 \text { aletas } \\
\text { por metro. } \\
\text { - } \text { GEWA-TX19 } \\
\text { - } \text { GEWA-SE } \\
\text { - Turbo-B }\end{array}$ & $\begin{array}{l}\mathrm{R}-11, \mathrm{R}-12, \mathrm{R}-22 \\
\mathrm{R}-113, \mathrm{R}-134 \mathrm{a}\end{array}$ & 4,4 e $26,7^{\circ} \mathrm{C}$ \\
\hline Diev et.al. & 1993 & $\begin{array}{l}\text { - disco horizontal de alumínio AK-4 com } \\
\text { microcanais }\end{array}$ & $\mathrm{R}-113$ & 1atm \\
\hline Gorenflo et al & 1993 & $\begin{array}{l}\text { - } \quad \text { tubo liso } \\
\text { - } \quad \text { tubo composto por micro-aletas trapezoidais, } \\
\text { com } 1418 \text { aletas por metro } \\
\text { - } \text { GEWA-TX19 } \\
\text { - GEWA-YX26 }\end{array}$ & $\begin{array}{l}\text { R-134a, R-152a, R-227, } \\
\text { propano }\end{array}$ & $0,035 \leq p_{r} \leq 0,5$ \\
\hline Semena et al & 1993 & $\begin{array}{l}\text { - disco horizontal de cobre recoberto com fibras } \\
\text { metálicas }\end{array}$ & $\begin{array}{c}\mathrm{H}_{2} \mathrm{O} \text {, álcool etílico, } \\
\text { acetona e líquidos } \\
\text { fluorgânicos diéletricos }\end{array}$ & $10 \mathrm{kPa} \leq p_{\text {sat }} \leq 100 \mathrm{kPa}$ \\
\hline Haider & 1994 & $\begin{array}{l}\text { - superfícies horizontais planas constituídas de } \\
\text { túneis }\end{array}$ & $\mathrm{R}-11, \mathrm{~N}_{2}$ e $\mathrm{H}_{2} \mathrm{O}$ & $1 \mathrm{~atm}$ \\
\hline Hsieh e Hsu & 1994 & $\begin{array}{ll} & \text { tubo liso } \\
\text { - } & \text { tubos aletados }\end{array}$ & $\mathrm{R}-114, \mathrm{H}_{2} \mathrm{O}, \mathrm{R}-134 \mathrm{a}$ & $\begin{array}{l}14,8,99,9 \text { e } \\
4,4^{\circ} \mathrm{C}\end{array}$ \\
\hline
\end{tabular}


Tabela 1.2 (continuação) Literatura sobre superfícies intensificadoras

\begin{tabular}{|c|c|c|c|c|}
\hline Autor & Ano & Geometria da Superfície & Fluido & $p_{\text {sat }}$ ou $T_{\text {sat }}$ \\
\hline Hong et al & 1994 & $\begin{array}{l}\text { - } \quad \text { superfícies GEWA-SE de cobre e alumínio, } \\
\text { com diferentes níveis de oxidação }\end{array}$ & $\mathrm{R}-11$ e $\mathrm{H}_{2} \mathrm{O}$ & 10 e $65^{\circ} \mathrm{C}$ \\
\hline $\begin{array}{l}\text { O’Connor e } \\
\text { You }\end{array}$ & 1994 & $\begin{array}{l}\text { - superfície retangular horizontal recoberta com } \\
\text { camadas de diferentes espessuras de uma mistura } \\
\text { de epoxi e flocos de prata. }\end{array}$ & FC-72 & $1 \mathrm{~atm}$ \\
\hline Li. e Hahne & 1995 & $\begin{array}{l}\text { - superfície horizontal de cobre com } 1024 \\
\text { aletas/m }\end{array}$ & $\mathrm{R}-11$ & $1 \mathrm{bar}$ \\
\hline $\begin{array}{l}\text { Kudritski e } \\
\text { Kolomiets }\end{array}$ & 1995 & $\begin{array}{l}\text { - } \text { superfícies com diferentes diâmetros e } \\
\text { acabamentos }\end{array}$ & $\mathrm{H}_{2} \mathrm{O}$ & $\begin{array}{l}0,02 \mathrm{e} \\
0,1 \mathrm{MPa}\end{array}$ \\
\hline Memory. et al & $\begin{array}{l}1995 \mathrm{a} \\
1995 \mathrm{~b}\end{array}$ & $\begin{array}{ll}\text { - } & \text { GEWA-K } \\
\text { - } & \text { GEWA-T } \\
\text { - } & \text { GEWA-YX } \\
\text { - } & \text { Turbo-B } \\
\text { - } & \text { Termoexcel-HE } \\
\text { - } & \text { tubo com superfície porosa de cobre e níquel }\end{array}$ & $\begin{array}{l}\text { R-114 e mistura R-114 e } \\
\text { óleo }\end{array}$ & $1 \mathrm{~atm}$ \\
\hline $\begin{array}{l}\text { O’Connor e } \\
\text { You }\end{array}$ & 1995 & $\begin{array}{l}\text { - } \quad \text { superfície de alumínio recoberta com uma } \\
\text { mistura composta por partículas de ouro }\end{array}$ & FC-72 & $1 \mathrm{~atm}$ \\
\hline Chang. e You & 1996 & $\begin{array}{l}\text { - superfícies planas de cobre recobertas com } \\
\text { partículas de cobre ou alumínio, posicionadas em } \\
\text { diferentes orientações. }\end{array}$ & FC-72 & 1atm \\
\hline Chien & 1996 & $\begin{array}{l}\text { - superfície tubular constituída de túneis } \\
\text { posicionada horizontal e verticalmente }\end{array}$ & $\mathrm{R}-11, \mathrm{R}-123$ e R-22 & $26,7^{\circ} \mathrm{C}$ \\
\hline $\begin{array}{l}\text { Danilova e } \\
\text { Tikhonov }\end{array}$ & 1996 & $\begin{array}{l}\text { - } \quad \text { superfície tubular de cobre recoberta com } \\
\text { arame de cobre }\end{array}$ & $\mathrm{R}-113$ & $1 \mathrm{~atm}$ \\
\hline $\begin{array}{l}\text { Benjamin } \\
\text { e Balakrihnan }\end{array}$ & 1997 & $\begin{array}{l}\text { - } \quad \text { superfícies de aço e alumínio com diferentes } \\
\text { acabamentos }\end{array}$ & $\begin{array}{c}\mathrm{H}_{2} \mathrm{O}, \mathrm{CCl}_{4}, \mathrm{n} \text {-hexano e } \\
\text { acetona }\end{array}$ & $1 \mathrm{~atm}$ \\
\hline Chang e You & $1997 \mathrm{a}$ & $\begin{array}{l}\text { - } \quad \text { superfície horizontal de cobre recoberta com } \\
\text { partículas de diamante de diferentes tamanhos }\end{array}$ & FC-72 & $1 \mathrm{~atm}$ \\
\hline Chang e You & $1997 b$ & $\begin{array}{l}\text { - } \quad \text { superfícies micro-porosas recobertas com } \\
\text { diferente materiais (ABM; CBM; DBM; DOA; } \\
\text { SOA) }\end{array}$ & FC-72 & $1 \mathrm{~atm}$ \\
\hline Chang e You & $1997 \mathrm{c}$ & $\begin{array}{ll}\text { - } & \text { tubo liso } \\
\text { - } & \text { tubo aletado com } 709 \text { aletas/m } \\
\text { - } & \text { tubos intensificadores comerciais } \\
\text { denominados Turbo-B e High-flux } \\
\text { - } & \text { tubo liso com micro-poros } \\
\text { - } & \text { tubo aletado com micro-poros }\end{array}$ & FC-87 e R-123 & $1 \mathrm{~atm}$ \\
\hline Hsieh e Weng & $1997 \mathrm{a}$ & $\begin{array}{ll}- & \text { tubo liso } \\
\text { - } & \text { tubos aletados }\end{array}$ & $\begin{array}{c}\mathrm{H}_{2} \mathrm{O}, \mathrm{R}-134 \mathrm{a} \text { e suas } \\
\text { misturas com óleo }\end{array}$ & 99,9 e $4,4^{\circ} \mathrm{C}$ \\
\hline
\end{tabular}


Tabela 1.2 (continuação) Literatura sobre superfícies intensificadoras

\begin{tabular}{|c|c|c|c|c|}
\hline Autor & Ano & Geometria da Superfície & Fluido & $p_{\text {sat }}$ ou $T_{\text {sat }}$ \\
\hline Hsieh e Weng & $1997 b$ & $\begin{array}{l}\text { - } \quad \text { tubos lisos } \\
\text { - } \quad \text { tubos com superfícies porosas de diferentes } \\
\text { partículas, } \mathrm{Mb}, \mathrm{Al} \text { e } \mathrm{Cu} . \\
\text { - } \quad \text { tubos perfurados }\end{array}$ & R-134a, R-407c & $4,4^{\circ} \mathrm{C}$ \\
\hline $\begin{array}{l}\text { Hübner e } \\
\text { Künstler }\end{array}$ & 1997 & $\begin{array}{l}\text { - GEWA-K19 com a superfície externa das } \\
\text { aletas lixada } \\
\text { - } \text { GEWA-K19 tratada com jato de areia } \\
\text { - } \quad \text { GEWA-K } 36\end{array}$ & $\begin{array}{l}\text { propano } \\
\text { n-hexano }\end{array}$ & $\begin{array}{l}0,06 \leq p_{r} \leq 0,08 \\
0,01 \leq p_{r} \leq 0,25\end{array}$ \\
\hline Luke & 1997 & $\begin{array}{l}\text { - } \quad \text { superfícies tubulares de cobre e aço com } \\
\text { diferentes acabamentos }\end{array}$ & propano & $\begin{array}{l}p_{r}=0,1, \quad 0,2, \\
0,4 \text { e } 0,5\end{array}$ \\
\hline $\begin{array}{l}\text { Reed e } \\
\text { Mudawar }\end{array}$ & 1997 & - $\quad$ aletas presas com pequena força de contato & FC-72 e FC-87 & $1 \mathrm{~atm}$ \\
\hline Zhou e Bier & 1997 & $\begin{array}{l}\text { - } \quad \text { superfície tubular de cobre recoberto com } \\
\text { material cerâmico composto por óxido de alumínio } \\
\text { e óxido de titânio. } \\
\text { - } \quad \text { superfície tubular de aço tratada com jato de } \\
\text { areia }\end{array}$ & $\begin{array}{l}\text { R-12, R-114, R-134a, } \\
\text { R-113, propano, n- } \\
\text { butano, i-pentano, três } \\
\text { diferentes misturas de n- } \\
\text { butano e propano }\end{array}$ & $\begin{array}{l}\text { valores de } \\
\text { pressão } \\
\text { reduzida entre } \\
0,025 \text { e } 0,7\end{array}$ \\
\hline Chien e Webb & 1998 & $\begin{array}{l}\text { - superfície tubular posicionada vertical e } \\
\text { horizontalmente constituída de túneis }\end{array}$ & $\begin{array}{l}\mathrm{R}-11, \mathrm{R}-123, \mathrm{R}-134 \mathrm{a} \text { e } \\
\mathrm{R}-22\end{array}$ & $1 \mathrm{~atm}$ e $26,7^{\circ} \mathrm{C}$ \\
\hline Hsieh et al & 1999 & $\begin{array}{l}\text { - tubo liso de cobre } \\
\text { - tubos aletados de cobre com diferentes } \\
\text { ângulos de aleta }\end{array}$ & $\mathrm{H}_{2} \mathrm{O}$ e $\mathrm{R}-134 \mathrm{a}$ & 99,9 e $4,4{ }^{\circ} \mathrm{C}$ \\
\hline
\end{tabular}

Finalmente, conclui-se que, futuras pesquisas referentes a intensificação da transferência de calor deverão buscar os seguintes objetivos:

O desenvolvimento de modelos analíticos e correlações, caso possível, aplicáveis a um número extenso de fluidos.

Estudos de aplicação, visando definir onde cada técnica de intensificação pode ser efetivamente utilizada.

Avanços nos métodos de manufatura, proporcionando, além de reduções de custos, a viabilização comercial de novas superfícies.

Estudos conjuntos de desempenho e manufatura de superfícies tubulares externa e internamente intensificadoras. 


\subsubsection{Ebulição Nucleada de Misturas de Refrigerante e Óleo de Lubrificação}

O ciclo de compressão a vapor incorpora um compressor, equipamento que apresenta partes móveis, as quais, devido às suas características operacionais e construtivas, necessitam ser lubrificadas. Assim, é necessária a utilização de óleo lubrificante neste equipamento. Este óleo, devido a características construtivas do equipamento, entra em contato com o refrigerante no compressor, sendo mecanicamente arrastado até o condensador. Dali, como o óleo é solúvel na fase líquida do refrigerante, é transportado ao evaporador onde se deposita em virtude da evaporação do refrigerante. O retorno do óleo ao compressor, teoricamente, deveria se dar em sua totalidade através do arrasto causado pelo escoamento do refrigerante. Para o caso de aplicações da amônia*, nas quais o refrigerante na fase líquido e o óleo lubrificante são imiscíveis, a utilização de equipamentos para separar o óleo lubrificante do refrigerante, não evita que uma certa quantidade de óleo atinja o evaporador.

A adição de óleo lubrificante pode alterar drasticamente o desempenho do evaporador pelo seu efeito no coeficiente de transferência de calor. Resultados experimentais demonstram que, para concentrações superiores a $3 \%$, verifica-se sistematicamente uma diminuição no coeficiente de transferência de calor com a concentração de óleo. Tal comportamento pode ser verificado na Fig. 1.8, baseada na correlação proposta por Hahne e Noworita (1984), a partir do R-11 à pressão atmosférica normal. Os estudos sobre ebulição nucleada de misturas compostas por refrigerante e óleo lubrificante caracterizam-se por um elevado número de lacunas e discordância entre diferentes autores. Daí a importância de pesquisas envolvendo a mudança de fase das misturas compostas por refrigerante líquido e óleo lubrificante.

A Tabela 1.3 apresenta um resumo das publicações envolvendo o estudo deste tema, incluindo características da superfície de transferência de calor, $T_{s a t}, \omega_{o}$, refrigerante e óleo lubrificante utilizados. Verifica-se que, embora existam alguns trabalhos envolvendo a ebulição em superfícies intensificadoras, nenhum dos estudos dedica-se aos refrigerantes e óleos de lubrificação recentemente introduzidos pela indústria frigorífica. As seguintes conclusões podem ser tiradas do breve estudo bibliográfico:

Na transição entre ebulição nucleada e convecção natural, a elevação da concentração de óleo acentua o afastamento entre as curvas de acréscimo e decréscimo de fluxo de calor na curva de ebulição, fenômeno denominado na literatura por histerese. Isto ocorre, segundo alguns autores, como resultado do incremento da tensão superficial e

* Recentemente foram desenvolvidos alguns óleos lubrificantes miscíveis com a amônia. 
conseqüente elevação da energia de ativação da cavidade.

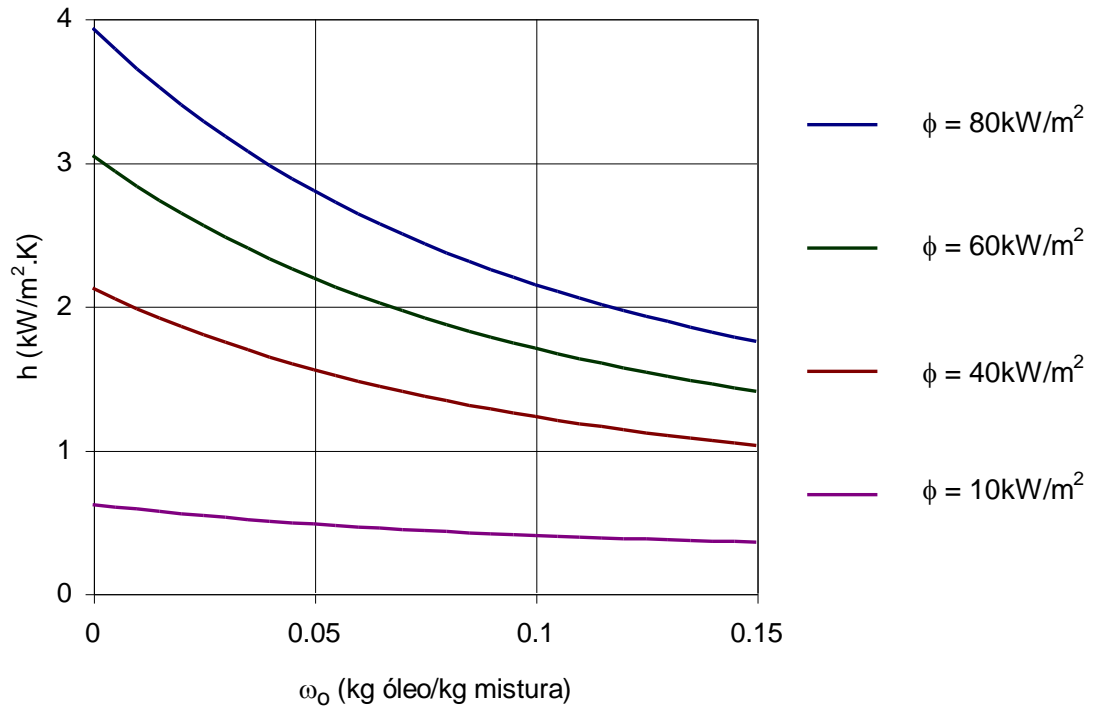

Figura 1.8 Variação do coeficiente de transferência de calor com a concentração de óleo, para $\phi$ constante, utilizando a correlação de Hahne e Noworyta (1984)

Tabela 1.3 Literatura referente a ebulição de misturas compostas por refrigerante e óleo de lubrificação

\begin{tabular}{|c|c|c|c|c|}
\hline $\begin{array}{l}\text { Autor } \\
\end{array}$ & Ano & Geometria da Superfície & Fluido & $\bar{p}_{\text {sat }}$ ou $T_{\text {sat }}$ \\
\hline Dougherty e Sauer & 1975 & $\begin{array}{l}\text { - superfícies comerciais de cobre } \\
\text { com diâmetros externos de 15,9 e } \\
28,6 \mathrm{~mm}\end{array}$ & $\begin{array}{l}\mathrm{R}-11 \text { e R-113 } \\
0 \% \leq \omega_{o} \leq 10 \% \\
\text { óleo mineral parafínico com } \\
v=31,8 \bullet 10^{-6} \mathrm{~m}^{2} / \mathrm{s} / 38^{\circ} \mathrm{C}\end{array}$ & $1 \mathrm{e} 2 \mathrm{~atm}$ \\
\hline $\begin{array}{l}\text { Chongrungreong e } \\
\text { Sauer }\end{array}$ & 1980 & $\begin{array}{l}\text { - superfícies comerciais de cobre } \\
\text { com diâmetros externos de } 15,9 \text {; } \\
22,2 \text { e } 28,6 \mathrm{~mm}\end{array}$ & $\begin{array}{l}\mathrm{R}-11 \\
\omega_{0}=0,5 \text { e } 10 \% \\
3 \text { óleos minerais parafínicos } \\
\text { com os seguintes valores de } \\
v \text {. } \\
31,8 \bullet 10^{-6} \mathrm{~m}^{2} / \mathrm{s} / 38^{\circ} \mathrm{C} \\
63,2 \bullet 10^{-6} \mathrm{~m}^{2} / \mathrm{s} / 38^{\circ} \mathrm{C} \\
113,0 \bullet 10^{-6} \mathrm{~m}^{2} / \mathrm{s} / 38^{\circ} \mathrm{C}\end{array}$ & $1 \mathrm{e} 2 \mathrm{~atm}$ \\
\hline Anikin et al & 1984 & - superfície tubular lisa & $\begin{array}{l}\mathrm{CCl}_{4} \text { e R-113 } \\
0 \% \leq \omega_{o}<80 \% \\
\text { respectivamente, com o óleo } \\
\mathrm{I}-40 \mathrm{a} \quad \mathrm{e} \text { óleo para } \\
\text { transformador }\end{array}$ & 59,2 e $101 \mathrm{kPa}$ \\
\hline
\end{tabular}


Tabela 1.3 (continuação) Literatura referente a ebulição de misturas compostas por refrigerante e óleo de lubrificação

\begin{tabular}{|c|c|c|c|c|}
\hline Autor & Ano & Geometria da Superfície & Fluido & $p_{\text {sat }}$ ou $T_{\text {sat }}$ \\
\hline Hahne e Noworyta & 1984 & $\begin{array}{l}\text { - superfície plana, horizontal } \\
\text { circular, de cobre com diâmetro } \\
\text { igual a } 120 \mathrm{~mm} \text { e } R p=1,6 \mu \mathrm{m}\end{array}$ & $\begin{array}{l}\mathrm{R}-11 \\
0 \% \leq \omega_{o} \leq 20 \% \\
\bullet \quad \text { dois óleos minerais } \\
\text { naftênicos com os seguintes } \\
\text { valores de } v \text { : } \\
65 \bullet 10^{-6} \mathrm{~m}^{2} / \mathrm{s} / 40^{\circ} \mathrm{C} \\
95 \bullet 10^{-6} \mathrm{~m}^{2} / \mathrm{s} / 40^{\circ} \mathrm{C} \\
\bullet \text { dois óleos sintéticos com } \\
\text { os seguintes valores de } v \text {. } \\
40 \bullet 10^{-6} \mathrm{~m}^{2} / \mathrm{s} / 40^{\circ} \mathrm{C} \\
33 \bullet 10^{-6} \mathrm{~m}^{2} / \mathrm{s} / 40^{\circ} \mathrm{C}\end{array}$ & $1 \mathrm{~atm}$ \\
\hline Jensen e Jackman & 1984 & $\begin{array}{l}\text { - superfície de aço inoxidável } \\
\text { com diâmetro externo igual a } \\
12,7 \mathrm{~mm}\end{array}$ & $\begin{array}{l}\mathrm{R}-113 \\
\omega_{o}=0,2,5 \text { e } 10 \% \\
\text { tipos de óleo não } \\
\text { especificados, com as } \\
\text { seguintes viscosidades: } \\
\mu=22,5 \bullet 10^{-3} \mathrm{~Pa} \bullet \mathrm{s} / 47,7^{\circ} \mathrm{C} \\
\mu=36,5 \bullet 10^{-3} \mathrm{~Pa} \bullet \mathrm{s} / 47,7^{\circ} \mathrm{C} \\
\mu=71,0 \bullet 10^{-3} \mathrm{~Pa} \bullet \mathrm{s} / 47,7^{\circ} \mathrm{C} \\
\mu=39,0 \bullet 10^{-3} \mathrm{~Pa} \bullet \mathrm{s} / 47,7^{\circ} \mathrm{C}\end{array}$ & $1 \mathrm{~atm}$ \\
\hline Yamazaki e Sakaguchi & 1986 & $\begin{array}{l}\text { - superfície de aço inoxidável } \\
\text { com diâmetro externo de } 20 \mathrm{~mm}\end{array}$ & $\begin{array}{l}\mathrm{R}-113 \\
0 \% \leq \omega_{o}<100 \% \\
\text { características do óleo não } \\
\text { especificadas }\end{array}$ & $1 \mathrm{~atm}$ \\
\hline Wanniarachchi et al & 1986 & $\begin{array}{l}\text { - superfície de cobre lisa com } \\
\text { diâmetro igual a } 15,9 \mathrm{~mm} \\
\text { - superfície de cobre e níquel } \\
\text { recoberta com partículas de cobre } \\
\text { e diâmetro igual a } 15,9 \mathrm{~mm}\end{array}$ & $\begin{array}{l}\mathrm{R}-114 \\
\omega_{o}=0,1,2,3,6 \text { e } 10 \% \\
\text { características do óleo não } \\
\text { especificadas }\end{array}$ & $-2,2$ e $6,7^{\circ} \mathrm{C}$ \\
\hline Silva & 1989 & $\begin{array}{l}\text { - superfície cilíndrica de latão } \\
\text { com diâmetro externo igual a } \\
\text { 14,2mm }\end{array}$ & $\begin{array}{l}\mathrm{R}-11, \mathrm{R}-113, \mathrm{R}-114 \\
\omega_{o}=0,1,3,5,10,20 \% \\
\text { óleo mineral parafínico com } \\
v=35 \bullet 10^{-3} \mathrm{~Pa} \bullet \mathrm{s} / 40^{\circ} \mathrm{C}\end{array}$ & $\begin{array}{l}30,7,36,1,47,5 \\
60,0,6,0,14,0^{\circ} \mathrm{C}\end{array}$ \\
\hline Saiz Jabardo e Silva & 1991 & $\begin{array}{l}\text { - superfície cilíndrica de latão } \\
\text { com diâmetro externo igual a } \\
14,2 \mathrm{~mm}\end{array}$ & $\begin{array}{l}\mathrm{R}-11, \mathrm{R}-113, \mathrm{R}-114 \\
\omega_{o}=0,1,3,5 \text { e } 7 \% \\
\text { óleo mineral parafínico com } \\
v=35 \bullet 10^{-3} \mathrm{~Pa} \bullet \mathrm{s} / 40^{\circ} \mathrm{C}\end{array}$ & $30,7,47,5$ e $6^{\circ} \mathrm{C}$ \\
\hline
\end{tabular}


Tabela 1.3 (continuação) Literatura referente a ebulição de misturas compostas por refrigerante e óleo de lubrificação

\begin{tabular}{|c|c|c|c|c|}
\hline Autor & Ano & Geometria da Superfície & Fluido & $p_{\text {sat }}$ ou $T_{\text {sat }}$ \\
\hline Webb e McQuade & 1993 & $\begin{array}{l}\text { - } \text { superfícies de cobre lisa com } \\
\text { diâmetro igual a } 17,5 \mathrm{~mm} \\
\text { - } \text { superfície GEWA-SE } \\
\text { - } \text { superfície Turbo-B }\end{array}$ & $\begin{array}{l}\mathrm{R}-11 \text { e R-123 } \\
\omega_{o}=0,0,5,1,2 \text { e } 5 \% \\
\text { óleo mineral não } \\
\text { especificado com } v=30,1 \bullet \\
10^{-6} \mathrm{~m}^{2} / \mathrm{s} / 40^{\circ} \mathrm{C}\end{array}$ & $4,4^{\circ} \mathrm{C}$ \\
\hline Memory et al & $1995 \mathrm{a}$ & $\begin{array}{l}\text { - } \text { superfície lisa com diâmetro } \\
\text { externo igual a } 15,9 \mathrm{~mm} \\
\text { - } \text { GEWA-K } 748 \text { aletas/m } \\
\text { - } \text { GEWA-K } 1024 \text { aletas/m } \\
\text { - } \text { GEWA-T } 748 \text { aletas/m } \\
\text { - } \text { GEWA-T } 1024 \text { aletas/m } \\
\text { - GEWA-YX } 1024 \text { aletas/m } \\
\text { - Termoexcel-HE } \\
\text { - Turbo-B } \\
\text { - } \text { superfície porosa High Flux }\end{array}$ & $\begin{array}{l}\mathrm{R}-114 \\
\omega_{o}=0,3 \text { e } 10 \% \\
\text { óleo mineral naftênico com } \\
v=62,5 \bullet 10^{-3} \mathrm{~Pa} \bullet \mathrm{s} / 40^{\circ} \mathrm{C}\end{array}$ & $2,2^{\circ} \mathrm{C}$ \\
\hline Hsieh e Weng & $1997 \mathrm{a}$ & $\begin{array}{l}\text { - superfícies tubulares de cobre } \\
\text { com diâmetro igual a } 27 \mathrm{~mm} \text { e } \\
\text { aletas com os seguintes ângulos de } \\
\text { inclinação } 30,45 \text { e } 60^{\circ} \mathrm{C}\end{array}$ & $\begin{array}{l}\text { R-134a e água } \\
\omega_{o}=0,2,5 \text { e } 10 \% \\
\text { óleo sintético poliol éster } \\
\text { com } v=74 \bullet 10^{-3} \mathrm{~Pa} \bullet \mathrm{s} / 40^{\circ} \mathrm{C}\end{array}$ & 4,4 e $99,9^{\circ} \mathrm{C}$ \\
\hline
\end{tabular}

*Nesta tabela não foram incluídos estudos envolvendo o efeito do óleo em banco de tubos, estes trabalhos estão listados na Tabela 1.4

Para concentrações de óleo lubrificante superiores a 3\%, verifica-se um decréscimo no coeficiente de transferência calor, quando comparado ao seu desempenho para refrigerante puro. Fato que ocorre tanto para superfícies lisas como intensificadoras.

A intensificação na transferência de calor para concentrações de óleo inferiores a 3\%, bem como os mecanismos responsáveis, ainda é um tema controvertido e pouco conhecido.

$>$ Os mecanismos considerados como responsáveis pelo decréscimo no coeficiente de transferência de calor para concentrações de óleo superiores a 3\% são: formação de uma camada rica em óleo junto a interface da bolha, dificultando a difusão de refrigerante através desta camada e consequentemente sua posterior evaporação; incremento da tensão superficial intensificando as forças de retenção da bolha; redução da movimentação de líquido junto a superfície devido ao incremento da viscosidade; variações de temperatura na interface da bolha que resultam em diferentes taxas de evaporação ao longo de sua interface e proporcionam, nesta região, valores de $\omega_{o}$ decrescentes a partir da superfície de transferência de calor em direção 
ao ápice da bolha. Assim, de forma análoga ao que ocorre como resultado de gradientes de temperatura, são gerados gradientes de tensão superficial os quais tendem a produzir escoamentos de líquido na região interfacial, só que neste caso, em sentido contrário ao gerado pelo gradiente de temperaturas, inibindo o arraste de líquido junto à superfície de aquecimento em direção ao seio do líquido e, consequentemente, seus efeitos convectivos.

\subsubsection{Estudo da Ebulição em Banco de Tubos}

Embora a ebulição nucleada em banco de tubos horizontais seja extensivamente utilizada em evaporadores na indústria petroquímica e de refrigeração, existem grandes incertezas sobre os mecanismos físicos que controlam o processo de transferência de calor. Estas incertezas refletem-se na reduzida precisão das correlações utilizadas no projeto destes equipamentos.

Os coeficientes de transferência de calor em ebulição nucleada para banco de tubos são, geralmente, superiores àqueles para um único tubo sob condições semelhantes. Este comportamento é verificado para o início da ebulição e fluxos de calor intermediários e é resultante da forte agitação do fluido junto à superfície dos tubos intermediários e superiores. Já, para fluxos de calor elevados, os tubos localizados na região superior, devido ao surgimento de bolsões estáveis de vapor nesta região, passam a apresentar desempenhos inferiores àquele de um único tubo. É interessante destacar que, independentemente de $\phi$, caso imersos no refrigerante líquido, os tubos inferiores apresentam desempenho semelhante ao de um único tubo.

$\mathrm{O}$ incremento na taxa de transferência de calor dos tubos superiores em relação aos inferiores, para as condições anteriormente especificadas, pode ser explicado pelos seguintes fatores:

A expansão volumétrica do fluido, como resultado da evaporação, induz uma forte agitação de fluido entre os tubos e eleva o número de tubos inundados, incrementando a transferência de calor devido ao mecanismo de convecção

$>\quad$ A elevada fração de vazio no escoamento do vapor entre os tubos, resulta em uma fina camada de líquido em suas superfícies, responsáveis por elevadas taxas de transferência de calor.

$>\quad \mathrm{O}$ escorregamento das bolhas junto à parede dos tubos superiores facilita novas nucleações. 
A Tabela 1.4 apresenta um resumo das principais publicações sobre ebulição nucleada em banco de tubos. Constata-se a existência de apenas um estudo, Danilova et al (1992), referente a amônia, refrigerante freqüentemente utilizado em evaporadores inundados, com a maioria dos trabalhos dedicando-se aos refrigerantes R-11 e R-113. Também é interessante destacar o reduzido número de trabalhos de otimização do desempenho deste tipo de trocador, através da análise da influência dos seguintes parâmetros: diâmetro dos tubos, distância e posicionamento relativo entre tubos, e número de linhas de tubos, que, apesar de estáticos, podem afetar drasticamente a dinâmica do escoamento vapor/líquido no interior do evaporador, alterando consequentemente seu desempenho.

Tabela 1.4 Literatura referente a ebulição em banco de tubos

\begin{tabular}{|c|c|c|c|}
\hline Autor & Ano & Características Experimentais & Fluido / $p_{\text {sat }}$ ou $T_{\text {sat }}$ \\
\hline Czikk et al & 1970 & $\begin{array}{l}\text { - banco de tubos com } 20 \text { superfícies lisas de cobre, } \\
D_{\text {ext }}=19 \mathrm{~mm} \\
\text { - banco de tubos com } 18 \text { superfícies corrugadas de cobre } \\
\text { e recobertas com material poroso, também de cobre, } \\
D_{\text {ext }}=25,4 \mathrm{~mm}\end{array}$ & $\begin{array}{l}\mathrm{R}-11 \text { e R-11 com óleo de } \\
\text { lubrificação para } \omega_{o}=2 \% / 1,11^{\circ} \mathrm{C}\end{array}$ \\
\hline Danilova e Dyundin & 1972 & $\begin{array}{l}\text { - banco de tubos com } 19 \text { superfícies de cobre com } 639 \\
\text { aletas } / \mathrm{m}, D_{e x t}=20,9 \mathrm{~mm} \\
\text { - banco de tubos com } 19 \text { superfícies de cobre com } 2092 \\
\text { aletas } / \mathrm{m}, D_{e x t}=19,15 \mathrm{~mm}\end{array}$ & $\begin{array}{l}\text { R-12 e R-22 puros e para misturas } \\
\text { destes refrigerantes com óleo de } \\
\text { lubrificação } /-20{ }^{\circ} \mathrm{C}<T_{\text {sat }}<30^{\circ} \mathrm{C}\end{array}$ \\
\hline Arai et al & 1977 & $\begin{array}{l}\text { - banco de tubos com } 225 \text { superfícies comerciais } \\
\text { Termoexcel-HE, } D_{\text {ext }}=16,4 \mathrm{~mm} \\
\text { - banco de tubos com } 225 \text { superfícies aletadas, } 748 \\
\text { aletas } / \mathrm{m}, D_{e x t}=18 \mathrm{~mm}\end{array}$ & $\begin{array}{l}\mathrm{R}-12 \text { e } \mathrm{R}-12 \text { com óleo } \\
\text { lubrificante para } \omega_{o}=0,5,1,8, \\
3,4 \text { e } 2,8 \% / 0 \text { e } 2{ }^{\circ} \mathrm{C}\end{array}$ \\
\hline Cornwell e Schüller & 1982 & - banco de tubos com 241 superfícies lisas, $D_{e x t}=19 \mathrm{~mm}$ & $\mathrm{R}-113 / 1 \mathrm{~atm}$ \\
\hline Hahne e Müller & 1983 & $\begin{array}{l}\text { - ensaios com } 2 \text { e } 18 \text { tubos para superfícies de cobre com } \\
\text { densidades de aletas iguais a } 767 \text { aletas } / \mathrm{m}, D_{\text {ext }}=18,9 \mathrm{~mm}\end{array}$ & $\mathrm{R}-11 / 1$ bar \\
\hline Hwang e Yao & 1986 & $\begin{array}{l}\text { - banco de tubos composto por superfícies de aço } \\
\text { inoxidável, com } R p=0,3 \mu \mathrm{m} \text { alinhadas verticalmente e } \\
\text { distribuídas em } 3 \text { colunas e } 16 \text { linhas, } D_{e x t}=19,1 \mathrm{~mm}\end{array}$ & $\mathrm{R}-113 / 1 \mathrm{~atm}$ \\
\hline Chan e Shoukri & 1987 & $\begin{array}{l}\text { - superfícies tubulares lisas de alumínio dispostas } \\
\text { conforme as seguintes configurações: } 3 \text { tubos verticalmente } \\
\text { alinhados; nove superfícies distribuídas em três linhas e } \\
\text { três colunas; } 27 \text { superfícies distribuídas em nove linhas e } \\
\text { três colunas, } D_{e x t}=19,1 \mathrm{~mm}\end{array}$ & $\mathrm{R}-113 / 1 \mathrm{~atm}$ \\
\hline Jensen e Hsu & 1988 & $\begin{array}{l}\text { - } 135 \text { tubos de aço inoxidável verticalmente alinhados } \\
\text { distribuídos em } 5 \text { colunas e } 27 \text { linhas, } D_{e x t}=7,94 \mathrm{~mm}\end{array}$ & $\begin{array}{l}\mathrm{R}-113 \mathrm{p} / p_{\text {sat }} \text { igual a } 200,400 \mathrm{e} \\
500 \mathrm{kPa}\end{array}$ \\
\hline
\end{tabular}


Tabela 1.4 (continuação) Literatura referente a ebulição em banco de tubos

\begin{tabular}{|c|c|c|c|}
\hline Autor & Ano & Características Experimentais & Fluido / $p_{\text {sat }}$ ou $T_{\text {sat }}$ \\
\hline Danilova et al & 1992 & $\begin{array}{l}\text { - banco de tubos compostos por superfícies de aço lisas } \\
\text { - banco de tubos composto por superfícies porosas } \\
\text { recobertas com } \mathrm{Al} \text { e Mg. } \\
\text { para ambas as configurações os } 12 \text { tubos foram dispostos } \\
\text { segundo triângulos equiláteros em } 5 \text { linhas, } D_{e x t}=20,0 \mathrm{~mm}\end{array}$ & amônia e R-22/ $-20^{\circ} \mathrm{C}<T_{\text {sat }}<20^{\circ} \mathrm{C}$ \\
\hline Gupte & 1992 & $\begin{array}{l}\text { - banco de tubos composto por superfícies Turbo-B } \\
\text { - banco de tubos composto por superfícies GEWA-SE. } \\
\text { - banco de tubos composto por superfícies aletadas com } \\
\text { densidade de aletas igual a } 1023 \text { aletas/m } \\
\text { cada banco era composto de } 21 \text { superfícies, distribuídas } \\
\text { segundo triângulos equiláteros em } 5 \text { linhas, com } D_{e x t}=19,0 \\
\text { mm }\end{array}$ & $\begin{array}{l}\mathrm{R}-11, \mathrm{R}-123 \text { e } \mathrm{R}-134 \mathrm{a} / 4,4^{\circ} \mathrm{C} \text { e } \\
26,7^{\circ} \mathrm{C}\end{array}$ \\
\hline Marto e Anderson & 1992 & $\begin{array}{l}\text { - banco de tubos formado por } 35 \text { superfícies de cobre } \\
\text { lisas dispostas segundo triângulos equiláteros distribuídas } \\
\text { em } 10 \text { linhas, } D_{e x t}=15,9 \mathrm{~mm}\end{array}$ & R-113 / 1atm \\
\hline Memory et al & 1994 & $\begin{array}{l}\text { - banco de tubos formado por } 15 \text { superfícies Turbo-B } \\
\text { localizadas na região central do banco, e } 20 \text { superfícies } \\
\text { lisas localizadas nas laterais. São dispostas segundo } \\
\text { triângulos equiláteros, num total de } 10 \text { linhas, } D_{e x t}=15,9 \\
\mathrm{~mm}\end{array}$ & R-113 / 1atm \\
\hline Webb e Chien & 1994 & $\begin{array}{l}\text { - } 21 \text { superfícies de cobre lisas distribuídas em } 6 \text { linhas e } \\
\text { posicionados segundo triângulos equiláteros, } D_{e x t}=16,8 \mathrm{~mm}\end{array}$ & $\mathrm{R}-113$ e $\mathrm{R}-123 / 18.9^{\circ} \mathrm{C}$ e $37.8^{\circ} \mathrm{C}$ \\
\hline Li e Hahne & 1995 & $\begin{array}{l}\text { - banco de tubos composto por superfícies de cobre com } \\
\text { densidade de aletas igual a } 1023 \text { aletas } / \mathrm{m} \text {, posicionadas em } \\
\text { linha verticalmente distribuídas em } 3 \text { colunas e } 6 \text { linhas, } \\
D_{e x t}=18,8 \mathrm{~mm}\end{array}$ & $\mathrm{R}-11 / 100 \mathrm{kPa}$ \\
\hline Memory et al & $1995 b$ & $\begin{array}{l}\text { - banco de tubos composto por superfícies GEWA-K } \\
D_{\text {ext }}=12,9 \mathrm{~mm} \\
\text { - banco de tubos composto por superfícies Turbo B, } \\
D_{\text {ext }}=15,9 \mathrm{~mm} \text {. } \\
\text { - banco de tubos composto por superfícies HighFlux, } \\
D_{\text {ext }}=15,7 \mathrm{~mm} \\
\text { cada banco de tubos é formado por } 15 \text { superfícies } \\
\text { intensificadoras localizadas na região central do banco, e } \\
20 \text { superfícies lisas localizadas nas laterais, cujo } D_{e x t}=15,9 \\
\text { mm. São dispostas segundo triângulos equiláteros, num } \\
\text { total de } 10 \text { linhas. }\end{array}$ & $\begin{array}{l}\text { R-114, e mistura composta por R- } \\
114 \text { e óleo lubrificante / } 1 \mathrm{~atm}\end{array}$ \\
\hline Roser et al & 1999 & $\begin{array}{l}\text { - banco de tubos composto por } 45 \text { superfícies de cobre } \\
\text { com } R_{a}=0,4 \mu \mathrm{m} \text { distribuídas em } 18 \text { linhas e cinco colunas } \\
\text { arranjadas segundo triângulos equiláteros }\end{array}$ & n-pentano/ 200, 300 e $500 \mathrm{kPa}$ \\
\hline
\end{tabular}




\subsubsection{Conclusões}

Com base neste breve estudo bibliográfico, conclui-se que a ebulição nucleada constitui uma área próspera para novas pesquisas, tanto na industria como na academia, sendo um tema caracterizado por certos aspectos obscuros. As pesquisas podem abranger desde a determinação da taxa de crescimento de uma bolha até a previsão do desempenho de um evaporador inundado composto por um banco de tubos e superfícies intensificadora, cujo fluido em ebulição é uma mistura composta por refrigerante halogenado e óleo de lubrificação. Devido ao grande número de tópicos relevantes no estudo deste mecanismo, as pesquisas devem concentrar esforços em determinados aspectos. Assim, embora se reconheça que o estudo de superfícies intensificadoras, ebulição de misturas compostas por refrigerante e óleo de lubrificação e banco de tubos sejam áreas prósperas para novas pesquisas, o presente trabalho dedica-se ao estudo teórico experimental da ebulição nucleada de refrigerantes halogenados puros em superfícies lisas, com a proposição de uma correlação genérica para estes fluidos, incluindo os efeitos do material e acabamento da superfície de transferência de calor.

\subsection{Escopo da Tese}

\subsubsection{Objetivos do Trabalho}

O presente trabalho tem como objetivo o levantamento de um banco de dados relativamente extenso, envolvendo parâmetros de superfície, diferentes refrigerantes halogenados e uma ampla faixa de pressões reduzidas. Estes resultados experimentais serão utilizados no desenvolvimento de uma correlação, teoricamente fundamentada e baseada em propriedades reduzidas, para o coeficiente de transferência de calor. Nos Capítulos 8 e 9 são apresentadas recomendações para trabalhos futuros e as principais conclusões deste trabalho.

\subsubsection{Análise da Literatura}

Conforme mostrado anteriormente, devido a existência de inúmeros tópicos 
relevantes no estudo da ebulição nucleada, a análise da literatura será limitada a publicações associadas ao tema do presente trabalho. Desta forma, serão analisados em profundidade os fundamentos da ebulição nucleada, Capítulo 2, e as principais correlações da literatura, Capítulo 3. Esta análise serve como embasamento para a discussão dos resultados experimentais e a proposição da correlação, respectivamente, nos Capítulo 6 e 7.

\subsubsection{Condições Experimentais}

\subsubsection{Refrigerantes}

Os refrigerantes ensaiados cujos resultados experimentais são utilizados para a verificação do modelo, Capítulo 7, são os seguintes: pouco voláteis (R-11 e R-123) e voláteis (R-12, R-134a, R-22). Estes resultados são previamente analisados e discutidos no Capítulo 6. Os Capítulo 4 e 5 apresentam, respectivamente, a descrição do equipamento e do procedimento experimental utilizados para o levantamento destes dados.

\subsubsection{Pressões de Saturação}

Os resultados experimentais foram levantados para pressões reduzidas relativas a temperaturas de saturação variando entre -14 e $93^{\circ} \mathrm{C}$, para os refrigerantes apresentados no item anterior. Embora nas aplicações não seja tão ampla a referida faixa de operação, é importante no sentido de determinar o efeito da pressão e da rugosidade superficial na taxa de transferência de calor.

\subsubsection{Características Superficiais}

Características da superfície podem influenciar a taxa de transferência de calor através de parâmetros tais como, o número de cavidades ativas, a freqüência e dinâmica de bolhas junto a superfície, relacionadas às características de acabamento e composição da 
superfície. Objetivando a incorporação na correlação proposta dos efeitos destes parâmetros, levantaram-se resultados para as seguintes condições:

$>$ acabamento superficial: $0,02 \mu \mathrm{m} \leq R a \leq 3,5 \mu \mathrm{m}$

$>$ composição: $\quad$ cobre, latão, aço inoxidável 


\section{Capítulo 2 - Fundamentos da Ebulição Nucleada}

\subsection{Introdução}

Este capítulo trata da análise da literatura referente aos fundamentos básicos da ebulição. São analisados estudos envolvendo a curva de ebulição, a formação e o crescimento de bolhas, os mecanismos físicos de transferência de calor e a influência de parâmetros físicos no coeficiente de transferência de calor. Tal análise, além de possibilitar o aprofundamento do estudo da Ebulição Nucleada, fundamenta a apresentação dos modelos para a previsão do coeficiente de transferência de calor, Capítulo 3, e permite justificar comportamentos observados nos resultados experimentais, Capítulo 6.

\subsection{Curva de Ebulição}

Nukiyama (1934) foi o primeiro a identificar os distintos regimes de ebulição, utilizando um equipamento rudimentar em face da tecnologia atual, composto por um fio horizontal de platina imerso num banho de água, ao qual era aplicada uma corrente elétrica. Mediram-se as temperaturas do banho, através da pressão de saturação, e do fio, através de sua resistência elétrica, com o auxílio de uma ponte de Wheatestone. Conhecendo-se previamente a corrente elétrica e a tensão aplicada ao fio, obteve-se a potência dissipada e construiu-se uma curva de $\phi$ vs $\Delta T$, denominada posteriormente de CURVA DE EBULIÇÃO. A Fig. 2.1 apresenta a curva de ebulição, à qual, com base no estudo 


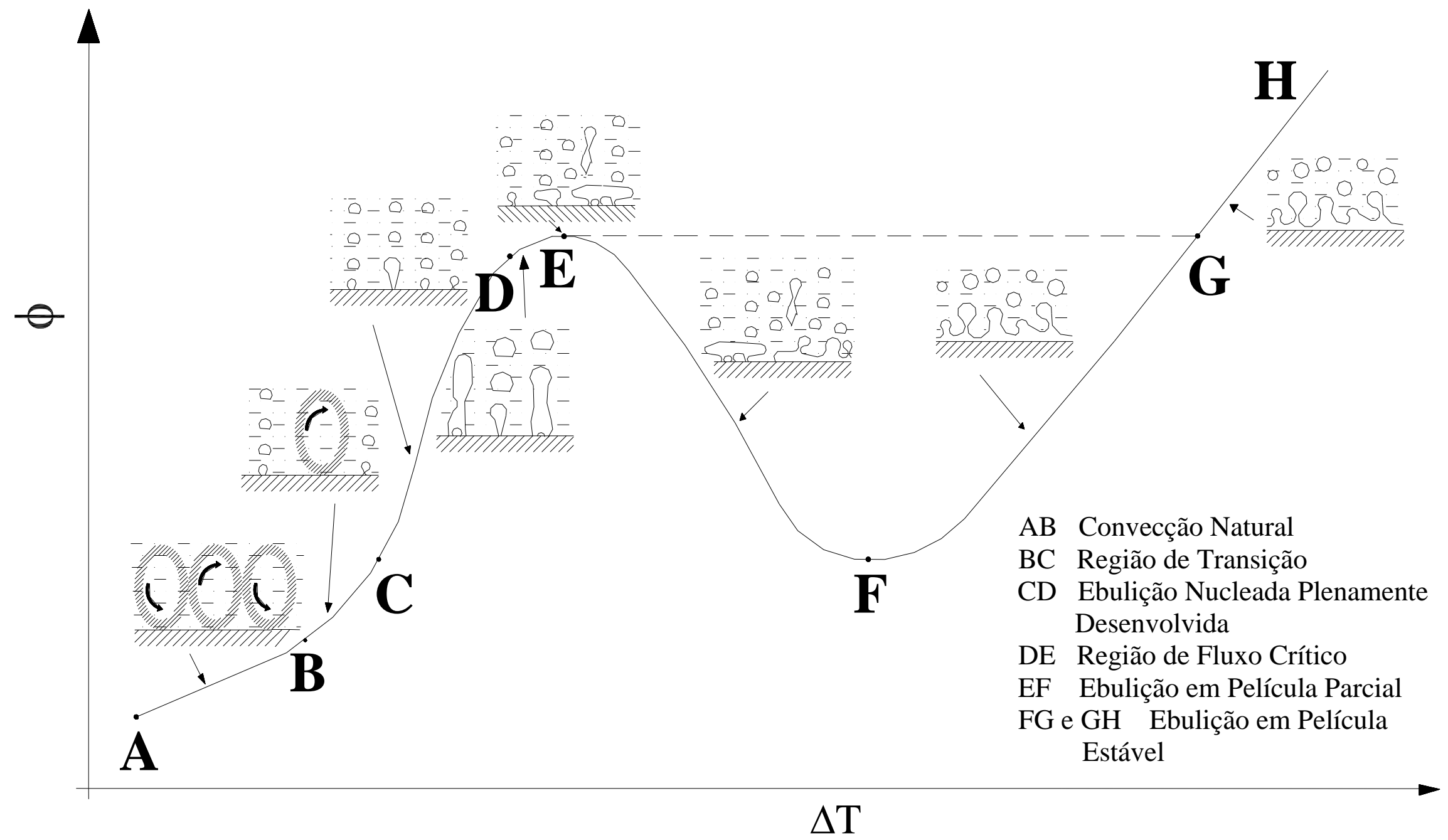

Figura 2.1 Ilustração esquemática da Curva de ebulição 
fotográfico realizado por Gaertner (1965), foi incorporada esquematicamente uma ilustração física dos distintos regimes. Estes caracterizam a ebulição, e podem ser divididos nos seis regimes seguintes:

AB - Convecção Natural. Regime no qual o calor é removido da superfície por convecção resultante de efeitos de empuxo no líquido.

BC - Ebulição Nucleada Parcial (transição). O início da ebulição nucleada ocorre quando o superaquecimento da superfície é suficiente para promover a nucleação de vapor na superfície aquecida. O mecanismo de transferência de calor por convecção natural é o principal responsável pela remoção de calor da superfície, embora já existam algumas cavidades ativas. A curva da Fig. 2.1 corresponde a uma superfície previamente submetida a ebulição, apresentando um número razoável de cavidades ativas. Caso contrário, a curva de ebulição apresentaria uma descontinuidade, como indicado nas Figs. 2.2a e 2.2b, ilustrando, respectivamente curvas levantadas em condições de imposição do fluxo de calor e da temperatura superficial.

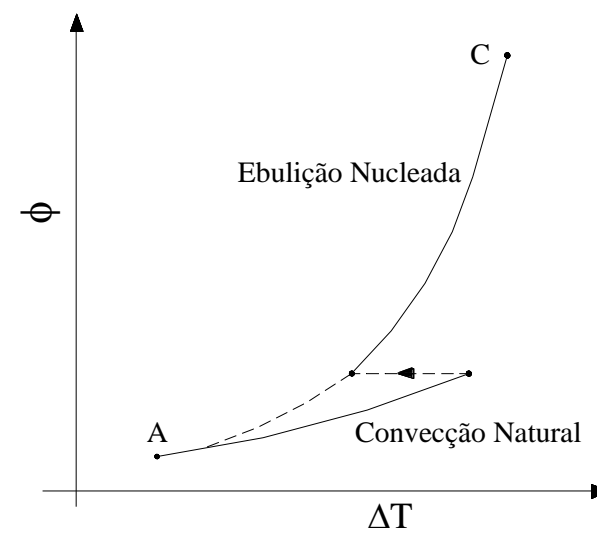

a)

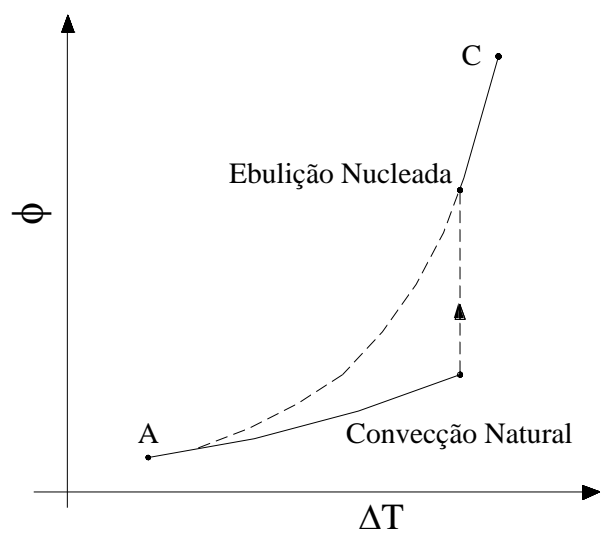

b)

Figura 2.2 Transição entre os regimes de convecção natural e ebulição nucleada. a) fluxo de calor controlado; b) superaquecimento controlado

\section{CD - Ebulição Nucleada Plenamente Desenvolvida ou simplesmente Ebuliçãa}

Nucleada. Esta região, objeto de estudo da presente pesquisa, caracteriza-se por apresentar, para elevadas variações no fluxo de calor, pequenas alterações no superaquecimento da superfície. Para fluxos de calor reduzidos, a superfície aquecida apresenta um número relativamente pequeno de cavidades ativas, fazendo com que surjam colunas de bolhas isoladas na superfície. Para elevados fluxos de calor, região (DE), tem-se o incremento do número de cavidades ativas, com colunas de bolhas 
começando a coalescer, do que resultam colunas de vapor e estruturas de vapor semelhantes a cogumelos.

E - Fluxo Crítico de Calor. Corresponde ao estado que marca o limite superior da ebulição nucleada, cuja característica física é a dificuldade de suprimento de líquido à superfície aquecida, tendo como resultado um significativo aumento da temperatura superficial. No caso do aquecimento elétrico ou nuclear, condições em que o fluxo de calor é imposto, quando a região de fluxo crítico é atingida, uma elevação do fluxo de calor (por menor que seja) promoverá a formação de um bolsão de vapor junto a superfície, o qual isolará termicamente a região. Com o fluxo de calor mantido, a temperatura superficial dá um salto, do ponto E até o G, indicado na Fig. 2.1 por uma linha tracejada.

EF - Regime de Transição (transição entre ebulição nucleada e ebulição em película). A transição é caracterizada pela existência de colunas instáveis de vapor sobre a superfície de aquecimento que proporcionam o desprendimento de grandes bolsões de vapor a intervalos aproximadamente regulares. Sendo uma região instável, é obtida somente em condições especiais, onde o parâmetro de controle é a temperatura da superfície, como ocorreria com aquecimento por vapor.

FG e GH - Ebulição em Película e em Película Estável. Estas regiões são caracterizadas por um filme de vapor em torno da superfície aquecida. Na ebulição em película, a transferência de calor entre a superfície aquecida e o líquido se dá por condução e convecção através do filme de vapor. A radiação passa a constituir-se no mecanismo principal com o incremento da temperatura da superfície, região denominada na literatura de ebulição em película estável, GH. O vapor é removido do filme através de bolhas que se destacam em intervalos regulares, e o acúmulo de vapor, com o incremento de $\Delta T$, resulta num aumento da espessura da película.

Embora os regimes compreendidos pelos pontos $\mathrm{E}$ e $\mathrm{H}$ encontrem diversas aplicações, uma discussão mais detalhada está fora do escopo deste trabalho, o qual se limitará ao regime de ebulição nucleada plenamente desenvolvida, típico das aplicações frigoríficas.

\subsection{Mecanismos Físicos Responsáveis pela Transferência de Calor}

Os mecanismos de transferência de calor aos quais se atribui a elevada taxa de 
transferência de calor em ebulição nucleada são:

Agitação do líquido promovida pelo desprendimento e colapso de bolhas. Os modelos baseados neste mecanismo consideram que o principal responsável pela remoção de calor junto à superfície aquecida seria a convecção forçada local, resultante da agitação promovida pelo desprendimento e colapso de bolhas. Ou seja, devido a forte agitação promovida pelas bolhas junto a superfície, o líquido junto a parede é renovado constantemente.

Evaporação de uma microcamada junto à base da bolha. Este mecanismo baseiase na hipótese de que as bolhas, ao crescerem, aprisionam uma camada de espessura muito reduzida de líquido superaquecido junto à superfície aquecida. Nesse mecanismo, ocorre a evaporação de líquido da microcamada e a condensação do vapor na parte superior da bolha, semelhante a um tubo de calor ("Heat Pipe"), sendo este o principal mecanismo de remoção de calor da superfície aquecida.

Termocapilaridade. Alguns modelos para transferência de calor em ebulição nucleada levam em consideração o mecanismo da termocapilaridade. Quando uma bolha se forma em uma cavidade da superfície de aquecimento, estabelecem-se movimentos de fluido junto a interface líquido-vapor, a partir da parede. Esses escoamentos de líquido em torno da bolha ocorrem devido a gradientes de tensão superficial resultantes da variação da temperatura ao longo da interface líquido-vapor. Daí o nome termocapilaridade. Este mecanismo encontra-se ilustrado na Fig. 2.3, Saiz Jabardo (1978), para um fio de platina vertical, imerso em um becker com água desionizada e não desgaseificada. Nesta figura, as mudanças de tonalidade no líquido indicam diferenças de densidade, com as regiões escuras junto a superfície sendo núcleos de vapor. Verifica-se, assim, o deslocamento do líquido a partir do núcleo de vapor em direção ao seio do líquido na forma de jatos.

Efeitos de micro-convecção. Este mecanismo admite que durante a ebulição nucleada, a alta taxa de transferência de calor da superfície aquecida para o banho ocorre por escoamentos convectivos ou por micropulsações decorrentes, respectivamente, do desprendimento e do rápido crescimento das bolhas. Como conseqüência, além do líquido junto à superfície deslocar-se paralelamente a ela, em sentidos que se alternam durante o ciclo da bolha, ele sofre rápidos movimentos, ora em direção ao banho, ora em direção a superfície.

Evaporação na linha de contato triplo. Localizada na base da bolha, corresponde à região de contato das três fases: sólido, líquido e vapor. A evaporação nesta região tem sido objeto de estudos recentes, com seus mecanismos sendo ainda pouco conhecidos. 


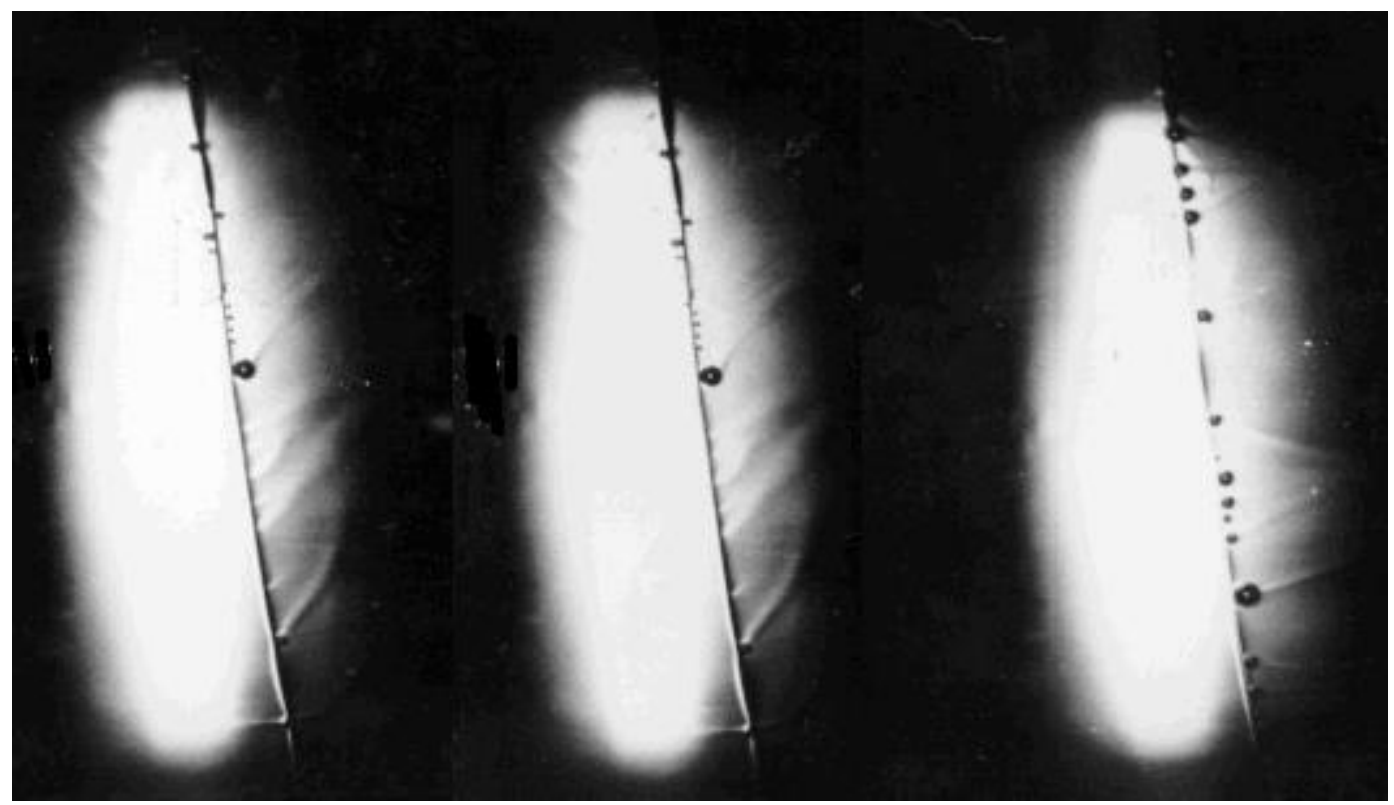

Figura 2.3 Ilustração da transferência de calor através do mecanismo de termocapilaridade Saiz Jabardo (1978).

\subsection{Formação e Crescimento de Bolhas}

Na termodinâmica elementar, a transição entre as fases líquida e gasosa se dá como uma sucessão de estados de equilíbrio estável. Na realidade, o fenômeno de nucleação de vapor ocorre em condições de não equilíbrio, com o líquido assumindo um estado metaestável de superaquecimento. Quando esta nucleação ocorre no seio do líquido, como resultado de sucessivos "colapsos" (estatísticos) de núcleos de elevada energia, denomina-se nucleação homogênea. Tal fenômeno é caracterizado pelo fato da concentração de núcleos energéticos ser extremamente sensível ao superaquecimento do líquido. A Tabela 2.1, elaborada por Saiz Jabardo (1988), baseada no modelo de Katz e Blender, para o R-22 à pressão atmosférica normal, ilustra claramente tal comportamento. Com a elevação da taxa de formação de núcleos de vapor por unidade de volume, $J$, a probabilidade de uma bolha exceder o tamanho crítico e crescer espontaneamente também é incrementada. Normalmente admite-se um valor de $J$ igual a $1 \cdot 10^{6}$ núcleos $/ \mathrm{cm}^{3}$.s como condição para a formação de vapor. Segundo este critério e a Tabela 2.1, a temperatura de mudança de fase do R-22 à pressão atmosférica em condições de nucleação homogênea é de aproximadamente $54^{\circ} \mathrm{C}$, $90^{\circ} \mathrm{C}$ acima daquela que ocorreria em condições de equilíbrio estável. Devido a nucleação 
homogênea não ser, geralmente, verificada em aplicações, este trabalho limita-se a uma visão geral do processo, não estendendo-se nesta análise.

Tabela 2.1 Efeito da temperatura na taxa de formação de núcleos de vapor

\begin{tabular}{cc}
\hline \hline temperatura do líquido $\left({ }^{\mathbf{0}} \mathbf{C}\right)$ & $\mathbf{n}^{\mathbf{0}}$ de núcleos de vapor/( $\left.\mathbf{c m}^{\mathbf{3}} \mathbf{s}\right)$ \\
\hline \hline 50 & $1,88 \cdot 10^{-12}$ \\
\hline 52 & $5,52 \cdot 10^{-3}$ \\
\hline 54 & $1,33 \cdot 10^{6}$ \\
\hline 56 & $7,96 \cdot 10^{10}$ \\
\hline 58 & $1,75 \cdot 10^{16}$ \\
\hline \hline
\end{tabular}

A vaporização ocorre, geralmente, junto a superfícies sólidas a partir das quais é transferido calor para o fluido, tratando-se de uma região na qual o líquido apresenta temperaturas superiores, favorecendo o surgimento de um núcleo de vapor. Tal nucleação é denominada de heterogênea e ocorre na grande maioria dos processos industriais. A existência de superfícies facilita a nucleação, não apenas pelo perfil de temperaturas junto a elas, mas por outras razões, entre as quais a existência de reentrâncias, cavidades, sujeiras ou gases aprisionados nestas irregularidades.

Uma vez ocorrida a nucleação de vapor em uma cavidade da superfície, inicia-se um processo cíclico de formação e desprendimento de bolhas, que geralmente é dividido em dois períodos distintos: tempo de espera, $t_{e}$, e tempo de crescimento, $t_{c}$. Quando uma bolha se destaca da parede, uma quantidade de líquido aquecido, é arrastada em direção ao seio do líquido, e um pequeno núcleo de vapor é deixado junto a cavidade ativa. Em virtude do afluxo de líquido frio de outras regiões, esse núcleo não começa a crescer imediatamente com o destacamento da bolha. Assim, devido a parede aquecer continuamente o líquido, sua temperatura eleva-se até que condições favoráveis ao crescimento da bolha sejam atingidas. Esse intervalo de tempo é denominado tempo de espera. Uma vez iniciado, o crescimento da bolha se dará até que as forças que tendem a removê-la da superfície superem aquelas que a retêm. O intervalo de tempo compreendido entre o início do crescimento e o desprendimento da bolha é denominado tempo de crescimento.

\subsubsection{Critério de Nucleação}

Como conseqüência dos processos transientes de transferência de calor durante o 
ciclo da bolha, o superaquecimento do líquido junto a uma cavidade ativa não é uniforme. $\mathrm{O}$ modelo proposto por Han e Griffith (1965a) permite a avaliação qualitativa de como a não uniformidade do superaquecimento e fatores como o subresfriamento do líquido, a pressão do sistema e o fluido em ebulição determinam a faixa de tamanhos de cavidades da superfície em condição de serem ativadas.

Este modelo admite, inicialmente, a existência de um embrião de vapor formado pelo vapor residual do desprendimento da bolha no processo intermitente de ebulição. Após o desprendimento de uma bolha, o volume ocupado por ela é substituído por líquido frio proveniente de regiões afastadas da superfície. Neste estágio, o fluido adjacente à superfície é idealizado como estando a temperatura do banho, $T_{\infty}$. Durante determinado período, o líquido junto a superfície é aquecido e ocorre o crescimento de uma camada de líquido superaquecido, como resultado da condução transiente, até atingir um determinado superaquecimento do líquido para o qual se inicia o crescimento do embrião de vapor. Embora em sistemas reais a difusão de calor junto a superfície também ocorra devido a efeitos de convecção, com o incremento de sua parcela de calor transferida com o afastamento da superfície, neste modelo admite-se uma camada, no interior da qual, o calor é transferido apenas através de difusão molecular. Externamente a esta camada tem-se o fluido com temperatura uniforme, constante e igual a $T_{\infty}$. Admite-se também $T_{p}$ uniforme e constante. Com base nestas idealizações, a transferência de calor da superfície para o líquido durante o período de espera foi modelada como condução transiente unidimensional, caracterizada pela seguinte equação diferencial:

$$
\frac{\partial T}{\partial t}=a \cdot \frac{\partial^{2} T}{\partial y^{2}}
$$

submetida às seguintes condições de contorno:

$$
t=0 \quad\left\{\begin{array}{lll}
T=T_{p} & p / & y=0 \\
T=T_{\infty} & p / & y>0
\end{array} \quad t>0 \quad\left\{\begin{array}{ccc}
T=T_{p} & p / & y=0 \\
T=T_{\infty} & p / & y \rightarrow \infty
\end{array}\right.\right.
$$

cuja solução é a seguinte:

$$
\frac{T-T_{p}}{T_{\infty}-T_{p}}=\operatorname{erf}\left(\frac{y}{2 \cdot \sqrt{a \cdot t}}\right)
$$

Com o objetivo de facilitar manipulações matemáticas, a espessura da camada 
limite térmica foi definida como a interseção com o eixo $y$, da reta tangente, em $y=0$, à curva dada pela Eq.(2.2) no gráfico $\left(T_{p}-T_{\infty}\right)$ vs $y$, resultando na seguinte equação:

$$
\delta=\sqrt{\pi \cdot a \cdot t}
$$

Deste modo, tem-se o superaquecimento do líquido variando linearmente a partir da superfície até $y=\delta$. Para distâncias da superfície superiores a $\delta$ a temperatura do fluido não seria mais afetada por $T_{p}$.

$\mathrm{Na}$ cavidade da superfície, o núcleo de vapor apresenta uma protuberância com formato hemisférico, em condição de equilíbrio estático e raio igual ao da cavidade, idealizada como tendo um formato cônico. A temperatura do vapor no interior da cavidade necessária para este equilíbrio foi obtida combinando as equações de Laplace* e de ClausiusClapeyron** e desprezando o volume específico do líquido em face do volume específico do vapor, o que é razoável na maioria dos casos, tendo-se como resultado:

$$
T_{b}=T_{s a t}+\frac{2 \cdot \sigma \cdot T_{s a t}}{r_{c} \cdot \rho_{v} \cdot h_{l v}}
$$

onde $T_{b}$ é a temperatura do vapor no interior da bolha.

Embora para que o núcleo de vapor esteja em equilíbrio com o líquido seja necessário que sua superfície seja isotérmica e adiabática, no modelo apenas esta última condição foi observada. Assim, da teoria do escoamento potencial e da analogia entre o escoamento de um fluido e a transferência de calor, é possível concluir que as linhas potenciais do escoamento de um fluido ao redor de um corpo hemisférico são equivalentes às linhas isotérmicas resultantes da condução transiente calor. Conclui-se, assim, que a distância entre a linha isotérmica passando pelo ápice da bolha e a superfície aquecida em uma região da superfície onde não mais existe a influência da bolha é igual a $3 / 2 \cdot r_{c}$. Desta forma, admitindo uma camada limite linear, a temperatura desta isotérmica é dada por $T=T_{p}-\left(T_{p}-T_{\infty}\right) \cdot\left(3 r_{c}\right) /(2 \delta)$. Finalmente, adotando-se como critério para o início do crescimento da bolha uma condição em que a temperatura da isotérmica passando pelo ápice da bolha seja igual a temperatura do vapor no interior da cavidade dada pela Eq. (2.4), obtém-se um intervalo entre um raio mínimo e um raio máximo das cavidades presentes sobre a superfície,

\footnotetext{
*A equação de Laplace consiste na condição de equilíbrio mecânico necessária para a existência de um núcleo de vapor e é dada pela equação ao lado:$$
p_{v}-p_{l}=\frac{2 \cdot \sigma}{r_{b}}
$$

**A equação de Clausius-Clapeyron, apresentada ao lado, pode ser determinada a partir das relações de Maxwell e seu resultado consiste na inclinação da curva de pressão de vapor. 
para os quais o crescimento de núcleos de vapor é possível. Os limites deste intervalo são dados pela seguinte equação:

$$
r_{c}=\frac{\delta}{3} \cdot \frac{\left(T_{p}-T_{s a t}\right)}{\left(T_{p}-T_{\infty}\right)} \cdot\left[1 \pm \sqrt{1-\frac{12 \cdot\left(T_{p}-T_{\infty}\right) \cdot T_{s a t} \cdot \sigma}{\left(T_{p}-T_{s a t}\right)^{2} \cdot \delta \cdot \rho_{v} \cdot h_{l v}}}\right]
$$

A Fig. 2.4 ilustra esquematicamente o intervalo de cavidades ativas para uma determinada condição. Através dela, conclui-se que com o decorrer do tempo e o incremento da espessura da camada limite ocorre uma condição em que a reta representando o superaquecimento do líquido Eq. (2.3) tangencia a curva de equilíbrio da bolha Eq. (2.4). Neste instante, caso a superfície possua uma cavidade preenchida com vapor e raio igual a $\left(r_{c}\right)_{f}$, o núcleo de vapor será ativado e iniciado o crescimento da bolha. Tal raio corresponde ao menor período de espera.

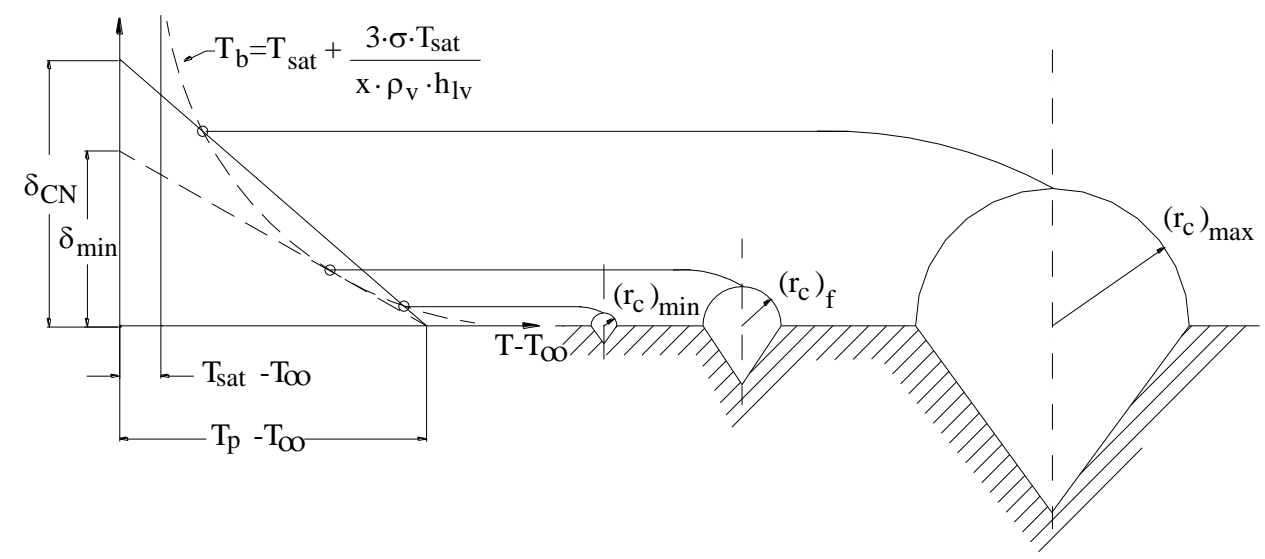

Figura 2.4 Ilustração do critério para início do crescimento de bolhas. Han e Griffith (1965a)

Logicamente, devido a efeitos de convecção natural no líquido, a camada limite térmica não cresce indefinidamente. Desta forma, define-se uma espessura máxima da camada limite, $\delta_{C N}$ delimitada por efeitos de convecção natural. Uma espessura da camada limite térmica $\delta_{C N}>\delta_{\min }$ resulta na ativação de cavidades com raios compreendidos entre $\left(r_{c}\right)_{\max }$ e $\left(r_{c}\right)_{\min }$. Cavidades com raio inferior a $\left(r_{c}\right)_{\min }$ não serão ativadas devido ao superaquecimento da superfície não permitir, pois a condição de $p_{b}>p_{s a t}+2 \cdot \sigma / r_{c}$ não é verificada. Já cavidades maiores que $\left(r_{c}\right)_{\max }$ serão inundadas com líquido, pois a pressão do vapor no interior da cavidade não é suficiente para manter um núcleo estável. Assim, fica exposto que o grau com que a distribuição de raios de cavidades na superfície se sobrepõe à 
faixa de cavidades potencialmente ativas, prevista pelo modelo, indica a densidade de cavidades ativas para um determinado superaquecimento. Este modelo também permite concluir que o decréscimo de $\delta_{C N}$ irá incrementar o superaquecimento necessário para o início da nucleação, melhorando as condições de resfriamento junto à superfície o gradiente de temperaturas fica mais acentuado e é possível que as condições para nucleação não possam ser satisfeitas, pois o "líquido está muito frio".

O modelo Hsu e Grahan apud Jabardo (1988), antecessor ao de Han e Griffith (1965a), difere deste pelo fato dos autores desconsiderarem a influência do núcleo de vapor nos gradientes de temperaturas no líquido, alterando desta forma a condição necessária para o crescimento da bolha.

\subsubsection{Crescimento da Bolha Junto a uma Parede Aquecida}

O crescimento de uma bolha sobre uma superfície aquecida pode ser idealizado, de uma maneira geral, como uma seqüência de estágios onde o crescimento é governado, inicialmente, pela inércia do líquido e, depois, por processos de transferência de calor. Embora ambos fatores ocorram concomitantemente durante todo o ciclo da bolha, a maior influência de um deles dependerá de variáveis como o fluido em ebulição, a aceleração gravitacional e o superaquecimento da superfície. Seu estudo envolve uma análise mais complexa, quando comparado ao crescimento de uma bolha em um campo de temperaturas uniforme, resultante da não existência de uma simetria esférica e da não uniformidade do campo de temperaturas do líquido junto à bolha.

Uma vez alcançada a condição para que a bolha inicie seu crescimento, a energia necessária para a evaporação do líquido junto à interface provém da região de líquido adjacente a bolha, aquecida durante o período de espera. Nos primeiros instantes do crescimento, o líquido junto a interface apresenta um superaquecimento elevado, de tal forma que a transferência de calor na interface não é o fator determinante da taxa de crescimento da bolha, e sim efeitos de inércia do líquido, pois com o embrião de vapor emergindo da cavidade ativa, ocorre, como resultado da elevada taxa de variação do seu raio de curvatura, uma rápida expansão da bolha. Este crescimento é resistido pelo líquido, inicialmente estático, que faz com que a bolha em seus primeiros estágios apresente um formato hemisférico. Deste modo, uma fina camada de líquido fica aprisionada entre a interface da bolha e a superfície aquecida. A evaporação nesta microcamada, segundo alguns autores, seria, a partir daí, o mecanismo responsável pelo crescimento da bolha, sendo sua 
taxa de crescimento o resultado de efeitos de inércia no líquido e da diferença entre o vapor formado na microcamada e o condensado nas regiões junto ao ápice da bolha. A evaporação desta microcamada explicaria variações drásticas na temperatura da superfície durante o ciclo da bolha, que, segundo Kenning e Yan (1996), para a ebulição da água a pressão atmosférica normal em uma superfície de cristal líquido, alcançam valores superiores a 16K. Este mecanismo ocorre em condições de microgravidade, elevados fluxo de calor e superaquecimento da superfície e valores reduzidos do ângulo de contato*, da entalpia de evaporação e da pressão do sistema. Nestas condições tem-se bolhas de tamanhos elevados, caracterizadas por um elevado tempo de espera e, uma vez iniciado o processo, altas taxas de crescimento da bolha. Este cenário ocorre em pressões reduzidas e metais líquidos.

No caso de bolhas com formato esférico, após um breve período dominado por efeitos de inércia, o mecanismo responsável pelo seu crescimento seria a evaporação do líquido localizado em uma camada limite térmica envolvendo toda a sua interface líquidovapor. Desta forma, com o crescimento da bolha controlado pela evaporação nesta "camada limite", a bolha apresenta uma taxa de crescimento inferior à situação anterior, resultando, consequentemente, em efeitos de inércia do líquido relativamente menores, permitindo que efeitos de tensão superficial se tornem relevantes e atuem de forma a resultar em um formato para a bolha aproximadamente esférico. Este mecanismo ocorre para fluxo de calor e superaquecimentos reduzidos, superfícies com cavidades moderadas e grandes, ângulos de contato moderados e elevados valores de pressão e $h_{l v}$. Tais condições resultam em bolhas de tamanho reduzidos e com baixas taxas de crescimento volumétrico.

Os modelos baseados neste mecanismo são denominados de modelo de "difusão", um deles o de Han e Griffith (1965a), despreza os efeitos de inércia do líquido ao redor da bolha e admite que o crescimento se dá apenas por efeitos de transferência de calor. Os autores consideram condução unidimensional em uma camada limite envolvendo a bolha, Eq. (2.1). Na solução da Eq (2.1) foram adotadas as condições de contorno e iniciais ilustradas na Fig. 2.5, determinando-se, desta forma, o gradiente de temperaturas instantâneo na interface.

\footnotetext{
* O ângulo de contato $\beta$ é definido como aquele delimitado pela interface líquido-vapor e a superfície, sendo medido a partir da região da superfície em contato com o líquido. A determinação do ângulo de contato e sua relação com a capacidade do líquido de molhar a superfície são ilustrados abaixo:
}

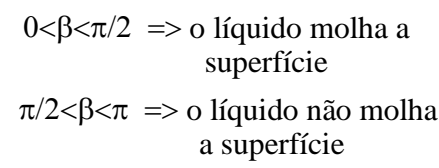

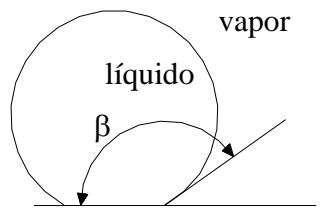

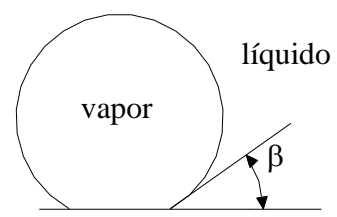


$\mathrm{t}=0$

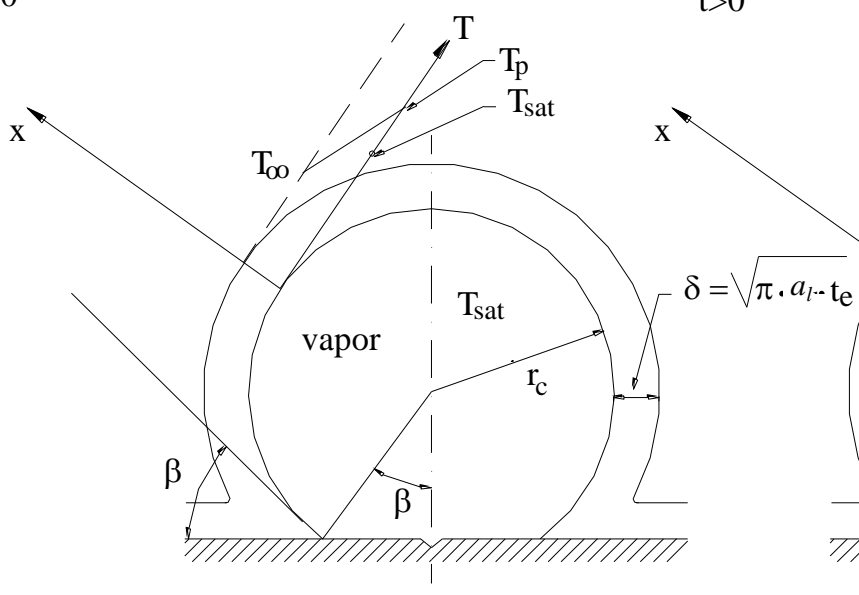

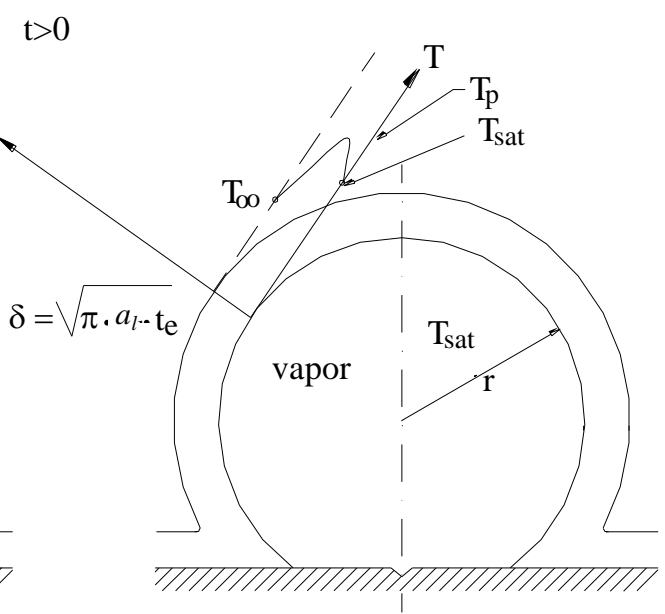

Figura 2.5 Condições iniciais e de contorno no modelo de Han e Griffth (1965a) para o crescimento de bolhas

Deste modo, através de um balanço de energia em toda a interface da bolha, admitindo que todo o calor transferido nas interfaces líquido-vapor e vapor-sólido fosse utilizado na evaporação do líquido e consequentemente no crescimento da bolha, obteve-se a seguinte equação para a variação do raio com o tempo:

$$
\left.\begin{array}{rl}
r-r_{c}=\frac{\varphi_{s} \cdot \varphi_{c}}{\varphi_{v}} \cdot \frac{a_{l} \cdot c_{l} \cdot \rho_{l}}{\rho_{v} \cdot h_{l v}} . \\
& {\left[\begin{array}{l}
\frac{2 \cdot\left(T_{p}-T_{s a t}\right)}{\sqrt{\pi \cdot a_{l}}} \cdot \sqrt{t}-\frac{\left(T_{p}-T_{s a t}\right) \cdot \delta}{4 \cdot a_{l}} \cdot \\
\frac{4 \cdot a_{l} \cdot t}{\delta^{2}} \cdot \operatorname{erf}\left(\frac{\delta}{\sqrt{4 \cdot a_{l} \cdot t}}\right)+ \\
\frac{2}{\sqrt{\pi}} \cdot \frac{\sqrt{4 \cdot a_{l} \cdot t}}{\delta} \cdot e^{\frac{-\delta^{2}}{4 \cdot a_{l} \cdot t}}-2 \cdot \operatorname{erfc}\left(\frac{\delta}{\sqrt{4 \cdot a_{l} \cdot t}}\right)
\end{array}\right]+\frac{\varphi_{b} \cdot h_{v s} \cdot\left(T_{p}-T_{s a t}\right)}{\varphi_{v} \cdot h_{l v} \cdot \rho_{v}} \cdot t}
\end{array}\right]
$$

Nesta equação, $h_{v s}$ é o coeficiente de transferência de calor na interface vaporsólido e $\varphi_{c}, \varphi_{s}, \varphi_{v}, \varphi_{b}$, são os fatores de forma definidos como funções do ângulo de contato.

Um trabalho interessante que trata do crescimento e destacamento de bolhas foi publicado por Mitrovic (1997). Para ele, a formação de vapor durante a fase de crescimento da bolha dá-se principalmente na região da linha de contato triplo. A Fig. 2.6 ilustra a linha de contato triplo na interface líquido-sólido-vapor. Segundo este modelo, a linha de contato triplo desliza sobre uma camada adsorvida de líquido junto a base da bolha, cuja manutenção seria resultante de forças intermoleculares entre sólido-líquido e líquido-líquido. A 
evaporação nesta micro-região tende a alterar o ângulo de contato (usualmente definido), sendo este função do fluxo de calor. Devido à evaporação e a efeitos de tensão superficial junto a base da bolha, a interface vapor-líquido apresenta um formato convexo.
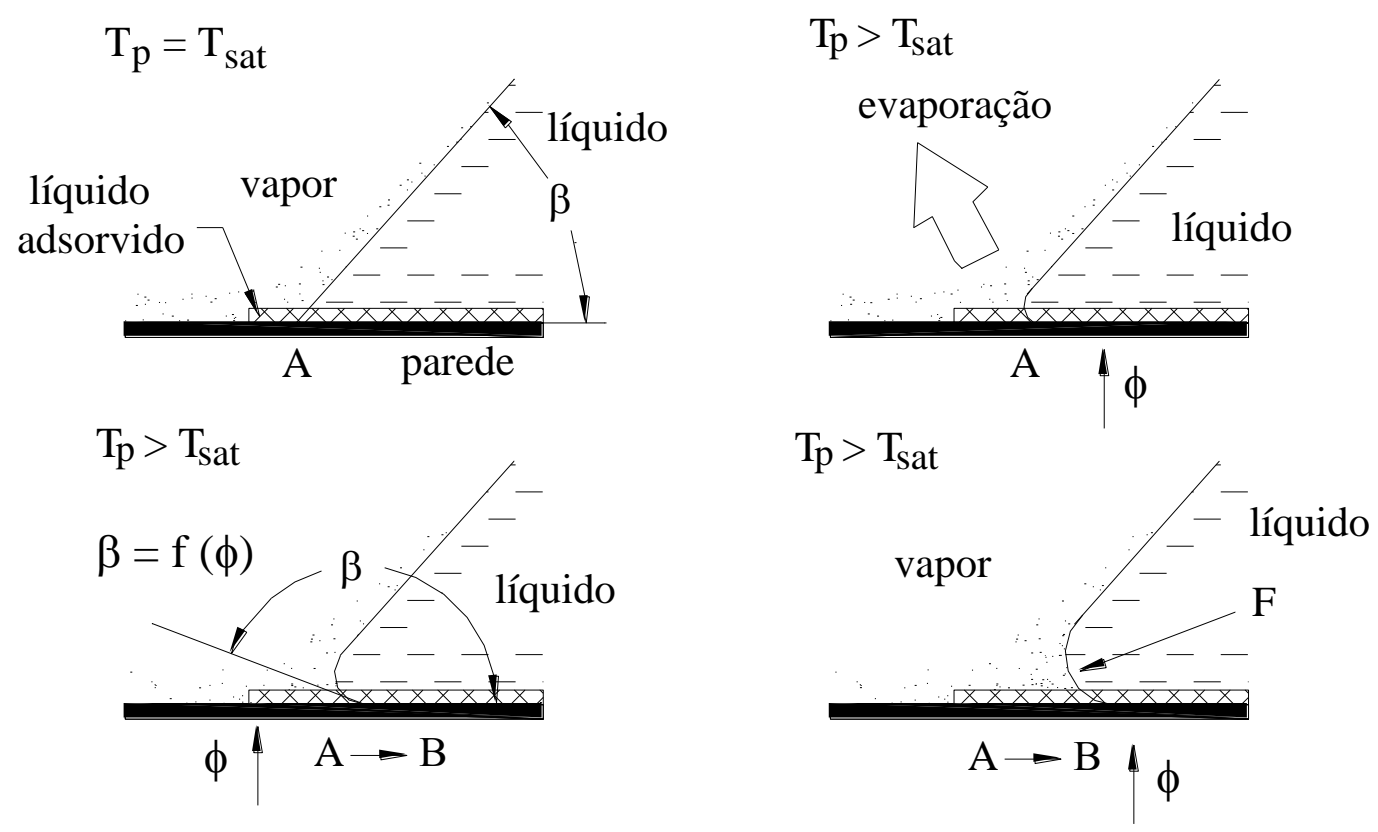

Figura 2.6 Evaporação na linha tripla, Mitrovic (1997)

A curvatura convexa estabelece uma força capilar, responsável pela remoção do líquido localizado entre a interface líquido-vapor e a superfície aquecida. Este mecanismo, ilustrado na Figs. 2.6 e 2.7, justificaria o deslocamento inicial da linha de contato triplo de A para $\mathrm{B}$ e o rápido incremento da área de vapor em contato com a parede durante a fase de crescimento da bolha verificado experimentalmente. Com o incremento de $R$, Fig. 2.7, a força resultante de efeitos de tensão superficial na superfície concavo-convexa, junto a base da bolha, é reduzida progressivamente até o ponto em que as forças devido a efeitos hidrodinâmicos a superem, fazendo com que a linha tripla de contato se mova, agora, de B para A, até o desprendimento da bolha, condição em que o valor de $r$ tende a 0. Como resultado da elevada curvatura na região de estrangulamento, surgem pressões capilares elevadas, que geram forças responsáveis pela deformação da bolha logo após o seu desprendimento, e, no caso de bolhas com maiores diâmetros, promovem um jato de líquido que penetra a bolha podendo resultar até em sua ruptura. Estas observações teóricas foram experimentalmente comprovadas pelo autor, verificando velocidades para o ápice do jato de 
líquido iguais à $1,7 \mathrm{~m} / \mathrm{s}^{2}$, podendo alcançar valores superiores a $6 \mathrm{~m} / \mathrm{s}^{2}$, logo após o desprendimento da bolha.



Figura 2.7 Desprendimento da bolha segundo Mitrovic (1997)

\subsubsection{Diâmetro e Freqüiência de Desprendimento e de Bolhas}

O diâmetro de desprendimento de bolhas e a frequiência com que são geradas são encontrados explicitamente na maioria das correlações para o coeficiente de transferência de calor. Atuam na determinação de tais aspectos mecanismos físicos envolvendo o crescimento, o desprendimento e a nucleação das bolhas, e o aquecimento do líquido junto a superfície.

Na previsão do diâmetro de desprendimento de uma bolha, os autores consideram um balanço entre as forças agindo sobre ela durante seu crescimento. Na maioria dos modelos, a tensão superficial tende a agir de forma a manter a bolha junto a superfície. Já efeitos de empuxo, embora dependam da orientação da superfície, favorecem o desprendimento. Tal hipótese é válida para uma superfície com face voltada para cima, na qual o empuxo atua diretamente a favor do desprendimento, por outro lado em superfícies com a face para baixo, ele procederá de forma a pressionar a bolha em direção a superfície, dificultando seu desprendimento. Consequentemente, em superfícies cilíndricas horizontais o efeito do empuxo variará ao redor do perímetro. Nas bolhas caracterizadas por elevadas taxas de crescimento, embora logo após o período de espera a inércia associada ao deslocamento do líquido resista ao crescimento, no final de seus ciclos de vida ela atuará de 
forma a "arrancá-las" da superfície. O forte movimento do líquido induzido pelo desprendimento de outras bolhas é outro fator que favorece o desprendimento. Finalmente, a taxa de crescimento da bolha, associada ao seu formato (hemisférico ou esférico), também afeta o desprendimento.

A Tabela 2.2 apresenta algumas das correlações para o diâmetro de desprendimento de bolhas. Constata-se que a maioria das correlações envolvem, basicamente, as propriedades termofísicas dos fluidos, o superaquecimento da parede e/ou o fluxo de calor específico, o ângulo de contato e a aceleração gravitacional, ajustando tais parâmetros aos resultados experimentais através de coeficientes e expoentes numéricos. A correlação proposta por Borishansky et al (1981) destaca-se por correlacionar $d_{b}$ através, apenas, de propriedades reduzidas $\left(p_{r}\right.$ e $\left.T_{r}\right)$ e de um "parâmetro" característico do fluido envolvendo a massa molecular e as propriedades críticas pressão e temperatura. Tal análise, embora um tanto simplista por não envolver fatores tais como a aceleração gravitacional, o fluxo de calor específico e o superaquecimento da superfície, destaca-se por considerar que propriedades termodinâmicas e de transportes podem ser substituídas por funções de $p_{r}$ e $T_{r}$. Esta abordagem é similar a adotada no presente trabalho, no qual se objetiva a determinação do coeficiente de transferência de calor como uma função das mesmas propriedades reduzidas.

Na Fig.2.8 são comparados os resultados de algumas destas correlações. Embora sejam verificadas grandes diferenças entre elas, principalmente para valores reduzidos de $p_{\mathrm{r}}$, as tendências em $d_{b}$ com o incremento da pressão reduzida são semelhantes, com os valores tornando-se próximo para $p_{\mathrm{r}}$ elevado. As diferenças verificadas podem ser resultantes da utilização pelos distintos autores, no ajuste das correlações, de diferentes dados experimentais, ou, segundo Carey (1992) de incertezas experimentais associadas a dificuldades na determinação exata de $d_{b}$.

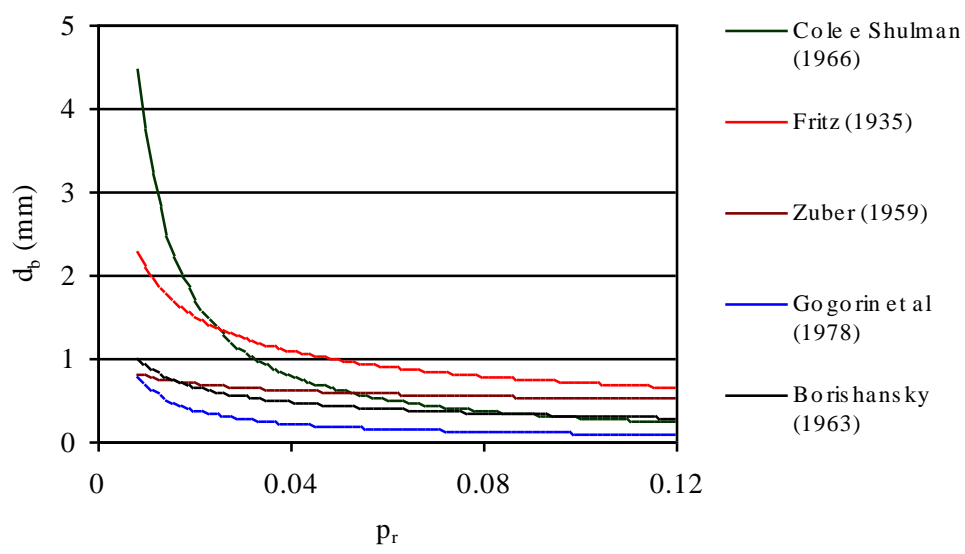

Figura 2.8 Variação de $d_{b} \operatorname{com} p_{r}, \mathrm{R}-11, \phi=20 \mathrm{~kW} / \mathrm{m}^{2}$ 
Tabela 2.2 Correlações para a determinação de $d_{b}$, Carey (1992).

\begin{tabular}{|c|c|c|}
\hline Autor & Correlação & Eq. $\mathbf{N}^{0}$ \\
\hline Fritz (1935) & $d_{b}=0,0208 \cdot \beta \cdot \sqrt{\frac{\sigma}{g \cdot \rho_{v l}}}$ & $(2.7)$ \\
\hline Zuber (1959) & $d_{b}=\left[\sigma \cdot \frac{\sigma}{g \cdot \rho_{v l}} \cdot \frac{k_{l} \cdot\left(T_{p}-T_{s a t}\right)}{\phi}\right]^{1 / 3}$ & $(2.8)$ \\
\hline Ruckenstein (1961) & $d_{b}=\left(\frac{3 \cdot \pi^{2} \cdot \rho_{l} \cdot \alpha_{l}}{g \cdot \rho_{v l}}\right)^{1 / 3} \cdot J a^{4 / 3}$ & $(2.9)$ \\
\hline Borishansky (1963) & $\begin{array}{l}\frac{d_{b}}{d_{b}(\text { Fritz) }}=-\frac{C}{d_{b}(\text { Fritz })}+\sqrt{\left(\frac{C}{d_{b}(\text { Fritz })}\right)^{2}+1} \\
\text { onde: } C=\frac{6}{g} \cdot \frac{\rho_{l}}{\rho_{v l}} \cdot\left(\frac{\rho_{v}}{\rho_{l}}\right)^{0,4} \cdot \frac{\phi}{h_{l v} \cdot \rho_{v}}\end{array}$ & $(2.10)$ \\
\hline Cole e Shulman (1966) & $d_{b}=\frac{1000}{p_{s a t}} \cdot \sqrt{\frac{\sigma}{g \cdot \rho_{v l}}} \operatorname{com} p_{\text {sat }} \mathrm{em} \mathrm{mmHg}$ & $(2.11)$ \\
\hline Cole (1967) & $d_{b}=0,04 \cdot J a \cdot \sqrt{\frac{\sigma}{g \cdot \rho_{v l}}}$ & $(2.12)$ \\
\hline Cole e Rohsenow (1968) & $\begin{array}{l}d_{b}=C \cdot\left(\frac{T_{s a t} \cdot c_{l} \cdot \rho_{l}}{\rho_{v} \cdot h_{l v}}\right)^{5 / 4} \cdot \sqrt{\frac{\sigma}{g \cdot \rho_{v l}}} \\
C=1,5 \cdot 10^{-4} \text { para a água; } C=4,65 \cdot 10^{-4} \text { demais fluidos }\end{array}$ & $(2.13)$ \\
\hline Gogonin (1978) & $\begin{array}{l}d_{b}=\frac{1,65 \cdot d^{*} \cdot \sigma}{g \cdot \rho_{v l}}+\left(\frac{15,6 \cdot \rho_{l}}{g \cdot \rho_{v l}}\right)^{1 / 3} \cdot\left[\frac{6 \cdot k_{l} \cdot\left(T_{p}-T_{s a t}\right)}{h_{l v} \cdot \rho_{v}}\right]^{2 / 3} \\
\text { onde } d^{*}=6,0 \cdot 10^{-3} \mathrm{~mm}\end{array}$ & $(2.14)$ \\
\hline Kutateladze e Gogonin (1979) & $\begin{array}{l}d_{b}=0,25 \cdot \sqrt{\frac{\sigma}{g \cdot \rho_{v l}}} \cdot\left(1+10^{5} \cdot K_{1}\right) \text { para } K_{l}<0,06 \\
\text { onde: } K_{1}=\frac{J a}{P r_{l}} \cdot\left[\left(\frac{g \cdot \rho_{l} \cdot \rho_{v l}}{\mu_{l}^{2}}\right) \cdot\left(\frac{\sigma}{g \cdot \rho_{v l}}\right)^{3 / 2}\right]^{-1}\end{array}$ & $(2.15)$ \\
\hline Borishansky (1981) & $d_{b}=5 \cdot 10^{5} \cdot p_{r}^{-0,46} \cdot\left(\frac{k_{B} \cdot T_{c}}{M \cdot p_{c}}\right)^{1 / 3}$ & $(2.16)$ \\
\hline Jensen e Memmel (1986) & $d_{b}=0,19 \cdot \sqrt{\frac{\sigma}{g \cdot \rho_{v l}}} \cdot\left(1,8+10^{5} \cdot K_{1}\right) ; \quad K_{l}$ da Eq. (2.15) & $(2.17)$ \\
\hline Stephan (1992) & $d_{b}=0,25 \cdot \sqrt{\frac{\sigma}{g \cdot \rho_{v l}}} \cdot\left(1+\left(\frac{J a}{P \eta_{\eta}}\right)^{2} \cdot \frac{1}{A r}\right)$ & $(2.18)$ \\
\hline
\end{tabular}


A frequiência de desprendimento de bolhas depende diretamente do período de espera, do diâmetro de desprendimento e da taxa de crescimento até alcançar este diâmetro. Deste modo, $f$ é função de $d_{b}$ e de todas as condições e propriedades, tanto as do fluido como as da superfície que afetam os períodos de espera e de crescimento da bolha, podendo ser definida conforme a seguinte equação:

$$
f=\frac{1}{t_{e}+t_{c}}
$$

A Tabela 2.3 apresenta algumas das correlações da literatura para a determinação de $f$. Os resultados fornecidos por estas correlações, de uso imediato, são valores médios com a freqüência de desprendimento de bolha apresentando um valor constante para uma determinada condição experimental caracterizada por $g$ e pela temperatura do fluido. Isto não ocorre na realidade, pois através de estudos utilizando filmadoras com captura de imagens de alta velocidade, verifica-se que diferentes cavidades ativas emitem bolhas a uma freqüência constante, mas com distintas frequências em cada cavidade. Cavidades com aberturas menores irão emitir bolhas com freqüência superior àquelas com aberturas mais largas, por estas apresentarem um período de espera superior. Tal fato pode ser verificado ao determinar-se o tempo de espera através da Eq. (2.5), proposta por Han e Griffth (1965a), para cavidades com diferentes dimensões.

Outros fatores contribuem para o fato das equações da Tabela 2.3 serem consideradas apenas aproximações, entre eles pode-se citar o fato de terem sido ajustadas e testadas para bancos de dados restritos, geralmente não constituído de refrigerantes halogenados, e envolverem, além das imprecisões experimentais na determinação de $f$, incertezas em $d_{b}$. Apesar disto, elas têm sido utilizadas como ferramentas úteis nas correlações para o coeficiente de transferência de calor.

\subsection{Fatores que Influenciam a Taxa de Transferência de Calor em Ebulição Nucleada}

Conforme apontado nos itens anteriores, a transferência de calor através do mecanismo de ebulição nucleada pode ser afetada por diversos parâmetros, tais como as propriedades termo-físicas do fluido, as características da superfície aquecida, o fluxo específico de calor, a pressão de operação e a aceleração gravitacional local. Para uma 
determinada situação, a variação de apenas um desses parâmetros pode alterar o coeficiente de transferência de calor em valores superiores a $100 \%$. Diante disto e para uma melhor compreensão dos capítulos seguintes, um sumário dos parâmetros mais importantes é apresentado a seguir:

Tabela 2.3 Correlações para a determinação de $f$

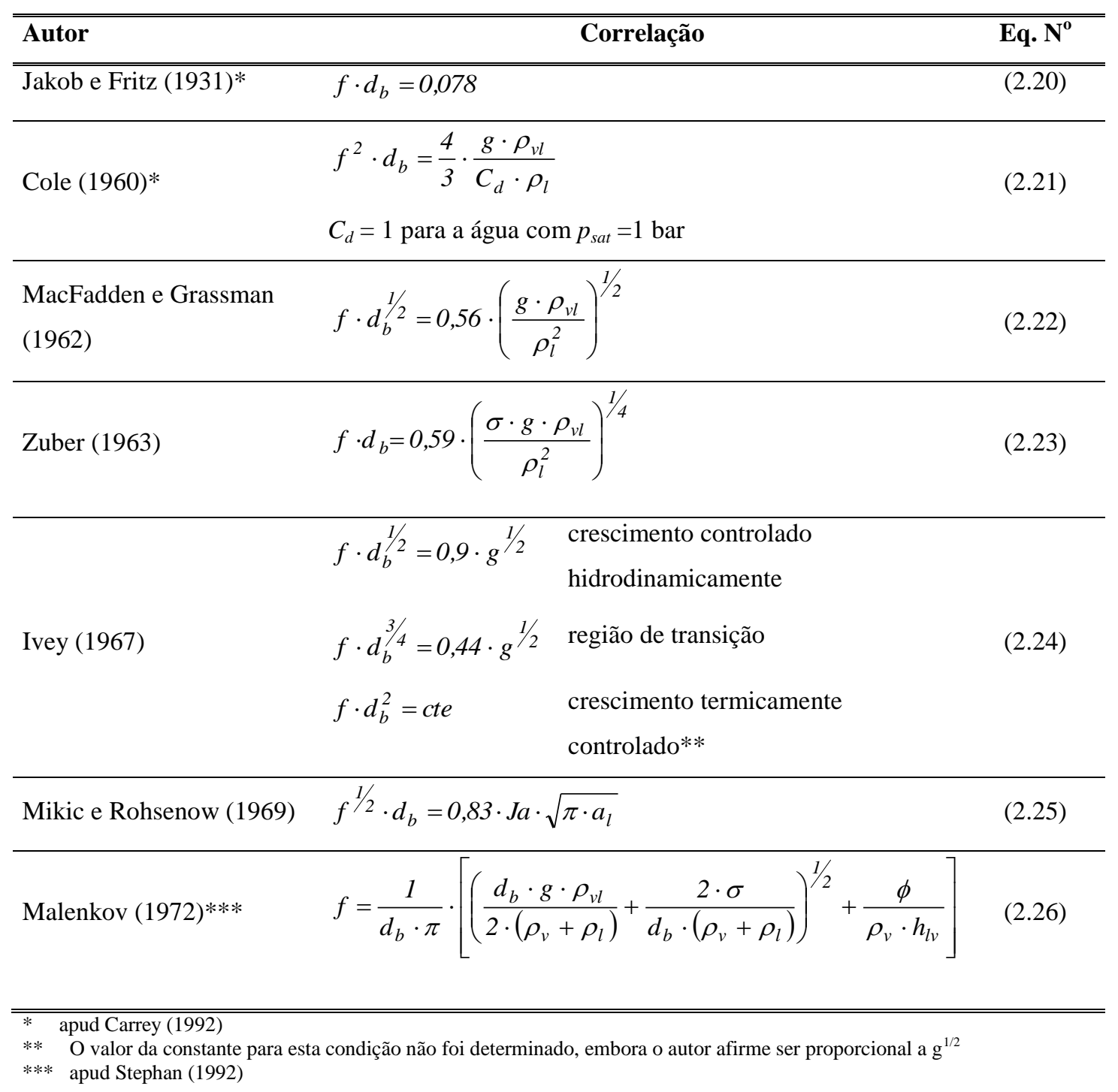

\subsubsection{Geometria, Material e Espessura da Superfície}

A ebulição nucleada em baixos fluxos de calor se caracteriza por um mecanismo de transferência de calor em que predominam os efeitos convectivos monofásicos. A 
importância relativa desses mecanismos depende das características geométricas da superfície. Experimentos demonstram que, para ebulição nucleada parcial, em condições semelhantes, o coeficiente de transferência de calor para uma superfície inclinada é superior ao correspondente a mesma superfície posicionada horizontalmente. Tal comportamento é, provavelmente, devido a alteração da camada limite térmica em conseqüência da inclinação, que facilita o escorregamento das bolhas ao longo da superfície aquecida, intensificando a transferência de calor. Já, para a ebulição nucleada plenamente desenvolvida, devido ao grande número de cavidades ativas, a orientação da superfície aquecida não é importante.

Os estudos de ebulição nucleada têm sido realizados para diferentes geometrias. Entre as mais utilizadas podem ser citadas fios metálicos, superfícies cilíndricas tubulares e superfícies planas com formatos retangulares ou circulares. A geometria parece exercer influência significativa no coeficiente de transferência de calor, especialmente na região de baixos fluxos de calor. Em seu banco de dados, elaborado a partir de resultados experimentais próprios e da literatura, Cooper (1984) verificou que, sistematicamente, o coeficiente de transferência de calor para superfícies cilíndricas horizontais de cobre era $70 \%$ superior ao das demais combinações de material e geometria. É possível que o formato da superfície exerça alguma influência na transição de convecção natural para ebulição nucleada por afetar a perfil de temperaturas junto a superfície.

Kudritskii e Kolomiets (1995) examinaram, para a água, a relação entre o tamanho da superfície e o diâmetro de desprendimento de bolhas, para pressões de saturação entre 0,02 e 0,1Mpa. Eles analisaram superfícies circulares com diâmetros entre 0,5 e 1,5mm, verificando que o tamanho da superfície exerce influência no superaquecimento necessário para o início da ebulição apenas na seguinte condição:

$$
0,1<\frac{\text { diâmetro da superfície }}{d_{b}}<2,5
$$

Eles também verificaram que, quando a razão entre a área de influência da bolha e da superfície é superior a 0,5, a área de influência da bolha aproxima-se da área projetada por esta no seu desprendimento. Deste modo, a região da superfície onde não ocorrem efeitos de ebulição nucleada tem sua área reduzida, resultando no incremento da taxa de transferência de calor. A partir da condição em que a área de influência da bolha é igual à da superfície, isto é $d_{b}=D_{\text {superficie }}$, diâmetro da superfície inferiores degradam o coeficiente de transferência de calor, devido ao incremento no tempo de crescimento da bolha, como resultado de efeitos convectivos. 
A condutividade térmica e as propriedades do material da superfície associadas à inércia térmica (densidade e calor especifico) parecem influenciar a taxa de transferência de calor, pois podem intensificar ou amortecer a variação da temperatura superficial durante os períodos de espera e crescimento de bolha e o perfil de temperaturas no interior da parede, influenciando, consequentemente, a freqüência de desprendimento de bolhas. Man et al (2000), através da solução de um modelo numérico para o crescimento de uma bolha isolada, considerando como mecanismo responsável a evaporação na linha de contato triplo, concluíram ser desprezível o efeito de $k_{p}$ na taxa de crescimento da bolha. Desta forma, estes autores assumem que o efeito de $k_{p}$ em $h$ dá-se através da influência em $t_{e}$ e $n / A$, neste caso afetando a interação entre cavidades vizinhas através da sua influência na distribuição de temperaturas na superfície nas proximidades de uma cavidade ativa. Gorenflo et al (1994) considerou a influência do material da superfície de transferência de calor, definindo um coeficiente de "penetração térmica", função da condutividade térmica, calor específico e densidade do material que compõe a superfície aquecida. Benjamin e Balakrishnan (1997) incorporaram o efeito do material da superfície em uma correlação* para a previsão da densidade de cavidades ativas, com $n / A$ sendo diretamente proporcional a raiz quadrada da razão entre os produtos $c \cdot \rho \cdot k$ do líquido e do material da superfície. Desta forma, segundo esta correlação, uma superfície de aço inoxidável apresentaria para uma mesma condição experimental, uma densidade de cavidades ativas 5 vezes superior a de cobre. Assim, admitindo que os efeitos em $t_{e}$ sejam inferiores àqueles sobre $n / A$ o coeficiente de transferência de calor também resultaria inferior. Na realidade, tal comportamento não se verifica, pois, segundo a maioria dos autores, o coeficiente de transferência de calor aumenta com $k_{p}$, como resultado da redução do período de espera e do incremento da densidade de cavidades ativas. Finalmente, Cooper (1984) não observou uma relação direta entre o coeficiente de transferência de calor e as propriedades do material da parede.

A Fig. 2.9, elaborada com os resultados experimentais de Berenson (1962), para o n-pentano, sob condições de pressão atmosférica normal, ilustra o efeito do material da superfície na taxa de transferência de calor. Nesta figura, o melhor desempenho para as superfícies de níquel foi atribuído à maior condutividade térmica ( $k_{\text {Niquel }}=90,7 \mathrm{~W} / \mathrm{m} \cdot \mathrm{K}, k_{\text {Inconel }}$ $=11,7 \mathrm{~W} / \mathrm{m} \mathrm{K})$. É interessante destacar que estas superfícies são constituídas por materiais de diferentes durezas, cujos tratamentos superficiais, embora semelhantes, podem conferir diferentes características superficiais, alterando, consequentemente, a densidade de cavidades ativas.

\footnotetext{
* Devido a correlação proposta por Benjamin e Balakrishnan Eq. (2.29) envolver o efeito de outros parâmetros, sua apresentação e uma discussão com maiores detalhes é realizada no item 2.5.2.
} 


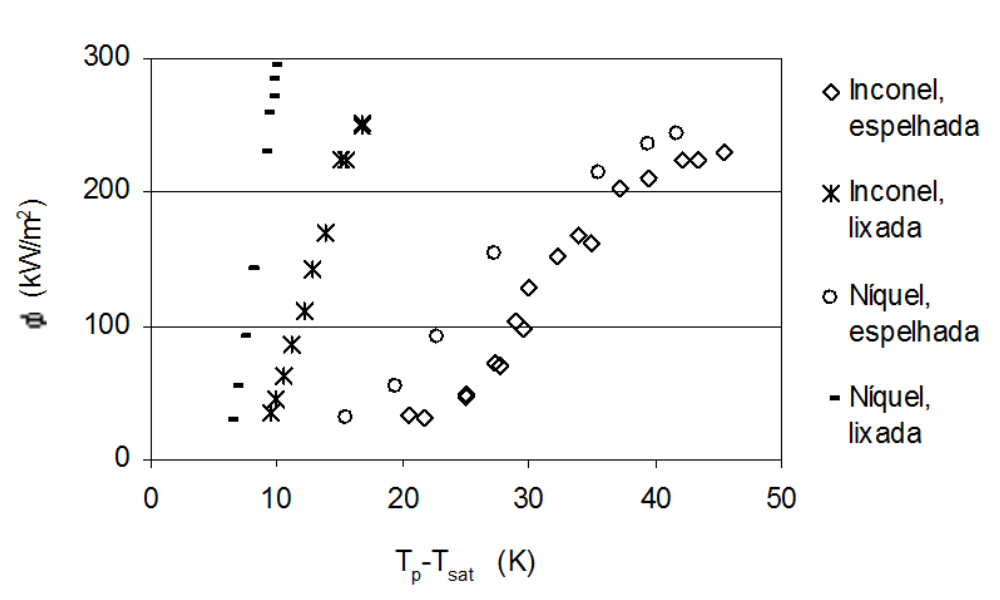

Figura 2.9 Influência do material da parede e do acabamento superficial na taxa de transferência de calor, Berenson (1962).

A espessura da parede também está associada à inércia térmica e afeta diretamente a variação de temperatura da superfície aquecida e, consequentemente, o mecanismo físico de transferência de calor. Entretanto, ela afeta o mecanismo de ebulição, apenas, até uma determinada dimensão denominada por Chai et al (2001) de "distância de penetração", a partir da qual maiores incrementos resultariam em efeitos desprezíveis. Esta "distância de penetração" tem seu valor reduzido com a elevação de $k_{\mathrm{p}}$. Dentro da faixa de dimensões em que a espessura da parede exerce influência, observa-se o aumento de $h$ com o seu incremento, como resultado da elevação na inércia térmica.

\subsubsection{Acabamento Superficial}

Um grande número de estudos comprovam a influência do acabamento superficial no desempenho térmico da superfície. Tem sido constatado que, com o aumento da rugosidade, a curva de ebulição é deslocada para a esquerda, resultando em superaquecimentos menores para um mesmo fluxo de calor.

Berenson (1962) constatou, para um mesmo superaquecimento, com a alteração apenas do acabamento superficial, intensificações na transferência de calor superiores a 500\%. Alguns dos resultados foram apresentados na Fig. 2.9. Sokol et al (1990) observaram reduções de $30 \%$ no fluxo específico de calor para a diminuição na rugosidade superficial, caracterizada por $R p^{*}$, de 1,0 para $0,8 \mu \mathrm{m}$. Seus resultados experimentais foram levantados

* No apêndice I encontram-se maiores detalhes sobre os diferentes parâmetros utilizados na caracterização do acabamento superficial em estudos envolvendo a ebulição nucleada 
para o propileno e o propano, com valores de $p_{r}$ inferiores a 0,2. Palm (1991) examinou o desempenho térmico de superfícies tubulares com diferentes acabamentos, para fluxos de calor inferiores a $30 \mathrm{~kW} / \mathrm{m}^{2}$, com o R-11 à pressão atmosférica normal. Ele verificou o incremento de $h$ com a rugosidade, com as superfícies apresentando a seguinte ordem crescente de desempenho: superfície polida, lixada, tratada com jato de areia e superfície recartilhada. Anderson e Mudawar (1989) compararam, para o FC-72 à pressão atmosférica, o desempenho de superfícies com os seguintes acabamentos: polida, tratada com jato de areia e com jato de vapor. Os autores concluíram que o incremento da rugosidade resultava na redução do superaquecimento necessário para o inicio da ebulição, na intensificação da transferência de calor no regime de ebulição nucleada plenamente desenvolvida e numa pequena redução no fluxo de crítico calor. Resultado semelhante ao de Sauer et al (1975), que levantou resultados experimentais para o R-11 em uma superfície de inconel, com 5 diferentes acabamentos superficiais.

Roy Chowdhury e Winterton (1985) analisaram a ebulição da água e do metanol em superfícies de alumínio e cobre, com diferentes acabamentos superficiais, à pressão atmosférica normal. Após lixadas, algumas destas superfícies sofreram um processo de anodização. Este processo não alterou o valor da rugosidade superficial, medida segundo o método CLA. Constatou-se que, para as superfícies apenas lixadas, a taxa de transferência de calor aumentava com a rugosidade superficial; já, para as superfícies anodizadas, a rugosidade não influenciava o desempenho. Através de micro-fotografias, verificou-se que as superfícies anodizadas, ainda que com rugosidades distintas, eram recobertas uniformemente com cavidades de aproximadamente $1 \mu \mathrm{m}$, enquanto as superfícies não anodizadas apresentavam, quando comparadas as anodizadas, números inferiores de cavidades, com tamanhos superiores e não uniformemente distribuídas. Berenson (1962) verificou um comportamento semelhante, com o valor absoluto da rugosidade não sendo um fator determinante na taxa de transferência de calor. Ele verificou que superfícies de um mesmo material, lixadas com um mesmo tipo de lixa, mas em distintos sentidos, apresentavam desempenhos discordantes. Seus resultados apresentam-se ilustrados na Fig. 6.10 .

Desta forma, embora Bier (1968) apud Dhir (1991) afirme, com base em resultados experimentais para a ebulição do R-11 em quatro diferentes acabamentos superficiais, que a relação entre o coeficiente de calor e a rugosidade pode ser aproximada por:

$$
h \approx R p^{\text {constante }},
$$


concluí-se que a relação direta não está entre a rugosidade superficial e a taxa de transferência de calor, mas desta com o número de cavidades ativas, que pode variar dependendo principalmente da técnica utilizada no acabamento.

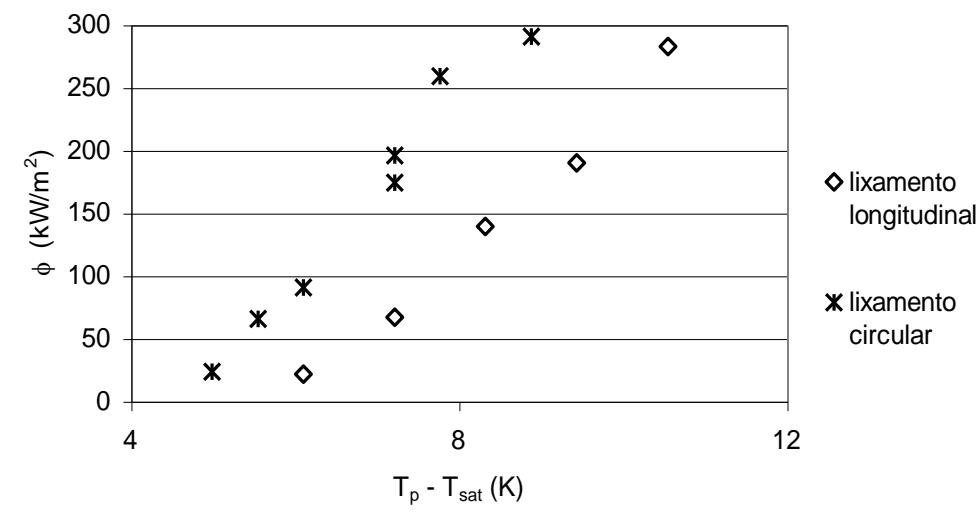

Figura 2.10 Efeito do sentido de lixamento na transferência de calor, n-pentano, $p_{\text {sat }}=100 \mathrm{kPa}$. Resultados experimentais de Berenson (1962)

Benjamin e Balakrishnan (1997), com base em resultados experimentais de outros autores e próprios, neste caso para a água, $\mathrm{CCl}_{4}$, n-hexano e acetona em superfícies de aço inoxidável e alumínio, desenvolveram a equação abaixo, estritamente empírica, para a previsão do número de cavidades ativas como função de propriedades da superfície de transferência de calor e do fluido refrigerante.

$$
n / A=218,8 \cdot \operatorname{Pr}^{1,63} \cdot \sqrt{\left(\frac{k_{l} \cdot \rho_{l} \cdot c_{l}}{k_{p} \cdot \rho_{p} \cdot c_{p}}\right)} \cdot \theta^{-0,4} \cdot(\Delta T)^{3}
$$

onde:

$$
\theta=14,5-4,5 \cdot\left(\frac{R a \cdot p_{s a t}}{\sigma}\right)+0,4 \cdot\left(\frac{R a \cdot p_{s a t}}{\sigma}\right)^{2}
$$

Nesta correlação a utilização do adimensional $\left(R a \cdot p_{\text {sat }}\right) / \sigma$, de certa forma, determina qualitativamente quão fácil é a nucleação, pois com o incremento da pressão de saturação, a tensão superficial diminui, o que resulta um incremento da razão $p_{\text {sat }} / \sigma$. Assim, mesmo para um valor reduzido de $R a$, a formação de bolhas seria facilitada. Tal adimensional eliminaria, segundo os autores, a idéia relativa de uma superfície rugosa, que, no caso de nucleação, depende também das propriedades do líquido. 
Benjamin e Balakrishnan (1997) concluem ainda, com base em seus resultados experimentais, que com o incremento de $R a$, inicialmente, ocorre uma redução no número de cavidades ativas, seguida do seu incremento. A correlação proposta não reflete tal conduta. A conclusão da existência de um valor mínimo para o número de cavidades ativas foi proposta com base em resultados experimentais levantados para $R a=0,02 \mu \mathrm{m}$ em uma superfície de aço inoxidável, e valores de $R a$ iguais a $0,52 \mu \mathrm{m}, 0,89 \mu \mathrm{m}$ e $1,17 \mu \mathrm{m}$ em uma única superfície de alumínio. Os valores de $R a$ associados a uma ordem crescente de $h$ e consequentemente de $n / A$, para um determinado superaquecimento, foi a seguinte: $1,17 \mu \mathrm{m}$, $0,02 \mu \mathrm{m}, 0,89 \mu \mathrm{m}$ e $0,52 \mu \mathrm{m}$. Com base nessas premissas, pode-se supor que o comportamento verificado experimentalmente, é resultante, também, de efeitos do material da superfície, uma vez que superfícies compostas de diferentes materiais apresentam desempenhos distintos. Entretanto, admitindo, conforme discutido no item anterior, que materiais com valores elevados do produto $(k \cdot \rho \cdot c)$ apresentam um desempenho superior, ao contrário do que sugere a Eq. (2.29), pode-se concluir que tal comportamento seja resultante de incertezas experimentais, principalmente relacionadas à determinação de $T_{p}$ para os diferentes corpos de ensaio (aço inoxidável e alumínio). Assim, conclui-se que, apesar dos dados experimentais levantados por estes autores sugerirem um valor mínimo para o número de cavidades ativas, o comportamento da correlação, à qual está associado um incremento monotônico de $n / A$ com $R a$, foi determinado pelo ajuste de dados que envolveu, também, resultados experimentais de outros autores. É interessante ressaltar que a correlação, ao invés de apresentar um valor mínimo para a relação $n / A=f(R a)$ dentro de determinada faixa, apresenta um máximo, cujo valor encontra-se, para as condições de ensaio, fora da faixa de rugosidades envolvidas no levantamento experimental ( $0,02 \leq R a \leq 1,17 \mu \mathrm{m})$.

Finalmente, conclui-se que, de uma maneira geral, os resultados experimentais levantados por diferentes autores indicam o incremento de $h$ com a rugosidade superficial. Tal incremento está relacionado com a densidade de cavidades ativas e é mais pronunciado a partir de superfícies com valores reduzidos de $R a$. Estas superfícies possuem um espectro estreito de tamanho de cavidades, caracterizadas por dimensões reduzidas, que exigem um superaquecimento elevado para a ativação e cujo valor é extremamente sensível às variações nas dimensões das cavidades na superfície. Esse comportamento pode ser verificado através do critério de ativação de cavidades de Han e Griffith (1965a). Já, superfícies suficientemente rugosas caracterizam-se por apresentarem uma ampla faixa de dimensões de cavidades disponíveis para nucleação, o que faz com que incrementos da rugosidade superficial não afetem de forma tão significativa a densidade cumulativa de cavidades ativas e, portanto, o coeficiente de transferência de calor, como ocorre no caso de superfícies mais 
lisas. Resultados obtidos por Kurihara (1956) corroboram o cenário físico descrito, tendo o referido autor proposto um limite máximo de rugosidade superficial correspondendo a um valor de $R p$ de $0,8 \mu \mathrm{m}$, acima do qual o coeficiente de transferência de calor não mais é afetado.

\subsection{3 Ângulo de Contato}

$\mathrm{O}$ incremento da capacidade do fluido de molhar a superfície pode ser caracterizado pela diminuição do ângulo de contato. Com a redução do ângulo $\beta$, a capacidade de retenção de vapor nas cavidades junto a superfície diminui em virtude do líquido molhar melhor a superfície, fazendo com que a curva de ebulição seja deslocada para a direita. A transição entre convecção natural e ebulição nucleada para líquidos que molham melhor uma superfície ocorre para superaquecimentos superiores. Isto acontece devido ao preenchimento das cavidades maiores com líquido, restando assim certa quantidade de vapor apenas nas cavidades menores, as quais exigem uma maior energia de ativação. Tais comportamentos são ilustrados, esquematicamente, na Fig. 2.11, comparandose dois fluidos com distintas características de interação com a superfície, caracterizadas pelo ângulo de contato.

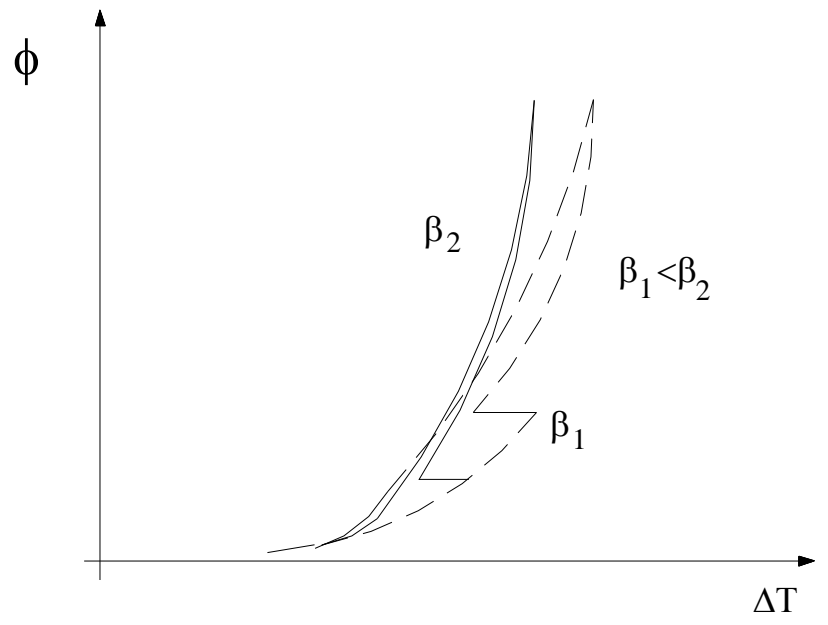

Figura 2.11 Ilustração esquemática da influência do ângulo de contato.

Berenson (1962) examinou a influência do ângulo de contato na transferência de calor. Foram utilizadas superfícies de cobre com acabamentos superficiais semelhantes, 
sendo a primeira, antes do ensaio, limpa com $\mathrm{CCl}_{4}$, e a outra, oxidada em ambiente externo. Seus resultados podem ser observados na Fig. 2.12, e permitem concluir a redução de $h$ para um mesmo superaquecimento, com o incremento do grau de oxidação da superfície e a redução do ângulo de contato. Roy Chowdhury e Winterton (1985) examinaram o efeito de $\beta$ através do levantamento de resultados experimentais para a água e o metanol sob condições de pressão atmosférica normal em superfícies de alumínio e cobre variando o ângulo de contato entre 0 e $128^{\circ}$. Os autores verificaram que, embora o decréscimo no ângulo de contato (líquido molhando com maior intensidade a superfície) tenha elevado o valor do fluxo crítico de calor e o nível da histerese, ele não alterou o desempenho da superfície na região de ebulição nucleada plenamente desenvolvida. Os resultados de Roy Chowdhury e Winterton (1985), para a ebulição nucleada plenamente desenvolvida, divergem dos de Wang e Dhir (1993), de acordo com os quais infere-se uma relação intrínseca entre o ângulo de contato e o número de cavidades ativas, refletida, consequentemente, no valor do coeficiente de transferência de calor. Eles verificaram que, para $\beta=90^{\circ}$ menos de $10 \%$ das cavidades em condições de ativar nucleavam, sendo que com a redução de $\beta$ para $18^{\circ}$, esta fração foi reduzida em mais de 20 vezes. Com base nesses resultados experimentais, eles desenvolveram a seguinte correlação para o número de cavidades ativas:

$$
n / A=5 \cdot 10^{-27} \cdot(1-\cos (\beta)) \cdot\left(\frac{4 \cdot \sigma \cdot T_{s a t}}{\rho_{v} \cdot h_{l v} \cdot\left(T_{p}-T_{s a t}\right)}\right)^{-6}
$$

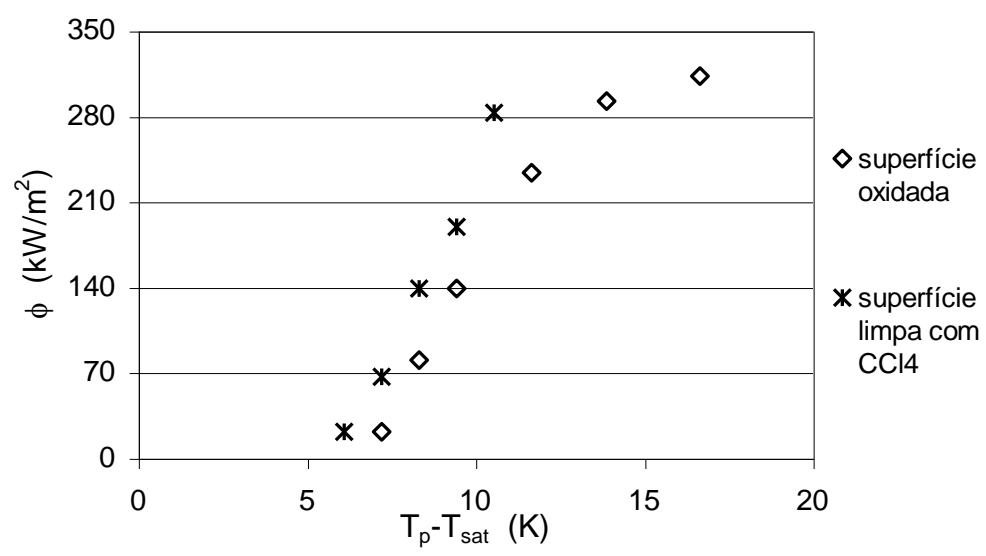

Figura 2.12 Efeito do ângulo de contato na curva de ebulição, n-pentano, $p_{\text {sat }}=100 \mathrm{kPa}$.

Resultados experimentais de Berenson (1962) 


\subsubsection{Contaminação da Superfície}

A deposição de materiais inertes ou a existência de fluidos estranhos sobre a superfície, ainda que solúveis, podem alterar o coeficiente de transferência de calor. Materiais inertes depositados junto a superfície podem atuar favorecendo a ativação de cavidades e elevando, consequentemente, o coeficiente de transferência de calor. Já a contaminação do refrigerante com outros fluidos, através da alteração do ângulo de contato e das propriedades de transporte do líquido, pode reduzir, como é o caso do óleo de lubrificação para concentrações superiores a 3\%, ou intensificar premeditadamente a transferência de calor.

Ainda que garantida a pureza do refrigerante e a limpeza do sistema, em superfícies submetidas a longos períodos de ebulição, a contaminação tende a ocorrer devido às mudanças físico-químicas do refrigerante e das próprias superfícies de transferência de calor. Estas mudanças podem alterar o valor de $h$ e resultam dos seguintes agentes: deposição de material inerte na superfície, reações químicas lentas da superfície com os gases dissolvidos no liquido ou com o vapor e reações químicas fortes do metal com soluções eletrolíticas concentradas. Estes dois últimos processos, ocorrendo durante longos períodos de tempo, podem causar perda de material e erosão. A danificação da superfície, resultante desses processos, e a deposição de material, podem afetar as características de nucleação alterando o ângulo de contato entre a interface líquido-vapor e a superfície aquecida, o que pode determinar a desativação de cavidades ou até mesmo a ativação de novas cavidades.

Chaudhri e McDougall (1969) analisaram, para o percloroetileno e o acetato isopropilico, em condições de pressão atmosférica normal, a relação entre o tempo de ebulição e o acabamento superficial. As superfícies utilizadas eram tubulares e compostas por cobre, aço duro e aço mole. Para cada material, a superfície apresentava as seguintes configurações: superfície comercial, constituída de várias imperfeições distribuídas de forma irregular com algumas cavidades tendo profundidades superiores a 0,254 $\mathrm{mm}$, e superfície tratada, com cavidades distribuídas de forma regular e profundidade inferior a 0,0254 mm. A ebulição foi dividida em dois períodos: inicial, de curta duração, que terminava com o início da redução na taxa de transferência de calor, resultado do decréscimo no número de cavidades ativas pela expulsão gradual de gás inerte existente, inicialmente nas cavidades; e permanente, caracterizado pelo contínuo decréscimo no número de cavidades ativas resultante da condensação de vapor existente nos núcleos devido a mudanças locais na temperatura superficial ou a deposição compacta de material nas cavidades. A intensificação na transferência de calor para a superfície comercial, composta 
por aço mole, permaneceu por um período superior ao da superfície de aço duro. É interessante destacar que, após determinado período, todas as superfícies de aço apresentavam desempenhos similares. Para as superfícies de cobre, os autores verificaram que, após 50 horas em ebulição, elas intensificaram a transferência de calor em torno de 100\%. A intensificação ocorreria até a taxa de transferência de calor tornar-se estável, após 250 horas em ebulição, voltando a ocorrer novamente, após 350 horas. As superfícies permaneceram em ebulição durante 500 horas, período em que ainda se verificava o contínuo aumento na taxa de transferência de calor. Este comportamento foi atribuído ao incremento no número de cavidades ativas resultantes da erosão da superfície e deposição deste mesmo material sobre a superfície.

\subsubsection{Pressão do Sistema}

Como pode ser demonstrado por modelos de nucleação heterogênea, a elevação da pressão tende a reduzir o superaquecimento da superfície aquecida necessário para a nucleação. Tal característica resulta no deslocamento da curva de ebulição para a esquerda e no incremento de $h$, ilustrado na Fig 2.13, elaborada com base nos resultados de Silva (1989). Deste modo, a pressão é um fator de grande importância na predição do coeficiente de transferência de calor. Nas correlações que visam a determinação do coeficiente de transferência de calor em ebulição nucleada, a pressão pode ser encontrada explicita ou implicitamente, sendo, neste caso, através das propriedades do fluido. Para baixas pressões, a interação entre os efeitos de rugosidade e pressão é intensificada. Este comportamento é resultante do aumento da tensão superficial, o qual, devido a efeitos capilares, facilita a retenção de certa quantidade de vapor nas cavidades maiores. Assim, além da necessidade de um menor superaquecimento para a nucleação nestas cavidades, próximas nucleações são favorecidas.

\subsubsection{Gravidade Local}

A magnitude e a direção da aceleração gravitacional influenciam fatores como a hidrodinâmica convectiva, a camada limite térmica e a trajetória das bolhas. Estes efeitos exercem grande influência no desempenho térmico da superfície, principalmente para 
regimes de baixos fluxos de calor onde a convecção natural é responsável por uma grande parcela do calor transferido. Já, para ebulição nucleada plenamente desenvolvida, com a redução da gravidade local, o tamanho da bolha tende a ser significativamente incrementando. Isto ocorre devido a diminuição das forças de empuxo que atuam sobre a bolha. Desta forma, a área de contato entre a superfície e o líquido é reduzida, elevando-se, consequentemente, a resistência térmica e o superaquecimento. Assim, com a redução da aceleração gravitacional, a curva de ebulição se desloca para a direita.

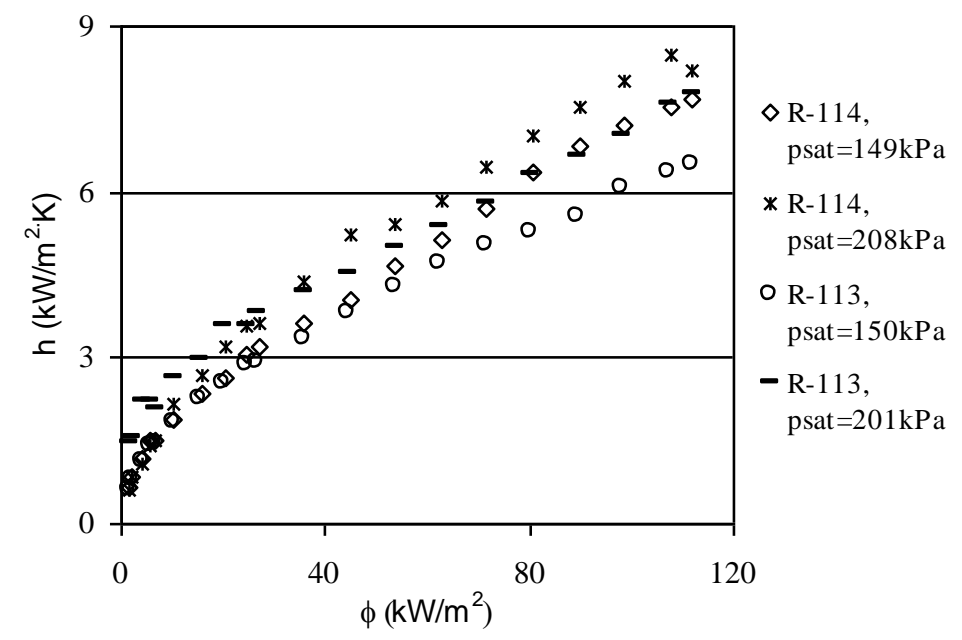

Figura 2.13 Efeito de $p_{\text {sat }}$ em $h$, segundo os resultados experimentais de Silva (1989).

Sob condições de microgravidade (acelerações gravitacionais da ordem de $1 \%$ da aceleração gravitacional terrestres normal), diversos são os fatores que podem afetar a transferência de calor. Embora eles não sejam ainda totalmente conhecidos, destacam-se os resultantes de efeitos de termocapilaridade e possíveis vibrações. Oka (1995), através de experimentos com o R-113 sob condições de microgravidade, verificou uma redução de cerca de $40 \%$ no coeficiente de transferência de calor no regime de ebulição nucleada plenamente desenvolvida, comparado ao valor obtido para condições de gravidade normal. $\mathrm{O}$ autor justificou tal comportamento como resultado da formação de bolhas grandes e de difícil desprendimento, o que, além de reduzir a frequiência de desprendimento, aumentaria a resistência térmica junto a parede aquecida.

\subsubsection{Subresfriamento do Líquido}

A Fig. 2.14 ilustra o comportamento da curva de ebulição, caso o líquido no banho 
estivesse subresfriado, ao invés de saturado, como normalmente admitido. Nos regimes de convecção natural e ebulição nucleada parcial, verifica-se que, no caso do líquido subresfriado, a curva de ebulição se situa à esquerda em relação àquela de líquido saturado, comportamento justificado pelo incremento da taxa de transferência de calor resultante de efeitos de convecção natural. No entanto, para fluxos de calor característicos de ebulição nucleada plenamente desenvolvida, as curvas para ebulição saturada e subresfriada "colapsam", sugerindo que, para este regime, a parcela de transferência de calor devida ao mecanismo estritamente convectivo monofásico torna-se desprezível.

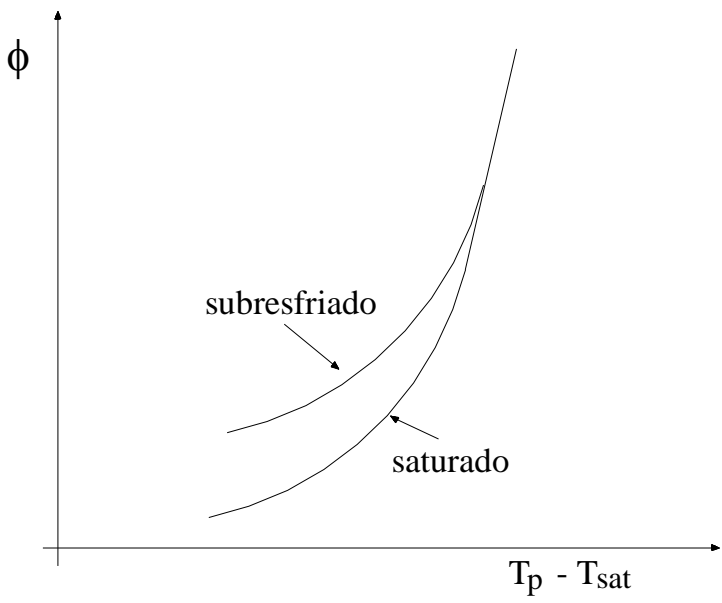

Figura 2.14 Influência do subresfriamento do fluido na curva de ebulição.

Judd et al. (1991) investigaram para o R-113 e a água, com diferentes valores de $\phi$, o efeito do subresfriamento no coeficiente de transferência de calor através do mecanismo de ebulição nucleada. Eles constataram, para um mesmo fluxo específico de calor em condições próximas à saturação, o incremento do superaquecimento da superfície com o subresfriamentodo do líquido, resultante da redução da freqüência de desprendimento de bolhas e do número de cavidades ativas. Resultados levantados através do modelo de Han e Griffith (1965a) corroboram tal comportamento, pois, segundo este modelo, o incremento de $\Delta T$ resulta na redução da faixa de valores de $r_{c}$ e no incremento do tempo de espera, redundando, respectivamente, nas reduções de $n / A, f$ e consequentemente de $h$. Com a elevação do subresfriamento a parcela do calor transferida através do mecanismo de convecção natural é incrementada. Desta forma, para um determinado $\phi$, com o incremento do subresfriamento a partir de uma valor nulo, a combinação de efeitos de convecção natural com a redução do número de cavidades ativas e da frequiência de desprendimento de bolhas faz com que o superaquecimento da parede apresente um valor máximo, a partir do qual 
maiores incrementos no subresfriamento resultam na redução do superaquecimento da superfície. Dentro deste cenário físico, uma vez atingida a completa inibição da formação de bolhas, o superaquecimento da superfície se reduz com o incremento do subresfriamento, a uma taxa constante.

\subsubsection{Gases não Condensáveis}

A presença de gases não condensáveis dissolvidos no líquido pode resultar, quando comparada à ebulição de fluidos puros, na elevação do coeficiente de transferência de calor para um mesmo superaquecimento. A Fig. 2.15 ilustra um núcleo de vapor em equilíbrio, para o qual considerando $p_{v} \approx p_{\text {sat }}\left(T_{p}\right)$ e aplicando a equação de Laplace, pode-se escrever a seguinte equação:

$$
\left[p_{\text {sat }}\left(T_{p}\right)+p_{g}\right]-p_{l}=\frac{2 \cdot \sigma}{R}
$$

Segundo esta equação, com $p_{g}=0$, a temperatura necessária para a existência de um núcleo de vapor em equilíbrio, escrita como função da pressão, é $p_{s a t}\left(T_{p}\right)=2 \cdot \sigma_{p} / R+p_{l}$. Já com a existência de gases incondensáveis, $p_{g}>0$, tal temperatura é reduzida, o que facilita o surgimento de um núcleo crítico.

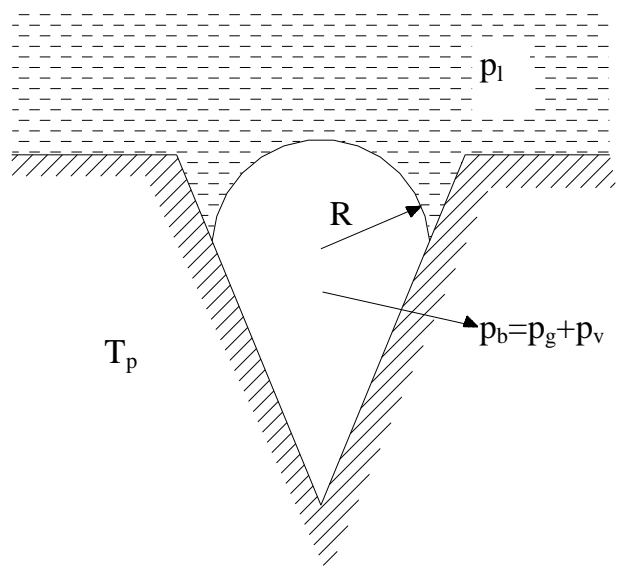

Figura 2.15 Núcleo de vapor.

You et al (1995) analisaram, para o FC-32, sob condições de pressão próximas a atmosférica, a influência de gases não condensáveis, com o objetivo de intensificar a taxa de transferência de calor. O FC-32 é utilizado, principalmente, no resfriamento de componentes 
eletrônicos. Ele é caracterizado por dissolver elevadas quantidades de gases e por apresentar valores reduzidos de tensão superficial, viscosidade, condutividade elétrica e do ângulo $\beta$. Esta última característica faz com que necessite uma maior energia para a ativação das cavidades e, consequentemente, valores elevados de $\Delta T$ para o início da ebulição. A superfície utilizada pelos autores foi um cilindro de quartzo, com diâmetro de aproximadamente $0,51 \mathrm{~mm}$, recoberto com platina e uma camada de silicone. Conforme esperado, o incremento na concentração de incondensáveis resultou na elevação de $h$, para um mesmo superaquecimento da superfície, e na redução da histerese, devido a necessidade de uma menor energia de ativação das cavidades. A presença de incondensáveis reduziu o superaquecimento necessário para o inicio da ebulição apenas para concentrações superiores à 0,005 mol gás/mol FC-32. 


\section{Capítulo 3 - Correlações da Literatura}

\subsection{Introdução}

Em ebulição nucleada plenamente desenvolvida é uma difícil tarefa indicar a melhor correlação para a determinação do coeficiente de transferência de calor. Thome (1996) através de suas comparações afirma que, para aplicações frigoríficas, as correlações mais adequadas seriam as de Cooper (1984) e do VDI-Wärmeatlas (1994), sendo esta última a que apresenta os melhores resultados para a amônia. Webb e Pais (1992) também comparam seu banco de dados com as correlações empíricas de Cooper (1984) e Stephan e Abdelsalam (1980), concluindo ser a primeira a mais precisa.

Desta forma, neste capítulo proceder-se-á à apresentação e à análise de algumas correlações para o coeficiente de transferência de calor em ebulição nucleada em superfícies lisas. Os métodos utilizados para correlacionar este coeficiente foram classificados em estritamente empíricos, semi-empíricos e baseados em propriedades reduzidas, que tomam por base uma extensão da Lei dos Estados Correspondentes aplicada às propriedades dos fluidos no estado de saturação. Embora não incorporem qualquer mecanismo físico, tais correlações caracterizam-se pela simplicidade e relativa precisão. As correlações estritamente empíricas se limitam ao ajuste de curvas, em certos casos, associados a uma análise dimensional. Já, os modelos semi-empíricos são baseados em modelos físicos, constituídos pelos mecanismos enumerados no Capítulo 2, elaborados segundo a ótica fenomenológica do autor e com coeficientes e expoentes ajustados por intermédio de resultados experimentais. 


\subsection{Correlações Estritamente Empíricas}

Estas correlações são resultado de análises de regressão a partir de um grande número de dados, os quais podem ser experimentais ou até mesmo gerados através de alguma correlação anterior. Tais correlações, embora não sejam baseadas em modelos físicos, apresentam uma boa precisão, podendo ser consideradas genéricas, dependendo da abrangência do banco de dados utilizado. Neste grupo destaca-se a correlação de Stephan e Abdelsalam (1980), freqüentemente utilizada na comparação com resultados experimentais levantados por diferentes autores.

\subsubsection{Correlação de Stephan e Abdelsalam (1980)}

Considerando a dificuldade na avaliação dos fenômenos físicos que regem a transferência de calor em ebulição nucleada, os autores propuseram um modelo estritamente empírico, baseado em um banco de dados de aproximadamente 5000 pontos experimentais, composto por fluidos que, devido às suas características, foram divididos em 4 grupos (água, hidrocarbonetos, fluídos criogênicos e refrigerantes halogenados).

Foi utilizado o princípio de que certo número de propriedades de transporte caracterizam o processo de transferência de calor, influenciando variáveis como o número de cavidades ativas, freqüência de desprendimento de bolhas, energia necessária para o crescimento da bolha e grau de agitação do líquido junto a parede. Assim, através de uma análise dimensional associada ao teorema dos Pi de Buckingham $(\pi)$, construíram produtos de grupos adimensionais, escolhendo os mais característicos para cada grupo de substâncias.

Para os refrigerantes halogenados, os autores obtiveram melhores resultados utilizando os seguintes adimensionais, comuns à maioria das correlações :

$>\quad$ Número de Prandtl do líquido, relacionando os efeitos de difusividade térmica e de quantidade de movimento.

$>\quad$ "Número de Reynolds", relativo à ebulição nucleada, associado ao efeito de agitação do líquido junto a parede na taxa de calor transferida.

$>\quad \rho_{v} / \rho_{l}$, associado à expansão do refrigerante em virtude da mudança de fase.

Através de uma análise de regressão do banco de dados, utilizando esses produtos, obteve-se a seguinte equação, específica para refrigerantes halogenados: 


$$
\frac{h \cdot d_{b}}{k_{l}}=207 \cdot\left(\frac{\phi \cdot d_{b}}{k_{l} \cdot T_{s a t}}\right)^{0,745} \cdot\left(\frac{\rho_{v}}{\rho_{l}}\right)^{0,581} \cdot\left(\frac{v_{l}}{a_{l}}\right)^{0,533} \cdot R_{p}{ }^{0,133}
$$

com $d_{b}$ determinado através da Eq. (2.7)

\subsection{Correlações Baseadas em Propriedades Reduzidas}

São correlações em que a influência das propriedades de transportes e termodinâmicas nos mecanismos físicos de transferência de calor são reduzidas a uma função das propriedades reduzidas $p_{r} \mathrm{e} T_{r}$. Parâmetros característicos do fluido refrigerante e da superfície de transferência de calor são introduzidos com o objetivo de terem seus efeitos incorporados à correlação. De forma análoga às estritamente empíricas, elas tem os parâmetros numéricos ajustados a extensos bancos de resultados experimentais.

\subsubsection{Correlação de Cooper (1984)}

Embora uma série de trabalhos envolvendo a correlação do coeficiente de transferência de calor na ebulição nucleada em termos de propriedades reduzidas tenham sido publicados anteriormente, Cooper (1984) foi o primeiro a formalizar esta abordagem.

Cooper (1982) observou que as correlações geralmente são baseadas em produtos adimensionais de propriedades ou desenvolvidas segundo o ponto de vista fenomenológico do autor. Analisando as propriedades físicas e de transporte da água, baseado na "lei dos estados correspondentes", verificou ser possível predizê-las através de correlações do tipo:

$$
(\text { propriedade })_{i}=p_{r}^{a_{i}} \cdot T_{r}^{b_{i}} \cdot\left(1-T_{r}\right)^{c_{i}} \cdot 10^{e_{i}}
$$

ou

$$
(\text { propriedade })_{i}=p_{r}^{a_{i}} \cdot\left(-\log _{10} p_{r}\right)^{d_{i}} \cdot 10^{e_{i}}
$$


Confirmando a possibilidade de desenvolvimento de uma correlação que não envolva um modelo físico do fenômeno de ebulição nucleada, mas a natureza das propriedades de saturação, ele mostrou que é possível propor uma correlação do tipo:

$$
\frac{h}{(\phi)^{m}}=\text { Constante } \cdot p_{r}^{A} \cdot\left(-\log _{10} p_{r}\right)^{B}
$$

Cooper (1984) obteve uma correlação precisa e simples utilizando um banco de dados experimentais e obtendo, através de análise de regressão, os parâmetros numéricos da Eq. (3.4). Seus resultados, independentemente do formato da superfície, foram expressos pela seguinte correlação:

$$
\frac{h}{(\phi)^{0,67}}=55 \cdot p_{r}^{0,12-0,2 \cdot \log R_{p}} \cdot\left(-\log p_{r}\right)^{-0,55} \cdot M^{-0,5}
$$

Apenas, no caso da utilização desta correlação para superfícies cilíndricas constituídas de cobre, Cooper (1984) sugere multiplicar o lado direito da Eq. (3.5) por 1,7.

\subsubsection{Correlação do VDI-Wärmeatlas (1994)}

Esta correlação foi elaborada admitindo a possibilidade de separar as influências relativas da pressão de saturação $\left(F_{p s a t}\right)$, do fluxo específico de calor $\left(F_{\phi}\right)$, e da superfície $\left(F_{p}\right)$, segundo a seguinte equação:

$$
\frac{h}{h_{0}}=F_{p s a t} \cdot F_{\phi} \cdot F_{p}
$$

Adotou-se $h_{0}$ conforme a norma ISO 4287/01:1984, determinado para um tubo de cobre com rugosidade aritmética média $R a_{0}=0,4 \mu \mathrm{m}$, pressão de referência igual a $p_{r 0}=0,1$, e um fluxo específico de calor de $20 \mathrm{~kW} / \mathrm{m}^{2}$. Alguns valores de $h_{0}$ são apresentados na Tabela 3.1.

O termo relativo a pressão foi ajustado através das seguintes equações: 


$$
\begin{array}{ll}
F_{p s a t}=1,73 \cdot p_{r}^{0,27}+\left(6,1+\frac{0,68}{1-p_{r}}\right) \cdot p_{r}^{2} & \text { para a água } \\
F_{p s a t}=1,2 \cdot p_{r}^{0,27}+\left(2,5+\frac{1}{1-p_{r}}\right) \cdot p_{r} & \text { para os demais fluidos }
\end{array}
$$

\begin{tabular}{|c|c|c|c|c|c|}
\hline Fluido & $h_{0}\left(W / m^{2} . K\right)$ & Fluido & $h_{0}\left(W / m^{2} \cdot K\right)$ & Fluido & $h_{0}\left(W / m^{2} \cdot K\right)$ \\
\hline $\mathrm{R}-11$ & 2800 & $\mathrm{R}-227$ & 3800 & tolueno & 2910 \\
\hline $\mathrm{R}-12$ & 4000 & RC-318 & 4200 & difenil & 2030 \\
\hline R-13 & 3900 & $\mathrm{R}-502$ & 3300 & metanol & 2770 \\
\hline R-13B1 & 3500 & água & 5600 & etanol & 3690 \\
\hline R-22 & 3900 & metano & 8060 & n-propanol & 3170 \\
\hline R-23 & 4400 & etano & 5210 & isopropanol & 2920 \\
\hline R-113 & 2650 & propano & 4000 & n-butanol & 2750 \\
\hline R-114 & 3800 & n-butano & 3300 & isobutanol & 2940 \\
\hline amônia & 7000 & n-pentano & 3070 & acetona & 3270 \\
\hline R-115 & 4200 & isopentano & 2940 & clorometano & 4790 \\
\hline R-123 & 2600 & n-hexano & 2840 & $\mathrm{CCl}_{4}$ & 2320 \\
\hline $\mathrm{R}-134 \mathrm{a}$ & 4500 & n-heptano & 2420 & $\mathrm{CF}_{4}$ & 4500 \\
\hline $\mathrm{R}-152 \mathrm{a}$ & 4000 & ciclohexano & 2420 & & \\
\hline $\mathrm{R}-226$ & 3700 & benzeno & 2730 & & \\
\hline
\end{tabular}

válidas para $p_{\text {sat }}>10 \mathrm{kPa}$ e $p_{r}<0,9$

Tabela 3.1 Valores referenciais de $h_{0}$

Nesta correlação os efeitos da superfície são divididos em duas parcelas: uma resultante das propriedades do material, $F_{p m}$, e a outra da rugosidade, $F_{p r}$, tal que os efeitos globais da superfície são apresentados como:

$$
F_{p}=F_{p r} \cdot F_{p m}
$$

Embora, para um mesmo superaquecimento da superfície, alterações na rugosidade não afetam somente o valor absoluto do fluxo específico de calor, mas também a sua relação com a pressão, estes efeitos são desprezados, admitindo que para valores intermediários de $\phi$ 
e pressões de saturação não muito elevadas, condições para as quais a correlação foi desenvolvida, eles não são relevantes. Assim, os fatores de influência da rugosidade e do fluxo de calor foram correlacionados através das seguintes equações:

$$
F_{\phi}=\left(\frac{\phi}{\phi_{0}}\right)^{m}
$$

onde:

$$
\begin{array}{ll}
m\left(p_{r}\right)=0,9-0,3 \cdot p_{r}^{0,15} & \text { para água e hélio } \\
m\left(p_{r}\right)=0,9-0,3 \cdot p_{r}^{0,3} & \text { para os demais fluidos } \\
F_{p r}=\left(\frac{R a}{R a_{0}}\right)^{0,133} &
\end{array}
$$

Os efeitos de parede associados ao material, através de sua influência no tempo de espera e na densidade de cavidades ativas relacionada à inércia térmica e ao perfil de temperaturas na superfície, foi expresso através da seguinte relação:

$$
h \approx s^{0,5} \quad \text { onde } \quad s=k_{p} \cdot \rho_{p} \cdot c_{p}
$$

Desta forma, utilizando como referência uma superfície de cobre, o parâmetro envolvendo a influência do material da superfície pode ser definido como:

$$
F_{p m}=\left(\frac{s}{s_{0}}\right)^{0,5}
$$

\subsubsection{Correlação de Leiner (1994)}

Leiner (1994), com base na Eq. (3.6), determinou uma correlação na qual a constante experimental, $h_{0}$, é função de parâmetros adimensionais específicos do líquido. Deste modo, elimina-se a necessidade de determinar uma constante empírica, tornando genérica a correlação anterior. Os parâmetros adotados foram os seguintes: fator de 
compressibilidade crítico, $z_{\text {crit }}$ caracterizando o fluido; calor específico adimensional, $c_{l}^{*}=\left(c_{l} / R\right)_{p_{r}=0,1}$ também caracterizando o fluido; parâmetro de "pressão do vapor", $K \cong\left[\frac{h_{l v}}{R \cdot T_{c r i t}}\right]_{p_{r} \ll 1}$ caracterizando o coeficiente angular da curva de pressão de saturação em função da temperatura (Clausius-Clapeyron). Os termos $\phi, h$ e $R a$ da Eq.(3.6) foram individualmente adimensionalisados e os restantes, excluindo o fator relativo à $p_{r}$, foram escritos como uma função de $c_{l}^{*}, z_{c r i t}$ e $K$, resultando a seguinte equação:

$$
\begin{aligned}
\frac{h}{p_{\text {crit }} \cdot\left(R / T_{\text {crit }}\right)^{1 / 2}=} & 0,4368 \cdot\left(c_{l}^{*}\right)^{0,2113} \cdot K^{-0,0521} \cdot z_{\text {crit }}^{-0,9166} \cdot 43000^{m-m_{0}} \cdot \\
& \left(1,2 \cdot p_{r}^{0,27}+2,5 \cdot p_{r}+\frac{p_{r}}{1-p_{r}}\right) \cdot\left[\frac{\phi}{p_{\text {crit }} \cdot\left(R \cdot T_{\text {crit }}\right)^{1 / 2}}\right]^{n} \cdot\left[\frac{R a}{\frac{R \cdot T_{\text {crit }} \cdot M}{N \cdot p_{\text {crit }}}}\right]^{0,133}
\end{aligned}
$$

onde :

$$
m-m_{0}=0,15-0,3 \cdot p_{r}^{0,3}
$$

Segundo o autor, esta equação apresentou desvio médio* igual à $\pm 13,6 \%$ quando comparada aos resultados determinados através da Eq. (3.6), para os fluidos com valores de $h_{0}$ relacionados na Tabela 3.1. É interessante destacar a proposição pelo autor de substituir $c_{l}^{*}$ por $c_{v}^{*}$ em trabalhos futuros. Esta sugestão, embora não encontre uma justificativa física plausível, baseia-se na verificação pelo autor de um certo grau de interdependência numérica entre $c_{l}^{*}$ e $K$, que com tal alteração seria eliminado, proporcionando, realmente, uma nova variável independente na correlação.

\subsubsection{Análise Comparativa das Correlações Empíricas e Baseadas em Propriedades Reduzidas}

As correlações classificadas nestes grupos, ao contrário das semi-empíricas, são

* desvio médio $=\frac{1}{n} \cdot \sum_{i=1}^{n} \frac{\mid(\text { valor } \quad E q . \quad(3.13))-(\text { valor } \quad E q . \quad(3.6)) \mid}{\text { valor } E q . \quad(3.6)}$ 
ajustadas através de extensos bancos de dados experimentais. Isto fez com que a análise de seus resultados fosse agrupada em um único item. Foram incluídas nesta análise as correlações de Stephan e Abdelsalam (1980), VDI-Wärmeatlas (1994) e Cooper (1984). Não foi incluída a de Leiner (1994) por ter sido ajustada ao modelo do VDI-Wärmeatlas (1994), resultando, desta forma, tendências semelhantes.

Nos estudos envolvendo a ebulição nucleada são utilizados diferentes parâmetros para a caracterização do acabamento superficial. Assim, enquanto as correlações de Stephan e Abdelsalam (1980) e Cooper (1984) utilizam a distância entre picos e vales (máxima), $R p$, VDI-Wärmeatlas (1994) e Leiner (1994) adotam a média aritmética de todas as distâncias absolutas do perfil a uma linha central média, $R a$. Por outro lado, deve ser destacado que na literatura especializada não se encontra uma clara relação entre as dimensões $R a$ e $R p$. Nessas condições, embora se reconheça a distinção conceitual desses parâmetros, optou-se por considerá-los iguais na comparação entre as correlações.

Uma forma interessante de comparação e avaliação das correlações levada a cabo neste estudo consiste em referir o coeficiente de transferência de calor àquele correspondente a um determinado parâmetro fixo, por exemplo, o fluxo específico de calor. Desta forma, ao invés de valores absolutos, são comparadas as tendências apresentadas pelas correlações com a variação de um determinado parâmetro.

As correlações de Cooper (1984) e Stephan e Abdelsalam (1980), ao contrário da do VDI-Wärmeatlas (1994), adotam um valor constante para o expoente do fluxo específico de calor. Gorenflo et al. (1994), além de considerar o efeito da pressão reduzida neste expoente, sugere a incorporação à correlação do VDI-Wärmeatlas (1994) de um parâmetro de rugosidade, destacando seus efeitos para superfícies com elevados valores de $R a$. Conclusão análoga à de Webb e Pais (1992), obtida através da análise de seus resultados experimentais. A Fig. 3.1 ilustra os comportamentos para distintas pressões reduzidas da razão $h(\phi) / h\left(\phi=10 \mathrm{~kW} / \mathrm{m}^{2}\right)$ proporcionados pelas correlações do VDI-Wärmeatlas (1994), Stephan e Abdelsalam (1980) e Cooper (1984). Verificam-se inclinações próximas para $p_{r}=0,1$, e a elevação apreciável com a redução de $p_{r}$ da diferença de inclinação entre elas.

A Fig. 3.2 ilustra a taxa de variação do coeficiente de transferência de calor com $p_{r}$. Nela verifica-se que as correlações de Stephan e Abdelsalam (1980) e a do VDI-Wärmeatlas (1994) apresentam tendências semelhantes e são mais sensíveis a alterações na pressão, quando comparadas à de Cooper (1984). Este autor, ao contrário dos demais, considerou os efeitos de interação da pressão de saturação com a rugosidade da superfície. Tais efeitos, conforme discutido no Capítulo 2, estão relacionados ao tamanho das cavidades ativas e a 
energia necessária para ativa-las. A Fig. 3.3 ilustra tal interação destacando sua importância no caso de valores reduzidos de $p_{r}$, condição em que seus efeitos tornam-se pronunciados.

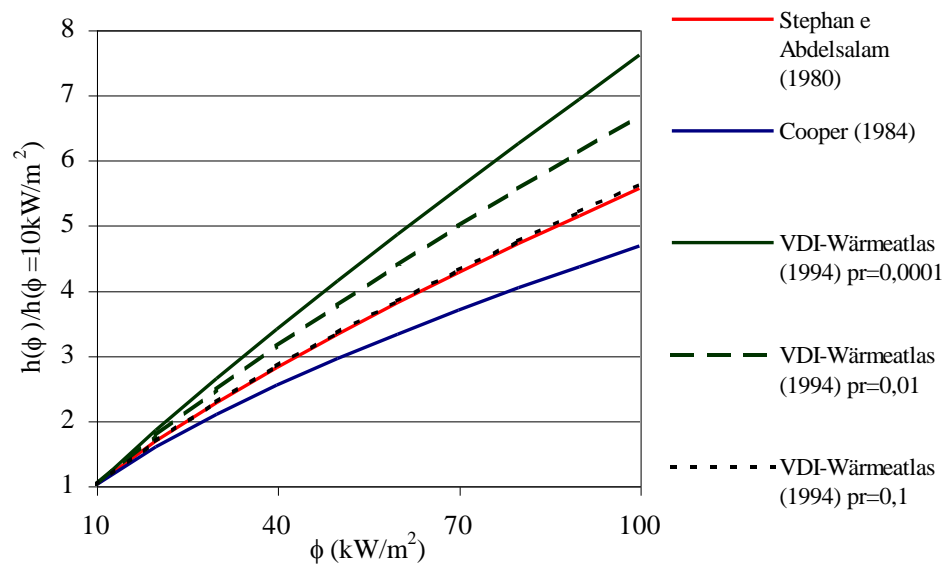

Figura 3.1 Efeito do expoente de $\phi$ na taxa de transferência de calor.

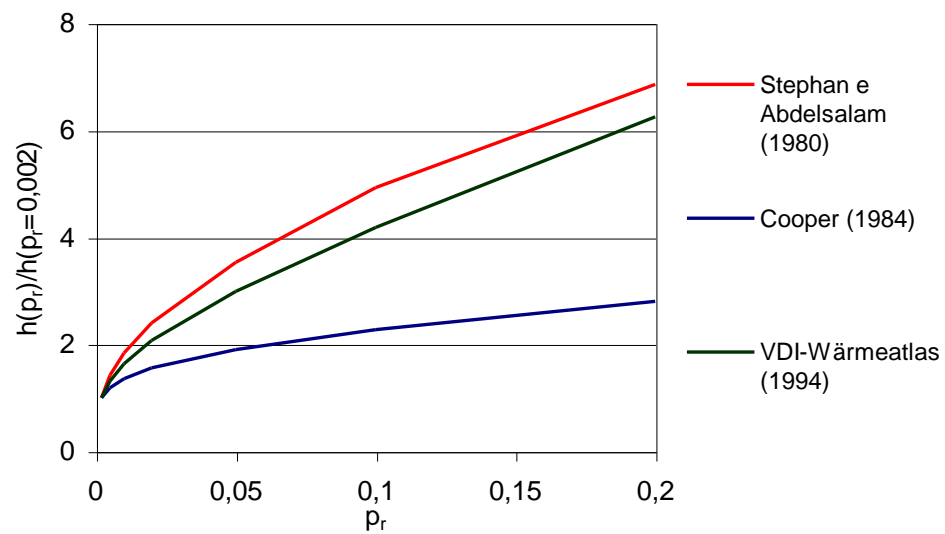

Figura 3.2 Efeito da pressão reduzida na taxa de transferência de calor para o R-11, $R a=R p=1 \mu \mathrm{m}$ e $\phi=30 \mathrm{~kW} / \mathrm{m}^{2}$.
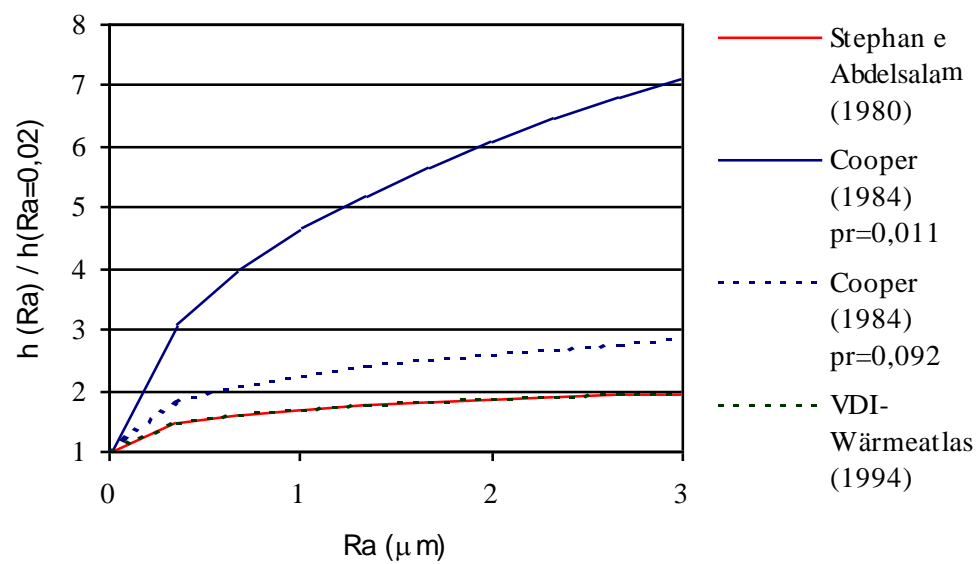

Figura 3.3 Variação da relação entre coeficiente de transferência de calor com $R a$. 
Cooper (1984), ainda que não inclua em sua correlação efeitos do material da superfície, uma vez que os considera desprezíveis, verificou, através de seu banco de dados, um ligeiro incremento do coeficiente de transferência de calor com $k_{p}$. Stephan e Abdelsalam (1980), embora desprezem efeitos das propriedades termofísicas do material, as incluem na correlação para a ebulição de fluidos criogênicos. No caso destes fluidos, uma pequena alteração em $\phi$ e, consequentemente, em $T_{p}$, resulta em grandes variações de $k_{p}$ e $c_{p}$, modificando drasticamente o coeficiente de transferência de calor, podendo, em casos extremos ter seu valor alterado de um fator 40. Tal comportamento se justifica pelo fato das propriedades serem muito mais sensíveis a baixas temperaturas que a altas. Ao contrário destes autores, o VDI-Wärmeatlas (1994) em sua correlação destaca, independentemente do fluido, a importância das propriedades termofísicas do material da superfície na taxa de transferência de calor, através do coeficiente $F_{p m}$, diretamente proporcional ao coeficiente de transferência de calor. A Tabela 3.2 apresenta seu valor para diferentes materiais a uma temperatura de 300K. Segundo esta tabela, o coeficiente de transferência de calor pode ser reduzido em até $2 / 3$ pela simples mudança do material da superfície de cobre para aço

Tabela 3.2 Valores de $F_{p m}$ para diferentes materiais

\begin{tabular}{cc}
\hline \hline Material & $\boldsymbol{F}_{\boldsymbol{p m}}$ \\
\hline \hline aço AISI 1010 & 0,386 \\
\hline cobre & 1 \\
\hline alumínio & 0,648 \\
\hline latão & 0,508 \\
\hline \hline
\end{tabular}

Os bancos de dados das três correlações analisadas envolveram resultados experimentais para superfícies planas, cilíndricas de diferentes diâmetros e fios metálicos. Embora os autores reconheçam a influência do formato da superfície, principalmente em fluxos de calor reduzidos, nenhum o incluiu em sua correlação. Tanto Cooper (1984) como o VDI-Wärmeatlas (1994) sugerem o incremento do coeficiente de transferência de calor com o diâmetro do tubo, fato atribuído ao arraste das bolhas ao redor da superfície. Cooper (1984) não tendo conseguido caracterizar o efeito de forma da superfície, sugere, para superfícies cilíndricas de cobre, um coeficiente de transferência de calor 1,7 vezes maior que para outras combinações de material e formato da superfície.

Finalmente com base nesta análise é possível concluir:

Embora as correlações de Stephan e Abdelsalam (1980) e VDI-Wärmeatlas (1994), no 
caso de condições típicas das aplicações, apresentem tendências próximas, nenhuma das correlações é genérica, a ponto de proporcionar resultados adequados para uma ampla gama de condições.

Considerando que os resultados fornecidos por estas correlações são caracterizados, principalmente pela amplitude dos respectivos bancos de dados, a determinação de uma correlação baseada em propriedades reduzidas torna-se preferível ao considerarse a simplicidade de utilização.

$>$ Esforços no sentido de desenvolver correlações mais abrangentes devem ser aprofundados, através do incremento da faixa de condições experimentais, visando os efeitos dos seguintes parâmetros: pressão, acabamento superficial, interação entre $p_{r} \mathrm{e}$ $R a$; e do material da superfície de transferência de calor.

A introdução de parâmetros que caracterizem o fluido, conforme sugerido por Cooper (1984) e Leiner (1994), deve ser explorada na tentativa de, para o caso dos refrigerantes halogenados, estender a correlação proposta a refrigerantes não incluídos no banco de dados inicial. A correlação do VDI-Wärmeatlas (1994), embora introduza um parâmetro característico do fluido, este é determinado experimentalmente.

\subsection{Correlações Semi-Empíricas}

São baseadas em modelos físicos segundo a ótica fenomenológica do autor. Estas correlações, embora se apresentem como generalizadas, aplicam-se muitas vezes a situações particulares, características do banco de dados para o qual foram ajustadas, que tende a ser, ao contrário das estritamente empíricas e baseadas em propriedades reduzidas, restrito. Tais modelos descrevem a física do processo parcialmente, uma vez que a transferência de calor durante a ebulição nucleada é resultado da ação concomitante de vários mecanismos. Dependendo de condições tais como, a magnitude de fluxo específico de calor, pressão, ângulo de contato entre a superfície e o líquido em ebulição, sub-resfriamento, etc, um ou mais mecanismos podem ser dominantes. Isto explica porque alguns modelos se ajustam perfeitamente a certas condições e falham em outras. Como exemplo, pode se citar o mecanismo da evaporação da microcamada, que, durante a década de 70 , parecia solucionar todas as dúvidas sobre ebulição nucleda e, hoje, é somente utilizado na ebulição de metais líquidos, dadas as características particulares da ebulição desses fluidos. 
Rohsenow (1952) desenvolveu um modelo considerando como mecanismo responsável pela transferência de calor a agitação do líquido junto a superfície aquecida devido ao desprendimento e colapso das bolhas, as quais deslocariam uma quantidade de líquido igual ao seu próprio volume. Considerou-se, primeiramente, que o calor é transferido através de condução diretamente da superfície para o líquido adjacente a parede. Com as bolhas servindo como agitadores, o autor pode assumir uma analogia com transferência de calor em convecção turbulenta forçada, correlacionando, assim, o número de Nusselt em termos dos números de Reynolds e Prandtl. O número de Reynolds foi referido ao diâmetro de desprendimento da bolha, relacionando as forças de inércia e viscosas associadas a agitação turbulenta promovida pelas bolhas.

$$
\operatorname{Re}_{b}=\frac{G_{v} \cdot d_{b}}{\mu_{l}}
$$

onde $G_{v}$ é a velocidade mássica média do vapor deixando a superfície, determinada por :

$$
G_{v}=\rho_{v} \cdot\left(\frac{\pi \cdot d_{b}^{3}}{6}\right) \cdot f \cdot(n / A)
$$

O diâmetro de desprendimento de bolhas foi determinada através da Eq. (2.7). Experimentalmente Rohsenow e Clark apud Rohsenow (1952) verificaram que o calor removido da parede pela ação das bolhas é proporcional à quantidade de calor associada à evaporação de líquido para formação das bolhas, podendo ser escrito como:

$$
\phi=C_{2} \cdot \frac{\pi \cdot d_{b}^{3}}{6} \cdot \rho_{v} \cdot h_{l v} \cdot(n / A) \cdot f
$$

Finalmente, combinando as Eqs. (2.7) , (3.14), (3.15), e (3.16), determina-se o número de Reynolds relativo ao diâmetro de desprendimento da bolha:

$$
\operatorname{Re}_{b}=\left(\frac{C_{l}}{C_{2}} \cdot \sqrt{2} \cdot \beta\right) \cdot \frac{\phi}{h_{l v} \cdot \mu_{l}} \cdot\left[\frac{\sigma}{g \cdot \rho_{v l}}\right]^{0,5}
$$


Ao contrário do número de Nusselt, o número de Stanton pode ser determinado independentemente do fluxo de calor, uma vez que:

$$
\begin{aligned}
& S t_{b}=\frac{N u_{b}}{R e_{b} \cdot P r_{l}} \\
& S t_{b}=\frac{C_{2} \cdot h_{l v}}{c_{l} \cdot \Delta T}
\end{aligned}
$$

Sendo o número de Nusselt função dos números de Reynolds e Prandtl e o número de Stanton definido conforme Eq. (3.18), o número de Stanton pode ser escrito como uma função dos números de Reynolds e de Prandtl, conforme indicado a seguir.

$$
S t_{b}=C_{3} \cdot \operatorname{Re}_{b}^{r} \cdot \operatorname{Pr}_{l}^{s}
$$

Combinando as Eqs. (3.17), (3.19) e (3.20), obtêm-se a forma final:

$$
\frac{c_{l} \cdot \Delta T}{h_{l v}}=\left[\frac{C_{3}}{C_{2}} \cdot\left(\frac{\sqrt{2} \cdot C_{1}}{C_{2}} \cdot \beta\right)^{r}\right] \cdot\left\{\frac{\phi}{h_{l v} \cdot \mu_{l}} \cdot\left[\frac{\sigma}{g \cdot \rho_{v l}}\right]^{0,5}\right\}^{r} \cdot\left(\frac{\mu_{l} \cdot c_{l}}{k_{l}}\right)^{s}
$$

onde:

$$
C_{s f}=\left[\frac{C_{3}}{C_{2}} \cdot\left(\frac{\sqrt{2} \cdot C_{1}}{C_{2}} \cdot \beta\right)^{r}\right] \quad \Rightarrow \text { coeficiente de sup erfície/líquido }
$$

Os valores $r$ e $s$ foram experimentalmente correlacionados, obtendo-se $r=0,33 \mathrm{e}$ $s=1,7$ para a maioria dos líquidos, com exceção da água, para a qual os valores que proporcionaram melhores resultados foram $s=1,0$ e $r=0,33$. O coeficiente $C_{s f}$ é função das características do par superfície/líquido, conforme pode ser observado na Eq. (3.21), onde o ângulo de contato $\beta$ é um de seus fatores determinantes. Para a água em superfície de cobre lisa obteve-se $C_{s f}=0,013$. O expoente $r$ também é função da combinação líquido e superfície, incorporando características como material e tipo de acabamento da superfície. Já o expoente $s$, segundo o autor, é função somente do tipo de acabamento, podendo variar entre 0,8 e 2,0. Vachon et al (1968), obtiveram experimentalmente o coeficiente $C_{s f}$ e o expoente $r$ para 
várias combinações de características de acabamento, composição da superfície aquecida e líquido em ebulição. Embora eles tenham realizado um estudo extenso, não determinaram valores de $C_{s f}, r$ e $s$ para a ebulição de refrigerantes halogenados. Sauer et al. (1975) determinaram valores de $C_{s f}$ para o R-11/Inconel para diferentes acabamentos superficiais. Pioro (1999) levantou, experimentalmente, valores para as constantes $C_{s f}$ e $r$ para a ebulição de água, etanol, R-113 e R-11 em superfícies de cobre, alumínio, aço e latão. As superfícies utilizadas eram planas de formato circular com $R_{a}$ entre 0,5 e 3,6 $\mu$ m. Saiz Jabardo e Silva (1991) determinaram valores de $C_{s f}$ para os refrigerantes R-11, R-113, R-114 e suas misturas com óleo de lubrificação em uma superfície de latão. Eles adotaram os valores de $r$ e $s$ sugeridos por Rohsenow (1952). Todos estes autores verificaram a redução no $C_{s f}$ com o incremento da rugosidade, que resulta na elevação do coeficiente de transferência de calor.

\subsubsection{Modelo de Foster e Zuber (1955)}

Foster e Zuber (1955) desenvolveram um modelo baseado na denominada "microconvecção" como principal mecanismo responsável pela transferência de calor na superfície aquecida. Este mecanismo consiste na remoção de calor através da convecção forçada promovida pelo movimento de expansão da bolha. O coeficiente de transferência de calor foi definido em termos dos parâmetros adimensionais típicos da convecção forçada conforme equação abaixo:

$$
N u=C_{1} \cdot \operatorname{Re}^{r} \cdot \operatorname{Pr}_{l}^{s}
$$

onde

$$
R e=\frac{d \cdot \frac{d(d)}{d t}}{v_{l}}
$$

Evidentemente, definiu-se o número de Prandtl em termos das propriedades do líquido. Para o cálculo do número de Reynolds, Eq. (3.23), admitiu-se como dimensão característica o diâmetro instantâneo da bolha, no presente caso para uma bolha crescendo no 
seio do liquido uniformemente aquecido*. A velocidade característica do líquido foi determinada como função da velocidade de crescimento da bolha. Estas variáveis foram determinadas através da seguinte equação anteriormente propostas pelos autores :

$$
d=2 \cdot J a \cdot\left(\pi \cdot a_{l} \cdot t\right)^{1 / 2}
$$

onde, o número de Jakob, relaciona as taxas de calor latente e sensível transferida durante a mudança de fase de líquido para vapor.

Determinou-se, assim, através da Eq. (3.23), o número de Reynolds independente do tempo, o mesmo não ocorrendo com o número de Nusselt. Deste modo, foi definida uma dimensão característica modificada, como:

$$
d=R_{0} \cdot\left[\frac{\rho_{l} \cdot\left(\frac{d}{2} \cdot \frac{1}{2} \cdot \frac{d(d)}{d t}\right)^{2}}{2 \cdot \sigma \cdot R_{0}}\right]^{1 / 4}
$$

onde $R_{0}$ é o raio da bolha obtido da equação de Laplace

Finalmente, combinado as Eqs. (3.22), (3.23), (3.24) e (3.25) determinou-se a seguinte equação:

$$
\frac{\phi}{\rho_{v} \cdot h_{l v}} \cdot\left(\frac{\pi}{a_{l}}\right)^{1 / 2} \cdot\left[\frac{\rho_{l} \cdot\left(\frac{2 \cdot \sigma}{p_{v}-p_{l}}\right)^{3}}{2 \cdot \sigma}\right]^{1 / 4}=C_{l} \cdot\left[\frac{\rho_{l}}{\mu_{l}} \cdot\left(\frac{\Delta T \cdot k_{l}}{\rho_{v} \cdot h_{l v}}\right)^{2} \cdot \frac{\pi}{a_{l}}\right]^{r} \cdot\left(\frac{c_{l} \cdot \mu_{l}}{k_{l}}\right)^{s}
$$

Os expoentes $r$ e $s$ foram determinados através da análise de regressão de um banco de dados experimentais, resultando iguais a 5/8 e 1/3, respectivamente. Para o coeficiente $C_{l}$, obteve-se o valor 0,0015, para a água a pressões variando entre 1 e 50 bar. Embora a literatura não apresente um estudo sistemático, o coeficiente $C_{l}$ é presumivelmente

\footnotetext{
* Cole e Shulman (1966) analisaram diferentes modelos para o diâmetro instantâneo da bolha tanto no seio de um líquido uniformemente superaquecido como junto a uma parede. Através de resultados experimentais, concluíram que, para números de Jakob inferiores a 100, a Eq. (3.24), para o diâmetro instantâneo da bolha no seio do líquido, pode também ser utilizada para a determinação do diâmetro junto a uma parede aquecida, com o acréscimo de uma constante multiplicativa igual à 0,5 . Para $100<\mathrm{Ja}<792$, condições de pressão sub-atmosféricas, pode-se utilizar a seguinte equação empírica: $d=5 \cdot J a \cdot \sqrt{a_{l} \cdot t}$, proporcionando resultados semelhantes a modelos mais complexos
} 
influenciado pelas condições da superfície e do líquido em ebulição, da mesma forma que o $C_{s f}$ proposto por Rohsenow (1952).

\subsubsection{Modelo de Zuber (1963)}

Este modelo foi desenvolvido através da analogia entre ebulição nucleada e convecção natural turbulenta. Inicialmente, os mecanismos de ascensão de bolhas devido a ebulição e devido ao borbulhamento de um gás através de uma superfície porosa inundada foram considerados similares. O processo de transferência de calor foi dividido em dois regimes: "laminar", caracterizado pelo desprendimento intermitente de bolhas; "turbulento", no qual ocorrem interferências entre as bolhas, que resultam em colunas contínuas de vapor. Para o primeiro regime, $d_{b}$ independe do número de cavidades ativas e o mecanismo responsável pela transferência de calor é a agitação do líquido, resultante do desprendimento de bolhas. Já, para o regime turbulento, o mecanismo responsável pela transferência de calor é a evaporação contínua de uma micro-camada pulsante, existente junto a base da bolha. $\mathrm{O}$ modelo desenvolvido, baseado na analogia entre convecção natural e ebulição nucleada, é válido apenas para o regime laminar.

Com base em trabalhos anteriores, envolvendo o estudo do comportamento de bolhas geradas através da injeção de gás através de uma superfície porosa, foi determinada a velocidade do vapor no regime laminar, dada pela seguinte equação:

$$
u_{v}=u_{t} \cdot(1-\alpha)
$$

onde $u_{t}$ é a velocidade terminal de uma bolha em um meio infinito, definida segundo Harmathy apud Zuber (1963) como:

$$
u_{t}=1,53 \cdot\left[\frac{\sigma \cdot g \cdot\left(\rho_{\nu l}\right)}{\rho_{l}^{2}}\right]^{1 / 4}
$$

e $\alpha$ a fração de vazio. No presente modelo, $\alpha$ foi considerado constante, independente da distância da superfície aquecida e igual ao seu valor junto à parede, $\alpha_{p}$, determinado como: 


$$
\alpha_{p}=\frac{\pi}{6} \cdot d_{b}^{3} \cdot(n / A) \cdot \frac{f}{u_{v}}
$$

É interessante destacar que, embora $\alpha_{p} \neq \alpha$, considerar $\alpha_{p}$ como representativo do fenômeno é um argumento válido, pois seus valores são próximos na região junto à parede, onde ocorre a maior parcela da transferência de calor, resultante da agitação do líquido.

Adotando a seguinte equação para o diâmetro instantâneo da bolha*

$$
d=4 \cdot J a \cdot \sqrt{\frac{a_{l} \cdot t}{\pi}}
$$

considerando $t_{c} \gg t_{e}{ }^{*}$ e combinado as Eqs. (2.7) e (2.19), respectivamente, para o diâmetro e a frequiência de desprendimento de bolhas, com as Eqs. (3.27) e (3.29), correlacionou-se a fração de vazio junto a parede como:

$$
\alpha_{p}=\frac{8}{3} \cdot(n / A) \cdot J a^{2} \cdot \frac{a_{l} \cdot d_{b}}{u_{t}}
$$

$\mathrm{Na}$ determinação do coeficiente de transferência de calor, foi considerada uma correlação típica de convecção natural, $N u=f\left(\operatorname{Ray}_{L}\right)$, com o número de Nusselt sendo proporcional a raiz cúbica do número de Rayleigh, conforme a seguinte equação:

$$
\frac{h \cdot L}{k_{l}}=\text { const } \cdot\left(\frac{g}{v_{l} \cdot \alpha_{l}} \cdot \gamma_{l} \cdot \Delta T \cdot L^{3}\right)^{1 / 3}
$$

Nesta equação, para um fluido monofásico, o incremento da temperatura da superfície reduz a densidade do líquido junto a superfície, induzindo o escoamento devido a efeitos de empuxo. Na ebulição nucleada, a densidade do fluido junto a superfície é alterada em virtude da presença de bolhas e do aquecimento do líquido. Assim, com o objetivo de determinar os efeitos de empuxo definiu-se a densidade da mistura (vapor e líquido) junto a superfície conforme a seguinte equação:

\footnotetext{
* A Eq. (3.30) foi determinada por Fritz e Ende apud Zuber (1963) e difere da Eq. (3.24), utilizada por Foster e Zuber (1955), apenas de uma constante multiplicativa.

** Esta hipótese não condiz com os resultados da literatura, onde verifica-se que, embora em estudos primordiais acreditava-se $t_{c}$ como aproximadamente igual à $t_{e}$, na realidade, na maioria das aplicações o tempo de espera chega a ser uma ordem de grandeza superior ao de crescimento.
} 


$$
\rho_{m, p}=\left(1-\alpha_{p}\right) \cdot \rho_{l, p}+\alpha_{p} \cdot \rho_{v}
$$

subtraindo $\rho_{l, s a t}$ de ambos os lados desta equação e introduzindo o coeficiente de expansão térmica, $\gamma$, obteve-se:

$$
\frac{\rho_{l, s a t}-\rho_{m, p}}{\rho_{l, s a t}}=\gamma \cdot \Delta T+\alpha_{p} \cdot \frac{\rho_{l, p}-\rho_{v}}{\rho_{l, s a t}}
$$

Finalmente, combinando as Eqs. (3.31) e (3.32) e Eq. (3.34) determina-se a seguinte expressão para o coeficiente de transferência de calor :

$$
\frac{h \cdot L}{k_{l}}=\text { const } \cdot\left(\frac{g \cdot L^{3}}{v_{l} \cdot a_{l}} \cdot\left(\gamma_{l} \cdot \Delta T+\frac{8}{3} \cdot(n / A) \cdot J a^{2} \cdot \frac{a_{l} \cdot d_{b}}{u_{t}} \cdot \frac{\rho_{l, p}-\rho_{v}}{\rho_{l, s a t}}\right)\right)^{1 / 3}
$$

Esta equação foi ajustada, através de resultados experimentais, para a água, acetona, $\mathrm{Cl}_{4}$ e $\mathrm{CS}_{2}$ a pressão atmosférica normal em superfície circulares e horizontais, obtendo-se um valor de 0,31 para a constante multiplicativa.

Através das Eqs.(3.27) e (3.29) obtém-se um valor máximo para $\alpha_{p}$ no regime laminar igual à 0,5 , a partir do qual as bolhas começariam a coalescer. Assim, considerando que a velocidade superficial do vapor é dada por $u_{s v}=u_{t} \cdot \alpha_{p} \cdot\left(1-\alpha_{p}\right)$, tem-se $u_{s v}=0,25 \cdot u_{t}$, e, admitindo que a energia transferida da parede é utilizada apenas na evaporação do fluido, $\phi=\rho_{v} \cdot h_{l v} \cdot u_{s v}$, a transição entre os regime "laminar" e "turbulento", ocorre para o fluxo específico de calor dado pela seguinte relação:

$$
\phi_{t}=\rho_{v} \cdot h_{l v} \cdot \frac{1,53}{4} \cdot\left[\frac{\sigma \cdot g \cdot\left(\rho_{v l}\right)}{\rho_{l}^{2}}\right]^{1 / 4}
$$

O autor comparou a Eq. (3.36) com seus resultados experimentais, verificando que para valores de $\phi$ superiores ao de transição, $d_{b}$ tinha seu valor reduzido, como resultado da interferência entre as bolhas e, conseqüente, mudança de regime. A partir deste ponto, a Eq. (3.35) não mais correlacionou os resultados experimentais.

Embora o superaquecimento da parede e as características superficiais influenciem diretamente a freqüência de desprendimento de bolhas e a densidade de cavidades ativas, 
segundo a Eq. (3.36), tais efeitos são desprezados e a transição entre regimes é função apenas das propriedades de transporte do fluido e da gravidade local.

\subsubsection{Modelo de Han e Griffith (1965b)}

Este trabalho foi pioneiro ao modelar o mecanismo físico de ebulição nucleada e não, apenas, determinar a taxa de transferência de calor como uma função de adimensionais característicos da convecção. Neste modelo, a superfície foi dividida em duas regiões de influência: a primeira, onde o calor é transferido através de convecção natural; e outra, sob influência das bolhas, onde a transferência de calor se dá através de uma combinação dos mecanismos de convecção forçada, resultante do desprendimento de bolhas, e condução transitória. É interessante destacar que este modelo só é válido para condições em que não ocorram interação entre as regiões de influência das bolhas, isto é $\phi$ não muito elevado.

Os autores especificaram a região de influência das bolhas como uma área circular, com centro na cavidade ativa, cujo diâmetro é $2 . d_{b}$. Este procedimento foi justificado através de um experimento, no qual, uma bola de raio $R$ é colocada na região inferior de um tanque cheio de água com o fundo recoberto de giz. Esta bola ao emergir causa distúrbios na camada de pó de giz apenas em uma região circular de diâmetro igual à $4 \cdot R$.

A taxa de transferência de calor na região sob efeito de convecção natural foi modelada segundo Fishenden e Saunders apud Han e Griffith (1965b), segundo as seguintes equações:

$>\quad$ Para regime laminar, $10^{5}<\operatorname{Ray}_{L}<2 \cdot 10^{7}$

$$
\phi_{C N}=0,54 \cdot \rho_{l} \cdot c_{l} \cdot\left(\frac{\gamma_{l} \cdot g \cdot \Delta T^{5} \cdot a_{l}^{3}}{\sqrt{A} \cdot v_{l}}\right)^{1 / 4}
$$

$>$ para regime turbulento, $2 \cdot 10^{5}<\operatorname{Ray}_{L}<3 \cdot 10^{10}$

$$
\phi_{C N}=0,14 \cdot \rho_{l} \cdot c_{l} \cdot\left(\frac{\gamma_{l} \cdot g \cdot \Delta T^{4} \cdot a_{l}^{2}}{v_{l}}\right)^{1 / 3}
$$




$$
\delta_{C N}=\frac{\rho_{l} \cdot c_{l} \cdot a_{l}}{\phi_{C N}} \cdot\left(T_{p}-T_{s a t}\right)
$$

Nas regiões sob influência das bolhas, a transferência de calor da superfície para o banho ocorre através de condução transitória numa camada de líquido, modelada como um corpo semi-infinito. Esta aproximação torna-se razoável em virtude da rápida substituição da camada de líquido aquecida junto a parede por líquido frio provindo do banho, comportamento resultante do desprendimento das bolhas. Assim os períodos envolvidos são reduzidos e, portanto, somente uma camada limitada da região é afetada. Desta forma, foi possível definir a espessura da camada limite térmica segundo a Eq. (2.3). Entretanto, devido à influência da bolha, $\delta$ não varia apenas com o tempo, mas, também, localmente $\mathrm{e}$ apresenta, ao final de um período $1 / f$, a configuração esquematicamente ilustrada na Fig. 3.2. Assim, com base nesta figura e na Eq. (2.3), definiu-se a espessura da camada limite térmica local, dentro da região de influência de bolhas, através das seguintes equações:

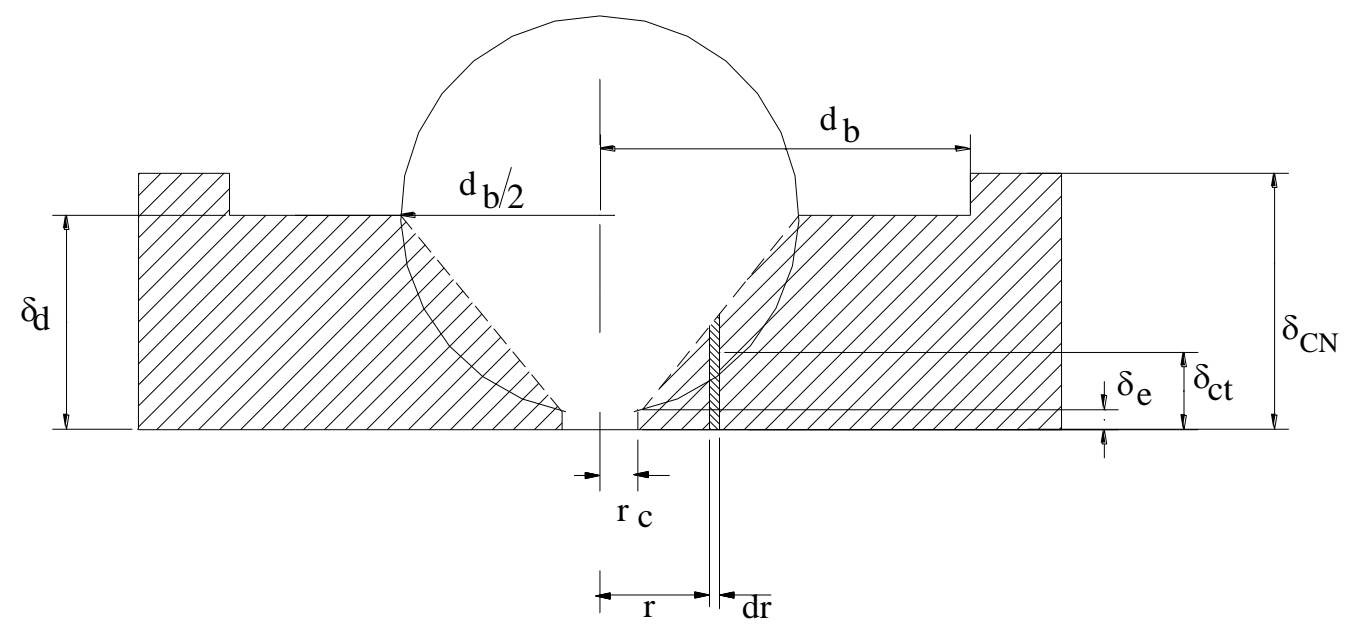

Figura 3.4 Camada limite térmica no momento do desprendimento da bolha

espessura da camada lime térmica ao final do período de espera,

$$
\delta_{e}=\sqrt{\pi \cdot a_{l} \cdot t_{e}}
$$

espessura da camada limite térmica instantânea entre o início do crescimento da bolha e o seu desprendimento, 


$$
\delta_{c t}=\sqrt{\pi \cdot a_{l} \cdot\left(t_{e}+t\right)} \quad \mathrm{p} / r_{c}<r<d_{b} / 2
$$

e espessura da camada limite térmica no momento de desprendimento da bolha.

$$
\delta_{d}=\sqrt{\frac{\pi \cdot a_{l}}{f}}
$$

Admitindo que $r_{c}<<d_{b} / 2$ e $\delta_{c t}$ variando linearmente com $r$, conforme ilustrado na Fig. 3.4, pode-se definir no momento do desprendimento da bolha a seguinte relação:

$$
\delta_{c t}=2 \cdot \frac{\delta_{d}-\delta_{e}}{d_{b}} \cdot r+\delta_{e}
$$

Considerando as propriedades do líquido constantes e admitindo que todo o calor transferido para o líquido resulta no seu aquecimento, determina-se localmente através da equação abaixo, a taxa de transferência de calor por unidade de área.

$$
\phi=\int_{0}^{\infty}\left(T-T_{\text {sat }}\right) \cdot c_{l} \cdot \rho_{l} \cdot d y=c_{l} \cdot \rho_{l} \cdot\left(T_{p}-T_{\text {sat }}\right) \cdot \int_{0}^{\infty} \operatorname{erfc} \frac{y}{2 \cdot \sqrt{a_{l} \cdot t}} \cdot d y=\frac{2 \cdot \rho_{l} \cdot c_{l} \cdot\left(T_{p}-T_{\text {sat }}\right) \cdot \delta}{\pi}
$$

Multiplicando-se a Eq.(3.44) pelo elemento de área dado por $2 \pi \cdot r \cdot d r$ e integrando em $r$, com ele variando de $r_{\mathrm{c}}$ a $d_{b}$, tem-se o calor total transferido para a camada limite térmica durante o período $1 / f$, que multiplicado pela densidade de cavidades ativas e pela frequiência de bolhas resulta no fluxo específico de calor devido à efeitos de ebulição propriamente dito, dado pela seguinte equação:

$$
\phi_{e b}=2 \cdot \rho_{l} \cdot c_{l} \cdot\left(T_{p}-T_{s a t}\right) \cdot(n / A) \cdot f \cdot\left[d_{b}^{2} \cdot \sqrt{\frac{\pi \cdot a_{l}}{f}}-\frac{1}{12} \cdot d_{b}^{2} \cdot\left(\sqrt{\frac{\pi \cdot a_{l}}{f}}-\sqrt{\pi \cdot a_{l} \cdot t_{e}}\right)\right]
$$

É interessante destacar, o acréscimo da região delimitada pela bolha e a linha tracejada à camada limite térmica, conforme ilustrado na Fig. (3.4), superestimando, desta forma a quantidade de calor transferida ao líquido através do mecanismo de condução transitória. 
O fluxo de calor total é dado pela soma das parcelas, da seguinte forma:

$$
\phi_{\text {total }}=\phi_{e b}+\phi_{C N} \cdot A_{C N} / A
$$

Neste modelo, $d_{b}$ e $f$ são determinados, respectivamente, através das Eqs. (2.7) e (2.19), com $t_{e}$ e $t_{c}$ sendo dados pelas Eqs. (2.5) e (2.6), considerando a ebulição de líquido saturado. Na determinação da densidade de cavidades ativas os autores adotaram uma hipótese simplista, assumindo em contato as áreas de influência de bolhas vizinhas, com $n / A$, desta forma, sendo dada pela seguinte equação:

$$
n / A=\frac{1}{2 \cdot d_{b}^{2} \cdot \sqrt{3}}
$$

\subsubsection{Modelo de Mikic e Rohsenow (1969)}

De forma análoga a Han e Griffith (1965b), Mikic e Rohsenow (1969) propuseram um modelo segundo o qual o fluxo de calor na superfície aquecida é resultante da superposição de efeitos associados à convecção natural e à ebulição nucleada propriamente dita. As bolhas, ao deixarem a superfície aquecida, promovem a migração de líquido frio para a superfície. Como resultado, a transferência de calor se dá através da condução transitória da superfície para a camada de líquido frio. Novamente, a área de influência da bolha foi igual a $\pi \cdot d_{b}^{2}$. O modelo admite que não haja interação entre regiões de influência das bolhas. Nestas, assumiu-se o mecanismo de condução pura entre a superfície e o líquido, modelada como um corpo semi-infinito. Desta forma, através da Eq. (2.2), foi determinado o fluxo de calor associado à condução transitória através da camada de líquido na região sob influência da bolha, dado pela seguinte relação:

$$
\phi=\frac{k_{l} \cdot \Delta T}{\sqrt{\pi \cdot a_{l} \cdot t}}
$$

Assumindo que as bolhas se destacam da superfície com uma frequiência $f$, o fluxo médio de calor associado a um ponto de nucleação particular é dado por: 


$$
(\phi)_{\text {medio }}=f \cdot \int_{0}^{1 / f} \phi \cdot d t
$$

Ao assumirem um fluxo de calor médio, dado pela Eq. (3.49), os autores desprezam os efeitos da bolha na camada limite térmica resultando em um valor constante para sua espessura instantânea em toda a região de influência da bolha. Desta forma, este modelo, quando comparado ao proposto por Han e Griffith (1965b), superestima os efeitos de transferência de calor através do mecanismo de condução transiente.

A definição de área de influência da bolha foi utilizada para determinar o fluxo médio devido a ebulição nucleada extensiva a toda a superfície aquecida:

$$
\phi_{e b}=\pi \cdot d_{b}^{2} \cdot(n / A) \cdot(\phi)_{\text {medio }}=2 \cdot \sqrt{\pi} \cdot \sqrt{k_{l} \cdot \rho_{l} \cdot c_{l}} \cdot \sqrt{f} \cdot d_{b}^{2} \cdot(n / A) \cdot \Delta T
$$

Para o cálculo do número de cavidades ativas, utilizou-se a seguinte correlação anteriormente proposta pelos autores:

$$
n / A=C_{1} \cdot r_{s}^{m} \cdot\left(\frac{h_{l v} \cdot \rho_{v}}{2 \cdot T_{s a t} \cdot \sigma}\right)^{m} \cdot \Delta T^{m}
$$

Os autores substituíram as Eq. (2.13), para $d_{\mathrm{b}},(2.23)$, para $f$, e (3.51) na (3.50) concluindo que o fluxo de calor pode ser expresso como função do superaquecimento e de algumas propriedades do fluido, conforme a equação abaixo.

$$
\frac{\phi_{e b} \cdot \sqrt{\frac{\sigma}{g \cdot\left(\rho_{v l}\right)}}}{\mu_{l} \cdot h_{l v}}=X \cdot(\varphi \cdot \Delta T)^{m+1}
$$

onde:

$$
\varphi^{m+1}=\frac{k_{l}^{1 / 2} \cdot \rho_{l}^{17 / 8} \cdot h_{l v}^{(m-23 / 8)} \cdot \rho_{v}^{(m-15 / 8)}}{\mu_{l} \cdot\left[\left(\rho_{v l}\right)\right]^{9 / 8} \cdot \sigma^{(m+1 l / 8)} \cdot T_{s a t}^{(m-15 / 8)}}
$$

$\mathrm{e}$

$$
X=\left(\frac{r_{s}}{2}\right)^{m} \cdot \frac{2}{\sqrt{\pi} \cdot g^{(9 / 8)}} \cdot C_{2}^{5 / 3} \cdot C_{3}^{1 / 2} \cdot C_{1}
$$

Nesta equação $C_{2}, C_{3}$ são as constantes multiplicativas nas Eqs. (2.13) e (2.23). 
O fluxo de calor total na superfície aquecida pode, assim, ser expresso pela Eq. (3.46), onde $\phi_{C N}$ é a componente do fluxo de calor devido à convecção natural, determinada através das Eqs. (3.37), e (3.38) anteriormente utilizadas no modelo de Han e Griffith (1965b).

Embora não fosse este o objetivo dos autores, é interessante notar que, explicitamente, efeitos como rugosidade, forma e material da superfície foram desconsiderados, estando relacionados ao expoente $m$ a aos coeficientes $C_{1}, C_{2}, C_{3}$ e $r_{s}$ que envolvem o levantamento de resultados empíricos.

\subsubsection{Modelo de Nishikawa e Fujita (1977)}

O modelo consiste no desenvolvimento de uma correlação, de forma similar à de Zuber (1963), através da analogia com convecção natural, neste caso, válida para toda região de ebulição nucleada. Os autores consideraram como o principal fator responsável pela transferência de calor a agitação do líquido junto a superfície aquecida induzida pela elevada densidade de cavidades ativas. Isto, como em convecção natural, permitiu aos autores escrever o coeficiente de transferência de calor, em termos do número de Nusselt, como função dos números adimensionais de Grashoff e Prandtl, conforme equação abaixo:

$$
N u=C_{l} \cdot\left(G r \cdot P r_{l}\right)^{m}
$$

Devido às diferentes características físicas entre os mecanismos de ebulição nucleada e convecção natural, os autores adotaram uma definição livre do número de Grashoff, relacionando os efeitos viscosos e de empuxo. Os efeitos de empuxo foram caracterizados por fatores tais como: densidade de cavidades ativas, diâmetro médio de desprendimento de bolhas e velocidade média de ascensão das bolhas. Deste modo, estes efeitos não são resultantes apenas da diferença entre volumes específicos e aceleração gravitacional, fatores que, embora considerados através da velocidade média de ascensão das bolhas, tornam-se desprezíveis em função da elevada agitação de líquido produzida pelas bolhas.

Através de dados experimentais, os autores constataram que:

$$
N u^{\text {constante }} \cdot \frac{\delta}{L}=\text { cons tante }
$$


resultado que pode ser inferido da Fig. 3.5, onde $\delta$ é a espessura da camada limite térmica e $L$ o comprimento característico. Com base nestes resultados, e devido às constantes da Eq. (3.54) apresentarem dois valores distintos, Nishikawa e Fujita (1977) dividiram o regime de ebulição nucleada plenamente desenvolvida em duas regiões, denominadas arbitrariamente de: regime de ebulição nucleada laminar e regime de ebulição nucleada turbulenta. A transição entre os regimes fica caracterizada pela mudança no coeficiente angular da curva do número de Nusset versus $\delta / L$, conforme pode ser observado na Fig. 3.5. Através de resultados experimentais, os autores caracterizaram a transição entre regimes como função exclusiva do comprimento característico $(L)$.

Semelhante ao fator de superfície de Rohsenow (1952), os autores propuseram um fator de nucleação $f_{\zeta}$, função da combinação líquido e superfície, o qual é determinado experimentalmente e descreve as características de nucleação da superfície aquecida. Para a água em ebulição em uma superfície limpa e lisa, tem-se $f_{\zeta}=1$. A correlação foi desenvolvida para pressão atmosférica. Assim, para pressões diferentes, foi necessário incorporar um fator de pressão, $F_{p s a t}$, dado por.

$$
F_{p s a t}=\left(\frac{p}{p_{\text {atm }}}\right)^{0,7} \cdot \frac{1+3 \cdot\left(p_{r}\right)^{3}}{1+3 \cdot\left(p_{\text {atm }} / p_{\text {crit }}\right)^{3}}
$$

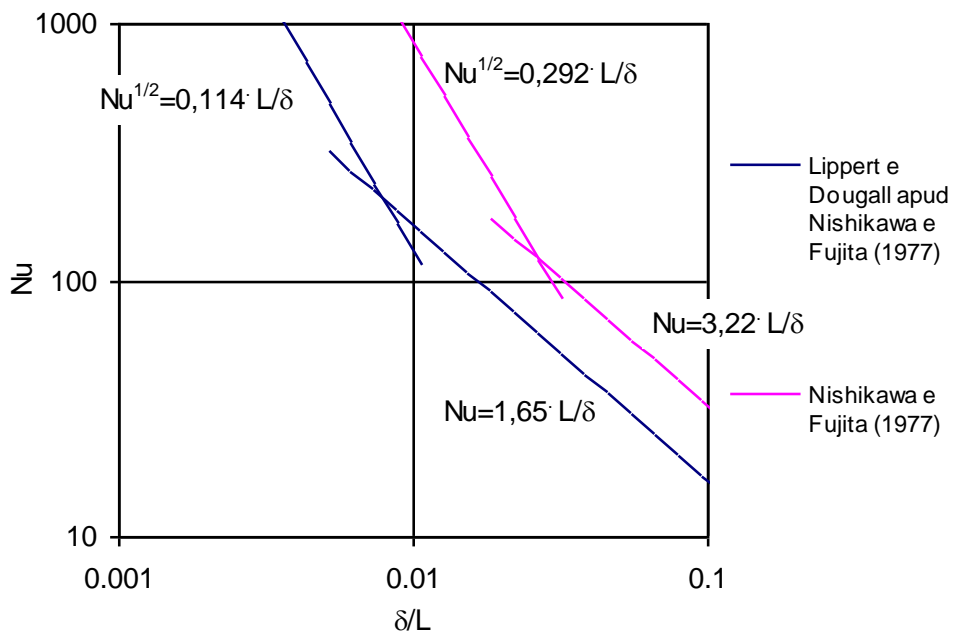

Figura 3.5 Relação entre o número de Nusselt e a espessura da camada limite térmica em ebulição nucleada para a água. 
Tal fator, segundo os autores, permitiria explicar a variação na energia necessária à formação da bolha com o aumento da pressão, relacionada à redução da tensão superficial. Ao contrário de Cooper (1984) e do VDI-Wärmeatlas (1994), com base em resultados experimentais, os autores não verificaram uma interação explícita entre a pressão e as características de superfície. Desta forma, combinando as Eqs. (3.53) e (3.54), e introduzindo os fatores relativos ao efeito de pressão e à interação entre o fluido e a superfície, o coeficiente de transferência de calor, dado em termos do número de Nusselt, pode ser determinado através das seguintes equações:

$$
\begin{aligned}
& N u=6,24 \cdot\left(f_{\zeta} \cdot F_{p s a t} \cdot X\right)^{2 / 3} \quad N u \leq N u_{t} \\
& N u=0,66 \cdot L^{-2 / 5} \cdot\left(f_{\zeta} \cdot F_{p s a t} \cdot X\right)^{4 / 5} \quad N u \geq N u_{t}
\end{aligned}
$$

onde

$$
\begin{aligned}
& X=\left(\frac{1}{Z^{2} \cdot M} \cdot \frac{c_{l} \cdot \rho_{l}^{2} \cdot g}{k_{l} \cdot \sigma \cdot h_{l v} \cdot \rho_{v}}\right)^{1 / 2} \cdot \phi \cdot L^{3 / 2} \quad Z=1976 \mathrm{~W} \quad M=900 \mathrm{~m}^{-1} \\
& \mathrm{e} \quad \mathrm{Nu} u_{t}=4,71 \cdot 10^{5} \cdot L^{2}
\end{aligned}
$$

\subsubsection{Modelo de Benjamin e Balakrishnan (1996).}

Benjamin e Balakrishnan (1996) e Judd e Hwang (1976) acrescentaram o mecanismo de transferência de calor devido à evaporação da microcamada aos mecanismos utilizados por Han e Griffith (1965b) e Mikic e Rohsenow (1969), dividindo a superfície em três regiões conforme ilustrado na Fig. 3.6.

A taxa de transferência de calor associada à evaporação da microcamada foi avaliada através do volume evaporado $V_{e m}$, o qual depende do perfil instantâneo (espessura) da microcamada. Judd e Hwang (1976) determinaram este perfil experimentalmente com a ajuda de um interferômetro laser e uma câmara de alta velocidade. Já Benjamin e Balakrishnan (1996), embora no seu modelo considerem mecanismos de transferência de calor similares, determinaram a taxa de transferência de calor associada a microcamada modelando seu perfil instantâneo. Neste caso, resultados experimentais foram utilizados 
apenas na verificação do modelo. Desta forma, considerando a similaridade dos modelos e a maior complexidades do proposto por Benjamin e Balakrishnan (1996), apenas este será analisado.

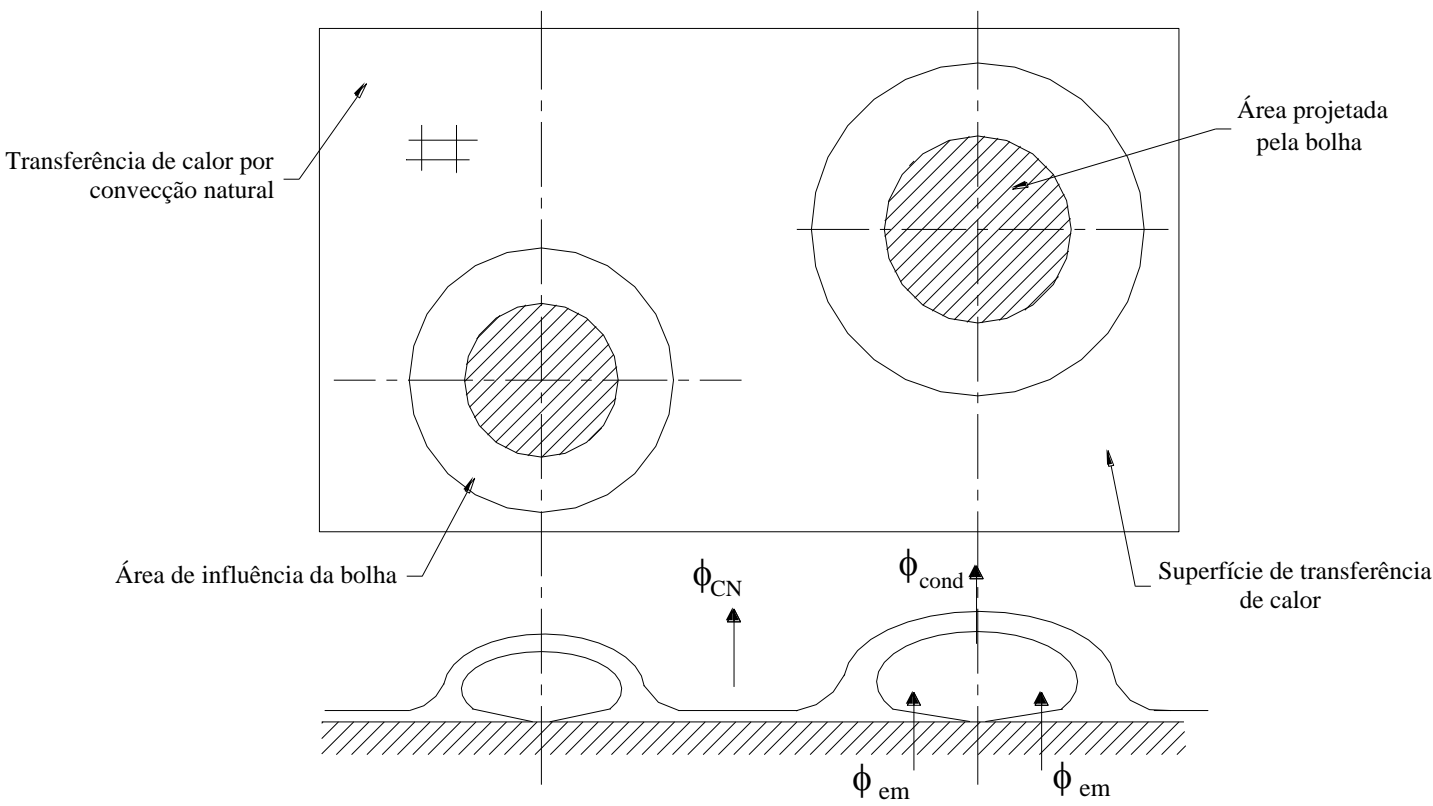

Figura 3.6 Mecanismos de transferência de calor no modelo de Benjamin e Balakrishnan (1996).

A correlação foi elaborada considerando os mecanismos físicos anteriormente citados, ocorrendo nos seguintes períodos do ciclo de vida da bolha:

evaporação da microcamada durante o período de crescimento;

$>\quad$ condução de calor transiente durante o período de espera;

$>\quad$ convecção natural durante todo o ciclo de vida da bolha.

Desta forma, embora os efeitos resultantes da evaporação da microcamada e desenvolvimento de uma camada limite térmica transiente ocorram em um mesmo local da superfície, conforme pode ser observado na Fig. (3.6), ambos ocorrem em períodos distintos, sem que um interfira no outro, permitindo escrever a superposição dos distintos mecanismos como:

$$
\phi=\phi_{e b}+\phi_{C N} \cdot \frac{A_{C N}}{A}=\left(\phi_{e m} \cdot t_{c}+\phi_{c o n d} \cdot t_{e}\right) \cdot f+\phi_{C N} \cdot \frac{A_{C N}}{A}
$$

Segundo os autores, a proposição acima só é correta se as bolhas vizinhas não interferirem entre si, comportamento verificado com valores reduzidos de $\phi$. Admitiu-se, 
ainda, que o crescimento da bolha se dá, apenas, pela evaporação da microcamada de forma que um balanço de energia nessa microcamada durante o período de crescimento da bolha resulta:

$$
-\frac{d}{d t}\left[A_{e m} \cdot e_{e m} \cdot \rho_{l} \cdot c_{l} \cdot\left(T_{p}-T_{s a t}\right)\right]=\phi_{A_{e m}} \cdot A_{e m}
$$

$A_{e m}$ e $e_{e m}$ são, respectivamente, a área e a espessura média instantâneas da microcamada, cujo produto fornece seu volume instantâneo. A área da microcamada pode ser escrita conforme a equação abaixo, cujo termo entre colchetes, segundo Torikai et al (1964) apud Benjamin e Balakrishnan (1996), é, aproximadamente constante, podendo ser substituído por $C_{l}$.

$$
A_{e m}=\frac{\pi \cdot d^{2}}{4} \cdot\left[1-\left(\frac{d_{s}}{d}\right)^{2}\right]=\frac{\pi \cdot d^{2}}{4} \cdot C_{1}
$$

onde $d_{s}$ é o diâmetro interno na superfície do circulo delimitado pela linha de contato triplo.

Benjamin e Balakrishnan (1996) utilizaram a equação de Sernas e Hooper (1969), Eq. (3.61), obtida considerando condução transitória de calor da parede para a microcamada, para a determinação do fluxo de calor na bolha associado à evaporação da microcamada:

$$
\phi_{A_{e m}}=\left(T_{p}-T_{s a t}\right) \cdot \sqrt{\frac{k_{p} \cdot \rho_{p} \cdot c_{p}}{\pi \cdot t}}
$$

Utilizando os resultados experimentais de Zmola (1950) e Siegel e Keshock (1964), Benjamin e Balakrishnan (1996) correlacionaram o diâmetro instantâneo da bolha como:

$$
d(t)=B \cdot A r^{0,135} \cdot\left[J a \cdot a_{l} \cdot t\right]^{1 / 2}
$$

Substituindo as Eqs. (3.60), (3.61) e (3.62) na Eq. (3.59) e solucionando a equação diferencial, com base no fato que, quando a bolha esta totalmente desenvolvida, a espessura da microcamada pode ser considerada nula, tem-se:

* $\mathrm{B}=1,55$ para água, $\mathrm{CCl}_{4}$, e $\mathrm{n}$-hexano; $\mathrm{B}=1 / 1,55$ para n-pentano e acetona. Não foram experimentalmente determinados valores de $B$ para outros fluidos. 


$$
e_{e m}=\frac{2}{3 \cdot t} \cdot \sqrt{\left(\frac{k_{p} \cdot \rho_{p} \cdot c_{p}}{\left(\rho_{l} \cdot c_{l}\right)^{2}}\right) \cdot\left(t_{c} \cdot \sqrt{t_{c}}-t \cdot \sqrt{t}\right)}
$$

O volume de líquido da microcamada, evaporado durante o tempo de crescimento da bolha, pode ser calculado como:

$$
V_{e m}=\frac{\int_{0}^{t_{c}} A_{e m} \cdot e_{e m} \cdot d t}{\int_{0}^{t_{c}} d t}
$$

Assim, substituindo as Eqs. (3.60), (3.63) na Eq.(3.64), avaliando as integrais e multiplicando o resultado por $(n / A)$ e $f$ determina-se, finalmente o fluxo específico de calor devido à evaporação da microcamada, associado ao tempo $t_{c}$, como:

$$
\phi_{e m}=\frac{C_{l} \cdot \sqrt{\pi}}{10} \cdot \sqrt{\frac{k_{p} \cdot \rho_{p} \cdot c_{p}}{k_{l} \cdot \rho_{l} \cdot c_{l}}} B^{2} \cdot A r^{0,27} \cdot\left(a_{l}\right)^{3 / 2} \cdot J a \cdot \sqrt{t_{c}} \cdot \rho_{l} \cdot h_{l v} \cdot(n / A)
$$

Ao contrário de Mikic e Rohsenow (1969), estes autores assumiram o mecanismo de condução transiente, apenas, durante o período de espera da bolha e não durante todo seu ciclo. Desta forma, o fluxo de calor médio resultante de efeitos de condução transiente determinado a partir da Eq. (3.48) resulta:

$$
\bar{\phi}_{\text {cond }}=\frac{\int_{0}^{t_{e}} \frac{k_{l} \cdot \Delta T}{\sqrt{\pi \cdot a_{l} \cdot t}} \cdot d t}{\int_{0}^{t_{e}} d t}=\frac{2 \cdot k_{l} \cdot \Delta T}{\sqrt{\pi \cdot a_{l} \cdot t_{e}}}
$$

Ao contrário de Judd e Hwang (1976) que adotaram uma área de influência de bolha igual a $0,45 \cdot \pi \cdot d_{b}^{2}$, Benjamin e Balakrishnan (1996), analogamente a Han e Griffith (1965b) e Mikic e Rohsenow (1969), consideraram uma área de influência de bolha igual a $\pi \cdot d_{b}^{2}$ Assim, multiplicando $\bar{\phi}_{\text {cond }}$ pela densidade de cavidades ativas e pela área de influência de bolhas, obtem-se a seguinte equação para a parcela de calor transferido devido à condução transitória: 


$$
\phi_{\text {cond }}=2 \cdot \sqrt{\left(\frac{k_{l} \cdot \rho_{l} \cdot c_{l}}{\pi \cdot t_{e}}\right)} \cdot\left((n / A) \cdot \pi \cdot d_{b}^{2}\right) \cdot \Delta T
$$

Na determinação da densidade de cavidades ativas, os autores adotaram o diâmetro e a frequiência de bolhas dados, respectivamente, pelas Eqs. (2.29), (2.18) e (2.26) Na determinação de $t_{e}$ e $t_{c}$ os autores aproximaram o tempo de espera como sendo três vezes o tempo de crescimento, resultado sugerido por Stephan (1992). No cálculo da componente devido à convecção natural foi utilizada a Eq. (3.38).

Este modelo apresenta um grande contraste em relação ao de Mikic e Rohsenow (1969) que considera a parcela devida a evaporação da microcamada desprezível. Já no modelo de Benjamin e Balakrishnan (1996), o fluxo de calor relativo a esse mecanismo corresponde a uma fração entre $45 \%$ e $50 \%$ do fluxo total de calor removido da superfície aquecida. Tal resultado é semelhante citado por Judd e Hwang (1976), onde o mecanismo de evaporação da microcamada também foi considerado significativo.

\subsubsection{Modelo de Haider e Webb (1997).}

Haider e Webb (1997) desenvolveram um modelo envolvendo a superposição dos efeitos de condução transiente e de micro-convecção no líquido proposto por Tien (1962). O modelo foi ajustado através de dados experimentais para o R-11 e R-123, refrigerantes de baixa pressão (pouco voláteis). Os autores começaram por verificar que alguns resultados experimentais não são propriamente explicados pelo modelo de Mikic e Rohsenow (1969). O argumento foi que aquele modelo não incorporava efeitos convectivos resultantes da substituição do vapor por líquido frio. Este efeito seria resultante da indução de vórtices locais pelo líquido no instante de desprendimento da bolha, do que resultaria uma combinação de escoamentos em torno de um ponto frontal de estagnação, promovendo um efeito de intensificação da transferência de calor. Além disso, é possível que o diâmetro da bolha possa aumentar em virtude da evaporação do líquido superaquecido transportado em sua esteira. Um esquema do modelo proposto pode ser encontrado na Fig. 3.7. Nele, percebese, que a cavidade age como um ponto de estagnação para o escoamento do líquido arrastado pelo desprendimento da bolha, determinando a espessura de uma camada limite térmica. $\mathrm{O}$ valor desta espessura, segundo os autores não pode ser explicado, apenas, por efeitos de condução transitória, conforme indicado em alguns dos modelos anteriormente apresentados, o que sugere, desta forma, a existência do referido mecanismo. 


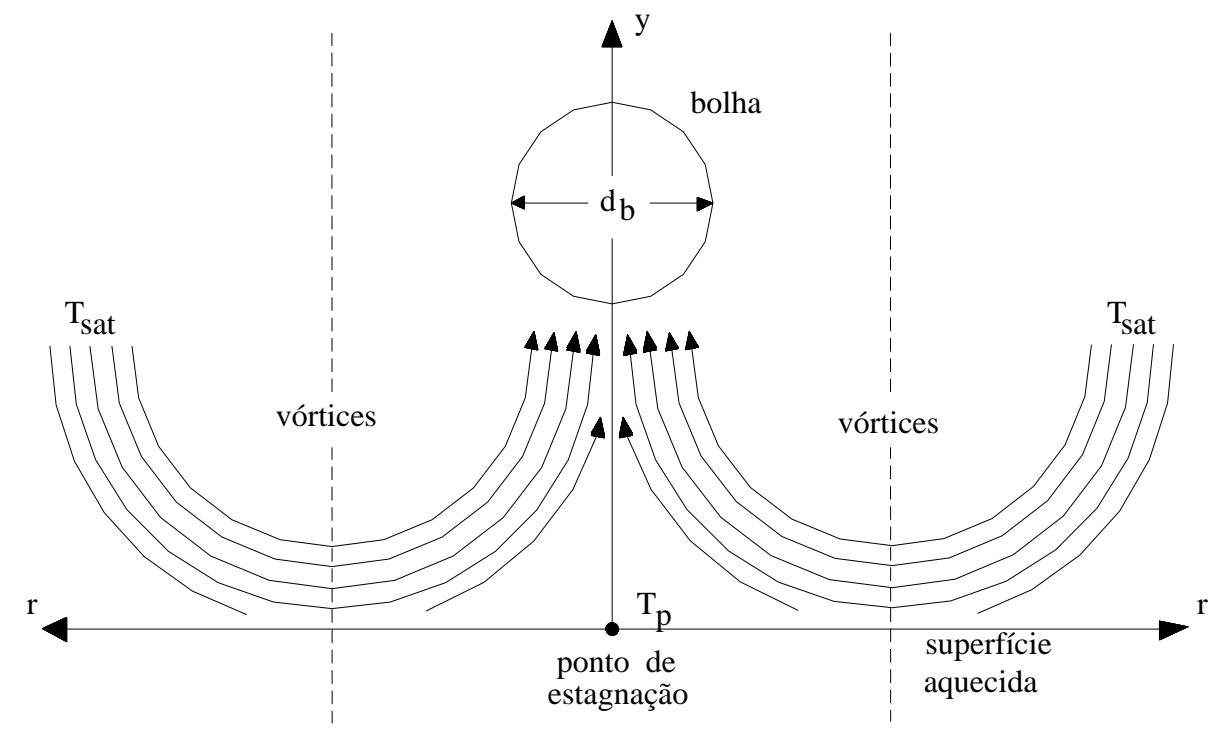

Figura 3.7 Acompanhamento do escoamento após o desprendimento de uma bolha segundo o modelo de Haider e Webb (1994).

Embora os efeitos de convecção natural nas regiões externas a área de influência da bolha sejam desprezados, admite-se tal área como sendo igual a $\pi \cdot d_{b}^{2}$. A transferência de calor latente devido à evaporação da microcamada também é considerada desprezível.

O modelo baseia-se na variação da espessura da camada limite térmica durante o ciclo de uma bolha, conforme ilustrado na Fig. 3.8. Na fase inicial, tal espessura foi modelada conforme a Eq. (2.3). Com o decorrer do tempo ela tende a permanecer constante, conforme indicado na Fig. 3.8, aproximando-se da solução de escoamento em torno de um ponto de estagnação, modelo proposto por Tien (1962), baseado na similaridade hidrodinâmica do campo de velocidades de uma coluna de bolhas ascendentes e um escoamento estagnado invertido. Assim, assumindo escoamento laminar em torno de um ponto de estagnação são válidas as seguintes relações:

$$
u_{\infty}=s \cdot r
$$

e

$$
\frac{h \cdot r}{k_{l}}=1,32 \cdot\left(\frac{u_{\infty} \cdot r}{v_{l}}\right)^{0,5} \cdot \operatorname{Pr}_{l}^{0,33}
$$




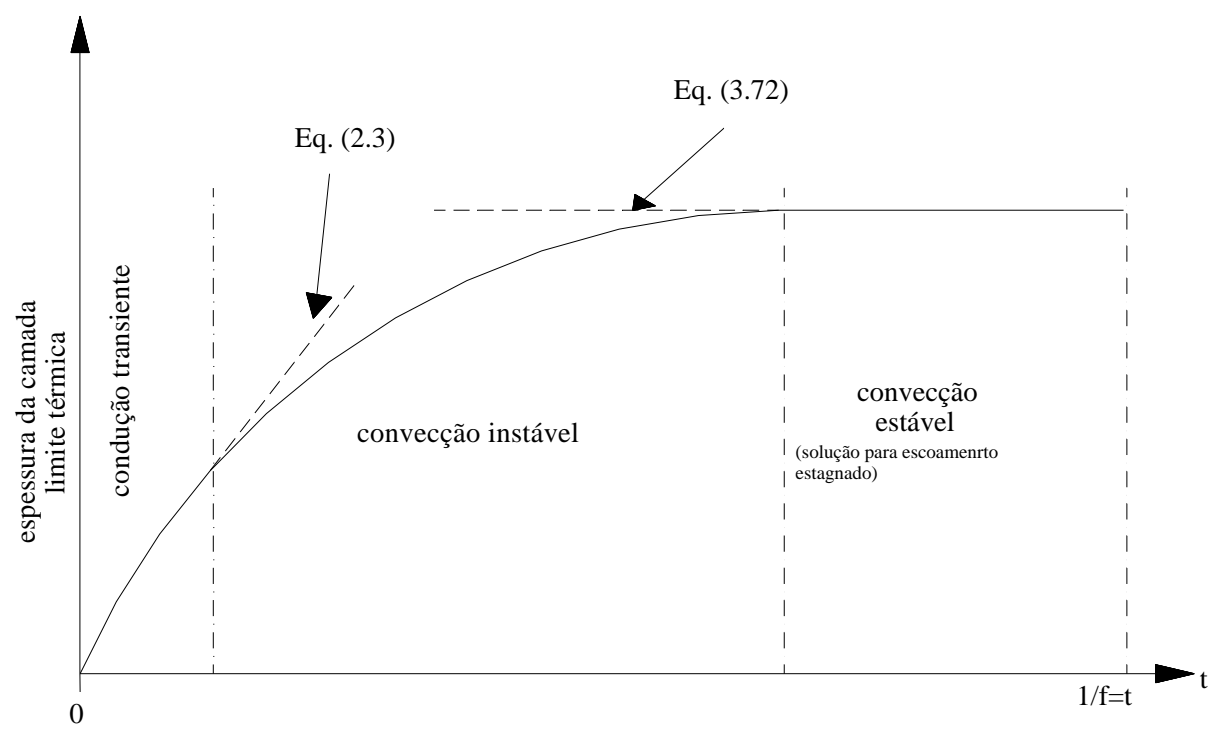

Figura 3.8 Crescimento da camada limite térmica durante o ciclo de uma bolha.

Sendo que " $u_{\infty}$ " é a velocidade radial da borda externa da camada limite hidrodinâmica, " $r$ " distância radial a partir do ponto de estagnação (cavidade ativa), e " $s$ " uma constante de proporcionalidade, relacionada ao campo de velocidades exterior à camada limite e que quantifica o gradiente de velocidades, sendo convenientemente normalizada como:

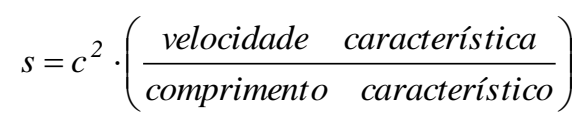

onde " $c$ " é um adimensional denominado de parâmetro de "densidade" de escoamento. A velocidade de ascensão da bolha e seu diâmetro de desprendimento foram escolhidos como propriedades características. Admitindo um perfil linear de temperatura, isto é $\delta_{a s} \cdot h=k_{l} \mathrm{e}$ combinando as Eqs. (3.68) e (3.69), resulta que a espessura da camada limite térmica para a condição assintótica é igual a:

$$
\delta_{a s}=\frac{1}{1,32} \cdot \sqrt{\frac{v_{l}}{s}} \cdot \operatorname{Pr}_{l}^{-1 / 3}
$$

É interessante ressaltar que, embora segundo Tien (1962) na teoria para um escoamento estagnado $\delta_{a s} \cdot h=3,22 \cdot k_{l}$, o fato de Webb e Pais (1997) adotarem $\delta_{a s} \cdot h=k_{l}$, 
pode ser relevado pela realização, ao final, de um ajuste da correlação à resultados experimentais.

Aproximando a velocidade de ascensão da bolha por $\pi \cdot f \cdot d_{b}$ e combinado este resultado com as Eqs. (3.70), (3.71) e (3.72) determina-se, como função de propriedades de transporte do líquido e da freqüência de bolhas, a espessura da camada limite térmica para a condição assintótica:

$$
\delta_{a s}=\frac{1}{1,32 \cdot c} \cdot \sqrt{\frac{v_{l}}{\pi \cdot f}} \cdot \operatorname{Pr}_{l}^{-1 / 3}
$$

O fluxo de calor devido à condução transiente é determinado através da Eq. (3.48), anteriormente referida. O fluxo de calor devido ao mecanismo de micro-convecção foi determinado através da definição da camada limite assintótica, Eq. (3.72), e da hipótese de $\delta_{a s} \cdot h=k_{l}$, resultando:

$$
\phi_{m c}=\frac{k_{l} \cdot \Delta T}{\delta}=1,32 \cdot c \cdot k_{l} \cdot \sqrt{\frac{\pi \cdot f}{v_{l}}} \cdot \operatorname{Pr}_{l}^{1 / 3} \cdot \Delta T
$$

O autores assumiram a superposição dos efeitos de condução transitória e de micro-convecção de acordo com a seguinte relação:

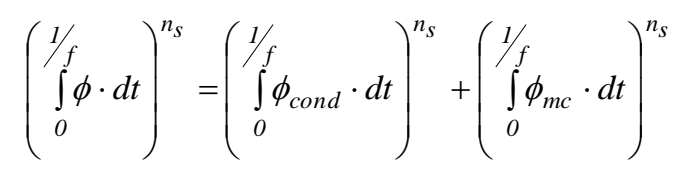

onde $n_{s}$ é uma constante empiricamente determinada. Substituindo-se as Eqs. (3.48) e (3.73) na equação acima e multiplicando-se o fluxo de calor obtido pelo número de cavidades ativas por unidade de área e pela área de influência da bolha, resulta:

$$
\phi=2 \cdot \sqrt{\pi \cdot k_{l} \cdot c_{l} \cdot f} \cdot d_{b}^{2} \cdot(n / A) \cdot(\Delta T) \cdot\left(1+\left(\frac{0,66 \cdot \pi \cdot c}{P r_{l}^{1 / 6}}\right)^{n_{s}}\right)^{1 / n_{s}}
$$

O expoente $n_{s}$ e o coeficiente $c$ que melhor se ajustam à equação acima, foram avaliados como sendo iguais a: 
para o R-11: $c=6,13$ e $n_{s}=2,0$;

para o R-123: $c=6,42$ e $n_{s}=2,0$.

Embora, segundo os autores, resultados adicionais sejam necessários, nota-se a possibilidade da extensão da correlação para outros fluidos, com a utilização de um único " $c$ ", visto a proximidade entre os valores apresentados para ambos os refrigerantes, sugerindo a independência do valor de " $c$ " em relação ao refrigerante.

Escrevendo o resultado expresso pela Eq. (3.75) em termos da correlação de Mikic e Rohsenow (1969), resulta:

$$
\frac{\phi}{\text { fluxo de calor det er minado pela Eq.(3.50) }}=\left(1+\left(\frac{0,66 \cdot \pi \cdot c}{\operatorname{Pr}_{l}^{1 / 6}}\right)^{n_{s}}\right)^{1 / n_{s}}
$$

É interessante notar que o termo $\left(0,66 \cdot \pi \cdot c / \operatorname{Pr}_{l}{ }^{1 / 6}\right)^{n_{s}}$ assume valores muito superiores à unidade, o que vem demostrar o reduzido efeito do mecanismo de condução transiente. Nessas condições, é possível afirmar que o mecanismo dominante é a microconvecção, efeito que foi desprezado pela maioria dos modelos anteriormente citados.

\subsubsection{Comparação dos Resultados Proporcionados pelas Correlações Semi- Empíricas}

Nesta seção foi elaborada uma análise comparativa dos modelos semi-empíricos estudados em termos de refrigerantes halogenados. Essas correlações foram consideradas para comparação pela sua simplicidade ou pelo fato de serem freqüientemente referidas na literatura. A presente análise revelou grandes discrepâncias, cujos resultados podem ser observados nas Figs. 3.9 e 3.10. Tal resultado pode estar relacionado ao fato da maioria das correlações envolverem coeficientes experimentais. Esses são determinados através do ajuste de dados para fluidos diferentes dos refrigerantes halogenados, conforme pode ser constatado na Tabela 3.3, que apresenta um sumário das características das correlações para ebulição nucleada utilizadas na comparação que se segue. Desta forma, embora existam correlações complexas, buscando abranger o maior número possível de parâmetros, de uma maneira geral, elas apenas refletem as características do banco de dados para o qual foram desenvolvidas. 


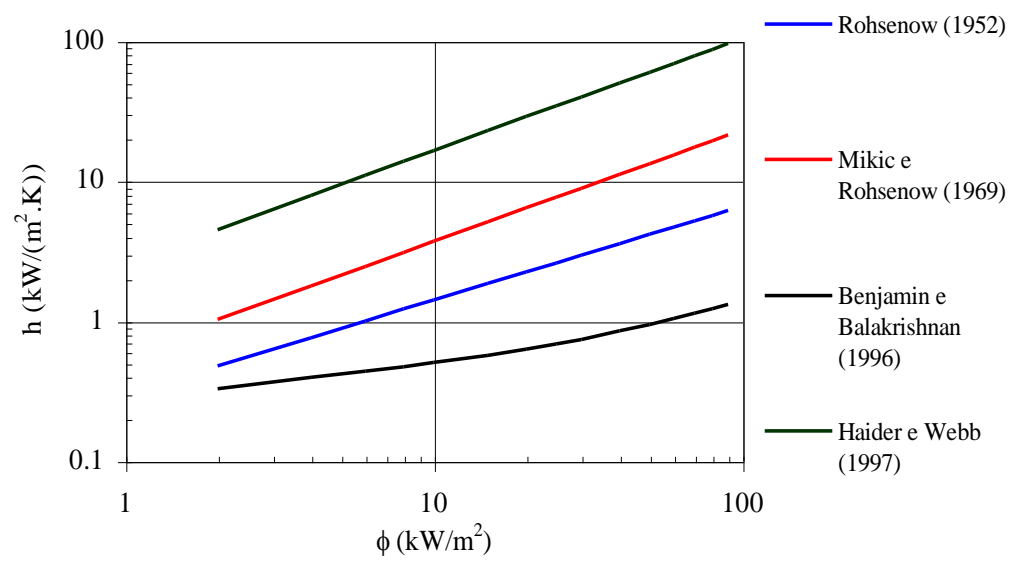

Figura 3.9 Comparação de algumas correlações da literatura; R-22, $R a=1 \mu \mathrm{m}$ e $T_{\text {sal }}=320 \mathrm{~K}$.

Uma rápida análise das figuras e da Tabela 3.3, permite concluir que, a grosso modo, não há relação entre os mecanismos considerados pelos autores no modelamento e a ordem de grandeza do coeficiente de transferência de calor, pois modelos que utilizam princípios semelhantes apresentaram resultados diferentes. Esta conclusão pode ser discutível, pois embora se trate de mecanismos semelhantes, o ajuste de coeficientes é realizado com bancos de dados distintos. Constata-se que, com a variação apenas da temperatura de saturação, altera-se a ordem crescente das curvas correspondentes às correlações.

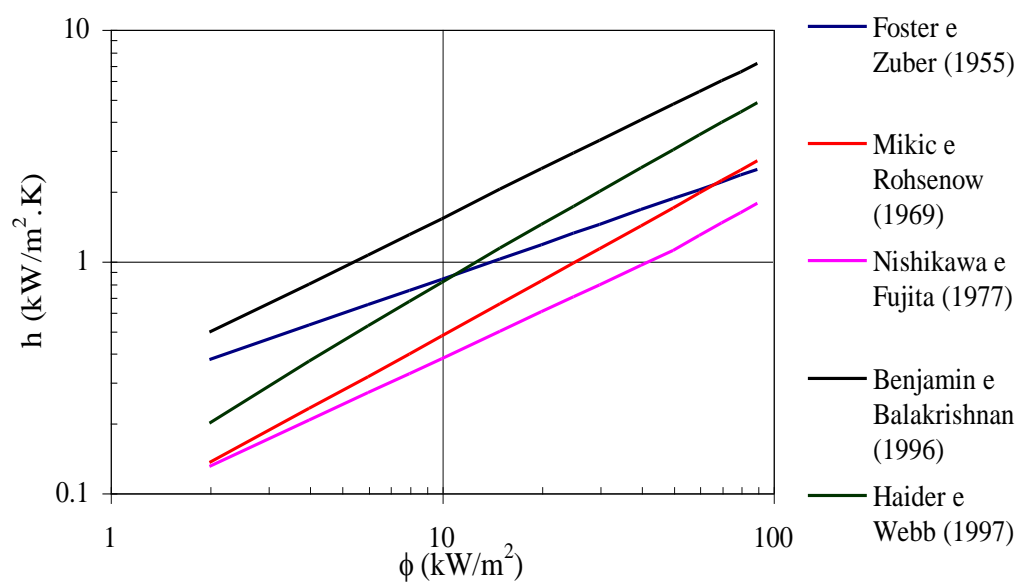

Figura 3.10 Comparação de algumas correlações da literatura; R-123, $R a=1 \mu \mathrm{m}$ e $T_{\text {sal }}=260 \mathrm{~K}$.

A correlação de Haider e Webb (1997), ilustrada na Fig. 3.9, apresentou valores superiores para o coeficiente de transferência de calor. Já na Fig. 3.10, elaborada para o R123, os maiores valores foram verificados para o modelo de Benjamin e Balakrishnan 
(1996). É interessante ressaltar que, ao contrário do modelo anteriormente citado, conforme Tabela 3.3, este não utiliza resultados experimentais para o R-123.

Tabela 3.3 Resumo das características dos modelos analisadas

\begin{tabular}{|c|c|c|}
\hline Modelos & Mecanismos & $\begin{array}{l}\text { Fluidos utilizados no banco de } \\
\text { dados }\end{array}$ \\
\hline Rohsenow (1952) & $\begin{array}{l}\text {-agitação do líquido promovida } \\
\text { pelo desprendimento e colapso de } \\
\text { bolhas. } \\
\text {-condução transiente }\end{array}$ & $\begin{array}{l}\mathrm{H}_{2} \mathrm{O}, \mathrm{CCl}_{4} \text {, benzeno, n-pentano, } \\
\text { álcool etílico, álcool isopropilico, } \\
\text { álcool n-butilico }\end{array}$ \\
\hline Foster e Zuber (1955) & $\begin{array}{lcc}\text {-convecçao promovida } & \text { pelo } \\
\text { mecanismo de expansão das } & \text { da } \\
\text { bolhas durante seu crescimento }\end{array}$ & $\begin{array}{l}\text { água, benzeno, álcool etílico, n- } \\
\text { pentano }\end{array}$ \\
\hline Tien (1962) & -escoamento estagnado invertido & água, acetona, n-hexano, $\mathrm{CCl}_{4}, \mathrm{CS}_{2}$ \\
\hline Zuber (1963) & com convecção natural & água, acetona, n-hexano, $\mathrm{CCl}_{4}, \mathrm{CS}_{2}$ \\
\hline Han e Griffith (1965b) & $\begin{array}{l}\text {-convecção natural } \\
\text {-condução transiente }\end{array}$ & água \\
\hline $\begin{array}{l}\text { Mikic e Rohsenow } \\
\text { (1969) }\end{array}$ & $\begin{array}{l}\text {-convecção Natural } \\
\text {-condução transiente }\end{array}$ & $\begin{array}{l}\text { n-pentano, álcool etílico, água, } \\
\text { benzeno }\end{array}$ \\
\hline $\begin{array}{l}\text { Nishikawa e Fujita } \\
\text { (1977) }\end{array}$ & $\begin{array}{l}\text {-analogia com convecção livre } \\
\text { considerando o número de Nussetl } \\
\text { função dos números de Grashof e } \\
\text { Prandtl }\end{array}$ & $\begin{array}{l}\text { água, benzeno, etanol, metano, } \\
\text { propano, n-butano, } \mathrm{CCl}_{4}, \mathrm{n} \text {-heptano }\end{array}$ \\
\hline $\begin{array}{l}\text { Benjamin e } \\
\text { Balakrishnan (1996) }\end{array}$ & $\begin{array}{l}\text {-evaporação da microcamada } \\
\text {-condução de calor transiente } \\
\text {-convecção natural turbulenta }\end{array}$ & $\begin{array}{l}\text { água, } \mathrm{CCl}_{4} \text {, acetona, n-hexano, } \mathrm{n} \text { - } \\
\text { pentano }\end{array}$ \\
\hline Haider e Webb (1997) & $\begin{array}{l}\text {-condução transiente } \\
\text {-micro-convecção }\end{array}$ & R-11 e R-123 \\
\hline
\end{tabular}

O coeficiente de transferência de calor resultante do modelo de Haider e Webb (1997) é sempre superior ao obtido pelo modelo de Mikic e Rohsenow (1969), conforme observado anteriormente. Podendo proporcionar um coeficiente de transferência de calor cerca de 200\% superior àquele do modelo de Mikic e Rohsenow (1969). Embora o efeito devido ao mecanismo de condução transiente seja igual para ambos os modelos, o efeito da micro-convecção, considerado no modelo de Haider e Webb (1997), predomina sobre aquele associado à convecção natural na região externa à de influência da bolha. É interessante 
destacar que o mecanismo de convecção natural na região externa à de influência da bolha, embora admitido desprezível por Haider e Webb (1997), é incorporado ao modelo de Mikic e Rohsenow (1969).

\subsection{Conclusões Gerais}

Com base no extenso estudo aqui apresentado, envolvendo correlações para o coeficiente de transferência de calor através do mecanismo de ebulição nucleada, foi possível extrair as seguintes conclusões:

Não existe uma correlação genérica, que proporcione resultados adequados para uma ampla gama de condições operacionais. As correlações apresentadas se baseiam em uma certa "arbitrariedade" fenomenológica do autor, com expoentes e coeficientes ajustados segundo um banco de dados experimental, comumente dirigido para alguma aplicação especifica.

$>$ Como regra geral, os bancos de dados são desenvolvidos para pressões e características superficiais (material, acabamento e geometria) diferentes das encontradas em aplicações frigoríficas, não envolvendo, em sua maioria, refrigerantes halogenados. Desta forma, para a formulação de uma correlação visando aplicações frigorificas, seria necessário sistematizar a pesquisa destes parâmetros na ebulição nucleada de refrigerantes halogenados. 


\section{Capítulo 4 - Equipamento Experimental}

\subsection{Introdução}

O aparato, ilustrado na Fig. 4.1, foi desenvolvido levando em consideração a aquisição de resultados experimentais para o estudo da transferência de calor através do mecanismo de ebulição nucleada. Em face do elevado número de tópicos relevantes no estudo deste tema, apontados no Capítulo 1, foi desenvolvida uma bancada versátil que, embora alguns dos itens abaixo não estejam no escopo deste trabalho, permite, com pequenas modificações, efetuar os seguintes estudos:

$>$ Ensaios experimentais envolvendo diferentes refrigerantes para uma ampla faixa de temperaturas, incluindo a amônia.

Análise do efeito do óleo de lubrificação no desempenho térmico da superfície.

$>$ Análise do desempenho térmico de superfícies intensificadoras.

$>$ Estudo dos mecanismos de transferência de calor em ebulição nucleada para um único tubo e para banco de tubos.

$>$ Estudos envolvendo a visualização do fenômeno.

\subsection{Detalhamento do Aparato Experimental}

A Fig. 4.2 apresenta um diagrama esquemático do circuito experimental. Nela constata-se, basicamente, a existência da seção de testes e de três circuitos de rejeição de calor. $\mathrm{O}$ aparato envolve ainda, um conjunto de equipamentos específicos para a aquisição de 
dados e outro para alimentação das resistências elétricas. A seção de testes, o circuito de etileno-glicol e alguns componentes do resfriador de líquido são isolados termicamente do ambiente externo. $\mathrm{O}$ isolamento foi efetuado através do recobrimento das tubulações e dos componentes com uma camada de espessura superior a $50 \mathrm{~mm}$ de espuma de polietileno. No sentido de facilitar a descrição da bancada experimental, os distintos componentes foram agrupados da forma indicada a seguir.

Figura 4.1 Bancada experimental para o estudo da ebulição nucleada. 


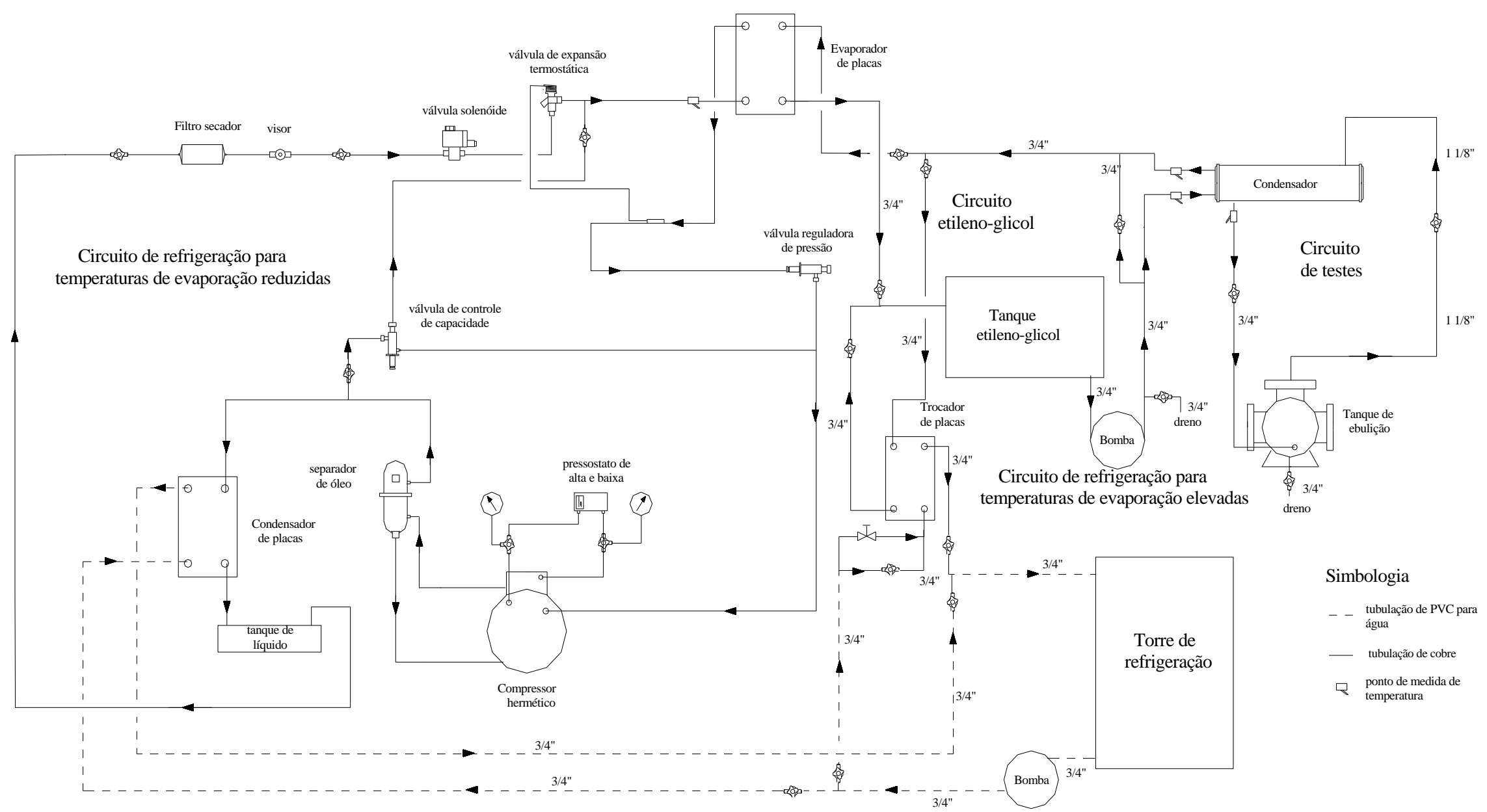

Figura 4.2 Diagrama esquemático da bancada experimental. 


\subsubsection{Seção de Testes}

A seção de testes encontra-se ilustrada à direita, na Fig. 4.1, sendo composta, basicamente, pela cuba de ebulição, a superfície de ensaio e o condensador. A cuba de ebulição foi construída em aço-carbono, com um volume interno de aproximadamente 40 litros, sendo testada hidrostaticamente para uma pressão de 3,1 MPa. Na Fig. 4.3 é possível visualizar seus detalhes, incluindo os locais onde são fixados os termopares blindados, o transdutor de pressão e a válvula de segurança. A tubulação interligando a cuba e o condensador principal foi construída em cobre, sendo dotada de válvulas de esfera para o isolamento desses componentes. No condensador e na cuba de ebulição foram conectadas válvulas de segurança do tipo plugue, "fusível", selecionadas para uma temperatura de saturação algo superior à máxima de ensaios. Para os refrigerantes mais voláteis, optou-se por válvulas que atuam para uma temperatura de $73^{\circ} \mathrm{C}$, correspondendo, para o R-22, um refrigerante de alta pressão, um valor de $p_{\text {sat }}$ de aproximadamente $3 \mathrm{MPa}$, adequando-se ao equipamento e aos objetivos deste trabalho. Já, para ensaios com refrigerantes pouco voláteis, optou-se por válvulas que atuam a uma temperatura de $103^{\circ} \mathrm{C}$, permitindo, desta forma, levantar resultados experimentais para pressões superiores.

Uma resistência elétrica de $1500 \mathrm{~W} / 220 \mathrm{~V}$, acessível através da tampa da cuba, foi instalada com o objetivo de auxiliar a retirada do refrigerante do circuito e permitir, no caso de ensaios com temperaturas elevadas, um rápido aquecimento do refrigerante.

\subsubsection{Superfície de Transferência de Calor}

Com o objetivo de analisar os efeitos na taxa de transferência de calor do material da superfície e verificar os resultados levantados, foram construídas quatro diferentes superfícies de testes. Termopares tipo $\mathrm{T}$ foram alojados em canais ao longo da superfície interna do tubo, conformados através de um processo de eletro-erosão. Estes termopares foram fixados em diferentes posições, através do preenchimento dos canais com uma resina epoxi de condutividade térmica igual à $0,72 \mathrm{~W} / \mathrm{m} .{ }^{\circ} \mathrm{C}$. Em duas das superfícies foram abertos um total de 8 canais, sendo fixados oito termopares. Na primeira, o objetivo foi de avaliar efeitos de condução axial, e na outra, verificar diferenças de temperaturas para uma mesma seção, ao longo da superfície externa do tubo, resultantes do mecanismo de ebulição 

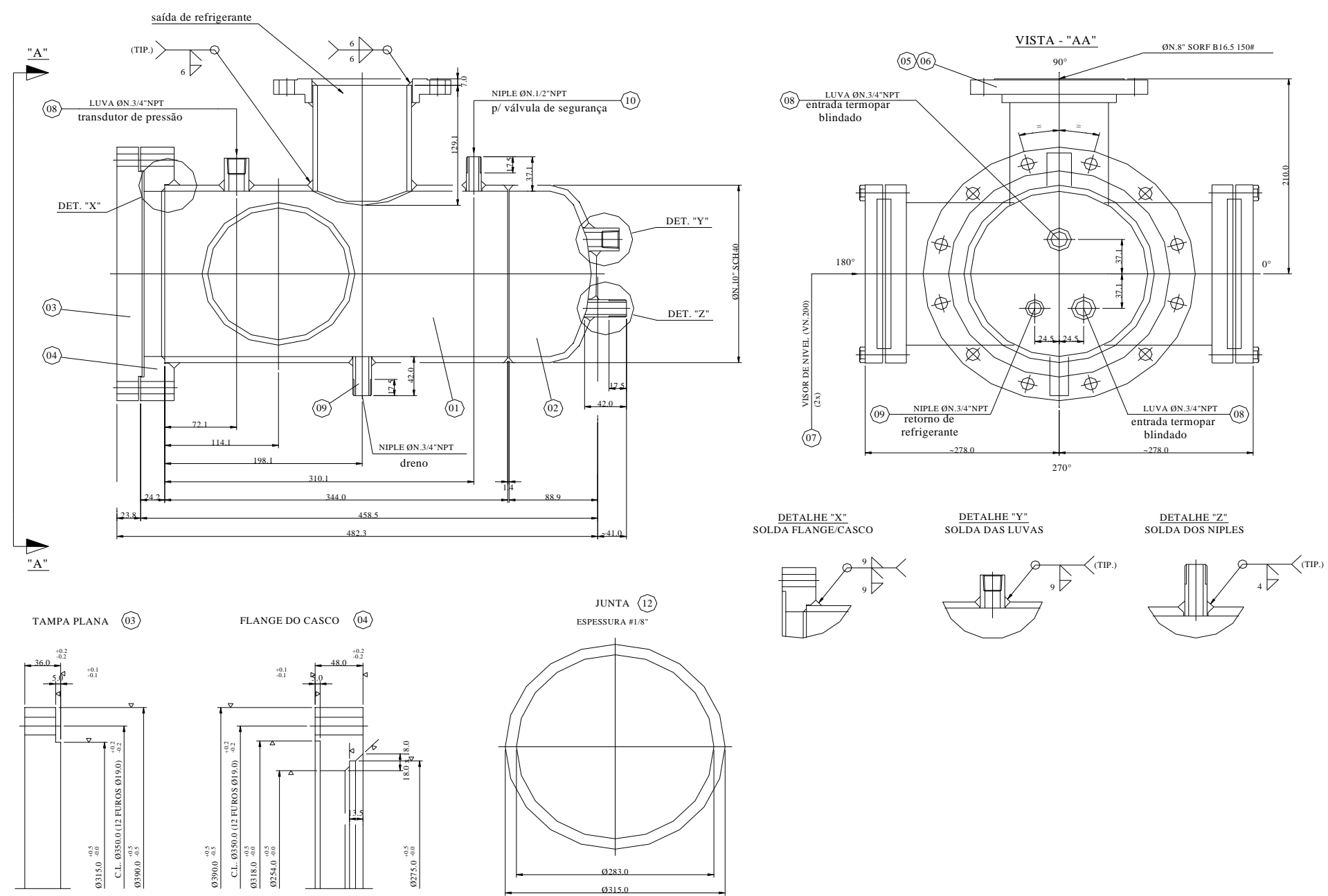

Figura 4.3 Cuba de ebulição 
nucleada. Nas demais foram abertos apenas quatro canais diametralmente opostos. Dentro de uma superfície tubular de cobre com espessura igual a $0,1 \mathrm{~mm}$, fixada no interior da superfície de testes através da resina epoxi anteriormente citada, foi alocada a resistência elétrica, do tipo cartucho, responsável pelo aquecimento da superfície de ensaio. O espaço entre a resistência elétrica e a superfície de cobre de espessura de $0,1 \mathrm{~mm}$ foi preenchido com graxa de silicone de condutividade térmica igual a $1,2 \mathrm{~W} / \mathrm{m} .{ }^{\circ} \mathrm{C}$. Após fixar a resistência elétrica, o espaço livre em uma das extremidades da superfície de testes foi preenchido com óxido de alumínio, soldando-se, em seguida, uma chapa de material semelhante ao da superfície de teste, que tinha, desta forma, vedada uma das suas extremidades. A Tabela 4.1 e a Fig. 4.4 resumem de maneira sucinta as características das superfície de testes e as posições onde se encontram alojados os termopares.

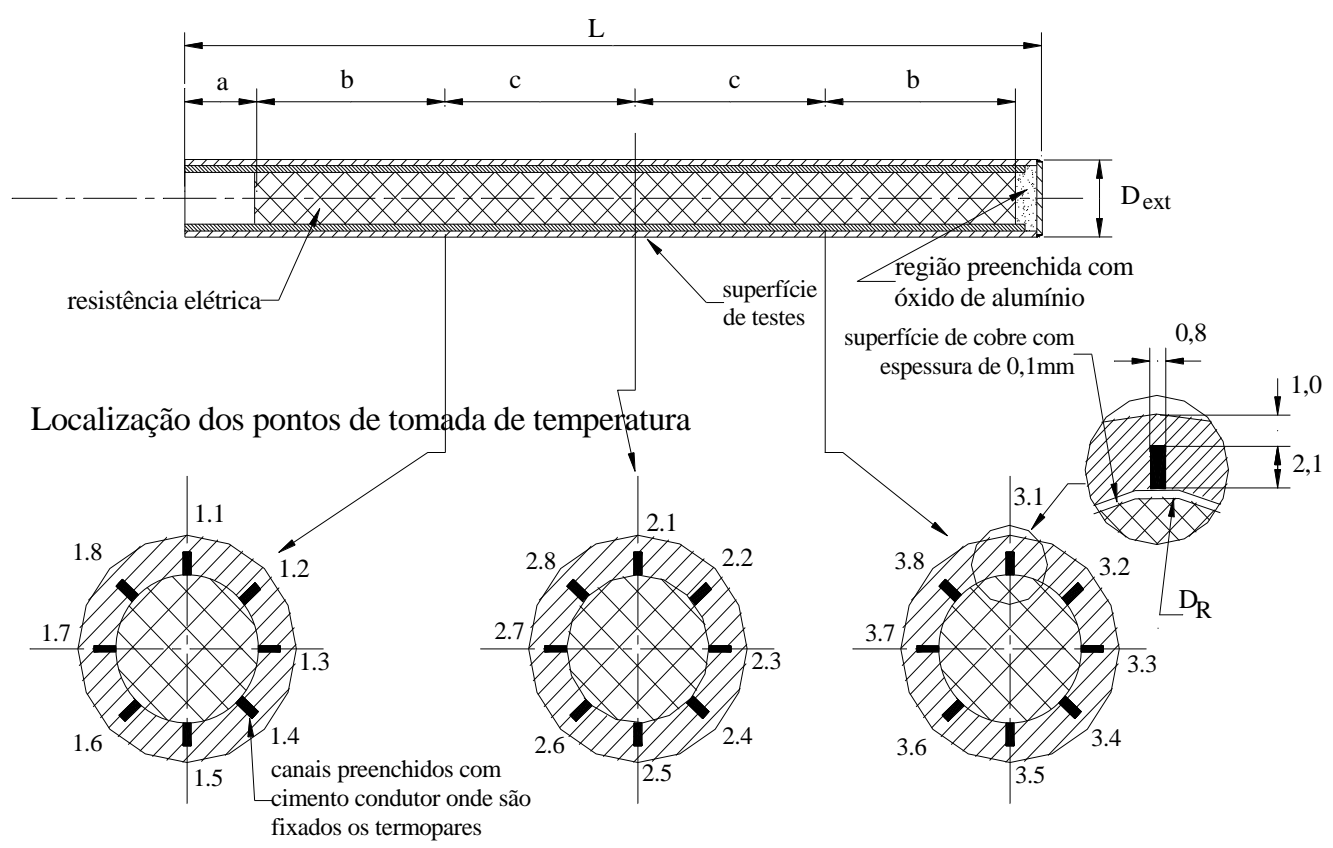

Figura 4.4 Superfície de testes, ilustrando o posicionamento dos termopares

A sustentação da superfície de teste na cuba foi feita por intermédio de um suporte de latão composto de uma flange, fixada por intermédio de parafusos à tampa da cuba. A superfície de teste foi fixada neste suporte, através de dispositivo composto por uma peça de latão externa e um anel de teflon, com uma das extremidades chanfrada. Este, além de reduzir a condução axial de calor da superfície de testes para o suporte, tinha o papel de junta 
de vedação ao ser pressionado contra a superfície cônica interna do suporte, através da peça externa. A montagem da superfície de testes no suporte e sua fixação no interior da cuba de ebulição são, esquematicamente, ilustrados na Fig. 4.5.

Tabela 4.1 Características das superfícies de testes.

\begin{tabular}{|c|c|c|c|c|c|}
\hline & & & & \\
\hline & & superfície 1 & superfície 2 & superfície 3 & superfície 4 \\
\hline \multicolumn{2}{|c|}{ Material } & cobre & cobre & latão & aço inoxidável \\
\hline \multicolumn{2}{|c|}{$\begin{array}{l}\text { Locais de medida de } \\
\text { temperatura }\end{array}$} & $\begin{array}{c}2.1,2.2,2.3,2.4,2.5 \\
2.6,2.7,2.8\end{array}$ & $\begin{array}{c}1.2,1.6,1.7,2.1 \\
2.3,2.5,3.8,3.4\end{array}$ & $2.1,2.3,2.5,2.7$ & $2.1,2.3,2.5,2.7$ \\
\hline \multirow{3}{*}{$\begin{array}{c}\mathrm{D} \\
\mathrm{i} \\
\mathrm{m} \\
\mathrm{e}\end{array}$} & $a$ & 35 & 35 & 35 & 35 \\
\hline & $b$ & ---- & 55 & $\begin{array}{ll}--- \\
\end{array}$ & $\begin{array}{ll}--- \\
\end{array}$ \\
\hline & $b+c^{*}$ & 105 & $\begin{array}{ll}--- \\
\end{array}$ & 105 & 105 \\
\hline \multirow{4}{*}{$\begin{array}{c}\mathrm{n} \\
\mathrm{s} \\
\tilde{\mathrm{o}} \\
\mathrm{e} \\
\mathrm{s} \\
(\mathrm{mm})\end{array}$} & $c$ & ---- & 50 & ---- & ---- \\
\hline & $L$ & 255 & 255 & 255 & 255 \\
\hline & $D_{\text {ext }}$ & $3 / 4 "$ & $3 / 4 "$ & $3 / 4 "$ & $3 / 4 "$ \\
\hline & $D_{R}$ & $1 / 2 "$ & $1 / 2 "$ & $1 / 2 "$ & $1 / 2 "$ \\
\hline \multicolumn{2}{|c|}{ Potência Elétrica $(\mathrm{W})^{* *}$} & 1500 & 1500 & 1500 & 1500 \\
\hline
\end{tabular}

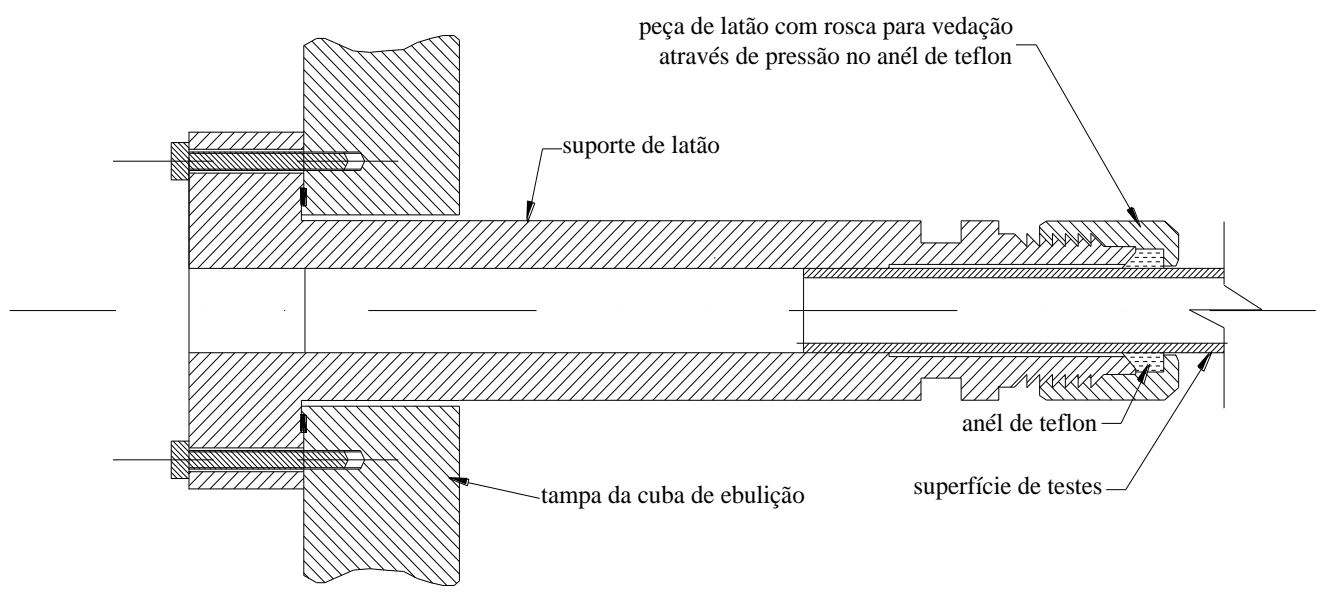

Figura 4.5 Montagem da superfície de ensaio. 


\subsubsection{Circuito Etileno/Glicol}

Em seu interior circula uma solução anticongelante constituída de $60 \%$ de etilenoglicol em água. Tem como função condensar o vapor gerado na cuba de ebulição, rejeitando calor nos trocadores de placa do circuito Resfriador de Líquido. A tubulação é de cobre com diâmetro igual a $3 / 4 "$, sendo dotada de válvulas de esfera que permitem a seleção do circuito resfriador de líquido e, consequentemente, a faixa de temperatura do ensaio.

$\mathrm{O}$ circuito de etileno-glicol incorpora um reservatório com capacidade de $0,15 \mathrm{~m}^{3}$ da mistura anticongelante. No interior deste reservatório foram instaladas uma resistência elétrica, $5000 \mathrm{~W} / 220 \mathrm{~V}$, e uma termoresistência de platina cuja resistência elétrica a $0^{\circ} \mathrm{C}$ é de $100 \Omega$, pt100. Estes componentes estão conectados a um dispositivo eletrônico que permite o controle da temperatura da mistura, mantendo-a no valor desejado. Uma bomba centrífuga circula a solução em circuito fechado, através dos trocadores de calor, retornando o fluido ao reservatório.

\subsubsection{Resfriador de Líquido}

Seu objetivo é resfriar a solução de água e etileno-glicol e, consequentemente, permitir a condensação do vapor gerado no tanque de ebulição. Este sistema pode ser dividido em dois sub-sistemas que atuam alternadamente através de manobra de válvulas: o primeiro, consistindo de um circuito frigorífico que opera para temperaturas reduzidas na cuba de ebulição, composto basicamente por condensador e evaporador do tipo placas, uma válvula de expansão, um compressor hermético com capacidade de $1,7 \mathrm{~kW}$ a $-23^{\circ} \mathrm{C}$, uma válvula controladora da capacidade de refrigeração, que compensa reduções de carga térmica do sistema, através da injeção de gás quente da descarga do compressor na entrada do evaporador e, finalmente, uma válvula reguladora de pressão, localizada na linha de sucção do compressor, com a função de proteger este equipamento quando em condições de pressão elevada no evaporador. A condensação do refrigerante ocorre no condensador secundário, com a utilização de água proveniente de uma torre de resfriamento. O refrigerante utilizado é o R-22. O segundo sub-sistema opera em temperaturas elevadas na cuba de ebulição, sendo composto basicamente por um trocador de placas, que resfria a solução anticongelante com água proveniente da torre de resfriamento. A vazão de água, neste trocador, é controlada através do fechamento e abertura de uma válvula de agulha. Em paralelo a esta válvula 
encontra-se uma válvula de esfera utilizada para resfriamentos rápidos da solução anticongelante.

\subsubsection{Sistema de Alimentação da Resistência Elétrica}

O fluxo de calor, através da superfície de ensaio, foi determinado por um autotransformador que alimenta a resistência elétrica. No presente trabalho, o fluxo de calor específico máximo na superfície de testes foi estabelecido como sendo da ordem de $140 \mathrm{~kW} / \mathrm{m}^{2}$. Estas resistências são do tipo cartucho com as características indicadas na Tabela 4.1. Efeitos de campo elétrico na superfície externa, foram eliminados com o aterramento direto da superfície de cobre, localizada entre a resistência elétrica e a superfície de testes. Este procedimento foi adotado pois, tanto a resina de epoxi quanto a graxa condutora, substâncias que evitam o contato físico direto com o equipamento, apresentam características de isolamento elétrico.

\subsubsection{Sistema de aquisição de dados}

O conjunto de equipamentos para aquisição de dados visa, basicamente, a determinação do superaquecimento da parede e a potência fornecida à superfície de transferência de calor. Isto permite o levantamento da curva de ebulição (fluxo de calor vs superaquecimento da superfície) para uma determinada pressão. Para as medidas de temperaturas foram utilizados termopares do tipo $\mathrm{T}$ (cobre-constantan), adequados às aplicações deste trabalho. Os fios dos termopares, para determinação da temperatura na superfície de testes, possuem diâmetro igual a 30 AWG, com encapamento de material plástico. A temperatura nas regiões inundadas e secas da cuba de ebulição, são obtidas através de termopares blindados com isolação mineral. São 10 o total de pontos de medida de temperatura diretamente relacionados com o presente estudo. Com o objetivo de auxiliar o monitoramento do sistema, também foram determinadas as temperaturas nos seguintes locais: entrada do evaporador; entrada e saída da solução anti-congelante do condensador principal; retorno do refrigerante em teste do condensador principal para a cuba de ebulição; e no interior do reservatório da solução de etileno-glicol e água. Os resultados fornecidos pelos termopares blindados (embora possam apresentar pequena diferença devido ao efeito 
de coluna do refrigerante) podem ser contrastados com a temperatura de saturação, avaliada por intermédio da pressão na cuba, lida através do transdutor de pressão que abrange uma faixa de operação de 0 a 13 bar.

A medida da potência elétrica e, indiretamente, do fluxo de calor, é efetuada por intermédio de um amperímetro e um voltímetro de precisão.

Os sinais elétricos resultantes dos transdutores são processados por um sistema de aquisição de dados da marca STRAWBERRY TREE, USA, incluindo 2 terminais de temperatura para 8 canais cada um (12 bits de resolução), 1 terminal para sinais elétricos com 8 canais e 2 placas conversoras A/D, de 16 canais cada uma, além do "software" "Work Bench for Windows 3.11". Os terminais de temperatura tem incorporada uma placa termostática que serve como referência para os termopares, substituindo o banho de gelo fundente para estabelecer a temperatura de referência $\left(0^{\circ} \mathrm{C}\right)$. Variações na temperatura ambiente são compensadas periodicamente por circuito compensador associado à placa isotérmica. Os sinais provenientes das placas conversoras são processados por um computador modelo IBM PC 486 DX4 100Mhz. 


\section{Capítulo 5 - Procedimento Experimental}

\section{$5.1 \quad$ Introdução}

O estudo do mecanismo de ebulição nucleada, por sofrer influência de diversos parâmetros, e, no caso da presente análise, envolver a determinação da temperatura externa de uma superfície cilíndrica em um banho de refrigerante, exige severas precauções experimentais. Tais cuidados referem-se ao procedimento utilizado no levantamento experimental, à limpeza do sistema, à determinação precisa das características superficiais e à determinação das incertezas nas medidas de temperatura e fluxo específico de calor. Este capítulo dedica-se à análise destes tópicos.

\subsection{Procedimento Experimental na Bancada}

\subsubsection{Carregamento do Sistema}

Antes do preenchimento da cuba de ebulição com o refrigerante de ensaio, foram tomados cuidados relativos à limpeza do sistema e à possível ocorrência de vazamentos. A existência, tanto de óleo como de partículas sólidas, pode alterar drasticamente o desempenho da superfície de testes, conforme discutido nos Capítulos 1 e 2 da pesquisa bibliográfica. A verificação da existência de vazamentos foi efetuada não só para evitar fugas de refrigerante mas também para não permitir uma possível entrada de ar no sistema. Isto ocorreria para o caso de ensaios com refrigerantes pouco voláteis, operando sob 
condições de pressões inferiores à atmosférica. Para esta situação, a pressão na cuba seria igual a soma das pressões parciais do refrigerante e do ar existente no sistema, resultando em uma estimativa errônea da pressão de saturação.

Previamente a cada condição de ensaio, caracterizada pelo refrigerante, a superfície de testes e seu acabamento superficial, lavava-se a cuba de ebulição com R-11. Em seguida, ela era vedada através da fixação da sua tampa e do suporte no qual encontra-se fixada a superfície de testes. A seguir era realizado vácuo no sistema (cuba de ebulição e condensador) até uma pressão absoluta de $2 \mathrm{kPa}$. Concomitantemente, para facilitar a eliminação da umidade e do ar existentes no sistema, circulava-se a solução anti-congelante pelo condensador principal com uma temperatura igual a $80^{\circ} \mathrm{C}$. O vácuo era mantido durante um período superior a 12 horas, após o que carregava-se o sistema com $\mathrm{N}_{2}$ até uma pressão de $800 \mathrm{kPa}$, para verificação de possíveis vazamentos. A seguir, realizava-se um novo vácuo e o sistema era carregado com o refrigerante no estado de vapor a partir das garrafas (ou depósitos) comerciais. Como resultado da diferença de pressão entre a cuba e o reservatório, o refrigerante evaporava e circulava através de mangueiras até a cuba. Já no interior do sistema, o refrigerante condensava ao entrar em contato com a superfície interna do condensador principal, no qual circulava a solução anticongelante com temperatura reduzida. Tal processo, similar a uma destilação, evitava que partículas estranhas, eventualmente existentes no refrigerante, fossem transportadas até a cuba e depositadas na superfície de testes. Quando o refrigerante atingia um nível de aproximadamente $35 \mathrm{~mm}$ acima da superfície de teste, o registro de entrada era fechado e cessava o carregamento.

Verificava-se a existência de gases não condensáveis, comparando, para a condição de equilíbrio, as temperaturas dos temopares blindados e a pressão da cuba com os valores de $T_{\text {sat }}$ e $p_{\text {sat }}$ tabelados no Handbook of Fundamentals (1997) da ASHRAE. No caso da não correspondência destes valores, o refrigerante no interior da cuba era aquecido e realizava-se uma purga no condensador principal através da qual tais gases eram eliminados. Esta purga era realizada de modo a não provocar alterações significativas no nível de refrigerante. A seguir, a superfície de testes era submetida a um fluxo específico de calor em torno de $70 \mathrm{~kW} / \mathrm{m}^{2}$, durante um período de 4 horas, para a remoção de gases ainda existentes nas reentrâncias da superfície.

Após a realização dos ensaios para determinado par refrigerante/superfície de transferência de calor, caracterizada pelo seu acabamento superficial, material e diâmetro, o sistema era drenado e a superfície de testes retirada. No caso da permanência do sistema inativo por períodos prolongados, tampava-se com uma flange a região onde era fixado o suporte da superfície de testes, seguida da realização de vácuo no sistema e de seu 
preenchimento com $\mathrm{N}_{2}$ até uma pressão de $600 \mathrm{kPa}$. Tal procedimento evitava o contato do interior da cuba de ebulição com o ar externo, o que resultaria sua oxidação. Quando o reinicio dos testes era imediato, a superfície era novamente preparada ou substituída e o procedimento descrito neste item repetido.

\subsubsection{Levantamento dos Resultados Experimentais}

Uma vez realizadas as etapas descritas anteriormente, ou seja, instalada a superfície e carregado o sistema, eram levantadas as curvas de ebulição para diferentes valores de $p_{\text {sat }}$. Tanto a escolha do $p_{\text {sat }}$ inicial como a ordem de acréscimo ou decréscimo no seu valor era aleatória. Repetia-se a condição inicial após a determinação das curvas de ebulição para os diferentes valores de $p_{\text {sat }}$ verificando-se, através da coincidência de resultados, a não alteração das características superficiais. A pressão no interior da cuba era determinada através do ajuste da temperatura da solução de etileno-glicol, atuando-se nos seguintes dispositivos: controlador eletrônico de temperatura, válvula de controle da capacidade de refrigeração para valores reduzidos de $T_{s a t}$ e da válvula de agulha no caso de valores elevados de $T_{\text {sat }}$.

Diariamente, antes do início dos testes, com o objetivo de evitar possíveis erros nas medidas de temperatura devido à oxidação das conexões dos termopares, eram verificadas as diferenças entre as temperaturas dos termopares inundados (termopares na superfície de teste e o termopar blindado e inundado), que deveriam ser inferiores a $0,3 \mathrm{~K}$, valor adotado arbitrariamente e igual a incerteza na medida de $\left(T_{p}-T_{s a t}\right)$.

A aquisição dos dados era efetuada com condições fixas de pressão e fluxo específico de calor. Este último parâmetro tinha seu valor elevado gradativamente até um máximo e, em seguida, reduzido, cobrindo uma faixa de 0,6 a $120 \mathrm{~kW} / \mathrm{m}^{2}$. Os testes visando apenas a análise da ebulição nucleada foram realizados somente para a redução do fluxo de calor a partir de um valor máximo. A pressão no interior da cuba era mantida constante, independente do fluxo de calor, com o ajuste da temperatura da solução anti-congelante através dos dispositivos citados anteriormente. $\mathrm{O}$ subresfriamento do líquido era verificado através da diferença entre as temperaturas indicadas pelos termopares blindados, devendo ser inferior à $0,3 \mathrm{~K}$. Adotou-se como critério para o início da aquisição uma variação inferior a $0,2 \mathrm{~K}$ na temperatura fornecida pelo termopar $T_{2.1}$ durante um período de 10 minutos. $\mathrm{O}$ sistema de aquisição foi ajustado de forma a gravar uma leitura (conjunto de medidas de todas as variáveis) a cada 1s, utilizando uma frequiência de aquisição de $11 \mathrm{~Hz}$. Os resultados 
foram extraídos da média de 60 leituras consecutivas, ou seja, da média dos valores lidos em um intervalo de 60s. Para cada condição experimental, caracterizada por $p_{\text {sat }}, \phi, R a$, refrigerante e material da superfície, foram realizadas as seguintes medições:

i. Tensão e corrente elétrica fornecidas para a resistência do tipo cartucho;

ii. Temperatura na superfície de testes;

iii. Temperatura do refrigerante e pressão do sistema.

\subsection{Preparação e Caracterização do Acabamento da Superfície de Testes}

Verifica-se no Capítulo 3 que os modelos para a previsão do coeficiente de transferência de calor utilizam diferentes parâmetros para a caracterização da superfície. $\mathrm{Na}$ opção por um determinado parâmetro são consideradas variáveis tais como: capacidade de caracterização do perfil da superfície*, facilidades laboratoriais e grau de evolução tecnológica disponível. Alguns destes parâmetros estão detalhados no Apêndice I. Reconhece-se que a utilização de um determinado parâmetro de acabamento superficial não caracteriza, diretamente, o raio das cavidades, mas sim o perfil da superfície. Apesar disto, é interessante ressaltar que superfícies com perfil aleatório**, possuindo valores reduzidos de $R a$, apresentariam cavidades de diâmetros inferiores. Desta forma, optou-se pela utilização deste parâmetro, levando em conta as seguintes considerações: segundo Whitehouse (1994) é um dos parâmetros que melhor caracteriza o perfil da superfície; as superfícies utilizadas apresentam um acabamento superficial de certa forma aleatório; há disponibilidade de um equipamento para medição; e a utilização deste parâmetro em trabalhos anteriores, permite uma comparação entre os resultados.

Diferentes métodos foram utilizados na elaboração do acabamento superficial. Tais procedimentos dependeram do material com o qual era composta a superfície de testes e do nível de rugosidade desejado. Para tanto, manipulou-se, de forma a obter o acabamento desejado, diferentes tratamentos envolvendo a remoção de material da superfície e o seu período de aplicação. Tais tratamentos foram realizados de modo a resultarem em alterações desprezíveis no diâmetro externo da superfície. Na confecção dos diferentes acabamentos

\footnotetext{
*Estes parâmetros foram desenvolvidos para aplicações na indústria mecânica. Desta forma, alguns deles tendem a destacar apenas características do perfil da superfície voltadas à tais aplicações e não caracterizar as irregularidades da superfície em sua totalidade

** Este termo foi utilizado no sentido de especificar uma superfície cujas cavidades não foram artificialmente elaboradas como a do trabalho de Roy Chowdhury e Winterton (1985), no qual o autor comparou superfícies com mesmo valor de $R_{a}$ mas uma com cavidades de diâmetros iguais à $1 \mu \mathrm{m}$ uniformemente distribuídas e outra, com cavidades de diferentes diâmetros e aleatoriamente distribuídas.
} 
foram utilizados jato de areia, lixas d'água $\mathrm{n}^{\circ} 220,1200$ e massa de polimento $\mathrm{N}^{\circ} 2$. $\mathrm{O}$ jato de areia era aplicado perpendicularmente à superfície de teste enquanto ela era girada em relação ao seu eixo central e deslocada na direção longitudinal, sendo ambos os movimentos realizados manualmente. As lixas eram aplicadas manualmente à superfície de teste em movimento rotacional com velocidade de 1200 RPM. O polimento era realizado aplicando-se, com o auxílio de papel fino, a massa na superfície a 1200 RPM. Os acabamentos em uma determinada superfície eram aplicados de forma crescente de $R a$, partindo-se de uma superfície polida até a superfície jateada. A Tabela. 5.1 apresenta de forma resumida os tratamentos aplicados a cada superfície e a correspondente faixa de $R a$ obtida.

Tabela 5.1 Descrição esquemática da preparação das superfícies de testes.

\begin{tabular}{|c|c|c|}
\hline $\begin{array}{l}\text { Material } \\
\text { Superfície }\end{array}$ & $\begin{array}{c}\text { Faixa de } R a \\
(\mu \mathrm{m})\end{array}$ & Descrição do Tratamento \\
\hline \multirow{4}{*}{ cobre } & 0,06 a 0,09 & lixa $\mathrm{N}^{\mathrm{o}} 1200$ e polimento durante um período superior a duas horas \\
\hline & 0,14 a 0,17 & $\operatorname{lixa} \mathrm{N}^{\circ} 1200$ \\
\hline & 0,4 a 0,8 & $\operatorname{lixa} \mathrm{N}^{\mathrm{o}} 220$ \\
\hline & 2,4 a 3,2 & jato de areia \\
\hline \multirow{3}{*}{$\begin{array}{l}\text { aço } \\
\text { inoxidável }\end{array}$} & 0,02 & lixa $\mathrm{N}^{0} 1200$ e polimento durante um período superior a três horas \\
\hline & 0,07 a 0,09 & lixa $\mathrm{N}^{0} 1200$ e polimento durante um período de cerca de 30 minutos \\
\hline & 0,15 a 0,18 & lixa $\mathrm{N}^{0} 1200$ \\
\hline \multirow{2}{*}{ latão } & 0,06 a 0,09 & lixa $\mathrm{N}^{\mathrm{o}} 1200$ e polimento durante um período superior a uma horas \\
\hline & 0,14 a 0,17 & lixa $\mathrm{N}^{\mathrm{O}} 1200$ e polimento \\
\hline
\end{tabular}

A seguir limpava-se a superfície e sua rugosidade superficial era determinada no Laboratório de Metrologia da EESC/USP. A Fig. 5.1 ilustra alguns dos perfis das superfícies de testes. O equipamento utilizado na medição foi um rugosímetro de precisão, fabricado pela Taylor-Hobson, tipo Talysurf 10, que permite uma ampliação máxima de 50.000 vezes. $\mathrm{O}$ valor de $R a$ era determinado em 10 diferentes comprimentos de amostra da superfície. Depois de ter sua rugosidade medida, ela era montada no suporte, lavada com R-11 e fixada na tampa da cuba de ebulição. Após terminados os ensaios para diferentes valores de $p_{\text {sat }}$ dentro de uma determinada condição experimental (caracterizada pelo refrigerante, a superfície de teste e o seu acabamento), a superfície era retirada da cuba, verificava-se visualmente a deposição de material e repetia-se o procedimento de medida de $R a$ com o 
objetivo de verificar alterações nas características superficiais quando submetida à ebulição durante determinado período.

a) $R a=0,02 \mu \mathrm{m}$; ampliações: horizontal 100x, vertical 20000x

b) $R a=0,50 \mu \mathrm{m}$; ampliações: horizontal $100 \mathrm{x}$, vertical $5000 \mathrm{x}$

c) $R a=2,3 \mu \mathrm{m}$; ampliações: horizontal 100x, vertical 1000x

Figura 5.1 Perfis das superfícies de testes. 


\subsection{Descrição dos Procedimentos Envolvendo a Determinação dos Parâmetros Medidos, dos Erros Experimentais e das Incertezas}

Considerando a necessidade de garantir a qualidade das medições, validando assim, a exatidão da correlação desenvolvida e possíveis conclusões envolvendo os efeitos de seus parâmetros, realizaram-se estimativas dos erros experimentais denominados de incertezas. Os erros significativos, verificados neste estudo, foram classificados como "determináveis" e "não determináveis", divididos ainda, dentro de cada grupo, em sistemáticos e aleatórios. O primeiro grupo teve seu erro sistemático eliminado e sua incerteza determinada. Tal grupo envolveu os seguintes parâmetros: $p_{s a t}, T_{s a t}$, área da superfície de transferência de calor, rugosidade superficial, temperaturas fornecidas pelos termopares e, finalmente, a tensão e a corrente fornecidas à resistência elétrica. Os procedimentos utilizados nas calibrações e nas análises e propagações de incertezas encontram-se detalhados no Apêndice II.

Parâmetros como fluxo específico de calor e a temperatura da superfície de testes, por terem seus resultados afetados, respectivamente, por efeitos de condução longitudinal na superfície de teste e por efeitos de resistência térmica, resultante de incertezas no posicionamento e no processo de fixação dos termopares, foram considerados pertencentes ao segundo grupo. Estes efeitos, caso desprezados poderiam subestimar, no caso de $T_{p}$, ou superestimar, no caso de $\phi$, o coeficiente de transferência de calor. A localização do termopar ou termopares ao longo da circunferência da superfície de ensaios também pode afetar $T_{p}$, pois, segundo alguns autores, em superfícies cilíndricas o coeficiente de transferência de calor varia ao longo da circunferência, comportamento resultante de diferença locais inerentes ao mecanismos físicos de transferência de calor e à dinâmica de bolhas.

Embora diversos trabalhos tenham sido consultados, Tabelas 1.2 e 1.3, poucos citam a análise destes efeitos. Tal consulta a literatura resultou na Tabela 5.2, que ilustra as técnicas empregadas na fixação dos termopares, os procedimentos adotados na suplantação de efeitos de condução longitudinal e de resistência térmica e variações em uma mesma seção de $T_{p}$ ao longo da circunferência da superfície. Sua análise permite extrair as seguintes conclusões:

não são verificadas grandes preocupações envolvendo efeitos de condução longitudinal e de resistência térmica entre a superfície de testes e o termopar;

$>T_{p}$ é dado pela média aritmética das temperaturas indicadas pelos termopares localizados na superfície de testes;

de uma maneira geral, a temperatura superficial tem seu valor incrementado ao longo da superfície, partindo da face inferior no sentido da superior. 
Tabela 5.2 Descrição do procedimento adotado por diferentes autores na determinação de $T_{p}$ e a variação do superaquecimento ao longo da circunferência.

\begin{tabular}{|c|c|}
\hline Autor & $\begin{array}{c}\text { Descrição dos procedimentos adotados e resultados relacionados à variação do } \\
\text { superaquecimento ao longo da circunferência* }\end{array}$ \\
\hline Silva & $\begin{array}{l}\text { - superfície de latão com } D_{e x t}=14,2 \mathrm{~mm} \text {. Os termopares foram fixados no interior de furos } \\
\text { longitudinais na parede da superfície, separados de } 90^{\circ} \\
\text { - efeitos de condução longitudinal foram corrigidos considerando as hastes em que a superfície } \\
\text { de ensaio estava fixada como aletas semi-infintas } \\
\text { - verificou-se a seguinte ordem decrescente de temperaturas: face superior, intermediária e } \\
\text { inferior. A diferença entre a temperatura superior e inferior apresentou valores entre } 2^{\circ} \mathrm{C} \text { para } \\
\text { convecção natural e } 0,5^{\circ} \mathrm{C} \text { para ebulição nucleada } \\
\text { - adotou-se como temperatura da superfície a média aritmética das temperaturas fornecidas } \\
\text { pelos termopares. }\end{array}$ \\
\hline Palm (1991) & $\begin{array}{l}\text { - duas configurações com } 4 \text { e } 6 \text { termopares, respectivamente separados de } 90^{\circ} \text { e } 60^{\circ} . \mathrm{Na} \\
\text { primeira configuração, os termopares foram fixados em ranhuras na superfície interna do tubo, } \\
\text { e, na segunda, em canais usinados sobre uma superfície que foi posicionada internamente à de } \\
\text { ensaios. Para ambas as configurações eles foram fixados através de uma resina epoxi } \\
\text { - efeitos circunferênciais e longitudinais foram desprezados } \\
\text { - temperatura da superfície dada pela média das temperaturas fornecidas pelos termopares }\end{array}$ \\
\hline & $\begin{array}{l}\text { - superfícies lisa, GEWA-K26, GEWA-TX19, GEWA-SE e Turbo-B com } D_{e x t} \simeq 19 \mathrm{~mm} \\
\text { - } 2 \text { termopares instalados em canais diametralmente opostos, apresentando temperaturas } \\
\text { semelhantes quando rotacionados e localizados em uma mesma posições azimutal. Ângulo } \\
\text { azimutal adotado para o posicionamento dos termopares e levantamento experimental de } 0^{\circ} \text { e } \\
180^{\circ} . T_{p} \text { dado pela média das temperaturas indicadas pelos termopares }\end{array}$ \\
\hline
\end{tabular}

Webb e Pais - embora a superfície e a resistência do tipo cartucho apresentem comprimentos, (1992) respectivamente, iguais a $177,8 \mathrm{~mm}$ e $152,4 \mathrm{~mm}$, e os termopares estejam localizados a apenas $50 \mathrm{~mm}$ da extremidade da superfície de ensaio, efeitos de condução longitudinal foram desprezados.

- GEWA-K26 maior superaquecimento para a face superior; GEWA SE superaquecimento superior na face inferior; Turbo-B o superaquecimento não variou ao longo da circunferência.

- demais superfícies não foram analisadas

- superfície lisa e superfície com 709 aletas/m, com e sem recobrimento com ABM, High-Flux e Turbo-B, apresentando diâmetros externos entre 12,7 e 17,2 mm, comprimento da superfície igual a $76,2 \mathrm{~mm}$ e da resistência $88,9 \mathrm{~mm}$.

Chang e You -3 termopares fixados no interior de furos a $25 \mathrm{~mm}$ de cada extremidade da superfície, a $90^{\circ}$ $(1997 c)$ um do outro. Os furos eram preenchidos com prata.

- diferença de temperatura entre os termopares: $95 \%$ do $\mathrm{FCC}^{* *} \pm 0,7 \mathrm{~K}$; próximo ao $\mathrm{FCC} \pm$ $2,6 \mathrm{~K}$.

- não foram caracterizados efeitos de variações de $T_{p}$ ao longo da circunferência da superfície.

\footnotetext{
* A não apresentação de determinados aspectos para alguns autores, foi devida a não citação do procedimento adotado ou do resultado obtido.

**FCC sigla adotada para representar o fluxo crítico de calor.
} 
Tabela 5.2 (Continuação) Descrição do procedimento adotado por diferentes autores na determinação de $T_{p}$ e a variação do superaquecimento ao longo da circunferência.

\section{Autor Descrição dos procedimentos adotados e resultados relacionados à variação do superaquecimento ao longo da circunferência*}

\footnotetext{
- superfícies lisa e recobertas com diferentes materiais**, com $D_{e x t}=19 \mathrm{~mm}$.

Hsieh e Weng - 4 termopares localizados no interior de furos longitudinais na parede da superfície, separados (1997b) de $90^{\circ}$, com diâmetro e comprimento, respectivamente, iguais a 1,2 e $100 \mathrm{~mm}$.

- $T_{p}$ dada pela média aritméticas das temperaturas indicadas pelos termopares.

- superfícies com diâmetros iguais a $25,4 \mathrm{~mm}$ e $90 \mathrm{~mm}$, respectivamente, de cobre e de aço, sendo esta última aletada

- 36 termopares fixados na seção central, em canais localizados em um superfície interna, posicionada internamente a superfície de transferência de calor. Os autores não citam
} Gorenflo et al comparações entre os resultados apresentados pelos termopares rotacionando a superfície

- $\left(T_{p}-T_{\text {sat }}\right)$ foi reduzido com o incremento do ângulo azimutal. Estes efeitos foram intensificados para $p_{r}=0,1$ e $\phi=20 \mathrm{~kW} / \mathrm{m}^{2}$, sendo que para $\phi$ e $p_{r}$, respectivamente, superiores e inferiores foram reduzidos. Para transferência de calor através de convecção natural não foram verificadas diferenças

- este comportamento foi atribuído ao arraste de bolhas junto a superfície, intensificando a evaporação e efeitos convectivos nas regiões inferiores da superfície

- superfícies de aço inoxidável com $D_{e x t}=19$, mm e $L=530 \mathrm{~mm}$.

- 3 termopares fixados externamente através de um processo de brasagem e espaçados de $90^{\circ}$

- a temperatura superficial tem seu valor incrementado progressivamente ao longo da superfície, partindo da face inferior no sentido da superior

Kang (2000) • comportamento justificado através da constatação de que as bolhas, geralmente, formam-se na região inferior, escorregam sobre a superfície, coalescendo com outras bolhas e desprendendo-se nas regiões superiores. Desta forma, seria formada uma região com vapor que reduziria a transferência de calor através da inibição do número de cavidades ativas na face superior. Ele considerou desprezível o efeito da rugosidade em $h$ para superfícies cilíndricas e horizontais quando comparado a outras configurações.

- foi adotado como $T_{p}$ a indicação do termopar localizado na face lateral por este representarar um valor médio

* A não apresentação de determinados aspectos para alguns autores, foi devida a não citação do procedimento adotado ou do resultado obtido.

** demais características verificar Tabela 1.2

No presente trabalho, com o objetivo de avaliar qualitativamente efeitos de resistência térmica entre a superfície de transferência de calor e o termopar e de condução longitudinal, foram desenvolvidos dois programas baseados em técnica de diferenças finitas, consistindo em balanços de energia para os nós em que foram discretizados dois diferentes cortes da superfície, ilustrados na Fig. 5.2. Em ambos os programas admitiu-se condução 
bidimensional, com as condições de contorno ilustradas nesta figura. O primeiro programa foi elaborado para a verificação do perfil de temperaturas longitudinal da superfície e do efeito do cimento condutor neste perfil, permitindo, assim, estimar o fluxo de calor longitudinal a partir de uma região central da superfície. Isto permitiu verificar, para uma determinada seção, a parcela do fluxo de calor imposto pela resistência elétrica que realmente atinge a superfície externa nesta mesma seção.

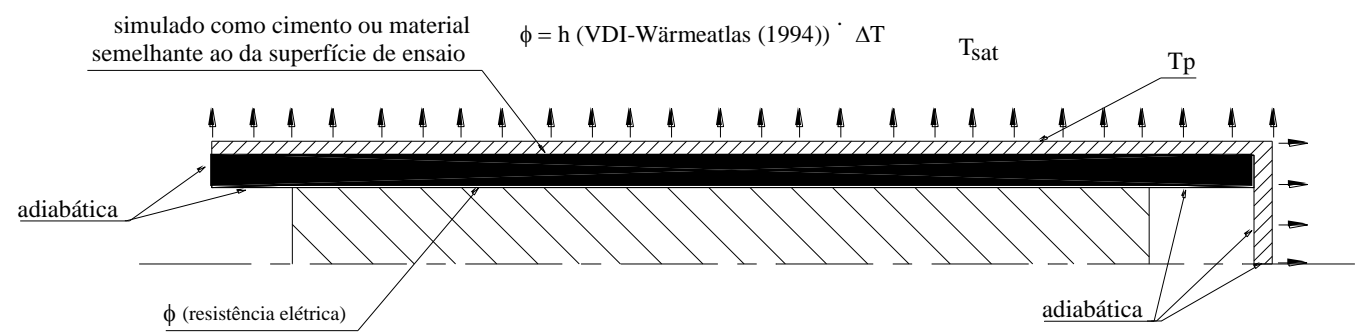

a)

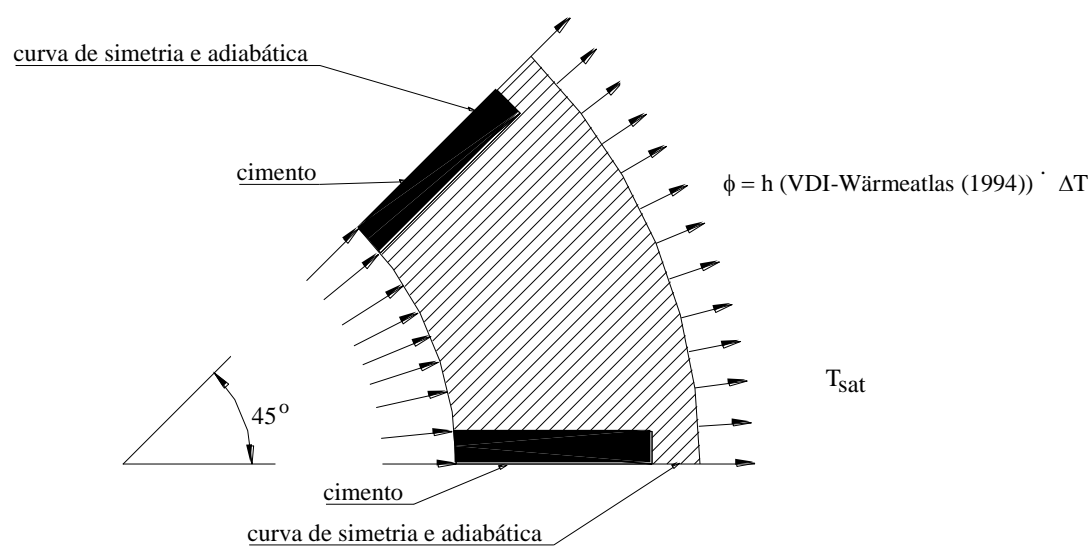

b)

Figura 5.2 Ilustração esquemática das condições experimentais simuladas numericamente. a) corte longitudinal, efeitos de condução axial; b) corte transversal, efeitos de resistência térmica radial.

O segundo programa, elaborado em coordenadas cilíndricas, consistiu em um corte radial da superfície de teste, cujos resultados ilustram a variação da temperatura na seção e o efeito do cimento nestas temperaturas. Desta forma, foi possível especular como a aleatoridade do posicionamento do termopar no interior dos canais altera a valor de $T_{p}$ indicado. No caso da variação de $T_{p}$ ao longo da circunferência da superfície de ensaio foi realizada uma análise para uma mesma condição experimental dos valores indicados pelos termopares antes e após girar-se a superfície. 
Finalmente, com base em tais análises, foram adotados e justificados os procedimentos utilizados na determinação da temperatura da superfície de testes e de $\phi$.

\subsubsection{Procedimento Utilizado na Determinação de $\phi$}

O primeiro programa anteriormente mencionado foi desenvolvido com o objetivo de avaliar os efeitos de condução longitudinal. Através dele foi estimada a relação entre o fluxo de calor longitudinal e o radial imposto pela resistência elétrica. Embora este programa utilize a correlação do VDI-Wärmeatlas (1994) na previsão do coeficiente de transferência de calor externo, podendo desta forma, introduzir erros inerentes a ela, buscou-se adotar condições de contorno próximas às experimentais.

As Figs. 5.3 e 5.4 ilustram os perfis de temperatura na região externa da superfície, para distintas condições, destacando os pontos entre os quais estariam fixados os termopares. Verifica-se que, nessa região, os gradientes de temperatura são reduzidos indicando um reduzido fluxo de calor longitudinal. Tais gradientes tornam-se ainda menores com a redução de $\phi$ e a elevação do coeficiente de transferência de calor externo através do incremento de $R a$ e $p_{\mathrm{r}}$. Consequentemente, efeitos de condução longitudinal seriam intensificados para ensaios envolvendo valores reduzidos de $R a$ e $p_{r}$ e elevados de $\phi$. No entanto, no caso do fluxo específico de calor, embora as perdas longitudinais em valores absolutos sejam incrementadas, como resultado de maiores gradientes de temperatura, seus valores relativos, isto é, a relação entre o calor transferido longitudinalmente e o radialmente é reduzida. Tal comportamento encontra-se ilustrado nas Figs. 5.5 e 5.6, determinadas através dos resultados estimados no programa, considerando o fluxo de calor longitudinal na parede a partir de uma seção da superfície de testes de espessura igual a $17 \mathrm{~mm}$, em cuja região central estariam fixados os termopares. Comparando estas figuras verifica-se também a redução, com a condutividade térmica do material da superfície, da relação entre o fluxo de calor longitudinal e o radial e, de forma análoga as Figs 5.3 e 5.4, verificam-se maiores efeitos de condução longitudinal com valores reduzidos de $R a$ e $p_{r}$.

Nas superfícies estudadas, o volume ocupado pelo material do qual são compostas é 10 vezes superior ao do cimento, para a superfície com 8 termopares e 21 vezes para a com 4 termopares, e a resistência térmica da superfície de testes pode ser determinada considerando as resistências individuais dos materiais em paralelo. Embora tais fatos façam com que o material de que é composta a superfície seja preponderante na perda de calor longitudinal, o cimento pode ter algum efeito, como se observa na Fig. 5.6, elaborada 
considerando duas configurações para a seção da superfície, ilustrada esquematicamente na Fig. 5.2. A primeira consiste na superfície constituída de cobre e cimento condutor e a outra constituída apenas por cobre. Nesta figura, verifica-se com o preenchimento dos canais da superfície de testes com cimento, ainda que em valores reduzidos, a diminuição da condução longitudinal.

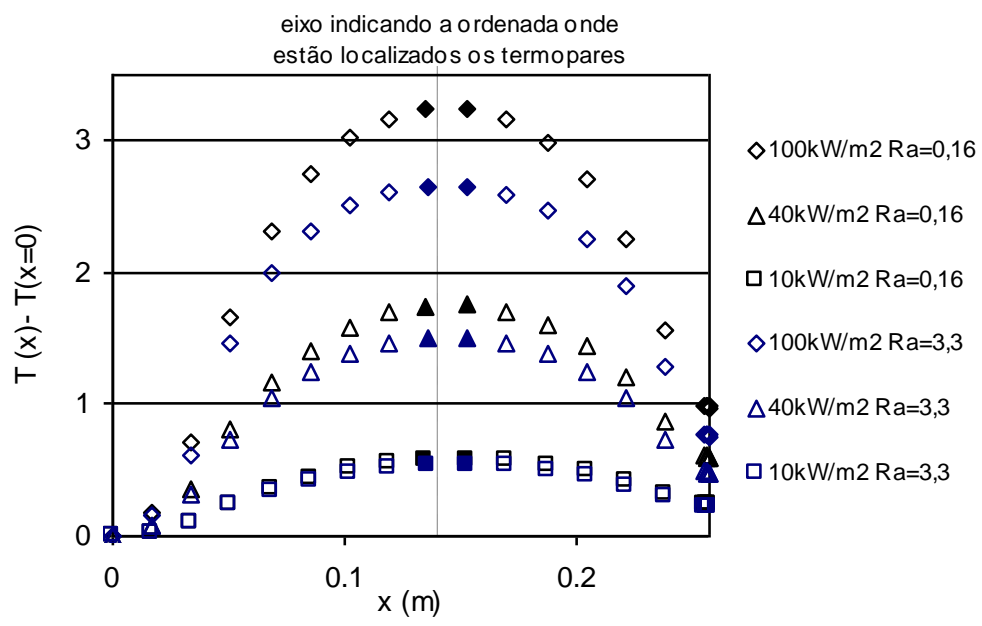

Figura 5.3 Perfil de temperaturas externo para a superfície de cobre, $\mathrm{R}-11, p_{r}=0,011$.

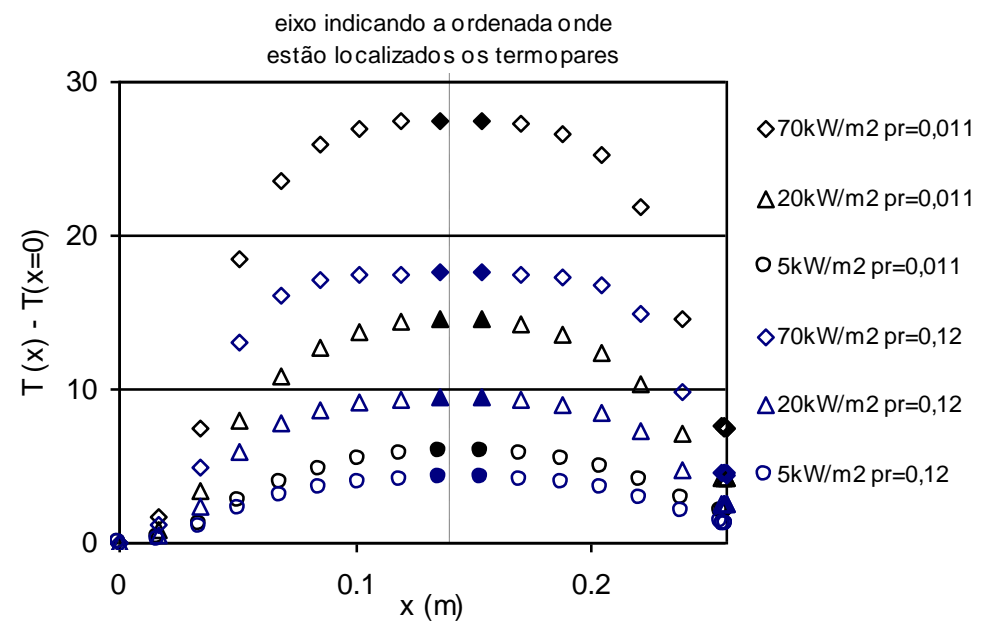

Figura 5.4 Perfil de temperaturas externo para a superfície de aço inoxidável, R-11, $R a=0,16 \mu \mathrm{m}$.

Com base nesta análise, podem ser extraídas as seguintes conclusões:

i. As perdas longitudinais para $\phi=1 \mathrm{~kW} / \mathrm{m}^{2}$, condição extrema em que as perdas são superiores, apresentaram-se inferiores a 8\%;

ii. Ao desprezar-se os efeitos de condução longitudinal, eleva-se o valor de $h$. Tal procedimento é compensado pela imprecisão no valor de $T_{p}$, que, conforme será 
discutido no próximo item, tem seu valor superestimado devido a efeitos de resistência de contato;

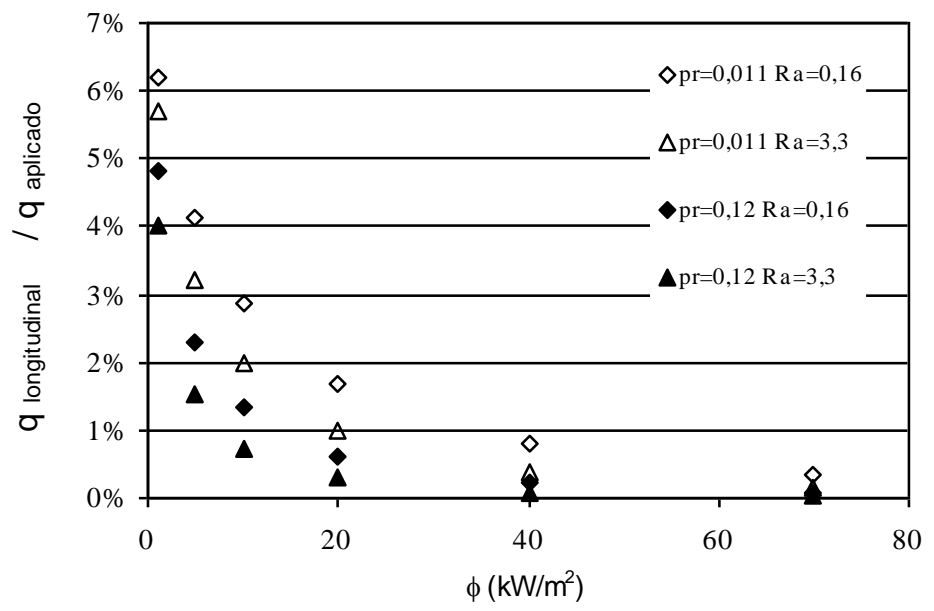

Figura 5.5 Relação entre o fluxo de calor longitudinal e o radial para a superfície de aço inoxidável, R-11.

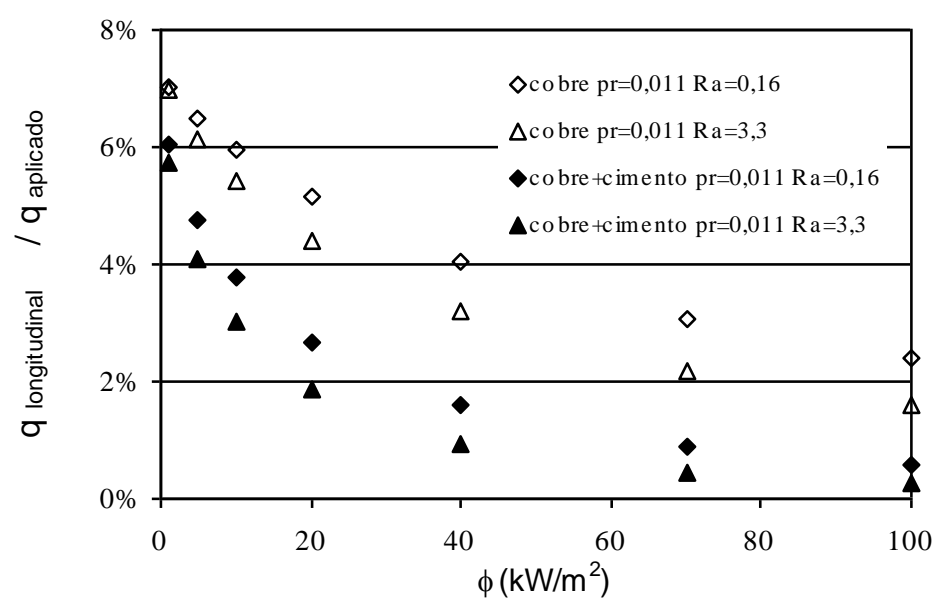

Figura 5.6 Relação entre o fluxo de calor longitudinal e o radial para a superfície de cobre R-11.

iii. Considerando os reduzidos valores verificados para o fluxo de calor longitudinal, não se justifica a utilização do programa desenvolvido para esta análise na correção do fluxo de calor radial. Isto introduziria novos erros, principalmente por tal programa basear-se em uma correlação da literatura, a qual já possui erros inerentes ao seu levantamento experimental.

Deste modo, admitiu-se os efeitos de condução longitudinal na região da superfície onde encontram-se fixados os termopares como sendo desprezíveis, e na determinação de $\phi$, referiu-se a potência aplicada à resistência elétrica à área externa da superfície aquecida, $\left(\pi \cdot D_{e x t} \cdot L_{R e s}\right)$, onde $L_{R e s}$ é o comprimento da resistência elétrica. 


\subsubsection{Procedimento Adotado na Determinação de $T_{p}$}

\subsubsection{Análise dos Efeitos de Resistência Térmica}

O procedimento utilizado na determinação da temperatura superficial em experimentos envolvendo a ebulição nucleada externamente a uma superfície cilíndrica é um dos fatores determinantes em seus resultados. Stephan e Abdelsalam (1980) e Kolev (1995) verificaram grandes discrepâncias e incoerências ao comparar resultados experimentais levantados por diferentes autores. No caso dos primeiros, tal conclusão foi baseada em um banco de dados envolvendo mais de 5000 resultados experimentais.

Nos estudos sobre a ebulição nucleada em superfícies cilíndricas, a fixação dos termopares geralmente ocorre no interior da parede, de forma a não afetar as características externas da superfície, que favoreceriam a nucleação. Desta forma, um dos fatores responsáveis pelos resultados experimentais díspares entre autores relaciona-se à fixação dos termopares e à resistência térmica entre o termopar e a superfície externa, resultante do procedimento adotado. Analogamente, segundo Morgan (1975), em levantamentos experimentais envolvendo o mecanismo da convecção natural externa a uma superfície cilíndrica, a diferença entre os dados de diferentes autores resulta de imprecisões semelhantes. No caso da ebulição nucleada, em estudos envolvendo fluxos de calor reduzidos, inferiores a $30 \mathrm{~kW} / \mathrm{m}^{2}$, a maioria deles, efeitos de resistência térmica são atenuados, ao contrário daqueles envolvendo valores elevados de $\phi$. Este comportamento ocorre devido a diferença entre a temperatura da superfície e a indicada pelo termopar, resultante de tais efeitos, ser incrementada $\operatorname{com} \phi$, conforme indica a lei de Fourier.

Embora seja possível eliminar a parcela do efeito da resistência térmica devido a parede do tubo através da equação Eq. (5.1), baseada na lei de Fourier, a imprecisão no posicionamento do termopar implica no desconhecimento da resistência entre o termopar e a superfície de transferência de calor. A Fig. 5.7 ilustra possíveis posicionamentos dos termopares nos canais, onde se verifica a imprecisão no posicionamento do termopar e constata-se que a temperatura indicada por ele envolve as temperaturas da região da superfície em contato com o termopar, do cimento condutor e até de uma possível região sem preenchimento, localizada no canal.

$$
T_{p}=T_{\text {termopar }}-\frac{\phi \cdot\left(D_{\text {ext }} / 2\right)}{k_{p}} \cdot \ln \left(\frac{D_{\text {ext }}}{D_{\text {termopar }}}\right)
$$




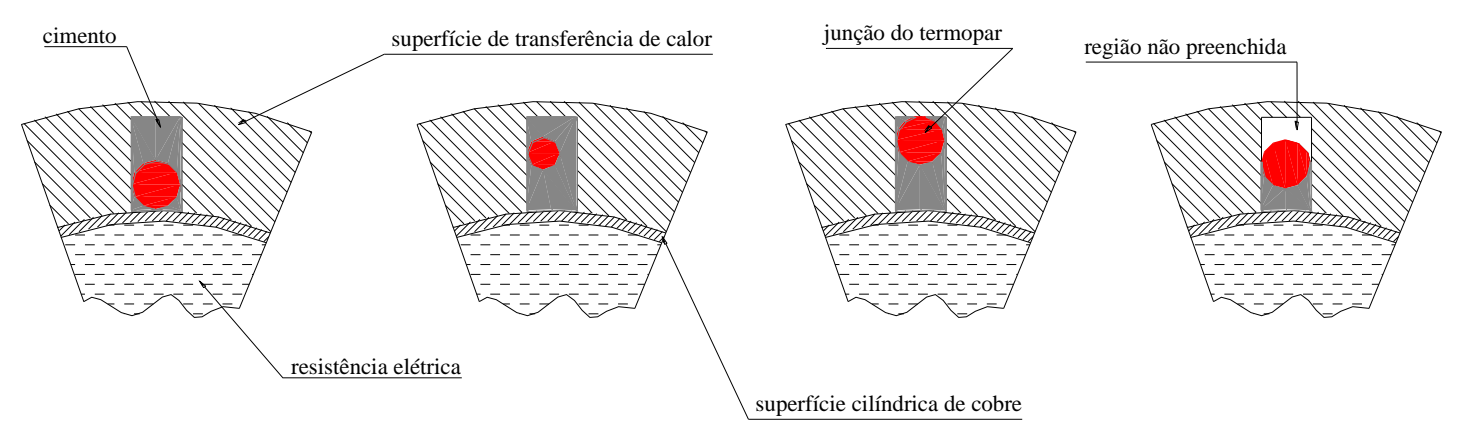

Figura 5.7 Ilustração esquemática das possíveis localizações da junta "quente" do termopar.

O contato físico entre a superfície de transferência de calor e o termopar foi verificado através da continuidade elétrica entre a superfície de transferência de calor e o termopar. Isto foi possível em virtude do cimento, embora condutor térmico, ser isolante elétrico. Assim, havendo contato entre o termopar e a superfície de testes, a resistência elétrica (entre o termopar e a superfície) deve apresentar valores reduzidos. Tal procedimento, embora não determine o valor da resistência de contato entre o termopar e a superfície de transferência de calor, garante o contato físico entre estes elementos, reduzindo, consequentemente, os efeitos da resistência térmica devido ao cimento condutor.

As Figs. 5.8a e 5.8b, baseadas nos resultados proporcionados pela simulação numérica, realizada para o corte radial da superfície ilustrado na Fig. 5.2, elucidam o efeito do cimento no perfil de temperaturas da parede da superfície de ensaio. Nelas constatam-se gradientes de temperaturas superiores no interior destes canais e em regiões da superfície próximas a eles. Seus valores são reduzidos com $\phi$ e com o incremento de $k_{p}$. Tais gradientes tendem a influenciar, segundo a localização do termopar no canal, o valor de $T_{p}$ ilustrado na Fig.5.2.

Embora alterações no coeficiente de transferência de calor externo não afetem os gradientes de temperaturas, é interessante ressaltar o elevado valor da temperatura superficial no caso destas figuras, elaboradas para a superfície de aço inoxidável. Isto é resultante do reduzido valor do coeficiente de transferência de calor externo, obtido através da correlação de VDI-Wärmeatlas (1994) que, conforme discutido anteriormente, foi incorporada ao programa de simulação. Tal valor é inferior ao encontrado no levantamento experimental realizado neste estudo, conforme pode ser verificado ao comparar as Figs 5.9a e 5.9b. 


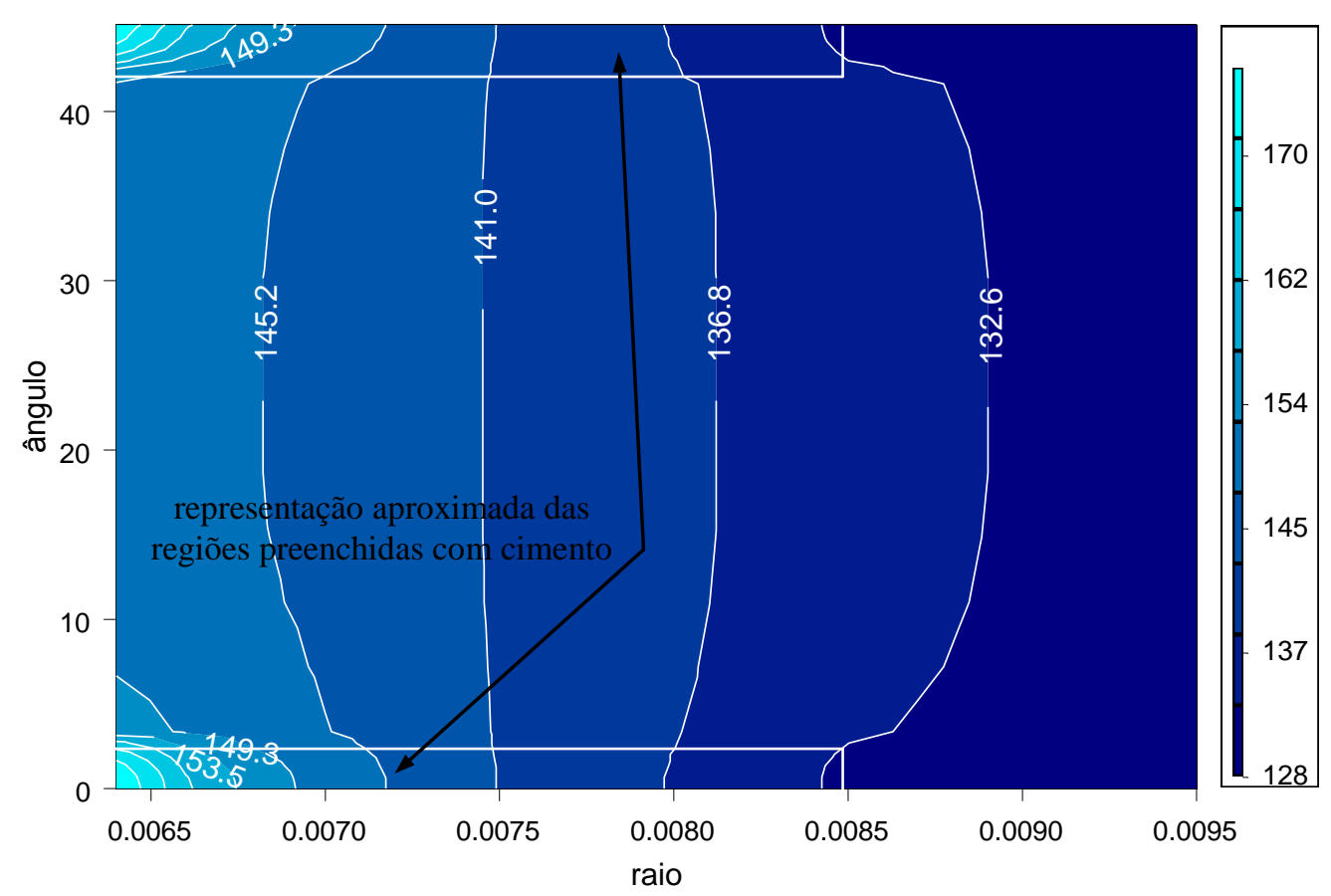

Figura 5.8a Simulação numérica dos perfis de temperaturas para o corte radial da superfície ilustrado na Fig.5.2.Superfície de aço inoxidável, $R a=0,16 \mu \mathrm{m}, \phi=70 \mathrm{~kW} / \mathrm{m}^{2}, \mathrm{R}-11$.

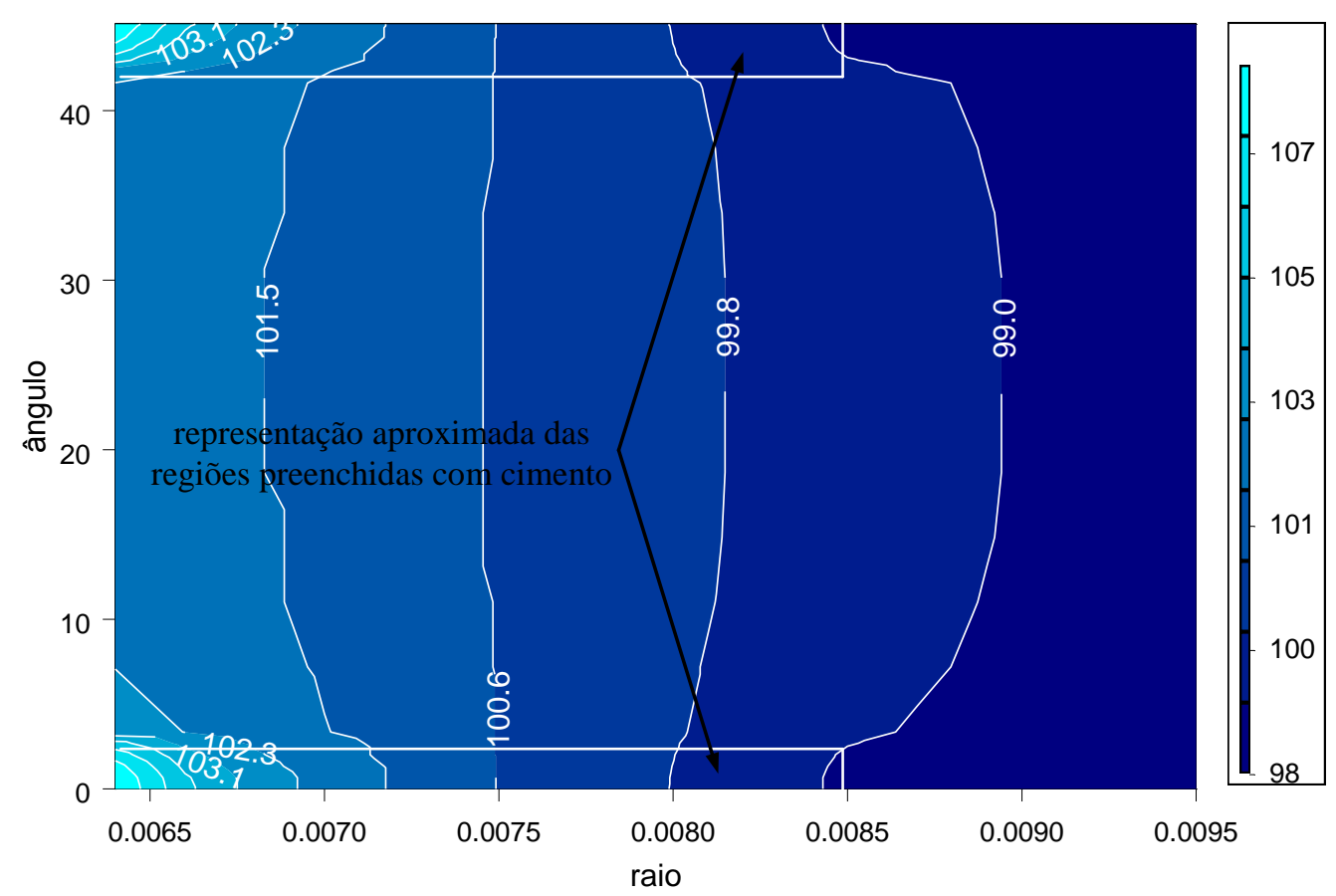

Figura 5.8b Simulação numérica dos perfis de temperaturas para o corte radial da superfície ilustrado na Fig.5.2. Superfície de aço inoxidável, $R a=0,16 \mu \mathrm{m}, \phi=20 \mathrm{~kW} / \mathrm{m}^{2}, \mathrm{R}-11$. 
As Figs 5.9a e 5.10a ilustram curvas de ebulição para os resultados obtidos através da simulação numérica. Na elaboração dessas figuras foram adotadas como temperaturas superficiais aquelas correspondentes à região localizada sobre um eixo de simetria que passa pelo centro do canal para diferentes posições radiais. Já as Figs. 5.9b e 5.10b, ilustram resultados experimentais determinados pelos diferentes termopares fixados na seção central do tubo nos canais distribuídos ao longo de sua circunferência. É interessante destacar que tais valores não foram corrigidos através da Eq. (5.1). Ao comparar-se os resultados experimentais, Figs. 5.9b e 5.10b, e os estimados, Figs. 5.9a e 5.10a, verificam-se comportamentos qualitativamente similares. Para os valores simulados numericamente, Figs. 5.9a e 5.10a, verifica-se, com o distanciamento radial a partir do centro da superfície, a aproximação entre as distintas curvas de ebulição. Tal comportamento, no caso das Figs. $5.9 \mathrm{~b}$ e $5.10 \mathrm{~b}$, indica uma localização dos termopares em uma região próxima à superfície externa do tubo, e consequentemente a redução de efeitos de resistência térmica do cimento e de contato.

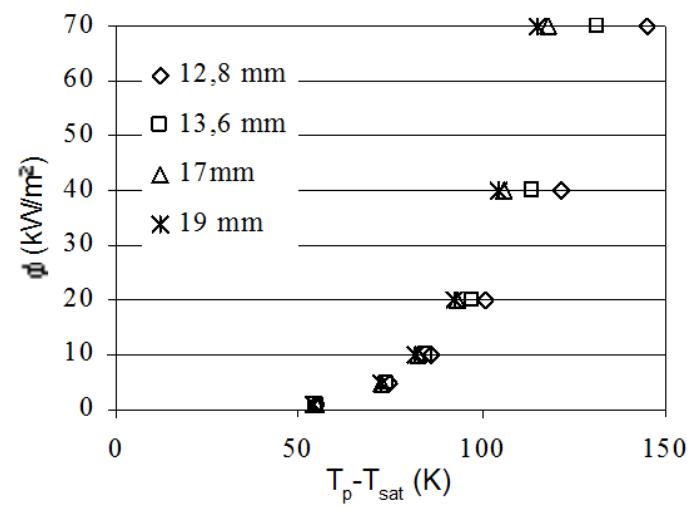

a) simulação numérica

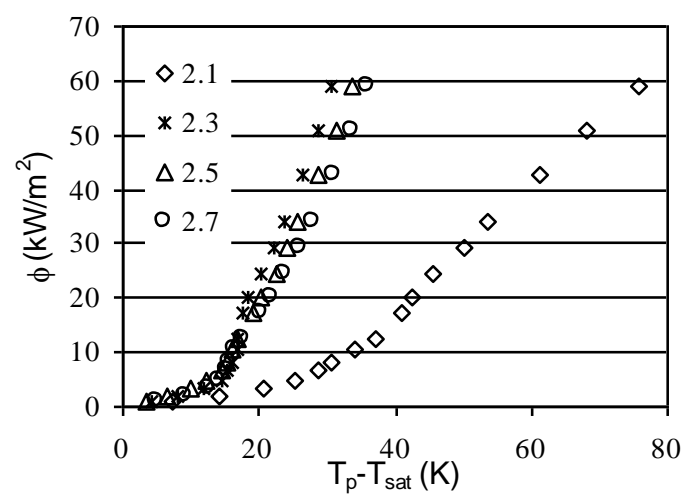

b) resultados experimentais*

Figura 5.9 Curvas de ebulição para o R-11, $p_{r}=0,011$, na superfície de aço inoxidável e $R a=0,16 \mu \mathrm{m}$, com diferentes posicionamentos para o termopar.

Deste modo, para a determinação de $T_{p}$, optou-se pelo termopar que indicasse a menor temperatura superficial. Este valor, admitindo o termopar em contato com a região do canal mais próxima a superfície externa, foi corrigido através da Eq. (5.1), eliminando o erro sistemático devido a resistência térmica do material da superfície de testes. A verificação na Fig. 5.10b de curvas de ebulição próximas, para diferente superfícies de ensaio mas com características semelhantes, submetidas a uma mesma condição experimental, corrobora para a adoção de tal procedimento.

*A designação dos símbolos por 2.1, 2.3, 2.5 e 2.7 na Fig. 5.9b, representam as junções dos termopares distribuídos ao longo da circunferência da superfície de testes conforme a Fig. 4.4. 


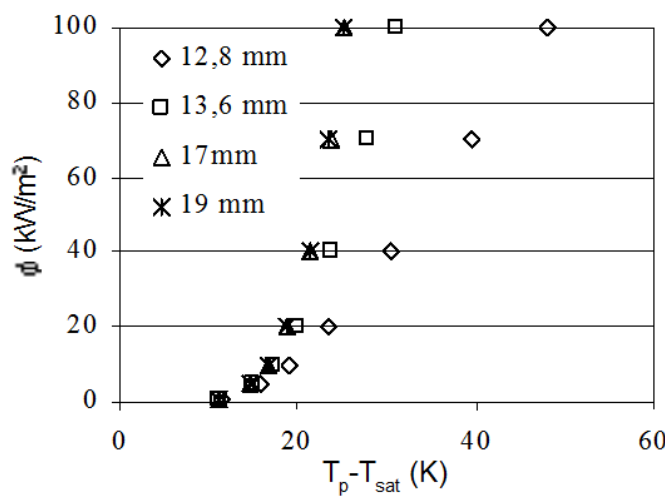

a) simulação numérica

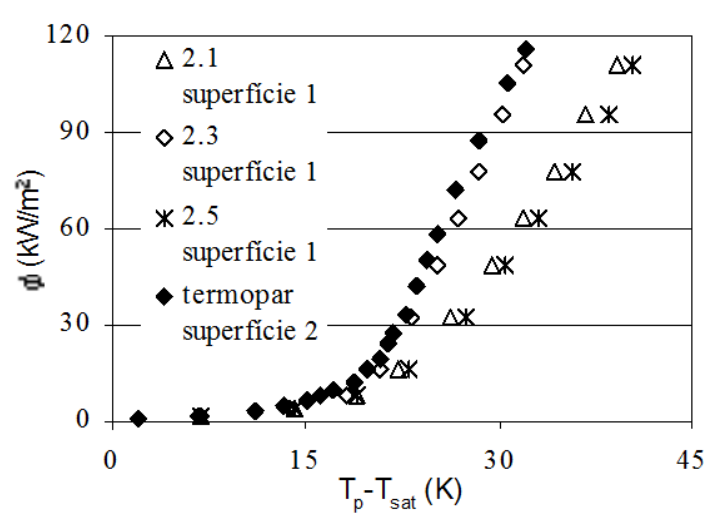

b) resultados experimentais*

Figura 5.10 Curvas de ebulição para o R-11, $p_{r}=0,011$, na superfície de cobre e $R a=0,17 \mu \mathrm{m}$, com diferentes posicionamentos para o termopar.

Não se verifica na Tabela 5.2 um procedimento similar ao adotado no presente estudo. Nestes trabalhos os efeitos de resistência térmica devido a fixação dos termopares, com exceção de Chang e You (1997c), não são abordados, e, geralmente, $T_{p}$ é dado pela média aritmética das temperaturas indicadas pelos termopares localizados na superfície de testes. Finalmente, reconhece-se que o procedimento adotado admite um valor para $T_{p}$ superior ao real, subestimando o valor de $h$ e, desta forma, incorrendo na não determinação de um erro sistemático resultante da resistência térmica entre o termopar e a superfície de ensaio. Apesar disto, ao considerar a impossibilidade da determinação deste erro, busca-se minimizá-lo, preocupação não levada a cabo na maioria dos trabalhos encontrados na literatura.

\subsubsection{Análise de Variações de $T_{p}$ ao Longo da Circunferência da Superfície de Testes}

Numa seção, a ocorrência de diferenças no mecanismo de transferência de calor ao longo da circunferência da superfície pode fazer com que a temperatura indicada pelo termopar dependa do seu posicionamento. Isto ocorreria independentemente de efeitos de resistência térmica resultantes da fixação, significando que um termopar, inicialmente, localizado na face superior, com a superfície sendo girada, indicaria, para a mesma condição experimental, diferentes temperaturas quando localizado na face lateral e inferior. Tal

\footnotetext{
*A designação dos símbolos por 2.1, 2.3 e 2.5 na Fig. 5.10b, representam as junções dos termopares distribuídos ao longo da circunferência da superfície de testes conforme a Fig. 4.4. As descrições das superfícies 1 e 2 desta figura encontram-se detalhadas na Tabela 4.1. A curva referente a superfície 2 na Fig. 5.10b consiste nas temperaturas fornecidas pelo termopar da seção central que indicou independente da condição os menores valores de $T_{p}$, quando comparado aos demais da mesma seção.
} 
comportamento faz com que a localização do termopar utilizado na determinação de $T_{p}$ influa no valor médio de $h$. Desta forma, este item trata de uma análise da distribuição de temperaturas ao longo da circunferência da superfície, com o objetivo de investigar, uma posição para o termopar utilizado na determinação de $T_{p}$, fixada através da rotação da superfície, tal que estes efeitos sejam minimizados.

\subsection{Procedimentos Adotados e Resultados Verificados na Literatura}

A Tabela 5.2 apresenta os resultados para a variação da temperatura ao longo do perímetro da superfície de transferência de calor e os procedimentos utilizados para contornar tais efeitos na determinação do $h$ médio de acordo com diferentes autores. Exceto Webb e Pais (1992), com a superfície GEWA-SE, maiores coeficientes de transferência de calor foram verificados nas regiões inferiores da superfície, diminuindo no sentido ascendentemente. Nesta tabela, verifica-se que $T_{p}$, de uma maneira geral, é determinado como a média aritmética das temperaturas medidas na superfície. Kang (2000), embora tenha verificado uma variação da temperatura ao longo da superfície similar à dos demais autores, adotou $T_{p}$ como a temperatura indicada pelo termopar localizado lateralmente, procedimento justificado por este ser um valor médio entre as temperaturas indicadas pelos termopares nas faces superior e inferior. Nestes trabalhos, efeitos de resistência térmica resultantes da parede da superfície foram corrigidos para levar em consideração o efeito de resistência térmica da parede. É interessante ressaltar que a repetição dos resultados, para a mesma condição experimental e diferentes termopares localizados numa mesma posição circunferêncial pela rotação do tubo foi citada apenas por Webb e Pais (1992).

A Tabela 5.3 foi elaborada com o objetivo de analisar a variação de $T_{p}$ ao longo do perímetro de uma superfície cilíndrica, admitindo similares os mecanismos de transferência de calor em ebulição nucleada para áreas discretas ao longo da circunferência de uma superfície cilíndrica e uma superfície plana de dimensões reduzidas posicionada em diferentes inclinações. Reconhece-se que tal consideração não seria válida para uma superfície com a face voltada para baixo. Através desta tabela, conclui-se que o efeito do ângulo de inclinação, segundo estes autores, é dependente tanto do valor absoluto de $\phi$ como do procedimento de obtenção da curva de ebulição, isto é, se obtida com a elevação do fluxo específico de calor ou com sua redução, a partir de um valor máximo. 
Tabela 5.3 Literatura envolvendo a análise da variação de $T_{p}$ com o ângulo de inclinação de uma superfície plana.

\begin{tabular}{|c|c|}
\hline$A$ & ltados \\
\hline & $\begin{array}{l}\text { - superfície plana, } \mathrm{H}_{2} \mathrm{O} \text { a } 1 \mathrm{~atm} \\
\text { - para valores reduzidos de } \phi \text {, o incremento do ângulo de inclinação intensificou a } \\
\text { transferência de calor. Já, com a elevação do fluxo de calor, coeficientes de transferência de } \\
\text { calor superiores foram obtidos com a redução do ângulo de inclinação. } \\
\text { - a intensificação verificada em fluxos de calor reduzidos e ângulos de inclinação elevados foi } \\
\text { justificada pela formação de bolhas grandes, que apesar de inibirem cavidades ativas isoladas, } \\
\text { ao serem arrastadas junto a superfície, intensificariam a transferência de calor através de dois } \\
\text { mecanismos: um de evaporação de um filme de líquido superaquecido existente na base da } \\
\text { bolha e outro devido a intensificação de efeitos convectivos junto a superfície. Para confirmar } \\
\text { tais efeitos, o autor comparou duas superfícies de diferentes rugosidades, verificando que para } \\
\text { tais condiçães elas apresentaram desempenhos semelhantes }\end{array}$ \\
\hline & $\begin{array}{l}\text { - superfícies planas micro-porosa e lisa e, FC-72, 1atm } \\
\text { - para a superfície microporosa, o efeito do ângulo de inclinação foi considerado desprezível, } \\
\text { como resultado do elevado número de cavidades ativas } \\
\text { - para a superfície lisa foram verificados os seguintes comportamentos: } \\
\text { - curva obtida com o incremento de } \phi \text {, o superaquecimento da superfície foi levemente } \\
\text { reduzido entre } 0^{\circ} \text { e } 45^{\circ} \text {, elevando-se drasticamente com o incremento da inclinação, para } \\
\text { ângulos entre } 90^{\circ} \text { e } 180^{\circ} \\
\text { - curva levantada para a redução de } \phi \text { a partir de um valor máximo; para fluxos de calor } \\
\text { reduzidos e intermediários, com o incremento da inclinação, ocorreu a elevação do } \\
\text { coeficiente de transferência de calor com exceção de } 180^{\circ} \text {. Já para fluxo de calor elevados o } \\
\text { efeito da inclinação tornou-se desprezível }\end{array}$ \\
\hline
\end{tabular}

5.4.2.2.2

Procedimento Adotado na Determinação da Variação de $T_{p}$ ao Longo do Perímetro da Superfície

Inicialmente é possível imaginar que, a variação de $T_{p}$ ao longo da circunferência da superfície de testes poderia ser avaliada através de uma comparação das temperaturas indicadas pelos termopares distribuídos ao longo da circunferência da superfície de ensaio. Este procedimento, somente, seria válido caso não existissem diferenças nas resistências térmicas entre a superfície e cada termopar, inerentes ao procedimento adotado na fixação dos termopares, como observado anteriormente. Outro procedimento a ser adotado seria girar a superfície e verificar para uma mesma condição experimental a diferença entre as temperaturas indicadas por um mesmo termopar localizado em duas posições diferentes, 
caracterizadas pelo ângulo $\theta^{*}$. A adoção deste procedimento seria afetada pela impossibilidade de se fixar um mesmo valor de $\phi$. Isto resulta das características do equipamento de alimentação da resistência elétrica e de variações na própria rede fornecedora de energia elétrica. No entanto caso estas diferenças apresentem valores elevados, tal análise poderia ser baseada em curvas de ebulição para um mesmo termopar localizado, com a rotação da superfície, em diferentes $\theta$. Tais curvas** encontram-se ilustradas na Fig. 5.11. Através dela é possível constatar que, para fluxos de calor elevados, temperaturas superiores ocorrem na região inferior da superfície, resultando, consequentemente, valores locais de $h$ inferiores nesta região. No caso de valores de $\phi$ inferiores, variações da temperatura superficial ao longo da circunferência não foram constatadas. Desta forma, para analisar tal condição, optou-se por referir a temperatura indicada por um determinado termopar a outro na mesma superfície. Assim elimina-se da comparação variações no $h$ médio, e são ilustrados efeitos da diferenças do mecanismo de ebulição ao longo do perímetro da superfície de transferência de calor e da resistência térmica entre a região externa da superfície e cada termopar.

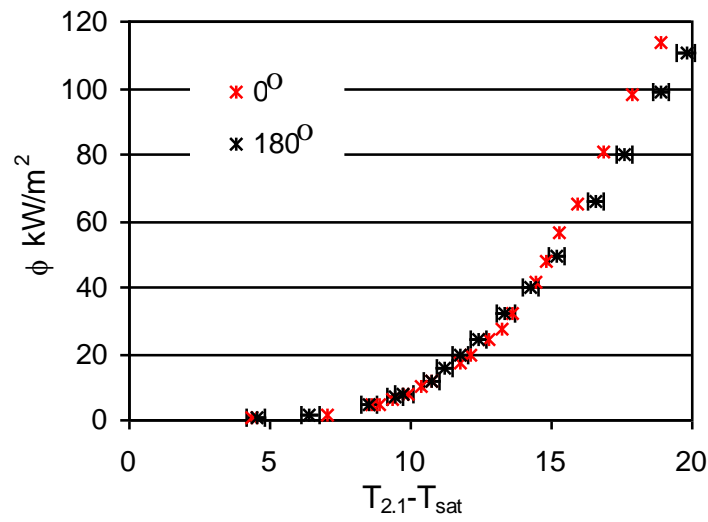

a)

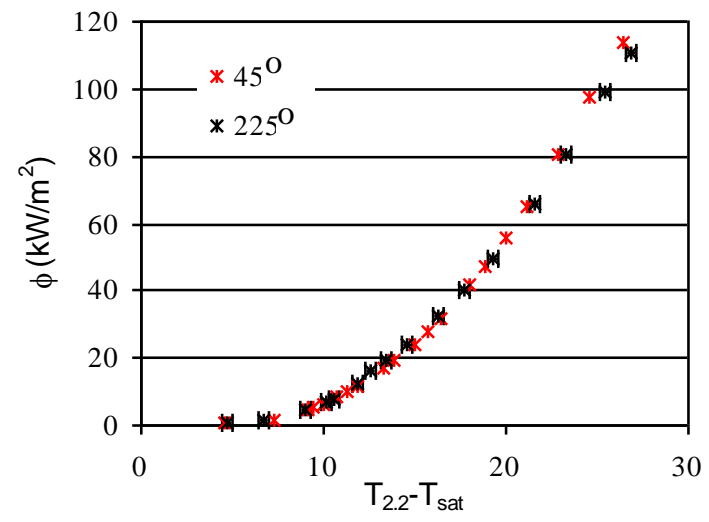

b)

Figura 5.11 Curvas de ebulição ilustrando a variação de $T_{p}$ ao longo da circunferência da superfície de cobre, para o R-11, $R a=0,17 \mu \mathrm{m}$ e $p_{r}=0,011$.

A diferença entre as temperaturas indicadas por dois termopares, designados por A e B, localizados em distintas posições ao longo da circunferência da superfície de ensaio, com base na Lei de Fourier, pode ser escrita como:

* O ângulo a partir do qual é determinada a posição circunferêncial do termopar, bem como suas posições iniciais, encontram-se ilustrados na figura ao lado.

** Embora tenham sido verificados comportamentos similares entre curvas de ebulição levantadas a partir de resultados obtidos para valores ascendentes de $\phi$, as curvas apresentadas neste item envolvem apenas resultados experimentais levantados com a redução de $\phi$ a partir de um valor máximo, com exceção, apenas, dos resultados envolvendo conveccão natural.

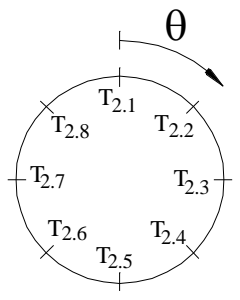




$$
\left(T_{A}-T_{B}\right)_{\text {indicados }}=\left(T_{A}-T_{B}\right)_{\text {externo }}+\phi \cdot\left(\frac{U_{B}-U_{A}}{U_{B} \cdot U_{A}}\right)
$$

onde $U$ é o coeficiente global de transferência de calor envolvendo a resistência térmica entre o termopar e a região externa da superfície em contato com o fluido. Segundo a Eq. (5.2), a diferença entre a temperatura indicada pelos termopares para uma mesma condição experimental pode ser separada em duas parcelas: a primeira, resultante de efeitos inerentes ao mecanismo de ebulição; e outra, resultante de efeitos de resistência térmica, os quais, considerando os valores de $U$ constantes, seriam apenas funções de $\phi$. Desta forma, para um mesmo fluxo específico de calor pode-se escrever a seguinte relação:

$$
\left(T_{A}-T_{B}\right)_{\text {indicados }}=\left(T_{A}-T_{B}\right)_{\text {externo }}+\text { cons tante }
$$

A partir desta equação, admitindo inicialmente os termopares A e B localizados, respectivamente, em $\theta$ igual a $0^{\circ}$ e $180^{\circ}$, podem ser verificados com a rotação da superfície de $180^{\circ}$ os cenários descritos a seguir, com base nos quais a análise dos resultados no próximo item é realizada.

i. Cenário 1-Temperatura superficial constante ao longo do perímetro da superfície

$$
\left[\left(T_{A}-T_{B}\right)_{\text {externo }}\right]_{0^{\circ}}=\left[\left(T_{A}-T_{B}\right)_{\text {externo }}\right]_{180^{\circ}}=0
$$

significando segundo a Eq. (5.2)

$$
\left[\left(T_{A}-T_{B}\right)_{\text {indicados }}\right]_{0^{\circ}}=\left[\left(T_{A}-T_{B}\right)_{\text {indicados }}\right]_{180^{\circ}}
$$

Esta igualdade ocorreria somente caso efeitos de variações de $T_{p}$ ao longo do perímetro da superfície fossem nulos, resultando desta forma em, $\left(T_{A}\right)_{\text {externo }}=\left(T_{B}\right)_{\text {externo }}$ independentemente de suas posições angulares. Tal comportamento resultaria em curvas $\left(T_{A}-T_{B}\right)_{\text {indicados }}$ vs $\phi$ para $\theta$ igual a $0^{\circ}$ e $180^{\circ}$ coincidentes.

ii. Cenário 2- Elevação de $T_{p}$ ao longo do perímetro da superfície no sentido ascendente

$$
\left[\left(T_{A}-T_{B}\right)_{\text {externo }}\right]_{0^{\circ}}>\left[\left(T_{A}-T_{B}\right)_{\text {externo }}\right]_{180^{\circ}}
$$

resultando segundo a Eq.(5.2) na seguinte relação:

$$
\left[\left(T_{A}-T_{B}\right)_{\text {indicados } J_{0}}>\left[\left(T_{A}-T_{B}\right)_{\text {indicados }}\right]_{180^{\circ}}\right.
$$

Esta desigualdade ocorreria caso fossem verificados, com a rotação da superfície, o incremento de $\left(T_{B}\right)_{\text {externo }}$ e a redução de $\left(T_{A}\right)_{\text {externo, }}$, permitindo concluir maiores temperaturas na região superior da superfície. Este comportamento resultaria 
numa curva $\left(T_{A}-T_{B}\right)_{\text {indicados }}$ vs $\phi$ para $\theta$ igual a $0^{\circ}$ posicionada acima da curva para $180^{\circ}$.

iii. Cenário 3 - Decréscimo de $T_{p}$ ao longo do perímetro da superfície no sentido ascendente.

$$
\left[\left(T_{A}-T_{B}\right)_{\text {externo }}\right]_{O^{\circ}}<\left[\left(T_{A}-T_{B}\right)_{\text {externo }}\right]_{180^{\circ}}
$$

substituindo a Eq.(5.2) na relação acima resulta:

$$
\left[\left(T_{A}-T_{B}\right)_{\text {indicados }}\right]_{0^{\circ}}<\left[\left(T_{A}-T_{B}\right)_{\text {indicados }}\right]_{180^{\circ}}
$$

Tal desigualdade seria verificada, caso com a rotação da superfície, ocorresse o incremento de $\left(T_{A}\right)_{\text {externo }}$ e a redução de $\left(T_{B}\right)_{\text {externo, }}$, permitindo concluir temperaturas superiores na região inferior da superfície. Este comportamento resultaria numa curva $\left(T_{A}-T_{B}\right)_{\text {indicados }}$ vs $\phi$ para $\theta$ igual a $0^{\circ}$ posicionada abaixo da curva para $180^{\circ}$.

\subsection{Resultados Verificados}

Inicialmente, para verificação do procedimento adotado foi analisado o comportamento da curva $\left(T_{2.1}-T_{2.4}\right)$ vs $\phi$, primeiro, para o termopar $T_{2.1}$ localizado na face superior e depois com a superfície girada em $180^{\circ}$ no sentido horário para as seguintes situações: transferência de calor através do mecanismo de convecção natural, Fig. 5.12a, cujo perfil de temperaturas é amplamente conhecido e consiste em uma temperatura máxima para $\theta=0$, decaindo com $\theta$; e segundo, para a ebulição nucleada, Figs. $5.12 \mathrm{~b}$ e $5.12 \mathrm{c}$, em que diferenças entre as temperaturas indicadas por um mesmo par de termopares localizados em posições simétricas em relação a um eixo perpendicular que passa pelo centro da superfície de ensaio deveriam apresentar curvas coincidentes.

Ao contrário de Gorenflo et al (2000), que no caso da convecção natural não verificou para um mesmo $\phi$ alterações na temperatura superficial ao longo da circunferência da superfície, através do procedimento utilizado verifica-se na Fig. 5.12a um resultado similar ao da literatura, em que ocorrem temperaturas maiores na região superior da superfície. Tal conclusão apoia-se no fato do comportamento verificado ser similar ao do Cenário 2, ilustrado no item anterior. No caso das Figs. 5.12b e 5.12c, constata-se que, independentemente da rotação, as tendências das curvas foram similares antes e após a rotação. Tal comportamento, já esperado, é similar ao do Cenário 1 e indica que a diferença entre as temperaturas indicadas pelos termopares é resultante, predominantemente, de efeitos de resistência térmica. 


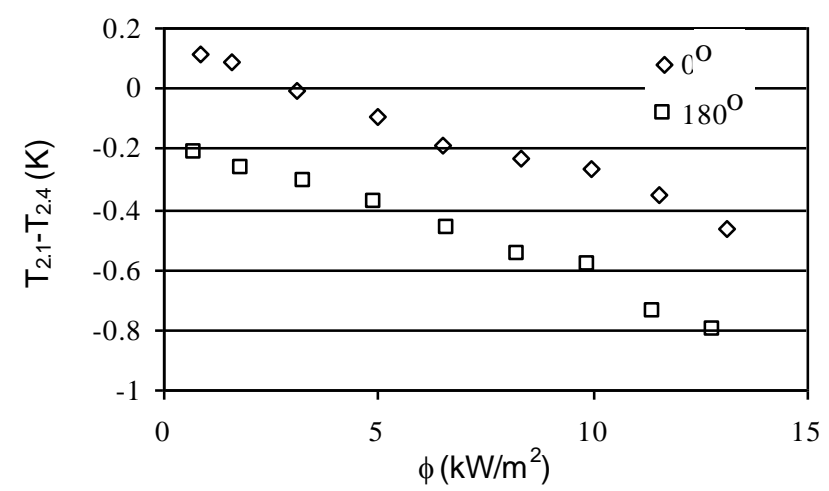

a) convecção natural

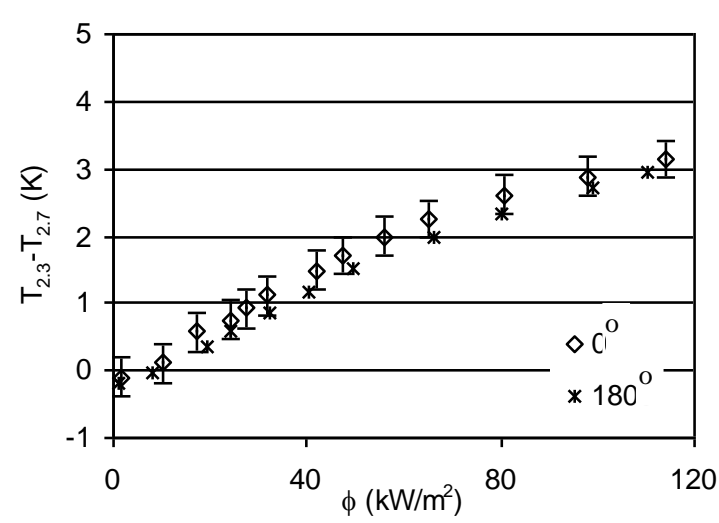

b) ebulição nucleada

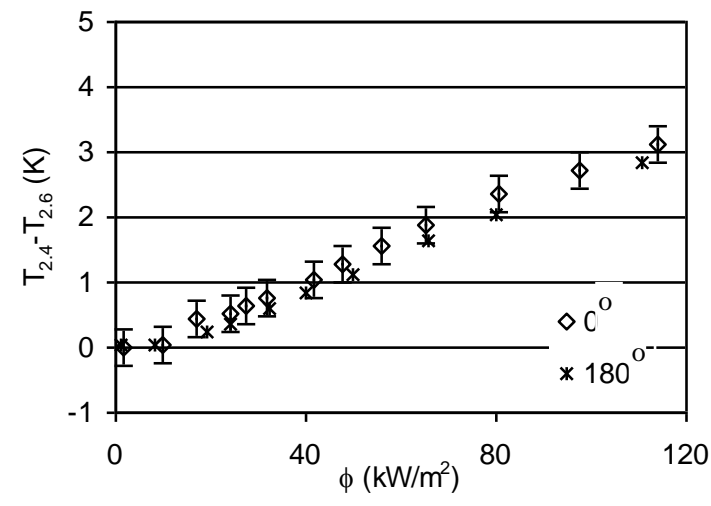

c) ebulição nucleada

Figura 5.12 Comparação ilustrativa da variação de $T_{p}$ ao longo do perímetro da superfície aquecida, R-11, cobre, $R a=0,17 \mu \mathrm{m}, p_{r}=0,011$.

As Figs. 5.13a, 5.13b e 5.13c, comparam, para a transferência de calor em ebulição nucleada, resultados de termopares localizados em hemisférios distintos da superfície. Elas ilustram que, inicialmente, na região em que efeitos de convecção natural são responsáveis por uma considerável parcela do calor total transferido para o fluido (valores reduzidos de $\phi$ ), temperaturas mais elevadas são verificadas na face superior. Tal comportamento é similar ao verificado para a convecção natural na Fig. 5.12a. Já, com fluxos de calor superiores o comportamento inverte-se e temperaturas mais elevadas passam a ser verificadas na face inferior da superfície. A conclusão, para valores reduzidos de $\phi$, de maiores temperaturas na face superior e, com sua elevação, da inversão deste comportamento, isto é, temperaturas superiores na face inferior, apoia-se na verificação de comportamentos, respectivamente, semelhantes aos dos Cenários 2 e 3.

A Fig.5.13d ilustra a variação com $\phi$ da diferença entre as temperaturas indicadas pelos termopares $T_{2.1}$ e $T_{2.8}$, localizados em um mesmo hemisfério, antes e depois da 
superfície ter sido girada de $180^{\circ}$. Inicialmente, na região da curva de ebulição em que o mecanismo de convecção natural é responsável por parcela significativa da transferência de calor total, ocorrem comportamentos similares para as curvas $\left(T_{2 . I}-T_{2.8}\right)$ vs $\phi$. Já, para valores superiores de $\phi$, verifica-se um comportamento similar ao do Cenário 3. Conclui-se assim que, embora em fluxos de calor reduzidos os termopares $T_{2.8}$ e $T_{2.1}$ indiquem temperaturas próximas, independentemente do hemisfério em que se localizam, para valores elevados de $\phi$ verifica-se, com a rotação da superfície, uma elevação em $T_{2.1}$ superior à $T_{2.8}$. Esta última conclusão se baseia não apenas na verificação de um comportamento similar ao do Cenário 3 , mas também no fato, anteriormente apontado, de, com valores elevados de $\phi$, tanto $T_{2.8}$ e $T_{2.1}$ apresentarem temperaturas superiores quando localizados na face inferior.



a)

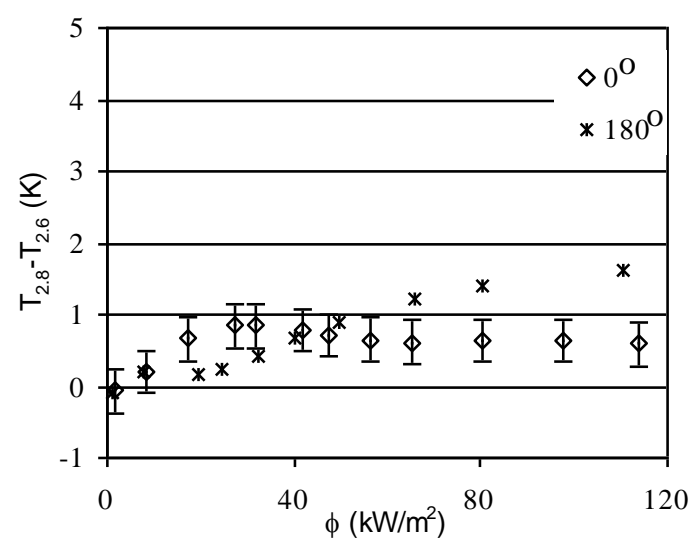

c)

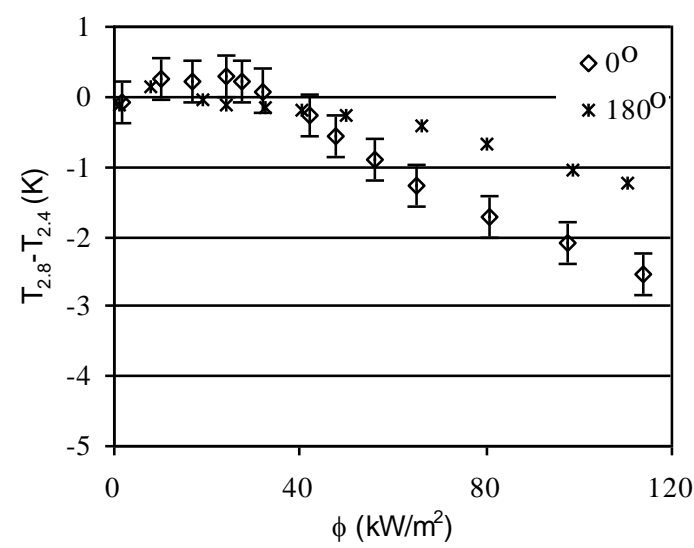

b)

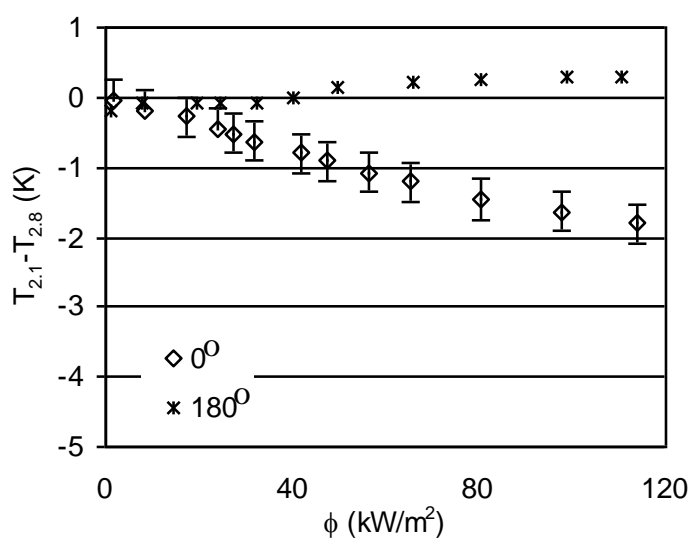

d)

Figura 5.13 Comparação ilustrativa da variação de $T_{p}$ ao longo do perímetro da superfície aquecida. R-11, cobre, $R a=0,17 \mu \mathrm{m}$ e $p_{r}=0,011$. 


\subsection{Conclusões}

Ao contrário do sugerido pela maioria dos trabalhos apresentados na Tabela 5.2, a variação do coeficiente de transferência de calor ao longo do perímetro da superfície depende do fluxo específico de calor. Verificou-se que, para valores de $\phi$, neste caso inferiores a $40 \mathrm{~kW} / \mathrm{m}^{2}$, o perfil de temperaturas da parede caracteriza-se por uma máximo em $\theta=0^{\circ}$ e por um decaimento até $\theta=180^{\circ}$. Este comportamento, similar ao observado na convecção natural, verificado pela maioria dos autores da literatura na ebulição nucleada, inverte-se para fluxos específicos de calor superiores a $40 \mathrm{~kW} / \mathrm{m}^{2}$. Esta inversão de comportamento de $T_{p}$ ao longo do perímetro da superfície de ensaio com $\phi$ é similar à verificada por Nishikawa et al (1984), Tabela 5.3, para uma superfície plana de dimensões reduzidas posicionada em diferentes inclinações.

Para valores de $\phi$ elevados, o resultado verificado se justifica, ainda que não necessariamente, através de visualizações, nas quais constata-se que, embora existam cavidades ativas em grande número na face inferior o destacamento de bolhas ocorre com maior intensidade na face superior da superfície. Desta forma, pode-se levantar a hipótese que, para fluxos de calor elevados, a forte agitação decorrente do desprendimento e colapso de bolhas na região superior tenda a intensificar a transferência de calor. Corrobora este cenário a migração, seguida do desprendimento, de bolhas formadas nas faces inferior e lateral para a região superior. Tal comportamento resultaria em temperaturas mais elevadas nas faces inferiores e laterais quando comparadas às da face superior.

No caso de valores de $\phi$ inferiores, ocorre o decréscimo no número de cavidades ativas e, consequentemente, a redução dos efeitos convectivos resultantes do desprendimento e colapso de bolhas. Tal comportamento é acompanhado pelo incremento da importância relativa de efeitos de convecção natural, responsáveis por parcela significativa do calor transferido da superfície em ebulição nucleada. Soma-se a isto o fato de, ao se reduzir $n / A$, o escorregamento de bolhas se dá de maneira mais esparsa, proporcionando, segundo um mecanismo proposto por Gorenflo et al (2000), a intensificação da transferência de calor. Este mecanismo consiste em que a bolha ao escorregar aprisiona, junto a sua base, uma fina camada de líquido superaquecido, que ao evaporar resfria a superfície. Tais mecanismos agindo concomitantemente justificariam o comportamento verificado para valores de $\phi$ inferiores.

\footnotetext{
*Este valor que pode ser considerado como de "transição" entre regimes de ebulição, é dependente das condições experimentais. Seu valor é reduzido em curvas de ebulição caracterizadas por coeficientes de transferência de calor superiores para um mesmo superaquecimento. Isto significa na elevação de $p_{r}, R a, k_{p}$ ou a utilização de refrigerantes mais voláteis.
} 
É interessante ressaltar que as explicações apresentadas para os comportamentos verificados para a variação da $T_{p}$ ao longo da circunferência da superfície são, apenas, hipóteses, carecendo de um estudo mais aprofundado, que foge ao escopo do presente trabalho.

Finalmente, com base na conclusão de que o coeficiente de transferência de calor varia ao longo da circunferência da superfície e na discordância entre os autores, incluindo o presente estudo, optou-se por procedimento análogo ao de Kang (2000), segundo o qual, adota-se $T_{p}$ como sendo a temperatura fornecida por um termopar posicionado lateralmente. Assim, opta-se por um valor médio, considerando que, de maneira geral, valores máximos e mínimos de $T_{p}$ ao longo da circunferência da superfície de transferência de calor, quando observados, ocorrem nas faces superior e inferior.

É interessante ressaltar a análise realizada no item 5.4.1, relativa a minimização de efeitos de resistência térmica, que combinada a presente análise proporciona a opção por posicionar lateralmente, através da rotação da superfície de testes, o termopar que forneceu a menor temperatura, independentemente de sua posição inicial.

\subsubsection{Procedimento de Determinação de $T_{\text {sat }}$}

A temperatura de saturação, embora não envolva uma análise complexa como $T_{p}$, não foi diretamente determinada e o procedimento utilizado dependeu do mecanismo de transferência de calor. Para a ebulição nucleada, foi avaliada como sendo a média aritmética das temperaturas fornecidas pelos termopares blindados. Já, na transferência de calor através do mecanismo de convecção natural, adotou-se a temperatura fornecida pelo termopar imerso no banho.

\subsubsection{Incertezas}

Uma análise de incertezas dos resultados experimentais e de sua propagação foi realizada e encontra-se detalhada no Apêndice II. As incertezas nos valores de $h$, para cada condição experimental, encontram-se no Apêndice III, que lista os resultados experimentais levantados.

$\mathrm{Na}$ estimativa das incertezas dos parâmetros envolvendo a temperatura superficial foram desprezados erros sistemáticos devido a resistência térmica inerente ao processo de fixação dos termopares. A Tabela 5.4 apresenta os valores das incertezas das variáveis 
medidas e as incertezas propagadas das variáveis calculadas. Ressalta-se o reduzido valor da incerteza de $\phi$ verificada para baixos fluxos de calor. Tal resultado provém de seu cálculo não envolver efeitos de condução longitudinal, procedimento adotado com base no fato da impossibilidade de determinação quantitativa destes efeitos.

Tabela 5.4 Incerteza dos parâmetros medidos e calculados.

\begin{tabular}{lc}
\hline \hline Parâmetros & Incerteza \\
\hline \hline Fluxo de calor $\phi=0,6 \mathrm{~kW} / \mathrm{m}^{2}$ & $1,78 \%$ \\
\hline Fluxo de calor $\phi=120 \mathrm{~kW} / \mathrm{m}^{2}$ & $0,30 \%$ \\
\hline Superaquecimento da parede, $\left(T_{p}-T_{\text {sat }}\right)$, para o fluxo mínimo de calor & $0,3 \mathrm{~K}$ \\
\hline Superaquecimento da parede, $\left(T_{p}-T_{\text {sat }}\right)$, para o fluxo máximo de calor & $0,3 \mathrm{~K}$ \\
\hline$R a$ ( valor mínimo) & $0,01 \mu \mathrm{m}$ \\
\hline$R a($ valor máximo) & $0,4 \mu \mathrm{m}$ \\
\hline Temperatura refrigerante líquido ( convecção natural) & $0,2 \mathrm{~K}$ \\
\hline Temperatura de saturação para ebulição nucleada & $0,2 \mathrm{~K}$ \\
\hline Temperatura superficial & $0,2 \mathrm{~K}$ \\
\hline Área de transferência de calor & $0,26 \%$ \\
\hline \hline
\end{tabular}

$\mathrm{Na}$ determinação das incertezas das variáveis medidas, considerou-se uma distribuição normal e foi assegurada uma confiabilidade de pelo menos $95 \%$.

A Tabela 5.5 e a Fig. 5.14 ilustram a variação da incerteza no coeficiente de transferência de calor com $\phi$, para diferentes condições experimentais. Verifica-se que as incertezas são incrementadas com a redução do superaquecimento da superfície. Tais

Tabela 5.5 Resumo ilustrativo das Incertezas no $h$ para o mecanismo de ebulição nucleada

\begin{tabular}{|c|c|c|c|}
\hline \multicolumn{2}{|r|}{ valores máximos } & \multicolumn{2}{|r|}{ valores mínimos } \\
\hline $\begin{array}{c}\text { Incerteza } \\
(\%)\end{array}$ & condição experimental & $\begin{array}{c}\text { Incerteza } \\
(\%)\end{array}$ & Condição experimental \\
\hline 7,4 & $\begin{array}{l}\text { R-134a; } p_{p}=0,260 ; R a=2,5 \mu \mathrm{m} ; \text { cobre; } \\
\phi=115 \mathrm{~kW} / \mathrm{m}^{2} ; h=24,4 \mathrm{~kW} / \mathrm{m}^{2} . \mathrm{K}\end{array}$ & 1,3 & $\begin{array}{l}\mathrm{R}-123 ; p_{r}=0,011 ; R a=0,16 \mu \mathrm{m} ; \text { cobre; } \\
\phi=114 \mathrm{~kW} / \mathrm{m}^{2} ; h=4,22 \mathrm{~kW} / \mathrm{m}^{2} . \mathrm{K}\end{array}$ \\
\hline 9,8 & $\begin{array}{l}\text { R-134a; } p_{p}=0,260 ; R a=2,5 \mu \mathrm{m} ; \text { cobre; } \\
\phi=67,0 \mathrm{~kW} / \mathrm{m}^{2} ; h=17,3 \mathrm{~kW} / \mathrm{m}^{2} . \mathrm{K}\end{array}$ & 1,0 & $\begin{array}{l}\text { R-11; } p_{r}=0,011 ; R a=0,02 \mu \mathrm{m} ; \text { aço inoxidável } \\
\phi=63 \mathrm{~kW} / \mathrm{m}^{2} ; h=1,62 \mathrm{~kW} / \mathrm{m}^{2} . \mathrm{K}\end{array}$ \\
\hline 11,0 & $\begin{array}{l}\text { R-134a; } p_{p}=0,260 ; R a=2,5 \mu \mathrm{m} ; \text { cobre; } \\
\phi=34,0 \mathrm{~kW} / \mathrm{m}^{2} ; h=10,8 \mathrm{~kW} / \mathrm{m}^{2} . \mathrm{K}\end{array}$ & 1,1 & $\begin{array}{l}\text { R-11; } p_{r}=0,011 ; R a=0,02 \mu \text { m;aço inoxidável; } \\
\phi=29,2 \mathrm{~kW} / \mathrm{m}^{2} ; h=0,87 \mathrm{~kW} / \mathrm{m}^{2} . \mathrm{K}\end{array}$ \\
\hline 19,5 & $\begin{array}{l}\text { R-134a; } p_{p}=0,260 ; R a=2,5 \mu \mathrm{m} ; \text { cobre; } \\
\phi=4,2 \mathrm{~kW} / \mathrm{m}^{2} ; h=2,27 \mathrm{~kW} / \mathrm{m}^{2} . \mathrm{K}\end{array}$ & 2,3 & $\begin{array}{l}\text { R-11; } p_{r}=0,011 ; R a=0,02 \mu \text { m;aço inoxidável; } \\
\phi=4,5 \mathrm{~kW} / \mathrm{m}^{2} ; h=0,26 \mathrm{~kW} / \mathrm{m}^{2} . \mathrm{K}\end{array}$ \\
\hline
\end{tabular}


condições são verificadas para valores reduzidos de $\phi$ e coeficientes de transferência de calor elevados.

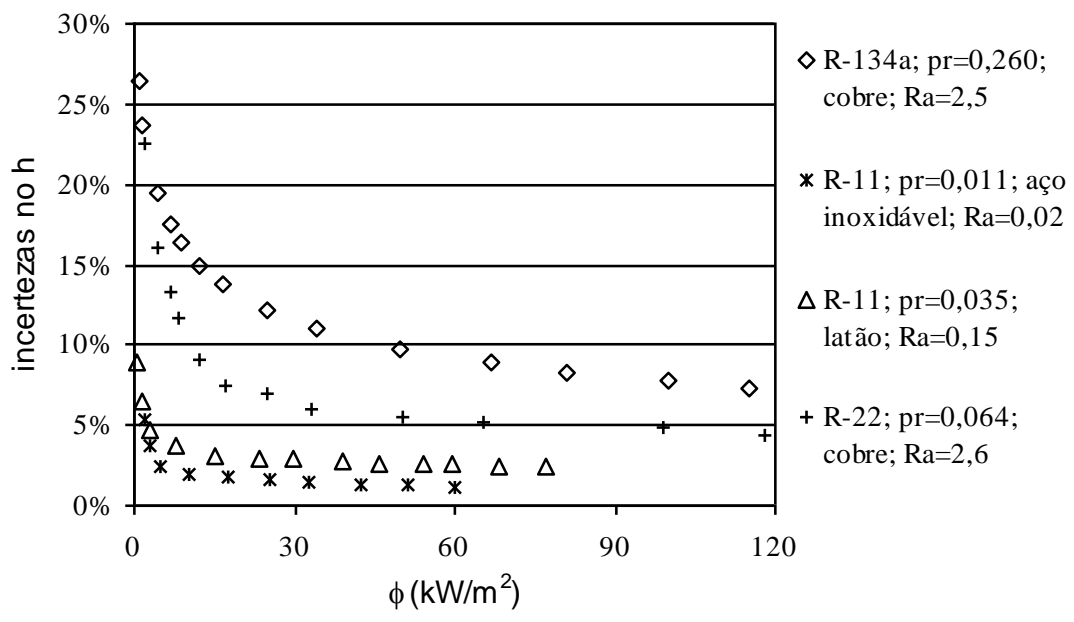

Figura 5.14 Incertezas experimentais na determinação de $h$. 


\section{Capítulo 6 - Resultados Experimentais}

\subsection{Introdução}

Neste capítulo são apresentados e discutidos os resultados experimentais levantados no presente trabalho, uma listagem dos quais se encontra no Apêndice III. Inicialmente, são analisados os dados obtidos para a transferência de calor através do mecanismo de convecção natural, que são comparados com correlações da literatura e utilizados na verificação das temperaturas indicadas pelos termopares, cujas junções estão localizadas na superfície de testes. Em seguida resultados experimentais envolvendo a transferência de calor através do mecanismo de ebulição nucleada são comparados com correlações e resultados da literatura. Ao final é realizada uma investigação minuciosa dos efeitos, na taxa de transferência de calor em ebulição nucleada, dos seguintes parâmetros: fluido refrigerante, pressão, acabamento superficial e material da superfície. Tal investigação é realizada com base no banco de dados levantado e na análise da literatura apresentada nos Capítulos 2 e 3. Este estudo envolve os resultados cujas condições experimentais se encontram resumidas na Tabela 6.1.

É interessante destacar que embora tenham sido levantadas curvas de ebulição para valores crescentes e decrescentes de $\phi$ a partir de um valor máximo, efeitos de histerese não serão incluídos nesta análise por fugirem ao escopo deste estudo. Discussões detalhadas sobre este fenômeno encontram-se nos Capítulos 2 e 5. Estes capítulos abordam, respectivamente, os fundamentos da ebulição, no qual este fenômeno é descrito, e o procedimento experimental realizado, onde se relatam o comportamento relativo à histerese, verificado experimentalmente, e de que forma seus efeitos foram considerados. 
Tabela 6.1 Condições experimentais do banco de dados levantado.

\begin{tabular}{|c|c|c|c|}
\hline $\begin{array}{c}\text { material da superfície/ } \\
\text { faixa de } \phi\left(\mathrm{kW} / \mathrm{m}^{2}\right)\end{array}$ & $\begin{array}{c}\text { fluido } \\
\text { refrigerante }\end{array}$ & $\begin{array}{c}\boldsymbol{R a} \\
(\mu \mathrm{m})\end{array}$ & $p_{r}$ \\
\hline \multirow{14}{*}{$\begin{array}{c}\text { cobre/ } \\
0,7 \leq \phi \leq 116,5\end{array}$} & \multirow[t]{3}{*}{ R-11 } & 0,17 & 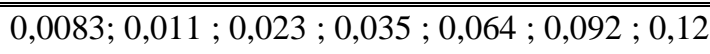 \\
\hline & & 0,45 & 0,$0083 ; 0,011 ; 0,023 ; 0,035 ; 0,064 ; 0,092 ; 0,12$ \\
\hline & & 2,3 & 0,$011 ; 0,023 ; 0,035 ; 0,064 ; 0,092 ; 0,12$ \\
\hline & \multirow{3}{*}{$\mathrm{R}-123$} & 0,16 & 0,$011 ; 0,023 ; 0,035 ; 0,064 ; 0,092 ; 0,12$ \\
\hline & & 0,47 & 0,$011 ; 0,023 ; 0,035 ; 0,064 ; 0,092 ; 0,12$ \\
\hline & & 3,3 & 0,$011 ; 0,023 ; 0,035 ; 0,064 ; 0,092 ; 0,12$ \\
\hline & \multirow[t]{2}{*}{$\mathrm{R}-12$} & 0,06 & 0,$050 ; 0,064 ; 0,092 ; 0,12 ; 0,18 ; 0,20 ; 0,26$ \\
\hline & & 0,51 & 0,$050 ; 0,064 ; 0,092 ; 0,12 ; 0,18 ; 0,20 ; 0,26$ \\
\hline & \multirow{3}{*}{$\mathrm{R}-22$} & 0,07 & 0,$064 ; 0,092 ; 0,12 ; 0,15 ; 0,18 ; 0,20$ \\
\hline & & 0,47 & 0,$064 ; 0,092 ; 0,12 ; 0,15 ; 0,18 ; 0,20$ \\
\hline & & 2,6 & 0,$064 ; 0,092 ; 0,12 ; 0,15 ; 0,18 ; 0,20$ \\
\hline & \multirow{3}{*}{ R-134a } & 0,07 & 0,$050 ; 0,064 ; 0,092 ; 0,12 ; 0,18 ; 0,20 ; 0,26$ \\
\hline & & 0,50 & 0,$050 ; 0,064 ; 0,092 ; 0,12 ; 0,18 ; 0,20 ; 0,26$ \\
\hline & & 2,5 & 0,$050 ; 0,064 ; 0,092 ; 0,12 ; 0,18 ; 0,20 ; 0,26$ \\
\hline \multirow{5}{*}{$\begin{array}{c}\text { latão / } \\
0,7 \leq \phi \leq 84,4\end{array}$} & $\mathrm{R}-11$ & 0,15 & 0,$011 ; 0,023 ; 0,035 ; 0,064 ; 0,092 ; 0,12$ \\
\hline & $\mathrm{R}-123$ & 0,16 & 0,$011 ; 0,023 ; 0,035 ; 0,064 ; 0,092 ; 0,12$ \\
\hline & $\mathrm{R}-12$ & 0,08 & 0,$050 ; 0,064 ; 0,092 ; 0,12 ; 0,18 ; 0,20 ; 0,26$ \\
\hline & $\mathrm{R}-22$ & 0,08 & 0,$064 ; 0,092 ; 0,12 ; 0,15 ; 0,18 ; 0,20$ \\
\hline & R-134a & 0,08 & 0,$050 ; 0,064 ; 0,092 ; 0,12 ; 0,18 ; 0,20 ; 0,26$ \\
\hline \multirow{4}{*}{$\begin{array}{c}\text { aço inoxidável / } \\
0,7 \leq \phi \leq 64,0\end{array}$} & \multirow{2}{*}{$\mathrm{R}-11$} & 0,02 & 0,$011 ; 0,023 ; 0,035 ; 0,064 ; 0,092 ; 0,12$ \\
\hline & & 0,16 & 0,$011 ; 0,023 ; 0,035 ; 0,064 ; 0,092 ; 0,12$ \\
\hline & $\mathrm{R}-123$ & 0,16 & 0,$011 ; 0,023 ; 0,035 ; 0,064 ; 0,092 ; 0,12$ \\
\hline & $\mathrm{R}-134 \mathrm{a}$ & 0,08 & 0,$064 ; 0,092 ; 0,12 ; 0,18 ; 0,20 ; 0,26$ \\
\hline
\end{tabular}

\subsection{Resultados para Convecção Natural}

No levantamento da curva de ebulição, ao elevar-se o fluxo de calor a partir de um valor nulo, a ativação das cavidades e conseqüente início da ebulição necessita de uma maior energia. Isto resulta em um elevado superaquecimento da superfície para que a primeira cavidade torne-se ativa. Com o início da ebulição a superfície é drasticamente resfriada. Tal comportamento encontra-se ilustrado na curva de ebulição da Fig. 6.1, levantada a partir de resultados experimentais obtidos na presente pesquisa. Nesta figura, a região compreendida 
por $\phi=0$ e o início da ebulição tem a convecção natural como mecanismo físico responsável pela transferência de calor da superfície aquecida para o banho. A transferência de calor, através deste mecanismo, surge como resultado de forças de volume atuando sobre o fluido, geradas pela associação do campo gravitacional e dos gradientes de densidade associados aos correspondentes de temperatura. O efeito líquido é o empuxo, responsável pelo surgimento de correntes de convecção.

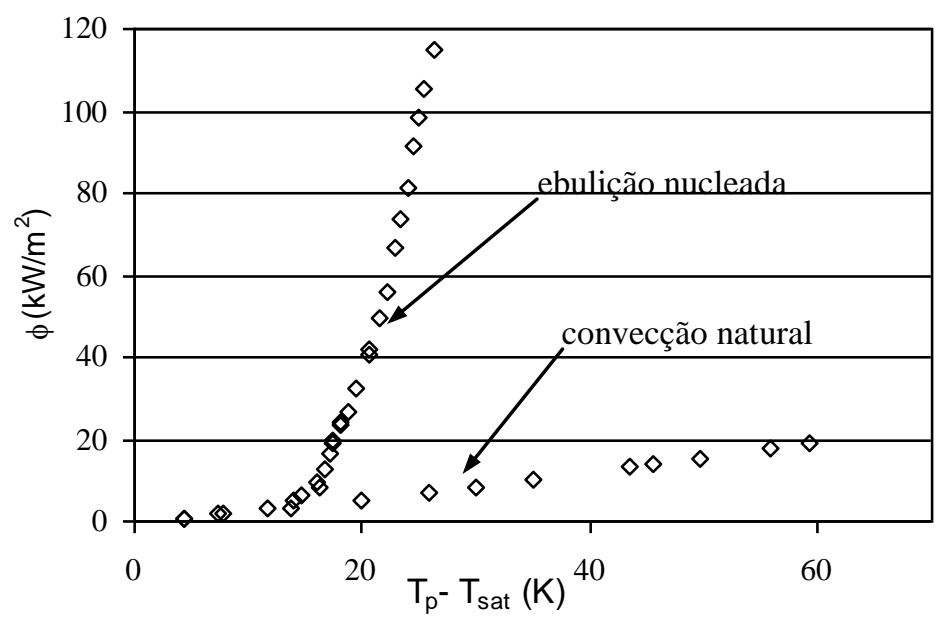

Figura 6.1 Curva de ebulição para o R-11 para $T_{s a l}=5,5^{\circ} \mathrm{C}$ sobre uma superfície cilíndrica de cobre com $D_{e x t}=19 \mathrm{~mm}$.

Embora a convecção natural não encontre aplicações diretas envolvendo refrigerantes halogenados, resultados abrangendo estes fluidos podem ser utilizados no ajuste de correlações, pois estas são baseadas, geralmente, em análises dimensionais, o que permite que sejam estendidas a outros fluidos.

Conforme descrito no Capítulo 3, a convecção natural encontra-se nos modelos físicos que admitem a superposição dos mecanismos de convecção e naqueles associados à ebulição propriamente dita, dividindo a superfície de transferência de calor em distintas regiões, conforme apresentado anteriormente. Entre tais modelos destacam-se o de Han e Griffith (1965b), Mikic e Rohsenow (1969) e Benjamin e Balakrishnan (1996). Para condições de ebulição envolvendo fluxos de calor reduzidos e/ou elevado grau de subresfriamento do refrigerante, condição para a qual a ativação de cavidades é inibida, a convecção natural é responsável por significativa parcela do calor transferido. Tal comportamento pode ser indicado pela relativa imprecisão das correlações para a ebulição nucleada plenamente desenvolvida, quando aplicadas a tais condições, nas quais ainda que ocorra a formação de bolhas, o mecanismo responsável pela maior parcela da transferência de calor é a convecção natural. 
Ainda que a convecção natural não seja o escopo principal deste estudo, ao determinar-se as curvas de ebulição, foram levantados resultados experimentais para o coeficiente de transferência de calor através deste mecanismo com o refrigerante no estado líquido próximo à saturação. Estes resultados foram utilizados na verificação das temperaturas fornecidas pelos termopares nas diferentes superfícies de testes. Tal procedimento baseia-se em que mudanças de material ou de acabamento superficial da superfície de testes, mantendo-se diâmetro, refrigerante, $T_{s a t}$ e $\phi$, não alteram o coeficiente de transferência de calor. Este fato pode ser utilizado na verificação do posicionamento das junções dos termopares localizadas no interior da superfície de testes, pois, caso estejam alojadas em posições similares, devem indicar, para diferentes tubos e sob condições semelhantes de fluxo de calor e refrigerante, uma mesma temperatura.

A Tabela 6.2 apresenta as condições experimentais em termos dos números de Rayleigh e Prandtl, adimensionais típicos de correlações para a convecção natural, para os quais foram levantados dados envolvendo este mecanismo físico. Resultados para os refrigerantes R-12, R-134a e R-22 e valores de $T_{\text {sat }}$ elevados não foram levantados em virtude da precocidade no surgimento de bolhas, como resultado da reduzida energia necessária para ativação de cavidades. Este comportamento, somado às incertezas nas medidas, impossibilitaria uma análise conclusiva envolvendo resultados experimentais para a convecção natural com tais temperaturas e refrigerantes.

Tabela 6.2 Características dos resultados experimentais levantados para convecção natural.

\begin{tabular}{lccccc}
\hline \hline refrigerante & $\boldsymbol{T}_{\text {sat }}\left({ }^{\boldsymbol{o}} \boldsymbol{C}\right)$ & $\boldsymbol{P r}$ & $\boldsymbol{R a y}_{\boldsymbol{D}}$ & $\boldsymbol{D}_{\text {ext }}(\mathbf{m m})$ & material \\
\hline \hline R-11 & $-2,2-25,0$ & $3,71-4,70$ & $2,83.10^{7}-4,8.10^{8}$ & 19 & $\begin{array}{c}\text { cobre, aço inoxidável e } \\
\text { latão }\end{array}$ \\
\hline R-123 & $5,5-24,0$ & $4,46-6,85$ & $3,23.10^{7}-6,53.10^{8}$ & 19 & $\begin{array}{c}\text { cobre, aço inoxidável e } \\
\text { latão }\end{array}$ \\
\hline \hline
\end{tabular}

Nas Figs. 6.2a e 6.2b são apresentadas comparações entre resultados experimentais, respectivamente, para uma única superfície com diferentes acabamentos superficiais e, entre três superfícies distintas constituídas de cobre, latão e aço inoxidável. Verificam-se valores de $T_{p}$, independentes do acabamento superficial e do material da superfície de teste. Ainda que este comportamento não permita determinar a resistência térmica entre a junção do termopar e a parede do canal onde se encontra alojada, ele é um indicador da repetitividade do processo de montagem para diferentes superfícies. Tal constatação, somada à análise referente à resistência de contato térmico apresentada no capítulo anterior, permite concluir a 
adequação do procedimento de montagem da superfície de testes e a minimização dos efeitos de contato térmico.

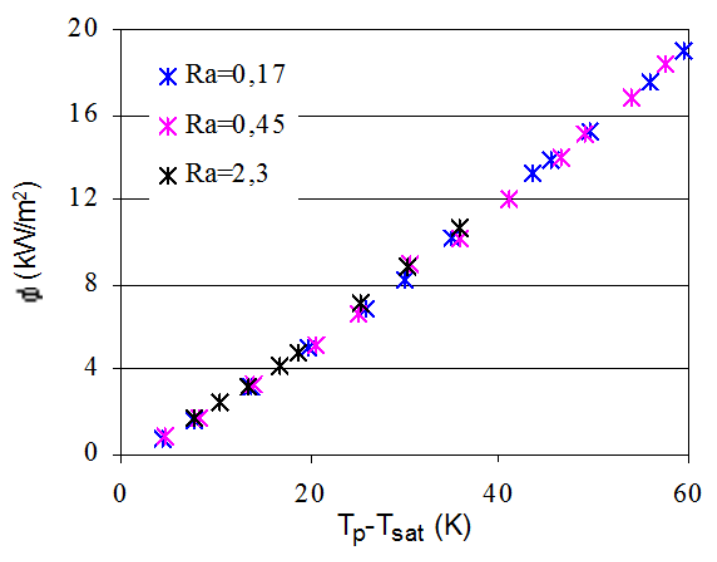

a) análise efeito rugosidade; cobre

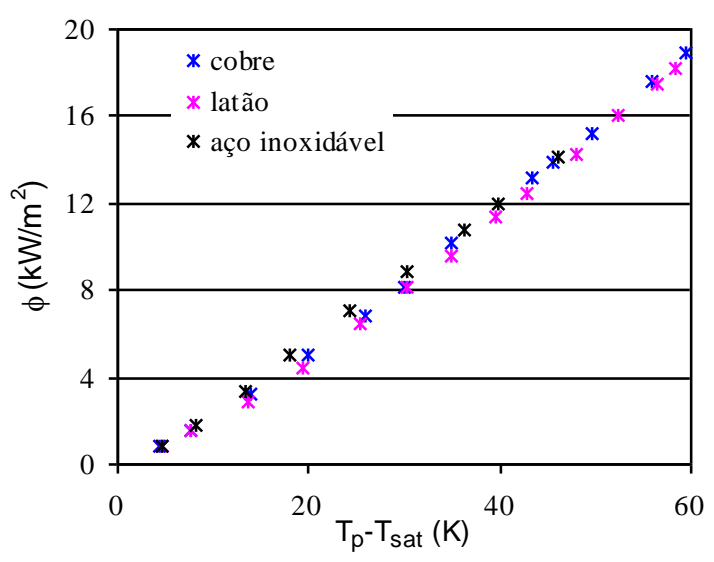

b) análise efeito material; $R a \cong 0,16 \mu \mathrm{m}$

Figura 6.2 Comparação de resultados para convecção natural, R-11, $T_{\text {sat }} \cong 5,5^{\circ} \mathrm{C}$.

Entre as correlações para a determinação do Nusselt médio em uma superfície cilíndrica destacam-se a de Churchill e Chu (1975) e a de Morgan (1975). A primeira apresenta desvios entre 1,9 e 12\%, para as condições experimentais da Tabela 6.2, quando comparada à correlação de Fishenden e Saunders, Eqs. (3.37) e (3.38), considerada pelos autores nos modelos apresentados no Capítulo 3. Já, a de Morgan (1975), apresenta um valor aproximadamente constante e igual a $-11,5 \%$. Tais correlações, excetuando a de Fishenden e Saunders, foram incluídas nesta análise por serem comumentemente encontradas na literatura e envolverem em seus ajustes bancos de dados extensos. As correlações de Churchill e Chu (1975) e Morgan (1975) são dadas, respectivamente, pelas seguintes expressões:

$$
\begin{aligned}
& N u^{1 / 2}=0,60+0,387 \cdot\left(\frac{\operatorname{Ray}_{D}}{\left[1+\left(\frac{0,559}{P r}\right)^{9 / 16}\right]^{16 / 9}}\right)^{1 / 6} \\
& N u=B \cdot\left(\operatorname{Ray}_{D}\right)^{m}
\end{aligned}
$$

onde os valores de $B$ e $m$ dependem do $R a y_{D}$, e encontram-se listados na tabela abaixo. 
Tabela 6.3 Valores de $B$ e $m$, Eq. (6.2), de acordo com Morgan (1975).

\begin{tabular}{clc}
\hline \hline Para $\boldsymbol{R a y}_{\boldsymbol{D}}$ entre & $\boldsymbol{B}$ & $\boldsymbol{m}$ \\
\hline \hline $10^{-10}$ e $10^{-2}$ & 0,675 & 0,058 \\
\hline $10^{-2}$ e $10^{2}$ & 1,02 & 0,148 \\
\hline $10^{2}$ e $10^{4}$ & 0,850 & 0,188 \\
\hline $10^{4}$ e $10^{7}$ & 0,480 & 0,250 \\
\hline $10^{7}$ e $10^{12}$ & 0,125 & 0,333 \\
\hline \hline
\end{tabular}

A Eq.(6.1) foi baseada em uma correlação anterior de Churchill, que envolveu a teoria da camada limite e a solução em séries das equações da conservação da quantidade de movimento e energia para cilindros. Admitiu-se $T_{p}$ constante e regime de escoamento laminar. Este modelo foi ajustado por Churchill e Chu (1975) a resultados experimentais, abrangendo os regimes laminar e turbulento. $\mathrm{O}$ banco de dados utilizado envolveu resultados experimentais para valores de $\operatorname{Pr}$ e $\operatorname{Ray}_{D}$, respectivamente, entre 0,02 e 100 , e $10^{-6}$ e $10^{13}$. Ainda, que a correlação tenha sido desenvolvida para $T_{p}$ constante os autores sugerem, como aproximação, sua utilização para fluxo de calor uniforme.

A Eq. (6.2) é a proposta por Morgan (1975). Trata-se de uma correlação estritamente empírica, relacionando os números de Nusselt e Rayleigh. Este ajuste envolveu resultados experimentais para água, ar, diferentes tipos de óleos, tolueno, hidróxido de sódio e etilenoglicol, levantados em mais de 60 trabalhos anteriores, com valores de Ray variando entre $10^{-8}$ e $10^{13}$

As Figs 6.3a e 6.3b apresentam comparações entre os resultados levantados no presente estudo e aqueles determinados através das Eqs. (6.1) e (6.2). Nelas verifica-se, que a despeito de incertezas envolvendo os dados experimentais, ambas as correlações fornecem resultados razoáveis principalmente para números de Nusselt inferiores a 60.

Embora a Eq. (6.2), proposta por Morgan (1975), correlacione melhor os resultados experimentais, ambas correlações apresentaram uma tendência a proporcionar resultados superiores aos experimentais. Tal comportamento poderia ser justificado por efeitos de resistência térmica entre a região externa da superfície e a junção do termopar, pois o incremento da temperatura superficial indicada, resultaria numa redução do valor experimental do $h$. Este argumento pode ser abandonado com base nos procedimentos adotados, descritos no capítulo anterior, e do reduzido fluxo específico de calor envolvido, fazendo com que tais efeitos sejam considerados desprezíveis na convecção natural. 
A condução longitudinal a partir da seção central do tubo não poderia ser responsável pelas diferenças entre resultados ilustradas na Fig. 6.3. Esta afirmação se baseia no procedimento adotado, pois caso seus efeitos fossem relevantes, estaria ocorrendo a adoção de um fluxo específico de calor da superfície para o fluido, superior ao real, superestimando, desta forma, o valor de $h$, comportamento oposto ao verificado. Ressalta-se que efeitos de condução longitudinal caso relevantes, dependeriam do material da superfície, conforme discutido no Capítulo 5. No entanto superfícies de distintos materiais apresentaram resultados similares, conforme ilustrada na Fig. 6.2b. A correlação de Churchil e Chu (1975) foi ajustada a resultados experimentais obtidos exclusivamente para superfícies com $T_{p}$ uniforme. Morgan (1975), ainda que seu ajuste envolva alguns resultados experimentais para $\phi$ uniforme, tratou resultados cuja maioria envolvia condições de $T_{p}$ uniforme. No presente trabalho os resultados experimentais foram levantados para uma distribuição de $\phi$ uniforme. Entretanto as diferenças ilustradas na Fig. 6.3, não poderiam estar relacionadas a este fato, pois neste caso o comportamento deveria ser oposto ao ilustrado, devido a numa mesma condição experimental, valores de Nusselt médio com $\phi$ uniforme tendem a ser superiores àqueles com $T_{p}$ uniforme.

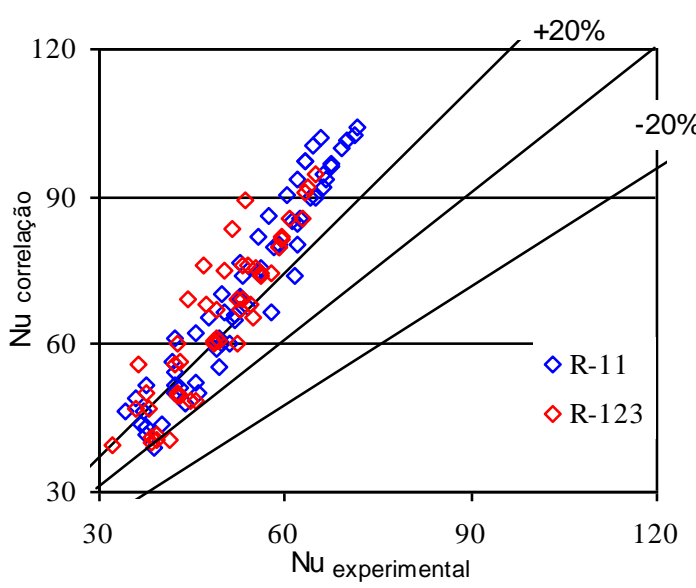

a) Churchill e Chu (1975)

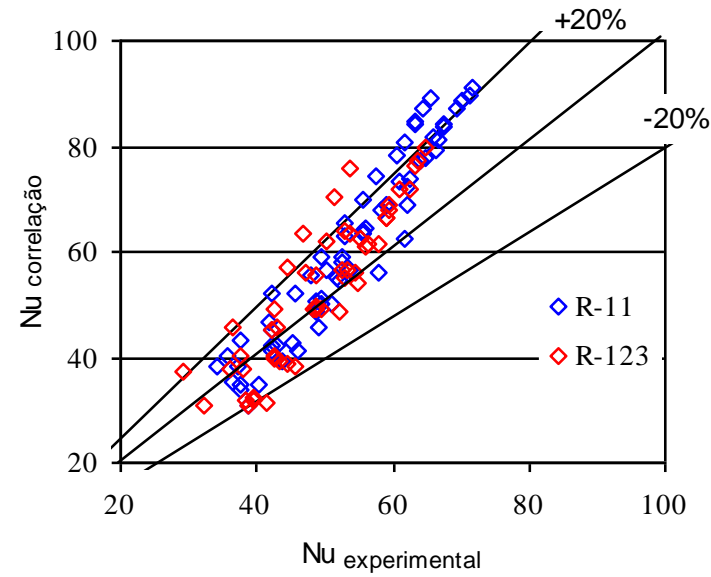

b) Morgan (1975)

Figura 6.3 Comparação dos resultados experimentais para convecção natural com correlações da literatura.

Finalmente, especula-se a possibilidade do comportamento verificado estar relacionado aos seguintes fatores:

As correlações apresentadas proporcionam um número de Nusselt médio sobre toda a periferia do cilindro, enquanto no presente estudo ele foi determinado com base na temperatura indicada por um único termopar localizado na face lateral da superfície de 
transferência de calor. Desta forma, supondo o valor do Nusselt nesta região inferior ao valor médio, as diferenças apresentadas na Fig. 6.3 poderiam ser justificadas.

Outro fator seria que resultados experimentais envolvendo valores de Rayleigh entre $10^{7}$ e $10^{8}$, os quais compreendem os do presente estudo, apresentaram, segundo Morgan (1975) e Churchill e Chu (1975), desvios superiores. Tal comportamento foi justificado pelos autores por tratar-se esta de uma região de transição entre os regimes laminar e turbulento.

\subsection{Resultados para Ebulição Nucleada}

Os resultados experimentais envolvendo a transferência de calor em ebulição nucleada são analisados neste item. Primeiramente, será feita uma comparação com resultados experimentais e correlações da literatura, seguida de uma análise detalhada, baseada na pesquisa bibliográfica, de efeitos individuais e mútuos na ebulição nucleada do fluxo específico de calor, do refrigerante, da pressão reduzida, do acabamento superficial e do material da superfície.

É interessante destacar que a inclusão de barras de incertezas se fará apenas quando relevante à análise. Este procedimento foi adotado por permitir uma melhor visualização dos gráficos e em virtude das incertezas, em geral, apresentarem valores reduzidos em face dos medidos, não influenciando, desta forma, possíveis conclusões.

\subsubsection{Comparação com Resultados Experimentais e Correlações da Literatura}

O objetivo deste item é verificar a adequação dos resultados experimentais e de suas tendências, através da comparação com correlações da literatura e resultados experimentais de outros autores. Tal análise, embora não valide os resultados experimentais, pode indicar sua coerência.

\subsubsection{Comparação com Resultados Experimentais de Outros Autores}

Apesar da ampla pesquisa bibliográfica realizada, foi levantado um número 
reduzido de resultados experimentais de outros autores envolvendo a ebulição de refrigerantes halogenados em superfícies cilíndricas lisas. Entre eles, os de Silva (1989) para os refrigerantes R-11, R-113 e R-114 puros e suas misturas com óleo de lubrificação do compressor, de Jensen (1985) para o R-113 e de Webb e Pais (1992), para R-11, R-123, R12, R-134a e R-22, neste caso através de ajustes de curvas do tipo $h=c \cdot \phi^{n}$ para cada condição experimental. Apenas resultados envolvendo os mesmos refrigerantes deste trabalho foram incluídos nesta análise.

Silva (1989) realizou um levantamento experimental envolvendo a ebulição de refrigerante, em uma superfície de latão com diâmetro externo igual a $14,2 \mathrm{~mm}$, conforme mostrado na Tabela 5.2. Ainda que não tenha determinado o valor de $R a$ para sua superfície, ele realizou o acabamento de forma similar ao presente estudo utilizando lixas d'água com diferentes numerações até atingir um acabamento mais fino. No caso do R-11 foram levantados resultados para valores de $T_{\text {sat }}$ iguais a 30,7, 36,1, 40,0. Na Fig. 6.4 estes resultados são comparados aos do presente estudo para a superfície de latão. Constatam-se, considerando as incertezas nas medidas de temperatura, resultados próximos e tendências semelhantes para as curvas $\phi$ vs $\Delta T$ com valores do fluxo específico de calor superiores a $30 \mathrm{~kW} / \mathrm{m}^{2}$. As diferenças verificadas com valores inferiores de $\phi$ não parecem ter uma justificativa baseada em efeitos de rugosidade, pois com a elevação do fluxo específico de calor elas seriam incrementadas e não reduzidas, conforme ilustrado na Fig.6.4. Por outro lado, o incremento nos efeitos de convecção natural, com a redução do diâmetro da superfície, conforme indicado pelas Eqs. (6.1) e (6.2) através da elevação do $h$, parecem justificar a redução superior no superaquecimento com $\phi$ para a superfície de Silva (1989), de menor diâmetro, quando comparada à redução verificada para os dados do presente estudo.

A Fig. 6.5 apresenta uma comparação, envolvendo condições experimentais semelhantes, entre os resultados do presente estudo e os de Webb e Pais (1992), determinados em uma superfície comercial de cobre com $D_{e x t}=19 \mathrm{~mm}$, cujo acabamento superficial não sofreu tratamento algum. Para a determinação da rugosidade da sua superfície, Webb e Pais (1992) compararam seus resultados com a correlação de Cooper (1984), determinando o valor de $R p$ que melhor correlacionava a Eq. (3.5) aos seus resultados, obtendo $R p=0,3 \mu \mathrm{m}$. No presente estudo, para verificação deste valor, foram tomadas dez amostras de tubo de cobre com diâmetro externo igual a $19 \mathrm{~mm}$, obtidas em distintos fornecedores, e determinados 5 valores de $R a$ individualmente para cada amostra. Obteve-se, assim, para superfícies comerciais de cobre um valor de $R a=0,6 \pm 0,2 \mu \mathrm{m}$. Ressalta-se, novamente, que apesar de não existir uma relação matemática entre eles, valores 
de $R p$ são superiores aos de $R a$ como resultado de suas próprias definições. Desta forma, conclui-se que a determinação de $R p$ segundo o procedimento utilizado por Webb e Pais (1992) consistiu apenas no ajuste de seus resultados experimentais à correlação de Cooper (1984).

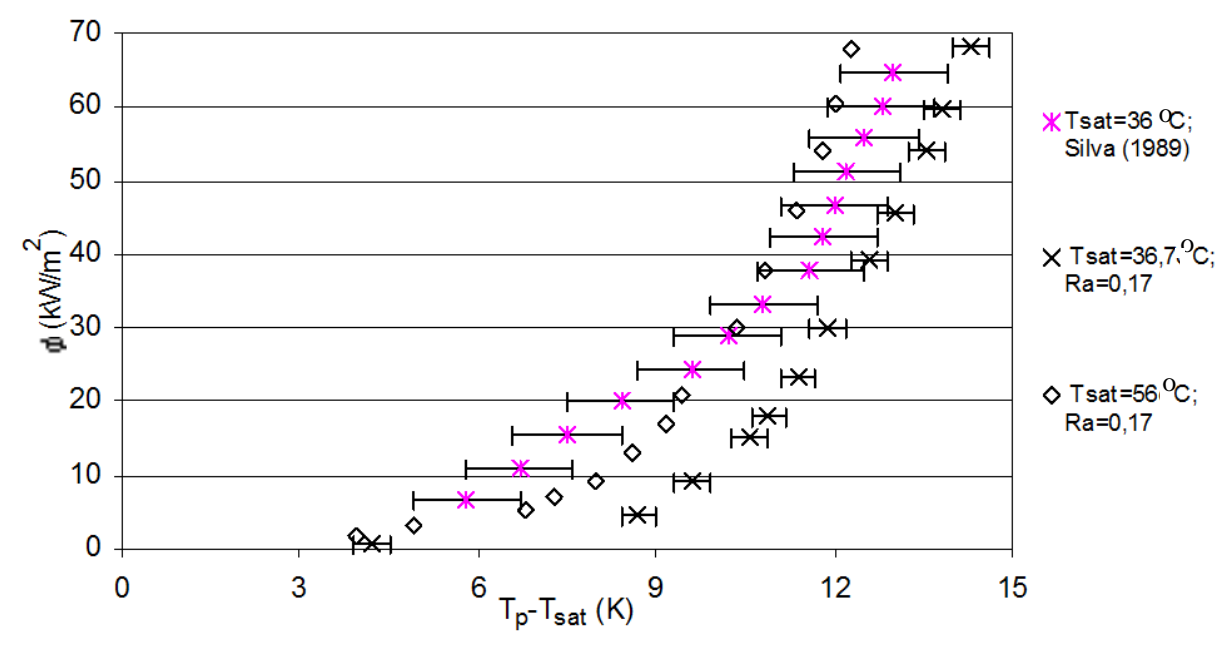

Figura 6.4 Comparação entre os resultados levantados neste estudo com os de Silva (1989).

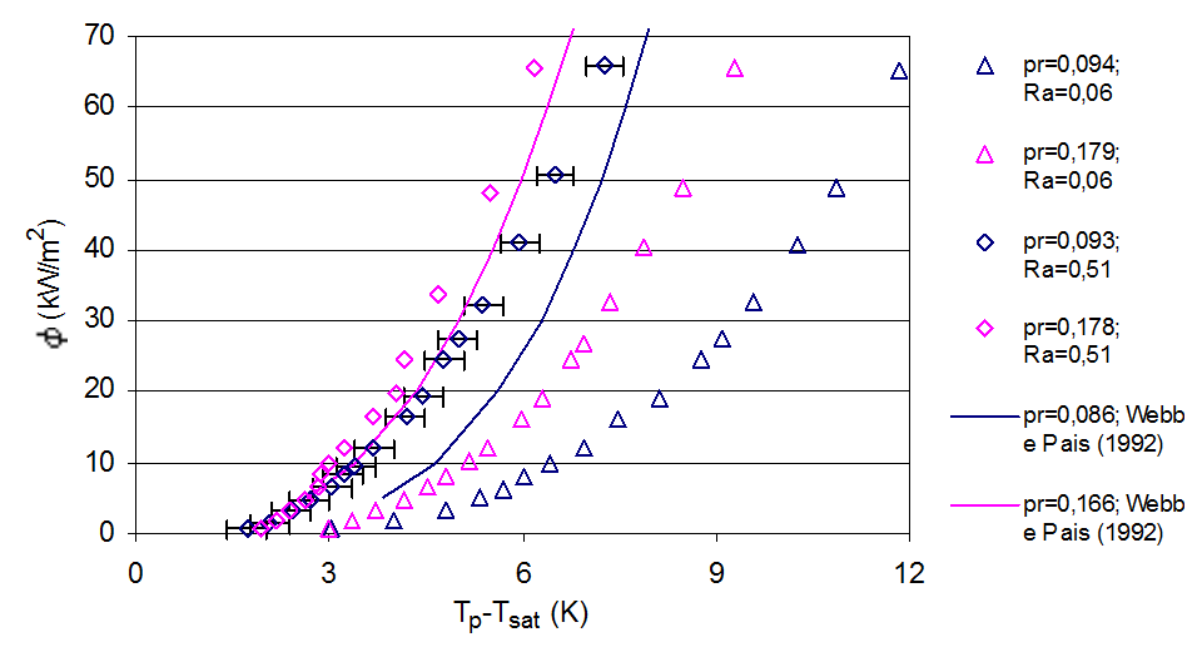

Figura 6.5 Comparação entre os resultados levantados neste estudo e os de Webb e Pais (1992) para o R-12.

Corrobora tal fato a proximidade entre os resultados de Webb e Pais (1992) e os do presente trabalho com valores de $R a$ próximos a $0,5 \mu \mathrm{m}$ ilustrados na Fig. 6.5. Apesar de reduzidas, as diferenças verificadas nesta figura entre os dois estudos são consistentes, pois valores superiores de $\Delta T$ para um mesmo $\phi$ são justificados pelo fato de Webb e Pais (1992) terem realizado seus levantamentos experimentais para valores de $p_{r}$ um pouco inferiores ao presente estudo. 
$\mathrm{Na}$ Tabela 6.4 são apresentadas, para as demais condições experimentais, diferenças entre os valores de $h$ obtidos por Webb e Pais (1992) e os do presente estudo com $R a$ em torno de $0,5 \mu \mathrm{m}$ e pressões reduzidas próximas. Nesta tabela, os resultados obtidos por Webb e Pais (1992) para o R-22 e para os refrigerantes R-134a e R-11 com as pressões reduzidas superiores, sugerem que a superfície utilizada por estes autores apresenta um valor de $R a$, ainda superior a $0,5 \mu \mathrm{m}$, considerando que os materiais das superfícies são semelhantes nesses estudos. No caso do R-11 isto pode estar também relacionado à diferença entre valores de $p_{r}$, que no presente trabalho, é igual a 0,023 e em Webb e Pais (1992) é 0,025, o que resultaria um $h$ superior para este último. Esta diferença em $p_{r}$, embora seja pequena, torna-se relevante em situações de baixas pressões reduzidas. Para as demais condições, considerando as diferenças entre as pressões reduzidas em que foram realizadas as comparações bem como as incertezas experimentais, conclui-se, através desta tabela, resultados razoavelmente próximos.

Tabela 6.4 Relação entre valores de $h$ do presente estudo e de Webb e Pais (1992).

\begin{tabular}{c|c|c|c|c|c|c|c|c|c|c|c}
\hline \multicolumn{10}{c}{$\left(\mathrm{h}_{\text {Webb e Pais (1992) }}-\mathrm{h}_{\text {experimental }}\right) / \mathrm{h}_{\text {experimental }}(\%)$} \\
\hline \hline \multicolumn{2}{c|}{} & \multicolumn{2}{c}{$\mathrm{R}-11$} & \multicolumn{2}{c}{$\mathrm{R}-123$} & \multicolumn{2}{c|}{$\mathrm{R}-12$} & \multicolumn{2}{c|}{$\mathrm{R}-134 \mathrm{a}$} & \multicolumn{2}{c}{$\mathrm{R}-22$} \\
\hline$p_{r}$ (aproximado) & 0,011 & 0,025 & 0,011 & 0,025 & 0,090 & 0,180 & 0,090 & 0,180 & 0,120 & 0,200 \\
\hline \multirow{2}{*}{$\phi$} & 20 & $-5,4$ & 34,5 & 16,7 & $-3,2$ & $-20,3$ & $-6,8$ & 15,1 & 30,7 & 18,5 & 29,1 \\
\cline { 2 - 11 }$\left(\mathrm{kW} / \mathrm{m}^{2}\right)$ & 40 & $-9,4$ & 20,2 & 0,4 & $-15,9$ & $-13,0$ & $-7,3$ & 4,3 & 31,3 & 19,3 & 24,3 \\
\cline { 2 - 11 } & 60 & $-11,4$ & 11,5 & $-7,3$ & $-22,9$ & $-6,9$ & $-5,8$ & $-2,1$ & 29,8 & 18,0 & 21,3 \\
\hline \hline
\end{tabular}

\subsubsection{Comparação com as Correlações}

As correlações apresentadas no estudo da literatura do Capítulo 3 foram ajustadas através de bancos de dados distintos, sendo seus resultados dependentes da abrangência dos respectivos bancos de dados. Embora se reconheça que a maioria deles não envolve refrigerantes halogenados, neste item, são comparados os coeficientes de transferência de calor experimentais e os fornecidos pelas correlações. É interessante ressaltar a não introdução da análise do modelo de Han e Griffith (1965b). Esta opção foi decorrente de sua utilização posterior na análise qualitativa das tendências verificadas nos resultados experimentais, devido a este modelo envolver explicitamente critérios de nucleação e a determinação dos períodos de espera e crescimento de bolhas, sem um ajuste a dados experimentais. 
Conforme indicado no Capítulo 3, em estudos envolvendo a ebulição nucleada são utilizados distintos parâmetros na caracterização do acabamento superficial. Por outro lado, deve ser destacado que, na literatura especializada, não se encontra uma clara relação entre eles. Nessas condições, embora se reconheça a distinção conceitual desses parâmetros, optou-se por considerá-los iguais na análise comparativa que se segue. As Figs. 6.6a a 6.6d ilustram a variação com $\phi$ dos resíduos, definidos conforme Eq. (6.3), apresentados por algumas correlações em relação aos resultados experimentais. Resultados similares, ainda que não ilustrados, podem ser estendidos às demais correlações e condições experimentais. De acordo com estas figuras, as correlações tendem a apresentar alterações na tendência dos resíduos, ou ainda resíduos superiores com valores reduzidos de $\phi$. Como elas foram ajustadas para condições de ebulição nucleada plenamente desenvolvida, é possível que as discrepâncias observadas com valores reduzidos do fluxo específico de calor estejam relacionadas à ocorrência de ebulição nucleada parcial (ou mesmo convecção natural) em que parcela do calor transferido na parede aquecida está relacionada à convecção natural, ainda que este mecanismo tenha sido incorporado a algumas das correlações analisadas.

$$
\text { resíduo }=\frac{(\text { valor correlação })-(\text { valor experimental })}{(\text { valor experimental })}
$$

Na Fig. 6.6 constata-se que os resultados mais próximos aos experimentais são os resultantes da correlação de Stephan e Abdelsalam (1980), embora ela incorpore o parâmetro de superfície $R p$. Como na realidade $R a<R p$ e nesta correlação $h$ é proporcional a $R p^{0,133}$, os resíduos deveriam ser algo superiores aos apresentados na Fig. 6a. Embora se caracterize por resíduos superiores à de Stephan e Abdelsalam (1980), os resultados da correlação do VDI-Wärmeatlas, dentro de certos limites, independem do fluxo de calor, o que permitiria ajustá-la facilmente aos resultados experimentais através da constante multiplicativa $h_{0}$. Os resultados proporcionados pela correlação de Cooper (1984), embora estejam afetados de uma subestimativa dos efeitos de rugosidade, ao considerar $R a=R p$, também apresentam resíduos de certa forma independentes de $\phi$. Os resíduos seriam ainda inferiores caso o fator multiplicativo sugerido por Cooper (1984) para superfícies cilíndricas de cobre, 1,7, fosse omitido. Finalmente, nesta figura, a correlação de Haider e Webb (1997), que utiliza um banco de dados limitado, envolvendo apenas os refrigerantes R-11 e R-123, apresentou resíduos significativamente superiores às demais. Seu ajuste foi realizado com base em resultados experimentais levantados por Nakayama et al (1980a, 1980b) e Chien (1996), com superfícies cujos acabamentos superficiais não foram indicados. 


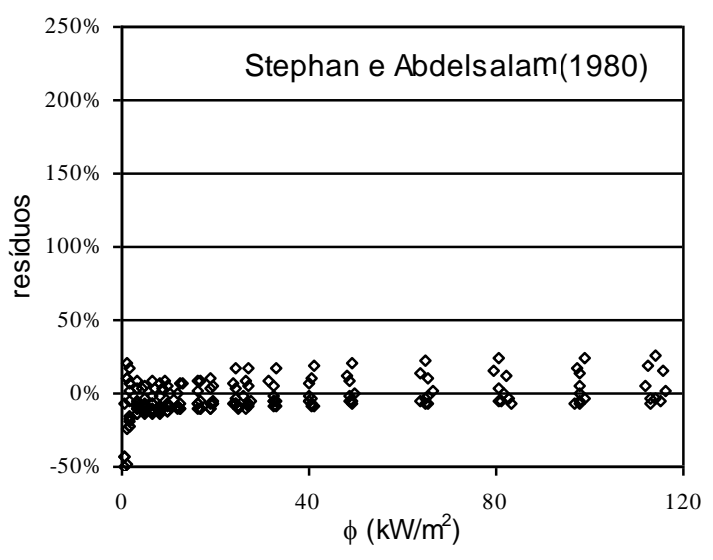

a)

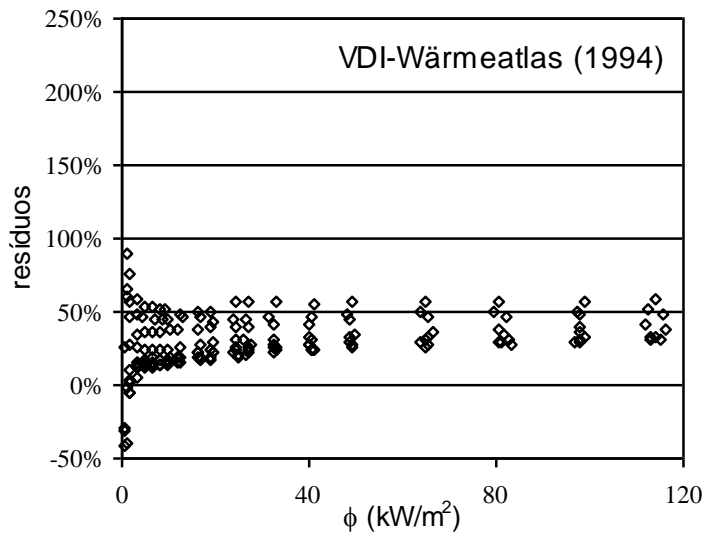

c)

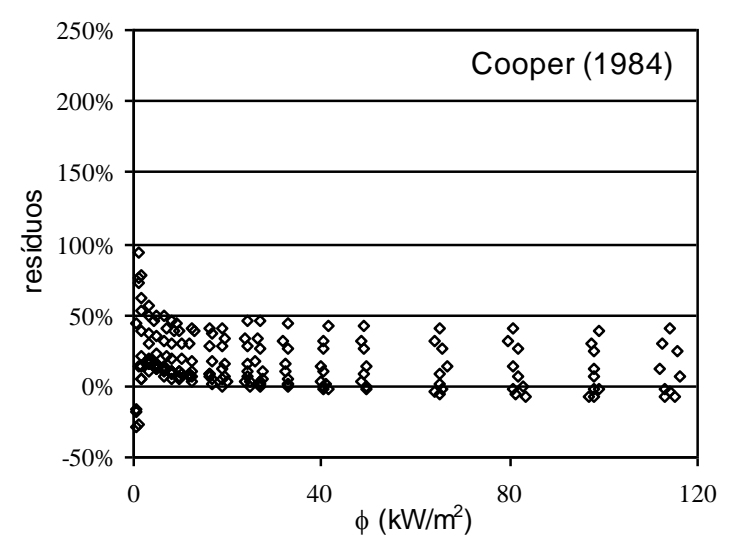

b)

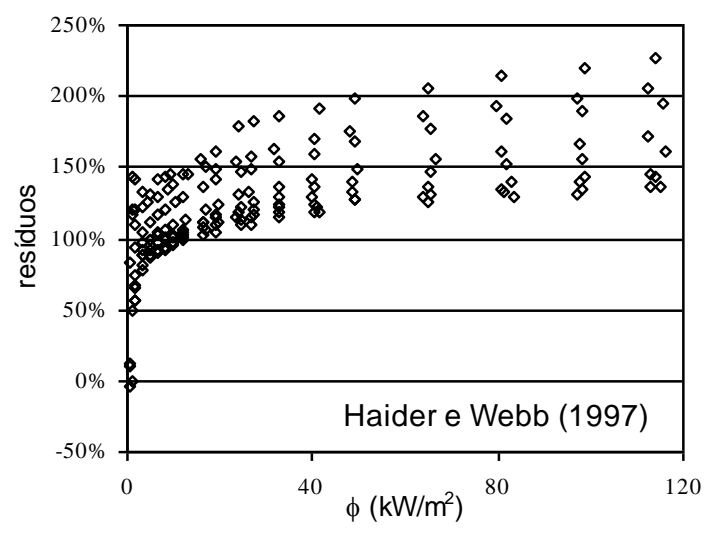

d)

Figura 6.6 Ilustração para algumas correlações do efeito de $\phi$ nos seus resíduos em relação aos resultados experimentais. R-12, cobre, $R a=0,06$ e $0,51 \mu \mathrm{m}, 0,05 \leq p_{r} \leq 0,260$.

A Tabela 6.5 apresenta os desvios médios para todas as correlações apresentadas no Capítulo 3, exceto a de Han e Griffith (1965b). Os valores dos desvios médios são definidos conforme a Eq. (6.4), e seus cálculos envolvem a totalidade dos resultados levantados para a condição experimental especificada na primeira coluna da tabela.

$$
\text { desvio médio }=\frac{1}{n} \cdot \sum_{i=1}^{n} \frac{\mid(\text { valor correlação })-(\text { valor exp erimental }) \mid}{(\text { valor exp erimental })}
$$

onde $n$ é o número de resultados experimentais.

Nesta tabela, com exceção da correlação de Haider e Webb (1997), verifica-se que correlações desenvolvidas com base em banco de dados* envolvendo refrigerantes halogenados, apresentam resultados mais próximos aos levantados neste trabalho, como é o

*A descrição dos bancos de dados experimentais utilizados no ajuste das correlações encontra-se no Capítulo 3. 
caso das correlações de Stephan e Abdelsalam (1980), Cooper (1984) e VDI-Wärmeatlas (1994). Entre elas, aquela que proporciona resultados mais próximos aos experimentais é a de Stephan e Abdelsalam (1980), apesar de admitir $R p$ como parâmetro característico da superfície. Ainda assim, por não envolver um parâmetro característico do material da superfície ela apresenta desvios médios elevados para a superfície de aço inoxidável. Tal fato se reflete nos reduzidos desvios verificados com os refrigerantes R-12 e R-22 para os quais foram levantados resultados experimentais apenas para as superfícies de cobre e latão. Estas, quando comparadas a de aço inoxidável, apresentam coeficientes de transferência de calor próximos.

A correlação do VDI-Wärmeatlas (1994), embora envolva explicitamente efeitos do material da superfície, através do produto $k_{p} \cdot \rho_{p} \cdot c_{p}$, apresentou um desvio médio superior para a superfície de aço inoxidável em relação as demais. Considerando efeitos do material através do mesmo parâmetro utilizado pelo VDI-Wärmeatlas (1994), a correlação de Benjamin e Balakrishnan (1996) apresentou desvios médios elevados e com valores próximos para as superfície de distintos materiais. É interessante ressaltar a redução do desvio médio proporcionado pela correlação de Haider e Webb (1997) com o incremento da rugosidade. Este comportamento pode ser resultante do fato da correlação não incorporar o efeito da rugosidade, embora, provavelmente, tenha sido desenvolvida a partir de superfícies rugosas.

As demais correlações, embora algumas tenham a pretensão de serem generalizadas, apresentam desvios médios elevados. Isto advêm de suas constantes e expoentes terem sido ajustados a condições distintas das deste estudo, além de não envolverem efeitos explícitos do acabamento superficial e do material da superfície. Considerando tal fato e objetivando minimizar efeitos de características experimentais, optou-se por analisá-las referindo o coeficiente de transferência de calor àquele correspondente a uma determinada condição experimental.

As Figs. 6.7 e 6.8 ilustram os resultados experimentais e os proporcionados pelas correlações em termos do parâmetro adimensional $h / h\left(\phi=10 \mathrm{~kW} / \mathrm{m}^{2}\right)$ em função do fluxo específico de calor. Nelas verifica-se que as curvas obtidas através das correlações de Rohsenow (1952), Foster e Zuber (1955), Stephan e Abdelsalam (1980), Cooper (1984), Haider e Webb (1997) e Benjamin e Balakrishnan (1996) não têm sua inclinação alterada com $p_{r}$. Com exceção desta última, tal comportamento seria de esperar, pelas formas gerais das correlações em que $\phi$ aparece como um fator multiplicativo, de expoente constante, dos demais parâmetros. No caso de Benjamin e Balakrishnan (1996), embora o fluxo de calor total seja o resultado da soma de distintas parcelas representativas dos efeitos que 
Tabela 6.5 Desvios médios entre os resultados experimentais e os das correlações.

\begin{tabular}{|c|c|c|c|c|c|}
\hline & $\begin{array}{c}\text { Stephan e } \\
\text { Abdelsalam } \\
\text { (1980) }\end{array}$ & $\begin{array}{l}\text { Cooper } \\
(1984)\end{array}$ & $\begin{array}{c}\text { VDI- } \\
\text { Wärmeatlas } \\
(1994)\end{array}$ & $\begin{array}{c}\text { Rohsenow } \\
\text { (1951) }\end{array}$ & $\begin{array}{c}\text { Foster e } \\
\text { Zuber (1955) }\end{array}$ \\
\hline cobre & $16 \%$ & $31 \%$ & $24 \%$ & $49 \%$ & $30 \%$ \\
\hline latão & $10 \%$ & $30 \%$ & $43 \%$ & $41 \%$ & $27 \%$ \\
\hline aço inoxidável & $37 \%$ & $17 \%$ & $72 \%$ & $28 \%$ & $65 \%$ \\
\hline R-11 & $20 \%$ & $27 \%$ & $39 \%$ & $41 \%$ & $41 \%$ \\
\hline R-123 & $22 \%$ & $30 \%$ & $34 \%$ & $51 \%$ & $40 \%$ \\
\hline R-12 & $12 \%$ & $17 \%$ & $26 \%$ & $34 \%$ & $27 \%$ \\
\hline R-22 & $10 \%$ & $38 \%$ & $28 \%$ & $38 \%$ & $25 \%$ \\
\hline R-134a & $18 \%$ & $30 \%$ & $44 \%$ & $54 \%$ & $33 \%$ \\
\hline $\boldsymbol{R} \boldsymbol{a}$ reduzido & $13 \%$ & $30 \%$ & $29 \%$ & $33 \%$ & $30 \%$ \\
\hline $\boldsymbol{R} \boldsymbol{a}$ intermediário & $15 \%$ & $32 \%$ & $21 \%$ & $51 \%$ & $24 \%$ \\
\hline $\boldsymbol{R} \boldsymbol{a}$ elevado & $20 \%$ & $30 \%$ & $22 \%$ & $70 \%$ & $41 \%$ \\
\hline \multirow[t]{2}{*}{ total } & $17 \%$ & $29 \%$ & $35 \%$ & $44 \%$ & $34 \%$ \\
\hline & $\begin{array}{l}\text { Zuber } \\
\text { (1963) }\end{array}$ & $\begin{array}{c}\text { Mikic e } \\
\text { Rohsenow } \\
\text { (1969) }\end{array}$ & $\begin{array}{c}\text { Nishikawa e } \\
\text { Fujita (1977) }\end{array}$ & $\begin{array}{c}\text { Benjamin e } \\
\text { Balakrishnan } \\
(1996)\end{array}$ & $\begin{array}{c}\text { Haider e } \\
\text { Webb (1997) }\end{array}$ \\
\hline cobre & $34 \%$ & $36 \%$ & $57 \%$ & $62 \%$ & $89 \%$ \\
\hline latão & $27 \%$ & $37 \%$ & $51 \%$ & $54 \%$ & $113 \%$ \\
\hline aço inoxidável & $34 \%$ & $82 \%$ & $29 \%$ & $47 \%$ & $183 \%$ \\
\hline R-11 & $38 \%$ & $32 \%$ & $50 \%$ & $46 \%$ & $76 \%$ \\
\hline R-123 & $35 \%$ & $38 \%$ & $46 \%$ & $50 \%$ & $100 \%$ \\
\hline R-12 & $29 \%$ & $40 \%$ & $58 \%$ & $66 \%$ & $109 \%$ \\
\hline R-22 & $28 \%$ & $41 \%$ & $56 \%$ & $71 \%$ & $119 \%$ \\
\hline R-134a & $28 \%$ & $62 \%$ & $52 \%$ & $64 \%$ & $143 \%$ \\
\hline $\boldsymbol{R} \boldsymbol{a}$ reduzido & $20 \%$ & $55 \%$ & $45 \%$ & $54 \%$ & $144 \%$ \\
\hline $\boldsymbol{R} \boldsymbol{a}$ intermediário & $35 \%$ & $22 \%$ & $59 \%$ & $63 \%$ & $73 \%$ \\
\hline $\boldsymbol{R} \boldsymbol{a}$ elevado & $53 \%$ & $28 \%$ & $72 \%$ & $74 \%$ & $27 \%$ \\
\hline total & $32 \%$ & $43 \%$ & $52 \%$ & $58 \%$ & $108 \%$ \\
\hline
\end{tabular}

* Nos modelos de Zuber (1962), Mikic e Rohsenow (1969) e Haider e Webb (1997) determinou-se $n / A$ segundo a Eq. (3.51) adotando a constante e o expoente sugeridos por Silva (1989). Nestes modelos $d_{b}$ e $f$ foram determinados, respectivamente, pelas Eqs. (2.13) e (2.23).

** Nos demais modelos foram adotadas as equações para $d_{b}, f$ e $n / A$, as contanstes e os expoentes sugeridos pelos autores originais.

***Nomenclatura utilizada: $R a_{\text {reduzidos }}<0,2 \mu \mathrm{m} ; R a_{\text {intermediário }} \approx 0,5 \mu \mathrm{m} ; R a_{\text {elevado }}>2 \mu \mathrm{m}$ 
intervêm no modelo, sua correlação apresenta uma forma similar. Tal comportamento é resultante da transferência de calor devido ao mecanismo de evaporação da microcamada ser dominante, fazendo com que os demais efeitos sejam desprezíveis.

Nas Figs. 6.7 e 6.8 constata-se, para as correlações de Zuber (1963), Mikic e Rohsenow (1969) e do VDI-Wärmeatlas (1994), a alteração da inclinação da curva $h / h\left(\phi=10 \mathrm{~kW} / \mathrm{m}^{2}\right)$ vs $\phi$ com a pressão reduzida. Nos modelos de Zuber (1963) e Mikic e Rohsenow (1969), este comportamento, embora quase imperceptível, é resultante do efeito de convecção natural.

De uma maneira geral, as correlações que apresentam variações na inclinação da curva $h / h\left(\phi=10 \mathrm{~kW} / \mathrm{m}^{2}\right)$ vs $\phi$ com a pressão se caracterizam por uma dependência explícita de $p_{r}$. Por outro lado, os resultados experimentais, com exceção daqueles para o R-12, não ilustrados nas figuras, em que a inclinação permaneceu aproximadamente constante, indicaram claramente a redução da inclinação com o incremento da pressão reduzida, comportamento que, em parte, foi incorporado à correlação do VDI-Wärmeatlas (1994), a qual proporciona inclinações razoavelmente coincidentes com as verificadas nos resultados experimentais. Este comportamento parece ocorrer com maior intensidade quando considerado a partir de valores reduzidos de $p_{r}$. É interessante ressaltar que as correlações de Stephan e Abdelsalam (1980) e Cooper (1984), embora apresentem uma inclinação constante, proporcionam resultados intermediários relativamente aos experimentais para as distintas pressões reduzidas.

Analogamente às figuras anteriores, a Fig. 6.9 ilustra os resultados experimentais e os proporcionados pelas correlações em termos de um parâmetro adimensional, neste caso $h / h\left(p_{r}=0,011\right)$ em função da pressão reduzida. Ressalta-se que as únicas correlações que incorporam explicitamente os efeitos de interação entre o acabamento superficial e a pressão reduzida são a de Cooper (1984) e a de Benjamin e Balakrishnan (1996). Excluindo-as, constata-se que, nesta figura, relativamente à inclinação da curva $h / h\left(p_{r}=0,011\right)$ vs $p_{r}$, as correlações podem ser divididas basicamente nos seguintes grupos:

> Inclinação superior à dos resultados experimentais: Mikic e Rohsenow (1969), Stephan e Abdelsalam (1980), VDI-Wärmeatlas (1994) e Haider e Webb (1997).

$>$ Inclinação inferior a dos resultados experimentais: Rohsenow (1952), Foster e Zuber (1955), Nishikawa e Fujita (1977). 

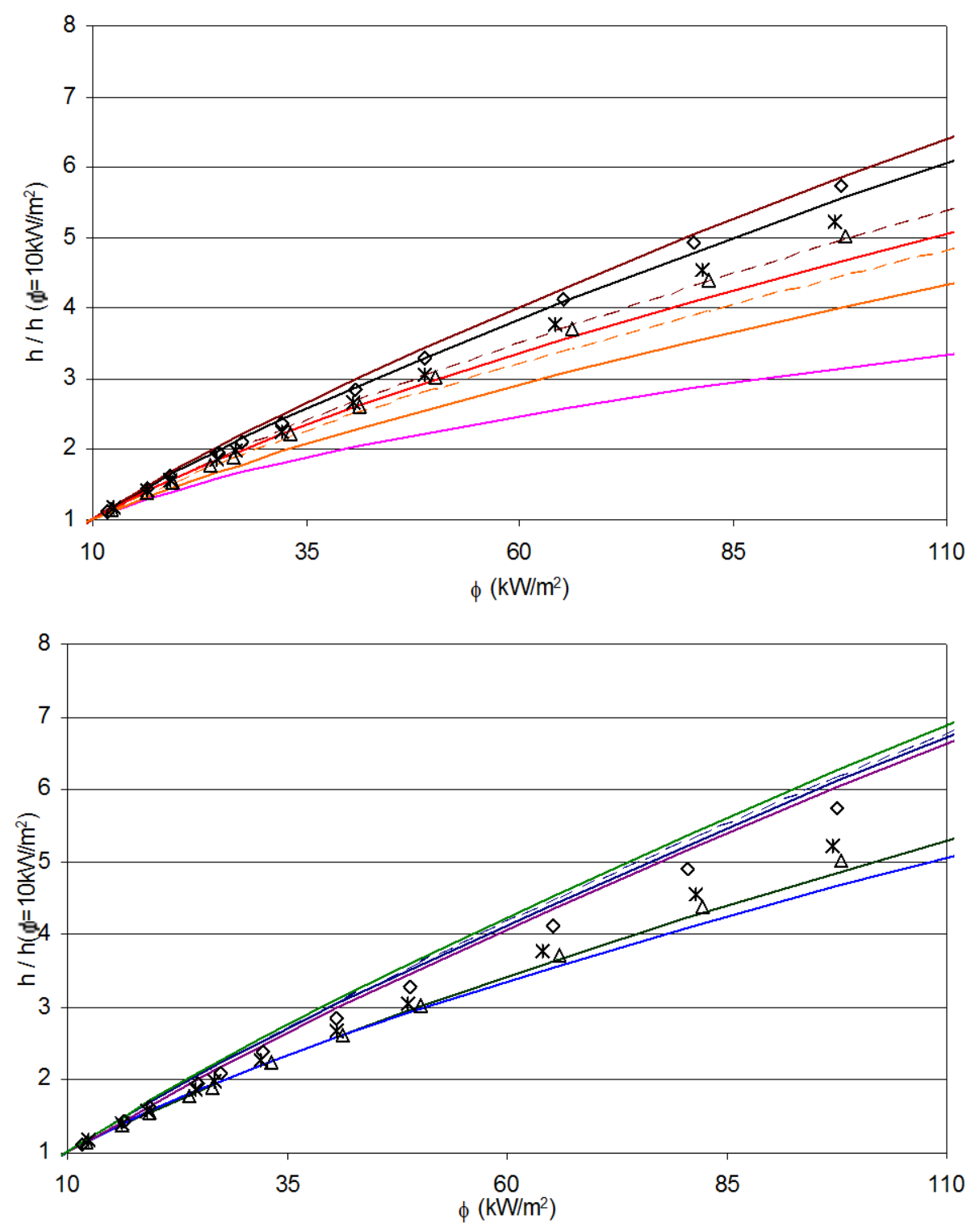

$\diamond \quad$ experimental $p r=0,064$

$\Delta \quad$ experimental $p r=0,260$

- Foster e Zuber (1955)

Zuber (1963) pr=0,260

. . . . . . Mikic e Rohsenow (1969) pr=0,260

Stephan e Abdelsalam(1980)

VDI-Wärmeatlas (1994) pr=0,064

Benjamin e Balakrishnan (1996)

* experimental $\mathrm{pr}=0,120$

Rohsenow (1952)

Zuber (1963) pr=0,064

Mikic e Rohsenow (1969) pr=0,064

Nishikaw a e Fujita (1977)

Cooper (1984)

VDI-Wärmeatlas(1994) pr=0,260

Haider e Webb (1997)

Figura 6.7 Variação do parâmetro adimensional $h / h\left(\phi=10 \mathrm{~kW} / \mathrm{m}^{2}\right)$ para o R-134a com $R a=0,07 \mu \mathrm{m}$ e a superfície de cobre. 

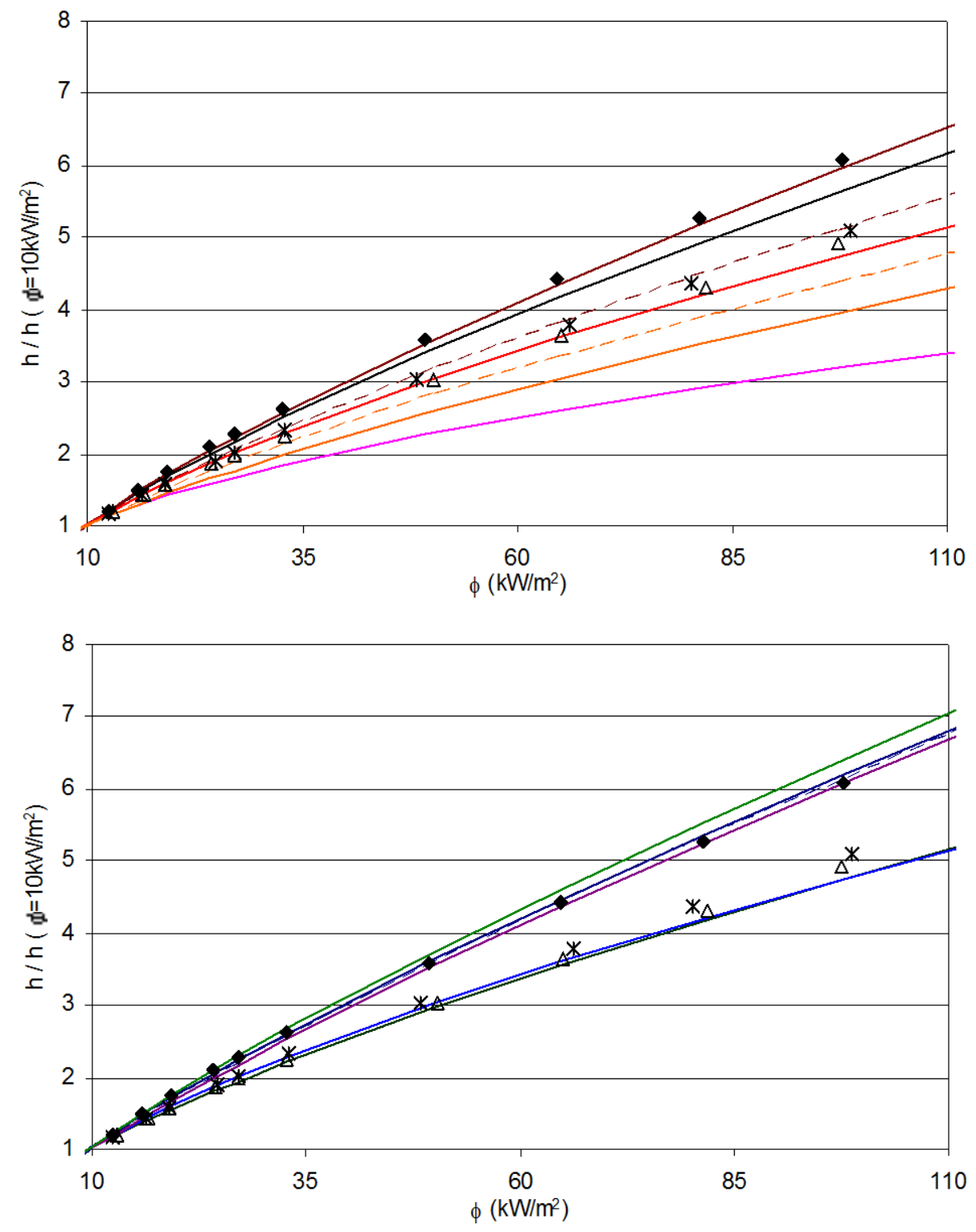

- experimental $\mathrm{pr}=0,064$

$\Delta \quad$ experimental $\mathrm{pr}=0,200$

- Foster e Zuber (1955)

- Zuber (1963) pr=0,200

..... . Mikic e Rohsenow (1969) $\mathrm{pr}=0,200$

Stephan e Abdelsalam(1980)

VDI-Wärmeatlas (1994) pr=0,064

* experimental $\mathrm{pr}=0,120$

Rohsenow (1952)

Zuber (1963) pr=0,064

Mikic e Rohsenow (1969) pr=0,064

Nishikaw a e Fujita (1977)

Benjamin e Balakrishnan (1996)

Cooper (1984)

. . . . . . VDI-Wärmeatlas(1994) $\mathrm{pr}=0,200$

Haider e Webb (1997)

Figura 6.8 Variação do parâmetro adimensional $h / h\left(\phi=10 \mathrm{~kW} / \mathrm{m}^{2}\right)$ para o R-22 com $R a=0,07 \mu \mathrm{m}$ e a superfície de cobre.

Verifica-se, através da análise dos bancos de dados utilizados pelos distintos autores, que com exceção de Mikic e Rohsenow, que o primeiro grupo utilizou resultados 
experimentais para refrigerantes halogenados, ao contrário do segundo, que envolveu basicamente dados para a água. Conforme ilustrado na Fig. 6.9, segundo a correlação de Cooper (1984), para um mesmo $p_{r}$, ocorre a redução da relação entre coeficientes de transferência de calor com o incremento de $R a$, comportamento oposto e em menor intensidade ao verificado experimentalmente. Resultado similar ocorre para o R-123. Apesar de não ilustrado nas figuras, constata-se, para os refrigerantes mais voláteis (R-12, R-22 e R134a), o incremento da relação $\mathrm{h} / \mathrm{h} \quad\left(p_{r}=\right.$ constante) com $\mathrm{Ra}$, embora verificado experimentalmente em menor intensidade, este comportamento é similar ao previsto pela correlação de Cooper (1984). Neste caso, o coeficiente de transferência de calor foi referido àquele obtido sob mesmas condições experimentais, mas com $p_{r} \approx 0,064$. Tal distinção de comportamento entre os refrigerantes pouco voláteis e os voláteis não é verificada ao se referir o coeficiente de transferência de calor a um mesmo valor de $p_{\mathrm{r}}$ igual a 0,064 . Neste ponto é interessante ressaltar que a correlação de Cooper (1984), ainda que envolva efeitos de interação entre $p_{r}$ e a rugosidade superficial, não prediz tal comportamento.

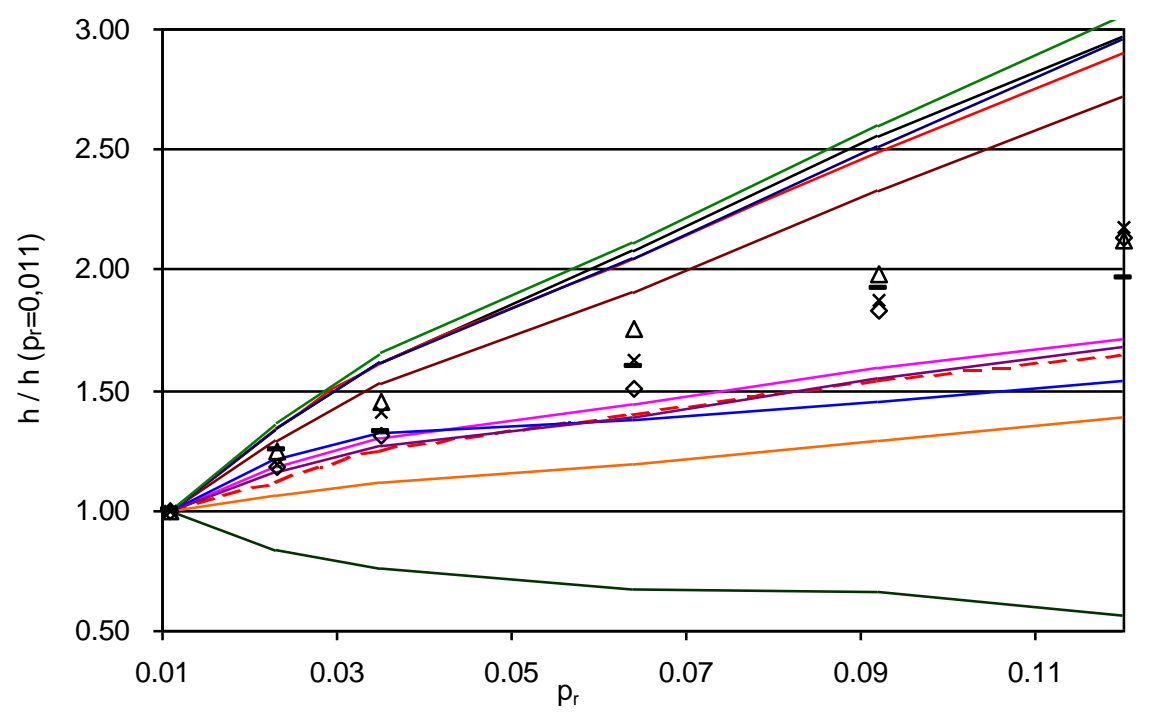

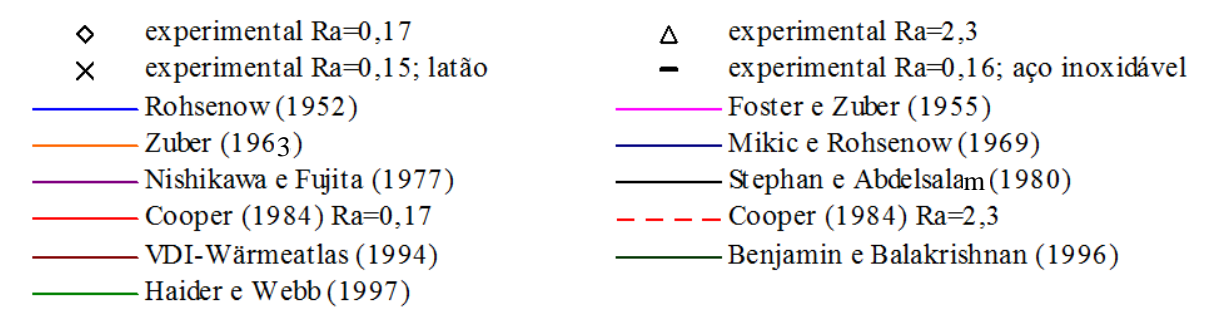

Figura 6.9 Variação do adimensional $h / h\left(p_{r}=0,011\right)$ com $p_{r}$ para o R-11 com $\phi=30 \mathrm{~kW} / \mathrm{m}^{2}, R a=0,17 \mu \mathrm{m}$, quando não especificado considerar a superfície de cobre.

Destaca-se também na Fig. (6.9) a redução do coeficiente de transferência de calor com o incremento da pressão para o modelo de Benjamin e Balakrishnan (1996). Tal 
comportamento é oposto àquele dos demais modelos e ao dos resultados experimentais, resultando do restrito banco de dados experimentais utilizado pelos autores, o qual, embora utilize 4 fluidos distintos (água, $\mathrm{CCl}_{4}$, acetona e $\mathrm{n}$-hexano) envolve resultados somente para $p_{s a t}=100 \mathrm{kPa}$. Desta maneira, seu ajuste não contempla variações na pressão reduzida. Segundo este modelo, apesar das parcelas da transferência de calor devido aos mecanismos de condução transiente e convecção natural terem seus valores elevados com o incremento de $p_{r}$, a parcela devido a evaporação da microcamada, mecanismo dominante, tem seu valor reduzido. Tal resultado, a despeito do incremento de $n / A$ (número específico de cavidades ativas), Eq. (2.29), decorre da redução com $p_{r}$ dos demais fatores da Eq. (3.65), aos quais a parcela do fluxo de calor total, transferida através deste mecanismo, é diretamente proporcional.

A Fig. 6.10 ilustra os resultados experimentais e os proporcionados pelas correlações que envolvem explicitamente efeitos do acabamento superficial em termos do parâmetro adimensional $h / h(R a=0,08 \mu \mathrm{m})$ em função de $R a$, para o refrigerante R-134a. Nesta figura, com exceção do modelo de Benjamin e Balakrishnan (1996), constata-se o incremento do adimensional $h / h(R a=0,08 \mu \mathrm{m})$ com a pressão reduzida.

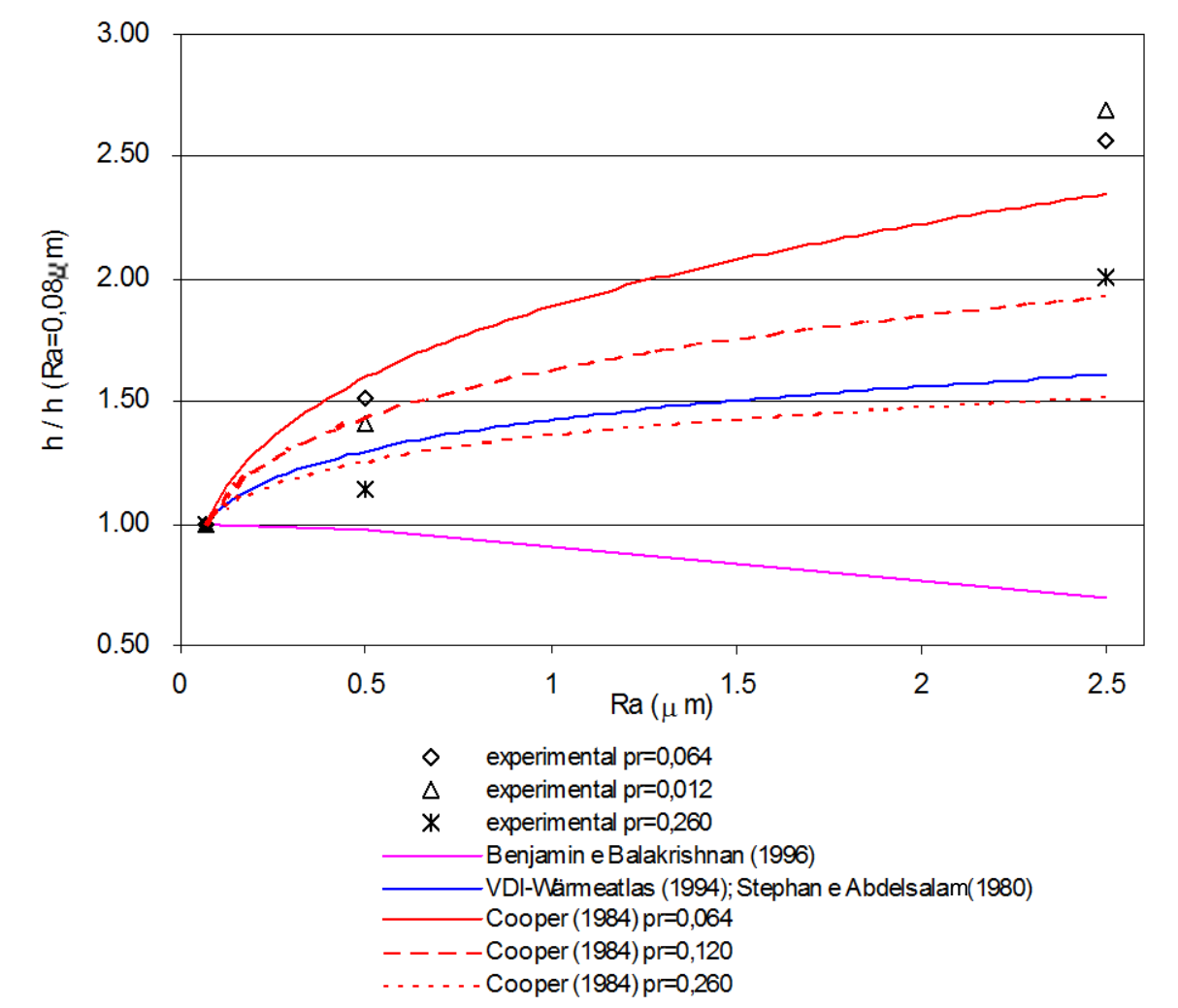

Figura 6.10 Variação do adimensional $h / h(R a=0,08 \mu \mathrm{m})$ com $R a$ para o R-134a com $\phi=30 \mathrm{~kW} / \mathrm{m}^{2}$, superfície de cobre. 
As correlações de Stephan e Abdelsalam (1980) e do VDI-Wärmeatlas (1994) não envolvem efeitos de interação entre $R a$ e $p_{r}$, sendo o efeito da rugosidade dado basicamente pela seguinte relação: (parâmetro de rugosidade ${ }^{0,133}$, resultando curvas coincidentes. Isto não condiz com o comportamento dos resultados experimentais, segundo os quais, para pressões reduzidas inferiores, alterações no acabamento superficial implicam em variações superiores do coeficiente de transferência de calor em relação àquelas verificada para valores de $p_{r}$ mais elevados. Este comportamento é similar ao apresentado pela correlação de Cooper (1984).

A correlação de Benjamin e Balakrishnan (1996) proporciona uma redução no adimensional $h$ / $h(R a=0,08 \mu \mathrm{m})$ com o incremento de $R a$. Tal fato decorre da Eq. (2.29), utilizada pelos autores na previsão do número de cavidades ativas, prever uma redução do número de cavidades ativas com o incremento de $R a$ e, consequentemente, do coeficiente de transferência de calor para este refrigerante, na faixa de rugosidades considerada. Uma discussão detalhada dos resultados proporcionados pela Eq. (2.29) foi realizada no Capítulo 2, item 2.5.2. Ressalta-se que os comportamentos verificados na Fig. 6.10 tanto para os resultados experimentais como para as correlações podem ser estendidos aos demais refrigerantes e condições experimentais.

Finalmente, a Tabela 6.6 ilustra os resultados experimentais e os proporcionado pelas correlações que envolvem explicitamente efeitos do material da superfície em termos do parâmetro adimensional $h / h$ (cobre), para o refrigerante R-123. Constata-se que, na correlação do VDI-Wärmeatlas (1994), os efeitos do material através do produto $\left(k_{p} \cdot \rho_{p} \cdot c_{p}\right)$ são superestimados quando comparados aos resultados experimentais. A correlação de Benjamin e Balakrishnan (1996), embora proporcione uma redução de $h$ para a superfície de latão próxima à verificada experimentalmente, apresenta coeficientes de transferência de calor superiores para a superfície de aço inoxidável, comportamento oposto ao verificado, o qual indica uma significativa redução de $h$ para este material. O comportamento apresentado pela correlação, conforme mencionado anteriormente, resulta do restrito banco de dados utilizado pelos autores no ajuste da Eq. (2.29). É interessante ressaltar o fato destas correlações envolverem o efeito do material através, apenas, de $k_{p}, \rho_{p}$ e $c_{p}$, não incluindo efeitos de interação entre o líquido em ebulição e a superfície de transferência de calor, associados ao ângulo de contato. Tais efeitos são analisados na próxima seção e, conforme sugerido por Wang e Dhir (1993), revelam-se extremamente importantes na previsão da taxa de transferência de calor através do mecanismo de ebulição nucleada. 
Tabela 6.6 Comparação entre os resultados das correlações e os experimentais da relação $h / h_{\text {cobre }}$ para diferentes materiais da superfície; R-123, $p_{r}=0,011, \phi=30 \mathrm{~kW} / \mathrm{m}^{2}, R a \approx 0,16 \mu \mathrm{m}$.

\begin{tabular}{lccc}
\hline \hline & experimental & $\begin{array}{c}\text { Benjamin e } \\
\text { Balakrishnan (1996) }\end{array}$ & $\begin{array}{c}\text { VDI-Wärmeatlas } \\
\mathbf{( 1 9 9 4 )}\end{array}$ \\
\hline \hline cobre & 1 & 1 & 1 \\
\hline latão & 0,946 & 0,957 & 0,481 \\
\hline aço inoxidável & 0,798 & 1,041 & 0,206 \\
\hline \hline
\end{tabular}

\subsubsection{Análise Paramétrica dos Fatores que Afetam a Ebulição Nucleada}

\subsubsection{Efeitos de $\phi$ em h e o Fluxo Crítico de Calor}

A elevação do coeficiente de transferência de calor com $\phi$ ocorre, principalmente, como resultado do incremento no número de cavidades ativas e depende de inúmeros fatores. Entre eles, podem ser citados o regime de ebulição, a pressão, o material e acabamento da superfície e o fluido refrigerante. No caso do regime de ebulição, com baixos fluxos específicos de calor tem-se uma taxa de variação de $h$ com $\phi$ reduzida constituindo o denominado regime de ebulição nucleada parcial. Neste regime, o mecanismo de transferência de calor dominante é ainda a convecção natural. Com o incremento de $\phi \mathrm{e}$, consequentemente, do superaquecimento da superfície, o número de cavidades ativas aumenta atingindo-se o regime de ebulição nucleada plenamente desenvolvida, no qual variações elevadas de $\phi$ resultam em pequenas alterações de $\left(T_{p}-T_{s a t}\right)$. A partir de um determinado fluxo de calor, numa região restrita da curva de ebulição, incrementos de $\phi$ resultam no decréscimo da inclinação da curva de ebulição até alcançar o fluxo crítico de calor.

O valor do fluxo crítico de calor depende de características como o material da superfície, a rugosidade superficial, o fluido refrigerante, a pressão e se o fluxo específico de calor através da superfície é incrementado gradualmente ou rapidamente até valores elevados. Segundo os resultados experimentais, o decréscimo da condutividade térmica do material da superfície e da pressão, bem como o incremento de $R a$, resultam na redução do $\phi$ necessário para a transição entre os regimes de ebulição nucleada e ebulição em película. Comportamento similar é verificado com a aplicação instantânea de um valor elevado de $\phi$, quando comparado a uma situação em que o fluxo específico de calor foi elevado gradualmente. No presente estudo, o alcance do fluxo crítico de calor resultou, algumas 
vezes, em danos na superfície de ensaio. Desta forma, embora não seja o propósito aqui estender-se na análise de tal tema, ele foi incluído, apenas, para justificar as diferenças no valor do $\phi$ máximo aplicado a cada superfície. Este valor foi limitado com o objetivo evitar o fluxo crítico e desta forma, uma possível danificação da superfície de ensaios. Com base neste procedimento, o valor de $\phi$ máximo aplicado às superfícies de latão e aço inoxidável foram, respectivamente, 90 e $70 \mathrm{~kW} / \mathrm{m}^{2}$. Para a superfície de cobre, embora o fluxo crítico de calor não tenha sido alcançado em condições de elevação gradual de $\phi$, o valor máximo aplicado foi $120 \mathrm{~kW} / \mathrm{m}^{2}$, devido a limitações da resistência elétrica do tipo cartucho, localizada no interior da superfície de ensaio. A figura abaixo ilustra uma das curvas de ebulição levantadas envolvendo a transição entre ebulição nucleada e em película.

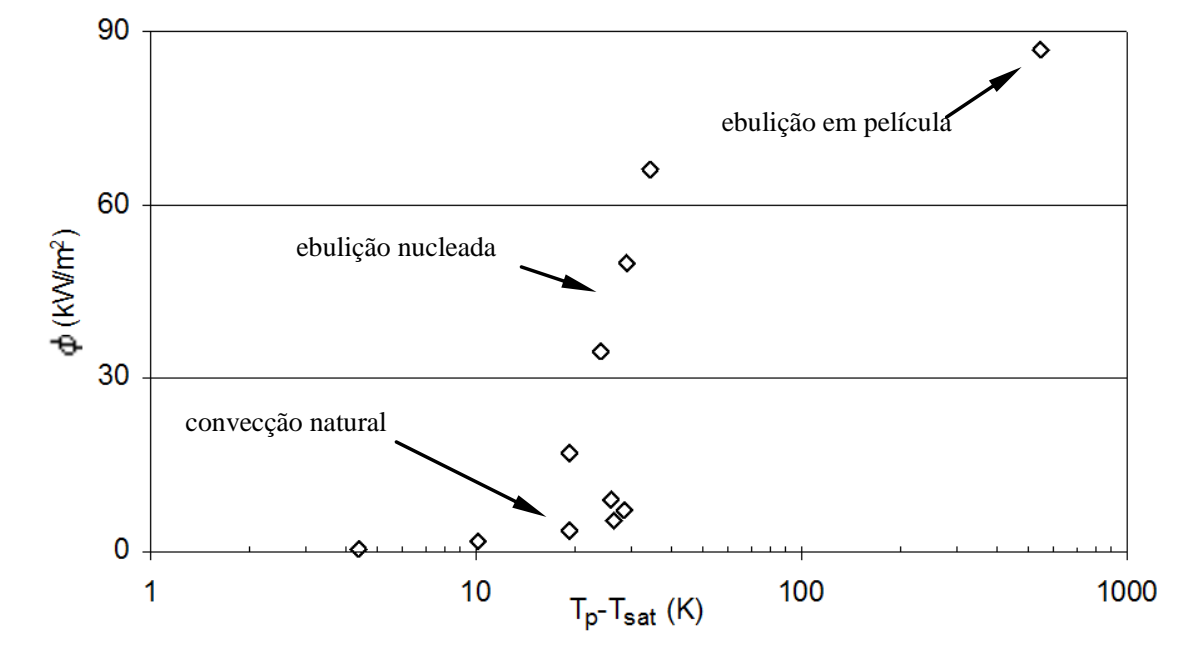

Figura 6.11 Curva de ebulição ilustrando a transição entre ebulição nucleada e em película com o R-11, superfície de aço inoxidável, $R a=0,02 \mu \mathrm{m}$, e $T_{\text {sat }}=24^{\circ} \mathrm{C}$.

Os demais fatores que afetam a variação de $h \operatorname{com} \phi$, citados anteriormente, serão analisados nos itens a seguir.

\subsubsection{Refrigerante}

De uma maneira geral os refrigerantes mais voláteis (R-12, R-22, R-134a) apresentaram coeficientes de transferência de calor superiores aos de baixa pressão (menos voláteis), R-11 e R-123. Já, na comparação dentro de cada grupo, o melhor desempenho depende da pressão reduzida, da rugosidade e do material da superfície. Tal fato resulta de diferenças entre as propriedades termodinâmicas e de transporte do refrigerante, além da 
interação com a superfície de transferência de calor. Estas propriedades influenciam a transferência de calor por modificarem o número de cavidades ativas, o formato e a dinâmica de bolhas junto à superfície e seus períodos de crescimento e espera. A Fig. 6.12 apresenta uma comparação entre as curvas de ebulição desses refrigerantes

As diferenças de desempenho ilustradas na Fig. 6.12 para os refrigerantes analisados podem ser justificadas através de duas propriedades dos refrigerantes que afetam concomitantemente o mecanismo de transferência de calor e estão relacionadas ao nível de agitação do líquido junto a superfície. Elas são a tensão superficial e o número de Prandtl do líquido. A influência da tensão superficial esta associada, principalmente, ao número de cavidades ativas, de forma que fluidos com valores de $\sigma$ superiores, conforme indicado pela Eq. (2.31), proposta por Wang e Dhir (1993), apresentam, para um mesmo superaquecimento, uma menor densidade de cavidades ativas.

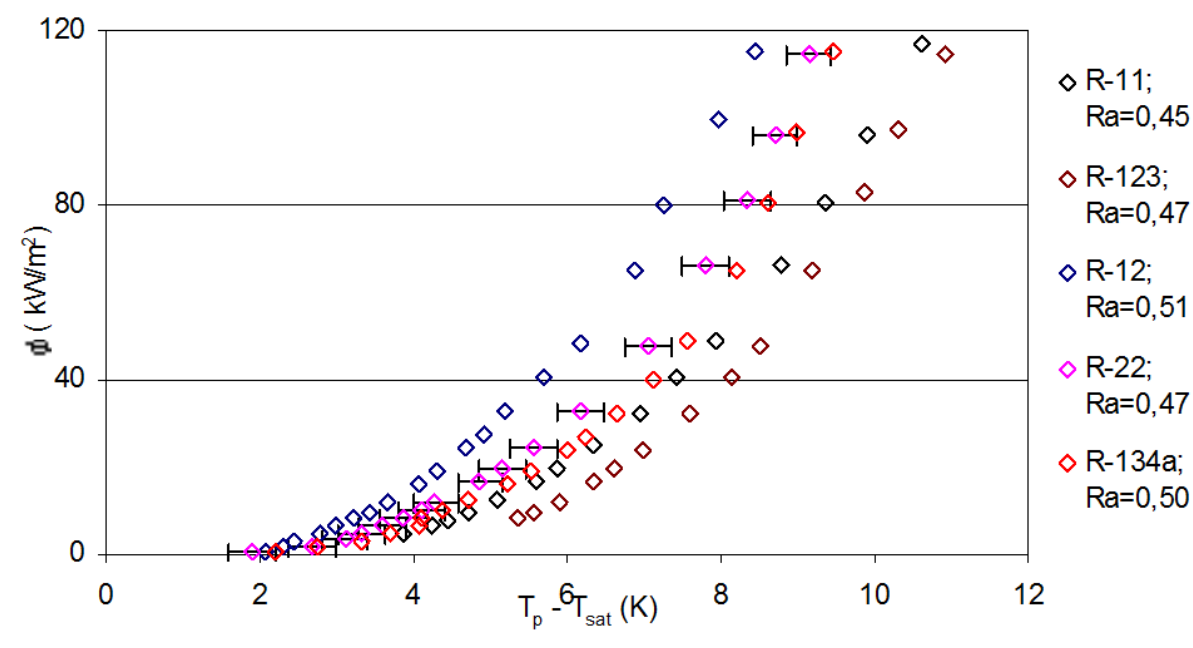

Figura 6.12 Comparação do desempenhos dos refrigerantes para $p_{r}=0,064$ na superfície de cobre.

No caso de $P r_{l}$ constata-se que sua influência se dá de forma inversa à verificada em um problema típico de camada limite (convecção forçada), no qual ocorre, com a elevação de $\operatorname{Pr}_{l}$, o incremento do coeficiente de transferência de calor. Na transferência de calor em ebulição nucleada, onde devido a características intrínsecas ao mecanismo físico, não se definem, propriamente, camadas limite térmica e cinemática, têm-se a redução de $h$ com o incremento de $\operatorname{Pr}_{l}$. Este comportamento, verificado na maioria das correlações, esta associado aos efeitos das propriedades de transporte $v_{l}$ e $a_{l}$ nos mecanismos de transferência de calor inerentes ao fenômeno de ebulição. $\mathrm{O}$ incremento da viscosidade cinemática atua de forma a reduzir efeitos convectivos proporcionados pelo crescimento e desprendimento de bolhas. Já, a redução da difusividade térmica tende a incrementar o período de espera. 
Ambos efeitos, que resultam na elevação da relação $v_{l} / a_{l}$, escrita em termos do número de Prandtl do líquido, proporcionam o decréscimo do coeficiente de transferência de calor.

Para a análise do efeito do refrigerante no coeficiente de transferência de calor através da $\sigma$ e de $P r$, elaborou-se a Tabela 6.7. Nela são comparados, para os distintos refrigerantes, valores destas propriedades relativas às do R-11. Os resultados apresentados parecem indicar, para uma mesma condição experimental, a seguinte ordem decrescente de h: R-12, R-22, R-134a, R-11 e R-123, que é similar a ilustrada na Fig. 6.12. Na tabela, constata-se que o R-12 com valores de $\sigma$ e $\operatorname{Pr}_{l}$, respectivamente, cerca de 10 e $20 \%$ inferiores ao R-11 apresentou um $h$ superior aos demais, seguido do R-22 cuja tensão superficial é similar à do R-11, mas apresenta um número de Prandtl do líquido inferior àquele dos demais refrigerantes. Os refrigerantes R-134a e R-123, embora apresentem uma tensão superficial inferior à do R-11, se caracterizam por valores de Prandtl superiores. No caso do R-134a, o efeito da tensão superficial em $n / A$ parece ser preponderante ao do $\mathrm{Pr}_{l}$, fazendo com que este refrigerante ainda tenha um desempenho superior ao R-11. Já no caso do R-123, tal fato não ocorre, pois embora sua tensão superficial seja próxima à do R-134a, o Prandtl é cerca de $10 \%$ superior ao deste refrigerante, proporcionando um desempenho inferior ao R-11.

Tabela 6.7 Comparação relativa do $P r_{l}$ e da $\sigma$ para distintos refrigerantes com $p_{r}=0,12$.

\begin{tabular}{lcccc} 
& $\mathrm{R}-123$ & $\mathrm{R}-12$ & $\mathrm{R}-22$ & $\mathrm{R}-134 \mathrm{a}$ \\
\hline \hline$\sigma / \sigma_{R-11}$ & 0,88 & 0,88 & 1,00 & 0,87 \\
\hline $\operatorname{Pr}_{l} / \operatorname{Pr}_{l R-11}$ & 1,21 & 0,79 & 0,62 & 1,12 \\
\hline \hline
\end{tabular}

É interessante ressaltar que esta análise individualizada do efeito do refrigerante através de suas propriedades é um tanto restrita por não incorporar, por exemplo, efeitos de superfície como a rugosidade e o material .

\subsubsection{Efeito da Pressão}

Independentemente do fluido, verificou-se que, com o incremento da pressão, a curva de ebulição se desloca para a esquerda. O nível de deslocamento depende do 
refrigerante, da rugosidade e material da superfície e da faixa de pressões reduzidas envolvida. Tal deslocamento resulta na elevação do coeficiente de transferência de calor. A Fig. 6.13 ilustra o referido efeito para a ebulição do R-11 em uma superfície de aço inoxidável. Nela constata-se que o efeito é mais significativo para valores reduzidos de $p_{r}$. Este comportamento pode ser estendido aos demais refrigerantes ensaiados.

$\mathrm{O}$ incremento de $h$ com $p_{r}$, ilustrado na Fig. 6.13, está relacionado à energia de ativação de núcleos ativos. Quanto menor a pressão, maior a energia de ativação. Além disso, com o incremento da pressão ocorre a redução da tensão superficial e de $P r_{l}$, cujo valor, conforme discutido no item anterior, é inversamente proporciona à $h$. Já, a redução de $\sigma$ resulta no decréscimo do período de espera e do $\left(r_{c}\right)_{\min }$, dados pelo modelo Han e Griffith (1965a). Neste caso permitindo que, para um mesmo superaquecimento da superfície, cavidades de menor diâmetro também sejam ativadas, elevando, desta forma, o valor de $n / A$. Finalmente, tanto a redução do período de espera como o incremento do número de cavidades ativas tendem a elevar o coeficiente de transferência de calor.

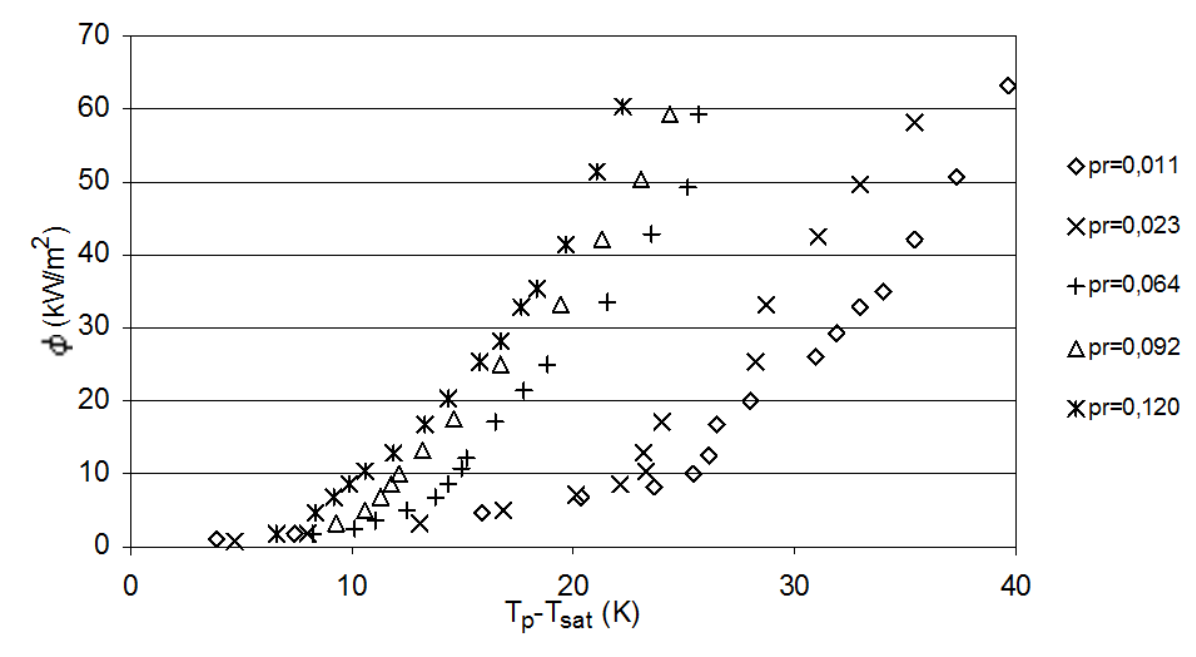

Figura 6.13 Efeito da pressão na curva de ebulição, R-11, $R a=0,02 \mu \mathrm{m}$, superfície de aço inoxidável.

Variações com a pressão reduzida de $P r_{l}, \sigma$ e $\left(r_{c}\right)_{\min }$, dado pela Eq. (2.5), são ilustrados na Fig. 6.14. Nesta figura, constatam-se taxas de variação dos parâmetros mais elevadas para valores reduzidos de $p_{r}$, o que justificaria variações de $h$ com $p_{r}$ superiores em tais condições. Tanto a tensão superficial como o $\left(r_{c}\right)_{\min }$ têm seus valores reduzidos com o incremento de $p_{r}$, independentemente do refrigerante. Já para o número de $P r_{l}$, na faixa de pressões ensaiada, a redução é verificada apenas para os refrigerantes R-11, R-123 e R-134a. Com os refrigerantes R-12 e R-22, verifica-se inicialmente um decréscimo de $P r_{l}$ até um 
valor mínimo, a partir do qual se eleva. Entretanto este incremento não é significativo na faixa de pressões ensaiadas, pois atinge um valor máximo de cerca de 1,09 vezes superior ao mínimo. Tal variação é inferior à da tensão superficial e, consequentemente, do $\left(r_{c}\right)_{\text {min }}$, fazendo com que estes efeitos, através do incremento de $n / A$, sejam dominantes.

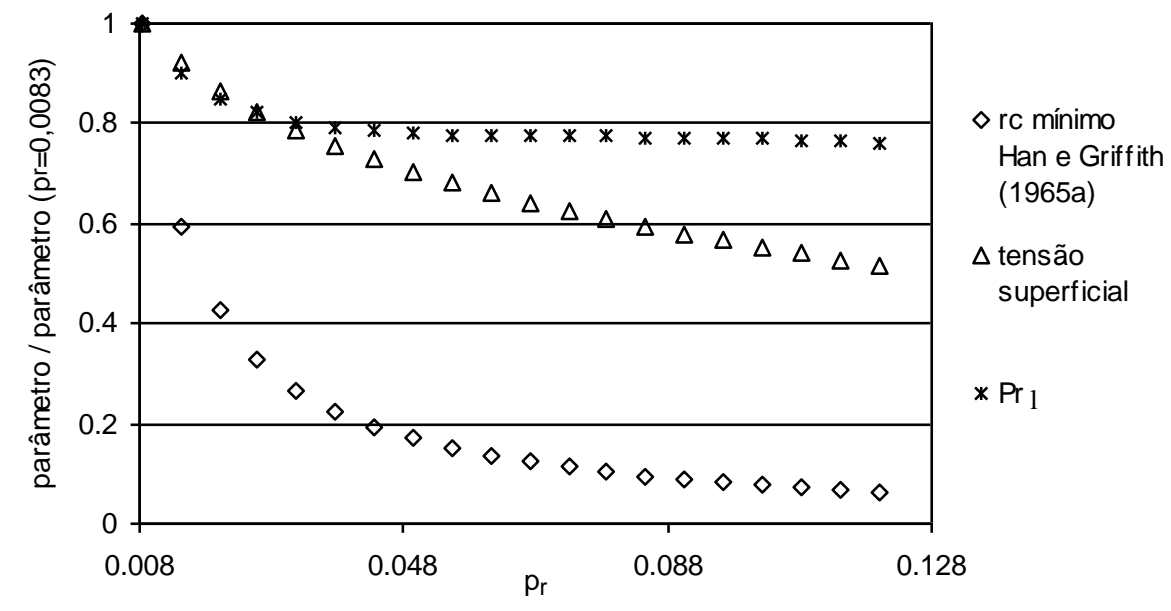

Figura 6.14 Variação com $p_{r}$ de $P r_{l}$, da $\sigma$ e do $\left(r_{c}\right)_{\text {min }}$ segundo Han e Griffith (1965a), R-11.

\subsubsection{Efeito do Acabamento Superficial}

Com o aumento da rugosidade, a curva de ebulição é deslocada para a esquerda, resultando em superaquecimentos menores para um mesmo fluxo específico de calor. Este comportamento parece ser determinado pela maior densidade de cavidades ativas proporcionada por uma superfície rugosa. Entretanto com o incremento de $R a$ verifica-se uma certa atenuação do efeito do acabamento superficial na transferência de calor. Tal comportamento parece ter uma justificativa de ordem física. Com efeito, à medida que se eleva a rugosidade da superfície aquecida, a faixa de tamanho de cavidades se amplia. Resultado distinto do verificado no presente estudo, e discutido no Capítulo 2, foi verificado por Benjamin e Balakrisnan (1996), no qual, inicialmente, foi constatada uma redução no valor de $h$ com o incremento de $R a$ para um mesmo $\Delta T$, com a ocorrência de um mínimo a partir do qual $h$ se eleva com $R a$. É interessante ressaltar que, segundo a pesquisa bibliográfica realizada, estes autores foram os únicos a sugerir tal comportamento.

Segundo Wang e Dhir (1993), somente uma fração das cavidades disponíveis (de tamanho adequado) para nucleação efetivamente se torna ativa. Apesar disso, o incremento da rugosidade é acompanhado por uma elevação da densidade de cavidades ativas, o que 
resulta no aumento do coeficiente de transferência de calor. Por outro lado, superfícies suficientemente rugosas ( $R a$ elevados) se caracterizam por apresentarem uma ampla faixa de cavidades disponíveis para nucleação, o que faz com que incrementos de $R a$ não afetem de forma tão significativa a densidade cumulativa* de cavidades ativas e, portanto, o coeficiente de transferência de calor, como ocorre no caso de superfícies mais lisas (ou de $R a$ inferiores). Resultados obtidos por Kurihara (1956) corroboram o cenário físico descrito, tendo o referido autor proposto um limite máximo de rugosidade superficial acima do qual o coeficiente de transferência de calor não mais é afetado. Cooper (1984), de certa forma concorda com as observações anteriores quando sugere que, para valores reduzidos de $p_{r}, \mathrm{o}$ coeficiente de transferência de calor é mais sensível a variações da própria pressão reduzida e da rugosidade. A Fig. 6.15 ilustra tal comportamento. Nela, para $\phi=50 \mathrm{~kW} / \mathrm{m}^{2}$ e $R a=0,17 \mu \mathrm{m}$, constata-se que a redução no superaquecimento, ao elevar-se $p_{r}$ de 0,011 para 0,023 , é igual a $3,4 \mathrm{~K}$, enquanto para $R a=2,3 \mu \mathrm{m}$ é de apenas $0,4 \mathrm{~K}$. No caso de uma elevação da rugosidade de $0,17 \mu \mathrm{m}$ para $2,3 \mu \mathrm{m}$, com $p_{r}=0,011$, verifica-se uma redução no superaquecimento de $11,2 \mathrm{~K}$, superior à redução com $p_{r}=0,12$, de $5,7 \mathrm{~K}$. Desta forma, concluise que tais tendências ilustradas na Fig. 6.15 concordam com Cooper (1984). Evidentemente, nesse mecanismo sugerido por Cooper (1984), a tensão superficial exerce um papel importante, uma vez que diminui com a pressão, favorecendo a nucleação.

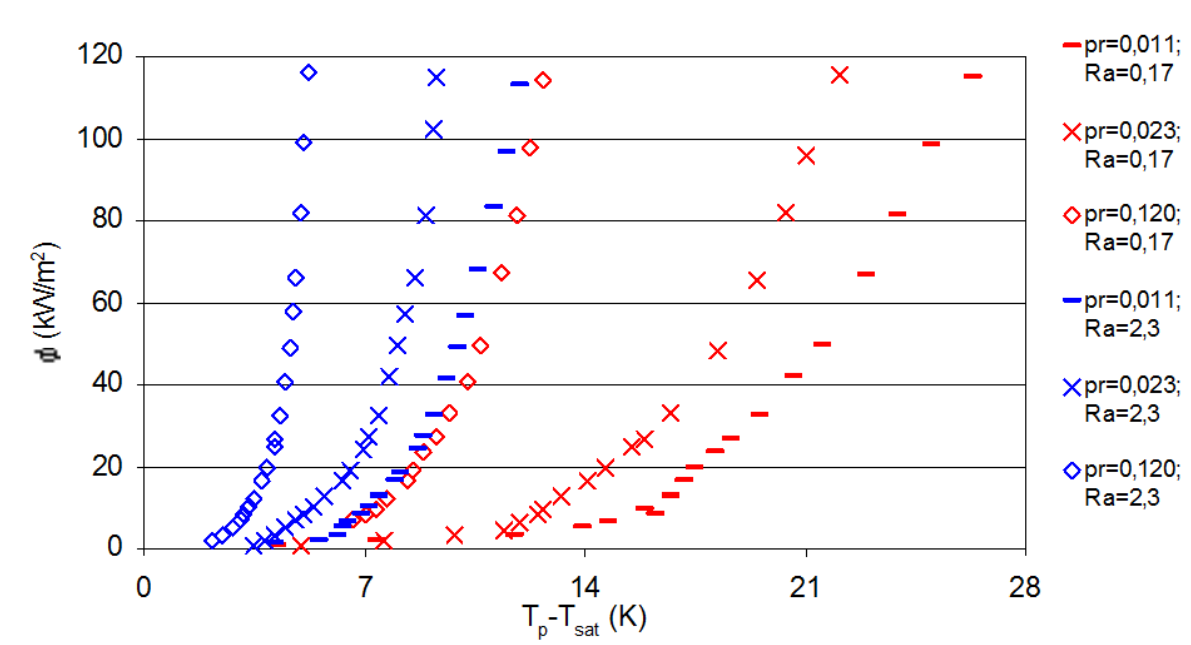

Figura 6.15 Ilustração do efeito da rugosidade para o R-11, superfície de cobre.

Embora o comportamento descrito tenha ocorrido para todos os fluidos, sua intensidade variou segundo o refrigerante. A Fig. 6.16 ilustra tal fato. Nela, o refrigerante R11 apresenta uma variação no superaquecimento da superfície superior ao R-123, ainda que a variação de $R a$ para este refrigerante tenha sido superior. No caso dos refrigerantes mais 
voláteis, um comportamento similar se verifica na Fig. 6.17, com o R-12 apresentando uma redução no superaquecimento superior ao R-134a, que, por sua vez, apresenta uma redução superior a do R-22.

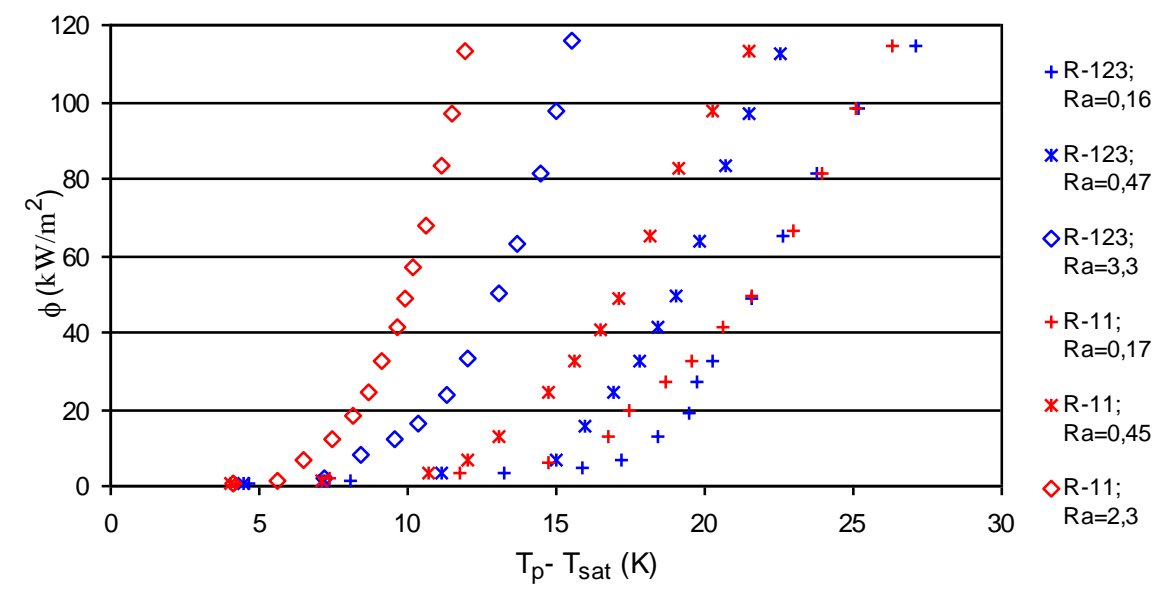

Figura 6.16 Análise comparativa do efeito da rugosidade para os refrigerantes de baixa pressão, $p_{r}=0,011$, superfície de cobre.

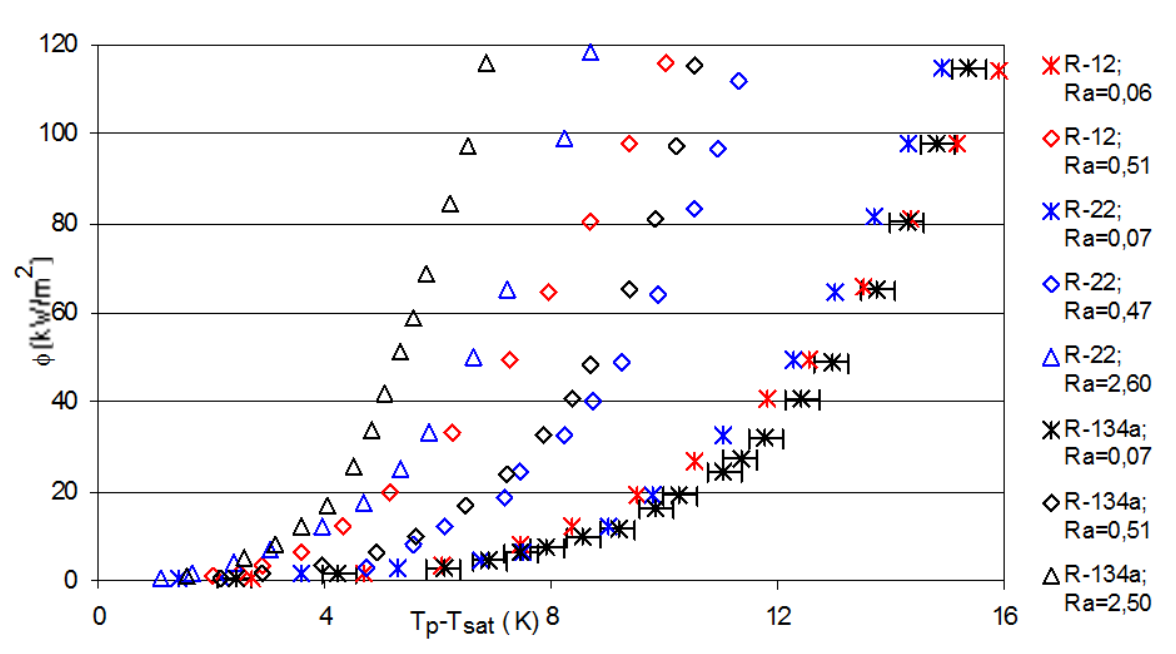

Figura 6.17 Análise comparativa do efeito da rugosidade para os refrigerantes de média pressão, $p_{r}=0,120$, superfície de cobre.

Este comportamento relativo entre os refrigerantes, em que alguns apresentam uma maior redução do superaquecimento com o incremento de $R a$, independe da pressão. Isto pode ser constatado na Figs. 6.18 e 6.19. Na primeira delas são verificados superaquecimentos similares para os refrigerantes R-11 e R-123, para um mesmo $\phi$, independentemente de $p_{r}$. Já, na Fig. 6.19, o R-11 passa a apresentar um superaquecimento inferior, independentemente da pressão reduzida. No caso do R-12, R-22 e R-134a, verificase comportamento similar, como ilustrado nas Figs. 6.20 e 6.21. 


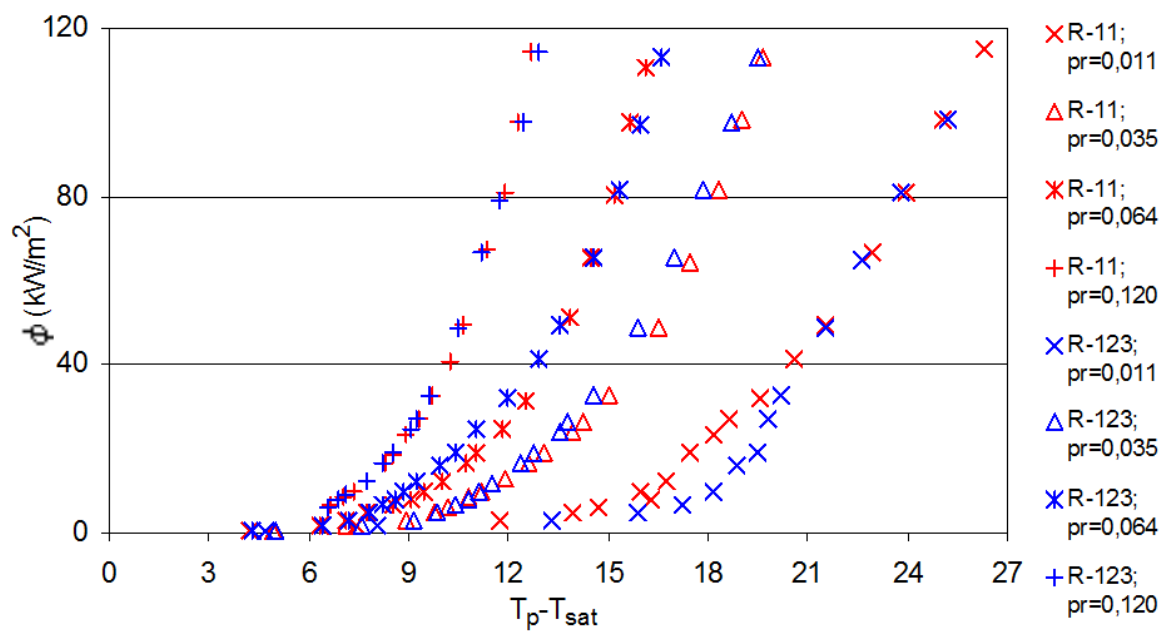

Figura 6.18 Comparação entre o R-11 e o R-123 para valores de $R a$ respectivamente iguais a 0,17 e $0,16 \mu \mathrm{m}$ para a superfície de cobre.



Figura 6.19 Comparação entre o R-11 e o R-123 para valores de $R a$ respectivamente iguais a 2,3 e $3,3 \mu \mathrm{m}$ para a superfície de cobre.

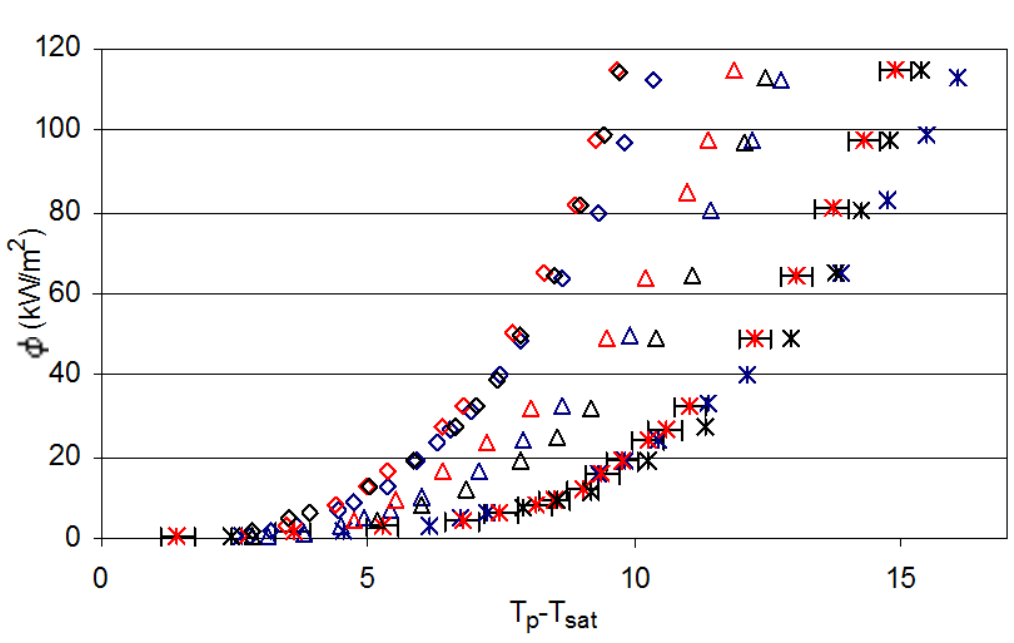

$$
\begin{aligned}
& \text { *R-12; } \\
& \text { pr }=0,064 \\
& \triangle \mathrm{R}-12 \text {; } \\
& \mathrm{pr}=0,120 \\
& \checkmark \mathrm{R}-12 \\
& \mathrm{pr}=0,200 \\
& \text { *R-22; } \\
& \mathrm{pr}=0,064 \\
& \triangle \mathrm{R}-22 \text {; } \\
& \text { pr }=0,120 \\
& \triangle \mathrm{R}-22 \text {; } \\
& \mathrm{pr}=0,200 \\
& \text { *R-134a; } \\
& \text { pr }=0,064 \\
& \triangle \mathrm{R}-134 \mathrm{a} \text {; } \\
& \mathrm{pr}=0,120 \\
& \mathrm{pr}=0,200
\end{aligned}
$$

Figura 6.20 Comparação entre o R-12 e o R-22 e R-134a para valores de $R a$ respectivamente iguais a $0,06,0,07$ e $0,07 \mu \mathrm{m}$ para a superfície de cobre. 


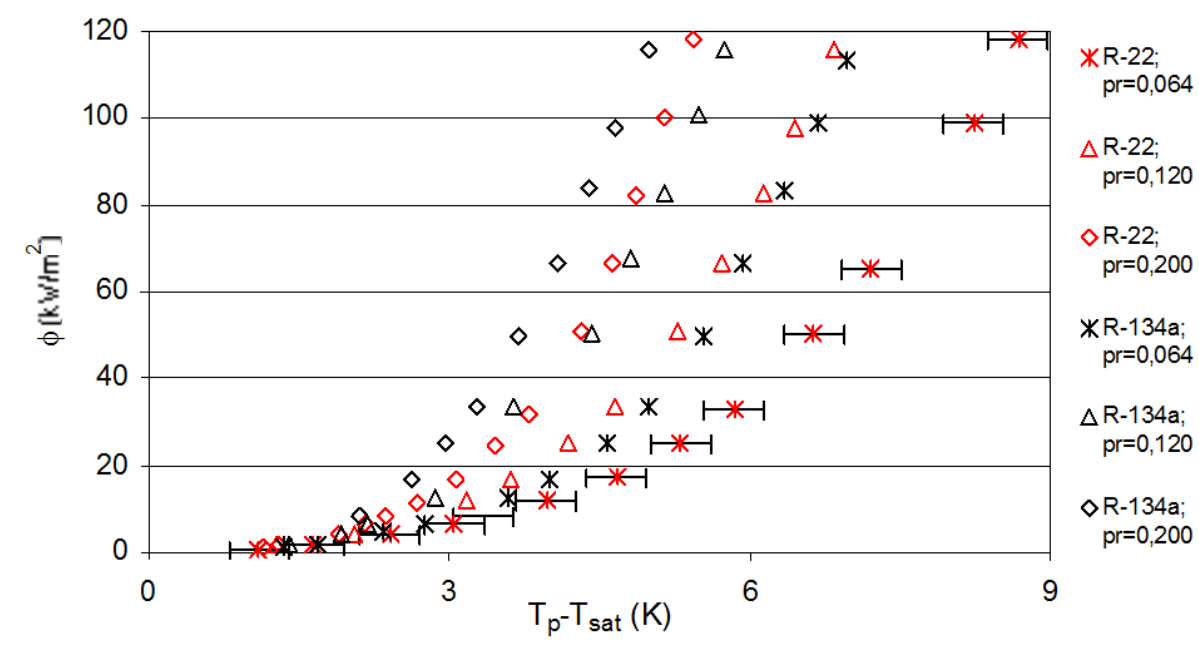

Figura 6.21 Comparação entre o R-22 e o R-134a para valores de $R a$ respectivamente iguais a 2,6 e 2,5 $\mu \mathrm{m}$ para a superfície de cobre.

Desta forma, através da variação no coeficiente de transferência de calor, ficam caracterizadas diferenças de "sensibilidade" a alterações no acabamento superficial entre os refrigerantes ensaiados, para um mesmo $\Delta T$ e $p_{r}$. A Tabela 6.8 ilustra tal comportamento, comparando resultados experimentais e o valor de $\left(r_{c}\right)_{\text {min }}$ dado pelo modelo de Han e Griffith (1965a), Eq. (2.5). Os resultados experimentais são introduzidos nesta comparação através da variação relativa de $h$ com $R a$, para $\phi \cong 50 \mathrm{~kW} / \mathrm{m}^{2}$ e $p_{r} \cong 0,064$, com $R a_{l}$ sendo a menor rugosidade ensaiada para cada refrigerante ( R-11 e R-123 $\approx 0,16 \mu \mathrm{m}$; R-12, R-22 e $\mathrm{R}-134 \mathrm{a} \approx 0,08 \mu \mathrm{m}$ ) e $R a_{2}$ o valor intermediário ( aproximadamente $0,5 \mu \mathrm{m}$ ).

Tabela 6.8 Comparação entre o $\left(r_{c}\right)_{\min }$ dado por Han e Griffith (1965a) e a variação de $h$ com $R a$.

\begin{tabular}{lccccc}
\cline { 2 - 5 } & $\mathrm{R}-11$ & $\mathrm{R}-123$ & $\mathrm{R}-12$ & $\mathrm{R}-22$ & $\mathrm{R}-134 \mathrm{a}$ \\
\hline \hline$\left(r_{c}\right)_{\min }$ & $0,37 \mu \mathrm{m}$ & $0,34 \mu \mathrm{m}$ & $0,29 \mu \mathrm{m}$ & $0,25 \mu \mathrm{m}$ & $0,26 \mu \mathrm{m}$ \\
\hline$\left[h\left(R a_{2}\right)-h\left(R a_{1}\right)\right] /\left(h\left(R a_{1}\right)\right)$ & 0,18 & 0,15 & 0,09 & 0,06 & 0,08 \\
$\frac{\left(R a_{2}-R a_{1}\right) / R a_{1}}{(20}$ & & & & \\
\hline
\end{tabular}

Os resultados apresentados indicam uma certa relação entre o $\left(r_{c}\right)_{\min }$ e as taxas de variação de $h$ com $R a$. Conclui-se que refrigerantes com $\left(r_{c}\right)_{\min }$ superiores apresentam maior "sensibilidade" a variações de acabamento superficial. Este resultado coincide com o modelo proposto por Kurihara (1956), no qual a variação em $n / A$ é proporcional a $e^{-1 / r_{C}}$. 
Finalmente, embora tenham sido apresentadas justificativas baseadas em estudos anteriores para os comportamentos dos resultados experimentais ilustrados nesta seção, elas podem ser consideradas apenas hipóteses, considerando que a literatura envolvendo tais efeitos é caracterizada por diversas lacunas. Estudos mais conclusivos envolveriam a determinação das dimensões das cavidades da superfície, de $n / A$ e de sua variação com $p_{r}$, $R a$, e o superaquecimento da superfície para os distintos refrigerantes. Objetivo que foge ao escopo da presente pesquisa.

\subsubsection{Efeito do Material da Superfície}

As Figs. 6.22 a 6.26 ilustram comparações para cada refrigerante entre curvas de ebulição para as superfícies de cobre, latão e aço inoxidável, considerando valores de $R a$ próximos. De maneira geral, verifica-se que as curvas de ebulição dos refrigerantes em superfícies de cobre e latão são próximas, o mesmo não ocorrendo quando se trata do aço inoxidável. O coeficiente angular das curvas depende do material, como se observa claramente naquelas figuras.

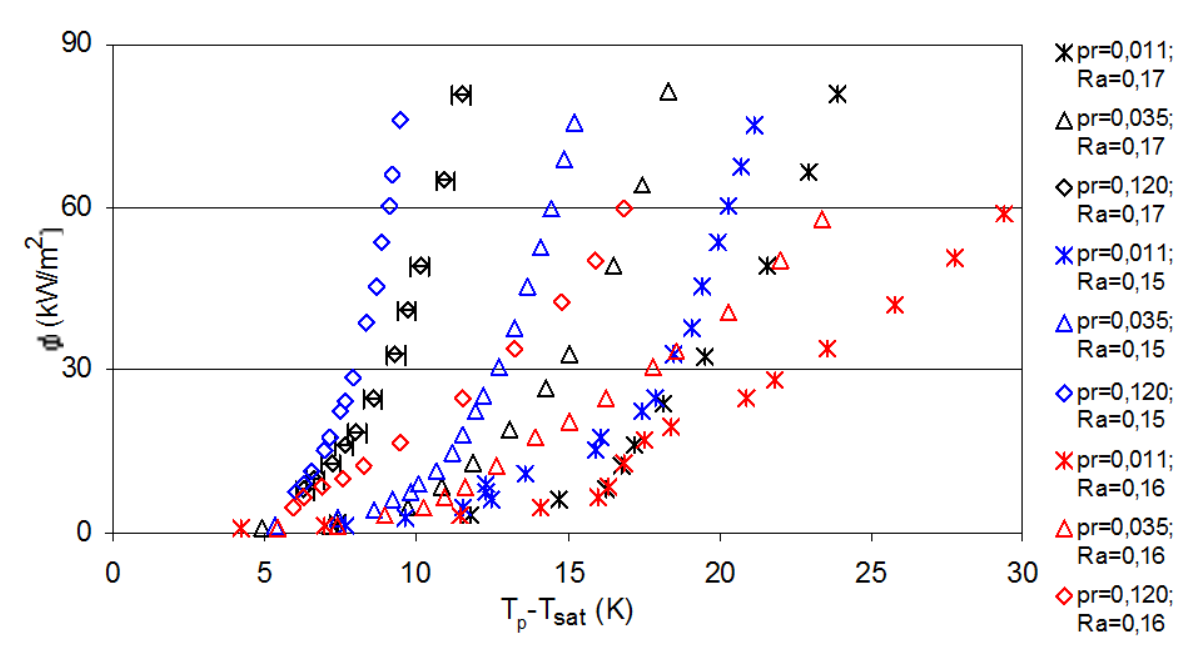

Figura 6.22 Comparação entre as curva de ebulição do R-11 para as superfícies de cobre, latão e aço inoxidável, cujos símbolos são de cores, respectivamente, preta, azul e vermelha.

Constata-se que, para os refrigerantes R-22, R-134a e R-11, a curva de ebulição associada à superfície de cobre se localiza à direita daquela de latão. No caso do refrigerante $\mathrm{R}-123$, superfícies de ambos os materiais proporcionam desempenhos similares para baixas pressões. Com o incremento da pressão, o latão passa a apresentar um desempenho superior. Para valores reduzidos da pressão, o R-12 apresenta um desempenho superior na superfície 
de cobre em relação à de latão. Entretanto, com o incremento da pressão, este comportamento inverte-se e a superfície de latão passa a apresentar um desempenho superior. Conforme sugerido na literatura, a superfície de aço inoxidável apresenta desempenho inferior às demais, independentemente da condição experimental.

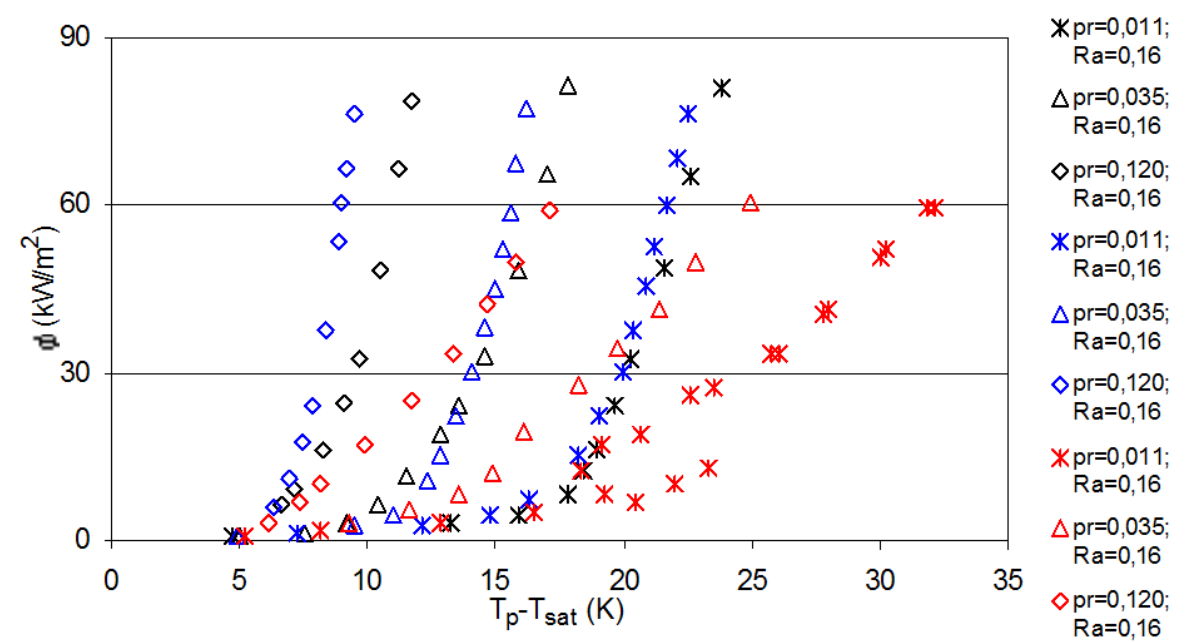

Figura 6.23 Comparação entre as curva de ebulição do R-123 para as superfícies de cobre, latão e aço inoxidável, cujos símbolos são de cores, respectivamente, preta, azul e vermelha.

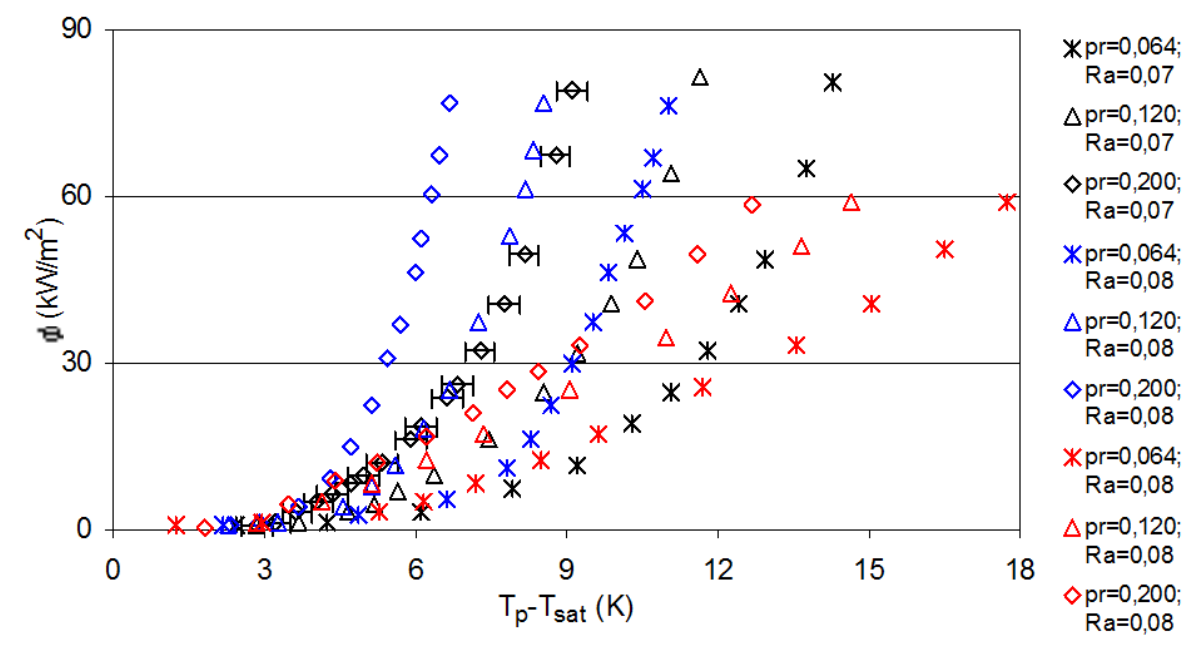

Figura 6.24 Comparação entre as curva de ebulição do R-134a para as superfícies de cobre, latão e aço inoxidável, cujos símbolos são de cores, respectivamente, preta, azul e vermelha.

Segundo a análise bibliográfica apresentada nos Capítulos 2 e 3, as diferenças de comportamento verificadas para as superfícies com distintos materiais podem ser decorrentes dos seguintes fatores:

Inércia térmica da superfície, a qual pode afetar os períodos de crescimento e espera da bolha e, no caso de bolhas com crescimento rápido, causar flutuações na 
temperatura da superfície que inibiriam a ativação de cavidades. Tais efeitos estariam relacionados ao produto $k_{p} \cdot \rho_{p} \cdot c_{p}$.

Capacidade do fluido de molhar a superfície, podendo alterar o número de cavidades ativas, através da inundação de cavidades maiores, além de afetar o períodos de espera e crescimento. Tais efeitos poderiam ser caracterizados através do ângulo de contato $\beta$.

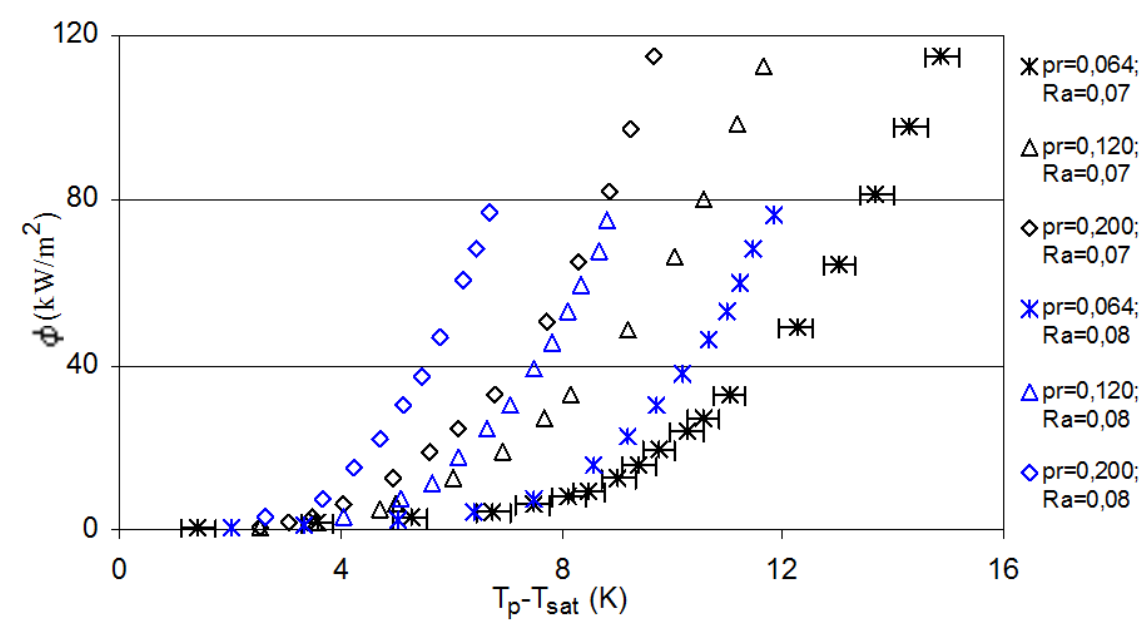

Figura 6.25 Comparação entre as curva de ebulição do R-22 para as superfícies de cobre e latão, cujos símbolos são de cores, respectivamente, preta e azul.

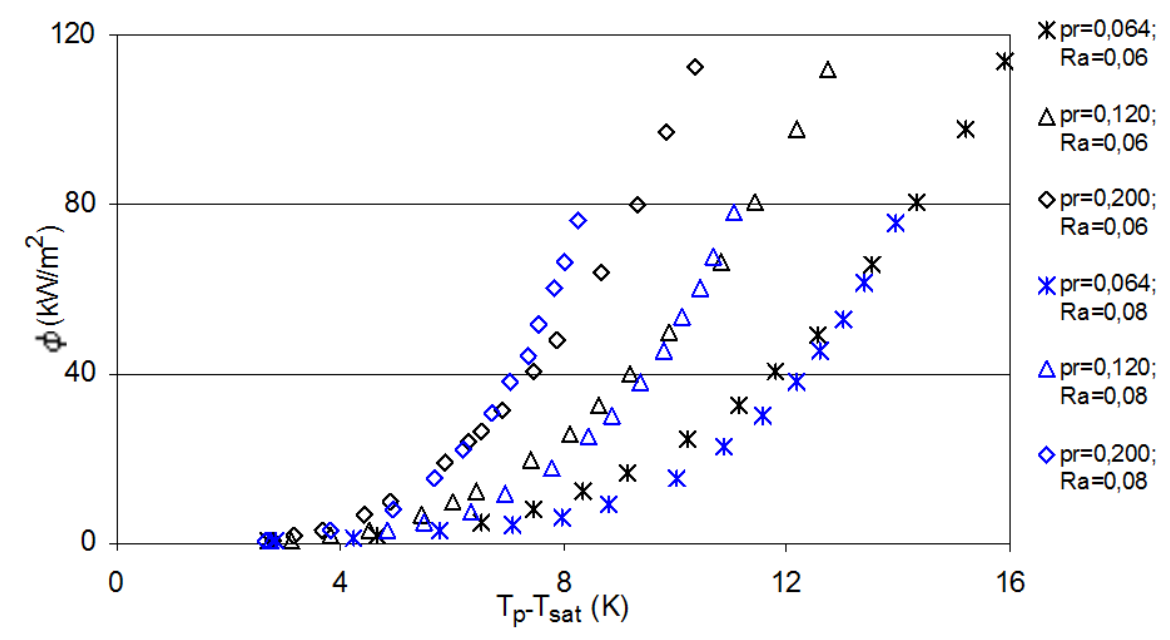

Figura 6.26 Comparação entre as curva de ebulição do R-12 para as superfícies de cobre e latão, cujos símbolos são de cores, respectivamente, preta e azul.

Para a análise do efeito destes fatores, foram elaboradas as Tabelas 6.9 e 6.10. A primeira apresenta uma comparação entre a tensão superficial, parâmetros de caracterização 
da inércia térmica e as alterações no coeficiente de transferência de calor com a mudança de material da superfície para os distintos refrigerantes sob as seguintes condições $\phi=50 \mathrm{~kW} / \mathrm{m}^{2}$, $p_{r}=0,064$ e rugosidades próximas a $0,5 \mu \mathrm{m}$. A tensão superficial foi introduzida em tal comparação pois, segundo a equação de Young*, ela é um dos fatores que alteram o ângulo de contato, apresentando uma relação inversamente proporcional ao valor do seu cosseno. Já a Tabela 6.10 apresenta, para a elevação de $p_{r}$ de 0,064 para 0,12 , a relação entre os coeficientes de transferência de calor com as distintas superfícies, para $\phi=50 \mathrm{~kW} / \mathrm{m}^{2}$ e valores de $R a$ próximos.

Tabela 6.9 Comparação da relação entre $h$, para os distintos materiais com $\sigma$ e parâmetros utilizados na literatura para caracterizar a superfície. $\phi=50 \mathrm{~kW} / \mathrm{m}^{2}, p_{r}=0,064$ e $R a \approx 0,5 \mu \mathrm{m}$

\begin{tabular}{|c|c|c|c|c|c|c|c|}
\hline & \multicolumn{2}{|c|}{ experimental } & \multicolumn{2}{|c|}{ Gorenflo et al (1994) } & \multicolumn{2}{|c|}{ Eq. (3.12) } & \multirow[t]{2}{*}{$\sigma(\mathbf{m N} / \mathbf{m})$} \\
\hline & $h_{\text {latão }} / h_{C u}$ & $h_{\text {inox }} / h_{C u}$ & $\left(s_{\text {latão }} / s_{C u}\right)^{0,25}$ & $\left(s_{\text {inox }} / s_{C u}\right)^{0,25}$ & $F_{p m}$ latão & $\overline{F_{p m} \text { inox }}$ & \\
\hline $\mathrm{R}-11$ & 1,24 & 0,71 & \multirow{5}{*}{0,71} & \multirow{5}{*}{0,45} & \multirow{5}{*}{0,51} & \multirow{5}{*}{0,20} & 14,0 \\
\hline $\mathrm{R}-123$ & 1,12 & 0,69 & & & & & 12,2 \\
\hline $\mathrm{R}-12$ & 0,80 & --- & & & & & 12,3 \\
\hline $\mathrm{R}-22$ & 1,17 & --- & & & & & 13,9 \\
\hline R-134a & 1,31 & 0,81 & & & & & 12,2 \\
\hline
\end{tabular}

Tabela 6.10 Variações de $h$ para as distintas superfícies $\phi=50 \mathrm{~kW} / \mathrm{m}^{2}, R a \approx 0,5 \mu \mathrm{m}$.

\begin{tabular}{lccc} 
& & $\frac{h\left(p_{r}=0,12\right)-h\left(p_{r}=0,064\right)}{h\left(p_{r}=0,064\right)}$ & \\
\cline { 2 - 4 } & & latão & aço inoxidável \\
\hline R-11 & 0,25 & 0,34 & 0,21 \\
\hline R-123 & 0,27 & 0,42 & 0,25 \\
\hline R-12 & 0,28 & 0,62 & --- \\
\hline R-22 & 0.31 & 0,36 & --- \\
\hline R-134a & 0,22 & 0,35 & 0,22 \\
\hline \hline
\end{tabular}

* Segundo a equação de Young, sob condições de equilíbrio, as forças de tensão superficial devem obedecer a seguinte relação:

$\cos \beta=\frac{\sigma_{s-v}-\sigma_{l-s}}{\sigma}$

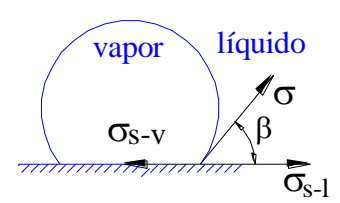


A Tabela 6.9, embora indique que a relação entre coeficientes de transferência de calor apresenta valores dependentes do fluido e não apenas do material da superfície, permite concluir a inexistência de uma relação explícita entre a tensão superficial e a intensidade nas variações de $h$ com a mudança de material. Já a relação entre os produtos $k_{p} \cdot \rho_{p} \cdot c_{p}$, ainda que possa justificar a redução no coeficiente de transferência de calor para o aço inoxidável, não é válida para a superfície de latão. Além de não relacionar estes efeitos ao fluido, superestima os efeitos de $k_{p}$, considerando que, para os materiais em questão, tanto $\rho_{p}$ como $c_{p}$ apresentam valores próximos. Tais resultados coincidem com as conclusões de Cooper(1984) ao analisar seu banco de dados, a partir do qual concluiu que o material da superfície afetava a transferência de calor para cada fluido com intensidade diferente, e com a condutividade da superfície apresentando um efeito apenas marginal neste comportamento. Mann et al (2000), conforme citado anteriormente, fixando o ângulo de contato, através de um modelo numérico, concluíram que efeitos da condutividade térmica da superfície na taxa de crescimento da bolha eram desprezíveis. Vale ressaltar que, segundo Sakashita e Kumada (2001), no caso da ebulição de líquido em superfícies com $k_{p}$ reduzido, por exemplo, o aço inoxidável, efeitos do material da superfície associados a inércia térmica podem ser relevantes.

Desta forma, partindo da hipótese de que efeitos de propriedades do material não são determinantes, sugere que efeitos do material através do ângulo de contato podem apresentar uma influência significativa. Trevoy e Johnson apud Bernardin et al (1997) indicam valores para o ângulo de contato entre a água e as superfícies de latão, cobre, aço inoxidável, respectivamente, iguais a $10,6^{\circ} 9,6^{\circ}$ e $5,4^{\circ}$. Tais diferenças, embora reduzidas, justificariam, qualitativamente, através da variação no número de cavidades ativas, os resultados para a relação entre os coeficientes de transferência de calor apresentados na Tabela 6.9.

Segundo Bikerman (1970), o ângulo de contato e, portanto, a capacidade do fluido molhar a superfície depende do próprio fluido, através da tensão superficial, e, desta forma, da temperatura, da limpeza da superfície, da sua cristalografia e rugosidade e da natureza química do sólido, efeito que, no caso dos metais, foi abordado por um número reduzido de estudos. Para os dados experimentais a partir dos quais foi levantada a Tabela 6.10, pode-se admitir que, com a elevação de $p_{r}$, as características superficiais permaneceram aproximadamente constantes, com variações apenas das propriedades do líquido. Considerando estruturas similares das superfícies de cobre, latão e aço inoxidável e um mesmo fluido, incrementos no $h$ resultantes de variações nas propriedades do líquido ou da ativação de cavidades relacionados à rugosidade da superfície e às propriedades dos fluido 
deveriam ser similares, independentemente do material da superfície, comportamento que não se verifica na Tabela 6.10. Por outro lado, considerando os efeitos do material da superfície como resultantes de alterações no ângulo de contato, caso a tensão superficial do líquido fosse preponderante na determinação de $\beta$, variações para um mesmo fluido em diferentes superfícies deveriam ser similares, comportamento não contemplado na Tabela 6.10. Este fato, somado à consideração que as superfícies ensaiadas são limpas e apresentam rugosidades próximas, indica a influência relevante no ângulo de contato, da cristalografia e da natureza química da superfície de transferência de calor.

Finalmente, conclui-se, analogamente a Rohsenow (1952), que alterações no coeficiente de transferência de calor devido à mudança do material da superfície não podem ser caracterizadas por propriedades termodinâmicas ou de transporte apenas do fluido ou da superfície. Elas são resultados da interação entre o par composto pelo fluido e a superfície, caracterizada pelo ângulo de contato, possivelmente um dos fatores preponderantes nestas alterações.

\subsubsection{Anomalias na Curva de Ebulição}

Um fenômeno interessante, que consiste, a "grosso modo", em descontinuidades da curva de ebulição, caracterizadas por "saltos", foi verificado para os refrigerantes pouco voláteis e valores reduzidos de $\phi$ e $p_{r}$. Este comportamento parece estar associado a variações intermitentes no número de cavidades ativas em regiões específicas da superfície, resultante de instabilidades no processo de ativação e desativação de cavidades. A intensidade destes "saltos" parece estar relacionada à condutividade térmica da superfície, apresentando a seguinte ordem decrescente, para os materiais analisados na presente pesquisa: aço inoxidável, latão e cobre. Tal fato encontra-se ilustrado nas Figs. 6.13, 6.15, $6.16,6.18,6.22$ e 6.23. Ressalta-se que as curvas de ebulição apresentadas nestas figuras foram levantadas para valores decrescentes de $\phi$, fazendo com que tal comportamento não estivesse associado a efeitos de histerese.

Através de observações visuais, constatou-se que tal comportamento está associado a um fenômeno físico que envolve a densidade de cavidades ativas, conforme mencionado anteriormente, e o período de espera das bolhas na superfície de transferência de calor. Verificou-se que, para valores reduzidos de $\phi$, a não uniformidade na distribuição das cavidades ativas é intensificada, tendo sido observado um número menor na face inferior. 
As bolhas formadas nesta região apresentavam diâmetros de desprendimento sensivelmente superiores aos da região superior e as freqüências de desprendimento, além de apresentarem valores inferiores, eram irregulares, com as bolhas apresentando elevados períodos de espera e crescimento, comportamento distinto do verificado na face superior onde a freqüência parecia ser constante e com valores de $t_{e}$ significativamente inferiores.

Um exemplo deste comportamento ocorreu com o R-123 para $\phi \cong 10 \mathrm{~kW} / \mathrm{m}^{2}$, $p_{r}=0,011$, em mudança de fase sobre uma superfície de aço inoxidável. Nas cavidades ativas da região inferior da superfície, além de ocorrer a formação de bolhas com diâmetros superiores, seu ciclo de vida chegava a apresentar valores de $t_{e}$ (período envolvendo o desprendimento de uma bolha e o início do crescimento de outra) superiores à trinta segundos, verificando-se, para um valor de $T_{\text {sat }}$ já estabilizado, variações superiores a $2,1^{\circ} \mathrm{C}$ na temperatura superficial indicada pelo termopar localizado na região inferior.

A redução de $n / A$ na região inferior da superfície pode ser justificada por temperaturas superficiais e, consequentemente, valores de $\left(T_{p}-T_{s a t}\right)$ inferiores aos da região superior, como resultado de efeitos convectivos do líquido. Isto resulta, segundo o modelo de Han e Griffith (1965a), na necessidade de ocorrência de cavidades com diâmetros superiores para que possam ser ativadas. No caso de superfícies pouco rugosas, para as quais o fenômeno da "descontinuidade" foi verificado, cavidades com dimensões elevadas encontram-se em número reduzido, quando comparadas às de diâmetros inferiores que têm condições propícias para a ativação na região superior da superfície, resultado do maior superaquecimento.

Efeitos convectivos resultantes do desprendimento de bolhas e de convecção natural parecem ser responsáveis pela desativação intermitente das cavidades nas regiões inferiores do tubo. O fluido frio, ao entrar em contato com a superfície, tenderia a resfriar esta região, podendo, inclusive, condensar o vapor remanescente nas cavidades. Isto as desativaria, exigindo um maior superaquecimento para uma nova nucleação, elevando consequentemente, o período de espera. Este mecanismo proporcionaria gradientes de temperatura ao longo do perímetro da superfície, intensificados com a redução de $k_{p}$, e que resultariam em um fluxo de calor inicial no sentido descendente. Neste cenário, a condutividade térmica da superfície afeta o perfil de temperaturas ao longo de seu perímetro e, consequentemente, o período de espera nas regiões inferiores do tubo para que se atinja a condição necessária para o crescimento, ou até mesmo, o surgimento de um núcleo de vapor. No cenário físico descrito, tal influência ocorre de forma que a ebulição em superfícies com $k_{p}$ superiores teriam, devido à efeitos de condução ao longo do seu perímetro, períodos de espera inferiores àquelas com valores de $k_{p}$ reduzidos. 


\section{Capítulo 7 - Desenvolvimento de uma Correlação Generalizada}

\subsection{Introdução}

Nos Capítulos 3 e 6, que envolvem comparações entre as correlações e delas com os resultados experimentais, foram verificadas diferenças significativas, incluindo tendências discordantes com a variação de um determinado parâmetro. Conforme indicado anteriormente, tais comportamentos resultam da natureza empírica das correlações e relacionam-se à abrangência do banco de dados experimentais utilizado pelos autores. Nesses capítulos destaca-se, também, a ausência de um levantamento experimental sistemático com o conseqüente ajuste de uma correlação que envolva efeitos do acabamento superficial, descrito através do $R a$, amplas faixas de $p_{r}$ e $\phi$, distintos materiais da superfície de transferência de calor e resultados experimentais apenas para refrigerantes halogenados. A correlação proposta pelo VDI-Wärmeatlas (1994), embora incorpore todos estes efeitos, apresenta resultados distintos dos do presente estudo, diferença que se intensifica com a variação do material da superfície. Assim, considerando que os resultados fornecidos pelas correlações analisadas são díspares e intrinsecamente relacionados à amplitude dos respectivos banco de dados, a determinação de uma correlação baseada nos resultados experimentais levantados no presente estudo, face à sua abrangência, torna-se lógica. Finalmente, o desenvolvimento desta correlação com base em propriedades reduzidas, ao invés de um modelo semi-empírico, ao se considerar a simplicidade deste método e sua razoável capacidade de predição, torna-se preferível. 
Desta forma, este capítulo trata do desenvolvimento de uma correlação visando aplicações frigorificas para o coeficiente de transferência de calor através do mecanismo de ebulição nucleada no regime plenamente desenvolvido com o fluido no estado saturado. Ela incorpora efeitos do fluxo específico de calor, da pressão de saturação, do fluido refrigerante e características da superfície de transferência de calor, sendo, segundo o Capítulo 2, classificada como do grupo baseado em propriedades reduzidas. Seu ajuste foi realizado através dos resultados experimentais levantados no presente trabalho, listados no Anexo III e analisados anteriormente no Capítulo 6.

\subsection{Correlações em Termos de $p_{r}$ e $T_{r}$}

\subsubsection{Fundamentos}

\subsubsection{Lei dos Estados Correspondentes}

Uma equação relacionando a pressão, a temperatura e o volume é denominada de equação de estado, que para os gases ideais é expressa através da seguinte relação:

$$
p \cdot v_{M o l}=\mathfrak{R} \cdot T
$$

Esta equação pode ser determinada a partir da teoria cinética dos gases admitindo as seguintes hipóteses:

$>$ As moléculas são separadas por grandes distâncias, sendo, desta forma, consideradas pontos de massa.

$>$ As forças intermoleculares não exercem influência na dinâmica de colisão das moléculas (choques perfeitamente elásticos).

Estas hipóteses são válidas para gases sob condições de baixas pressões. No entanto, com o incremento da pressão e conseqüente decréscimo no volume molar, as moléculas do gás se aproximam, resultando em que efeitos de forças intermoleculares tornem-se relevantes. Admitindo estes efeitos, van der Waals propôs a seguinte equação de estado: 


$$
p=\frac{\Re \cdot T}{v_{\text {mol }}-b}-\frac{a}{v_{m o l}^{2}}
$$

onde, a constante $b$ foi introduzida visando a correção do volume ocupado pelas moléculas e o termo $a / v_{m o l}^{2}$, considerando efeitos de atração mútua entre elas, levando em consideração as forças de atração, proporcionais ao quadrado da densidade. A Eq. (7.2) apresenta 3 raízes em $v_{\text {mol }}$ para qualquer valor de $p$ e $T$. No caso de temperaturas elevadas, independente da pressão, apenas uma destas raízes apresenta um valor real. Para temperaturas inferiores e dentro de uma determinada faixa de pressões, todas as raízes são reais, resultando em um valor máximo e um mínimo dentro da região do diagrama $p$ - $v_{m o l}$ onde experimentalmente verificam-se os fenômenos da condensação e evaporação. Já, para um determinado valor de $p$ e $T$, estas três raízes tornam-se idênticas, obtendo-se, neste mesmo diagrama, um ponto de inflexão para a isotérmica passando por ele, denominado de ponto (ou estado) crítico. $\mathrm{O}$ diagrama $p-v_{m o l}$ e o referido comportamento encontram-se ilustrados, esquematicamente, na Fig. 7.1.

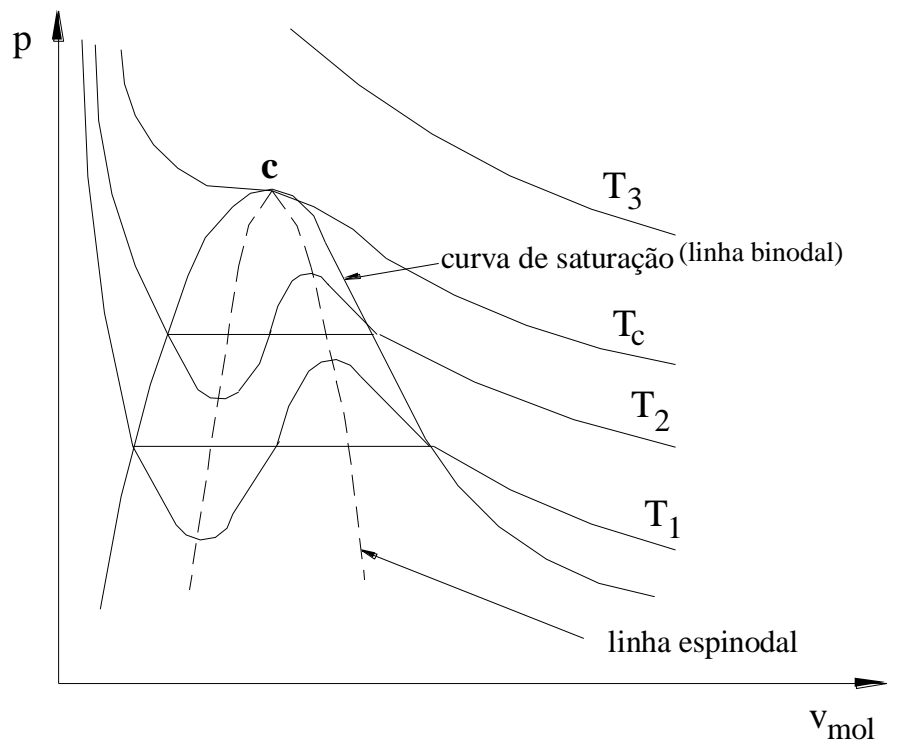

Figura 7.1 Isotérmicas baseadas na equação de estado de van der Waals.

A isotérmica que passa pelo ponto crítico, por este ser um ponto de inflexão, apresenta as seguinte propriedades:

$$
\left(\frac{\partial p}{\partial v_{m o l}}\right)_{T_{\text {crit }}}=0
$$




$$
\left(\frac{\partial^{2} p}{\partial v_{m o l}^{2}}\right)_{T_{c r i t}}=0
$$

Diferenciando-se a Eq. (7.2) e aplicando as propriedades do ponto crítico, dadas pelas Eq. (7.3) e (7.4), determina-se as constantes $a$ e $b$ em termos de $T_{c}$ e $p_{c}$, que substituídas na equação de van der Waals, Eq. (7.2), resultam na seguinte equação:

$$
\left(p_{r}+\frac{3}{v_{r}^{2}}\right) \cdot\left(3 \cdot v_{r}-1\right)=8 \cdot T_{r}
$$

que consiste em uma equação "genérica" que não incorpora constantes características do fluido.

Segundo Bejan (1997), o principal resultado da equação de estado proposta por van der Waals, Eq. (7.5), seria a sugestão da existência de uma única função relacionando $p_{r}$, $T_{r}$ e $v_{r}$ válida para todos as substâncias puras. Este comportamento leva a Lei dos Estados Correspondentes, que consiste na existência de uma equação de estado válida para todas as substâncias (puras ou misturas), quando $p, T$ e $v$ são normalizados em relação aos seus respectivos valores no ponto crítico. Isto indica que, a um determinado ponto $\mathrm{M}_{\mathrm{A}}$ do diagrama $p(v, T)$ de uma substância $\mathrm{A}$, corresponde um determinado ponto $\mathrm{B}$, no diagrama $p(v, T)$ da substância $\mathrm{B}$, de forma que ambos os pontos são representados por um único ponto quando o diagrama é expresso através de coordenadas reduzidas $p_{r}\left(v_{r}, T_{r}\right)$.Na prática, verifica-se que esta relação é válida apenas para grupos de substâncias cuja constituição molecular é relativamente similar.

Função similar à dos parâmetros $a \mathrm{e} b$, introduzidos na Eq. (7.1) por van der Waals, ainda que fisicamente tenha outra conotação, tem o fator de compressibilidade que expressa a diferença de comportamento de uma determinada substância em relação aos gases ideais. Este parâmetro é definido segundo a equação abaixo e apresenta valor igual a 1 para os gases ideais.

$$
z=\frac{p \cdot v_{m o l}}{\mathfrak{R} \cdot T}
$$

e em termos de propriedades reduzidas: 


$$
z=z_{c r i t} \cdot \frac{p_{r} \cdot v_{r}}{T_{r}}
$$

onde:

$$
z_{c r i t}=\frac{p_{c r i t} \cdot v_{c r i t}}{R \cdot T_{c r i t}}
$$

denominado de fator de compressibilidade no ponto crítico.

Assim, admitindo a possibilidade de determinação de $v_{r}$ através de uma função de $p_{r}$ e $T_{r}$, o fator de compressibilidade seria dado por uma função do seguinte tipo:

$$
z=z\left(p_{r} ; T_{r} ; z_{c r i t}\right)
$$

Diagramas de $z$ vs $p$ tendo $T$ como parâmetro, denominados de diagramas de compressibilidade, quando construídos em função de $p_{r}$ e $T_{r}$ são aproximadamente coincidentes, ainda que obtidos para distintas substâncias. Tal comportamento é condizente com a Lei dos Estados Correspondentes. Estes diagramas são denominados de generalizados e têm sua precisão incrementada quando introduzido o efeito do terceiro parâmetro da Eq. (7.9), de forma a ter-se diagramas de compressibilidade dependentes da faixa de valores de $z_{\text {crit }}$. Tal fator introduziria efeitos de diferenças de características moleculares entre os distintos fluidos.

Uma alternativa à utilização de $z_{\text {crit }}$, segundo Prausnitz (1986), foi proposta por Pitzer e seus colaboradores, sendo denominada de fator acêntrico. Sua definição foi arbitrária, partindo da constatação experimental de que fluidos com um campo simétrico de forças moleculares, tais como o argônio, xenônio e o metano, denominados por eles de “ fluidos simples", apresentam um valor de 0,1 para a pressão reduzida no estado de saturação, à $T_{r}$ de 0,7 . Com base neste comportamento foi definido o fator acêntrico como:

$$
\omega=-\log _{10}\left(p_{r}\right)-1
$$

Desta forma, segundo esta equação, o fator acêntrico apresenta um valor nulo para as substâncias denominadas de simples, apresentando um valor crescente com o incremento da polaridade da molécula. 


\subsubsection{Propriedades em termos de $p_{r}$ e $T_{r}$}

Argumentos baseados nas relações de Maxwell e na teoria cinética podem ser utilizados para demonstrar que propriedades como $h_{l v}, c, \mu, k \mathrm{e} \sigma$, encontradas nas correlações para determinação do coeficiente de transferência de calor em ebulição nucleada, podem ser consideradas propriedades termodinâmicas secundárias. Desta forma, podem ser determinadas através das propriedades termodinâmicas primitivas $T, p$ e $v$. Este fato indica a possibilidade da extensão da Lei dos Estados Correspondente a tais propriedades.

Reid et al (1987) apresentam um amplo levantamento da literatura envolvendo métodos e equações para a determinação de propriedades termodinâmicas e de transporte de diversas substâncias nos estados líquido e de vapor. Entre os métodos verificados, relacionados ao presente estudo, destacam-se aqueles que utilizam uma extensão da Lei dos Estados Correspondentes para a predição das propriedades anteriormente mencionadas. Estes métodos permitem determinar as propriedades termodinâmicas e de transporte através de correlações envolvendo $T_{r}$ e $p_{r}$, podendo, ainda, incorporar algum parâmetro molecular da substância em questão, como o fator de compressibilidade no ponto crítico, o acêntrico e a massa molecular. É interessante ressaltar, no caso da massa molecular, a possibilidade de aproximação, com relativa precisão, das propriedades de transporte e termodinâmicas no estado de saturação a um dado valor de $p_{r}$, através de funções simples, tais como:

$$
(\text { propriedade })_{i} \propto M^{a_{i}}
$$

Corrobora este cenário, a determinação por Ribatski e Saiz Jabardo (2000), de correlações envolvendo apenas propriedades reduzidas para $\rho_{l}, \rho_{v}, c_{l}, c_{p v}, \mu_{l}, \mu_{v}, k_{l}, k_{v}, h_{l}, h_{v}$, $h_{l v}$ e $\sigma$, no estado saturado, baseadas em um banco de dados envolvendo 14 refrigerantes halogenados. Estas correlações são distintas para cada propriedade e apresentam um formato relativamente simples segundo a equação abaixo:

$$
\left(\frac{\text { propriedade }}{\text { propriedade } \text { condição referência }_{i}}\right)_{i}=10^{a_{i}} \cdot p_{r}^{b_{i}} \cdot T_{r}^{c_{i}} \cdot\left(1-T_{r}\right)^{d_{i}}
$$

Na elaboração de tais correlações adotou-se uma escala relativa aos valores críticos para a temperatura e a pressão, e outra relativa a $T_{r}=0,7$ ou a pressão atmosférica normal no caso das propriedades de transporte. 


\subsubsection{Correlações em Termos de $p_{r}$ e $T_{r}$}

Conforme citado na introdução deste capítulo e nos anteriores foram verificadas grandes diferenças entre os resultados fornecidos pelas correlações. Embora elas forneçam resultados numéricos discordantes, é possível generalizá-las como equações do tipo:

$$
\frac{h}{(\phi)^{m}}=\text { cons tante } \cdot f(\beta) \cdot g^{a} \cdot\left[\prod_{i=1}^{n}\left(\begin{array}{c}
\text { parâmetros } \\
\text { de } \\
\text { sup erfície }
\end{array}\right)_{i}^{b_{i}}\right] \cdot\left[\prod_{i=1}^{n}\left(\begin{array}{c}
\text { propriedade } \\
\text { de } \\
\text { transporte }
\end{array}\right)_{i}^{c_{i}}\right]
$$

A Tabela 7.1 apresenta algumas dessas correlações, escritas conforme a equação acima. A partir daí, considerando válida a correlação das propriedades de transporte de refrigerantes halogenados por propriedades reduzidas e, sendo as correlações para o coeficiente de transferência de calor compostas por propriedades de transporte, é lógico imaginar a possibilidade de representação das correlações apresentadas na Tabela 7.1 como funções de $p_{r}$ e $T_{r}$. Dentro deste contexto, a Fig. 7. 2 apresenta uma avaliação comparativa do coeficiente de transferência de calor obtido através de correlações, para o R-22, em função da pressão reduzida. Verificam-se tendências similares entre as correlações, embora, conforme esperado, ocorram diferenciações pronunciadas para baixas pressões reduzidas e, embora não ilustrado nesta figura, nas proximidades do ponto crítico. Resultados semelhantes aos do R-22 são obtidos com os demais refrigerantes halogenados.

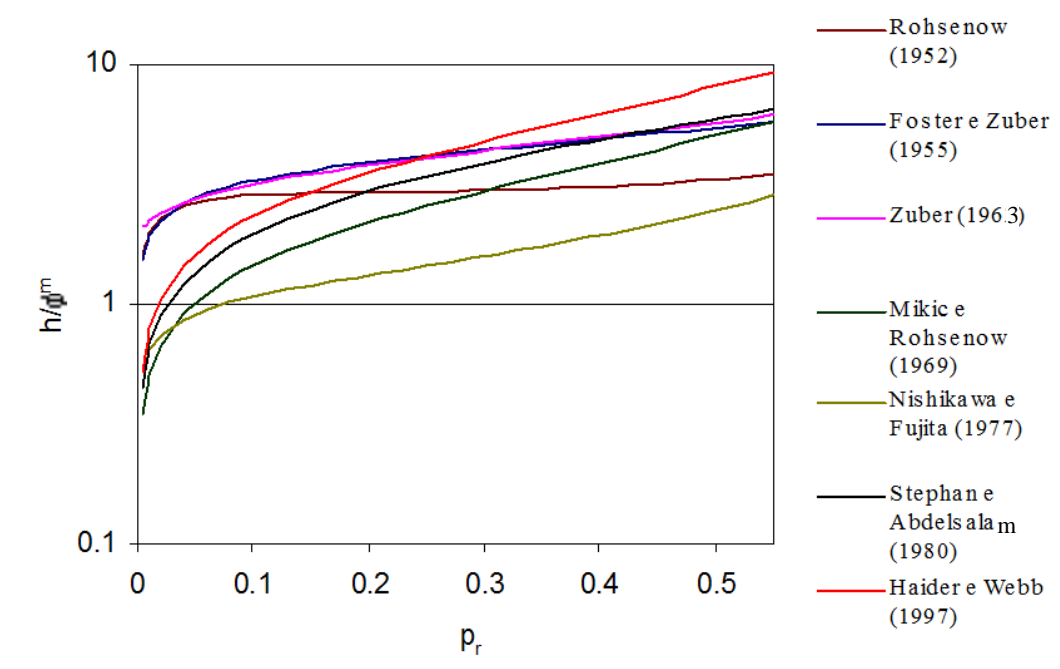

Figura 7.2 Comparação de tendências do coeficiente de transferência de calor com $p_{r}$ para distintas correlações; R-22, $\phi=35 \mathrm{~kW} / \mathrm{m}^{2}$, superfície lisa. 
Tabela 7.1 Correlações da literatura escritas conforme Eq. (7.12).

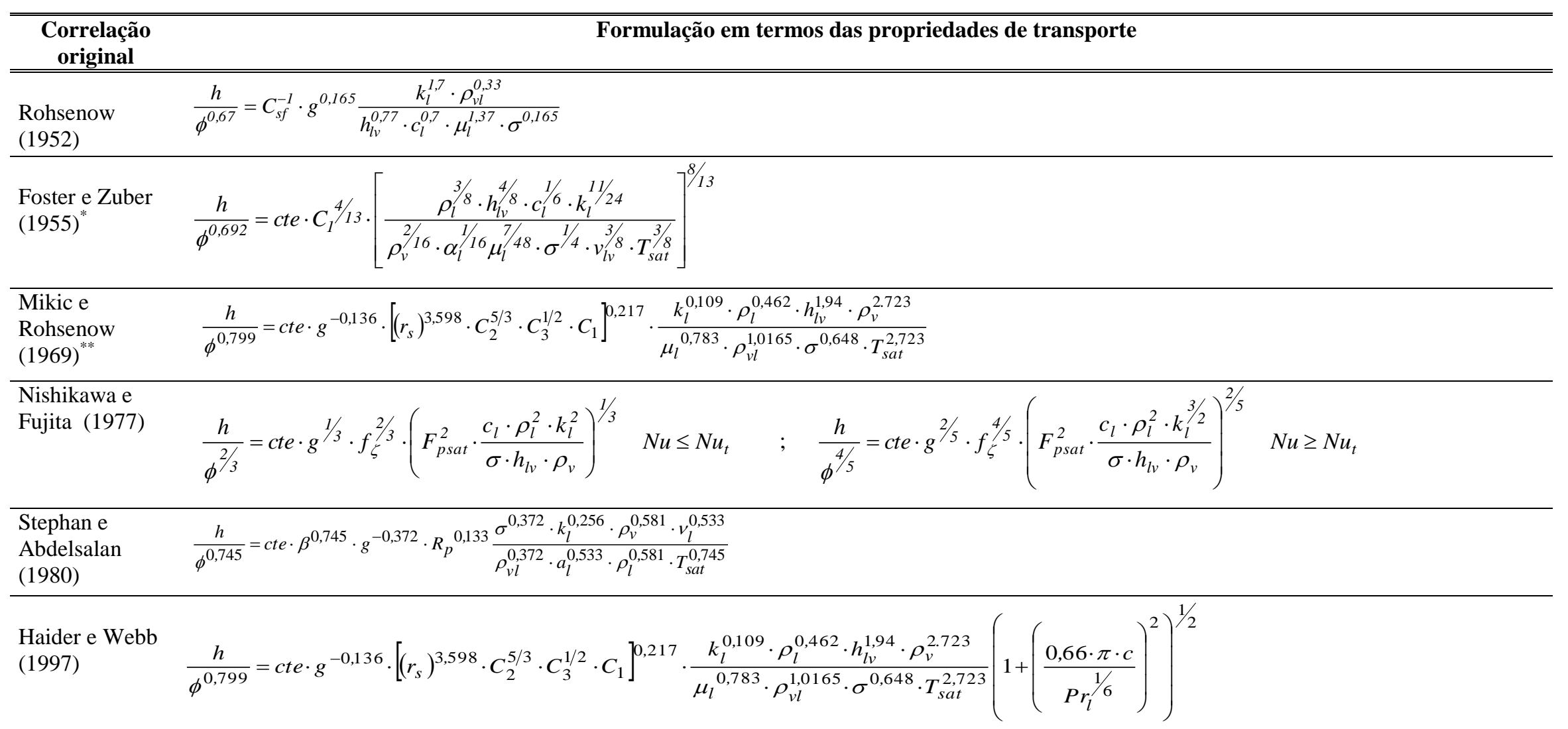

No modelo de Foster e Zuber (1955), para efeito de aproximação, substituiu-se $\Delta p$ por $\Delta T \cdot(d p / d T)_{\text {sat }}$, pela aplicação da relação de Clausius-Clapeyron. Obteve-se, assim, uma correlação composta exclusivamente por propriedades dos refrigerantes, onde: $(d P / d T)_{s a t}=h_{l v} /\left(v_{l v} \cdot T_{s a t}\right)$. Esta aproximação introduz um certo erro, que depende de $\Delta T$. Este, entretanto, para a faixa de pressões analisada neste estudo, pode ser considerado desprezível, embora possa se tornar apreciável para baixas pressões.

No modelo de Mikic e Rohsenow (1969), não está incluída a parcela de transferência de calor devido a convecção natural. O expoente utilizado nesta correlação foi determinado experimentalmente em Silva (1989), resultando igual a 3,598. 
Nessas condições, a Tabela 7.2, desenvolvida a partir de distintas correlações da literatura, apresenta as formas correspondentes em termos da temperatura reduzida, segundo a seguinte equação:

$$
\frac{h}{\phi^{m}}=(\text { constante } \quad \text { característica do fluido }) \cdot T_{r}^{a}
$$

Tabela 7.2 Correlações para $h$ escritas em termos de $T_{r}$ e desvio médio relativo as correlações originais.

\begin{tabular}{|c|c|c|c|c|c|c|}
\hline \multirow{2}{*}{ Correlações } & \multirow{2}{*}{$\mathbf{a}$} & \multicolumn{4}{|c|}{ constante } & \multirow{2}{*}{$\begin{array}{c}\text { desvio } \\
\text { médio (\%) }\end{array}$} \\
\hline & & R-22 & R-11 & R-134a & R-123 & \\
\hline Rohsenow (1952) & 2,88 & 2,60 & 2,19 & 2,45 & 2,08 & 3,47 \\
\hline Foster e Zuber (1955) & 3,14 & 8,47 & 6,83 & 7,56 & 6,32 & 4,66 \\
\hline Zuber (1963) & 4,43 & 7,50 & 7,21 & 7,10 & 7,38 & 1,67 \\
\hline Mikic e Rohsenow (1969) & 2,68 & 6,47 & 4,32 & 3,91 & 3,14 & 7,08 \\
\hline Nishikawa e Fujita (1977) & 5,14 & 4,57 & 5,58 & 6,71 & 5,43 & 3,93 \\
\hline Stephan e Abdelsalam (1980) & 3,83 & 7,30 & 7,91 & 7,55 & 7,47 & 20,7 \\
\hline Haider e Webb (1997) & 2,19 & 4,98 & 4,10 & 5,91 & 4,78 & 3,65 \\
\hline
\end{tabular}

* Os resultados originais forma determinados para $\phi=35 \mathrm{~kW} / \mathrm{m}^{2}$ e uma superfície lisa com valores de $p_{r}$ entre 0,005 e 0,30 . ** Os valores de " $m$ " encontram-se listados na Tabela 7.1, com exceção do de Zuber (1963), cujo valor depende das correlações adotadas para $n / A$ e $d_{b}$, que, no presente caso, foram, respectivamente, as Eqs. (2.7) e (3.51), obtendo-se desta forma $m \cong 2 / 3$.

Nesta tabela verifica-se que, com a incorporação de uma constante multiplicativa característica do fluido, as correlações listadas podem ser escritas apenas como funções de $T_{r}$, apresentando desvios médios reduzidos em relação aos seus resultados originais. É interessante destacar que, neste caso, variáveis como rugosidade superficial, gravidade local e comprimento característico estão incorporadas à constante multiplicativa.

Finalmente, considerando tais resultados, no desenvolvimento da correlação, a determinação dos efeitos de $p_{\text {sat }}$ através de alterações nas propriedades termodinâmicas e de transportes se dará através de uma função envolvendo o produto de $p_{r}$ e $T_{r}$ com o ajuste de expoentes numéricos individuais. Ajustes para estes efeitos envolvendo os produtos $p_{r}$ (1$\left.T_{r}\right)$, e $p_{r} \cdot{ }^{\cdot} \log _{10}\left(p_{r}\right)$ também serão analisados, com base nos seguintes aspectos:

A tensão superficial, cujos efeitos sobre $h$ mostraram-se extremamente relevantes no capítulo anterior, tende a zero no ponto crítico e apresenta um comportamento que pode ser aproximado por constante $\left(1-T_{r}\right)$. De forma análoga, o comportamento de $h_{l v}$ pode ser aproximado através de constante $\left(1-T_{r}\right)^{0,38 .}$. 
> Uma significativa simplificação pode ser obtida na correlação de tais efeitos através de uma única propriedade reduzida. A Equação de Antoine, Eq. (7.14), que nada mais é do que a equação de Clausius-Clapeyron modificada, sugere a substituição de $T_{r}$ por $-\log _{10}\left(T_{r}\right)$, procedimento similar ao adotado por Cooper (1984).

$$
\ln \left(p_{\text {sat }}\right)=A-\frac{B}{T_{\text {sat }}+C}
$$

\subsubsection{Incorporação de um Parâmetro Característico do Fluido}

Analogamente ao que ocorre em equações para a determinação das propriedades termodinâmicas e de transporte, a introdução de um parâmetro envolvendo características moleculares do fluido na correlação para determinação do coeficiente de transferência de calor pode correlacionar os efeitos da mudança do refrigerante em $h$, fornecendo à correlação um caráter genérico. Com este objetivo, Cooper (1984) incorporou à sua correlação a massa molecular, e Leiner (1994) introduziu a constante multiplicativa $h_{0}$ da correlação do VDIWärmeatlas (1994), através dos adimensionais $z_{c r i t}, c^{*} \mathrm{e} K$, incorporando o resultado à Eq. (3.13).

As Figs. 7.3a, 7.3b e 7.4 ilustram os comportamentos relativos entre si de $M, \omega$ e dos parâmetros adimensionais utilizados por Leiner (1994). A elaboração de tais figuras envolveu apenas refrigerantes halogenados. Através delas verifica-se que não há uma relação clara entre os valores de $\omega \mathrm{e} M$, o mesmo não ocorre entre os demais parâmetros que tendem a apresentar uma interdependência numérica ou $\operatorname{com} M$, ou com $\omega$. Isto permite que tais parâmetros sejam divididos em dois grupos distintos, um composto por $\omega, z_{c r i t}$ e $K$ e outro por $M$ e $c^{*}$. Com base neste resultado, conclui-se que a inclusão na correlação de mais de um parâmetro de cada grupo resultaria em uma certa redundância de comportamentos. Optou-se, desta forma, por analisar, apenas a incorporação à correlação do fator acêntrico e da massa molecular.

Para constatar a validade da incorporação destes fatores à correlação proposta, foram levantados através das correlações analisadas, valores de $h$ para distintos refrigerantes halogenados, para $p_{r}=0,1$, cujos resultados encontram-se ilustrados nas Figs. 7.5 e 7.6. Tal procedimento foi realizado com o objetivo de levantar uma certa relação entre a taxa de transferência de calor e os parâmetros $M$ e $\omega$. 


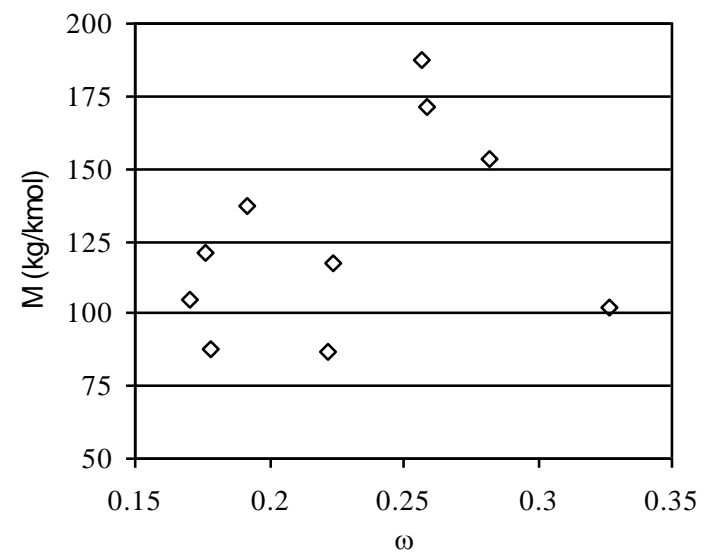

a)

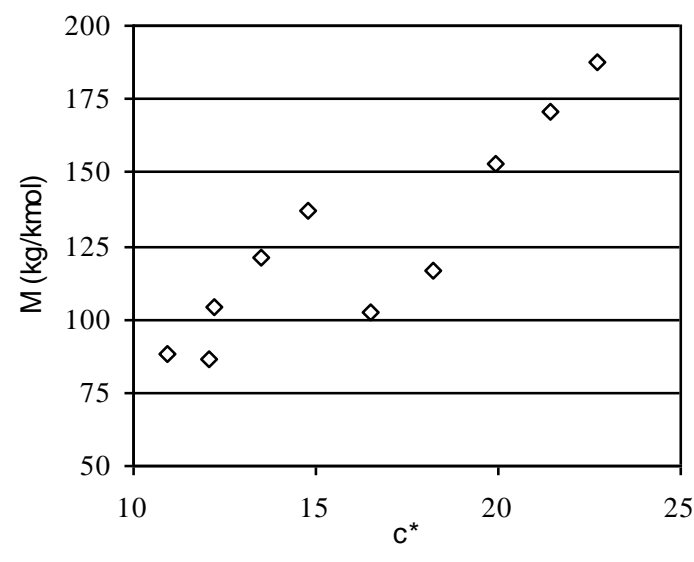

b)

Figura 7.3 Comparação entre os valores de $M, \omega$ e $c^{*}$ para refrigerantes halogenados

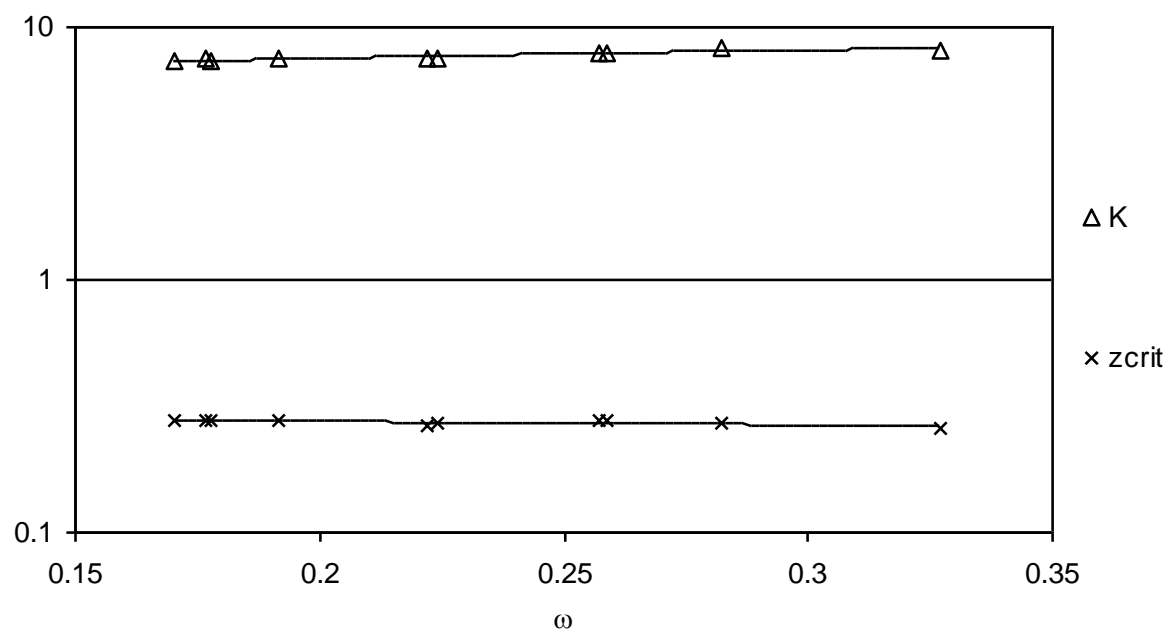

Figura 7.4 Comparação entre os valores de $\omega, z_{\text {crit }}$ e $K$ para refrigerantes halogenados

Na Fig. 7.5, com exceção da correlação de Stephan e Abdelsalam (1980), todas as demais apresentaram uma redução no coeficiente de transferência de calor com o incremento da massa molecular, cujo comportamento pode ser representado por uma função do tipo $M^{\text {-constante }}$.Tal comportamento não se verifica na Fig. 7.6, na qual não é possível estabelecer uma relação direta entre $h$ e $\omega$.

Finalmente, com base nos argumentos desenvolvidos neste item será analisada a possibilidade de incorporação da massa molecular e do fator acêntrico, ainda que neste caso não tenha sido verificada, segundo modelos da literatura, uma relação direta entre o mesmo e o coeficiente de transferência de calor. 




Figura 7.5 Variação de $h \operatorname{com} M$ segundo distintas correlações, para $p_{r}=0,1$.

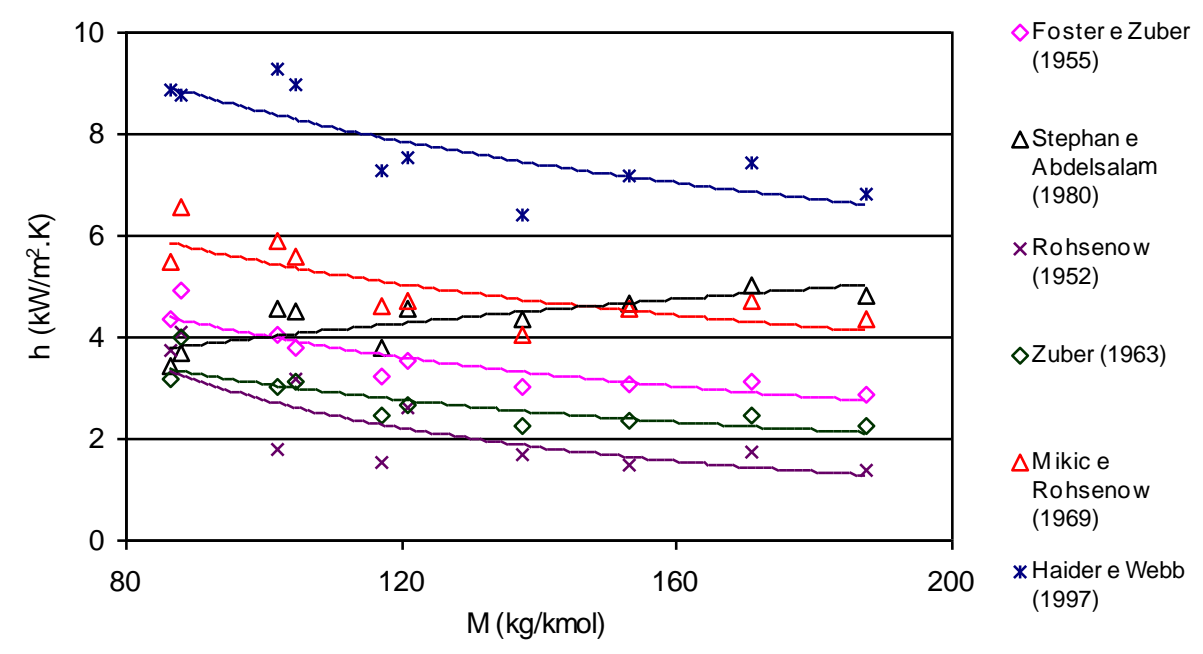

Figura 7.6 Variação de $h \operatorname{com} \omega$ segundo distintas correlações com $p_{r}=0,1$

\subsection{Efeitos do Fluxo Específico de Calor}

Quando as correlações para a determinação do coeficiente de transferência de calor através do mecanismo de ebulição nucleada são escritas conforme a Eq. (7.12), verifica-se um expoente $m$, geralmente, constante para cada correlação e cujo valor varia entre 0,5 e 0,8 . O valor deste expoente está relacionado à inclinação da curva de ebulição, que conforme ilustrado em diversas figuras do capítulo anterior e sugerido por Gorenflo et al (1994), depende de características como a pressão reduzida, o acabamento superficial e o material da superfície de transferência de calor. Assim, conclui-se que alterações em $h$ não dependem 
apenas de variações no valor absoluto de $\phi$ mas também da sua interação com a pressão e a superfície de transferência de calor. Isto permite especular que a adoção de valores constantes de $m$ por vários autores pode ser resultante da característica do banco de dados utilizado ou, ainda, da reduzida melhora na correlação dos resultados experimentais com um expoente variável.

Cooper (1984) analisou a possibilidade de correlacionar $m$ através de uma equação envolvendo o efeito da pressão reduzida, com o seguinte aspecto:

$$
m=m_{1}-m_{2} \cdot p_{r}
$$

Optando, ao final, por um expoente constante, devido a que a utilização de tal equação resulta numa redução desprezível dos desvios em relação aos resultados experimentais.

Conforme apontado anteriormente, Gorenflo et al (1994), ainda que tenham sugerido a influência de outros parâmetros neste expoente, propõem, inicialmente, correlacioná-lo considerando efeitos do acabamento superficial e da pressão reduzida, conforme a seguinte equação:

$$
m=m_{1}-m_{2} \cdot p_{r}^{0,3}-m_{3} \cdot \ln (R a)
$$

concluindo, ao final, um ganho desprezível com um ajuste incorporando $R a$. Neste caso, ao contrário do proposto por Cooper (1994), que considera uma variação linear de $m$ com $p_{r}$, incorpora-se o comportamento verificado experimentalmente segundo o qual a inclinação da curva de ebulição e, consequentemente, do expoente $m$ variam com a pressão. A Fig. 7.7, baseada nos resultados experimentais levantados neste trabalho, ilustra este comportamento. A determinação do coeficiente $m$ para a elaboração desta figura consistiu no ajuste de curvas, para distintas condições experimentais caracterizadas por $p_{r}$, com um programa de análise estatística, comercialmente denominado de MINITAB. Comportamentos similares aos da Fig. 7.7 são verificados para as superfícies de latão e aço inoxidável, independentemente do acabamento superficial.

Finalmente, partindo das conclusões de Cooper (1984), Gorenflo et al (1994) e da análise dos resultados experimentais, no presente trabalho serão exploradas as possibilidades de um expoente $m$ constante e de sua correlação através de equações similares as Eqs. (7.15) e (7.16), neste caso desprezando-se os efeitos do acabamento superficial. 


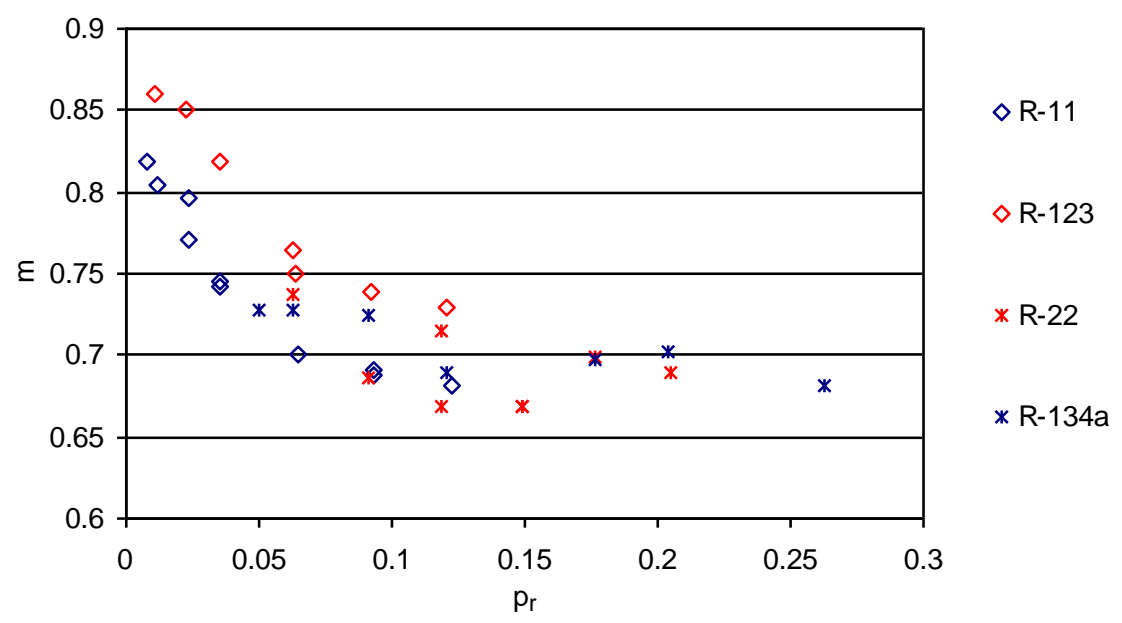

Figura 7.7 Variação do expoente $m \operatorname{com} p_{r}$ para distintos refrigerantes. superfície de cobre e $R a \approx 0,5 \mu \mathrm{m}$

\subsection{Efeitos da Superfície}

A pesquisa bibliográfica e a análise dos resultados experimentais indicaram que o coeficiente de transferência de calor em ebulição nucleada é fortemente afetado por características da superfície de transferência de calor. Entre elas, as dimensões, o formato, seu material e o acabamento superficial. Na correlação desenvolvida no presente estudo, como resultado de restrições na abrangência do banco de dados experimentais levantado, serão incorporados apenas efeitos do acabamento superficial, através de $R a$ e do material da superfície através de distintas constantes.

\subsubsection{Acabamento Superficial}

A maioria das correlações que adotam explicitamente o efeito do acabamento superficial na transferência de calor através de um parâmetro de rugosidade, o fazem da seguinte forma:

$$
F_{R a}=R a^{b_{1}}
$$

Tal procedimento não condiz com o comportamento ilustrado no capítulo anterior, segundo qual verificou-se que a influência do acabamento superficial na transferência de calor se dá 
não apenas através do valor absoluto de $R a$, mas de sua interação com a pressão reduzida, com o refrigerante e o material da superfície. Ainda que tenha sido verificada na análise dos resultados experimentais, no desenvolvimento da presente correlação, a introdução da interação entre rugosidade, refrigerante e material da superfície, não foi implementada devido aos seguintes aspectos:

Os resultados experimentais levantados representam características globais permitindo apenas especulações sobre os mecanismos físicos locais envolvidos.

$>$ Objetiva-se uma correlação simples e de uso imediato, o que não seria alcançado através de um modelamento matemático dos mecanismos físicos atuando no processo de transferência de calor.

$>\quad \mathrm{O}$ reduzido decréscimo dos desvios médios em relação aos resultados experimentais alcançado pela correlação em face do incremento de sua complexidade.

Desta forma, apenas efeitos da interação entre $R a$ e $p_{r}$ são considerados, os quais, conforme indicado no Capítulo 6 e sugerido por Cooper (1984) e Gorenflo et al (1994), são mais relevantes. A incorporação de tais efeitos deve ser realizada através de uma função matemática cujos resultados coincidam com o comportamento experimental. Assim, seus resultados devem indicar efeitos de alterações no acabamento superficial mais intensos com valores reduzidos de $p_{r}$. Equações simples, conforme as apresentadas abaixo, se caracterizam por representarem este comportamento, podendo serem facilmente incorporadas à correlação proposta

$$
\begin{aligned}
& F_{R a}=R a^{b_{1}-b_{2} \cdot p_{r}} \\
& F_{R a}=R a^{b_{1} \cdot\left[-\log \left(p_{r}\right)\right]} \\
& F_{R a}=R a^{b_{1} \cdot\left(l-p_{r}\right)}
\end{aligned}
$$

Entretanto, a utilização destas relações para valores de $R a$ inferiores e superiores a 1 resulta, para cada intervalo, em diferentes tendências de comportamento para $F_{R a}$, com o incremento de $p_{r}$. Isto é, para valores de $R a$ inferiores a 1, tem-se o incremento com a pressão reduzida de $F_{R \mathrm{a}}$, já para valores de $R a$ superiores a 1 , tem-se a sua redução. Tal dificuldade pode ser contornada pela incorporação de uma constante multiplicativa arbitrária à base, de forma que ela apresente, dentro da faixa de rugosidades do presente banco de

* Os expoentes $b_{1}$ e $b_{2}$ encontrados nas Eqs (7.17) a (7.22) consistem em constantes numéricas cujos valores podem ser determinados através do ajuste de cada equação aos resultados experimentais. 
dados, apenas valores inferiores ou superiores a 1 . No presente trabalho optou-se por multiplicar $R a$ por $1 / 5$ nas Eqs. (7.18), (7.19) e (7.20)de forma a obter valores para a base sempre inferiores a 1. Procedimento similar foi adotado por Nishikawa et al apud Stephan (1992).

Outra forma de incorporar efeitos de interação entre $R a$ e $p_{r}$ é a que envolve a manipulação matemática da Eq. (7.18), obtendo-se uma equação similar expressa através da seguinte relação:

$$
F_{R a}=p_{r}^{b_{2} \cdot[-\log (R a)]}
$$

Nela, diferentes tendências relacionadas a valores de $R a$ inferiores ou superiores a 1 são eliminadas, dentro da faixa de rugosidades característica do banco de dados, através da multiplicação de $F_{R a}$ por $p_{r}^{b l}$, fazendo com que o expoente da pressão reduzida apresente, dentro desta faixa, apenas valores positivos ou apenas negativos. Este procedimento, adotado por Cooper (1984), resulta na seguinte relação:

$$
F_{R a}=p_{r}{ }^{b_{1}+b_{2}[-\log (R a)]}
$$

Finalmente, no presente estudo serão analisadas as possibilidades do ajuste de efeitos de rugosidade através das Eqs. (7.17), (7.18), (7.19) (7.20) e (7.22), optando-se ao final pelo formato que melhor se adequar aos resultados experimentais.

\subsubsection{Material da Superfície}

No capítulo anterior indicou-se a impossibilidade de caracterização dos efeitos do material da superfície na curva de ebulição através de propriedades de transporte apenas da superfície ou do fluido refrigerante. Destaca-se que a caracterização de tais efeitos através do produto $k_{p} \rho_{p} c_{p}$, freqüentemente encontrada na literatura, não condiz com o comportamento verificado experimentalmente, segundo o qual estes efeitos resultam da interação entre o par composto pelo fluido e a superfície, embora não necessariamente possam ser caracterizados pelo ângulo de contato. No presente estudo, devido a limitações experimentais e por fugir ao seu escopo, medições de $\beta$ não foram realizadas. Finalmente, os efeito da superfície poderiam ser melhor analisados caso incorporados a modelos complexos envolvendo os 
mecanismos físicos de transferência de calor na superfície e no fluido refrigerante, e não a uma correlação desenvolvida para uso imediato.

Com base em tais premissas, optou-se por caracterizar o efeito do material na correlação através apenas de uma constante multiplicativa característica do material. Tal procedimento, ainda que com abrangência limitada aos materiais analisados neste estudo (comuns em aplicações), permitiu representar de maneira satisfatória os resultados experimentais.

\subsection{Procedimento Utilizado}

O procedimento utilizado na elaboração da correlação para o coeficiente de transferência de calor através do mecanismo de ebulição nucleada inicia-se com a seleção, segundo alguns critérios, dos resultados experimentais representativos do fenômeno físico. Devido ao efeito da histerese, discutido detalhadamente no Capítulo 2, só foram considerados valores experimentais determinados durante a redução do fluxo de calor. Esta consideração é válida, pois os equipamentos tendem a operar durante um elevado número de horas com acréscimos e decréscimos no fluxo de calor sem que atinja a região de convecção natural por um prolongado intervalo de tempo. Deste modo, não ocorre a desativação de cavidades e se opera com valores de coeficiente de transferência de calor similares aos da curva de redução de fluxo de calor. Além disso, também foram desprezados resultados correspondentes à região da curva de ebulição em que efeitos de convecção natural são preponderantes. Tais resultados foram caracterizados ad hoc como aqueles envolvendo valores de $\phi$ inferiores a $4 \mathrm{~kW} / \mathrm{m}^{2}$. Desta forma, o banco de dados efetivamente utilizado no ajuste da correlação consiste em uma parcela com apenas 2590 pontos experimentais do total de 3300 apresentados no Apêndice III. Através de análises de regressão destes resultados, utilizando um programa estatístico comercialmente denominado de MINITAB, foi levantada a correlação proposta na pesquisa.

Os distintos parâmetros que afetam o coeficiente de transferência de calor foram incorporados à correlação, buscando um formato similar à Eq. (7.12), modificada em função de propriedades reduzidas. Desta forma, foram analisadas distintas possibilidades de incorporação dos parâmetros que afetam $h$, resultando consequentemente em distintas correlações. Ao final, optou-se, segundo critérios baseados nos desvios médios apresentados, pela que melhor correlacionasse os resultados experimentais. 
A Tabela 7.3 apresenta de maneira esquemática os efeitos correlacionados e as formas como foram equacionados e incorporados às distintas correlações levantadas.

Tabela 7.3 Parâmetros que afetam $h$ e as formas como foram correlacionados

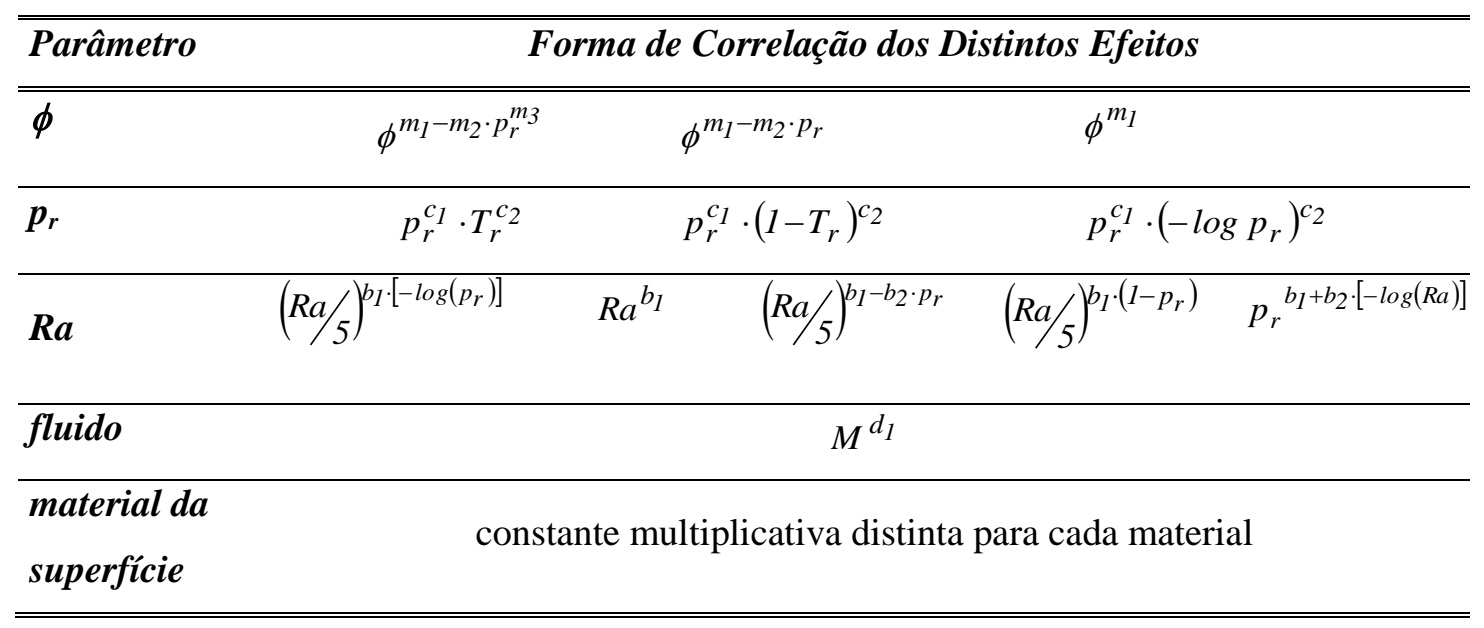

Com base nesta tabela e considerando a combinação de todas as possibilidades de caracterização de cada efeito, através de apenas uma relação, obteve-se um total de 45 correlações, cujos expoentes, coeficientes multiplicativos e desvios médios em relação aos resultados experimentais encontram-se listados no Apêndice IV.

O procedimento envolvendo o ajuste dos coeficientes e expoentes foi realizado da seguinte forma:

i. Inicialmente determinaram-se correlações do tipo $h=$ constante. $\phi^{m}$, para cada curva de ebulição. Os valores individuais de $m$ levantados, foram ajustados através de regressões envolvendo as determinações de $m_{1}, m_{2}$ e $m_{3}$. Para a forma de correlação envolvendo $p_{r}$ no expoente, adotou-se ad hoc $m_{l}=0,9$, analogamente ao VDIWärmeatlas (1994), a partir do qual o expoente $m$ com o incremento de $p_{r}$ seria reduzido. Este valor para $m_{l}$ é superior aos valores experimentais do expoente do termo do fluxo específico de calor levantados nesta pesquisa, e aos encontrados nas correlações apresentadas no Capítulo 3. No caso do ajuste envolvendo um valor de $m$ constante, este expoente foi determinado como a média aritmética dos valores obtidos para cada condição experimental.

ii. Com base nos resultados anteriores, foram determinados valores para a razão entre o coeficiente de transferência de calor e as três formas distintas de correlacionar os efeitos do fluxo específico de calor. Assim, através de análises de regressão foram determinados os valores dos expoentes $c_{1}$ e $c_{2}$, correlacionando a razão dada por 
$\mathrm{h} /\left(\right.$ correlação de efeitos de $\phi$ ) a efeitos de $p_{r}$, segundo as diferentes formas de correlacioná-los apresentadas na Tabela 7.3.

iii. A etapa seguinte consistiu em ajustar os expoentes $b_{1}$ e $b_{2}$, através de novas regressões, correlacionando a razão dada por $h /\left[\left(\right.\right.$ efeitos de $\left.p_{r}\right)$.(efeitos de $\left.\left.\phi\right)\right]$ às distintas formas de equacionamento dos efeitos de rugosidade.

iv. A incorporação da massa molecular à correlação consistiu apenas no seu ajuste, através do expoente $d_{l}$ à razão dada por $h /\left[\left(\right.\right.$ efeitos de $\left.p_{r}\right)$ (efeitos de $\left.\phi\right)$ (efeitos de $R a)]$.

v. Finalmente foram determinadas as constantes características do material da superfície, definidas como a média aritmética para cada material da superfície dos valores obtidos para a razão dada por: $h /\left[\left(\right.\right.$ efeitos de $\left.p_{r}\right) \cdot($ efeitos de $\phi)($ efeitos de $\left.R a) M^{d_{l}}\right]$

Através das Figs. 7.8 e 7.9*, é possível comparar as possibilidades de incorporação dos efeitos do fluido através da massa molecular e do fator acêntrico de Pitzer. Na Fig. 7.8 verifica-se um comportamento médio caracterizado pelo decréscimo da razão $h /[$ (efeitos de $\left.p_{r}\right)$ (efeitos de $\left.\phi\right)$ (efeitos de $\left.R a\right)$ ] com a massa molecular. Este comportamento difere do verificado para esta mesma razão com $\omega$, ilustrado na Fig. 7.9, do qual não se notam tendências claras. Isto indica uma melhor caracterização dos efeitos do fluido refrigerante na determinação do coeficiente de transferência de calor através da massa molecular. Este resultado coincide com aquele verificado anteriormente para as demais correlações e justifica o fato de não ter sido incluído o fator acêntrico de Pitzer para a caracterização do fluido refrigerante na correlação desenvolvida no presente trabalho.

\subsection{Correlação Resultante}

Através do procedimento descrito no item anterior, foram levantadas um total de 45 correlações, que se encontram, junto com os seus desvios médios, listadas no Apêndice IV. Desta forma, tiveram de ser adotados alguns critérios para a seleção da correlação final, que são os seguintes:

i. Desvios médios individuais para cada refrigerante, $p_{r}$ e material da superfície inferiores a $15 \%$.

ii. Comportamento de seus resultados com a variação de um determinado parâmetro condizente com o fenômeno físico.

\footnotetext{
* As Figs. 7.8 e 7.9 foram elaboradas com base na correlação final proposta neste trabalho.
} 
iii. Simplicidade.

iv. Menor desvio médio total.

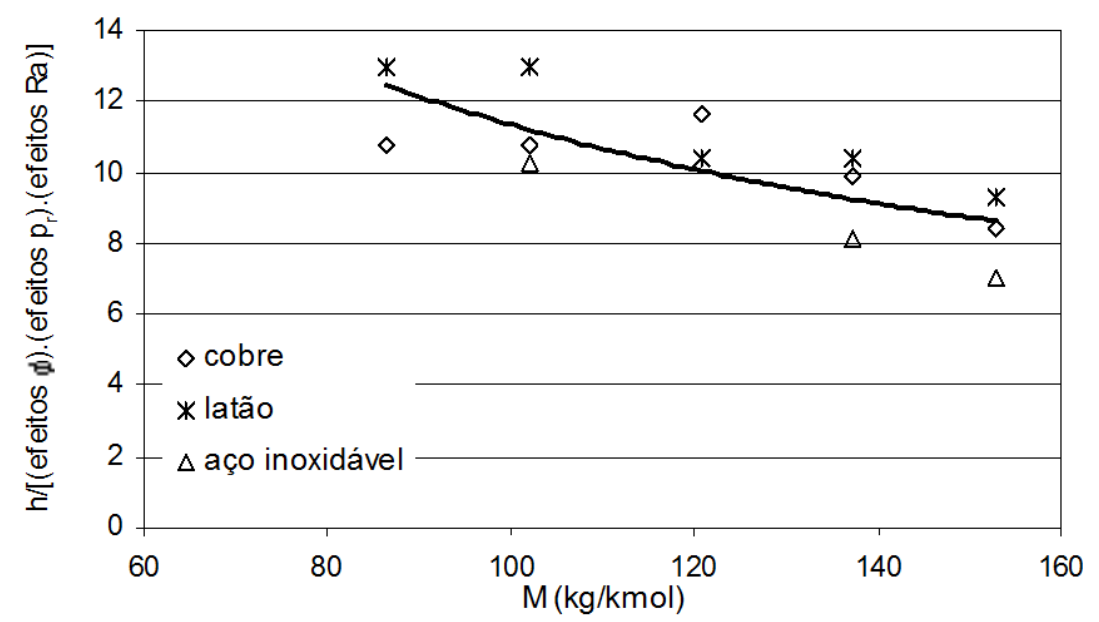

Figura 7.8 Variação de $h /\left[\left(\right.\right.$ efeitos de $\left.p_{r}\right)$ (efeitos de $\left.\phi\right) \cdot($ efeitos de $\left.R a)\right]$ com $M$ baseada na correlação proposta.

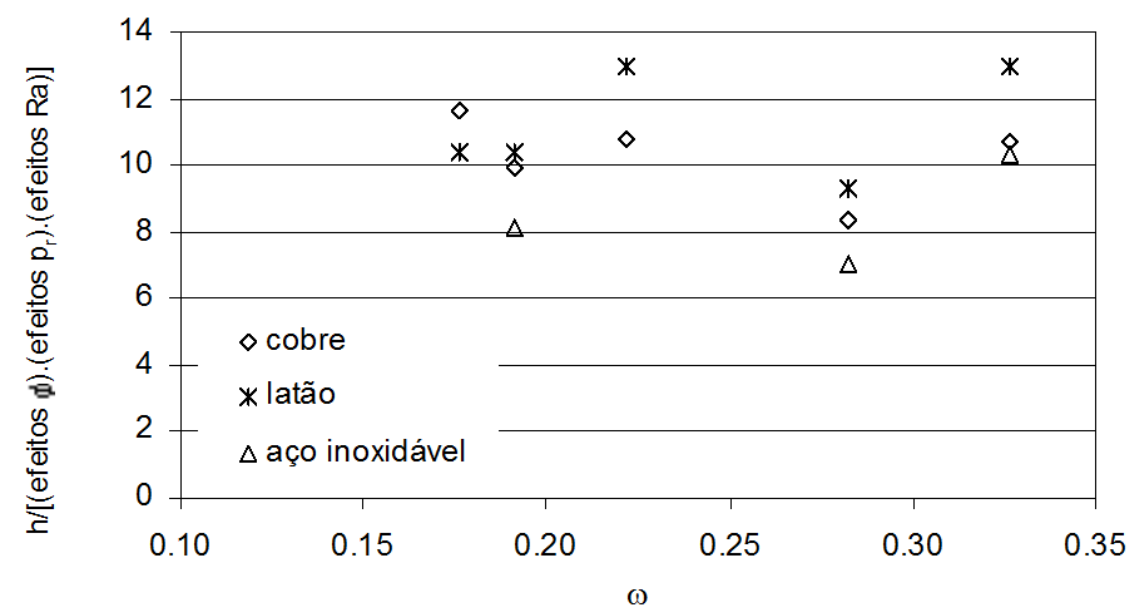

Figura 7.9 Variação de $h /\left[\left(\right.\right.$ efeitos de $\left.p_{r}\right)$ (efeitos de $\left.\phi\right)$ (efeitos de $\left.\left.R a\right)\right]$ com $\omega$ baseada na correlação proposta.

Finalmente, a correlação a que se chegou no presente trabalho, isto é, aquela que melhor se ajustou aos resultados experimentais e aos critérios mencionados anteriormente foi a seguinte:

$$
\frac{h}{\phi^{m}}=f_{p} \cdot p_{r}^{0,45} \cdot\left[-\log \left(p_{r}\right)\right]^{-0,8} \cdot R a^{0,2} \cdot M^{-0,5}
$$


onde $m=0,9-0,3 \cdot p_{r}^{0,2}$

$\operatorname{com} f_{p}=100 \mathrm{p} /$ superfície de cobre; $f_{p}=110 \mathrm{p} /$ superfície de latão; $f_{p}=85 \mathrm{p} /$ superfície de aço inoxidável.

Destaca-se nesta correlação o valor do expoente da massa molecular, similar ao de Cooper (1984), e valores próximos aos do VDI-Wärmeatlas (1994) para os coeficientes e o expoente envolvidos na determinação de $m$. Tais resultados (ou tendências) permitem concluir que o banco de dados do presente estudo apresenta tendências similares às verificadas no de Cooper (1984), no que diz respeito ao efeito do fluido, e no do VDIWärmeatlas (1994), relativamente ao coeficiente angular da curva de ebulição.

\subsection{Análise de Curvas de Resíduos e dos Desvios Médios}

A análise dos desvios médios e da curva de resíduos, definidos conforme Eq. (6.3), consistiu na verificação de desvios médios elevados associados a determinado parâmetro experimental e de tendências condizentes com as dos resultados levantados na bancada de testes. Tal análise envolveu a comparação dos resultados experimentais com aqueles resultantes da Eq. (7.23). É interessante ressaltar que esta análise não busca a validação da correlação proposta, mas sim verificar a adequação de seus resultados aos levantados experimentalmente.

A Tabela 7.4 apresenta valores dos desvios médios calculados segundo a Eq. (6.4). Os resultados dessa tabela podem ser considerados razoáveis, haja vista que os desvios médios resultantes são razoavelmente inferiores aos das demais correlações, cujos valores foram anteriormente apresentados na Tabela 6.5. Tal comportamento independe dos particulares parâmetros de comparação fixados, caracterizados nesta tabela pelo refrigerante e material da superfície.

Na Tabela 7.4 verifica-se um desvio médio sensivelmente superior aos demais para o R-12 na superfície de cobre. Este resultado advêm de os outros refrigerantes apresentarem valores experimentais de $h$ próximos para as superfície de cobre e de latão, o mesmo não ocorrendo para o R-12, que conforme discutido detalhadamente no capítulo anterior, apresentou resultados para a superfície de latão razoavelmente superiores aos da de cobre. Desta forma, este comportamento, por ser distinto dos demais, não é adequadamente contemplado pela correlação final. Tal comportamento poderia ser incluído 
à correlação caso fossem utilizadas distintas constantes multiplicativas para o R-12 nas superfícies de cobre e latão. Este procedimento além de não permitir uma redução significativa no desvio apresentado, no que tange à elaboração de uma correlação visando aplicações distintas das compreendidas pelo banco de dados levantado, limitaria sua aplicação através da necessidade de determinação de uma constante empírica característica do par fluido refrigerante e material da superfície.

Tabela 7.4 Desvios médios da Eq. (7.23) em relação aos resultados experimentais

\begin{tabular}{lcccc} 
& \multicolumn{5}{c}{ desvio médio (\%) } \\
\cline { 2 - 5 } & cobre & latão & aço inoxidável & total \\
\hline $\boldsymbol{R}-11$ & 11,5 & 6,4 & 10,4 & 10,1 \\
\hline $\boldsymbol{R}-123$ & 6,0 & 9,5 & 12,4 & 8,2 \\
\hline $\boldsymbol{R}-134 \boldsymbol{a}$ & 8,6 & 9,3 & 12,2 & 10,0 \\
\hline $\boldsymbol{R}-\mathbf{2 2}$ & 8,9 & 5,6 & ----- & 8,1 \\
\hline $\boldsymbol{R}-12$ & 14,4 & 7,4 & ----- & 12,2 \\
\hline total & 9,8 & 7,6 & 12,5 & $\mathbf{9 , 6}$ \\
\hline \hline
\end{tabular}

A Fig. 7.10 compara os resultados de $h$ correlacionados através da Eq. (7.23) e os experimentais, envolvendo o total de pontos experimentais levantados. Nesta figura constatase que os valores correlacionados encontram-se em sua maioria entre $\pm 20 \%$ dos valores experimentais. Na Fig. 7.11, resultados para fluxos específicos de calor e, consequentemente, valores de $h$ inferiores são ressaltados constatando-se que os resíduos se localizam consistentemente dentro de uma faixa de $\pm 30 \%$. É interessante ressaltar que no caso de valores de $\phi$ inferiores a $10 \mathrm{~kW} / \mathrm{m}^{2}$ os resíduos passam a localizar-se numa faixa mais ampla. Tal comportamento, comum às demais correlações analisadas, justifica-se através de dois aspectos: o primeiro, relacionado às incertezas dos resultados experimentais, que se elevam com a redução de $\phi$ e, consequentemente, de $h$, conforme sugerido no Capítulo 5; e o segundo, por esta ser uma região de ebulição nucleada parcial em que o mecanismo físico de convecção natural é responsável por uma parcela significativa do calor removido da superfície, ao contrário da região de ebulição nucleada plenamente desenvolvida, objeto da presente correlação, onde estes efeitos tornam-se irrelevantes.

A Fig. 7.12 ilustra variações com a pressão reduzida do desvio médio, cujo valor foi calculado individualmente a partir de todos os resultados experimentais levantados para um determinado valor de $p_{r}$. Nela, apesar da extensa faixa de $p_{r}$ envolvida, não se verificam 
tendências para o desvio médio, que a "grosso modo" pode ser considerado independente da pressão reduzida.

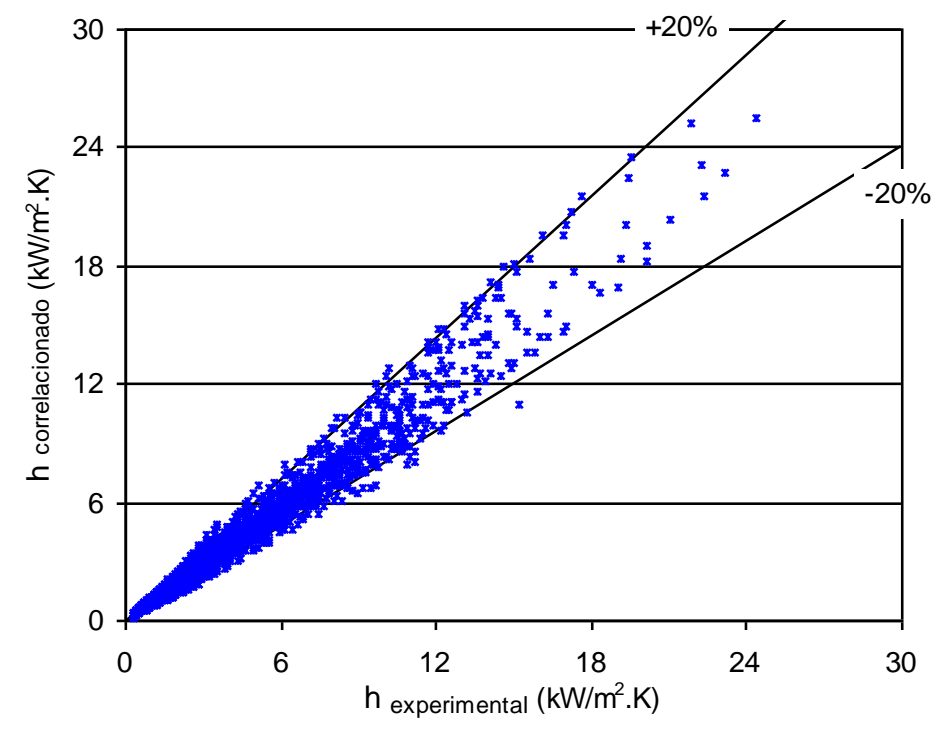

Figura 7.10 Curva comparativa dos resultados experimentais com os proporcionados pela Eq. (7.23).

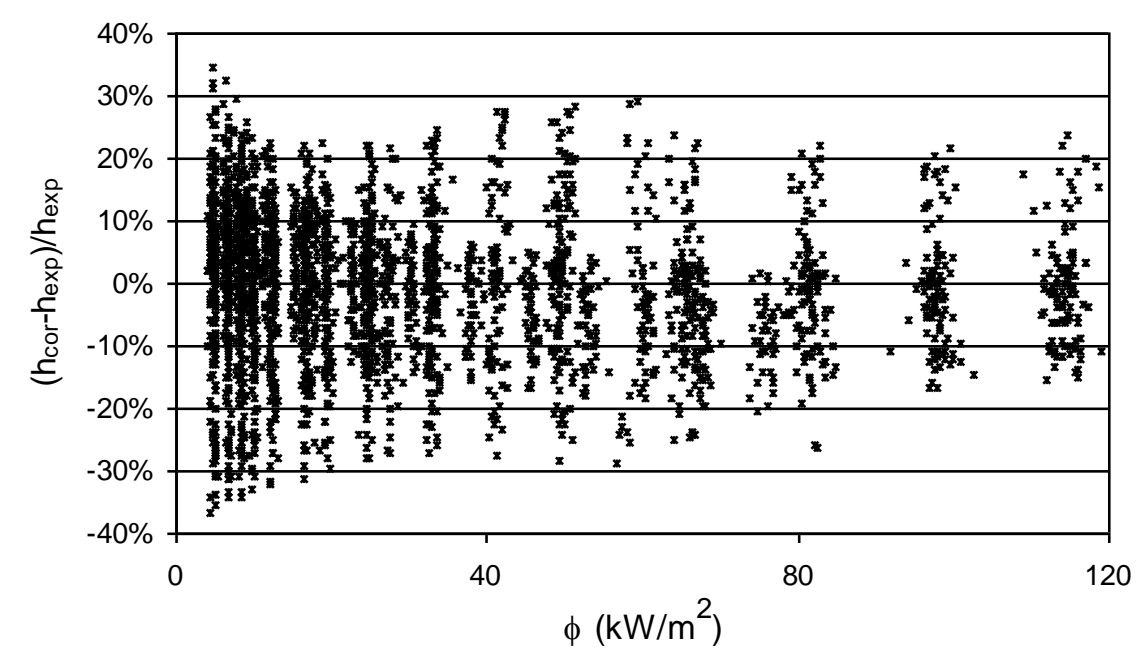

Figura 7.11 Curva de resíduos para os resultados apresentados pela Eq. (7.23) em relação ao banco de dados experimentais.

A Fig. 7.13 ilustra variações com $R a$ do desvio médio, cujo cálculo envolve individualmente todos os resultados experimentais obtidos para cada acabamento superficial e refrigerante. Nela verificam-se distintas tendências do desvio médio com $R a$. 


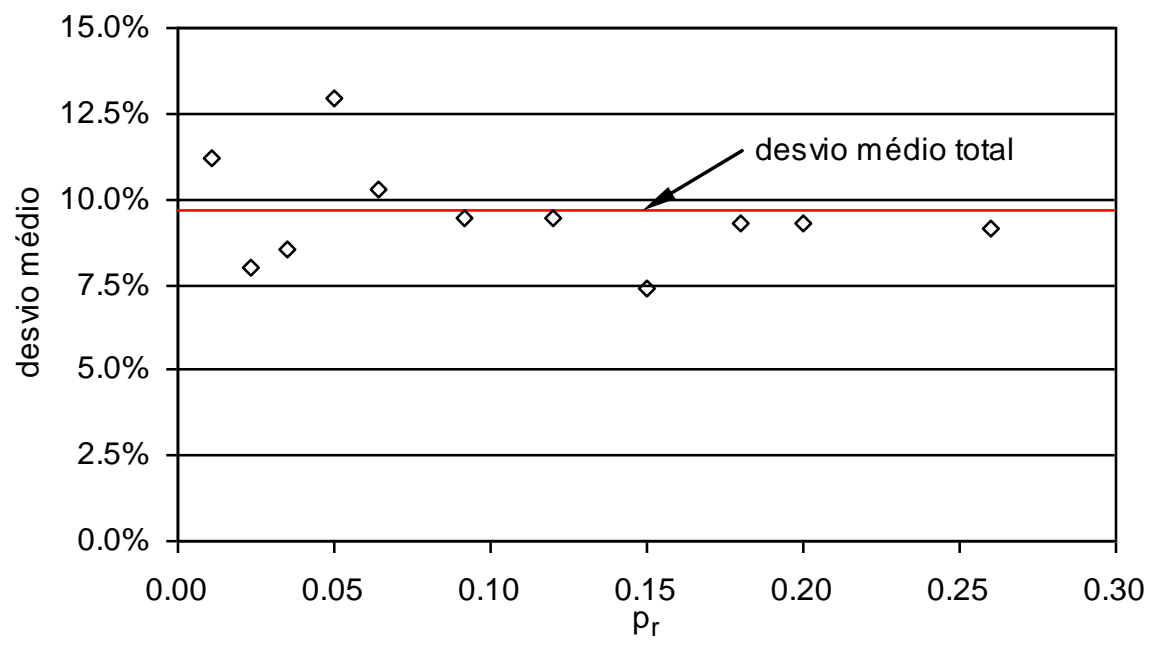

Figura 7.12 Variação com $p_{r}$ do desvio médio dos resultados fornecidos pela Eq. (7.23) em relação aos experimentais.

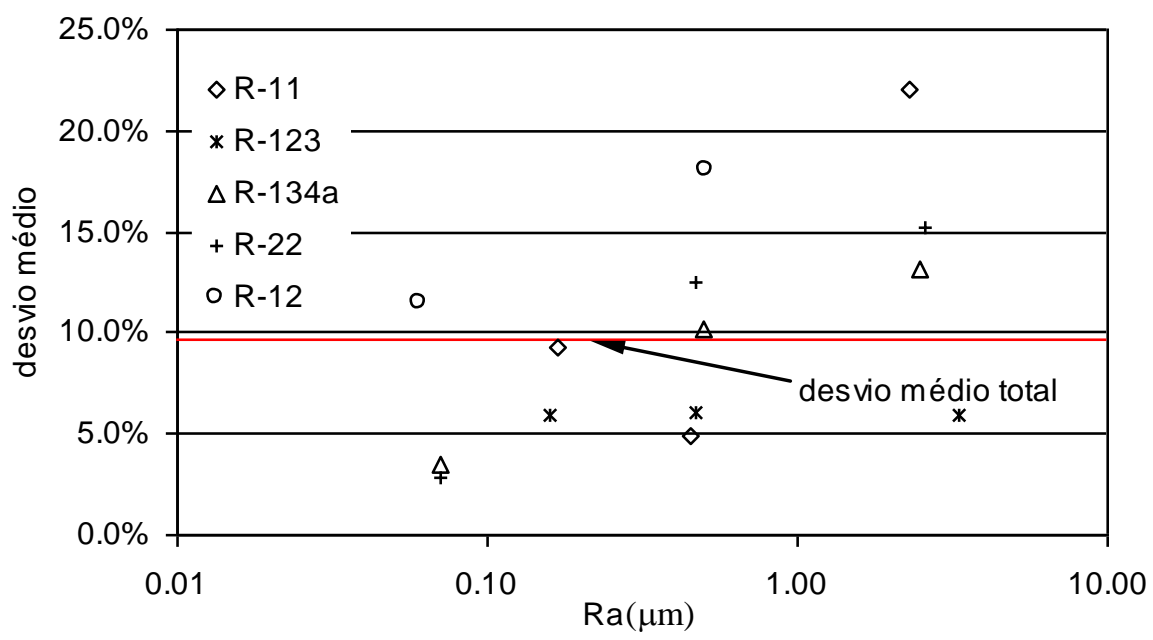

Figura 7.13 Variação com $R a$ do desvio médio dos resultados fornecidos pela Eq. (7.23) em relação aos experimentais, com a superfície de cobre.

Embora não necessariamente, este comportamento pode ser decorrente da combinação dos seguintes aspectos: a correlação representa um comportamento médio dos distintos refrigerantes dado por $R a^{0,2}$; e a ebulição é afetada pelo acabamento superficial para os refrigerantes analisados de maneira distinta, conforme discutido detalhadamente no capítulo anterior. Variações mais significativas do desvio médio se verificam para os refrigerantes R11 e R-12, respectivamente, de baixa e média pressão que, conforme concluído no capítulo anterior, quando comparados aos refrigerantes classificados quanto à pressão pertencentes ao mesmo grupo, apresentam uma maior "sensibilidade" a variações no acabamento superficial. 
Ainda que efeitos de interação entre a pressão e o acabamento superficial tenham sido ressaltados, a Eq. (7.23) não os contempla ao admitir um expoente constante para $R a$. Conforme indicado nos itens anteriores, tentativas da incorporar tais efeitos foram realizadas, não resultando na redução dos desvios médios nem na eliminação das tendências ilustradas na Fig. 7.13. Desta forma, optou-se por incorporar os efeitos do acabamento superficial através de uma expressão mais "simples", em termos de $R a^{0,2}$. 


\section{Capítulo 8 - Conclusões e Recomendações}

\subsection{Considerações Gerais}

A presente pesquisa, apesar de extensa, concentrou-se em aspectos restritos do estudo da ebulição nucleada, face ao elevado número de tópicos relevantes envolvendo este tema. O estudo consistiu em uma análise teórico experimental, com o desenvolvimento de uma correlação dos parâmetros que afetam a ebulição nucleada de refrigerantes halogenados em superfícies cilíndricas lisas. Os parâmetros cujos efeitos foram analisados são o fluxo específico de calor, a pressão, o refrigerante, o material da superfície e o seu acabamento superficial. Para tanto foi projetado e construído um aparato que permitiu levantar resultados experimentais abrangendo variações destes distintos parâmetros dentro de amplas faixas. A análise destes resultados possibilitou a verificação de comportamentos físicos inéditos conforme a literatura consultada. Destaca-se a análise minuciosa dos efeitos da condução longitudinal e da resistência térmica de contato entre a superfície de transferência de calor e os termopares utilizados na determinação de $T_{p}$, que permitiu, ao final, a proposição de um procedimento baseado em seus resultados.

As recomendações apresentadas para futuras pesquisas apresentadas referem-se a uma continuidade deste trabalho que permitam a verificação e a análise de comportamentos verificados, ou ainda, a complementação do banco de dados levantados. É interessante ressaltar que temas não relacionados diretamente a este trabalho como o estudo de superfícies intensificadoras, misturas compostas por refrigerante e óleo de lubrificação e banco de tubos, embora não citados no item relativo a recomendações para trabalhos futuros, também devem ser considerados. 
Finalmente, a pesquisa bibliográfica efetuada e apresentada nos Capítulos 1, 2 e 3, ainda que envolva apenas uma parcela da literatura realmente consultada, indica que as chaves para o entendimento dos mecanismos físicos e dos fenômenos envolvidos na ebulição nucleada permanecem sem solução, incentivando pesquisadores criativos a explorarem este tema e determinarem como e porque tais mecanismos e fenômenos ocorrem. Tais respostas poderão resultar no desenvolvimento de novas tecnologias ou ainda no aperfeiçoamento das já existentes. Assim, conclui-se que o tema "ebulição nucleada" é, ainda, tanto uma ciência como uma tecnologia incipiente.

\subsection{Conclusões}

Os objetivos inicialmente propostos foram satisfatoriamente atingidos. A seguir são apresentadas sumariamente as principais conclusões deste trabalho.

Através da extensa pesquisa bibliográfica realizada verificou-se que o estudo da ebulição nucleada, apesar de ter sido iniciado há mais de 70 anos, constitui-se num tema atual, ao qual diversos pesquisadores têm se dedicado, caracterizado por inúmeras lacunas. Infelizmente, verificar origem da literatura consultada, são raras as pesquisas no Brasil relativas a este tema.

$>$ Levantou-se um elevado número de correlações na literatura para o regime de ebulição nucleada plenamente desenvolvida, tendo sido agrupadas em três categorias: correlações estritamente empíricas, baseadas exclusivamente em bancos de dados; correlações semi-empíricas, nas quais modelos físicos são correlacionados através de dados experimentais; e baseadas em propriedades reduzidas, nas quais o coeficiente de transferência de calor é função apenas de propriedades reduzidas primitivas pressão, $p_{r}$ e temperatura, $T_{r}$.

As correlações levantadas na literatura e os bancos de dados utilizados pelos correspondentes autores foram discutidos e amplamente analisados. Concluiu-se que, embora com a pretensão de genéricas, apresentam, com a variação de um determinado parâmetro, comportamentos distintos e uma elevada dispersão entre seus resultados. Estas correlações foram comparadas aos resultados levantados no presente estudo, com aquela proposta por Stephan e Abdelsalam (1980), apresentando um desvio médio inferior às demais e igual a 17\%.

Ao contrário da grande maioria dos trabalhos analisados, verificou-se a variação do coeficiente de transferência de calor ao longo do perímetro da superfície e este sendo 
dependente do fluxo específico de calor. Observou-se que, para valores de $\phi$ reduzidos, o perfil de temperaturas da parede caracteriza-se por um máximo em $\theta=0$, ápice da superfície, e por um decaimento até $\theta=180^{\circ}$. Este comportamento, similar ao verificado pelos poucos autores que constataram o fenômeno de variação de $T_{p}$ ao longo do perímetro da circunferência da superfície, inverte-se para fluxos de calor superiores.

$>$ Foram levantados resultados experimentais envolvendo a transferência de calor através do mecanismo de convecção natural, tendo sido comparados às correlações de Churchill e Chu (1975) e de Morgan (1975). Esta última apresenta resultados mais próximos aos experimentais, resultando num desvio médio da ordem de $14 \%$.

De uma maneira geral, os refrigerantes mais voláteis (R-12, R-22, R-134a) apresentaram, para um mesmo valor de $p_{r}$, coeficientes de transferência de calor superiores aos de baixa pressão (menos voláteis), R-11 e R-123. Já na comparação dentro de cada grupo, o melhor desempenho dependeu da pressão reduzida, da rugosidade e do material da superfície.

A rugosidade e a pressão tendem a elevar o coeficiente de transferência de calor, com seus efeitos sendo mais intensos em valores reduzidos de $R a$ e $p_{r}$. A taxa de incremento depende do refrigerante e da superfície, estando relacionada, no caso de $R a$, principalmente ao número de cavidades ativas. No caso de variações na pressão, fatores como a freqüência e o diâmetro de bolhas também são afetados. Variações de $\sigma$ e da razão entre as propriedades de transportes $v$ e $\alpha$, caracterizada pelo número de Prandtl, parecem indicar através de seus efeitos nos mecanismos físicos envolvidos, os comportamentos verificados.

Embora a grande maioria das correlações que envolvem efeitos do material da superfície os incorporem através do produto $k_{p} \rho_{p} c_{p}$, verificou-se que alterações no coeficiente de transferência de calor devido à mudança do material da superfície não podem ser caracterizadas por propriedades termodinâmicas ou de transporte exclusivas do fluido ou do material da superfície. Elas são resultados da interação entre o par composto pelo fluido e a superfície, podendo ser caracterizadas, ainda que não necessariamente, pelo ângulo de contato.

No regime de ebulição nucleada parcial foram verificados para a curvas levantadas com a redução do fluxo de calor a partir de uma valor máximo, descontinuidades caracterizadas por "saltos" na curva de ebulição. Tal fenômeno parece estar relacionado à aparente ativação intermitente das cavidades, sendo influenciado pela condutividade térmica do material da superfície e associado a efeitos de convecção 
natural. Sua intensidade foi superior no caso de valores reduzidos de $p_{r}$ e refrigerantes menos voláteis, apresentando a seguinte ordem decrescente com o material da superfície: aço inoxidável, latão e cobre.

Desenvolveu-se, com base no banco de dados levantado, uma correlação Eq. (7.23) para refrigerantes halogenados visando a determinação do coeficiente de transferência de calor em ebulição nucleada plenamente desenvolvida. Esta correlacionou razoavelmente, apesar de sua abrangência, o banco de dados utilizado, apresentando um desvio médio total da ordem de $9,6 \%$, resultado inferior ao das demais correlações, como seria de se esperar. A correlação desenvolvida prima pela facilidade de uso, requerendo apenas o conhecimento da pressão e da rugosidade, além da pressão no estado crítico e da massa molecular, parâmetros facilmente encontrados na literatura. Verificou-se a impossibilidade da incorporação à correlação dos efeitos do fluido refrigerante através do fator acêntrico de Pitzer.

\subsection{Recomendações para Futuros Trabalhos}

O estudo desenvolvido levanta algumas lacunas ou pontos de discordância entre distintos autores, que foram, com base nos resultados experimentais e em sua análise, ressaltados. Com base nestes resultados e objetivando a continuidade da presente pesquisa, as seguintes sugestões para futuros trabalhos podem ser enumeradas:

Levantamentos experimentais envolvendo superfícies cilíndricas e planas com diferentes dimensões afim de investigar seus efeitos no coeficiente de transferência de calor e incorporá-los à correlação proposta.

$>\quad$ Verificação dos resultados relativos à variação de $T_{p}$ ao longo do perímetro da superfície, acompanhada da investigação através de uma filmadora com captura de imagem de alta velocidade da dinâmica de bolhas ao seu redor. A incorporação destes resultados a um modelo físico envolvendo características da superfície de transferência de calor poderão indicar os mecanismos determinantes tanto do perfil de temperaturas ao longo do perímetro da superfície como do fenômeno físico relacionado a "saltos" na curva de ebulição.

Realização de um estudo aprofundado e local da interação de efeitos do material, do fluido e do acabamento superficial na transferência de calor, envolvendo aspectos como dimensão das cavidades na superfície, o ângulo de contato, o número de 
cavidades ativas, o perfil de temperaturas na superfície junto às cavidades e os períodos de espera e crescimento de bolhas. Somente desta forma, com base nestes resultados, poderão ser identificados os mecanismos físicos envolvidos e de que forma se dá a influência de cada parâmetro nos comportamentos verificados.

A determinação e análise de resultados experimentais para a amônia. Tal estudo é importante em virtude da pouca incidência de pesquisas para este refrigerante, ainda que comumente encontrado em instalações frigoríficas de grande porte, denominadas industriais. Deve-se notar que a amônia não afeta a camada de ozônio.

O levantamento de resultados experimentais para hidrocarbonetos puros e suas misturas e refrigerantes compostos por misturas não azeotrópicas. A análise da possibilidade de incorporação destes resultados à correlação proposta deve ser estendida com base no fato da Lei dos Estados Correspondentes poder ser aplicada a fluidos puros e misturas. 


\section{Bibliografia}

Abernethy, R. B.; Thompson, J. W. (1973). Handbook, uncertainty in gas turbine measurements. Arnold Engineering Development Center, Arnold Air Force Station, Tennessee

Anderson, T. M.; Mudawar, I. (1989). Microelectronic cooling by enhanced pool boiling of a dielectric fluorocarbon liquid. Journal of Heat Transfer, v.111, p.752-759.

Anikin, A. I.; Danilova, G. N.; Mirmov, N. I. (1984). Generalized correlation for coefficients of boiling heat transfer of oil-refrigerant mixtures in tubes. Heat Transfer-Soviet Research, v.16, p. 42-52.

Arai, N.; Fukushima, T.; Arai, A.; Tadakatsu, N.; Fujie, K.; Nakayama, Y. (1977). Heat transfer tubes enhancing boiling and condensation in heat exchangers of a refrigerating machine. ASHRAE Transactions, v. 83, part II, p. 58-70.

Arshad, J.; Thome, J. R. (1983). Enhanced boiling surfaces: Heat transfer mechanism mixture boiling . In: ASME-JSME Thermal Engineering Joint Conference, New York, v.1, p.191-197.

Asakavicius, J. P.; Zukauskav, A. A., Gaigalis, V. A. (1979). Heat Transfer from freon 113, ethyl alcohol and water with screen wicks. Heat Transfer - Soviet Research, v.11, p. 92100 .

Bejan, A. (1997). Advanced Engineering Thermodynamics. 2. ed. New York, John Wiley \& Sons.

Benjamin, R. J.; Balakrishnan, A. R. (1996). Nucleate pool boiling heat transfer of pure liquids at low to moderate heat fluxes. Int. J. Heat Mass Transfer, v.39, p.2495-2504. 
Benjamin, R. J.; Balakrishnan, A. R. (1997). Nucleation site density in pool boiling of saturated pure liquids: Effects of surface microroughness and surface and liquid physical properties. Experimental Thermal and Fluid Science, v.15, p. 32-42.

Berenson, P. J. (1962). Experiments on pool boiling heat transfer. Int. J. Heat Mass Transfer, v. 5 , p. $985-999$.

Bergles, A. E. (1997). Enhancement of pool boiling. Int. J. Refrig. v.20, p. 545-551.

Bernardin, J. D.; Mudawar, I.; Walsh, C. B.; Franses, E. I. (1997). Contact angle temperature dependence for water droplets on practical aluminum surfaces. Int. J. Heat Mass Transfer, v.40, p.1017-1033.

Bikerman, J. J. (1970). Physical Surfaces. New York, Academic Press, Inc.

Carey, Van P. (1992). Liquid-Vapor Phase Change Phenomena: an introduction to the Thermophysics of Vaporization and Condensation Processes in Heat Transfer Equipaments. New York, Hemisphere Publishing Corporation.

Chai, L. H.; Peng, X. F.; Wang, B. X. (2000). Nucleation site interaction during boiling. Int. J. Heat Mass Transfer, v.43, p.4249-4258.

Chan, A. M.; Shoukri, M. (1987). Boiling characteristics of small multitube bundles. Journal of Heat Transfer, v.109, p.753-760.

Chang, J. Y.; You, S. M. (1996). Heater orientation effects on pool boiling of micro-porousenhanced surfaces in saturated FC-72. Journal of Heat Transfer, v.118, p.937-943.

Chang, J. Y.; You, S. M. (1997a). Boiling heat transfer phenomena from micro-porous and porous surfaces in saturated FC-72. Int. J. Heat Mass Transfer, v.40, p.4437-4447.

Chang, J. Y.; You, S. M. (1997b). Enhanced boiling heat transfer from micro-porous surfaces: effects of a coating composition. Int. J. Heat Mass Transfer, v.40, p.4449-4460.

Chang, J. Y.; You, S. M. (1997c). Enhanced boiling heat transfer from micro-porous cylindrical surfaces in saturated FC-87 and R-123. Journal of Heat Transfer, v.119, p.319-325.

Chaudhri, I. H.; McDougall, I. R. (1969). Ageing studies in nucleate pool boiling of isopropyl acetate and perchloroethylene. Int. J. Heat Mass Transfer, v.12, p. 681-688.

Chien, L. (1996). Mechanism and analysis of nucleate boiling on structured surfaces. University Park. 216p. Tese (doutorado) - Department of Mechanical Engineering, Pennsylvania State University.

Chien, L.; Webb, R. L. (1998). A nucleate boiling model for structured enhanced surfaces. Int. J. Heat Mass Transfer, v.41, p. 2183-2195. 
Chongrungrong, S.; Sauer, H. J. (1980). Nucleate boiling performance of refrigerants and refrigerants-oil mixtures. Journal of Heat Transfer, v.102, p.701-705.

Chuah, Y. K.; Carey, V. P. (1987). Boiling heat transfer in a shallow fluidized particulate bed. Journal of Heat Transfer, v.109, p.196-203.

Churchill, S. W.; Chu, H. H. S. (1975). Correlating equations for laminar and turbulent free convection from a horizontal cylinder. Int. J. Heat Mass Transfer, v.18, p. 1049-1053.

Cole, R.; Shulman, H. L. (1966). Bubble growth rates at high Jakob numbers. Int. J. Heat Mass Transfer, v.9, p. 1377-1390.

Collier, J. G.; Thome, J. R. (1996). Convective boiling and condensation. 3. ed. New York, Oxford University Press.

Cooper, M. G. (1982). Correlations for nucleate boiling - formulation using reduced properties. PCH PhsycoChemical Hydrodynamics, v. 3, pp. 89-111.

Cooper, M. G. (1984). Heat flow rates in saturated nucleate pool boiling - A wide ranging examination using reduced properties. Advances in Heat Transfer, v.16, p.157-238.

Corman, J. C.; McLaughlin, M. H. (1976). Boiling augmentation with structured surfaces. ASHRAE Transactions, v.71, part.1, p.231-237.

Cornwell, K.; Schüller, R. B. (1982). A study of boiling outside a tube bundle using high speed photography. Int. J. Heat and Mass Transfer, v.25, p.683-690

Czikk, A. M.; Gottzmann, C. F.; Ragi, E. G.; Withers, J.G.; Habdas, E. P. (1970). Performance of advanced heat transfer tubes in refrigerant-flooded liquid coolers. ASHRAE Transactions, v. 76, part. I, p. 96-109.

Danilova, G. N.; Dyundin, V. A. (1972). Heat Transfer with freons 12 and 22 boiling at bundles of finned tubes. Heat Transfer-Soviet Research, v. 4, p. 48-54.

Danilova, G. N.; Dyundin, V. A.; Soloviyov, A. G. (1992). Heat transfer in boiling of R-717 and R-22 refrigerants on multirow tube bundles. Heat Transfer Research, v. 24, p. 889893.

Danilova, G. N.; Tikhonov, A. V. (1996). R-113 boiling heat transfer modeling on porous metallic matrix surfaces. Int. J. Heat and Fluid Flow, v. 17, p. 45-51.

Dhir, V. K.; Lienhard, J. (1971). Laminar film condensation on plane and axisymmetric bodies in nonuniform gravity. Journal of Heat Transfer, v. 93, p. 97-100.

Dhir, V. K. (1991). Nucleate and transition boiling heat transfer under pool and external flow conditions. Int. J. Heat and Fluid Flow, v. 12, p. 290-314. 
Diev, M. D.; Leontiev, A. I.; Slovyanskikh, D. V.; Nikonov, A. A. (1993). Heat Transfer in R-113 boiling on surfaces with regular microrelief.. Heat Transfer Research, v. 4, part. I, p.47-50.

Dittus, F. W.; Boelter, L. M. K (1930). Heat transfer in automobile radiators of the tubular type. University of California Publications in Engineering, v. 2, p. 443-461.

Dougherty, R. L.; Sauer, H. J. (1974). Nucleate pool boiling of refrigerant-oil mixtures from tubes. ASHRAE Transactions, v.80, p.175-193.

Foster, H. K.; Zuber, N. (1955). Bubble dynamics and boiling heat transfer. AIChe Journal, v.1, p.531-535.

Furse, F. G. (1965). Heat transfer to refrigerants 11 and 12 boiling over a horizontal cooper surface. ASHRAE Transactions, v.71, part.1, p.231-237.

Gaertner, R. F. (1965) Photographic study of nucleate pool boiling on a horizontal surface. Journal of Heat Transfer, v. 87, p.17-29.

Gorenflo, D.; Caplanis, S.; Künstler, W. (1993). Enhanced pool boiling heat transfer to new refrigerants. In: International Conference Energy Efficiency in Refrigeration and Global Warming Impact, Comissão B1/2, International Institute of Refrigeration, University of Ghent, Bélgica, p. 327-334.

Gorenflo, D.; Luke, A.; Künstler, W.; Buschmeier, M. (1994). Prediction of pool boiling heat transfer with new refrigerants. In : $C f c$ 's the day after, Padova, spt. 21-23, p.557563.

Gorenflo, D.; Hübner, P.; Fust. W.; Luke, A.; Danger, E.; Chandra, U. (2000). Pool boiling heat transfer and bubble formation of natural refrigerants on horizontal tube, In. Joint Conference of the International Institute of Refrigeration Sections $B$ and E, University of Purdue, West Lafayette, Indiana.

Gupte, N. S. (1992). Simulation of boiling in flooded refrigerant evaporators. University Park. 264p. Tese (doutorado) - Departament of Mechanical Engineering, Pennsylvania State University

Hahne, E.; Müller, J. (1983). Boiling on a finned tube and a finned tube bundle. Int. J. Heat Mass Transfer, v.26, p.849-859.

Hahne, E.; Noworyta, A. (1984). Calculation of heat tranfer coefficients for nucleate boiling in binary mixtures of refrigerants-oil. Int. Comm. Heat Mass Transfer, v.11, p. 417-427.

Hahne, E.; Qiu-Rong, C.; Windisch, R. (1991). Pool boiling heat transfer on finned tubes na experimental and theoretical study. Int. J. Heat Mass Transfer, v.34, p.2071-2079. 
Haider, S. I. (1994) A theoretical and experimental study of nucleate pool boiling enhancement on structured surfaces. University Park. 272p. Tese (doutorado) Departament of Mechanical Engineering, Pennsylvania State University.

Haider, S.I.; Webb, R.L. (1997). A transient micro-convection model of nucleate pool boiling. Journal of Heat Mass Transfer, v.40, n.15, p.3675-3688.

Han, C. Y.; Griffith, P. (1965a). The Mechanism of heat transfer in nucleate pool boiling part. I. Int. J. Heat Mass Transfer, v.8, p.887-904.

Han, C. Y.; Griffith, P. (1965b). The Mechanism of heat transfer in nucleate pool boiling part. II. Int. J. Heat Mass Transfer, v.8, p.905-914.

Hong, K. T.; Imadojemu, H. E.; Webb, R. L. (1994). Pool boiling of R-11 refrigerant and water on oxidized enhanced tubes. Publications of ASME, Fundamentals of Phase Change: Boiling and Condensation, HTD - v. 273, p. 1-9.

Hsieh, S. Ś.; Hsu, P. T. (1994). Nucleate boiling characteristics of R-114, distilled water $\left(\mathrm{H}_{2} \mathrm{O}\right)$ and $\mathrm{R}-134 \mathrm{a}$ on plain and rib-roughened tube geometries. Int. J. Heat Mass Transfer, v.37, p.1423-1432.

Hsieh, S. S.; Weng, C. J. (1997a). Nucleate pool boiling heat transfer coefficients of distilled water $\left(\mathrm{H}_{2} \mathrm{O}\right)$ and $\mathrm{R}-134 \mathrm{a} /$ oil mixtures from rib-roughened surfaces. Journal of Heat Transfer , v.119, p.142-151.

Hsieh, S. S.; Weng, C. J. (1997b). Nucleate pool boiling from coated surfaces in saturated R134a and R-407c. Int. J. Heat Mass Transfer. v.40, p.519-532.

Hsieh, S. S.; Weng, C. J.; Chiou, J. J. (1999). Nucleate pool boiling on ribbed surfaces with micro-roughness at low and moderate heat flux. Journal of Heat Transfer, v. 121, p. 376384.

Hübner, P.; Künstler, W. (1997). Pool boiling at finned tubes: influence of surface roughness and shape of the fins. Int. J. Refrig., v.20, p. 575-582.

Hwang, T. H.; Yao, S. C. (1986). Crossflow boiling heat transfer in tube bundles, Int. Comm. Heat Mass Transfer, v.13, p.493-502.

Ivey, H. J. (1967). Relationships between bubble frequency, departure diameter and rise velocity in nucleate boiling. Int. J. Heat Mass Transfer, v.10, p.1023-1040.

Jensen, M. K.; Jackman, D. L. (1984). Prediction of nucleate pool boiling heat transfer coefficients of refrigerants-oil mixtures. Journal of Heat Transfer, v.106, p.185-190.

Jensen, M. K. (1985). Resultados experimentais para a ebulição do R-113 e suas misturas com óleo de lubrificação. Comunicação Pessoal. 
Jensen, M. K.; Hsu, J. T. (1988). A parametric study of boiling heat transfer in a horizontal tube bundle. Journal of Heat Transfer, v.110, p.976-981.

Judd, R. L.; Hwang, K. S. (1976). A comprehensive model for nucleate pool boiling including microlayer evaporation. Journal of Heat Transfer, v. 98, p.623-629.

Judd, R. L.; Merte, H. Jr.; Ulucakli, M. E. (1991). Variation of superheat with subcooling in nucleate pool boiling. Journal of Heat Transfer, v.113, p.201-208.

Kang, M. G. (2000). Effect of surface roughness on poll boiling heat transfer. Int. J. Heat Mass Transfer, v.43 , p. 4073-4085.

Kartsounes, G. T. (1975). A study of treatment on pool boiling heat transfer in refrigerant 12. ASHRAE Transactions, v.18, p. 320-326.

Kenning, D. B. R.; Yan, Y. (1996). Pool boiling heat transfer on a thin plate: features revealed by liquid crystal thermography. Int. J. Heat Mass Transfer, v.39, p.3117-3137.

Kolev, N. I, (1995). How accurately can we predict nucleate boiling ? Experimental Thermal and Fluid Science, v. 10, p. 370-378.

Kudristskii, G. R.; Kolomiets, E. A. (1995). Effect of geometric characteristics of heating surfaces on heat transfer and the onset of boiling of heat transfer agent. Heat Transfer Research, v. 16, p.18-21.

Kurihara, H. M. (1956). Fundamental factors affecting boiling coefficients. Lafayette, Indiana. 130p. Tese (doutorado) - Department of Chemical Engineering, Purdue University.

Leiner, W. (1994). Heat Transfer by nucleate pool boiling - general correlation based on thermodynamic similarity. Int. J. Heat Mass Transfer, v. 37, p. 763-769.

Li, Z.; Hahne, E. (1995). Boiling heat transfer on finned tube bundle with lower tubes heated with constant heat flux. Experimental Thermal and Fluid Science, v. 11, p. 174-180.

Luke, A. (1997). Pool boiling heat transfer from horizontal tubes with different surface roughness. Int. J. Refrig., v.20, p. 561-574.

Ma, T.; Liu, X.; Wu, J.; Li, H. (1986). Effects of geometrical shapes and parameters of reentrant grooves on nucleate pool boiling heat transfer from porous surfaces. In: $8^{\text {th }}$ International Heat Transfer Conference, San Francisco, v. 4, p. 2013-2018.

MacFadden, P. W.; Grassman, P. (1962). The relation between bubble frequency and diameter during nucleate pool boiling. Int. J. Heat Mass Transfer, v.5, p.169-173.

Mann, M.; Stephan, K.; Stephan, P. (2000). Influence of heat conduction in the wall on nucleate boiling heat transfer. Int. J. Heat Mass Transfer, v.43 , p.2193-2203. 
Marto, R.; Lepere, V. J. (1982). Pool boiling heat transfer from enhanced surfaces to dielectric fluids. Journal of Heat Transfer, v.104, p. 292-299.

Marto, P. J.; Anderson, C. L. (1992). Nucleate boiling characteristics of R-113 in a small tube bundle. Journal of Heat Transfer, v.114, p. 425-433.

Matijevic, M.; Djuric, M.; Zavargo, Z.; Novakovic, M. (1992). Improving heat transfer with pool boiling by covering of heating surface with metallic spheres. Heat Transfer Engineering, v.13, p. 49-57.

Memory, S. B.; Chilman, S. V.; Marto, P. J. (1994). Nucleate pool boiling of a Turbo-B bundle in R-113. Journal of Heat Transfer, v. 116, p. 670-678.

Memory, S. B.; Sugiyama, D. C.; Marto, P. J. (1995a). Nucleate pool boiling of R-114 and R-114-oil mixtures from smooth and enhanced surfaces-I . Singles tubes. Int. J. Heat Mass Transfer, v.38, p.1347-1361.

í

Memory, S. B.; Akcasayar, N.; Eraydin, H.; Marto, P. J. (1995b). Nucleate pool boiling of R-114 and R-114-oil mixtures from smooth and enhanced surfaces-II . Tube bundles. Int. J. Heat Mass Transfer, v.38, p.1363-1376.

Mikic, B. B.; Rohsenow, W. M. (1969). A new correlation of pool-boiling data including the effect of heating surface characteristics. Journal of Heat Tranfer, v.91, p.245-250.

Mitrovic, J. (1997). Formation of a liquid jet after detachment of a vapour bubble. Int. J. Heat Mass Transfer, v.40 , p. 4309-4317.

Morgan, V. T. (1975). The overall convective heat transfer from smooth circular cylinders. Advances in Heat Transfer, v. 11, p. 199-264.

Mofat, R. J. (1988). Describing the uncertainties in experimental results. Experimental Thermal and Fluid Science, v. 1, p. 3-17

Nakayama, W.; Daikoku, T.; Kuwahara, H.; Nakajima, T. (1980a). Dynamic model of enhanced boiling heat transfer on porous surfaces Part I: Experimental Investigation. Journal of Heat Transfer, v. 102, p. 445-450.

Nakayama, W.; Daikoku, T.; Kuwahara, H.; Nakajima, T. (1980b). Dynamic model of enhanced boiling heat transfer on porous surfaces Part II: Analytical Modeling. Journal of Heat Transfer, v. 102, p. 451-456.

Nakayama, W.; Daikoku, T.; Nakajima, T. (1982). Effects of pore diameters and system pressure on saturated pool nucleate boiling heat transfer from porous surfaces. Journal of Heat Transfer, v.104, p. 286-291.

Nishikawa, K.; Fujita, Y. (1977). Correlation of nucleate boiling heat transfer based on buble population density. Int. J. Heat Mass Transfer, v.20, p.233-245. 
Nishikawa, K.; Fujita, Y.; Ushida, S.; Ohta, H. (1984). Effects of surface configuration on nucleate boiling heat transfer. Int. J. Heat Mass Transfer, v.27, p.1559-1571.

Nukiyama, S. (1934) reeditado em (1966). The maximum and minimum values of the heat $\mathrm{Q}$ transmitted from metal to boiling water under atmospheric pressure. Int. J. Heat Mass Transfer, v.9, p.1419-1433.

O’Connor, J. P.; YOU, S. M. (1994). A painting technique to enhance pool boiling heat transfer in saturated FC-72. Publications of ASME, Fundamentals of Phase Change: Boiling and Condensation, HTD - v. 273, p. 11-18.

O'Connor, J. P.; You, S. M. (1995). A painting technique to enhance pool boiling heat transfer in saturated FC-72. Journal of Heat Transfer, v.117, p. 387-393.

Oka, T.; Abe, Y.; Mori, Y. H.; Nagashima, A. (1995). Pool boiling of n-pentane, CFC-113, and water under reduced gravity: parabolic flight experiments with a transparent heater. Journal of Héat Transfer, v.117, p. 408-417.

Palm, B. (1991). Enhancement of boiling heat transfer by aid of perforated metal foils. Estocolmo. 214p. Tese (doutorado) - Department of Applied Thermodynamics and Refrigeration, The Royal Institute of Technology.

Petukhov, B. S.; Kovalev, S. A.; Geshele, V. D. (1981). Heat transfer in boiling on finned surfaces. Heat Transfer-Soviet Research, v.13, p.51-60.

Pioro, I. L. (1999). Experimental evaluation of constants for the Rohsenow pool boiling correlation. Int. J. Heat Mass Transfer, v.40, p.2379-2392.

Prausnitz, J. M. (1986). Molecular Thermodynamics of Fluid-Phase Equilibria. 2 ed. Englewood Cliffs, New Jersey, Prentice-Hall Inc..

Rayney, K. N.; You, S. M.(2001). Effects of heater size and orientation on poll boiling heat transfer from microporous coated surfaces. Int. J. Heat Mass Transfer, v.44, p.2589-2599.

Reed, S. J.; Mudawar, I. (1997). Enhancement of boiling heat transfer using highly wetting liquids with pressed-on fins at low contact forces. Int. J. Heat Mass Transfer, v.40, p.2379-2392.

Reid, C. R.; Prausnitz, J. M.; Poling, B. E. (1986). The Properties of Gases and Liquids. 4 ed. New York, McGraw-Hill Book Company.

Ribatski, G.; Saiz Jabardo, J. M. (2000). Nucleate Boiling of Halocarbon Refrigerants - Heat Transfer Correlations. International Journal of HVAC\&R RESEARCH, v. 6, p. 349-367.

Ribeiro, R. (1998). Investigação experimental do mecanismo de transferência de calor em ebulição nucleada. São Paulo. 183p. Tese (Doutorado) - Escola Politécnica, Universidade de São Paulo. 
Rohsenow, W. M. (1952). A method of correlating heat transfer data for surface boiling liquids. Transactions of ASME, v.74, p. 969-976.

Roser, R.; Thonon, B.; Mercier, P. (1999). Experimental investigations on boiling of npentane across a horizontal tube bundle: two-phase flow and heat transfer characteristics. Int. J. Refrig., v.22, p. 536-547.

Roy Chowdhury, S. K.; Medrow, R. H. S. (1985) Surface effects in pool boiling. Int. J. Heat Mass Transfer, v.28, p.1881-1889.

Saiz Jabardo, J. M. (1978). Fotos ilustrando a transferência de calor através do mecanismo de termocapilaridade. Department of Mechanical Engineering, University of Illinois at Urbana-Champaign.

Saiz Jabardo, J. M. (1988). Transferência de calor em escoamentos bifásicos. Notas de aula. Departamento de Engenharia Mecânica, Escola Politécnica, Universidade de São Paulo, São Paulo. i

Saiz Jabardo, J. M.; Silva, C. L. (1991). Modeling of the nucleate boiling of refrigerant-oil mixtures. In: $18^{\text {th }}$ International Congress of Refrigeration, Montreal, Canada.

Saiz Jabardo, J. M.; Bandarra, E. P.; Lima, C. U. S. (1999). New correlation for convective boiling of pure halocarbon refrigerants flowing in horizontal tubes. Journal of the Brazilian Society of Mechanical Sciences, v. 11, p. 245-258.

Sakashita, H.; Kumada, T. (20001). Method for predicting boiling curves of saturated nucleate boiling. Int. J. Heat Mass Transfer, v.44, p.673-682.

Sauer, Jr. H. J.; Medrow, R. A.; Sinnarwalla, A. M. (1975). Effects of surface condition on nucleate boiling of refrigerant-11, ASHRAE Transactions, v.81, part. 2, p. 274-281.

Semena, M. G.; Kravets, V. YU.; Fridrikhson, YU. V.; Brik, D. S. (1993). Pressure effects on heat transfer of a liquid boiling on a surface with a capillary-porous coating. Heat Transfer Soviet Research, v.25, p. 836-840.

Sernas, V.; Hooper, F. C. (1969). The initial vapor bubble growth on a heated wall during nucleate boiling. Int. J. Heat Mass Transfer, v.28, p.1881-1889.

Silva, C. L. (1989). Investigação experimental da ebulição de misturas refrigerante-óleo. São Paulo. 261p. Tese (Doutorado) - Escola Politécnica, Universidade de São Paulo

Sokol, P.; Blein, P.; Gorenflo, D.; Rott, W.; Schömann, H. (1990). Pool boiling heat transfer from plain and finned tubes to propane and propylene, In: 9th Int Heat Transfer Conf., Jerusalem, v.1, p.75-86.

Stephan, K. ; Abdelalam, M. (1980). Heat-transfer correlations for natural convective boiling. Int. J. Heat Mass Transfer, v.23, p.73-87. 
Stephan, K. (1992). Heat Transfer in Condensation and Boiling. Berlin, Springer-Verlag.

Tewari, P. K.; Verma, R. K.; Ramani, M. P. S. . (1986). Effect of surface roughness e polymeric additive on nucleate pool boiling at subatmospheric pressures. Int. Comm. Heat mass transfer., v.13, p.503-514.

Thome, J. R. (1989). Nucleate pool boiling of hydrocarbon mixtures on a GEWA-TX tube. Heat Transfer Engineering., v.10, p.37-44.

Thome, J. R. (1996). Boiling of new refrigerants: a state-of-the-art review. Int. J. Refrig., v. 19, p.435-457

Tien, C. L. (1962). A hydrodynamic model for nucleate pool boiling. Int. J. Heat Mass Transfer, v. 5, p. 533-540

Vachon. R. I. ; Nix, G. H.; Tanger, G. E. (1968). Evaluation of constants for the Rohsenow pool-boiling correlation. Journal of Heat Transfer, v. 90 , p.239-247

VDI-Wärmeatlas (1994). 7. ed., Düsseldorf, VDI-Verlag. (apud Collier e Thome (1996) e Ribeiro (1998))

Wang, C. H.; Dhir, V. K. (1993). Effect of surface wettability on active nucleation site density during pool boiling of water on a vertical surface. Journal of Heat Transfer, v. 115 , p.659-669.

Wanniarachchi, A. S.; Marto, P. J.; Reilly, J. T. (1987). Effect of oil on pool boiling performance of R-114 from enhanced surfaces. 2d ASME-JSME, Thermal Engineering Joint Conference, Honolulu, HI, v. 1, p. 531-537.

Wanniarachchi, A. S.; Marto, P. J.; Reilly, J. T. (1986). The effect of oil contamination on the performance of R-114 from a porous-coated surface. ASHRAE Transactions, v. 92, part. IIB, p. 525-538.

Webb, R. L.; Pais, C. (1991). Pool boiling data for five refrigerants on three tube geometries. ASHRAE Transactions, v.97, p. 72-78.

Webb, R. L.; Pais, C. (1992). Nucleate pool boiling data for five refrigerants on plain, integral-fin and enhanced tube geometries. Int. J. Heat Mass Transfer, v.35, p.18931904.

Webb, R. L.; McQuade, W. F. (1993). Pool boiling of R-11 and R-123 oil-refrigerant mixtures on plain and enhanced tube geometries. ASHRAE Transactions, v. 99, part. I, p. 1225-1236.

Webb, R. L. (1994). Principles of Enhanced Heat Transfer. New York, John Wiley \& Sons. 
Webb, R. L.; Chien, L. H. (1994). Correlation of convective vaporization on banks of plain tubes using refrigerants. Heat Transfer Engineering, v. 15, p. 57-69.

Whitehouse, D. J. (1994). Handbook of surface metrology. Bristol, Institute of Physics Publications.

Yamazaki, H.; Sakaguchi, S. (1986). Heat transfer in nucleate boiling of oil-freon R-113 mixtures. Bulletin of JSME, v. 29, p. 129-135.

You, S. M.; Simon, T. W.; Bar-Cohen, A.; Hong, Y. S. (1995). Effects of dissolved gas content on pool boiling of a highly wetting fluid. Journal of Heat Transfer, v. 117, p.687692.

Zhou, X.; Bier, K. (1997). Pool boiling heat transfer from a horizontal coated with oxide ceramics. Int. J. Refrig., v.20, p. 552-560.

Zuber, N. (1963). Nucleate boiling. The region of isolated bubbles and the similarity with natural convection. Int. J. Heat Mass Transfer, v.6, p.53-78. 


\section{i. Parâmetros para Caracterização do Acabamento Superficial}

Os modelos apresentados na pesquisa bibliográfica, que envolvem a análise do efeito do acabamento superficial na taxa de transferência de calor, utilizam distintos parâmetros para caracterização da superfície. Desta forma, este anexo foi incorporado com o objetivo de descrever resumidamente alguns desses parâmetros, cujas definições são utilizadas na análise de diferenças entre resultados experimentais e correlações dos distintos autores citados.

Na opção por um determinado parâmetro são consideradas variáveis tais como: capacidade de caracterização da superfície, facilidades laboratoriais e grau de evolução tecnológica disponível. Muitos dos parâmetros, aqui discutidos, são resultados do desenvolvimento histórico deste tema e não são utilizados atualmente. Os parâmetros mais comuns e cronologicamente ilustrados na Fig. 1 são os seguintes:

$\boldsymbol{R}_{t}$ Consiste na maior diferença de nível entre picos e vales, para um determinado comprimento de superfície, assumindo-se um perfil plano. $\boldsymbol{R}_{z}$ Este parâmetro é definido como o valor médio entre as 5 maiores distâncias entre picos e vales. O motivo para a utilização de um valor médio, ainda que envolvendo valores máximos, é a redução dos efeitos de não representatividade de um único valor. Este parâmetro é utilizado para pequenos comprimentos, proporcionando uma certa idéia da rugosidade superficial em locais onde apenas uma medida pode ser tomada.

$>\quad$ Rautiefe separa o perfil em duas linhas paralelas tal que a superior tenha acima 5\% do material existente no perfil e a inferior 95\%. Este parâmetro, embora caracterize razoavelmente o perfil da superfície, exige segundo Whitehouse (1994) métodos estatístico e equipamentos avançados. 
$\boldsymbol{R} \boldsymbol{p}$ Este parâmetro, encontrado em diversos trabalhos envolvendo a ebulição nucleada, é utilizado segundo diferentes definições. Ele consiste, basicamente, na profundidade do perfil, podendo, em alguns casos, ser definido como a distância entre o perfil e uma linha de referência traçada a partir dos picos mais elevados, conforme ilustrado na Fig. 1. Outra definição é, simplesmente, o pico máximo a partir de uma linha posicionada no meio do perfil, definida de forma a termos a área do perfil acima desta linha igual à área abaixo. Um parâmetro de vale correspondente pode ser definido a partir desta mesma linha. Geralmente as definições de $R p$, diferem na proposição da linha de referência.

a)

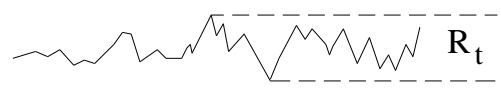

b)



c)

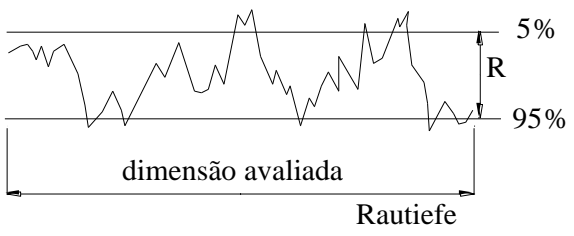

d)

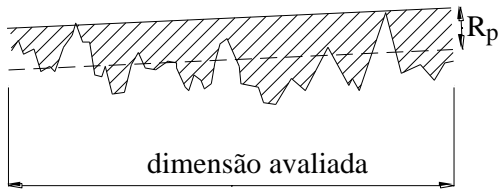

e)



f)

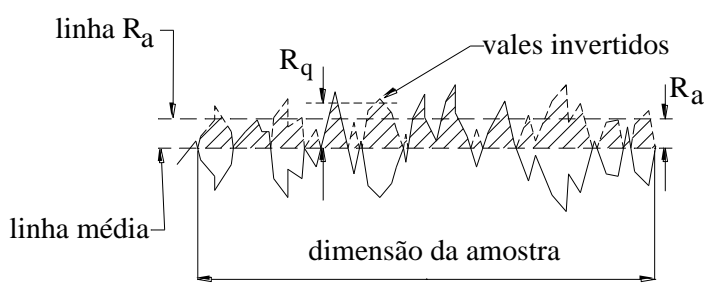

Figura 1 Parâmetros utilizados na caracterização do acabamento superficial

$\boldsymbol{R}_{t m}$ Este parâmetro é dado pela média dos valores de $R_{t}$ tomados para 5 amostras adjacentes de comprimento.

$\boldsymbol{R} \boldsymbol{a}$ Um método óbvio de incrementar a caracterização da rugosidade é medir a amplitude em todo o perfil, ao invés de apenas as maiores distâncias entre picos e vales. Destes métodos, o mais utilizado é o $R a$ definido através da seguinte equação: 
$R_{a}=\frac{1}{L} \cdot \int_{0}^{L}|z| \cdot d x$

onde, $z=f(x)$ é o perfil determinado a partir de uma linha de referência, e $L$ o comprimento da amostra. Uma denominação comumentemente encontrada na literatura para este método é valor CLA (center line average). Devido a sua aceitação e aos bons resultados proporcionados, este método é, atualmente, o mais utilizado.

$\boldsymbol{R}_{\boldsymbol{q}}$. Este parâmetro, em certo aspecto similar ao anterior, é definido como:

$R_{q}=\frac{1}{L} \cdot \int_{0}^{L} z^{2} \cdot d x$

Whitehouse (1994) classificou estes parâmetros em relação a facilidade de medida e a capacidade de caracterização da superfície da seguinte forma:

Tabela 1 Classificação dos parâmetros de rugosidade segundo Whitehouse (1994)

\begin{tabular}{ccc}
\hline \hline Parâmetro & Facilidade de medição & Caracterização da superfície \\
\hline \hline$R_{q}$ & Muito difícil & Excelente \\
\hline$R a$ & Difícil & Ótima \\
\hline$R_{t m}$ & Moderada & Boa \\
\hline$R_{t}$ & Fácil & Ruim \\
\hline \hline
\end{tabular}




\section{i. Propagação de Incertezas}

Geralmente, em trabalhos experimentais algumas das variáveis que se deseja determinar não são obtidas diretamente, mas através de parâmetros primários, a partir dos quais elas são calculadas. Estas incertezas podem ser determinadas propagando as incertezas dos resultados primários pelo método da soma quadrática dos efeitos de cada uma das variáveis proposto por Kline e McClintock apud Moffat (1988). Segundo este método, admitindo $R$ uma função das variáveis $x_{1}, x_{2}, x_{3}, \ldots, x_{n}$., de forma que $R=R\left(x_{1}, x_{2}, x_{3}, \ldots, x_{n}\right) \mathrm{e}$ $w\left(x_{1}\right), w\left(x_{2}\right), w\left(x_{3}\right), \ldots, w\left(x_{n}\right)$ as incertezas nas variáveis independentes, a incerteza do parâmetro dependente $R$ pode ser calculada por:

$$
w(R)=\left[\left(\frac{\partial R}{\partial x_{1}} \cdot w\left(x_{1}\right)\right)^{2}+\left(\frac{\partial R}{\partial x_{2}} \cdot w\left(x_{2}\right)\right)^{2}+\left(\frac{\partial R}{\partial x_{3}} \cdot w\left(x_{3}\right)\right)^{2}+\ldots+\left(\frac{\partial R}{\partial x_{n}} \cdot w\left(x_{n}\right)\right)^{2}\right]^{1 / 2}
$$

Segundo esse método o intervalo de confiança para a incerteza nos resultados é o mesmo que o da incerteza nas variáveis independentes, neste trabalho adotado como $95 \%$.

\section{ii. Incerteza na Área da Superfície de Transferência de Calor}

A área de transferência de calor foi calculada como $A=\pi \cdot D_{e x t} \cdot L_{R e s}$, onde $D_{e x t}$ é o diâmetro externo da superfície e $L_{R e s}$ o comprimento da resistência elétrica. Estas medidas foram realizadas com um paquímetro, apresentando, respectivamente, os seguintes resultados: $19,00 \pm 0,05 \mathrm{~mm}$ e $210,00 \pm 0,05 \mathrm{~mm}$. Substituindo estes valores na Eq. (ii), 
determinada a partir da Eq. ( i ), obteve-se uma incerteza inferior à $0,03 \%$ na área da superfície de transferência de calor.

$$
\frac{w(A)}{A}=\left[\left(\frac{w\left(D_{0}\right)}{D_{0}}\right)^{2}+\left(\frac{w(L)}{L}\right)^{2}\right]^{1 / 2}
$$

\section{iii. Incerteza na Determinação do Fluxo Específico de Calor}

A incerteza no fluxo específico de calor foi determinada desprezando-se efeitos de condução longitudinal. Desta forma foi possível referir a potência elétrica aplicada a resistência do tipo cartucho a área de transferência de calor dada por $A=\pi \cdot D_{\text {ext }} \cdot L_{R e s}$, conforme procedimento descrito no Capítulo 5.

A medida da potência elétrica fornecida à resistência foi determinada através de um voltímetro e um amperímetro, cujas incertezas nas medidas destes instrumentos são respectivamente iguais a $0,1 \mathrm{~V}$ e $0,01 \mathrm{~A}$. Finalmente, sendo o fluxo específico de calor dado pela razão entre a potência elétrica e a área da superfície de transferência de calor, $\phi=(V \cdot I) / A$ e com base na Eq. ( i ) obtêm-se a seguinte equação para a determinação da incerteza em $\phi$ :

$$
w(\phi)=\left[\left(\frac{V}{A} \cdot w(I)\right)^{2}+\left(\frac{I}{A} \cdot w(V)\right)^{2}+\left(\frac{V \cdot I}{A^{2}} \cdot w(A)\right)\right]^{1 / 2}
$$

\section{iv. Incertezas na Determinação de Ra}

A determinação da incerteza envolvendo o valor de $R a$ foi calculada a partir das 20 medições realizadas em distintos comprimentos de amostra da superfície de transferência de calor, sendo 10 delas realizadas antes dos ensaios e 10 após. Com base nestes valores foi definida, para cada superfície, a incerteza no seu valor de $R a$, cujo resultado foi determinado através do produto do desvio padrão experimental, Eq. ( iv ), pelo $t$ de student para um limite de confiança de 95\%, apresentando um valor igual a 2,093 para 19 graus de liberdade. 
$s_{x}=\left[\frac{1}{20-1} \cdot \sum_{i=1}^{20}\left(X_{i}-\bar{X}\right)^{2}\right]^{1 / 2}$

\section{v. Incerteza na Determinação da Pressão de Saturação}

Devido a não disponibilidade de um equipamento adequado para a calibração dos transdutores de pressão adotou-se as relações entre pressão e corrente fornecidas pelo fabricante. Os erros associados às medidas também foram retirados do catálogo do fabricante. Seus valores são os seguintes:

Erro típico: $\quad 0,3 \%$ do fundo de escala

Erro máximo: $1 \%$ fundo de escala

Para garantir uma confiabilidade de pelo menos 95\% nas medidas, adotou-se o valor máximo de $1 \%$. Portanto considerando a faixa de medição dos transdutores de -1 a 12 bar obteve-se uma incerteza de $12 \mathrm{kPa}(\mathrm{P}=95 \%)$

\section{vi. Levantamento das Incertezas Envolvendo a Determinação de Temperaturas}

\section{vi.i. $\quad$ Temperaturas Indicadas pelos Termopares}

Os termopares utilizados foram calibrados para uma faixa de temperaturas entre -30 e $90^{\circ} \mathrm{C}$, utilizando como referência termômetros de imersão de precisão, $1 / 20^{\circ} \mathrm{C}$ (com rastreabilidade NIST). No processo de calibração, inseriram-se os termopares e o termômetro em um banho termostático. Desse modo, levantou-se, para a faixa de temperatura de ensaio, as diferenças entre as temperaturas medidas nos termopares, determinadas através do conjunto termopar, sistema de aquisição de dados e computador pessoal, e a fornecida pelo termômetro, que foi considerada como sendo a temperatura real. Foram levantadas curvas de calibração partindo-se de $-30{ }^{\circ} \mathrm{C}$ até $90^{\circ} \mathrm{C}$. Após atingir a temperatura de $90^{\circ} \mathrm{C}$, reduzia-se seu valor até $-30{ }^{\circ} \mathrm{C}$. As diferenças entre as temperaturas indicadas pelos termopares e a dos termômetros foram determinadas dentro desta faixa a cada intervalo de $10^{\circ} \mathrm{C}$. Seguindo este procedimento foram levantadas 5 curvas de calibração.

Com base nestes dados, a regressão linear da curva $T_{\text {termopar }}$ vs $T_{\text {termômetro }}$ forneceu a seguinte relação: 


$$
T_{\text {termopar }}=0,007+1,00 \cdot T_{\text {termômetro }}
$$

Com base neste resultado adotou-se $T_{\text {termopar }}=T_{\text {termômetro }}$

As incertezas relativas as medidas foram determinadas através do procedimento sugerido por Abernethy e Thompson (1973), resultando para um intervalo de confiança de $95 \%$ igual a $\pm 0,16{ }^{\circ} \mathrm{C}$, aproximada para $\pm 0,2{ }^{\circ} \mathrm{C}$.

Tal procedimento consistiu em levantar distintas curvas de calibração com a elevação gradual do parâmetro de leitura até um máximo seguido de sua redução até o valor inicial. Este procedimento, segundo os autores, objetiva incorporar ao processo de determinação das incertezas efeitos de não linearidade e histerese relacionados a efetuação da medida. Com base nos resultados levantados experimentalmente determinou-se o desvio padrão para cada nível do parâmetro medido, neste caso a temperatura, definido como:

$$
s_{i}=\sqrt{\frac{\sum_{j=1}^{n}\left(\bar{T}_{j}-\bar{T}\right)}{n-1}}
$$

onde

$n$ é o número de curvas de calibração levantadas.

$\bar{T}_{j}=\frac{T(\text { temperatura } \text { curva incremento })+Y(\text { temperatura curva decréscimo })}{2}$ para a $j$ curva de calibração.

$\bar{T}$ média aritmética de todas as temperaturas medidas naquele nível de temperatura

O desvio padrão total foi determinado por:

$$
s=i \sqrt{\sum_{i=1}^{k} s_{i}^{2}}
$$

onde $\mathrm{k}$ é o número de níveis de temperaturas

O número de graus de liberdade para determinação do valor do $t$ de student foi obtido segundo o método de Welch-Satterthwaite, através da seguinte equação: 


$$
g l=\frac{\left(\sum_{i=1}^{k} s_{i}^{2}\right)^{2}}{\sum_{i=1}^{k} \frac{s_{i}^{4}}{g l_{i}}}
$$

onde $g l_{i}$ é o número de graus de liberdade em cada nível de temperatura dado pelo número de curvas levantadas menos 1

Finalmente, conhecendo-se o número de graus de liberdade total, determina-se o valor do $t$ de Student obtendo-se a incerteza total na medida da temperatura com um intervalo de confiança de $95 \%$ dada por $t_{95}{ }^{\circ} s$.

\section{vi.ii. $\quad$ Temperatura de Saturação (ou refrigerante no estado líquido)}

Neste caso o cálculo da incerteza depende do mecanismo de transferência de calor devido a temperatura do refrigerante líquido ter sido definida de forma distinta para a convecção natural e a ebulição nucleada. No primeiro mecanismo a temperatura do refrigerante líquido foi dada pelo valor indicado pelo termopar inundado na cuba de ebulição desta foram sua incerteza é igual à incerteza primária indicada pelo termopar. No caso do regime de ebulição nucleada a temperatura de saturação foi calculada como a média aritmética das temperaturas indicadas pelo termopar inundado e pelo termopar localizado na região de vapor no interior da cuba. Desta forma a incerteza é dada por:

$$
w\left(T_{\text {sat }}\right)=\sqrt{\left[\frac{1}{2} \cdot w \cdot\left(T_{\text {inund }}\right)\right]^{2}+\left[\frac{1}{2} \cdot w \cdot\left(T_{\text {seco }}\right)\right]^{2}}
$$

Através desta equação obteve-se um valor igual a $0,14 \mathrm{~K}$ aproximado para $0,2 \mathrm{~K}$, valor similar ao da transferência de calor através do mecanismo de convecção natural.

\section{vi.iii. $\quad$ Temperatura da superfície}

A temperatura da superfície foi determinada, segundo o procedimento descrito e justificado detalhadamente no Capítulo 5, através da leitura de um único termopar. Este foi 
admitido em contato com a região do canal mais próxima a superfície externa e seu valor indicado foi corrigido através da equação de Fourrier, Eq. (5.1), eliminando um erro sistemático devido a resistência térmica do material da superfície de testes. Erros sistemáticos devido ao cimento condutor e à resistência térmica de contato, não tiveram seus efeitos considerados. Assim, de acordo com a Eq. ( i ), a incerteza em $T_{p}$ foi determinada segundo a seguinte equação:

$$
w\left(T_{p}\right)=\sqrt{\left[w\left(T_{\text {termopar }}\right)\right]^{2}+\left[\left(\frac{D_{\text {ext }}}{2 \cdot k_{p}}\right) \cdot \ln \left(\frac{D_{\text {ext }}}{D_{\text {termopar }}}\right) \cdot w(\phi)\right]^{2}}
$$

Neste caso as incertezas na determinação do $D_{e x t}$ e $D_{\text {termopar }}$ foram consideradas desprezíveis.

\section{vi.iv. Superaquecimento da Superfície}

O superaquecimento da superfície foi determinado como $\left(T_{p}-T_{s a t}\right)$, desta forma segundo a Eq. ( i ) sua incerteza é dada por:

$$
w\left(T_{p}-T_{\text {sat }}\right)=\sqrt{\left(\left(w\left(T_{p}\right)\right)^{2}+\left(w\left(T_{\text {sat }}\right)\right)^{2}\right)}
$$

\section{vii. Incertezas na determinação do coeficiente de transferência de calor}

O coeficiente de transferência de calor é definido como a razão entre o fluxo específico de calor e o superaquecimento da superfície. Desta forma, com base na Eq. ( i ) suas incertezas foram calculadas através da seguinte relação:

$$
w(h)=\sqrt{\left[\frac{w(\phi)}{\left(T_{p}-T_{\text {sat }}\right)}\right]^{2}+\left[\frac{\phi}{\left(T_{p}-T_{\text {sat }}\right)} \cdot w\left(T_{p}-T_{\text {sat }}\right)\right]^{2}}
$$


i. Resultados para o $R-11$

\begin{tabular}{|c|c|c|c|c|}
\hline $\begin{array}{c}p_{\text {sat }} \\
(\boldsymbol{k P a})\end{array}$ & $\begin{array}{l}T_{\text {sat }} \\
\left({ }^{o} \mathrm{C}\right)\end{array}$ & $\begin{array}{c}\Delta \boldsymbol{T} \\
\left({ }^{o} \boldsymbol{C}\right)\end{array}$ & $\begin{array}{c}h \\
\left(k W / m^{2}\right)\end{array}$ & $\begin{array}{c}\text { incerteza } \\
(\%)\end{array}$ \\
\hline \multicolumn{5}{|c|}{ Superfície de cobre ; Ra $=0,17 \pm 0,04 \mu \mathrm{m}$} \\
\hline 35 & $-2,2$ & 3,8 & 195 & 18,2 \\
\hline 34 & $-2,3$ & 7,6 & 220 & 20,6 \\
\hline 34 & $-2,4$ & 13,9 & 242 & 22,2 \\
\hline 34 & $-2,5$ & 19,2 & 255 & 23,4 \\
\hline 35 & $-2,2$ & 16,8 & 402 & 24,5 \\
\hline 35 & $-2,1$ & 17,0 & 490 & 25,5 \\
\hline 35 & $-2,3$ & 18,6 & 679 & 26,3 \\
\hline 35 & $-2,5$ & 20,2 & 1.229 & 25,0 \\
\hline 35 & $-2,4$ & 21,9 & 1.869 & 23,9 \\
\hline 36 & $-2,2$ & 24,0 & 2.437 & 23,0 \\
\hline 36 & $-2,2$ & 25,3 & 2.923 & 21,6 \\
\hline 36 & $-2,2$ & 26,8 & 3.431 & 20,6 \\
\hline 36 & $-2,2$ & 25,9 & 3.125 & 19,5 \\
\hline 36 & $-2,1$ & 24,7 & 2.711 & 18,7 \\
\hline 36 & $-2,2$ & 23,1 & 2.138 & 18,1 \\
\hline 36 & $-2,2$ & 22,1 & 1.916 & 17,4 \\
\hline 36 & $-2,3$ & 20,9 & 1.537 & 17,2 \\
\hline 36 & $-2,3$ & 20,6 & 1.313 & 16,8 \\
\hline 36 & $-2,2$ & 20,3 & 1.189 & 15,9 \\
\hline 36 & $-2,3$ & 20,0 & 954 & 16,2 \\
\hline 36 & $-2,3$ & 19,8 & 824 & 14,7 \\
\hline 36 & $-2,2$ & 18,6 & 642 & 13,9 \\
\hline 36 & $-2,2$ & 17,9 & 552 & 11,8 \\
\hline 36 & $-2,2$ & 18,1 & 489 & 7,4 \\
\hline 36 & $-2,1$ & 16,8 & 390 & 4,2 \\
\hline 35 & $-2,1$ & 15,7 & 315 & 2,4 \\
\hline 35 & $-2,2$ & 12,4 & 262 & 3,1 \\
\hline 35 & $-2,2$ & 6,8 & 233 & 5,4 \\
\hline 35 & $-2,2$ & 3,7 & 199 & 9,8 \\
\hline 50 & 5,5 & 4,3 & 184 & 7,0 \\
\hline 50 & 5,5 & 7,7 & 207 & 4,1 \\
\hline 49 & 5,5 & 13,8 & 235 & 2,4 \\
\hline 49 & 5,5 & 19,9 & 252 & 1,7 \\
\hline 49 & 5,4 & 26,0 & 265 & 1,4 \\
\hline 48 & 5,3 & 29,9 & 274 & 1,2 \\
\hline 49 & 5,2 & 35,0 & 290 & 1,1 \\
\hline 49 & 5,4 & 43,4 & 305 & 0,9 \\
\hline 49 & 5,5 & 45,5 & 305 & 0,9 \\
\hline 49 & 5,5 & 49,6 & 307 & 0,8 \\
\hline 49 & 5,6 & 55,8 & 315 & 0,7 \\
\hline 49 & 5,5 & 59,3 & 320 & 0,7 \\
\hline
\end{tabular}

\begin{tabular}{|c|c|c|c|c|}
\hline $\begin{array}{c}p_{\text {sat }} \\
(\boldsymbol{k P a})\end{array}$ & $\begin{array}{l}T_{\text {sat }} \\
\left({ }^{o} \mathrm{C}\right)\end{array}$ & $\begin{array}{c}\Delta \boldsymbol{\Delta T} \\
\left({ }^{o} \mathrm{C}\right)\end{array}$ & $\begin{array}{c}h \\
\left(k W / m^{2}\right)\end{array}$ & $\begin{array}{c}\text { incerteza } \\
(\%)\end{array}$ \\
\hline 50 & 5,4 & 17,4 & 1.085 & 2,1 \\
\hline 2,0 & 5,4 & 43,4 & 1.340 & 2,0 \\
\hline 1,7 & 5,5 & 45,5 & 1.983 & 1,7 \\
\hline 1,6 & 5,4 & 49,6 & 2.514 & 1,6 \\
\hline 1,5 & 5,5 & 55,8 & 3.146 & 1,5 \\
\hline 1,4 & 5,6 & 59,3 & 3.718 & 1,4 \\
\hline 1,4 & 5,5 & 17,4 & 4.128 & 1,4 \\
\hline 1,3 & 5,5 & 18,2 & 4.361 & 1,3 \\
\hline 1,4 & 5,4 & 20,6 & 3.922 & 1,4 \\
\hline 1,5 & 5,5 & 22,2 & 3.390 & 1,5 \\
\hline 1,5 & 5,4 & 23,4 & 2.906 & 1,5 \\
\hline 1,6 & 5,4 & 24,5 & 2.284 & 1,6 \\
\hline 1,7 & 5,4 & 25,5 & 2.021 & 1,7 \\
\hline 1,8 & 5,4 & 26,3 & 1.662 & 1,8 \\
\hline 1,9 & 5,4 & 25,0 & 1.443 & 1,9 \\
\hline 2,0 & 5,3 & 23,9 & 1.310 & 2,0 \\
\hline 2,1 & 5,4 & 23,0 & 1.112 & 2,1 \\
\hline 2,1 & 5,3 & 21,6 & 960 & 2,1 \\
\hline 2,2 & 5,3 & 20,6 & 754 & 2,2 \\
\hline 2,3 & 5,3 & 19,5 & 617 & 2,3 \\
\hline 2,3 & 5,3 & 18,7 & 510 & 2,3 \\
\hline 2,5 & 5,4 & 18,1 & 436 & 2,5 \\
\hline 2,7 & 5,4 & 17,4 & 357 & 2,7 \\
\hline 3,2 & 5,4 & 17,2 & 283 & 3,2 \\
\hline 5,0 & 5,5 & 16,8 & 234 & 5,0 \\
\hline 8,5 & 5,5 & 15,9 & 198 & 8,5 \\
\hline 106 & 24.1 & 4.8 & 171 & 6.4 \\
\hline 108 & 24,0 & 8,0 & 193 & 4,0 \\
\hline 108 & 24,0 & 14,7 & 227 & 2,3 \\
\hline 107 & 24,2 & 20,1 & 238 & 1,8 \\
\hline 103 & 24,1 & 11,3 & 575 & 3,2 \\
\hline 103 & 24,0 & 13,8 & 1.160 & 2,6 \\
\hline 104 & 24,2 & 16,7 & 1.995 & 2,1 \\
\hline 103 & 24,0 & 18,3 & 2.681 & 1,9 \\
\hline 104 & 24,1 & 19,5 & 3.451 & 1,8 \\
\hline 104 & 24,2 & 20,3 & 4.020 & 1,7 \\
\hline 104 & 24,1 & 21,2 & 4.694 & 1,7 \\
\hline 104 & 24,2 & 22,1 & 5.238 & 1,6 \\
\hline 104 & 24,1 & 21,0 & 4.571 & 1,7 \\
\hline 104 & 24,0 & 20,4 & 4.034 & 1,7 \\
\hline 104 & 24,0 & 19,4 & 3.361 & 1,8 \\
\hline 103 & 23,9 & 18,2 & 2.635 & 1,9 \\
\hline
\end{tabular}




\begin{tabular}{|c|c|c|c|c|}
\hline $\begin{array}{c}p_{\text {sat }} \\
(\boldsymbol{k P a})\end{array}$ & $\begin{array}{l}T_{\text {sat }} \\
\left({ }^{o} \boldsymbol{C}\right)\end{array}$ & $\begin{array}{c}\Delta T \\
\left({ }^{o} C\right)\end{array}$ & $\begin{array}{c}h \\
\left(k W / m^{2}\right)\end{array}$ & $\begin{array}{c}\text { incerteza } \\
(\%)\end{array}$ \\
\hline 103 & 24,1 & 16,7 & 1.960 & 2,1 \\
\hline 103 & 24,0 & 15,9 & 1.693 & 2,2 \\
\hline 103 & 24,0 & 15,5 & 1.598 & 2,3 \\
\hline 103 & 24,0 & 14,6 & 1.352 & 2,4 \\
\hline 103 & 24,0 & 14,1 & 1.189 & 2,5 \\
\hline 103 & 24,0 & 13,3 & 962 & 2,7 \\
\hline 103 & 24,1 & 12,7 & 774 & 2,8 \\
\hline 103 & 24,0 & 12,5 & 672 & 2,9 \\
\hline 103 & 24,0 & 11,9 & 537 & 3,0 \\
\hline 103 & 24,0 & 11,4 & 418 & 3,2 \\
\hline 103 & 23,9 & 9,9 & 324 & 3,7 \\
\hline 103 & 23,9 & 7,6 & 217 & 4,9 \\
\hline 102 & 23,9 & 4,9 & 174 & 7,4 \\
\hline 158 & 36,7 & 19,7 & 5.766 & 1,8 \\
\hline 158 & 36,7 & 19,0 & 5.175 & 1,8 \\
\hline 158 & 36,8 & 18,3 & 4.452 & 1,9 \\
\hline 158 & 36,6 & 17,5 & 3.683 & 2,0 \\
\hline 158 & 36,7 & 16,5 & 2.970 & 2,1 \\
\hline 158 & 36,7 & 15,0 & 2.185 & 2,3 \\
\hline 157 & 36,7 & 14,3 & 1.863 & 2,5 \\
\hline 157 & 36,7 & 14,0 & 1.718 & 2,5 \\
\hline 158 & 36,7 & 13,1 & 1.453 & 2,7 \\
\hline 158 & 36,8 & 12,6 & 1.306 & 2,8 \\
\hline 158 & 36,7 & 11,9 & 1.072 & 3,0 \\
\hline 157 & 36,6 & 11,2 & 878 & 3,2 \\
\hline 158 & 36,8 & 10,8 & 793 & 3,3 \\
\hline 159 & 36,9 & 10,2 & 626 & 3,5 \\
\hline 158 & 36,9 & 9,8 & 515 & 3,7 \\
\hline 158 & 36,8 & 9,0 & 358 & 4,1 \\
\hline 158 & 36,7 & 7,1 & 232 & 5,2 \\
\hline 158 & 36,7 & 4,9 & 167 & 7,5 \\
\hline 285 & 56,2 & 16,2 & 6.848 & 2,2 \\
\hline 285 & 56,4 & 15,7 & 6.243 & 2,2 \\
\hline 285 & 56,3 & 15,1 & 5.325 & 2,3 \\
\hline 286 & 56,4 & 14,5 & 4.538 & 2,4 \\
\hline 284 & 56,3 & 13,9 & 3.701 & 2,5 \\
\hline 285 & 56,3 & 12,5 & 2.512 & 2,8 \\
\hline 283 & 56,2 & 11,8 & 2.109 & 3,0 \\
\hline 282 & 56,1 & 11,1 & 1.724 & 3,2 \\
\hline 284 & 56,3 & 10,7 & 1.561 & 3,3 \\
\hline 284 & 56,3 & 10,0 & 1.249 & 3,5 \\
\hline 284 & 56,3 & 9,5 & 1.043 & 3,7 \\
\hline 284 & 56,3 & 9,1 & 908 & 3,9 \\
\hline 284 & 56,2 & 8,6 & 768 & 4,1 \\
\hline 283 & 56,2 & 7,8 & 613 & 4,6 \\
\hline 283 & 56,1 & 7,1 & 458 & 5,0 \\
\hline 284 & 56,1 & 6,3 & 275 & 5,8 \\
\hline 413 & 70,1 & 14,1 & 8.063 & 2,5 \\
\hline 413 & 70,1 & 13,5 & 7.134 & 2,6 \\
\hline 412 & 70,1 & 13,0 & 6.224 & 2,7 \\
\hline 411 & 70,0 & 12,5 & 5.263 & 2,8 \\
\hline 411 & 70,0 & 11,7 & 4.178 & 3,0 \\
\hline 412 & 70,1 & 11,3 & 3.676 & 3,1 \\
\hline 411 & 70,0 & 10,6 & 3.046 & 3,3 \\
\hline 411 & 70,0 & 9,9 & 2.440 & 3,5 \\
\hline 410 & 69,9 & 9,4 & 2.035 & 3,7 \\
\hline 412 & 70,1 & 9,1 & 1.831 & 3,8 \\
\hline 411 & 70,1 & 8,3 & 1.455 & 4,2 \\
\hline 412 & 70,1 & 8,0 & 1.247 & 4,4 \\
\hline 412 & 70,1 & 7,6 & 1.088 & 4,6 \\
\hline 411 & 70,0 & 7,2 & 930 & 4,9 \\
\hline 410 & 70,0 & 6,7 & 736 & 5,3 \\
\hline 408 & 69,8 & 6,1 & 533 & 5,8 \\
\hline
\end{tabular}

\begin{tabular}{|c|c|c|c|c|}
\hline $\begin{array}{c}p_{\text {sat }} \\
(\boldsymbol{k P a})\end{array}$ & $\begin{array}{c}T_{\text {sat }} \\
\left({ }^{\circ} \boldsymbol{C}\right)\end{array}$ & $\begin{array}{c}\Delta T \\
\left({ }^{o} \boldsymbol{C}\right) \\
\end{array}$ & $\begin{array}{c}h \\
\left(k W / m^{2}\right)\end{array}$ & $\begin{array}{c}\text { incerteza } \\
(\%)\end{array}$ \\
\hline & & & & \\
\hline 540 & 80,9 & 12,7 & 9.040 & 2,8 \\
\hline 541 & 80,9 & 12,3 & 7.955 & 2,8 \\
\hline 539 & 80,8 & 11,9 & 6.832 & 2,9 \\
\hline 539 & 80,9 & 11,3 & 5.935 & 3,1 \\
\hline 538 & 80,8 & 10,7 & 4.631 & 3,3 \\
\hline 537 & 80,7 & 10,2 & 3.959 & 3,4 \\
\hline 541 & 80,9 & 9,7 & 3.407 & 3,6 \\
\hline 541 & 81,0 & 9,3 & 2.951 & 3,8 \\
\hline 540 & 80,9 & 8,9 & 2.646 & 3,9 \\
\hline 540 & 80,9 & 8,5 & 2.216 & 4,1 \\
\hline 540 & 80,9 & 8,3 & 2.002 & 4,2 \\
\hline 540 & 80,9 & 7,7 & 1.576 & 4,5 \\
\hline 541 & 80,9 & 7,3 & 1.329 & 4,8 \\
\hline 538 & 80,8 & 7,1 & 1.201 & 5,0 \\
\hline 535 & 80,5 & 6,7 & 1.008 & 5,3 \\
\hline 539 & 80,8 & 12,5 & 9.174 & 2,8 \\
\hline 540 & 80,8 & 12,1 & 8.256 & 2,9 \\
\hline 539 & 80,7 & 11,5 & 7.024 & 3,0 \\
\hline 539 & 80,8 & 10,9 & 5.944 & 3,2 \\
\hline 538 & 80,7 & 10,1 & 4.865 & 3,4 \\
\hline 539 & 80,8 & 9,7 & 4.279 & 3,6 \\
\hline 540 & 80,8 & 9,3 & 3.551 & 3,7 \\
\hline 539 & 80,8 & 8,6 & 2.877 & 4,1 \\
\hline 540 & 80,8 & 8,0 & 2.352 & 4,4 \\
\hline 539 & 80,8 & 7,6 & 2.107 & 4,6 \\
\hline 541 & 80,9 & 7,2 & 1.761 & 4,8 \\
\hline 539 & 80,7 & 6,7 & 1.491 & 5,3 \\
\hline 536 & 80,6 & 6,3 & 1.303 & 5,6 \\
\hline
\end{tabular}

Superfície de cobre ; Ra=0,45 $\pm 0,07 \mu \mathrm{m}$

\begin{tabular}{|c|c|c|c|c|}
\hline 34 & $-2,5$ & 4,1 & 193 & 7,3 \\
\hline 34 & $-2,5$ & 7,4 & 214 & 4,2 \\
\hline 34 & $-2,4$ & 13,6 & 245 & 2,4 \\
\hline 34 & $-2,4$ & 18,3 & 264 & 1,9 \\
\hline 34 & $-2,3$ & 21,6 & 301 & 1,6 \\
\hline 35 & $-2,4$ & 13,4 & 633 & 2,7 \\
\hline 35 & $-2,5$ & 15,1 & 1.047 & 2,4 \\
\hline 35 & $-2,5$ & 17,2 & 1.907 & 2,1 \\
\hline 35 & $-2,4$ & 18,7 & 2.622 & 1,9 \\
\hline 35 & $-2,3$ & 20,0 & 3.284 & 1,8 \\
\hline 36 & $-2,0$ & 21,0 & 3.875 & 1,7 \\
\hline 36 & $-1,6$ & 22,2 & 4.449 & 1,6 \\
\hline 35 & $-2,4$ & 20,6 & 3.593 & 1,7 \\
\hline 35 & $-2,4$ & 19,9 & 3.215 & 1,8 \\
\hline 35 & $-2,5$ & 19,2 & 2.892 & 1,8 \\
\hline 35 & $-2,4$ & 18,7 & 2.630 & 1,9 \\
\hline 35 & $-2,4$ & 18,0 & 2.261 & 2,0 \\
\hline 35 & $-2,4$ & 17,1 & 1.910 & 2,1 \\
\hline 35 & $-2,4$ & 17,1 & 1.910 & 2,1 \\
\hline 35 & $-2,4$ & 16,0 & 1.508 & 2,2 \\
\hline 35 & $-2,4$ & 14,4 & 845 & 2,5 \\
\hline 35 & $-2,5$ & 13,8 & 721 & 2,6 \\
\hline 35 & $-2,5$ & 13,6 & 615 & 2,7 \\
\hline 35 & $-2,4$ & 13,2 & 490 & 2,8 \\
\hline 35 & $-2,4$ & 12,8 & 367 & 2,9 \\
\hline 35 & $-2,3$ & 12,1 & 268 & 3,1 \\
\hline 35 & $-2,3$ & 7,8 & 206 & 4,8 \\
\hline 35 & $-2,2$ & 4,6 & 190 & 8,0 \\
\hline 49 & 5,6 & 4,7 & 185 & 6,5 \\
\hline 49 & 5,5 & 8,2 & 210 & 3,9 \\
\hline 49 & 5,5 & 14,0 & 238 & 2,4 \\
\hline 49 & 5,4 & 20,6 & 252 & 1,7 \\
\hline 49 & 5,5 & 25,0 & 264 & 1,4 \\
\hline
\end{tabular}




\begin{tabular}{|c|c|c|c|c|}
\hline $\begin{array}{c}p_{\text {sat }} \\
(\boldsymbol{k P a})\end{array}$ & $\begin{array}{l}T_{\text {sat }} \\
\left({ }^{\circ} \mathrm{C}\right)\end{array}$ & $\begin{array}{c}\Delta T \\
\left({ }^{o} C\right)\end{array}$ & $\begin{array}{c}h \\
\left(k W / m^{2}\right)\end{array}$ & $\begin{array}{c}\text { incerteza } \\
(\%)\end{array}$ \\
\hline 49 & 5,6 & 30,7 & 291 & 1,2 \\
\hline 49 & 5,6 & 35,7 & 284 & 1,1 \\
\hline 49 & 5,6 & 40,9 & 295 & 1,0 \\
\hline 48 & 5,6 & 46,5 & 302 & 0,9 \\
\hline 48 & 5,5 & 49,0 & 307 & 0,8 \\
\hline 48 & 5,4 & 54,0 & 313 & 0,8 \\
\hline 48 & 5,5 & 57,6 & 319 & 0,7 \\
\hline 50 & 5,4 & 14,1 & 1.429 & 2,5 \\
\hline 50 & 5,4 & 16,5 & 2.527 & 2,1 \\
\hline 50 & 5,4 & 17,7 & 3.237 & 2,0 \\
\hline 50 & 5,5 & 18,6 & 3.926 & 1,9 \\
\hline 50 & 5,4 & 19,7 & 4.543 & 1,8 \\
\hline 50 & 5,4 & 20,7 & 5.084 & 1,7 \\
\hline 50 & 5,5 & 21,5 & 5.272 & 1,6 \\
\hline 51 & 5,5 & 20,2 & 4.827 & 1,7 \\
\hline 50 & 5,4 & 19,1 & 4.334 & 1,8 \\
\hline 50 & 5,3 & 18,2 & 3.575 & 1,9 \\
\hline 50 & 5,3 & 17,1 & 2.849 & 2,1 \\
\hline 50 & 5,4 & 16,5 & 2.481 & 2,1 \\
\hline 50 & 5,3 & 15,6 & 2.081 & 2,3 \\
\hline 50 & 5,3 & 14,7 & 1.657 & 2,4 \\
\hline 50 & 5,3 & 14,2 & 1.367 & 2,5 \\
\hline 50 & 5,3 & 13,7 & 1.230 & 2,6 \\
\hline 50 & 5,3 & 13,1 & 1.003 & 2,7 \\
\hline 50 & 5,2 & 12,8 & 774 & 2,8 \\
\hline 50 & 5,3 & 12,6 & 662 & 2,9 \\
\hline 50 & 5,3 & 12,0 & 562 & 3,0 \\
\hline 50 & 5,3 & 11,2 & 432 & 3,3 \\
\hline 50 & 5,3 & 10,7 & 312 & 3,5 \\
\hline 50 & 5,3 & 7,1 & 219 & 5,2 \\
\hline 50 & 5,5 & 4,0 & 184 & 9,0 \\
\hline 105 & 24,2 & 16,9 & 6.587 & 2,1 \\
\hline 104 & 24,1 & 16,1 & 5.837 & 2,2 \\
\hline 103 & 24,0 & 15,3 & 5.259 & 2,3 \\
\hline 104 & 24,2 & 14,4 & 4.500 & 2,4 \\
\hline 104 & 24,1 & 13,4 & 3.654 & 2,6 \\
\hline 104 & 24,1 & 12,8 & 3.157 & 2,7 \\
\hline 104 & 24,2 & 12,5 & 2.722 & 2,8 \\
\hline 103 & 24,2 & 11,5 & 2.090 & 3,0 \\
\hline 103 & 24,1 & 10,8 & 1.581 & 3,2 \\
\hline 103 & 24,0 & 10,3 & 1.192 & 3,4 \\
\hline 103 & 24,0 & 9,8 & 997 & 3,6 \\
\hline 103 & 24,0 & 9,6 & 859 & 3,7 \\
\hline 103 & 24,0 & 9,4 & 697 & 3,8 \\
\hline 102 & 23,9 & 8,6 & 539 & 4,2 \\
\hline 102 & 23,8 & 8,0 & 397 & 4,5 \\
\hline 102 & 23,9 & 6,9 & 249 & 5,3 \\
\hline 103 & 23,9 & 4,9 & 172 & 7,4 \\
\hline 105 & 24,0 & 4,9 & 158 & 6,4 \\
\hline 106 & 24,0 & 8,8 & 191 & 3,7 \\
\hline 107 & 24,1 & 14,1 & 217 & 2,4 \\
\hline 101 & 24,4 & 20,6 & 250 & 1,7 \\
\hline 100 & 24,2 & 25,4 & 262 & 1,4 \\
\hline 101 & 24,0 & 30,6 & 275 & 1,2 \\
\hline 101 & 24,0 & 34,5 & 284 & 1,1 \\
\hline 103 & 24,0 & 9,9 & 1.212 & 3,6 \\
\hline 103 & 24,0 & 10,5 & 1.527 & 3,3 \\
\hline 103 & 24,1 & 12,5 & 2.627 & 2,8 \\
\hline 103 & 24,1 & 13,8 & 3.560 & 2,5 \\
\hline 103 & 24,2 & 14,9 & 4.402 & 2,3 \\
\hline 103 & 24,1 & 15,7 & 5.102 & 2,2 \\
\hline 103 & 24,2 & 16,7 & 5.924 & 2,1 \\
\hline 103 & 24,2 & 17,5 & 6.485 & 2,0 \\
\hline 103 & 24,0 & 16,6 & 5.795 & 2,1 \\
\hline
\end{tabular}

\begin{tabular}{|c|c|c|c|c|}
\hline $\begin{array}{c}p_{\text {sat }} \\
(\boldsymbol{k P a})\end{array}$ & $\begin{array}{c}T_{\text {sat }} \\
\left({ }^{o} C\right)\end{array}$ & $\begin{array}{c}\Delta T \\
\left({ }^{o} C\right) \\
\end{array}$ & $\begin{array}{c}\boldsymbol{h} \\
\left(\boldsymbol{k} W / m^{2}\right)\end{array}$ & $\begin{array}{c}\text { incerteza } \\
(\%)\end{array}$ \\
\hline 103 & 24,0 & 15,7 & 5.028 & 2,2 \\
\hline 103 & 24,0 & 15,0 & 4.435 & 2,3 \\
\hline 102 & 24,0 & 13,9 & 3.565 & 2,5 \\
\hline 103 & 24,1 & 12,5 & 2.595 & 2,8 \\
\hline 102 & 24,0 & 11,7 & 2.072 & 3,0 \\
\hline 103 & 24,1 & 10,7 & 1.533 & 3,3 \\
\hline 102 & 24,0 & 10,1 & 1.204 & 3,5 \\
\hline 102 & 24,0 & 9,7 & 1.029 & 3,7 \\
\hline 102 & 24,0 & 9,4 & 883 & 3,8 \\
\hline 102 & 24,0 & 8,9 & 708 & 4,0 \\
\hline 102 & 24,0 & 8,5 & 562 & 4,2 \\
\hline 102 & 24,0 & 7,8 & 407 & 4,6 \\
\hline 102 & 24,0 & 6,3 & 256 & 5,7 \\
\hline 102 & 23,9 & 4,5 & 175 & 8,2 \\
\hline 158 & 36,7 & 15,1 & 7.566 & 2,3 \\
\hline 158 & 36,7 & 14,3 & 6.808 & 2,4 \\
\hline 157 & 36,6 & 13,5 & 5.875 & 2,6 \\
\hline 158 & 36,8 & 12,6 & 5.153 & 2,8 \\
\hline 157 & 36,6 & 11,6 & 4.113 & 3,0 \\
\hline 158 & 36,7 & 10,4 & 3.087 & 3,3 \\
\hline 157 & 36,6 & 9,7 & 2.538 & 3,6 \\
\hline 157 & 36,6 & 9,1 & 2.149 & 3,8 \\
\hline 157 & 36,6 & 8,7 & 1.826 & 4,0 \\
\hline 157 & 36,6 & 8,0 & 1.499 & 4,4 \\
\hline 157 & 36,6 & 7,7 & 1.282 & 4,6 \\
\hline 157 & 36,6 & 7,4 & 1.091 & 4,7 \\
\hline 157 & 36,6 & 7,2 & 905 & 4,9 \\
\hline 157 & 36,6 & 6,9 & 694 & 5,1 \\
\hline 157 & 36,5 & 6,5 & 509 & 5,5 \\
\hline 157 & 36,6 & 5,7 & 288 & 6,4 \\
\hline 158 & 36,6 & 4,3 & 171 & 8,5 \\
\hline 157 & 36,8 & 15,4 & 7.282 & 2,3 \\
\hline 157 & 36,7 & 14,7 & 6.639 & 2,4 \\
\hline 157 & 36,7 & 13,9 & 5.813 & 2,5 \\
\hline 157 & 36,7 & 13,1 & 4.996 & 2,7 \\
\hline 157 & 36,8 & 12,1 & 4.068 & 2,9 \\
\hline 157 & 36,7 & 10,8 & 2.971 & 3,2 \\
\hline 156 & 36,7 & 10,1 & 2.452 & 3,5 \\
\hline 156 & 36,7 & 9,4 & 2.044 & 3,7 \\
\hline 156 & 36,6 & 9,0 & 1.814 & 3,9 \\
\hline 157 & 36,8 & 8,3 & 1.481 & 4,2 \\
\hline 157 & 36,7 & 7,9 & 1.230 & 4,4 \\
\hline 157 & 36,7 & 7,6 & 1.057 & 4,6 \\
\hline 157 & 36,8 & 7,4 & 877 & 4,8 \\
\hline 157 & 36,8 & 7,0 & 715 & 5,1 \\
\hline 157 & 36,7 & 6,4 & 525 & 5,6 \\
\hline 157 & 36,7 & 5,3 & 284 & 6,7 \\
\hline 157 & 36,6 & 4,2 & 178 & 8,6 \\
\hline 285 & 56,3 & 13,4 & 8.596 & 2,6 \\
\hline 284 & 56,2 & 12,6 & 7.762 & 2,8 \\
\hline 285 & 56,4 & 11,9 & 6.998 & 2,9 \\
\hline 284 & 56,3 & 11,1 & 5.941 & 3,1 \\
\hline 284 & 56,3 & 10,3 & 4.801 & 3,4 \\
\hline 283 & 56,2 & 9,7 & 4.210 & 3,6 \\
\hline 284 & 56,3 & 9,1 & 3.572 & 3,8 \\
\hline 283 & 56,2 & 8,3 & 2.935 & 4,2 \\
\hline 284 & 56,3 & 7,6 & 2.512 & 4,6 \\
\hline 283 & 56,3 & 7,2 & 2.251 & 4,8 \\
\hline 283 & 56,3 & 6,7 & 1.844 & 5,2 \\
\hline 283 & 56,3 & 6,2 & 1.578 & 5,6 \\
\hline 283 & 56,3 & 5,9 & 1.384 & 5,9 \\
\hline 283 & 56,3 & 5,6 & 1.142 & 6,3 \\
\hline 283 & 56,2 & 5,3 & 903 & 6,6 \\
\hline
\end{tabular}




\begin{tabular}{|c|c|c|c|c|}
\hline $\begin{array}{c}p_{\text {sat }} \\
(\boldsymbol{k P a})\end{array}$ & $\begin{array}{l}T_{\text {sat }} \\
\left({ }^{\circ} \boldsymbol{C}\right)\end{array}$ & $\begin{array}{c}\Delta T \\
\left({ }^{o} C\right)\end{array}$ & $\begin{array}{c}h \\
\left(k W / m^{2}\right)\end{array}$ & $\begin{array}{c}\text { incerteza } \\
(\%)\end{array}$ \\
\hline 283 & 56,3 & 4,8 & 648 & 7,3 \\
\hline 283 & 56,2 & 4,3 & 359 & 8,3 \\
\hline 283 & 56,1 & 3,8 & 215 & 9,4 \\
\hline 410 & 69,9 & 11,5 & 9.994 & 3,0 \\
\hline 410 & 70,0 & 10,8 & 9.097 & 3,2 \\
\hline 409 & 69,9 & 10,1 & 8.021 & 3,4 \\
\hline 410 & 70,0 & 9,4 & 6.827 & 3,7 \\
\hline 410 & 70,0 & 8,6 & 5.609 & 4,0 \\
\hline 408 & 69,8 & 7,6 & 4.379 & 4,6 \\
\hline 410 & 70,0 & 6,9 & 3.554 & 5,1 \\
\hline 410 & 70,0 & 6,4 & 3.050 & 5,4 \\
\hline 411 & 70,0 & 6,0 & 2.626 & 5,8 \\
\hline 409 & 70,0 & 5,5 & 2.186 & 6,3 \\
\hline 409 & 69,9 & 5,2 & 1.902 & 6,7 \\
\hline 409 & 69,9 & 5,0 & 1.689 & 7,0 \\
\hline 410 & 70,0 & 4,7 & 1.411 & 7,5 \\
\hline 409 & 69,9 & 4,4 & 1.148 & 8,0 \\
\hline 407 & 69,7 & 4,0 & 827 & 8,8 \\
\hline & & & & \\
\hline 411 & 70,0 & 11,7 & 9.979 & 3,0 \\
\hline 411 & 70,0 & 11,0 & 8.523 & 3,2 \\
\hline 411 & 70,0 & 10,4 & 7.918 & 3,3 \\
\hline 410 & 70,0 & 9,7 & 6.693 & 3,6 \\
\hline 410 & 70,0 & 8,9 & 5.516 & 3,9 \\
\hline 411 & 70,1 & 8,4 & 4.903 & 4,1 \\
\hline 410 & 70,0 & 7,8 & 4.188 & 4,5 \\
\hline 411 & 70,1 & 7,1 & 3.482 & 4,9 \\
\hline 410 & 70,0 & 6,6 & 2.902 & 5,3 \\
\hline 411 & 70,0 & 6,3 & 2.651 & 5,5 \\
\hline 409 & 69,9 & 5,7 & 2.121 & 6,1 \\
\hline 410 & 69,9 & 5,4 & 1.819 & 6,5 \\
\hline 411 & 70,0 & 5,2 & 1.673 & 6,7 \\
\hline 410 & 70,0 & 4,9 & 1.406 & 7,2 \\
\hline 408 & 69,8 & 4,4 & 1.092 & 7,9 \\
\hline 406 & 69,6 & 4,1 & 789 & 8,5 \\
\hline 537 & 80,7 & 10,6 & 11.033 & 3,3 \\
\hline 539 & 80,8 & 9,9 & 9.702 & 3,5 \\
\hline 539 & 80,8 & 9,3 & 8.654 & 3,7 \\
\hline 538 & 80,8 & 8,8 & 7.557 & 4,0 \\
\hline 536 & 80,6 & 7,9 & 6.191 & 4,4 \\
\hline 538 & 80,8 & 7,4 & 5.482 & 4,7 \\
\hline 539 & 80,9 & 6,9 & 4.689 & 5,0 \\
\hline 541 & 81,0 & 6,3 & 3.914 & 5,5 \\
\hline 540 & 81,0 & 5,9 & 3.322 & 5,9 \\
\hline 541 & 81,0 & 5,6 & 2.985 & 6,2 \\
\hline 541 & 81,0 & 5,1 & 2.423 & 6,9 \\
\hline 540 & 80,9 & 4,7 & 2.034 & 7,4 \\
\hline 538 & 80,8 & 4,4 & 1.809 & 7,8 \\
\hline 536 & 80,7 & 4,2 & 1.569 & 8,2 \\
\hline 534 & 80,5 & 3,9 & 1.247 & 9,0 \\
\hline
\end{tabular}

\begin{tabular}{|c|c|c|c|c|}
\hline $\left.\begin{array}{c}p_{\text {sat }} \\
(\boldsymbol{k P a})\end{array}\right)$ & $\begin{array}{r}T_{\text {sat }} \\
\left({ }^{o} \boldsymbol{C}\right)\end{array}$ & $\begin{array}{c}\Delta T \\
\left({ }^{o} C\right)\end{array}$ & $\begin{array}{c}h \\
\left(k W / m^{2}\right)\end{array}$ & $\begin{array}{c}\text { incerteza } \\
(\%)\end{array}$ \\
\hline 51 & 5,5 & 11,9 & 9.619 & 2,9 \\
\hline 51 & 5,4 & 11,9 & 8.949 & 2,9 \\
\hline 51 & 5,5 & 11,1 & 6.617 & 3,1 \\
\hline 51 & 5,4 & 10,7 & 5.490 & 3,3 \\
\hline 51 & 5,4 & 10,4 & 4.891 & 3,4 \\
\hline 50 & 5,4 & 9,9 & 4.070 & 3,5 \\
\hline 51 & 5,5 & 9,5 & 3.521 & 3,7 \\
\hline 51 & 5,5 & 9,1 & 3.019 & 3,8 \\
\hline 51 & 5,5 & 8,8 & 2.653 & 4,0 \\
\hline 50 & 5,4 & 8,4 & 2.358 & 4,1 \\
\hline 50 & 5,4 & 8,2 & 2.168 & 4,3 \\
\hline 50 & 5,4 & 7,4 & 1.687 & 4,7 \\
\hline 50 & 5,4 & 6,9 & 1.379 & 5,1 \\
\hline 50 & 5,5 & 6,7 & 1.254 & 5,2 \\
\hline 50 & 5,5 & 6,6 & 1.027 & 5,4 \\
\hline 50 & 5,5 & 6,2 & 771 & 5,7 \\
\hline 50 & 5,5 & 6,0 & 558 & 5,9 \\
\hline 50 & 5,5 & 5,7 & 283 & 6,3 \\
\hline 50 & 5,6 & 3,8 & 215 & 9,5 \\
\hline & & & & \\
\hline 50 & 5,6 & 11,9 & 9.481 & 2,9 \\
\hline 50 & 5,5 & 11,5 & 8.395 & 3,0 \\
\hline 50 & 5,6 & 11,1 & 7.498 & 3,1 \\
\hline 50 & 5,6 & 10,6 & 6.408 & 3,3 \\
\hline 49 & 5,5 & 10,2 & 5.554 & 3,4 \\
\hline 49 & 5,4 & 9,9 & 4.941 & 3,5 \\
\hline 50 & 5,6 & 9,6 & 4.286 & 3,6 \\
\hline 50 & 5,6 & 9,2 & 3.533 & 3,8 \\
\hline 49 & 5,6 & 8,9 & 3.055 & 3,9 \\
\hline 50 & 5,6 & 8,7 & 2.796 & 4,0 \\
\hline 49 & 5,6 & 8,1 & 2.252 & 4,3 \\
\hline 49 & 5,6 & 8,0 & 2.082 & 4,4 \\
\hline 49 & 5,5 & 7,4 & 1.682 & 4,7 \\
\hline 49 & 5,6 & 7,1 & 1.413 & 4,9 \\
\hline 49 & 5,6 & 6,9 & 1.228 & 5,1 \\
\hline 49 & 5,6 & 6,5 & 1.028 & 5,4 \\
\hline 49 & 5,6 & 6,3 & 766 & 5,6 \\
\hline 49 & 5,6 & 6,2 & 554 & 5,8 \\
\hline 49 & 5,7 & 5,6 & 294 & 6,5 \\
\hline 49 & 5,7 & 4,2 & 231 & 8,6 \\
\hline & & & & \\
\hline 104 & 24,2 & 9,3 & 12.368 & 3,8 \\
\hline 104 & 24,2 & 9,2 & 11.140 & 3,8 \\
\hline 103 & 24,1 & 8,9 & 9.118 & 3,9 \\
\hline 103 & 24,2 & 8,6 & 7.697 & 4,0 \\
\hline 103 & 24,1 & 8,3 & 6.847 & 4,2 \\
\hline 103 & 24,2 & 8,1 & 6.155 & 4,3 \\
\hline 103 & 24,1 & 7,8 & 5.365 & 4,4 \\
\hline 103 & 24,1 & 7,4 & 4.377 & 4,7 \\
\hline 103 & 24,2 & 7,2 & 3.819 & 4,9 \\
\hline 103 & 24,2 & 7,0 & 3.491 & 5,0 \\
\hline 103 & 24,2 & 6,6 & 2.904 & 5,3 \\
\hline 103 & 24,2 & 6,3 & 2.598 & 5,6 \\
\hline 103 & 24,2 & 5,7 & 2.183 & 6,1 \\
\hline 103 & 24,2 & 5,4 & 1.892 & 6,5 \\
\hline 103 & 24,1 & 5,0 & 1.600 & 6,9 \\
\hline 102 & 24,1 & 4,8 & 1.404 & 7,3 \\
\hline 102 & 24,1 & 4,5 & 1.090 & 7,8 \\
\hline 103 & 24,1 & 4,2 & 784 & 8,4 \\
\hline 102 & 24,1 & 3,8 & 444 & 9,3 \\
\hline 102 & 24,0 & 3,5 & 242 & 10,2 \\
\hline 157 & 36,7 & 7,8 & 14.606 & 4,4 \\
\hline 157 & 36,8 & 7,7 & 12.718 & 4,5 \\
\hline 157 & 36,7 & 7,6 & 10.871 & 4,6 \\
\hline 157 & 36,8 & 7,3 & 8.791 & 4,8 \\
\hline
\end{tabular}

Superfície de cobre ; Ra=2,3 $\pm \mathbf{0 , 3} \mathbf{\mu m}$
\begin{tabular}{|c|c|c|c|c|}
\hline 50 & 5,5 & 7,7 & 225 & 4,8 \\
\hline 50 & 5,5 & 10,4 & 239 & 3,6 \\
\hline 50 & 5,5 & 13,5 & 240 & 2,9 \\
\hline 50 & 5,6 & 16,7 & 250 & 2,4 \\
\hline 49 & 5,5 & 18,7 & 258 & 2,1 \\
\hline 51 & 5,5 & 7,2 & 915 & 4,9 \\
\hline 50 & 5,5 & 8,5 & 1.972 & 4,1 \\
\hline 51 & 5,4 & 9,6 & 3.331 & 3,6 \\
\hline 51 & 5,4 & 10,2 & 4.946 & 3,4 \\
\hline 51 & 5,5 & 10,7 & 6.101 & 3,3 \\
\hline 50 & 5,3 & 11,2 & 7.175 & 3,1 \\
\hline 51 & 5,4 & 11,6 & 8.584 & 3,0 \\
\hline
\end{tabular}




\begin{tabular}{|c|c|c|c|c|}
\hline $\begin{array}{c}p_{\text {sat }} \\
(\boldsymbol{k P a})\end{array}$ & $\begin{array}{l}T_{\text {sat }} \\
\left({ }^{o} C\right)\end{array}$ & $\begin{array}{c}\Delta T \\
\left({ }^{o} C\right)\end{array}$ & $\begin{array}{c}h \\
\left(k W / m^{2}\right)\end{array}$ & $\begin{array}{c}\text { incerteza } \\
(\%)\end{array}$ \\
\hline 157 & 36,7 & 7,2 & 8.034 & 4,8 \\
\hline 157 & 36,8 & 7,1 & 7.083 & 4,9 \\
\hline 157 & 36,7 & 6,8 & 5.959 & 5,1 \\
\hline 156 & 36,6 & 6,6 & 5.108 & 5,3 \\
\hline 156 & 36,5 & 6,4 & 4.477 & 5,4 \\
\hline 156 & 36,6 & 6,1 & 4.001 & 5,7 \\
\hline 157 & 36,7 & 5,8 & 3.381 & 6,0 \\
\hline 156 & 36,7 & 5,5 & 2.978 & 6,3 \\
\hline 156 & 36,6 & 5,0 & 2.415 & 7,0 \\
\hline 156 & 36,6 & 4,6 & 2.138 & 7,5 \\
\hline 156 & 36,6 & 4,4 & 1.960 & 7,9 \\
\hline 156 & 36,6 & 4,1 & 1.628 & 8,5 \\
\hline 157 & 36,7 & 3,8 & 1.287 & 9,2 \\
\hline 156 & 36,6 & 3,5 & 972 & 10,1 \\
\hline 156 & 36,6 & 3,1 & 539 & 11,5 \\
\hline 156 & 36,6 & 2,9 & 331 & 12,3 \\
\hline 283 & 56,2 & 6,5 & 17.505 & 5,3 \\
\hline 283 & 56,2 & 6,4 & 15.202 & 5,4 \\
\hline 283 & 56,3 & 6,3 & 13.094 & 5,5 \\
\hline 283 & 56,2 & 6,1 & 10.965 & 5,7 \\
\hline 282 & 56,1 & 5,8 & 8.607 & 6,0 \\
\hline 282 & 56,2 & 5,6 & 7.391 & 6,3 \\
\hline 282 & 56,2 & 5,3 & 6.180 & 6,5 \\
\hline 282 & 56,2 & 5,1 & 5.222 & 6,8 \\
\hline 282 & 56,2 & 5,0 & 4.944 & 6,9 \\
\hline 282 & 56,2 & 4,7 & 4.123 & 7,3 \\
\hline 282 & 56,2 & 4,6 & 3.645 & 7,6 \\
\hline 282 & 56,2 & 4,2 & 2.896 & 8,2 \\
\hline 282 & 56,2 & 3,9 & 2.500 & 8,9 \\
\hline 283 & 56,2 & 3,8 & 2.244 & 9,2 \\
\hline 282 & 56,2 & 3,5 & 1.886 & 9,9 \\
\hline 283 & 56,3 & 3,3 & 1.527 & 10,6 \\
\hline 283 & 56,3 & 3,0 & 1.136 & 11,6 \\
\hline 283 & 56,3 & 2,6 & 892 & 13,4 \\
\hline 282 & 56,2 & 2,3 & 357 & 15,3 \\
\hline 412 & 70,1 & 5,7 & 20.365 & 6,1 \\
\hline 411 & 70,1 & 5,6 & 17.696 & 6,2 \\
\hline 409 & 69,9 & 5,5 & 15.089 & 6,3 \\
\hline 410 & 70,0 & 5,3 & 12.624 & 6,6 \\
\hline 410 & 70,0 & 5,1 & 11.148 & 6,8 \\
\hline 410 & 70,0 & 5,0 & 9.811 & 6,9 \\
\hline 410 & 70,0 & 4,9 & 8.493 & 7,1 \\
\hline 411 & 70,1 & 4,7 & 6.969 & 7,4 \\
\hline 411 & 70,1 & 4,5 & 5.999 & 7,7 \\
\hline 412 & 70,1 & 4,5 & 5.518 & 7,8 \\
\hline 411 & 70,1 & 4,1 & 4.400 & 8,4 \\
\hline 411 & 70,1 & 4,1 & 4.083 & 8,5 \\
\hline 411 & 70,0 & 3,7 & 3.225 & 9,3 \\
\hline 410 & 70,0 & 3,5 & 2.838 & 9,9 \\
\hline 412 & 70,2 & 3,4 & 2.482 & 10,3 \\
\hline 411 & 70,1 & 3,2 & 2.136 & 10,9 \\
\hline 410 & 70,0 & 2,9 & 1.682 & 11,9 \\
\hline 408 & 69,8 & 2,6 & 1.299 & 13,2 \\
\hline 406 & 69,7 & 2,2 & 783 & 15,5 \\
\hline 540 & 80,8 & 5,2 & 22.211 & 6,6 \\
\hline 539 & 80,8 & 5,1 & 19.514 & 6,8 \\
\hline 539 & 80,8 & 5,0 & 16.592 & 7,0 \\
\hline 539 & 80,8 & 4,8 & 13.873 & 7,3 \\
\hline 539 & 80,8 & 4,7 & 12.173 & 7,3 \\
\hline 538 & 80,7 & 4,6 & 10.661 & 7,5 \\
\hline 538 & 80,8 & 4,5 & 9.179 & 7,8 \\
\hline 539 & 80,8 & 4,3 & 7.487 & 8,0 \\
\hline 538 & 80,8 & 4,2 & 6.437 & 8,3 \\
\hline
\end{tabular}

\begin{tabular}{|c|c|c|c|c|}
\hline $\begin{array}{c}p_{\text {sat }} \\
(\boldsymbol{k P a})\end{array}$ & $\begin{array}{l}T_{\text {sat }} \\
\left({ }^{o} \boldsymbol{C}\right)\end{array}$ & $\begin{array}{c}\Delta T \\
\left({ }^{o} C\right)\end{array}$ & $\begin{array}{c}h \\
\left(k W / m^{2}\right)\end{array}$ & $\begin{array}{c}\text { incerteza } \\
(\%)\end{array}$ \\
\hline 538 & 80,8 & 4,1 & 5.970 & 8,4 \\
\hline 539 & 80,8 & 3,9 & 5.087 & 8,9 \\
\hline 537 & 80,7 & 3,8 & 4.391 & 9,2 \\
\hline 538 & 80,8 & 3,5 & 3.488 & 9,9 \\
\hline 538 & 80,7 & 3,3 & 3.009 & 10,5 \\
\hline 535 & 80,5 & 3,1 & 2.614 & 11,1 \\
\hline 531 & 80,2 & 3,0 & 2.263 & 11,5 \\
\hline 530 & 80,2 & 2,8 & 1.758 & 12,2 \\
\hline 529 & 80,1 & 2,5 & 1.310 & 13,8 \\
\hline 526 & 79,9 & 2,1 & 768 & 16,2 \\
\hline
\end{tabular}

Superfície de latão ; Ra=0,15 $\pm 0,03 \mu \mathrm{m}$

\begin{tabular}{|c|c|c|c|c|}
\hline 50 & 5,6 & 21,2 & 3.556 & 1,4 \\
\hline 50 & 5,5 & 20,7 & 3.256 & 1,4 \\
\hline 50 & 5,5 & 20,3 & 2.982 & 1,4 \\
\hline 50 & 5,4 & 19,9 & 2.701 & 1,5 \\
\hline 50 & 5,5 & 19,5 & 2.330 & 1,5 \\
\hline 50 & 5,5 & 19,1 & 1.982 & 1,5 \\
\hline 49 & 5,4 & 18,5 & 1.786 & 1,6 \\
\hline 49 & 5,4 & 17,9 & 1.404 & 1,7 \\
\hline 49 & 5,5 & 17,5 & 1.281 & 1,7 \\
\hline 49 & 5,4 & 16,1 & 1.107 & 1,8 \\
\hline 49 & 5,5 & 15,9 & 968 & 1,9 \\
\hline 49 & 5,5 & 13,6 & 825 & 2,2 \\
\hline 49 & 5,6 & 12,3 & 736 & 2,4 \\
\hline 49 & 5,6 & 12,3 & 625 & 2,5 \\
\hline 49 & 5,6 & 12,4 & 506 & 2,5 \\
\hline 49 & 5,7 & 11,5 & 405 & 2,7 \\
\hline 49 & 5,7 & 9,7 & 309 & 3,2 \\
\hline 49 & 5,7 & 7,7 & 202 & 4,1 \\
\hline 49 & 5,7 & 4,2 & 185 & 7,2 \\
\hline 50 & 5,5 & 4,6 & 175 & 6,6 \\
\hline 50 & 5,5 & 7,7 & 200 & 4,2 \\
\hline 50 & 5,6 & 13,7 & 214 & 2,5 \\
\hline 49 & 5,6 & 19,3 & 231 & 1,8 \\
\hline 49 & 5,6 & 25,2 & 245 & 1,5 \\
\hline 49 & 5,6 & 30,3 & 255 & 1,3 \\
\hline 49 & 5,6 & 34,9 & 262 & 1,1 \\
\hline 49 & 5,6 & 39,6 & 273 & 1,0 \\
\hline 49 & 5,6 & 42,9 & 277 & 1,0 \\
\hline 49 & 5,6 & 48,0 & 283 & 0,9 \\
\hline 49 & 5,6 & 52,3 & 292 & 0,8 \\
\hline 49 & 5,6 & 56,5 & 295 & 0,8 \\
\hline 49 & 5,6 & 58,3 & 297 & 0,7 \\
\hline 50 & 5,5 & 16,9 & 1.160 & 2,1 \\
\hline 50 & 5,4 & 19,2 & 1.959 & 1,8 \\
\hline 50 & 5,5 & 19,9 & 2.665 & 1,8 \\
\hline 50 & 5,6 & 20,8 & 3.257 & 1,7 \\
\hline 50 & 5,5 & 21,2 & 3.559 & 1,7 \\
\hline 50 & 5,6 & 20,8 & 3.295 & 1,7 \\
\hline 50 & 5,5 & 20,2 & 2.968 & 1,7 \\
\hline 50 & 5,5 & 19,9 & 2.704 & 1,8 \\
\hline 50 & 5,6 & 19,5 & 2.392 & 1,8 \\
\hline 50 & 5,5 & 19,1 & 1.993 & 1,9 \\
\hline 50 & 5,6 & 18,5 & 1.640 & 1,9 \\
\hline 50 & 5,5 & 17,9 & 1.409 & 2,0 \\
\hline 50 & 5,5 & 18,1 & 1.246 & 2,0 \\
\hline 50 & 5,5 & 17,5 & 1.005 & 2,1 \\
\hline 50 & 5,5 & 16,9 & 903 & 2,1 \\
\hline 50 & 5,5 & 15,1 & 753 & 2,4 \\
\hline 50 & 5,5 & 13,1 & 692 & 2,8 \\
\hline 50 & 5,5 & 12,4 & 616 & 2,9 \\
\hline 50 & 5,5 & 12,4 & 481 & 3,0 \\
\hline 50 & 5,5 & 11,4 & 380 & 3,2 \\
\hline 50 & 5,5 & 9,8 & 302 & 3,8 \\
\hline
\end{tabular}




\begin{tabular}{|c|c|c|c|c|}
\hline $\begin{array}{c}p_{\text {sat }} \\
(\boldsymbol{k P a})\end{array}$ & $\begin{array}{l}T_{\text {sat }} \\
\left({ }^{\circ} \mathrm{C}\right)\end{array}$ & $\begin{array}{c}\Delta T \\
\left({ }^{o} C\right)\end{array}$ & $\begin{array}{c}h \\
\left(k W / m^{2}\right)\end{array}$ & $\begin{array}{c}\text { incerteza } \\
(\%)\end{array}$ \\
\hline 50 & 5,5 & 7,5 & 201 & 5,0 \\
\hline 49 & 5,5 & 3,9 & 177 & 9,4 \\
\hline 103 & 24,2 & 5,3 & 160 & 5,9 \\
\hline 104 & 24,2 & 8,5 & 184 & 3,8 \\
\hline 104 & 24,2 & 14,6 & 207 & 2,4 \\
\hline 104 & 24,2 & 20,1 & 224 & 1,8 \\
\hline 103 & 24,1 & 10,9 & 572 & 2,8 \\
\hline 103 & 24,1 & 12,6 & 1.231 & 2,3 \\
\hline 103 & 24,1 & 14,2 & 2.214 & 2,0 \\
\hline 103 & 24,1 & 15,3 & 3.062 & 1,9 \\
\hline 103 & 24,1 & 16,0 & 3.829 & 1,8 \\
\hline 103 & 24,2 & 17,1 & 4.950 & 1,7 \\
\hline 103 & 24,1 & 16,3 & 4.297 & 1,8 \\
\hline 103 & 24,2 & 15,5 & 3.437 & 1,9 \\
\hline 103 & 24,1 & 15,0 & 3.004 & 1,9 \\
\hline 103 & 24,2 & 14,5 & 2.589 & 2,0 \\
\hline 103 & 24,2 & 14,0 & 2.128 & 2,1 \\
\hline 103 & 24,1 & 13,6 & 1.860 & 2,1 \\
\hline 103 & 24,1 & 13,4 & 1.703 & 2,2 \\
\hline 103 & 24,2 & 12,8 & 1.420 & 2,3 \\
\hline 103 & 24,2 & 12,5 & 1.236 & 2,3 \\
\hline 103 & 24,2 & 11,9 & 935 & 2,5 \\
\hline 103 & 24,2 & 11,8 & 786 & 2,5 \\
\hline 103 & 24,1 & 11,5 & 669 & 2,6 \\
\hline 103 & 24,1 & 10,7 & 550 & 2,8 \\
\hline 103 & 24,2 & 9,9 & 461 & 3,1 \\
\hline 103 & 24,2 & 8,6 & 357 & 3,6 \\
\hline 103 & 24,1 & 6,7 & 234 & 4,6 \\
\hline 103 & 24,1 & 4,8 & 165 & 6,5 \\
\hline 100 & 24,1 & 16,8 & 4.416 & 1,7 \\
\hline 101 & 24,2 & 16,6 & 4.088 & 1,7 \\
\hline 101 & 24,2 & 16,3 & 3.761 & 1,8 \\
\hline 101 & 24,2 & 15,8 & 3.266 & 1,8 \\
\hline 101 & 24,2 & 15,5 & 2.987 & 1,9 \\
\hline 101 & 24,2 & 14,9 & 2.456 & 1,9 \\
\hline 101 & 24,3 & 14,4 & 2.139 & 2,0 \\
\hline 101 & 24,3 & 13,7 & 1.641 & 2,1 \\
\hline 100 & 24,2 & 13,1 & 1.356 & 2,2 \\
\hline 100 & 24,2 & 12,8 & 1.169 & 2,3 \\
\hline 100 & 24,2 & 12,0 & 949 & 2,5 \\
\hline 101 & 24,2 & 11,2 & 805 & 2,6 \\
\hline 100 & 24,2 & 10,4 & 756 & 2,9 \\
\hline 100 & 24,2 & 9,8 & 625 & 3,1 \\
\hline 101 & 24,2 & 9,1 & 493 & 3,3 \\
\hline 100 & 24,2 & 8,0 & 387 & 3,8 \\
\hline 100 & 24,2 & 6,2 & 244 & 5,0 \\
\hline 100 & 24,2 & 4,3 & 179 & 7,1 \\
\hline 157 & 36,7 & 14,7 & 5.243 & 2,4 \\
\hline 158 & 36,7 & 14,3 & 4.767 & 2,4 \\
\hline 157 & 36,7 & 13,8 & 4.320 & 2,5 \\
\hline 157 & 36,7 & 13,5 & 3.989 & 2,6 \\
\hline 157 & 36,7 & 13,0 & 3.517 & 2,7 \\
\hline 158 & 36,8 & 12,6 & 3.111 & 2,8 \\
\hline 158 & 36,8 & 11,9 & 2.521 & 2,9 \\
\hline 157 & 36,7 & 11,4 & 2.060 & 3,1 \\
\hline 157 & 36,7 & 10,9 & 1.660 & 3,2 \\
\hline 157 & 36,7 & 10,6 & 1.447 & 3,3 \\
\hline 157 & 36,8 & 10,0 & 1.114 & 3,5 \\
\hline 157 & 36,8 & 9,6 & 959 & 3,7 \\
\hline 158 & 36,8 & 9,3 & 827 & 3,8 \\
\hline 157 & 36,8 & 9,1 & 674 & 3,9 \\
\hline 157 & 36,8 & 8,7 & 530 & 4,1 \\
\hline 157 & 36,8 & 7,8 & 405 & 4,6 \\
\hline
\end{tabular}

\begin{tabular}{|c|c|c|c|c|}
\hline $\begin{array}{c}p_{\text {sat }} \\
(\boldsymbol{k P a})\end{array}$ & $\begin{array}{r}T_{\text {sat }} \\
\left({ }^{o} \mathrm{C}\right) \\
\end{array}$ & $\begin{array}{c}\Delta T \\
\left({ }^{o} C\right) \\
\end{array}$ & $\begin{array}{c}\boldsymbol{h} \\
\left(\boldsymbol{k} W / m^{2}\right)\end{array}$ & $\begin{array}{c}\text { incerteza } \\
(\%)\end{array}$ \\
\hline 157 & 36,8 & 5,7 & 257 & 6,4 \\
\hline 157 & 36,6 & 4,2 & 165 & 8,7 \\
\hline 156 & 365 & $15 ?$ & 4974 & 19 \\
\hline 156 & 36.6 & 14.9 & 4.639 & 1.9 \\
\hline 156 & 36,6 & 14,4 & 4.150 & 2,0 \\
\hline 156 & 36,6 & 14,1 & 3.725 & 2,0 \\
\hline 156 & 36,6 & 13,7 & 3.326 & 2,1 \\
\hline 156 & 36,6 & 13,2 & 2.872 & 2,2 \\
\hline 155 & 36,5 & 12,7 & 2.412 & 2,3 \\
\hline 155 & 36,5 & 12,2 & 2.062 & 2,4 \\
\hline 156 & 36,6 & 12,0 & 1.888 & 2,4 \\
\hline 155 & 36,6 & 11,5 & 1.560 & 2,5 \\
\hline 155 & 36,6 & 11,1 & 1.348 & 2,6 \\
\hline 155 & 36,5 & 10,6 & 1.078 & 2,7 \\
\hline 155 & 36,5 & 10,0 & 894 & 2,9 \\
\hline 155 & 36,6 & 9,8 & 797 & 3,0 \\
\hline 155 & 36,5 & 9,2 & 658 & 3,2 \\
\hline 155 & 36,6 & 8,6 & 529 & 3,5 \\
\hline 155 & 36,5 & 7,4 & 402 & 4,1 \\
\hline 155 & 36,5 & 5,3 & 263 & 5,7 \\
\hline 155 & 36,5 & 4,4 & 176 & 7,0 \\
\hline 283 & 56,4 & 12,5 & 5.950 & 2,3 \\
\hline 283 & 56,4 & 12,3 & 5.525 & 2,3 \\
\hline 283 & 56,3 & 12,0 & 5.047 & 2,4 \\
\hline 283 & 56,4 & 11,8 & 4.599 & 2,4 \\
\hline 283 & 56,4 & 11,4 & 4.041 & 2,5 \\
\hline 283 & 56,4 & 10,9 & 3.473 & 2,6 \\
\hline 283 & 56,4 & 10,4 & 2.907 & 2,8 \\
\hline 282 & 56,3 & 9,4 & 2.204 & 3,0 \\
\hline 283 & 56,3 & 9,2 & 1.829 & 3,1 \\
\hline 282 & 56,3 & 8,6 & 1.535 & 3,4 \\
\hline 284 & 56,5 & 8,0 & 1.150 & 3,6 \\
\hline 282 & 56,3 & 7,3 & 951 & 4,0 \\
\hline 282 & 56,3 & 6,8 & 804 & 4,3 \\
\hline 282 & 56,3 & 4,9 & 624 & 6,1 \\
\hline 281 & 56,1 & 3,9 & 491 & 7,6 \\
\hline 412 & 70,1 & 10,9 & 6.971 & 2,6 \\
\hline 413 & 70,2 & 10,7 & 6.425 & 2,7 \\
\hline 412 & 70,1 & 10,4 & 5.794 & 2,7 \\
\hline 412 & 70,1 & 10,2 & 5.245 & 2,8 \\
\hline 411 & 70,0 & 9,8 & 4.544 & 2,9 \\
\hline 410 & 70,0 & 9,4 & 3.847 & 3,0 \\
\hline 411 & 70,1 & 9,0 & 3.350 & 3,2 \\
\hline 411 & 70,1 & 8,7 & 2.958 & 3,3 \\
\hline 411 & 70,1 & 8,5 & 2.674 & 3,4 \\
\hline 410 & 70,0 & 8,1 & 2.213 & 3,5 \\
\hline 411 & 70,1 & 7,8 & 1.921 & 3,7 \\
\hline 411 & 70,1 & 7,4 & 1.550 & 3,9 \\
\hline 410 & 70,0 & 7,0 & 1.306 & 4,1 \\
\hline 409 & 70,0 & 6,8 & 1.121 & 4,3 \\
\hline 410 & 70,0 & 6,5 & 914 & 4,4 \\
\hline 406 & 69,7 & 6,2 & 737 & 4,7 \\
\hline 538 & 80,8 & 9,3 & 8.231 & 3,1 \\
\hline 539 & 80,8 & 9,0 & 7.483 & 3,1 \\
\hline 539 & 80,8 & 8,9 & 6.888 & 3,2 \\
\hline 538 & 80,8 & 8,6 & 6.145 & 3,3 \\
\hline 539 & 80,9 & 8,3 & 5.529 & 3,4 \\
\hline 539 & 80,8 & 8,0 & 4.734 & 3,5 \\
\hline 538 & 80,8 & 7,7 & 3.886 & 3,7 \\
\hline 538 & 80,8 & 7,3 & 3.160 & 3,9 \\
\hline 537 & 80,8 & 6,8 & 2.564 & 4,2 \\
\hline 539 & 80,9 & 6,6 & 2.324 & 4,3 \\
\hline
\end{tabular}




\begin{tabular}{|c|c|c|c|c|}
\hline $\begin{array}{c}p_{\text {sat }} \\
(\boldsymbol{k P a})\end{array}$ & $\begin{array}{l}\boldsymbol{T}_{\text {sat }} \\
\left({ }^{\circ} \boldsymbol{C}\right)\end{array}$ & $\begin{array}{c}\Delta \boldsymbol{\Delta T} \\
\left({ }^{\circ} \mathrm{C}\right)\end{array}$ & $\begin{array}{c}h \\
\left(k W / m^{2}\right)\end{array}$ & $\begin{array}{c}\text { incerteza } \\
(\%)\end{array}$ \\
\hline 537 & 80,7 & 6,3 & 1.884 & 4,6 \\
\hline 542 & 81,1 & 5,9 & 1.555 & 4,9 \\
\hline 542 & 81,1 & 5,7 & 1.367 & 5,1 \\
\hline 542 & 81,1 & 5,4 & 1.153 & 5,3 \\
\hline 541 & 81,1 & 4,9 & 876 & 5,9 \\
\hline 541 & 81,1 & 4,6 & 628 & 6,4 \\
\hline 541 & 81,1 & 3,9 & 439 & 7,5 \\
\hline 541 & 81,1 & 2,6 & 288 & 11,0 \\
\hline 541 & 81,0 & 9,4 & 8.054 & 3,0 \\
\hline 538 & 80,7 & 9,2 & 7.146 & 3,1 \\
\hline 541 & 81,0 & 9,1 & 6.665 & 3,1 \\
\hline 541 & 81,0 & 8,9 & 6.046 & 3,2 \\
\hline 541 & 81,0 & 8,7 & 5.270 & 3,3 \\
\hline 541 & 81,0 & 8,4 & 4.644 & 3,4 \\
\hline 541 & 81,0 & 7,9 & 3.604 & 3,6 \\
\hline 542 & 81,0 & 7,6 & 3.193 & 3,7 \\
\hline 542 & 81,0 & 7,5 & 2.987 & 3,8 \\
\hline 541 & 81,0 & 7,1 & 2.471 & 4,0 \\
\hline 542 & 81,1 & 6,9 & 2.179 & 4,1 \\
\hline 541 & 80,9 & 6,5 & 1.729 & 4,4 \\
\hline 541 & 80,9 & 6,3 & 1.459 & 4,6 \\
\hline 539 & 80,8 & 6,0 & 1.241 & 4,8 \\
\hline
\end{tabular}

\begin{tabular}{|c|c|c|c|c|}
\hline \multicolumn{5}{|c|}{ Superfície de aço inoxidável ; $R a=0,02 \pm 0,01 \mu \mathrm{m}$} \\
\hline 50 & $5,5^{3}$ & 0,7 & 1.130 & 37,9 \\
\hline 49 & 5,5 & 1,6 & 1.113 & 17,5 \\
\hline 49 & 5,4 & 2,7 & 992 & 10,6 \\
\hline 49 & 5,5 & 3,6 & 981 & 8,0 \\
\hline 49 & 5,5 & 15,2 & 293 & 2,1 \\
\hline 49 & 5,6 & 19,5 & 312 & 1,7 \\
\hline 48 & 5,6 & 24,8 & 321 & 1,4 \\
\hline 48 & 5,6 & 27,5 & 317 & 1,3 \\
\hline 49 & 5,6 & 26,6 & 379 & 1,3 \\
\hline 48 & 5,3 & 27,1 & 477 & 1,2 \\
\hline 49 & 5,5 & 39,6 & 1.592 & 1.0 \\
\hline 49 & 5,4 & 37,3 & 1.357 & 1,0 \\
\hline 48 & 5,6 & 35,5 & 1.185 & 1,0 \\
\hline 48 & 5,5 & 34,0 & 1.026 & 1,1 \\
\hline 49 & 5,5 & 32,9 & 1.000 & 1,1 \\
\hline 48 & 5,6 & 31,9 & 916 & 1,2 \\
\hline 48 & 5,6 & 30,9 & 838 & 1,2 \\
\hline 48 & 5,5 & 28,0 & 710 & 1,3 \\
\hline 48 & 5,5 & 26,5 & 631 & 1,4 \\
\hline 48 & 5,6 & 26,2 & 483 & 1,5 \\
\hline 48 & 5,6 & 25,4 & 397 & 1,5 \\
\hline 48 & 5,6 & 23,6 & 351 & 1,7 \\
\hline 48 & 5,5 & 20,4 & 328 & 1,9 \\
\hline 48 & 5,6 & 15,9 & 285 & 2,4 \\
\hline 48 & 5,6 & 7,4 & 244 & 5,0 \\
\hline 48 & 5,6 & 3,9 & 229 & 9,1 \\
\hline & & & & \\
\hline 102 & 24,2 & 35,5 & 1.642 & 1,1 \\
\hline 101 & 24,0 & 32,9 & 1.511 & 1,1 \\
\hline 101 & 24,0 & 31,1 & 1.367 & 1,2 \\
\hline 101 & 24,0 & 28,7 & 1.156 & 1,3 \\
\hline 101 & 24,0 & 28,2 & 899 & 1,3 \\
\hline 101 & 24,0 & 24,0 & 711 & 1,5 \\
\hline 101 & 24,1 & 23,2 & 555 & 1,6 \\
\hline 101 & 24,0 & 23,3 & 442 & 1,6 \\
\hline 101 & 24,0 & 22,1 & 395 & 1,7 \\
\hline 101 & 24,1 & 20,1 & 353 & 1,9 \\
\hline 101 & 24,1 & 16,9 & 296 & 2,3 \\
\hline 101 & 24,0 & 13,0 & 250 & 2,9 \\
\hline 101 & 24,0 & 8,0 & 205 & 4,7 \\
\hline
\end{tabular}

\begin{tabular}{|c|c|c|c|c|}
\hline $\begin{array}{c}p_{\text {sat }} \\
(\boldsymbol{k P a})\end{array}$ & $\begin{array}{c}\boldsymbol{T}_{\text {sat }} \\
\left({ }^{\circ} \mathrm{C}\right)\end{array}$ & $\begin{array}{c}\Delta \boldsymbol{T} \\
\left({ }^{o} \mathrm{C}\right)\end{array}$ & $\begin{array}{c}h \\
\left(k W / m^{2}\right)\end{array}$ & $\begin{array}{c}\text { incerteza } \\
(\%)\end{array}$ \\
\hline 102 & 24,1 & 4,7 & 179 & 7,7 \\
\hline 282 & 56,2 & 25,6 & 2.309 & 1,4 \\
\hline 283 & 56,3 & 25,2 & 1.958 & 1,4 \\
\hline 282 & 56,3 & 23,5 & 1.818 & 1,5 \\
\hline 283 & 56,3 & 21,5 & 1.558 & 1,7 \\
\hline 282 & 56,3 & 18,8 & 1.327 & 1,9 \\
\hline 281 & 56,2 & 17,8 & 1.201 & 2,0 \\
\hline 281 & 56,2 & 16,5 & 1.044 & 2,2 \\
\hline 282 & 56,2 & 15,2 & 789 & 2,4 \\
\hline 282 & 56,2 & 14,9 & 711 & 2,4 \\
\hline 282 & 56,3 & 14,4 & 586 & 2,5 \\
\hline 282 & 56,3 & 13,7 & 495 & 2,7 \\
\hline 282 & 56,2 & 12,5 & 402 & 2,9 \\
\hline 281 & 56,2 & 11,1 & 313 & 3,4 \\
\hline 281 & 56,1 & 10,2 & 257 & 3,7 \\
\hline 281 & 56,0 & 8,3 & 206 & 4,5 \\
\hline 408 & 69,8 & 24,4 & 2.431 & 1,5 \\
\hline 409 & 70,0 & 23,0 & 2.196 & 1,5 \\
\hline 408 & 69,9 & 21,3 & 1.979 & 1,7 \\
\hline 408 & 69,9 & 19,4 & 1.716 & 1,8 \\
\hline 408 & 69,9 & 16,8 & 1.481 & 2,1 \\
\hline 408 & 69,9 & 14,5 & 1.200 & 2,4 \\
\hline 409 & 70,0 & 13,2 & 990 & 2,7 \\
\hline 409 & 70,0 & 12,1 & 829 & 2,9 \\
\hline 409 & 70,0 & 11,7 & 721 & 3,1 \\
\hline 408 & 69,9 & 11,3 & 614 & 3,2 \\
\hline 408 & 69,9 & 10,6 & 480 & 3,4 \\
\hline 407 & 69,8 & 9,3 & 352 & 3,9 \\
\hline 541 & 80,9 & 22,2 & 2.720 & 1,6 \\
\hline 541 & 80,9 & 21,1 & 2.433 & 1,7 \\
\hline 542 & 81,1 & 19,6 & 2.114 & 1,8 \\
\hline 542 & 81,1 & 18,4 & 1.926 & 1,9 \\
\hline 541 & 81,0 & 17,6 & 1.865 & 2,0 \\
\hline 541 & 80,9 & 16,7 & 1.698 & 2,1 \\
\hline 543 & 81,1 & 15,7 & 1.607 & 2,3 \\
\hline 542 & 81,0 & 14,3 & 1.425 & 2,5 \\
\hline 543 & 81,1 & 13,3 & 1.270 & 2,7 \\
\hline 544 & 81,1 & 11,8 & 1.092 & 3,0 \\
\hline 543 & 81,1 & 10,6 & 958 & 3,3 \\
\hline 543 & 81,0 & 9,9 & 866 & 3,6 \\
\hline 542 & 81,0 & 9,1 & 751 & 3,9 \\
\hline 540 & 80,9 & 8,4 & 555 & 4,3 \\
\hline 537 & 80,8 & 6,6 & 274 & 5,5 \\
\hline
\end{tabular}

Superfície de aço inoxidável ; $R a=0,16 \pm 0,04 \mu \mathrm{m}$

\begin{tabular}{|c|c|c|c|c|}
\hline 48 & 5,1 & 4,6 & 193 & 5,0 \\
\hline 48 & 5,2 & 8,1 & 215 & 3,0 \\
\hline 48 & 5,3 & 13,4 & 246 & 1,9 \\
\hline 48 & 5,5 & 18,1 & 278 & 1,5 \\
\hline 48 & 5,7 & 24,3 & 292 & 1,2 \\
\hline 48 & 5,4 & 20,2 & 430 & 1,3 \\
\hline 48 & 5,4 & 22,3 & 780 & 1,0 \\
\hline 49 & 5,5 & 20,0 & 1.221 & 1,1 \\
\hline 49 & 5,6 & 23,2 & 1.458 & 1,5 \\
\hline 50 & 5,8 & 25,4 & 1.629 & 1,4 \\
\hline 50 & 5,7 & 27,5 & 1.811 & 1,3 \\
\hline 49 & 5,7 & 29,4 & 2.001 & 1,2 \\
\hline 49 & 5,6 & 27,8 & 1.817 & 1,3 \\
\hline 49 & 5,7 & 25,8 & 1.630 & 1,4 \\
\hline 49 & 5,6 & 23,6 & 1.450 & 1,5 \\
\hline 49 & 5,4 & 21,8 & 1.300 & 1,6 \\
\hline 49 & 5,5 & 20,9 & 1.196 & 1,7 \\
\hline 49 & 5,5 & 18,4 & 1.063 & 2,0 \\
\hline
\end{tabular}




\begin{tabular}{|c|c|c|c|c|}
\hline $\begin{array}{c}p_{\text {sat }} \\
(\boldsymbol{k P a})\end{array}$ & $\begin{array}{c}T_{\text {sat }} \\
\left({ }^{o} \mathrm{C}\right)\end{array}$ & $\begin{array}{c}\Delta T \\
\left({ }^{o} C\right)\end{array}$ & $\begin{array}{c}h \\
\left(k W / m^{2}\right)\end{array}$ & $\begin{array}{c}\text { incerteza } \\
(\%)\end{array}$ \\
\hline 49 & 5,5 & 17,6 & 977 & 2,0 \\
\hline 49 & 5,6 & 16,9 & 755 & 2,1 \\
\hline 49 & 5,6 & 16,3 & 535 & 2,3 \\
\hline 49 & 5,7 & 16,0 & 427 & 2,3 \\
\hline 48 & 5,7 & 14,1 & 353 & 2,7 \\
\hline 48 & 5,7 & 11,4 & 286 & 3,3 \\
\hline 48 & 5,7 & 7,0 & 235 & 5,3 \\
\hline 48 & 5,6 & 4,2 & 214 & 8,6 \\
\hline 102 & 24,2 & 25,8 & 2.351 & 1,2 \\
\hline 102 & 24,1 & 24,1 & 2.089 & 1,2 \\
\hline 101 & 24,1 & 22,5 & 1.894 & 1,3 \\
\hline 101 & 24,0 & 20,2 & 1.622 & 1,5 \\
\hline 101 & 24,0 & 18,8 & 1.470 & 1,6 \\
\hline 101 & 24,1 & 18,0 & 1.393 & 1,6 \\
\hline 101 & 24,1 & 16,5 & 1.237 & 1,8 \\
\hline 101 & 24,0 & 15,6 & 1.087 & 1,9 \\
\hline 101 & 24,0 & 14,4 & 892 & 2,1 \\
\hline 101 & 24,0 & 13,3 & 768 & 2,2 \\
\hline 101 & 24,0 & 12,8 & 684 & 2,3 \\
\hline 101 & 24,1 & 12,5 & 535 & 2,4 \\
\hline 101 & 24,1 & 11,6 & 444 & 2,6 \\
\hline 101 & 24,1 & 10,8 & 283 & 2,9 \\
\hline 101 & 24,1 & 7,6 & 224 & 4,1 \\
\hline 101 & 24,0 & 4,2 & 173 & 7,2 \\
\hline 156 & 36,7 & 23,4 & 2.487 & 1,6 \\
\hline 156 & 36,6 & 22,0 & 2.289 & 1,6 \\
\hline 156 & 36,8 & 20,2 & 2.013 & 1,7 \\
\hline 156 & 36,8 & 18,6 & 1.809 & 1,9 \\
\hline 155 & 36,6 & 17,8 & 1.720 & 2,0 \\
\hline 156 & 36,7 & 16,3 & 1.532 & 2,2 \\
\hline 156 & 36,8 & 15,0 & 1.371 & 2,4 \\
\hline 156 & 36,7 & 13,9 & 1.254 & 2,5 \\
\hline 155 & 36,6 & 12,6 & 992 & 2,8 \\
\hline 156 & 36,7 & 11,6 & 761 & 3,1 \\
\hline 156 & 36,7 & 10,9 & 613 & 3,3 \\
\hline 156 & 36,7 & 10,2 & 485 & 3,5 \\
\hline 155 & 36,7 & 8,9 & 377 & 4,1 \\
\hline 155 & 36,6 & 7,4 & 226 & 5,0 \\
\hline 155 & 36,6 & 5,5 & 162 & 6,8 \\
\hline 283 & 56,4 & 20,4 & 2.882 & 1,8 \\
\hline 283 & 56,4 & 19,2 & 2.617 & 1,8 \\
\hline 283 & 56,3 & 17,9 & 2.347 & 2,0 \\
\hline 282 & 56,2 & 16,1 & 2.065 & 2,2 \\
\hline 283 & 56,4 & 14,2 & 1.770 & 2,5 \\
\hline 282 & 56,3 & 12,0 & 1.392 & 2,9 \\
\hline 282 & 56,3 & 10,7 & 1.191 & 3,3 \\
\hline 283 & 56,4 & 9,9 & 1.045 & 3,6 \\
\hline 282 & 56,3 & 9,4 & 903 & 3,8 \\
\hline 282 & 56,3 & 9,0 & 743 & 3,9 \\
\hline 283 & 56,4 & 8,5 & 603 & 4,2 \\
\hline 282 & 56,3 & 7,4 & 448 & 4,9 \\
\hline 282 & 56,3 & 6,8 & 369 & 5,3 \\
\hline 282 & 56,2 & 6,0 & 281 & 6,0 \\
\hline 410 & 70,1 & 17,4 & 3.405 & 2,0 \\
\hline 412 & 70,2 & 16,4 & 3.073 & 2,1 \\
\hline 412 & 70,2 & 15,0 & 2.771 & 2,3 \\
\hline 411 & 70,1 & 13,6 & 2.494 & 2,6 \\
\hline 410 & 70,1 & 12,4 & 2.270 & 2,8 \\
\hline 410 & 70,0 & 11,5 & 2.159 & 3,0 \\
\hline 410 & 70,0 & 10,3 & 1.931 & 3,4 \\
\hline 412 & 70,2 & 9,4 & 1.745 & 3,7 \\
\hline 412 & 70,2 & 8,3 & 1.499 & 4,2 \\
\hline
\end{tabular}

\begin{tabular}{|c|c|c|c|c|}
\hline $\begin{array}{c}p_{\text {sat }} \\
(\boldsymbol{k P a})\end{array}$ & $\begin{array}{l}T_{\text {sat }} \\
\left({ }^{o} \boldsymbol{C}\right)\end{array}$ & $\begin{array}{c}\Delta T \\
\left({ }^{o} C\right)\end{array}$ & $\begin{array}{c}h \\
\left(k W / m^{2}\right)\end{array}$ & $\begin{array}{c}\text { incerteza } \\
(\%)\end{array}$ \\
\hline 412 & 70,2 & 7,7 & 1.339 & 4,6 \\
\hline 411 & 70,1 & 7,1 & 1.197 & 4,9 \\
\hline 411 & 70,1 & 6,7 & 1.050 & 5,3 \\
\hline 411 & 70,1 & 6,1 & 811 & 5,8 \\
\hline 410 & 70,1 & 5,6 & 586 & 6,3 \\
\hline 529 & 80.0 & 16.9 & 3.541 & 2,1 \\
\hline 530 & 80,1 & 15,9 & 3.157 & 2,2 \\
\hline 529 & 80,0 & 14,8 & 2.869 & 2,4 \\
\hline 529 & 80,0 & 13,3 & 2.544 & 2,6 \\
\hline 530 & 80,1 & 11,5 & 2.158 & 3,0 \\
\hline 530 & 80,1 & 9,5 & 1.788 & 3,7 \\
\hline 529 & 80,1 & 8,2 & 1.510 & 4,3 \\
\hline 530 & 80,1 & 7,6 & 1.356 & 4,6 \\
\hline 529 & 80,0 & 6,9 & 1.225 & 5,1 \\
\hline 525 & 79,7 & 6,3 & 1.079 & 5,6 \\
\hline 524 & 79,6 & 5,9 & 839 & 6,0 \\
\hline
\end{tabular}




\section{ii. Resultados para o $R-123$}

\begin{tabular}{|c|c|c|c|c|}
\hline $\begin{array}{c}p_{\text {sat }} \\
(\boldsymbol{k P a})\end{array}$ & $\begin{array}{l}T_{\text {sat }} \\
\left({ }^{o} \mathrm{C}\right)\end{array}$ & $\begin{array}{c}\Delta T \\
\left({ }^{o} C\right)\end{array}$ & $\begin{array}{c}\boldsymbol{h} \\
\left(\boldsymbol{k} W / \boldsymbol{m}^{2}\right)\end{array}$ & $\begin{array}{c}\text { incerteza } \\
(\%)\end{array}$ \\
\hline \multicolumn{5}{|c|}{ Superfície de cobre ; Ra $=0,16 \pm 0,04 \mu \mathrm{m}$} \\
\hline 40 & 5,5 & 3,9 & 190 & 7,7 \\
\hline 40 & 5,6 & 7,7 & 211 & 4,1 \\
\hline 40 & 5,6 & 14,1 & 233 & 2,4 \\
\hline 40 & 5,7 & 20,3 & 250 & 1,7 \\
\hline 40 & 5,7 & 25,7 & 261 & 1,4 \\
\hline 40 & 5,4 & 16,3 & 499 & 2,3 \\
\hline 40 & 5,5 & 17,7 & 981 & 2,0 \\
\hline 41 & 5,5 & 19,7 & 1.686 & 1,8 \\
\hline 40 & 5,4 & 21,3 & 2.346 & 1,7 \\
\hline 41 & 5,5 & 22,4 & 2.873 & 1,6 \\
\hline 40 & 5,4 & 23,7 & 3.448 & 1,5 \\
\hline 40 & 5,4 & 25,2 & 3.900 & 1,4 \\
\hline 41 & 5,6 & 27,1 & 4.221 & 1,3 \\
\hline 41 & 5,5 & 25,2 & 3.896 & 1,4 \\
\hline 41 & 5,4 & 23,8 & 3.420 & 1,5 \\
\hline 41 & 5,5 & 22,6 & 2.880 & 1,6 \\
\hline 41 & 5,5 & 21,5 & 2.275 & 1,6 \\
\hline 41 & 5,5 & 20,2 & 1.606 & 1,8 \\
\hline 41 & 5,5 & 19,8 & 1.372 & 1,8 \\
\hline 40 & 5,4 & 19,6 & 1.232 & 1,8 \\
\hline 40 & 5,3 & 19,5 & 980 & 1,9 \\
\hline 40 & 5,4 & 18,9 & 860 & 1,9 \\
\hline 40 & 5,4 & 18,4 & 688 & 2,0 \\
\hline 40 & 5,4 & 18,2 & 550 & 2,0 \\
\hline 40 & 5,4 & 17,8 & 467 & 2,1 \\
\hline 40 & 5,4 & 17,2 & 391 & 2,2 \\
\hline 40 & 5,3 & 15,9 & 308 & 2,4 \\
\hline 40 & 5,3 & 13,3 & 251 & 2,9 \\
\hline 40 & 5,4 & 8,1 & 205 & 4,6 \\
\hline 40 & 5,4 & 4,7 & 182 & 7,8 \\
\hline 85 & 23,1 & 5,0 & 175 & 6,2 \\
\hline 85 & 23,1 & 8,6 & 197 & 3,7 \\
\hline 85 & 23,1 & 13,5 & 250 & 2,4 \\
\hline 85 & 23,1 & 20,7 & 242 & 1,7 \\
\hline 85 & 23,3 & 25,1 & 265 & 1,4 \\
\hline 84 & 23,1 & 12,8 & 637 & 2,8 \\
\hline 84 & 23,0 & 14,4 & 1.132 & 2,5 \\
\hline 84 & 23,0 & 16,6 & 1.975 & 2,1 \\
\hline 84 & 23,0 & 18,0 & 2.728 & 2,0 \\
\hline 85 & 23,2 & 18,9 & 3.406 & 1,9 \\
\hline 84 & 23,1 & 20,1 & 4.151 & 1,7 \\
\hline
\end{tabular}

\begin{tabular}{|c|c|c|c|c|}
\hline $\begin{array}{c}p_{\text {sat }} \\
(\boldsymbol{k P a})\end{array}$ & $\begin{array}{c}T_{\text {sat }} \\
\left({ }^{o} C\right)\end{array}$ & $\begin{array}{c}\Delta T \\
\left({ }^{o} C\right)\end{array}$ & $\begin{array}{c}\boldsymbol{h} \\
\left(\boldsymbol{k} W / \boldsymbol{m}^{2}\right)\end{array}$ & $\begin{array}{c}\text { incerteza } \\
(\%)\end{array}$ \\
\hline 84 & 23,0 & 20,9 & 4.716 & 1,7 \\
\hline 85 & 23,2 & 22,0 & 5.195 & 1,6 \\
\hline 84 & 23,1 & 21,1 & 4.656 & 1,7 \\
\hline 85 & 23,1 & 20,0 & 4.084 & 1,8 \\
\hline 84 & 23,0 & 18,8 & 3.390 & 1,9 \\
\hline 84 & 22,9 & 17,8 & 2.675 & 2,0 \\
\hline 84 & 22,8 & 16,6 & 1.985 & 2,1 \\
\hline 84 & 22,9 & 16,0 & 1.679 & 2,2 \\
\hline 84 & 22,9 & 15,8 & 1.594 & 2,2 \\
\hline 84 & 22,9 & 15,2 & 1.273 & 2,3 \\
\hline 84 & 23,0 & 14,8 & 1.109 & 2,4 \\
\hline 84 & 23,0 & 14,6 & 823 & 2,5 \\
\hline 84 & 23,1 & 13,7 & 599 & 2,7 \\
\hline 84 & 23,0 & 13,2 & 521 & 2,8 \\
\hline 84 & 23,0 & 11,2 & 283 & 3,3 \\
\hline 84 & 22,9 & 7,9 & 202 & 4,8 \\
\hline 84 & 22,9 & 4,7 & 173 & 7,7 \\
\hline 129 & 34,9 & 19,5 & 5.820 & 1,8 \\
\hline 128 & 34,8 & 18,7 & 5.234 & 1,9 \\
\hline 128 & 34,7 & 17,8 & 4.576 & 2,0 \\
\hline 128 & 34,7 & 16,9 & 3.885 & 2,1 \\
\hline 128 & 34,8 & 15,9 & 3.069 & 2,2 \\
\hline 128 & 34,7 & 14,5 & 2.264 & 2,4 \\
\hline 127 & 34,7 & 13,8 & 1.919 & 2,5 \\
\hline 128 & 34,7 & 13,5 & 1.800 & 2,6 \\
\hline 128 & 34,7 & 12,8 & 1.504 & 2,8 \\
\hline 128 & 34,7 & 12,4 & 1.342 & 2,9 \\
\hline 127 & 34,6 & 11,5 & 1.031 & 3,1 \\
\hline 127 & 34,6 & 11,1 & 885 & 3,2 \\
\hline 127 & 34,6 & 10,8 & 770 & 3,3 \\
\hline 127 & 34,6 & 10,4 & 626 & 3,4 \\
\hline 127 & 34,6 & 9,8 & 496 & 3,7 \\
\hline 127 & 34,6 & 9,1 & 357 & 4,0 \\
\hline 127 & 34,6 & 7,6 & 214 & 4,9 \\
\hline 127 & 34,5 & 5,0 & 164 & 7,4 \\
\hline 233 & 53,1 & 16,6 & 6.832 & 2,1 \\
\hline 234 & 53,3 & 15,9 & 6.080 & 2,2 \\
\hline 233 & 53,2 & 15,3 & 5.329 & 2,3 \\
\hline 233 & 53,1 & 14,6 & 4.508 & 2,4 \\
\hline 232 & 53,1 & 13,5 & 3.658 & 2,6 \\
\hline 232 & 53,1 & 12,9 & 3.235 & 2,7 \\
\hline
\end{tabular}




\begin{tabular}{|c|c|c|c|c|}
\hline $\begin{array}{c}p_{\text {sat }} \\
(\boldsymbol{k P a})\end{array}$ & $\begin{array}{c}T_{\text {sat }} \\
\left({ }^{o} \mathrm{C}\right)\end{array}$ & $\begin{array}{c}\Delta T \\
\left({ }^{o} C\right)\end{array}$ & $\begin{array}{c}h \\
\left(k W / m^{2}\right)\end{array}$ & $\begin{array}{c}\text { incerteza } \\
(\%)\end{array}$ \\
\hline 233 & 53,2 & 12,0 & 2.688 & 2,9 \\
\hline 233 & 53,2 & 11,0 & 2.262 & 3,2 \\
\hline 233 & 53,2 & 10,4 & 1.849 & 3,4 \\
\hline 233 & 53,2 & 10,0 & 1.643 & 3,5 \\
\hline 232 & 53,1 & 9,2 & 1.330 & 3,8 \\
\hline 232 & 53,2 & 8,9 & 1.124 & 4,0 \\
\hline 233 & 53,2 & 8,6 & 962 & 4,1 \\
\hline 233 & 53,2 & 8,2 & 796 & 4,3 \\
\hline 233 & 53,2 & 7,8 & 627 & 4,5 \\
\hline 232 & 53,1 & 7,2 & 432 & 5,0 \\
\hline 233 & 53,1 & 6,4 & 246 & 5,7 \\
\hline 233 & 53,0 & 4,3 & 145 & 8,5 \\
\hline 337 & 65,8 & 14,5 & 7.889 & 2,4 \\
\hline 336 & 65,8 & 13,7 & 10.860 & 2,5 \\
\hline 337 & 65,9 & 13,3 & 6.170 & 2,6 \\
\hline 337 & 65,9 & 12,7 & 5.171 & 2,7 \\
\hline 336 & 65,8 & 11,9 & 4.120 & 2,9 \\
\hline 336 & 65,8 & 10,8 & 3.006 & 3,2 \\
\hline 336 & 65,8 & 10,3 & 2.657 & 3,4 \\
\hline 336 & 65,8 & 9,9 & 2.450 & 3,5 \\
\hline 336 & 65,8 & 9,4 & 2.016 & 3,7 \\
\hline 336 & 65,8 & 9,1 & 1.795 & 3,9 \\
\hline 336 & 65,9 & 8,7 & 1.445 & 4,0 \\
\hline 336 & 65,9 & 8,1 & 1.174 & 4,4 \\
\hline 335 & 65,8 & 7,9 & 1.086 & 4,4 \\
\hline 335 & 65,7 & 7,4 & 892 & 4,8 \\
\hline 333 & 65,6 & 7,0 & 713 & 5,1 \\
\hline 332 & 65,4 & 6,9 & 627 & 5,2 \\
\hline 443 & 76,1 & 12,9 & 8.838 & 2,7 \\
\hline 442 & 76,0 & 12,4 & 7.856 & 2,8 \\
\hline 442 & 76,0 & 11,7 & 6.721 & 3,0 \\
\hline 442 & 76,0 & 11,2 & 5.949 & 3,1 \\
\hline 443 & 76,1 & 10,5 & 4.646 & 3,3 \\
\hline 441 & 76,0 & 9,6 & 3.379 & 3,6 \\
\hline 441 & 75,9 & 9,3 & 2.922 & 3,8 \\
\hline 441 & 75,9 & 9,1 & 2.704 & 3,8 \\
\hline 443 & 76,0 & 8,6 & 2.207 & 4,1 \\
\hline 442 & 76,1 & 8,2 & 2.005 & 4,2 \\
\hline 441 & 75,9 & 7,8 & 1.590 & 4,5 \\
\hline 443 & 76,0 & 7,1 & 1.324 & 4,9 \\
\hline 439 & 75,8 & 6,9 & 1.165 & 5,1 \\
\hline 438 & 75,7 & 6,6 & 966 & 5,4 \\
\hline \multicolumn{5}{|c|}{ Superfície de cobre; $R a=0,47 \pm 0,04 \mu \mathrm{m}$} \\
\hline 40 & 5,7 & 4,3 & 189 & 7,0 \\
\hline 40 & 5,7 & 7,9 & 208 & 4,0 \\
\hline 40 & 5,7 & 14,0 & 234 & 2,4 \\
\hline 40 & 5,8 & 18,9 & 253 & 1,8 \\
\hline 40 & 5,8 & 24,5 & 266 & 1,5 \\
\hline 40 & 5,8 & 29,7 & 277 & 1,2 \\
\hline 41 & 5,5 & 14,7 & 663 & 2,5 \\
\hline 41 & 5,6 & 15,6 & 1.054 & 2,3 \\
\hline 41 & 5,6 & 17,6 & 1.911 & 2,0 \\
\hline 41 & 5,7 & 18,9 & 2.622 & 1,9 \\
\hline 41 & 5,6 & 19,7 & 3.227 & 1,8 \\
\hline 41 & 5,6 & 20,7 & 3.999 & 1,7 \\
\hline 41 & 5,7 & 21,5 & 4.589 & 1,6 \\
\hline 41 & 5,8 & 22,6 & 4.995 & 1,6 \\
\hline 41 & 5,6 & 21,5 & 4.501 & 1,6 \\
\hline 41 & 5,6 & 20,7 & 4.018 & 1,7 \\
\hline 41 & 5,6 & 19,8 & 3.210 & 1,8 \\
\hline 41 & 5,8 & 19,1 & 2.608 & 1,8 \\
\hline 41 & 5,7 & 18,4 & 2.233 & 1,9 \\
\hline 41 & 5,6 & 17,8 & 1.843 & 2,0 \\
\hline
\end{tabular}

\begin{tabular}{|c|c|c|c|c|}
\hline $\begin{array}{c}p_{\text {sat }} \\
(\boldsymbol{k P a})\end{array}$ & $\begin{array}{c}T_{\text {sat }} \\
\left({ }^{o} C\right)\end{array}$ & $\begin{array}{c}\Delta T \\
\left({ }^{o} C\right) \\
\end{array}$ & $\begin{array}{c}h \\
\left(k W / m^{2}\right)\end{array}$ & $\begin{array}{c}\text { incerteza } \\
(\%)\end{array}$ \\
\hline 41 & 5,6 & 17,3 & 1.580 & 2,0 \\
\hline 41 & 5,6 & 17,0 & 1.422 & 2,1 \\
\hline 40 & 5,5 & 16,4 & 1.180 & 2,2 \\
\hline 41 & 5,6 & 15,9 & 961 & 2,3 \\
\hline 41 & 5,6 & 15,7 & 765 & 2,3 \\
\hline 41 & 5,6 & 15,4 & 645 & 2,4 \\
\hline 41 & 5,6 & 15,4 & 532 & 2,4 \\
\hline 41 & 5,5 & 15,0 & 459 & 2,5 \\
\hline 41 & 5,5 & 14,3 & 347 & 2,6 \\
\hline 41 & 5,5 & 11,1 & 281 & 3,4 \\
\hline 41 & 5,5 & 7,2 & 232 & 5,2 \\
\hline 40 & 5,5 & 4,5 & 177 & 8,1 \\
\hline 85 & 22,9 & 5,0 & 166 & 6,2 \\
\hline 86 & 22,9 & 8,4 & 193 & 3,8 \\
\hline 86 & 22,9 & 14,5 & 222 & 2,3 \\
\hline 86 & 22,9 & 20,9 & 238 & 1,7 \\
\hline 84 & 22,9 & 11,7 & 556 & 3,1 \\
\hline 84 & 22,8 & 13,1 & 1.261 & 2,7 \\
\hline 84 & 23,0 & 14,6 & 2.252 & 2,4 \\
\hline 84 & 23,0 & 15,7 & 3.121 & 2,2 \\
\hline 85 & 23,1 & 16,6 & 3.970 & 2,1 \\
\hline 85 & 23,1 & 17,2 & 4.670 & 2,0 \\
\hline 84 & 23,0 & 18,0 & 5.402 & 1,9 \\
\hline 84 & 23,0 & 18,8 & 6.144 & 1,9 \\
\hline 84 & 22,9 & 17,9 & 5.317 & 1,9 \\
\hline 84 & 22,9 & 17,3 & 4.686 & 2,0 \\
\hline 84 & 22,9 & 16,5 & 3.856 & 2,1 \\
\hline 84 & 22,9 & 15,8 & 3.129 & 2,2 \\
\hline 84 & 23,0 & 15,2 & 2.587 & 2,3 \\
\hline 84 & 22,9 & 14,8 & 2.211 & 2,4 \\
\hline 84 & 22,9 & 14,0 & 1.716 & 2,5 \\
\hline 84 & 22,9 & 13,6 & 1.423 & 2,6 \\
\hline 84 & 22,8 & 13,3 & 1.247 & 2,7 \\
\hline 84 & 22,9 & 12,9 & 960 & 2,8 \\
\hline 84 & 22,9 & 12,6 & 816 & 2,8 \\
\hline 84 & 22,9 & 12,3 & 679 & 2,9 \\
\hline 83 & 22,8 & 12,0 & 544 & 3,0 \\
\hline 84 & 22,9 & 11,6 & 419 & 3,2 \\
\hline 83 & 22,9 & 10,8 & 310 & 3,4 \\
\hline 83 & 22,9 & 7,3 & 214 & 5,1 \\
\hline 83 & 22,8 & 4,9 & 177 & 7,5 \\
\hline 128 & 34,7 & 16,4 & 6.966 & 2,2 \\
\hline 128 & 34,8 & 15,8 & 6.152 & 2,2 \\
\hline 128 & 34,7 & 15,2 & 5.296 & 2,3 \\
\hline 128 & 34,8 & 14,5 & 4.554 & 2,4 \\
\hline 128 & 34,7 & 13,7 & 3.566 & 2,6 \\
\hline 128 & 34,8 & 13,2 & 3.137 & 2,7 \\
\hline 128 & 34,7 & 12,6 & 2.567 & 2,8 \\
\hline 128 & 34,7 & 11,9 & 2.076 & 3,0 \\
\hline 127 & 34,6 & 11,3 & 1.703 & 3,1 \\
\hline 127 & 34,6 & 11,0 & 1.487 & 3,2 \\
\hline 127 & 34,6 & 10,5 & 1.132 & 3,4 \\
\hline 128 & 34,7 & 10,2 & 969 & 3,5 \\
\hline 128 & 34,7 & 9,8 & 821 & 3,6 \\
\hline 127 & 34,7 & 9,7 & 688 & 3,7 \\
\hline 127 & 34,6 & 9,5 & 530 & 3,8 \\
\hline 127 & 34,6 & 9,1 & 375 & 4,0 \\
\hline 128 & 34,6 & 7,3 & 250 & 5,0 \\
\hline 128 & 34,6 & 5,2 & 181 & 7,1 \\
\hline 232 & 52,9 & 13,6 & 8.259 & 2,6 \\
\hline 233 & 52,9 & 12,6 & 7.610 & 2,8 \\
\hline 233 & 52,9 & 12,1 & 6.723 & 2,9 \\
\hline 232 & 52,8 & 11,3 & 5.701 & 3,1 \\
\hline
\end{tabular}




\begin{tabular}{|c|c|c|c|c|}
\hline $\begin{array}{c}p_{\text {sat }} \\
(\boldsymbol{k P a})\end{array}$ & $\begin{array}{c}T_{\text {sat }} \\
\left({ }^{o} \mathrm{C}\right)\end{array}$ & $\begin{array}{c}\Delta T \\
\left({ }^{o} C\right)\end{array}$ & $\begin{array}{c}h \\
\left(k W / m^{2}\right)\end{array}$ & $\begin{array}{c}\text { incerteza } \\
(\%)\end{array}$ \\
\hline 233 & 53,1 & 10,5 & 4.719 & 3,3 \\
\hline 233 & 53,0 & 9,9 & 4.104 & 3,5 \\
\hline 232 & 53,0 & 9,4 & 3.410 & 3,7 \\
\hline 231 & 52,8 & 8,6 & 2.803 & 4,0 \\
\hline 233 & 53,1 & 7,8 & 2.153 & 4,5 \\
\hline 232 & 53,0 & 7,2 & 1.497 & 4,8 \\
\hline 232 & 52,9 & 6,9 & 1.403 & 5,0 \\
\hline 232 & 52,9 & 6,7 & 1.201 & 5,2 \\
\hline 232 & 52,9 & 6,5 & 1.004 & 5,4 \\
\hline 231 & 52,8 & 6,2 & 759 & 5,7 \\
\hline 228 & 52,5 & 5,8 & 526 & 6,1 \\
\hline 231 & 52,9 & 13,8 & 8.253 & 2,6 \\
\hline 233 & 53,1 & 13,1 & 7.415 & 2,6 \\
\hline 231 & 53,0 & 12,6 & 6.468 & 2,8 \\
\hline 232 & 53,1 & 11,9 & 5.508 & 2,9 \\
\hline 231 & 53,0 & 11,1 & 4.447 & 3,1 \\
\hline 231 & 52,9 & 10,5 & 3.877 & 3,3 \\
\hline 232 & 53,1 & 10,0 & 3.311 & 3,5 \\
\hline 231 & 53,0 & 9,2 & 2.647 & 3,8 \\
\hline 231 & 53,0 & 8,3 & 1.960 & 4,2 \\
\hline 231 & 53,0 & 7,7 & 1.500 & 4,6 \\
\hline 231 & 52,9 & 7,4 & 1.333 & 4,7 \\
\hline 231 & 53,0 & 7,2 & 1.188 & 4,9 \\
\hline 231 & 53,0 & 7,0 & 917 & 5,0 \\
\hline 231 & 53,0 & 6,7 & 715 & 5,2 \\
\hline 231 & 53,0 & 6,5 & 486 & 5,5 \\
\hline 230 & 52,9 & 5,8 & 282 & 6,2 \\
\hline 338 & 65,8 & 11,8 & 9.571 & 3,0 \\
\hline 338 & 65,9 & 11,3 & 8.677 & 3,1 \\
\hline 337 & 65,7 & 10,7 & 7.712 & 3,3 \\
\hline 336 & 65,7 & 10,1 & 6.471 & 3,4 \\
\hline 335 & 65,7 & 9,4 & 5.257 & 3,7 \\
\hline 336 & 65,7 & 8,9 & 4.623 & 3,9 \\
\hline 337 & 65,9 & 8,3 & 3.908 & 4,2 \\
\hline 337 & 65,8 & 7,9 & 3.428 & 4,4 \\
\hline 337 & 65,8 & 7,7 & 3.204 & 4,5 \\
\hline 336 & 65,7 & 7,2 & 2.651 & 4,9 \\
\hline 337 & 65,8 & 6,9 & 2.403 & 5,1 \\
\hline 337 & 65,8 & 6,4 & 1.928 & 5,5 \\
\hline 338 & 65,9 & 6,1 & 1.650 & 5,7 \\
\hline 337 & 65,8 & 5,9 & 1.402 & 5,9 \\
\hline 336 & 65,7 & 5,6 & 1.182 & 6,2 \\
\hline 334 & 65,6 & 5,3 & 957 & 6,6 \\
\hline 444 & 76,0 & 10,9 & 10.518 & 3,2 \\
\hline 444 & 76,0 & 10,3 & 9.429 & 3,4 \\
\hline 443 & 75,9 & 9,9 & 8.433 & 3,5 \\
\hline 444 & 76,0 & 9,2 & 7.073 & 3,8 \\
\hline 442 & 75,9 & 8,5 & 5.616 & 4,1 \\
\hline 442 & 75,9 & 8,1 & 5.006 & 4,3 \\
\hline 442 & 75,9 & 7,6 & 4.246 & 4,6 \\
\hline 443 & 75,9 & 7,0 & 3.396 & 5,0 \\
\hline 443 & 75,9 & 6,6 & 2.974 & 5,3 \\
\hline 444 & 76,0 & 6,3 & 2.617 & 5,5 \\
\hline 444 & 76,0 & 5,9 & 2.072 & 5,9 \\
\hline 442 & 75,9 & 5,5 & 1.774 & 6,3 \\
\hline 440 & 75,7 & 5,4 & 1.555 & 6,5 \\
\hline \multicolumn{5}{|c|}{ Superfície de cobre ; Ra=3,3 $\pm 0,3 \mu \mathrm{m}$} \\
\hline 40 & 5,2 & 4,2 & 194 & 7,2 \\
\hline 40 & 5,3 & 7,4 & 218 & 4,2 \\
\hline 40 & 5,4 & 14,2 & 238 & 2,3 \\
\hline 40 & 5,3 & 7,2 & 678 & 5,0 \\
\hline 41 & 5,3 & 7,5 & 865 & 4,7 \\
\hline
\end{tabular}

\begin{tabular}{|c|c|c|c|c|}
\hline $\begin{array}{c}p_{\text {sat }} \\
(\boldsymbol{k P a})\end{array}$ & $\begin{array}{r}T_{\text {sat }} \\
\left({ }^{o} \mathrm{C}\right) \\
\end{array}$ & $\begin{array}{c}\Delta T \\
\left({ }^{o} C\right) \\
\end{array}$ & $\begin{array}{c}\boldsymbol{h} \\
\left(\boldsymbol{k} W / m^{2}\right)\end{array}$ & $\begin{array}{c}\text { incerteza } \\
(\%)\end{array}$ \\
\hline 41 & 5,2 & 8,1 & 1.042 & 4,4 \\
\hline 41 & 5,2 & 9,0 & 1.378 & 3,9 \\
\hline 41 & 5,2 & 9,6 & 1.620 & 3,6 \\
\hline 41 & 5,2 & 10,7 & 2.281 & 3,3 \\
\hline 41 & 5,3 & 11,4 & 2.866 & 3,1 \\
\hline 41 & 5,2 & 12,4 & 3.996 & 2,8 \\
\hline 41 & 5,3 & 13,4 & 5.003 & 2,6 \\
\hline 41 & 5,3 & 14,2 & 5.795 & 2,5 \\
\hline 41 & 5,2 & 14,8 & 6.580 & 2,4 \\
\hline 41 & 5,3 & 15,5 & 7.475 & 2,2 \\
\hline 41 & 5,1 & 15,0 & 6.501 & 2,3 \\
\hline 41 & 5,2 & 14,5 & 5.648 & 2,4 \\
\hline 41 & 5,1 & 13,7 & 4.635 & 2,6 \\
\hline 41 & 5,2 & 13,1 & 3.859 & 2,7 \\
\hline 41 & 5,1 & 12,0 & 2.744 & 2,9 \\
\hline 41 & 5,1 & 11,3 & 2.130 & 3,1 \\
\hline 41 & 5,2 & 10,3 & 1.572 & 3,4 \\
\hline 41 & 5,2 & 9,6 & 1.281 & 3,7 \\
\hline 41 & 5,2 & 8,4 & 955 & 4,2 \\
\hline 40 & 5,2 & 8,0 & 516 & 4,5 \\
\hline 40 & 5,2 & 7,2 & 237 & 5,1 \\
\hline 84 & 23,0 & 12,4 & 9.382 & 2,8 \\
\hline 84 & 23,1 & 11,8 & 8.256 & 2,9 \\
\hline 84 & 23,1 & 11,2 & 7.060 & 3,1 \\
\hline 84 & 23,1 & 10,7 & 6.131 & 3,3 \\
\hline 84 & 23,1 & 9,9 & 4.996 & 3,5 \\
\hline 84 & 23,1 & 9,4 & 4.349 & 3,7 \\
\hline 84 & 23,1 & 8,9 & 3.658 & 3,9 \\
\hline 84 & 23,1 & 8,3 & 2.980 & 4,2 \\
\hline 84 & 23,1 & 7,4 & 2.217 & 4,7 \\
\hline 84 & 23,2 & 6,9 & 1.809 & 5,1 \\
\hline 84 & 23,2 & 6,5 & 1.574 & 5,4 \\
\hline 84 & 23,2 & 6,1 & 1.278 & 5,7 \\
\hline 84 & 23,1 & 5,8 & 1.153 & 6,1 \\
\hline 84 & 23,1 & 5,2 & 801 & 6,8 \\
\hline 83 & 23,1 & 4,5 & 399 & 7,9 \\
\hline 83 & 23,1 & 3,9 & 211 & 9,3 \\
\hline 129 & 34,8 & 10,9 & 10.521 & 3,2 \\
\hline 128 & 34,7 & 10,4 & 9.378 & 3,3 \\
\hline 128 & 34,7 & 9,9 & 8.200 & 3,5 \\
\hline 129 & 34,8 & 9,5 & 6.932 & 3,7 \\
\hline 128 & 34,7 & 8,7 & 5.576 & 4,0 \\
\hline 128 & 34,7 & 7,9 & 4.207 & 4,4 \\
\hline 128 & 34,7 & 7,3 & 3.355 & 4,8 \\
\hline 129 & 34,8 & 6,6 & 2.529 & 5,3 \\
\hline 128 & 34,8 & 6,0 & 2.020 & 5,8 \\
\hline 128 & 34,7 & 5,4 & 1.593 & 6,5 \\
\hline 128 & 34,7 & 4,9 & 1.312 & 7,1 \\
\hline 128 & 34,7 & 4,4 & 963 & 7,9 \\
\hline 128 & 34,7 & 3,7 & 439 & 9,5 \\
\hline 234 & 53,1 & 9,2 & 12.346 & 3,8 \\
\hline 233 & 53,1 & 8,8 & 11.020 & 3,9 \\
\hline 233 & 53,1 & 8,4 & 9.833 & 4,1 \\
\hline 234 & 53,1 & 8,0 & 8.237 & 4,4 \\
\hline 233 & 53,0 & 7,4 & 6.711 & 4,7 \\
\hline 233 & 53,0 & 6,6 & 4.988 & 5,2 \\
\hline 233 & 53,1 & 6,1 & 3.890 & 5,7 \\
\hline 234 & 53,2 & 5,5 & 2.963 & 6,3 \\
\hline 233 & 53,1 & 5,1 & 2.438 & 6,8 \\
\hline 234 & 53,2 & 4,5 & 1.851 & 7,8 \\
\hline 233 & 53,1 & 4,2 & 1.593 & 8,4 \\
\hline 232 & 53,0 & 3,7 & 1.062 & 9,5 \\
\hline 229 & 52,6 & 2,9 & 511 & 11,9 \\
\hline
\end{tabular}




\begin{tabular}{|c|c|c|c|c|}
\hline $\begin{array}{c}p_{\text {sat }} \\
(\boldsymbol{k P a})\end{array}$ & $\begin{array}{l}\boldsymbol{T}_{\text {sat }} \\
\left({ }^{\circ} \boldsymbol{C}\right)\end{array}$ & $\begin{array}{c}\Delta T \\
\left({ }^{o} C\right)\end{array}$ & $\begin{array}{c}h \\
\left(k W / m^{2}\right)\end{array}$ & $\begin{array}{c}\text { incerteza } \\
(\%)\end{array}$ \\
\hline 342 & 66,0 & 8,2 & 13.986 & 4,3 \\
\hline 341 & 65,9 & 7,9 & 12.591 & 4,4 \\
\hline 339 & 65,8 & 7,4 & 10.956 & 4,7 \\
\hline 339 & 65,8 & 7,0 & 9.358 & 5,0 \\
\hline 340 & 65,9 & 6,5 & 7.541 & 5,4 \\
\hline 339 & 65,8 & 5,9 & 5.630 & 5,9 \\
\hline 339 & 65,9 & 5,5 & 4.502 & 6,4 \\
\hline 339 & 65,8 & 4,9 & 3.389 & 7,0 \\
\hline 339 & 65,9 & 4,5 & 2.703 & 7,7 \\
\hline 338 & 65,8 & 4,1 & 2.076 & 8,6 \\
\hline 336 & 65,6 & 3,8 & 1.729 & 9,3 \\
\hline 335 & 65,5 & 3,4 & 1.322 & 10,3 \\
\hline 339 & 65,9 & 8,4 & 13.783 & 4,2 \\
\hline 338 & 65,9 & 8,0 & 12.330 & 4,3 \\
\hline 338 & 65,9 & 7,5 & 10.650 & 4,6 \\
\hline 339 & 65,9 & 7,1 & 9.153 & 4,9 \\
\hline 339 & 65,9 & 6,6 & 7.574 & 5,2 \\
\hline 337 & 65,8 & 6,0 & 5.564 & 5,8 \\
\hline 337 & 65,8 & 5,5 & 4.398 & 6,3 \\
\hline 339 & 65,9 & 4,9 & 3.260 & 7,1 \\
\hline 339 & 66,0 & 4,5 & 2.687 & 7,7 \\
\hline 339 & 65,9 & 4,0 & 2.059 & 8,7 \\
\hline 445 & 75,8 & 7,5 & 14.943 & 4,6 \\
\hline 443 & 75,8 & 7,2 & 13.590 & 4,8 \\
\hline 443 & 75,8 & 6,9 & 12.080 & 5,0 \\
\hline 444 & 75,9 & 6,5 & 10.267 & 5,4 \\
\hline 445 & 75,9 & 6,0 & 8.237 & 5,8 \\
\hline 445 & 75,9 & 5,4 & 6.111 & 6,4 \\
\hline 446 & 76,0 & 5,0 & 5.005 & 6,9 \\
\hline 444 & 75,8 & 4,5 & 3.647 & 7,6 \\
\hline 443 & 75,8 & 4,1 & 2.902 & 8,4 \\
\hline 444 & 75,8 & 3,9 & 2.493 & 8,9 \\
\hline 444 & 75,8 & 3,8 & 2.268 & 9,2 \\
\hline 442 & 75,7 & 3,5 & 1.901 & 10,0 \\
\hline 446 & 76,0 & 7,6 & 14.756 & 4,6 \\
\hline 446 & 76,0 & 7,3 & 13.372 & 4,7 \\
\hline 446 & 76,0 & 7,0 & 11.645 & 5,0 \\
\hline 444 & 75,9 & 6,6 & 9.992 & 5,3 \\
\hline 446 & 76,0 & 6,1 & 7.832 & 5,7 \\
\hline 445 & 75,9 & 5,6 & 5.931 & 6,2 \\
\hline 446 & 76,0 & 5,1 & 4.743 & 6,8 \\
\hline 445 & 76,0 & 4,6 & 3.560 & 7,5 \\
\hline 446 & 76,0 & 4,2 & 2.854 & 8,2 \\
\hline 445 & 76,0 & 3,9 & 2.470 & 8,8 \\
\hline 445 & 76,0 & 3,8 & 2.173 & 9,2 \\
\hline 443 & 75,8 & 3,4 & 1.806 & 10,1 \\
\hline 441 & 75,7 & 2,9 & 1.322 & 11,8 \\
\hline 439 & 75,5 & 2,4 & 682 & 14,3 \\
\hline
\end{tabular}

\begin{tabular}{|c|c|c|c|c|}
\hline $\begin{array}{c}p_{\text {sat }} \\
(\boldsymbol{k P a})\end{array}$ & $\begin{array}{r}T_{\text {sat }} \\
\left({ }^{o} \mathrm{C}\right)\end{array}$ & $\begin{array}{c}\Delta T \\
\left({ }^{o} C\right)\end{array}$ & $\begin{array}{c}h \\
\left(k W / m^{2}\right)\end{array}$ & $\begin{array}{c}\text { incerteza } \\
(\%)\end{array}$ \\
\hline 40 & 5,4 & 20,4 & 1.879 & 1,7 \\
\hline 41 & 5,5 & 20,7 & 2.207 & 1,7 \\
\hline 41 & 5,6 & 21,2 & 2.514 & 1,7 \\
\hline 41 & 5,5 & 21,6 & 2.824 & 1,6 \\
\hline 41 & 5,5 & 22,0 & 3.057 & 1,6 \\
\hline 41 & 5,6 & 22,5 & 3.389 & 1,6 \\
\hline 41 & 5,6 & 22,1 & 3.096 & 1,6 \\
\hline 41 & 5,5 & 21,6 & 2.768 & 1,6 \\
\hline 41 & 5,6 & 21,2 & 2.492 & 1,7 \\
\hline 41 & 5,6 & 20,8 & 2.203 & 1,7 \\
\hline 40 & 5,5 & 20,4 & 1.863 & 1,7 \\
\hline 41 & 5,5 & 20,0 & 1.519 & 1,8 \\
\hline 41 & 5,5 & 19,3 & 1.301 & 1,9 \\
\hline 41 & 5,6 & 19,0 & 1.171 & 1,9 \\
\hline 40 & 5,4 & 18,4 & 970 & 2,0 \\
\hline 40 & 5,5 & 18,2 & 838 & 2,0 \\
\hline 40 & 5,4 & 17,9 & 614 & 2,1 \\
\hline 40 & 5,4 & 16,9 & 527 & 2,2 \\
\hline 40 & 5,5 & 16,3 & 472 & 2,3 \\
\hline 40 & 5,4 & 15,8 & 396 & 2,4 \\
\hline 40 & 5,4 & 14,8 & 305 & 2,6 \\
\hline 40 & 5,5 & 12,1 & 247 & 3,2 \\
\hline 40 & 5,5 & 7,2 & 202 & 5,2 \\
\hline 40 & 5,6 & 4,2 & 168 & 8,6 \\
\hline
\end{tabular}

\begin{tabular}{|c|c|c|c|c|}
\hline 86 & 22,6 & 4,8 & 135 & 6,6 \\
\hline 86 & 22,6 & 8,6 & 167 & 3,9 \\
\hline 86 & 22,6 & 15,9 & 201 & 2,2 \\
\hline 86 & 22,6 & 20,9 & 211 & 1,8 \\
\hline 87 & 22,7 & 26,7 & 229 & 1,4 \\
\hline 87 & 22,8 & 32,0 & 237 & 1,2 \\
\hline 85 & 23,5 & 13,4 & 680 & 2,7 \\
\hline 84 & 23,1 & 13,8 & 814 & 2,6 \\
\hline 84 & 23,1 & 14,8 & 1.048 & 2,4 \\
\hline 84 & 23,1 & 15,3 & 1.440 & 2,3 \\
\hline 84 & 23,2 & 16,0 & 1.907 & 2,2 \\
\hline 84 & 23,1 & 16,5 & 2.287 & 2,1 \\
\hline 84 & 23,2 & 16,9 & 2.693 & 2,1 \\
\hline 84 & 23,2 & 17,3 & 3.057 & 2,0 \\
\hline 85 & 23,2 & 17,6 & 3.375 & 2,0 \\
\hline 85 & 23,4 & 17,9 & 3.774 & 2,0 \\
\hline 85 & 23,3 & 18,2 & 4.144 & 1,9 \\
\hline 85 & 23,3 & 18,0 & 3.816 & 1,9 \\
\hline 84 & 23,1 & 17,7 & 3.395 & 2,0 \\
\hline 84 & 23,2 & 17,4 & 3.020 & 2,0 \\
\hline 84 & 23,1 & 17,1 & 2.707 & 2,1 \\
\hline 84 & 23,1 & 16,6 & 2.248 & 2,1 \\
\hline 84 & 23,0 & 16,1 & 1.823 & 2,2 \\
\hline 84 & 23,1 & 15,8 & 1.589 & 2,2 \\
\hline 84 & 23,0 & 15,6 & 1.441 & 2,3 \\
\hline 84 & 23,1 & 15,3 & 1.165 & 2,3 \\
\hline 84 & 23,0 & 15,0 & 1.006 & 2,4 \\
\hline 83 & 23,0 & 14,8 & 759 & 2,4 \\
\hline 83 & 23,0 & 14,4 & 628 & 2,5 \\
\hline 83 & 22,9 & 13,8 & 545 & 2,7 \\
\hline 83 & 22,9 & 13,0 & 465 & 2,8 \\
\hline 83 & 22,9 & 12,5 & 379 & 3,0 \\
\hline 83 & 22,8 & 10,8 & 291 & 3,5 \\
\hline 83 & 22,8 & 7,7 & 191 & 4,9 \\
\hline 83 & 22,8 & 4,7 & 160 & 7,9 \\
\hline 128 & 34,7 & 16,1 & 4.795 & 2,2 \\
\hline 129 & 34,8 & 15,8 & 4.277 & 2,2 \\
\hline 128 & 34,6 & 15,5 & 3.795 & 2,3 \\
\hline 128 & 34,8 & 15,2 & 3.433 & 2,3 \\
\hline 128 & 34,7 & 14,9 & 3.036 & 2,3 \\
\hline
\end{tabular}

Superfície de latão ; Ra=0,16 $\mathbf{0 , 0 2} \boldsymbol{\mu} \mathbf{m}$
\begin{tabular}{|c|c|c|c|c|}
\hline 40 & 5,3 & 3,9 & 158 & 7,9 \\
\hline 40 & 5,4 & 8,2 & 183 & 4,0 \\
\hline 40 & 5,5 & 14,0 & 206 & 2,5 \\
\hline 40 & 5,5 & 19,7 & 226 & 1,8 \\
\hline 40 & 5,5 & 25,6 & 237 & 1,5 \\
\hline 40 & 5,5 & 16,6 & 473 & 2,3 \\
\hline 40 & 5,4 & 16,4 & 547 & 2,3 \\
\hline 40 & 5,3 & 17,4 & 603 & 2,1 \\
\hline 40 & 5,4 & 17,9 & 675 & 2,1 \\
\hline 40 & 5,4 & 17,9 & 839 & 2,0 \\
\hline 40 & 5,3 & 19,0 & 1.201 & 1,9 \\
\hline 40 & 5,4 & 19,7 & 1.534 & 1,8 \\
\hline
\end{tabular}




\begin{tabular}{|c|c|c|c|c|}
\hline $\begin{array}{c}p_{\text {sat }} \\
(\boldsymbol{k P a})\end{array}$ & $\begin{array}{l}T_{\text {sat }} \\
\left({ }^{o} C\right)\end{array}$ & $\begin{array}{c}\Delta T \\
\left({ }^{o} C\right)\end{array}$ & $\begin{array}{c}h \\
\left(k W / m^{2}\right)\end{array}$ & $\begin{array}{c}\text { incerteza } \\
(\%)\end{array}$ \\
\hline 128 & 34,6 & 14,6 & 2.614 & 2,4 \\
\hline 128 & 34,7 & 14,1 & 2.139 & 2,5 \\
\hline 128 & 34,7 & 13,6 & 1.824 & 2,6 \\
\hline 128 & 34,7 & 13,5 & 1.664 & 2,6 \\
\hline 127 & 34,7 & 13,1 & 1.352 & 2,7 \\
\hline 127 & 34,6 & 12,8 & 1.209 & 2,8 \\
\hline 127 & 34,7 & 12,3 & 884 & 2,9 \\
\hline 127 & 34,6 & 12,2 & 729 & 2,9 \\
\hline 127 & 34,6 & 12,1 & 629 & 3,0 \\
\hline 127 & 34,6 & 11,8 & 538 & 3,1 \\
\hline 127 & 34,5 & 11,0 & 411 & 3,3 \\
\hline 127 & 34,5 & 9,5 & 311 & 3,9 \\
\hline 126 & 34,4 & 6,8 & 209 & 5,5 \\
\hline 127 & 34,4 & 4,9 & 154 & 7,6 \\
\hline 232 & 53,0 & 13,3 & 5.719 & 2,7 \\
\hline 232 & 53,0 & 12,9 & 5.194 & 2,7 \\
\hline 232 & 53,0 & 12,6 & 4.752 & 2,8 \\
\hline 232 & 53,0 & 12,5 & 4.428 & 2,8 \\
\hline 231 & 52,9 & 12,0 & 3.739 & 2,9 \\
\hline 232 & 53,1 & 11,7 & 3.211 & 3,0 \\
\hline 232 & 53,1 & 11,2 & 2.681 & 3,1 \\
\hline 232 & 53,0 & 10,9 & 2.285 & 3,2 \\
\hline 232 & 53,1 & 10,6 & 2.114 & 3,3 \\
\hline 231 & 53,0 & 10,3 & 1.720 & 3,4 \\
\hline 232 & 53,0 & 10,0 & 1.469 & 3,5 \\
\hline 231 & 53,0 & 9,6 & 1.202 & 3,7 \\
\hline 231 & 53,0 & 9,3 & 964 & 3,8 \\
\hline 231 & 53,0 & 9,0 & 831 & 3,9 \\
\hline 231 & 53,0 & 8,8 & 693 & 4,1 \\
\hline 231 & 53,0 & 8,4 & 562 & 4,3 \\
\hline 231 & 52,9 & 7,5 & 397 & 4,8 \\
\hline 232 & 52,9 & 6,2 & 247 & 5,9 \\
\hline 336 & 65,9 & 11,4 & 6.909 & 3,1 \\
\hline 337 & 65,9 & 11,0 & 6.007 & 3,2 \\
\hline 336 & 65,8 & 10,9 & 5.617 & 3,2 \\
\hline 337 & 65,9 & 10,6 & 4.967 & 3,3 \\
\hline 336 & 65,8 & 10,4 & 4.395 & 3,4 \\
\hline 336 & 65,8 & 10,0 & 3.755 & 3,5 \\
\hline 336 & 65,8 & 9,7 & 3.151 & 3,6 \\
\hline 335 & 65,7 & 9,4 & 2.664 & 3,7 \\
\hline 336 & 65,8 & 9,2 & 2.500 & 3,8 \\
\hline 335 & 65,7 & 8,8 & 1.941 & 4,0 \\
\hline 442 & 76,0 & 9,3 & 6.430 & 3,7 \\
\hline 442 & 75,9 & 9,1 & 5.809 & 3,8 \\
\hline 443 & 76,0 & 8,8 & 5.169 & 3,9 \\
\hline 443 & 75,9 & 8,6 & 4.436 & 4,1 \\
\hline 444 & 76,0 & 8,2 & 3.695 & 4,3 \\
\hline 444 & 76,1 & 7,9 & 3.124 & 4,4 \\
\hline 444 & 76,1 & 7,6 & 2.928 & 4,6 \\
\hline 443 & 76,0 & 7,3 & 2.384 & 4,8 \\
\hline 444 & 76,1 & 7,1 & 2.142 & 4,9 \\
\hline 443 & 76,0 & 6,7 & 1.715 & 5,2 \\
\hline 443 & 76,0 & 6,4 & 1.412 & 5,5 \\
\hline 441 & 75,8 & 6,2 & 1.232 & 5,7 \\
\hline 443 & 76,1 & 9,5 & 8.083 & 3,7 \\
\hline 442 & 76,0 & 9,2 & 7.259 & 3,8 \\
\hline 443 & 76,0 & 9,0 & 6.743 & 3,9 \\
\hline 443 & 76,0 & 8,8 & 6.099 & 3,9 \\
\hline 443 & 76,0 & 8,6 & 5.233 & 4,0 \\
\hline 442 & 75,9 & 8,4 & 4.525 & 4,1 \\
\hline 441 & 75,9 & 8,1 & 3.659 & 4,3 \\
\hline 442 & 75,9 & 7,8 & 3.116 & 4,5 \\
\hline
\end{tabular}

\begin{tabular}{|c|c|c|c|c|}
\hline $\begin{array}{c}\boldsymbol{p}_{\text {sat }} \\
(\boldsymbol{k P a})\end{array}$ & $\begin{array}{c}\boldsymbol{T}_{\text {sat }} \\
\left({ }^{\circ} \boldsymbol{C}\right)\end{array}$ & $\begin{array}{c}\Delta \boldsymbol{T} \\
\left({ }^{o} \boldsymbol{C}\right)\end{array}$ & $\begin{array}{c}\boldsymbol{h} \\
\left(\boldsymbol{k} \mathbf{W} / \boldsymbol{m}^{2}\right)\end{array}$ & $\begin{array}{c}\text { incerteza } \\
(\boldsymbol{\%})\end{array}$ \\
\hline 444 & 76,1 & 7,7 & 2.926 & 4,5 \\
\hline 441 & 75,9 & 7,5 & 2.404 & 4,7 \\
\hline 444 & 76,1 & 7,3 & 2.077 & 4,8 \\
\hline 443 & 76,0 & 7,0 & 1.624 & 5,0 \\
\hline 443 & 76,0 & 6,7 & 1.317 & 5,2 \\
\hline 442 & 75,9 & 6,5 & 1.161 & 5,4 \\
\hline 440 & 75,8 & 6,3 & 999 & 5,6 \\
\hline
\end{tabular}

\section{Superfície de aço inoxidável ; $R a=0,16 \pm 0,02 \mu \mathrm{m}$}

\begin{tabular}{|c|c|c|c|c|}
\hline 40 & 5,5 & 4,5 & 193 & 6,8 \\
\hline 40 & 5,5 & 7,2 & 223 & 4,3 \\
\hline 40 & 5,7 & 13,8 & 252 & 2,4 \\
\hline 40 & 5,7 & 19,6 & 259 & 1,8 \\
\hline 40 & 5,7 & 24,8 & 274 & 1,4 \\
\hline 39 & 5,7 & 30,0 & 278 & 1,2 \\
\hline 39 & 5,7 & 35,7 & 291 & 1,1 \\
\hline 39 & 5,8 & 40,8 & 291 & 1,0 \\
\hline 39 & 5,8 & 44,9 & 296 & 0,9 \\
\hline 40 & 5,5 & 4,1 & 203 & 7,3 \\
\hline 40 & 5,6 & 8,1 & 208 & 3,9 \\
\hline 40 & 5,7 & 14,5 & 235 & 2,3 \\
\hline 40 & 5,7 & 20,2 & 254 & 1,7 \\
\hline 40 & 5,7 & 25,1 & 266 & 1,4 \\
\hline 39 & 5,6 & 31,3 & 279 & 1,2 \\
\hline 39 & 5,6 & 35,7 & 283 & 1,1 \\
\hline 39 & 5,6 & 42,2 & 293 & 0,9 \\
\hline 41 & 5,6 & 32,1 & 1.852 & 1,0 \\
\hline 41 & 5,6 & 30,0 & 1.699 & 1,0 \\
\hline 41 & 5,6 & 28,0 & 1.477 & 1,1 \\
\hline 41 & 5,5 & 26,0 & 1.282 & 1,2 \\
\hline 41 & 5,5 & 23,3 & 1.082 & 1,3 \\
\hline 41 & 5,6 & 20,7 & 933 & 1,5 \\
\hline 41 & 5,6 & 19,6 & 888 & 1,5 \\
\hline 41 & 5,7 & 18,4 & 698 & 1,7 \\
\hline 41 & 5,7 & 18,6 & 562 & 1,7 \\
\hline 41 & 5,6 & 19,3 & 433 & 1,7 \\
\hline 41 & 5,7 & 19,7 & 356 & 1,7 \\
\hline 41 & 5,7 & 17,1 & 292 & 1,9 \\
\hline 41 & 5,7 & 12,8 & 247 & 2,6 \\
\hline 40 & 5,7 & 8,1 & 213 & 3,9 \\
\hline 41 & 5,7 & 4,7 & 191 & 6,5 \\
\hline 40 & 5,5 & 31,8 & 1.867 & 1,0 \\
\hline 40 & 5,7 & 30,2 & 1.731 & 1,0 \\
\hline 40 & 5,6 & 27,8 & 1.455 & 1,1 \\
\hline 40 & 5,6 & 25,7 & 1.299 & 1,2 \\
\hline 40 & 5,6 & 23,5 & 1.179 & 1,3 \\
\hline 40 & 5,6 & 22,6 & 1.145 & 1,3 \\
\hline 40 & 5,6 & 20,2 & 958 & 1,5 \\
\hline 40 & 5,5 & 19,2 & 890 & 1,6 \\
\hline 40 & 5,6 & 23,3 & 553 & 1,4 \\
\hline 40 & 5,6 & 22,0 & 461 & 1,5 \\
\hline 40 & 5,6 & 21,3 & 388 & 1,5 \\
\hline 40 & 5,6 & 20,5 & 348 & 1,6 \\
\hline 40 & 5,6 & 16,4 & 313 & 2,0 \\
\hline 40 & 5,6 & 13,3 & 255 & 2,5 \\
\hline 40 & 5,7 & 7,7 & 213 & 4,1 \\
\hline 40 & 5,7 & 5,2 & 176 & 5,9 \\
\hline 83 & 23,0 & 27,1 & 2.150 & 1,1 \\
\hline 83 & 23,1 & 25,6 & 1.976 & 1,2 \\
\hline 83 & 23,1 & 23,6 & 1.783 & 1,2 \\
\hline 83 & 23,1 & 21,8 & 1.526 & 1,4 \\
\hline 83 & 23,0 & 20,4 & 1.363 & 1,5 \\
\hline
\end{tabular}




\begin{tabular}{|c|c|c|c|c|}
\hline $\begin{array}{c}p_{\text {sat }} \\
(\boldsymbol{k P a})\end{array}$ & $\begin{array}{c}T_{\text {sat }} \\
\left({ }^{o} \mathrm{C}\right)\end{array}$ & $\begin{array}{c}\Delta T \\
\left({ }^{o} C\right)\end{array}$ & $\begin{array}{c}h \\
\left(k W / m^{2}\right)\end{array}$ & $\begin{array}{c}\text { incerteza } \\
(\%)\end{array}$ \\
\hline 83 & 23,0 & 19,5 & 1.278 & 1,5 \\
\hline 83 & 23,1 & 17,9 & 1.108 & 1,7 \\
\hline 83 & 23,1 & 17,5 & 973 & 1,7 \\
\hline 83 & 23,1 & 15,6 & 813 & 1,9 \\
\hline 83 & 23,1 & 14,9 & 682 & 2,0 \\
\hline 83 & 23,2 & 13,8 & 607 & 2,2 \\
\hline 83 & 23,2 & 13,2 & 510 & 2,3 \\
\hline 83 & 23,2 & 11,7 & 422 & 2,6 \\
\hline 83 & 23,2 & 11,0 & 315 & 2,8 \\
\hline 83 & 23,1 & 8,0 & 214 & 3,9 \\
\hline 83 & 23,1 & 5,3 & 173 & 5,8 \\
\hline 129 & 34,9 & 24,9 & 2.438 & 1,2 \\
\hline 129 & 35,0 & 22,8 & 2.192 & 1,3 \\
\hline 129 & 35,0 & 21,3 & 1.941 & 1,4 \\
\hline 128 & 34,9 & 19,7 & 1.748 & 1,5 \\
\hline 128 & 34,9 & 18,2 & 1.523 & 1,6 \\
\hline 128 & 34,9 & 17,2 & 1.389 & 1,7 \\
\hline 128 & 34,9 & 16,0 & 1.221 & 1,8 \\
\hline 129 & 35,0 & 15,5 & 1.108 & 1,9 \\
\hline 128 & 34,9 & 14,8 & 825 & 2,0 \\
\hline 129 & 35,0 & 14,1 & 731 & 2,1 \\
\hline 128 & 34,9 & 13,5 & 630 & 2,2 \\
\hline 129 & 35,0 & 12,5 & 540 & 2,4 \\
\hline 129 & 35,0 & 11,6 & 468 & 2,6 \\
\hline 129 & 35,0 & 9,3 & 338 & 3,3 \\
\hline 128 & 35,0 & 8,2 & 211 & 3,8 \\
\hline 128 & 34,9 & 5,2 & 162 & 6,0 \\
\hline 234 & 53,3 & 21,5 & 2.811 & 1,4 \\
\hline 235 & 53,3 & 19,9 & 2.542 & 1,5 \\
\hline 234 & 53,2 & 18,5 & 2.262 & 1,6 \\
\hline 233 & 53,1 & 16,7 & 1.981 & 1,7 \\
\hline 231 & 52,9 & 15,3 & 1.768 & 1,9 \\
\hline 231 & 52,9 & 14,8 & 1.710 & 2,0 \\
\hline 232 & 53,0 & 13,5 & 1.469 & 2,2 \\
\hline 232 & 53,1 & 12,9 & 1.361 & 2,3 \\
\hline 232 & 53,1 & 11,4 & 1.071 & 2,6 \\
\hline 232 & 53,1 & 11,0 & 903 & 2,7 \\
\hline 232 & 53,1 & 10,9 & 780 & 2,7 \\
\hline 232 & 53,1 & 10,5 & 632 & 2,8 \\
\hline 232 & 53,0 & 9,9 & 505 & 3,0 \\
\hline 231 & 53,0 & 8,6 & 385 & 3,5 \\
\hline 231 & 52,9 & 7,0 & 250 & 4,4 \\
\hline 231 & 52,9 & 5,6 & 154 & 5,6 \\
\hline 337 & 65,7 & 18,4 & 3.220 & 1,6 \\
\hline 336 & 65,8 & 17,0 & 2.981 & 1,7 \\
\hline 336 & 65,8 & 15,8 & 2.646 & 1,8 \\
\hline 336 & 65,7 & 14,2 & 2.312 & 2,0 \\
\hline 336 & 65,7 & 12,7 & 1.975 & 2,3 \\
\hline 335 & 65,7 & 10,8 & 1.575 & 2,7 \\
\hline 335 & 65,6 & 9,6 & 1.334 & 3,0 \\
\hline 336 & 65,6 & 8,8 & 1.161 & 3,3 \\
\hline 336 & 65,7 & 8,3 & 1.031 & 3,5 \\
\hline 336 & 65,7 & 7,8 & 881 & 3,7 \\
\hline 335 & 65,7 & 7,2 & 711 & 4,0 \\
\hline 335 & 65,7 & 6,6 & 504 & 4,5 \\
\hline 334 & 65,6 & 5,5 & 314 & 5,4 \\
\hline 333 & 65,4 & 4,3 & 200 & 7,1 \\
\hline 338 & 65,9 & 18,6 & 3.109 & 1,6 \\
\hline 336 & 65,8 & 17,6 & 2.918 & 1,6 \\
\hline 337 & 65,8 & 16,5 & 2.552 & 1,7 \\
\hline 337 & 65,8 & 14,8 & 2.242 & 2,0 \\
\hline 337 & 65,8 & 13,9 & 2.043 & 2,1 \\
\hline
\end{tabular}

\begin{tabular}{|c|c|c|c|c|}
\hline $\begin{array}{c}p_{\text {sat }} \\
(\boldsymbol{k P a})\end{array}$ & $\begin{array}{r}T_{\text {sat }} \\
\left({ }^{o} \boldsymbol{C}\right)\end{array}$ & $\begin{array}{c}\Delta T \\
\left({ }^{o} C\right)\end{array}$ & $\begin{array}{c}h \\
\left(k W / m^{2}\right)\end{array}$ & $\begin{array}{c}\text { incerteza } \\
(\%)\end{array}$ \\
\hline 337 & 65,9 & 13,2 & 1.929 & 2,2 \\
\hline 336 & 65,8 & 11,8 & 1.659 & 2,4 \\
\hline 337 & 65,9 & 11,1 & 1.526 & 2,6 \\
\hline 336 & 65,7 & 9,9 & 1.251 & 2,9 \\
\hline 337 & 65,8 & 9,3 & 1.052 & 3,1 \\
\hline 337 & 65,8 & 9,0 & 951 & 3,3 \\
\hline 336 & 65,8 & 8,4 & 776 & 3,5 \\
\hline 337 & 65,8 & 8,0 & 648 & 3,7 \\
\hline 336 & 65,8 & 7,5 & 440 & 3,9 \\
\hline 336 & 65,7 & 6,0 & 273 & 5,0 \\
\hline 443 & 75,9 & 17,1 & 3.471 & 1,7 \\
\hline 441 & 75,8 & 15,8 & 3.177 & 1,8 \\
\hline 442 & 75,8 & 14,7 & 2.885 & 2,0 \\
\hline 443 & 75,9 & 13,4 & 2.501 & 2,2 \\
\hline 443 & 75,9 & 12,3 & 2.256 & 2,3 \\
\hline 443 & 75,9 & 11,7 & 2.142 & 2,5 \\
\hline 443 & 75,9 & 10,4 & 1.872 & 2,8 \\
\hline 442 & 75,8 & 9,9 & 1.735 & 2,9 \\
\hline 445 & 76,0 & 8,7 & 1.451 & 3,3 \\
\hline 444 & 76,0 & 8,2 & 1.252 & 3,5 \\
\hline 444 & 75,9 & 7,7 & 1.117 & 3,7 \\
\hline 443 & 75,9 & 7,3 & 966 & 4,0 \\
\hline 441 & 75,7 & 6,7 & 742 & 4,3 \\
\hline 438 & 75,6 & 6,1 & 540 & 4,8 \\
\hline 444 & 75,9 & 17,4 & 3.494 & 1,7 \\
\hline 444 & 75,9 & 15,9 & 3.180 & 1,8 \\
\hline 442 & 75,7 & 14,7 & 2.804 & 2,0 \\
\hline 443 & 75,8 & 13,5 & 2.483 & 2,1 \\
\hline 442 & 75,7 & 12,4 & 2.205 & 2,3 \\
\hline 442 & 75,8 & 11,9 & 2.113 & 2,4 \\
\hline 442 & 75,8 & 10,7 & 1.818 & 2,7 \\
\hline 443 & 75,8 & 10,1 & 1.690 & 2,9 \\
\hline 444 & 75,9 & 9,0 & 1.408 & 3,2 \\
\hline 442 & 75,8 & 8,5 & 1.217 & 3,4 \\
\hline 444 & 75,8 & 8,1 & 1.060 & 3,6 \\
\hline 444 & 75,9 & 7,5 & 905 & 3,8 \\
\hline 440 & 75,7 & 6,9 & 693 & 4,2 \\
\hline
\end{tabular}


iii. Resultados para o $R-12$

\begin{tabular}{|c|c|c|c|c|}
\hline $\begin{array}{c}p_{\text {sat }} \\
(\boldsymbol{k P a})\end{array}$ & $\begin{array}{l}T_{\text {sat }} \\
\left({ }^{o} \mathrm{C}\right)\end{array}$ & $\begin{array}{c}\Delta T \\
\left({ }^{o} C\right) \\
\end{array}$ & $\begin{array}{c}h \\
\left(k W / m^{2}\right) \\
\end{array}$ & $\begin{array}{c}\text { incerteza } \\
(\%)\end{array}$ \\
\hline \multicolumn{5}{|c|}{ Superfície de cobre ; Ra=0,06 $\pm 0,02 \mu \mathrm{m}$} \\
\hline 209 & $-11,2$ & 17,2 & 6.574 & 2,1 \\
\hline 208 & $-11,2$ & 16,4 & 5.920 & 2,1 \\
\hline 209 & $-11,1$ & 15,7 & 5.316 & 2,2 \\
\hline 207 & $-11,2$ & 14,7 & 4.419 & 2,4 \\
\hline 207 & $-11,2$ & 13,0 & 3.164 & 2,7 \\
\hline 207 & $-11,1$ & 13,0 & 3.115 & 2,7 \\
\hline 208 & $-11,1$ & 12,2 & 2.667 & 2,9 \\
\hline 208 & $-11,0$ & 11,4 & 2.337 & 3,1 \\
\hline 208 & $-11,0$ & 11,2 & 2.206 & 3,1 \\
\hline 207 & $-11,1$ & 10,4 & 1.838 & 3,4 \\
\hline 207 & $-11,1$ & 10,0 & 1.654 & 3,5 \\
\hline 207 & $-11,1$ & 9,2 & 1.321 & 3,8 \\
\hline 207 & $-11,0$ & 8,6 & 1.122 & 4,1 \\
\hline 207 & $-11,0$ & 8,3 & 999 & 4,3 \\
\hline 207 & $-11,0$ & 7,8 & 853 & 4,5 \\
\hline 206 & $-11,0$ & 7,3 & 648 & 4,8 \\
\hline 206 & $-11,0$ & 6,3 & 501 & 5,7 \\
\hline 205 & $-11,0$ & 4,9 & 350 & 7,3 \\
\hline 205 & $-11,0$ & 2,5 & 305 & 13,9 \\
\hline 210 & $-11,1$ & 17,3 & 6.663 & 2,1 \\
\hline 208 & $-11,2$ & 16,6 & 5.914 & 2,1 \\
\hline 208 & $-11,2$ & 15,8 & 5.127 & 2,2 \\
\hline 209 & $-11,1$ & 14,9 & 4.281 & 2,3 \\
\hline 207 & $-11,2$ & 14,0 & 3.524 & 2,5 \\
\hline 207 & $-11,2$ & 13,3 & 3.021 & 2,6 \\
\hline 207 & $-11,2$ & 12,6 & 2.599 & 2,8 \\
\hline 207 & $-11,2$ & 11,9 & 2.280 & 3,0 \\
\hline 207 & $-11,1$ & 11,4 & 2.060 & 3,1 \\
\hline 207 & $-11,1$ & 10,8 & 1.812 & 3,2 \\
\hline 207 & $-11,1$ & 10,4 & 1.573 & 3,4 \\
\hline 206 & $-11,1$ & 9,4 & 1.255 & 3,7 \\
\hline 206 & $-11,2$ & 9,1 & 1.102 & 3,9 \\
\hline 206 & $-11,2$ & 8,7 & 959 & 4,1 \\
\hline 206 & $-11,1$ & 8,3 & 793 & 4,3 \\
\hline 205 & $-11,2$ & 7,7 & 647 & 4,6 \\
\hline 205 & $-11,2$ & 6,7 & 489 & 5,3 \\
\hline 204 & $-11,1$ & 4,9 & 338 & 7,3 \\
\hline 205 & $-11,1$ & 2,7 & 316 & 13,1 \\
\hline 263 & $-4,6$ & 15,9 & 7.171 & 2,2 \\
\hline 263 & $-4,7$ & 15,2 & 6.433 & 2,3 \\
\hline
\end{tabular}

\begin{tabular}{|c|c|c|c|c|}
\hline $\begin{array}{c}p_{\text {sat }} \\
(\boldsymbol{k P a})\end{array}$ & $\begin{array}{l}T_{\text {sat }} \\
\left({ }^{o} \boldsymbol{C}\right)\end{array}$ & $\begin{array}{c}\Delta T \\
\left({ }^{o} C\right)\end{array}$ & $\begin{array}{c}\boldsymbol{h} \\
\left(\boldsymbol{k} W / \boldsymbol{m}^{2}\right)\end{array}$ & $\begin{array}{c}\text { incerteza } \\
(\%)\end{array}$ \\
\hline 262 & $-4,7$ & 14,3 & 5.634 & 2,4 \\
\hline 263 & $-4,7$ & 13,5 & 4.849 & 2,6 \\
\hline 262 & $-4,7$ & 12,5 & 3.932 & 2,8 \\
\hline 262 & $-4,6$ & 11,8 & 3.443 & 3,0 \\
\hline 261 & $-4,6$ & 11,1 & 2.953 & 3,1 \\
\hline 260 & $-4,7$ & 10,5 & 2.561 & 3,3 \\
\hline 260 & $-4,7$ & 10,2 & 2.423 & 3,4 \\
\hline 261 & $-4,6$ & 9,5 & 2.003 & 3,7 \\
\hline 260 & $-4,7$ & 9,1 & 1.824 & 3,8 \\
\hline 260 & $-4,7$ & 8,4 & 1.468 & 4,2 \\
\hline 260 & $-4,7$ & 7,9 & 1.256 & 4,5 \\
\hline 260 & $-4,6$ & 7,4 & 1.100 & 4,7 \\
\hline 260 & $-4,6$ & 7,0 & 921 & 5,0 \\
\hline 260 & $-4,7$ & 6,5 & 742 & 5,4 \\
\hline 260 & $-4,6$ & 6,0 & 552 & 5,9 \\
\hline 260 & $-4,6$ & 4,7 & 369 & 7,6 \\
\hline 259 & $-4,6$ & 2,7 & 296 & 13,1 \\
\hline 261 & $-4,7$ & 16.0 & 7.045 & 2,2 \\
\hline 261 & $-4,7$ & 15,5 & 6.388 & 2,3 \\
\hline 261 & $-4,7$ & 14,7 & 5.614 & 2,4 \\
\hline 261 & $-4,8$ & 13,9 & 4.690 & 2,5 \\
\hline 261 & $-4,7$ & 12,8 & 3.804 & 2,7 \\
\hline 261 & $-4,7$ & 12,1 & 3.312 & 2,9 \\
\hline 262 & $-4,6$ & 11,4 & 2.883 & 3,1 \\
\hline 260 & $-4,7$ & 10,8 & 2.518 & 3,2 \\
\hline 260 & $-4,8$ & 10,5 & 2.301 & 3,3 \\
\hline 261 & $-4,7$ & 9,8 & 1.973 & 3,6 \\
\hline 260 & $-4,7$ & 9,3 & 1.738 & 3,8 \\
\hline 259 & $-4,7$ & 8,5 & 1.410 & 4,1 \\
\hline 260 & $-4,7$ & 8,0 & 1.208 & 4,4 \\
\hline 260 & $-4,6$ & 7,6 & 1.072 & 4,6 \\
\hline 260 & $-4,6$ & 7,2 & 926 & 4,9 \\
\hline 259 & $-4,7$ & 6,8 & 734 & 5,2 \\
\hline 259 & $-4,7$ & 6,2 & 542 & 5,8 \\
\hline 258 & $-4,7$ & 4,6 & 351 & 7,8 \\
\hline 258 & $-4,7$ & 2,6 & 303 & 13,4 \\
\hline 390 & 7,2 & 14,1 & 8.246 & 2,5 \\
\hline 388 & 7,0 & 13,3 & 7.340 & 2,6 \\
\hline 390 & 7,2 & 12,6 & 6.478 & 2,8 \\
\hline 389 & 7,1 & 11,8 & 5.521 & 2,9 \\
\hline 389 & 7,1 & 10,9 & 4.476 & 3,2 \\
\hline
\end{tabular}




\begin{tabular}{|c|c|c|c|c|}
\hline $\begin{array}{c}p_{\text {sat }} \\
(\boldsymbol{k P a})\end{array}$ & $\begin{array}{l}T_{\text {sat }} \\
\left({ }^{o} \mathrm{C}\right)\end{array}$ & $\begin{array}{c}\Delta T \\
\left({ }^{o} C\right)\end{array}$ & $\begin{array}{c}h \\
\left(k W / m^{2}\right)\end{array}$ & $\begin{array}{c}\text { incerteza } \\
(\%)\end{array}$ \\
\hline 389 & 7,1 & 10,3 & 3.949 & 3,4 \\
\hline 388 & 7,1 & 9,6 & 3.397 & 3,6 \\
\hline 388 & 7,1 & 9,1 & 3.019 & 3,8 \\
\hline 388 & 7,1 & 8,8 & 2.796 & 4,0 \\
\hline 387 & 7,1 & 8,1 & 2.338 & 4,3 \\
\hline 388 & 7,1 & 7,5 & 2.148 & 4,7 \\
\hline 389 & 7,1 & 7,0 & 1.750 & 5,0 \\
\hline 390 & 7,2 & 6,4 & 1.517 & 5,4 \\
\hline 389 & 7,2 & 6,0 & 1.340 & 5,8 \\
\hline 388 & 7,2 & 5,7 & 1.123 & 6,2 \\
\hline 388 & 7,1 & 5,3 & 940 & 6,6 \\
\hline 387 & 7,1 & 4,8 & 709 & 7,3 \\
\hline 386 & 7,1 & 4,0 & 427 & 8,8 \\
\hline 386 & 7,1 & 3,0 & 292 & 11,7 \\
\hline 497 & 15,1 & 12,8 & 8.793 & 2,8 \\
\hline 498 & 15,2 & 12,2 & 8.024 & 2,9 \\
\hline 498 & 15,2 & 11,4 & 7.050 & 3,0 \\
\hline 496 & 15,1 & 10,8 & 6.156 & 3,2 \\
\hline 496 & 15,1 & 9,9 & 5.003 & 3,5 \\
\hline 496 & 15,1 & 9,2 & 4.343 & 3,8 \\
\hline 497 & 15,2 & 8,6 & 3.772 & 4,0 \\
\hline 497 & 15,2 & 8,1 & 3.195 & 4,3 \\
\hline 496 & 15,1 & 7,9 & 3.057 & 4,4 \\
\hline 495 & 15,1 & 7,4 & 2.643 & 4,7 \\
\hline 495 & 15,1 & 7,1 & 2.357 & 4,9 \\
\hline 494 & 15,1 & 6,4 & 1.954 & 5,4 \\
\hline 497 & 15,2 & 6,0 & 1.651 & 5,8 \\
\hline 497 & 15,2 & 5,7 & 1.450 & 6,1 \\
\hline 496 & 15,2 & 5,4 & 1.238 & 6,4 \\
\hline 496 & 15,2 & 4,9 & 976 & 7,1 \\
\hline 495 & 15,1 & 4,5 & 708 & 7,8 \\
\hline 494 & 15,1 & 3,8 & 407 & 9,2 \\
\hline 494 & 15,1 & 3,1 & 244 & 11,4 \\
\hline 737 & 29,1 & 11,1 & 10.427 & 3,2 \\
\hline 733 & 29,0 & 10,5 & 9.316 & 3,3 \\
\hline 735 & 29,1 & 10,0 & 8.230 & 3,5 \\
\hline 735 & 29,1 & 9,3 & 7.068 & 3,7 \\
\hline 736 & 29,1 & 8,5 & 5.766 & 4,1 \\
\hline 736 & 29,1 & 7,9 & 5.105 & 4,4 \\
\hline 735 & 29,1 & 7,4 & 4.431 & 4,7 \\
\hline 735 & 29,1 & 7,0 & 3.849 & 5,0 \\
\hline 734 & 29,0 & 6,8 & 3.604 & 5,1 \\
\hline 735 & 29,1 & 6,3 & 3.026 & 5,5 \\
\hline 734 & 29,1 & 6,0 & 2.721 & 5,8 \\
\hline 734 & 29,0 & 5,5 & 2.209 & 6,4 \\
\hline 736 & 29,1 & 5,2 & 1.951 & 6,7 \\
\hline 735 & 29,1 & 4,8 & 1.688 & 7,2 \\
\hline 734 & 29,1 & 4,5 & 1.444 & 7,7 \\
\hline 736 & 29,2 & 4,2 & 1.154 & 8,4 \\
\hline 734 & 29,1 & 3,7 & 884 & 9,4 \\
\hline 737 & 29,2 & 3,3 & 495 & 10,5 \\
\hline 737 & 29,2 & 3,0 & 277 & 11,8 \\
\hline 851 & 34,6 & 10,4 & 10.839 & 3,4 \\
\hline 849 & 34,5 & 9,8 & 9.899 & 3,5 \\
\hline 849 & 34,5 & 9,3 & 8.557 & 3,7 \\
\hline 852 & 34,6 & 8,7 & 7.377 & 4,0 \\
\hline 853 & 34,7 & 7,9 & 6.118 & 4,4 \\
\hline 852 & 34,7 & 7,5 & 5.415 & 4,7 \\
\hline 850 & 34,6 & 6,9 & 4.561 & 5,0 \\
\hline 850 & 34,6 & 6,6 & 4.059 & 5,3 \\
\hline 850 & 34,6 & 6,3 & 3.755 & 5,5 \\
\hline 851 & 34,6 & 5,9 & 3.253 & 5,9 \\
\hline 851 & 34,6 & 5,8 & 2.911 & 6,0 \\
\hline
\end{tabular}

\begin{tabular}{|c|c|c|c|c|}
\hline $\begin{array}{c}p_{\text {sat }} \\
(\boldsymbol{k P a})\end{array}$ & $\begin{array}{c}T_{\text {sat }} \\
\left({ }^{\circ} \mathrm{C}\right)\end{array}$ & $\begin{array}{c}\Delta T \\
\left({ }^{o} C\right)\end{array}$ & $\begin{array}{c}h \\
\left(k W / m^{2}\right)\end{array}$ & $\begin{array}{c}\text { incerteza } \\
(\%)\end{array}$ \\
\hline 850 & 34,6 & 5,4 & 2.408 & 6,5 \\
\hline 849 & 34,6 & 4,9 & 1.972 & 7,1 \\
\hline 849 & 34,6 & 4,7 & 1.829 & 7,3 \\
\hline 848 & 34,5 & 4,4 & 1.533 & 7,9 \\
\hline 847 & 34,5 & 4,0 & 1.120 & 8,8 \\
\hline 848 & 34,5 & 3,7 & 875 & 9,5 \\
\hline 848 & 34,5 & 3,2 & 518 & 11,0 \\
\hline 847 & 34,5 & 2,8 & 300 & 12,7 \\
\hline 1095 & 147 & 93 & 12255 & 37 \\
\hline 1.094 & 44.6 & 89 & 11.152 & 39 \\
\hline 1.095 & 44,7 & 8,3 & 9.650 & 4,2 \\
\hline 1.094 & 44,7 & 7,8 & 8.356 & 4,5 \\
\hline 1.094 & 44,7 & 7,2 & 6.845 & 4,8 \\
\hline 1.094 & 44,7 & 6,8 & 6.112 & 5,1 \\
\hline 1.095 & 44,7 & 6,3 & 5.190 & 5,5 \\
\hline 1.095 & 44,7 & 6,0 & 4.502 & 5,8 \\
\hline 1.094 & 44,7 & 5,8 & 4.151 & 6,0 \\
\hline 1.095 & 44,7 & 5,2 & 3.680 & 6,7 \\
\hline 1.095 & 44,7 & 4,9 & 3.272 & 7,1 \\
\hline 1.093 & 44,6 & 4,5 & 2.742 & 7,8 \\
\hline 1.095 & 44,7 & 4,2 & 2.227 & 8,2 \\
\hline 1.094 & 44,7 & 4,1 & 2.020 & 8,6 \\
\hline 1.095 & 44,7 & 3,9 & 1.714 & 9,0 \\
\hline 1.090 & 44,6 & 3,5 & 1.398 & 9,9 \\
\hline 1.094 & 44,6 & 3,2 & 1.010 & 10,8 \\
\hline 1.096 & 44,6 & 2,9 & 568 & 12,0 \\
\hline 1.093 & 44,5 & 2,6 & 339 & 13,5 \\
\hline
\end{tabular}

Superfície de cobre; $\mathrm{Ra}=0,51 \pm 0,05 \mu \mathrm{m}$

\begin{tabular}{|c|c|c|c|c|}
\hline 210 & $-11,0$ & 10,7 & 10.509 & 3,3 \\
\hline 209 & $-11,1$ & 10,1 & 9.544 & 3,4 \\
\hline 209 & $-11,1$ & 9,6 & 8.545 & 3,6 \\
\hline 207 & $-11,2$ & 8,8 & 7.370 & 4,0 \\
\hline 209 & $-11,0$ & 8,0 & 6.078 & 4,3 \\
\hline 208 & $-11,0$ & 7,0 & 4.676 & 4,9 \\
\hline 209 & $-10,8$ & 6,4 & 3.949 & 5,5 \\
\hline 208 & $-11,1$ & 5,9 & 3.249 & 5,9 \\
\hline 209 & $-11,0$ & 5,6 & 2.920 & 6,2 \\
\hline 208 & $-11,0$ & 5,0 & 2.446 & 7,0 \\
\hline 207 & $-11,1$ & 4,7 & 2.107 & 7,5 \\
\hline 208 & $-11,0$ & 4,5 & 1.838 & 7,8 \\
\hline 207 & $-11,1$ & 4,1 & 1.610 & 8,4 \\
\hline 208 & $-11,0$ & 3,8 & 1.272 & 9,1 \\
\hline 207 & $-10,9$ & 3,5 & 899 & 9,9 \\
\hline 207 & $-10,9$ & 3,0 & 528 & 11,6 \\
\hline 207 & $-10,8$ & 2,3 & 350 & 15,5 \\
\hline 209 & -11.1 & 11.0 & 10.308 & 32 \\
\hline 209 & $-11,0$ & 10,2 & 9.510 & 3,4 \\
\hline 210 & $-11,0$ & 9,7 & 8.466 & 3,6 \\
\hline 209 & $-11,0$ & 8,9 & 7.176 & 3,9 \\
\hline 209 & $-11,1$ & 8,1 & 6.179 & 4,3 \\
\hline 208 & $-11,1$ & 7,6 & 5.420 & 4,6 \\
\hline 208 & $-11,0$ & 7,0 & 4.552 & 4,9 \\
\hline 207 & $-11,1$ & 6,4 & 3.790 & 5,4 \\
\hline 208 & $-11,1$ & 5,9 & 3.249 & 5,9 \\
\hline 209 & $-10,9$ & 5,6 & 2.976 & 6,2 \\
\hline 209 & $-10,9$ & 5,2 & 2.565 & 6,7 \\
\hline 208 & $-10,9$ & 4,7 & 2.120 & 7,5 \\
\hline 207 & $-11,0$ & 4,4 & 1.859 & 8,0 \\
\hline 208 & $-10,9$ & 4,1 & 1.601 & 8,5 \\
\hline 208 & $-10,8$ & 4,0 & 1.223 & 8,7 \\
\hline 208 & $-10,8$ & 3,7 & 870 & 9,4 \\
\hline 207 & $-10,7$ & 3,1 & 505 & 11,4 \\
\hline 207 & $-10,7$ & 2,5 & 316 & 14,0 \\
\hline
\end{tabular}




\begin{tabular}{|c|c|c|c|c|}
\hline $\begin{array}{c}p_{\text {sat }} \\
(\boldsymbol{k P a})\end{array}$ & $\begin{array}{c}T_{\text {sat }} \\
\left({ }^{\circ} \boldsymbol{C}\right)\end{array}$ & $\begin{array}{c}\Delta T \\
\left({ }^{o} C\right)\end{array}$ & $\begin{array}{c}h \\
\left(k W / m^{2}\right)\end{array}$ & $\begin{array}{c}\text { incerteza } \\
(\%)\end{array}$ \\
\hline 261 & $-4,8$ & 10,0 & 11.547 & 3,5 \\
\hline 262 & $-4,7$ & 9,4 & 10.429 & 3,7 \\
\hline 261 & $-4,7$ & 8,7 & 9.284 & 4,0 \\
\hline 260 & $-4,8$ & 8,0 & 8.105 & 4,4 \\
\hline 260 & $-4,9$ & 7,3 & 6.776 & 4,8 \\
\hline 260 & $-4,8$ & 6,3 & 5.343 & 5,5 \\
\hline 260 & $-4,7$ & 5,6 & 4.438 & 6,2 \\
\hline 260 & $-4,7$ & 5,1 & 3.842 & 6,7 \\
\hline 260 & $-4,8$ & 4,8 & 3.427 & 7,3 \\
\hline 259 & $-4,8$ & 4,3 & 2.789 & 8,0 \\
\hline 261 & $-4,7$ & 4,2 & 2.371 & 8,3 \\
\hline 261 & $-4,6$ & 3,8 & 2.184 & 9,1 \\
\hline 261 & $-4,7$ & 3,6 & 1.860 & 9,7 \\
\hline 260 & $-4,7$ & 3,3 & 1.499 & 10,5 \\
\hline 259 & $-4,7$ & 2,9 & 1.128 & 12,1 \\
\hline 258 & $-4,7$ & 2,5 & 624 & 14,1 \\
\hline 258 & $-4,7$ & 2,0 & 453 & 17,2 \\
\hline 385 & 6,7 & 9,1 & 12.547 & 3,8 \\
\hline 386 & 6,7 & 8,7 & 11.644 & 4,0 \\
\hline 385 & 6,7 & 7,9 & 10.313 & 4,4 \\
\hline 385 & 6,7 & 7,3 & 9.096 & 4,8 \\
\hline 386 & 6,8 & 6,5 & 7.777 & 5,3 \\
\hline 384 & 6,7 & 6,0 & 6.867 & 5,8 \\
\hline 384 & 6,7 & 5,4 & 5.985 & 6,4 \\
\hline 383 & 6,7 & 5,0 & 5.472 & 6,9 \\
\hline 384 & 6,7 & 4,8 & 5.126 & 7,3 \\
\hline 386 & 6,9 & 4,5 & 4.391 & 7,8 \\
\hline 385 & 6,8 & 4,2 & 3.942 & 8,3 \\
\hline 384 & 6,8 & 3,7 & 3.268 & 9,4 \\
\hline 384 & 6,8 & 3,4 & 2.832 & 10,2 \\
\hline 384 & 6,7 & 3,2 & 2.604 & 10,8 \\
\hline 384 & 6,8 & 3,0 & 2.209 & 11,4 \\
\hline 384 & 6,8 & 2,7 & 1.827 & 12,9 \\
\hline 384 & 6,8 & 2,4 & 1.311 & 14,4 \\
\hline 385 & 6,8 & 2,1 & 794 & 16,9 \\
\hline 385 & 6,9 & 1,7 & 460 & 20,2 \\
\hline 500 & 15,2 & 8,4 & 13.624 & 4,1 \\
\hline 500 & 15,2 & 8,0 & 12.537 & 4,4 \\
\hline 497 & 15,1 & 7,3 & 11.020 & 4,8 \\
\hline 498 & 15,2 & 6,9 & 9.466 & 5,0 \\
\hline 500 & 15,3 & 6,2 & 7.893 & 5,6 \\
\hline 499 & 15,3 & 5,7 & 7.066 & 6,1 \\
\hline 495 & 15,1 & 5,2 & 6.366 & 6,7 \\
\hline 497 & 15,2 & 4,9 & 5.575 & 7,1 \\
\hline 497 & 15,2 & 4,7 & 5.200 & 7,4 \\
\hline 497 & 15,2 & 4,3 & 4.443 & 8,1 \\
\hline 498 & 15,3 & 4,1 & 3.980 & 8,5 \\
\hline 497 & 15,2 & 3,7 & 3.286 & 9,5 \\
\hline 497 & 15,2 & 3,4 & 2.820 & 10,2 \\
\hline 497 & 15,2 & 3,2 & 2.583 & 10,8 \\
\hline 497 & 15,2 & 3,0 & 2.150 & 11,7 \\
\hline 497 & 15,2 & 2,8 & 1.718 & 12,6 \\
\hline 496 & 15,1 & 2,4 & 1.291 & 14,3 \\
\hline 495 & 15,2 & 2,3 & 703 & 15,1 \\
\hline 495 & 15,2 & 2,1 & 397 & 16,9 \\
\hline 732 & 29,0 & 7,9 & 14.269 & 4,4 \\
\hline 734 & 29,1 & 7,4 & 13.124 & 4,7 \\
\hline 732 & 28,9 & 6,7 & 11.894 & 5,2 \\
\hline 734 & 29,0 & 6,2 & 10.587 & 5,6 \\
\hline 732 & 29,0 & 5,5 & 8.788 & 6,3 \\
\hline 732 & 29,0 & 4,7 & 7.154 & 7,4 \\
\hline 731 & 28,9 & 4,2 & 5.916 & 8,3 \\
\hline
\end{tabular}

\begin{tabular}{|c|c|c|c|c|}
\hline $\begin{array}{c}p_{\text {sat }} \\
(\boldsymbol{k P a})\end{array}$ & $\begin{array}{c}T_{\text {sat }} \\
\left({ }^{\circ} \boldsymbol{C}\right)\end{array}$ & $\begin{array}{c}\Delta T \\
\left({ }^{o} C\right)\end{array}$ & $\begin{array}{c}h \\
\left(k W / m^{2}\right)\end{array}$ & $\begin{array}{c}\text { incerteza } \\
(\%)\end{array}$ \\
\hline 732 & 29,0 & 4,0 & 4.878 & 8,6 \\
\hline 731 & 29,0 & 3,7 & 4.525 & 9,5 \\
\hline 734 & 29,0 & 3,2 & 3.739 & 10,7 \\
\hline 732 & 29,0 & 3,0 & 3.314 & 11,6 \\
\hline 731 & 28,9 & 2,9 & 2.940 & 12,1 \\
\hline 735 & 29,1 & 2,8 & 2.357 & 12,2 \\
\hline 733 & 29,1 & 2,6 & 1.866 & 13,3 \\
\hline 733 & 29,1 & 2,4 & 1.394 & 14,5 \\
\hline 733 & 29,1 & 2,2 & 800 & 16,1 \\
\hline 732 & 29,1 & 1,9 & 466 & 18,0 \\
\hline 850 & 34,6 & 7,4 & 15.139 & 4,7 \\
\hline 847 & 34,6 & 6,9 & 14.007 & 5,0 \\
\hline 850 & 34,7 & 6,4 & 12.742 & 5,4 \\
\hline 848 & 34,6 & 5,9 & 11.046 & 5,9 \\
\hline 849 & 34,6 & 5,3 & 9.302 & 6,5 \\
\hline 850 & 34,7 & 4,5 & 7.281 & 7,7 \\
\hline 850 & 34,7 & 4,0 & 6.091 & 8,7 \\
\hline 850 & 34,7 & 3,6 & 5.238 & 9,6 \\
\hline 851 & 34,7 & 3,4 & 4.767 & 10,1 \\
\hline 850 & 34,7 & 3,2 & 3.831 & 10,9 \\
\hline 850 & 34,7 & 3,1 & 3.141 & 11,2 \\
\hline 849 & 34,7 & 3,0 & 2.789 & 11,8 \\
\hline 849 & 34,7 & 2,8 & 2.385 & 12,4 \\
\hline 848 & 34,6 & 2,6 & 1.863 & 13,4 \\
\hline 848 & 34,7 & 2,4 & 1.405 & 14,3 \\
\hline 848 & 34,6 & 2,1 & 778 & 16,6 \\
\hline 850 & 34,6 & 1,9 & 388 & 18,8 \\
\hline 1.089 & 446 & 70 & 16.530 & 50 \\
\hline 1.089 & 44,6 & 6,5 & 15.138 & 5,4 \\
\hline 1.084 & 44,4 & 5,9 & 13.691 & 5,8 \\
\hline 1.083 & 44,4 & 5,5 & 12.175 & 6,3 \\
\hline 1.084 & 44,4 & 4,8 & 10.225 & 7,2 \\
\hline 1.087 & 44,5 & 4,7 & 8.824 & 7,3 \\
\hline 1.084 & 44,4 & 4,3 & 7.597 & 8,1 \\
\hline 1.084 & 44,4 & 3,9 & 6.388 & 9,0 \\
\hline 1.086 & 44,5 & 3,5 & 5.257 & 9,8 \\
\hline 1.087 & 44,5 & 3,4 & 4.796 & 10,1 \\
\hline 1.086 & 44,5 & 3,1 & 3.946 & 11,2 \\
\hline 1.086 & 44,5 & 2,9 & 3.472 & 12,0 \\
\hline 1.088 & 44,6 & 2,8 & 2.953 & 12,2 \\
\hline 1.088 & 44,6 & 2,7 & 2.476 & 13,0 \\
\hline 1.087 & 44,5 & 2,5 & 1.956 & 14,0 \\
\hline 1.086 & 44,4 & 2,0 & 1.567 & 17,2 \\
\hline 1.087 & 44,4 & 1,5 & 1.032 & 22,4 \\
\hline 1.080 & 44,1 & 1,3 & 517 & 27,2 \\
\hline \multicolumn{5}{|c|}{ Superfície de latão; $R a=0,08 \pm 0,01 \mu \mathrm{m}$} \\
\hline 209 & $-11,1$ & 15,0 & 4.936 & 2,4 \\
\hline 209 & $-11,1$ & 14,8 & 4.532 & 2,4 \\
\hline 209 & $-11,1$ & 14,5 & 4.158 & 2,4 \\
\hline 210 & $-11,0$ & 14,1 & 3.827 & 2,5 \\
\hline 208 & $-11,2$ & 13,8 & 3.352 & 2,5 \\
\hline 208 & $-11,2$ & 13,3 & 2.852 & 2,6 \\
\hline 208 & $-11,2$ & 12,7 & 2.383 & 2,8 \\
\hline 208 & $-11,2$ & 12,3 & 2.027 & 2,9 \\
\hline 208 & $-11,1$ & 11,9 & 1.844 & 3,0 \\
\hline 207 & $-11,2$ & 11,5 & 1.582 & 3,1 \\
\hline 208 & $-11,2$ & 11,2 & 1.383 & 3,2 \\
\hline 206 & $-11,2$ & 10,5 & 1.086 & 3,4 \\
\hline 207 & $-11,1$ & 9,8 & 923 & 3,6 \\
\hline 208 & $-11,1$ & 9,3 & 815 & 3,8 \\
\hline 208 & $-11,0$ & 8,5 & 755 & 4,2 \\
\hline 208 & $-11,0$ & 7,3 & 615 & 4,9 \\
\hline 207 & $-11,0$ & 6,0 & 498 & 6,0 \\
\hline
\end{tabular}




\begin{tabular}{|c|c|c|c|c|}
\hline $\begin{array}{c}p_{\text {sat }} \\
(\boldsymbol{k P a})\end{array}$ & $\begin{array}{c}T_{\text {sat }} \\
\left({ }^{o} C\right)\end{array}$ & $\begin{array}{c}\Delta \boldsymbol{T} \\
\left({ }^{o} \boldsymbol{C}\right)\end{array}$ & $\begin{array}{c}h \\
\left(k W / m^{2}\right)\end{array}$ & $\begin{array}{c}\text { incerteza } \\
(\%)\end{array}$ \\
\hline 207 & $-11,0$ & 4,1 & 351 & 8,7 \\
\hline 207 & $-10,9$ & 2,5 & 312 & 13,9 \\
\hline 265 & $-4,7$ & 14,0 & 5.440 & 2,5 \\
\hline 264 & $-4,8$ & 13,7 & 4.962 & 2,5 \\
\hline 264 & $-4,7$ & 13,4 & 4.572 & 2,6 \\
\hline 264 & $-4,7$ & 13,0 & 4.080 & 2,7 \\
\hline 263 & $-4,8$ & 12,6 & 3.594 & 2,8 \\
\hline 263 & $-4,8$ & 12,2 & 3.143 & 2,9 \\
\hline 262 & $-4,8$ & 11,5 & 2.612 & 3,0 \\
\hline 263 & $-4,7$ & 11,1 & 2.250 & 3,1 \\
\hline 262 & $-4,8$ & 10,9 & 2.068 & 3,2 \\
\hline 262 & $-4,8$ & 10,3 & 1.738 & 3,4 \\
\hline 261 & $-4,8$ & 10,0 & 1.517 & 3,5 \\
\hline 261 & $-4,8$ & 9,5 & 1.235 & 3,7 \\
\hline 261 & $-4,8$ & 8,8 & 1.032 & 4,0 \\
\hline 261 & $-4,8$ & 8,4 & 888 & 4,2 \\
\hline 262 & $-4,7$ & 8,0 & 771 & 4,4 \\
\hline 262 & $-4,7$ & 7,1 & 636 & 5,0 \\
\hline 262 & $-4,7$ & 5,8 & 509 & 6,1 \\
\hline 261 & $-4,6$ & 4,2 & 364 & 8,4 \\
\hline 261 & $-4,6$ & 2,9 & 271 & 12,4 \\
\hline 386 & 6,7 & 12,2 & 6.161 & 2,9 \\
\hline 385 & 6,7 & 11,9 & 5.659 & 2,9 \\
\hline 383 & 6,6 & 9,9 & 3.072 & 3,5 \\
\hline 383 & 6,7 & 9,4 & 2.632 & 3,7 \\
\hline 384 & 6,7 & 9,2 & 2.460 & 3,8 \\
\hline 384 & 6,7 & 8,7 & 2.040 & 4,0 \\
\hline 384 & 6,7 & 8,3 & 1.792 & 4,2 \\
\hline 385 & 6,7 & 7,8 & 1.424 & 4,5 \\
\hline 384 & 6,8 & 7,4 & 1.237 & 4,8 \\
\hline 385 & 6,8 & 7,0 & 1.073 & 5,0 \\
\hline 384 & 6,8 & 6,7 & 903 & 5,2 \\
\hline 384 & 6,8 & 6,2 & 715 & 5,7 \\
\hline 383 & 6,8 & 5,4 & 561 & 6,6 \\
\hline 383 & 6,8 & 4,2 & 398 & 8,4 \\
\hline 383 & 6,8 & 2,9 & 269 & 12,4 \\
\hline 500 & 15,2 & 11,0 & 7.094 & 3,2 \\
\hline 499 & 15,2 & 10,7 & 6.304 & 3,3 \\
\hline 500 & 15,3 & 10,4 & 5.756 & 3,3 \\
\hline 499 & 15,2 & 10,1 & 5.257 & 3,4 \\
\hline 497 & 15,1 & 9,8 & 4.636 & 3,5 \\
\hline 497 & 15,1 & 9,4 & 4.043 & 3,7 \\
\hline 497 & 15,1 & 8,8 & 3.386 & 3,9 \\
\hline 498 & 15,2 & 8,4 & 2.954 & 4,1 \\
\hline 499 & 15,2 & 8,3 & 2.760 & 4,2 \\
\hline 498 & 15,2 & 7,8 & 2.289 & 4,5 \\
\hline 498 & 15,2 & 7,5 & 2.025 & 4,7 \\
\hline 498 & 15,2 & 7,0 & 1.638 & 5,0 \\
\hline 497 & 15,1 & 6,6 & 1.385 & 5,3 \\
\hline 498 & 15,2 & 6,3 & 1.204 & 5,5 \\
\hline 498 & 15,2 & 5,8 & 1.024 & 6,1 \\
\hline 498 & 15,2 & 5,5 & 862 & 6,4 \\
\hline 497 & 15,2 & 4,8 & 631 & 7,3 \\
\hline 497 & 15,2 & 3,8 & 399 & 9,4 \\
\hline 496 & 15,2 & 2,8 & 263 & 12,8 \\
\hline 737 & 29,1 & 8,9 & 8.616 & 3,9 \\
\hline 737 & 29,1 & 8,7 & 7.908 & 4,0 \\
\hline 738 & 29,1 & 8,5 & 7.166 & 4,1 \\
\hline 736 & 29,0 & 8,2 & 6.369 & 4,2 \\
\hline 735 & 29,0 & 7,9 & 5.766 & 4,4 \\
\hline 734 & 28,9 & 7,5 & 4.996 & 4,6 \\
\hline 734 & 28,9 & 7,1 & 4.237 & 4,9 \\
\hline
\end{tabular}

\begin{tabular}{|c|c|c|c|c|}
\hline $\begin{array}{c}p_{\text {sat }} \\
(\boldsymbol{k P a})\end{array}$ & $\begin{array}{l}T_{\text {sat }} \\
\left({ }^{o} \boldsymbol{C}\right)\end{array}$ & $\begin{array}{c}\Delta T \\
\left({ }^{o} C\right)\end{array}$ & $\begin{array}{c}h \\
\left(k W / m^{2}\right)\end{array}$ & $\begin{array}{c}\text { incerteza } \\
(\%)\end{array}$ \\
\hline 734 & 28,9 & 6,9 & 3.621 & 5,1 \\
\hline 734 & 28,9 & 6,7 & 3.354 & 5,2 \\
\hline 735 & 28,9 & 6,3 & 2.807 & 5,5 \\
\hline 737 & 29,1 & 6,0 & 2.492 & 5,8 \\
\hline 734 & 28,9 & 5,7 & 2.038 & 6,1 \\
\hline 736 & 29,0 & 5,4 & 1.757 & 6,4 \\
\hline 733 & 28,9 & 5,1 & 1.498 & 6,8 \\
\hline 736 & 29,0 & 4,9 & 1.290 & 7,1 \\
\hline 736 & 29,0 & 4,5 & 1.021 & 7,7 \\
\hline 735 & 29,0 & 4,1 & 734 & 8,5 \\
\hline 735 & 29,0 & 3,3 & 438 & 10,6 \\
\hline 735 & 29,0 & 2,7 & 290 & 13,1 \\
\hline 855 & 34,7 & 8,0 & 9.376 & 4,3 \\
\hline 853 & 34,6 & 7,8 & 8.614 & 4,4 \\
\hline 854 & 34,6 & 7,7 & 7.935 & 4,5 \\
\hline 854 & 34,6 & 7,4 & 7.163 & 4,7 \\
\hline 853 & 34,6 & 7,1 & 6.392 & 4,9 \\
\hline 854 & 34,6 & 6,8 & 5.648 & 5,1 \\
\hline 854 & 34,6 & 6,3 & 4.721 & 5,5 \\
\hline 854 & 34,6 & 6,0 & 4.148 & 5,7 \\
\hline 853 & 34,6 & 5,9 & 3.831 & 5,9 \\
\hline 853 & 34,6 & 5,5 & 3.176 & 6,3 \\
\hline 853 & 34,6 & 5,3 & 2.848 & 6,6 \\
\hline 853 & 34,6 & 4,9 & 2.317 & 7,0 \\
\hline 852 & 34,5 & 4,7 & 1.927 & 7,5 \\
\hline 853 & 34,6 & 4,5 & 1.713 & 7,7 \\
\hline 852 & 34,6 & 4,3 & 1.394 & 8,2 \\
\hline 854 & 34,6 & 4,1 & 1.111 & 8,6 \\
\hline 852 & 34,5 & 3,8 & 797 & 9,3 \\
\hline 852 & 34,5 & 3,2 & 446 & 10,9 \\
\hline 1.102 & 44,7 & 7,2 & 10.563 & 4,8 \\
\hline 1.101 & 44,6 & 7,0 & 9.735 & 5,0 \\
\hline 1.103 & 44,7 & 6,8 & 9.027 & 5,1 \\
\hline 1.100 & 44,6 & 6,5 & 8.013 & 5,3 \\
\hline 1.102 & 44,7 & 6,3 & 7.116 & 5,5 \\
\hline 1.098 & 44,6 & 6,0 & 6.182 & 5,8 \\
\hline 1.099 & 44,6 & 5,7 & 5.257 & 6,1 \\
\hline 1.097 & 44,6 & 5,5 & 4.673 & 6,4 \\
\hline 1.097 & 44,5 & 5,3 & 4.293 & 6,6 \\
\hline 1.100 & 44,6 & 4,9 & 3.395 & 7,1 \\
\hline 1.104 & 44,7 & 4,8 & 3.217 & 7,2 \\
\hline 1.101 & 44,7 & 4,4 & 2.549 & 7,9 \\
\hline 1.100 & 44,7 & 4,2 & 2.167 & 8,3 \\
\hline 1.103 & 44,7 & 4,1 & 1.832 & 8,5 \\
\hline 1.098 & 44,6 & 3,9 & 1.622 & 9,0 \\
\hline 1.098 & 44,6 & 3,7 & 1.227 & 9,5 \\
\hline 1.097 & 44,5 & 3,4 & 861 & 10,3 \\
\hline 1.097 & 44,5 & 3,1 & 499 & 11,5 \\
\hline
\end{tabular}


iv. Resultados para o $R-22$

\begin{tabular}{|c|c|c|c|c|}
\hline $\begin{array}{c}p_{\text {sat }} \\
(\boldsymbol{k P a})\end{array}$ & $\begin{array}{c}T_{\text {sat }} \\
\left({ }^{o} C\right)\end{array}$ & $\begin{array}{c}\Delta T \\
\left({ }^{o} C\right)\end{array}$ & $\begin{array}{c}\boldsymbol{h} \\
\left(\boldsymbol{k} W / \boldsymbol{m}^{2}\right)\end{array}$ & $\begin{array}{c}\text { incerteza } \\
(\%)\end{array}$ \\
\hline \multicolumn{5}{|c|}{ Superfície de cobre ; Ra $=0,07 \pm 0,02 \mu \mathrm{m}$} \\
\hline 313 & $-13,1$ & 14,9 & 7.722 & 2,4 \\
\hline 312 & $-13,1$ & 14,3 & 6.827 & 2,4 \\
\hline 311 & $-13,1$ & 13,7 & 5.930 & 2,5 \\
\hline 310 & $-13,1$ & 13,0 & 4.968 & 2,7 \\
\hline 310 & $-13,1$ & 12,3 & 4.027 & 2,8 \\
\hline 309 & $-13,1$ & 11,0 & 2.963 & 3,2 \\
\hline 309 & $-13,1$ & 10,6 & 2.557 & 3,3 \\
\hline 309 & $-13,1$ & 10,3 & 2.357 & 3,4 \\
\hline 310 & $-13,0$ & 9,8 & 1.977 & 3,6 \\
\hline 309 & $-13,0$ & 9,4 & 1.690 & 3,7 \\
\hline 308 & $-13,1$ & 9,0 & 1.366 & 3,9 \\
\hline 308 & $-13,0$ & 8,5 & 1.123 & 4,1 \\
\hline 308 & $-13,0$ & 8,1 & 995 & 4,3 \\
\hline 308 & $-12,9$ & 7,5 & 878 & 4,7 \\
\hline 307 & $-12,9$ & 6,8 & 694 & 5,2 \\
\hline 307 & $-12,9$ & 5,3 & 555 & 6,7 \\
\hline 306 & $-12,9$ & 3,6 & 475 & 9,8 \\
\hline 305 & $-13,0$ & 1,4 & 517 & 24,3 \\
\hline 449 & $-2,6$ & 13,1 & 8.761 & 2,7 \\
\hline 450 & $-2,6$ & 12,6 & 7.665 & 2,8 \\
\hline 450 & $-2,5$ & 12,1 & 6.765 & 2,9 \\
\hline 448 & $-2,6$ & 11,4 & 5.692 & 3,1 \\
\hline 448 & $-2,6$ & 10,5 & 4.600 & 3,3 \\
\hline 451 & $-2,5$ & 9,4 & 3.543 & 3,7 \\
\hline 450 & $-2,5$ & 8,6 & 3.101 & 4,0 \\
\hline 450 & $-2,5$ & 8,4 & 2.877 & 4,1 \\
\hline 449 & $-2,6$ & 7,9 & 2.421 & 4,4 \\
\hline 450 & $-2,5$ & 7,7 & 2.192 & 4,5 \\
\hline 449 & $-2,5$ & 7,1 & 1.764 & 4,9 \\
\hline 448 & $-2,5$ & 6,8 & 1.480 & 5,2 \\
\hline 448 & $-2,6$ & 6,5 & 1.279 & 5,4 \\
\hline 448 & $-2,5$ & 6,1 & 1.075 & 5,7 \\
\hline 448 & $-2,5$ & 5,6 & 897 & 6,2 \\
\hline 447 & $-2,5$ & 5,0 & 685 & 7,1 \\
\hline 446 & $-2,4$ & 3,3 & 481 & 10,8 \\
\hline 446 & $-2,5$ & 1,9 & 420 & 18,2 \\
\hline 596 & 5,8 & 11,6 & 9.645 & 3,0 \\
\hline 594 & 5,8 & 11,2 & 8.842 & 3,1 \\
\hline 593 & 5,8 & 10,6 & 7.582 & 3,3 \\
\hline 595 & 5,8 & 10,1 & 6.576 & 3,5 \\
\hline
\end{tabular}

\begin{tabular}{|c|c|c|c|c|}
\hline $\begin{array}{c}p_{\text {sat }} \\
(\boldsymbol{k P a})\end{array}$ & $\begin{array}{l}T_{\text {sat }} \\
\left({ }^{\circ} \mathrm{C}\right)\end{array}$ & $\begin{array}{c}\Delta T \\
\left({ }^{o} C\right)\end{array}$ & $\begin{array}{c}\boldsymbol{h} \\
\left(\boldsymbol{k} W / \boldsymbol{m}^{2}\right)\end{array}$ & $\begin{array}{c}\text { incerteza } \\
(\%)\end{array}$ \\
\hline 591 & 5,7 & 9,2 & 5.260 & 3,8 \\
\hline 591 & 5,7 & 8,2 & 4.032 & 4,3 \\
\hline 591 & 5,7 & 7,7 & 3.522 & 4,5 \\
\hline 591 & 5,7 & 7,5 & 3.314 & 4,7 \\
\hline 592 & 5,7 & 6,9 & 2.757 & 5,0 \\
\hline 591 & 5,8 & 6,5 & 2.481 & 5,3 \\
\hline 591 & 5,8 & 6,0 & 2.045 & 5,8 \\
\hline 591 & 5,8 & 5,7 & 1.735 & 6,2 \\
\hline 590 & 5,7 & 5,4 & 1.510 & 6,5 \\
\hline 588 & 5,7 & 5,0 & 1.239 & 7,0 \\
\hline 590 & 5,8 & 4,7 & 1.040 & 7,4 \\
\hline 589 & 5,8 & 4,3 & 786 & 8,2 \\
\hline 589 & 5,9 & 3,5 & 469 & 10,0 \\
\hline 588 & 5,9 & 2,5 & 324 & 13,9 \\
\hline 593 & 5,8 & 11,9 & 9.662 & 2,9 \\
\hline 593 & 5,7 & 11,4 & 8.583 & 3,1 \\
\hline 591 & 5,6 & 11,0 & 7.702 & 3,2 \\
\hline 590 & 5,6 & 10,2 & 6.243 & 3,4 \\
\hline 593 & 5,8 & 9,5 & 5.184 & 3,7 \\
\hline 590 & 5,7 & 8,1 & 3.943 & 4,3 \\
\hline 591 & 5,7 & 7,7 & 3.641 & 4,5 \\
\hline 593 & 5,8 & 7,2 & 3.306 & 4,8 \\
\hline 594 & 5,8 & 6,7 & 2.813 & 5,2 \\
\hline 593 & 5,8 & 6,4 & 2.561 & 5,5 \\
\hline 593 & 5,8 & 5,9 & 2.058 & 5,9 \\
\hline 593 & 5,8 & 5,5 & 1.773 & 6,3 \\
\hline 590 & 5,7 & 5,2 & 1.573 & 6,7 \\
\hline 590 & 5,7 & 5,1 & 1.342 & 6,9 \\
\hline 589 & 5,7 & 4,7 & 1.000 & 7,4 \\
\hline 588 & 5,7 & 3,5 & 479 & 10,2 \\
\hline 737 & 12,7 & 10,7 & 10.594 & 3,3 \\
\hline 738 & 12,7 & 10,3 & 9.525 & 3,4 \\
\hline 738 & 12,7 & 9,8 & 8.419 & 3,5 \\
\hline 736 & 12,7 & 9,1 & 7.002 & 3,8 \\
\hline 739 & 12,8 & 8,5 & 5.740 & 4,1 \\
\hline 735 & 12,7 & 7,5 & 4.347 & 4,6 \\
\hline 737 & 12,7 & 7,1 & 3.813 & 4,9 \\
\hline 737 & 12,7 & 6,8 & 3.591 & 5,1 \\
\hline 737 & 12,7 & 6,3 & 3.084 & 5,5 \\
\hline 735 & 12,7 & 5,9 & 2.791 & 5,9 \\
\hline 736 & 12,8 & 5,5 & 2.285 & 6,3 \\
\hline
\end{tabular}




\begin{tabular}{|c|c|c|c|c|}
\hline $\begin{array}{c}p_{\text {sat }} \\
(\boldsymbol{k P a})\end{array}$ & $\begin{array}{l}T_{\text {sat }} \\
\left({ }^{\circ} \mathrm{C}\right)\end{array}$ & $\begin{array}{c}\Delta T \\
\left({ }^{o} C\right)\end{array}$ & $\begin{array}{c}h \\
\left(k W / m^{2}\right)\end{array}$ & $\begin{array}{c}\text { incerteza } \\
(\%)\end{array}$ \\
\hline 735 & 12,7 & 5,1 & 1.928 & 6,8 \\
\hline 738 & 12,8 & 4,9 & 1.672 & 7,2 \\
\hline 737 & 12,8 & 4,6 & 1.459 & 7,5 \\
\hline 737 & 12,8 & 4,3 & 1.156 & 8,2 \\
\hline 736 & 12,8 & 3,9 & 836 & 9,0 \\
\hline 735 & 12,8 & 3,3 & 503 & 10,6 \\
\hline 735 & 12,8 & 2,6 & 312 & 13,4 \\
\hline 741 & 12,7 & 10,9 & 10.485 & 3,2 \\
\hline 739 & 12,7 & 10,5 & 9.200 & 3,3 \\
\hline 736 & 12,6 & 10,1 & 7.851 & 3,4 \\
\hline 737 & 12,6 & 9,5 & 6.846 & 3,7 \\
\hline 737 & 12,7 & 8,7 & 5.603 & 4,0 \\
\hline 737 & 12,7 & 7,6 & 4.319 & 4,6 \\
\hline 738 & 12,7 & 7,1 & 3.867 & 4,9 \\
\hline 739 & 12,8 & 6,8 & 3.607 & 5,1 \\
\hline 737 & 12,7 & 6,2 & 3.070 & 5,6 \\
\hline 737 & 12,7 & 5,9 & 2.826 & 5,9 \\
\hline 736 & 12,7 & 5,3 & 2.281 & 6,5 \\
\hline 736 & 12,7 & 5,0 & 1.980 & 6,9 \\
\hline 738 & 12,8 & 4,8 & 1.734 & 7,3 \\
\hline 738 & 12,8 & 4,5 & 1.466 & 7,8 \\
\hline 737 & 12,8 & 4,2 & 1.202 & 8,4 \\
\hline 737 & 12,8 & 3,7 & 878 & 9,3 \\
\hline 736 & 12,8 & 3,2 & 501 & 10,9 \\
\hline 735 & 12,8 & 2,6 & 308 & 13,6 \\
\hline 883 & 18,8 & 9,2 & 12.214 & 3,8 \\
\hline 883 & 18,8 & 8,9 & 11.154 & 3,9 \\
\hline 883 & 18,8 & 8,4 & 9.453 & 4,1 \\
\hline 880 & 18,7 & 7,9 & 8.396 & 4,4 \\
\hline 881 & 18,8 & 7,3 & 6.715 & 4,8 \\
\hline 878 & 18,7 & 6,4 & 5.099 & 5,4 \\
\hline 877 & 18,6 & 6,0 & 4.462 & 5,8 \\
\hline 877 & 18,6 & 5,8 & 4.229 & 5,9 \\
\hline 876 & 18,6 & 5,5 & 3.548 & 6,4 \\
\hline 879 & 18,7 & 5,2 & 3.145 & 6,7 \\
\hline 879 & 18,7 & 4,8 & 2.589 & 7,2 \\
\hline 877 & 18,6 & 4,5 & 2.148 & 7,7 \\
\hline 879 & 18,7 & 4,3 & 1.903 & 8,0 \\
\hline 877 & 18,6 & 4,1 & 1.658 & 8,5 \\
\hline 876 & 18,6 & 3,7 & 1.274 & 9,3 \\
\hline 877 & 18,6 & 3,5 & 932 & 10,1 \\
\hline 875 & 18,6 & 3,0 & 532 & 11,8 \\
\hline 874 & 18,6 & 2,5 & 334 & 13,9 \\
\hline 879 & 18,7 & 10,0 & 11.103 & 3,5 \\
\hline 878 & 18,7 & 9,7 & 9.989 & 3,6 \\
\hline 878 & 18,7 & 9,2 & 8.790 & 3,8 \\
\hline 878 & 18,7 & 8,7 & 7.436 & 4,0 \\
\hline 874 & 18,5 & 8,0 & 6.060 & 4,4 \\
\hline 876 & 18,6 & 7,1 & 4.736 & 4,9 \\
\hline 879 & 18,7 & 6,4 & 4.055 & 5,4 \\
\hline 879 & 18,7 & 6,3 & 3.877 & 5,5 \\
\hline 879 & 18,7 & 5,8 & 3.318 & 6,0 \\
\hline 880 & 18,8 & 5,5 & 3.059 & 6,4 \\
\hline 879 & 18,8 & 5,0 & 2.505 & 7,0 \\
\hline 878 & 18,8 & 4,7 & 2.125 & 7,4 \\
\hline 878 & 18,7 & 4,5 & 1.841 & 7,8 \\
\hline 876 & 18,7 & 4,2 & 1.554 & 8,3 \\
\hline 877 & 18,7 & 3,9 & 1.273 & 8,9 \\
\hline 876 & 18,7 & 3,6 & 927 & 9,8 \\
\hline 877 & 18,7 & 3,0 & 515 & 11,7 \\
\hline 876 & 18,7 & 2,3 & 316 & 15,3 \\
\hline 1.026 & 24,0 & 9,3 & 12.072 & 3,7 \\
\hline
\end{tabular}

\begin{tabular}{|c|c|c|c|c|}
\hline $\begin{array}{c}p_{\text {sat }} \\
(\boldsymbol{k P a})\end{array}$ & $\begin{array}{c}\boldsymbol{T}_{\text {sat }} \\
\left({ }^{o} \boldsymbol{C}\right)\end{array}$ & $\begin{array}{c}\Delta T \\
\left({ }^{o} C\right)\end{array}$ & $\begin{array}{c}h \\
\left(k W / m^{2}\right)\end{array}$ & $\begin{array}{c}\text { incerteza } \\
(\%)\end{array}$ \\
\hline 1.028 & 24,1 & 9,0 & 10.922 & 3,9 \\
\hline 1.024 & 24,0 & 8,5 & 9.495 & 4,1 \\
\hline 1.026 & 24,1 & 8,0 & 8.035 & 4,3 \\
\hline 1.025 & 24,1 & 7,4 & 6.599 & 4,7 \\
\hline 1.024 & 24,0 & 6,5 & 5.057 & 5,3 \\
\hline 1.025 & 24,1 & 6,1 & 4.489 & 5,7 \\
\hline 1.024 & 24,1 & 5,9 & 4.123 & 5,9 \\
\hline 1.028 & 24,1 & 9.7 & 11.857 & 3,6 \\
\hline 1.024 & 24,0 & 9,3 & 10.516 & 3,7 \\
\hline 1.027 & 24,1 & 8,9 & 9.232 & 3,9 \\
\hline 1.029 & 24,2 & 8,3 & 7.824 & 4,2 \\
\hline 1.026 & 24,2 & 7,7 & 6.504 & 4,5 \\
\hline 1.023 & 24,0 & 6,8 & 4.817 & 5,1 \\
\hline 1.024 & 24,1 & 6,4 & 4.251 & 5,4 \\
\hline 1.027 & 24,2 & 6,1 & 3.983 & 5,7 \\
\hline 1.027 & 24,2 & 5,6 & 3.379 & 6,2 \\
\hline 1.028 & 24,2 & 5,4 & 3.091 & 6,5 \\
\hline 1.028 & 24,3 & 5,0 & 2.595 & 7,0 \\
\hline 1.028 & 24,2 & 4,6 & 2.143 & 7,6 \\
\hline 1.028 & 24,2 & 4,4 & 1.893 & 8,0 \\
\hline 1.027 & 24,2 & 4,1 & 1.582 & 8,5 \\
\hline 1.026 & 24,2 & 3,8 & 1.284 & 9,1 \\
\hline 1.025 & 24,2 & 3,5 & 916 & 10,1 \\
\hline 1.026 & 24,2 & 3,0 & 539 & 11,5 \\
\hline 1.024 & 24,1 & 2,6 & 324 & 13,7 \\
\hline
\end{tabular}

Superfície de cobre; $\mathrm{Ra}=0, \mathbf{4 7} \pm 0,05 \mu \mathrm{m}$

\begin{tabular}{|c|c|c|c|c|}
\hline 317 & $-12,8$ & 11,3 & 9.866 & 3,1 \\
\hline 316 & $-12,9$ & 10,9 & 8.838 & 3,2 \\
\hline 314 & $-12,9$ & 10,5 & 7.894 & 3,3 \\
\hline 312 & $-13,1$ & 9,9 & 6.500 & 3,5 \\
\hline 311 & $-13,1$ & 9,2 & 5.296 & 3,8 \\
\hline 313 & $-12,9$ & 8,7 & 4.624 & 4,0 \\
\hline 315 & $-12,8$ & 8,2 & 3.952 & 4,2 \\
\hline 315 & $-12,7$ & 7,5 & 3.277 & 4,7 \\
\hline 314 & $-12,7$ & 7,2 & 2.626 & 4,9 \\
\hline 313 & $-12,7$ & 7,0 & 2.432 & 5,0 \\
\hline 312 & $-12,9$ & 6,1 & 1.995 & 5,7 \\
\hline 311 & $-12,9$ & 5,8 & 1.704 & 6,0 \\
\hline 311 & $-12,9$ & 5,6 & 1.483 & 6,3 \\
\hline 311 & $-12,9$ & 5,5 & 1.158 & 6,4 \\
\hline 310 & $-12,9$ & 5,2 & 940 & 6,7 \\
\hline 309 & $-12,9$ & 4,7 & 667 & 7,4 \\
\hline 309 & $-12,8$ & 3,5 & 474 & 10,0 \\
\hline 309 & $-12,7$ & 2,3 & 363 & 15,3 \\
\hline 458 & $-2,2$ & 9,9 & 11.164 & 3,5 \\
\hline 457 & $-2,2$ & 9,5 & 10.111 & 3,7 \\
\hline 456 & $-2,2$ & 9,1 & 8.968 & 3,8 \\
\hline 458 & $-2,1$ & 8,6 & 7.724 & 4,1 \\
\hline 458 & $-2,1$ & 7,9 & 6.161 & 4,4 \\
\hline 454 & $-2,3$ & 6,8 & 4.745 & 5,1 \\
\hline 455 & $-2,2$ & 6,3 & 3.912 & 5,5 \\
\hline 455 & $-2,2$ & 5,8 & 3.327 & 6,0 \\
\hline 455 & $-2,2$ & 5,4 & 3.019 & 6,5 \\
\hline 455 & $-2,1$ & 4,9 & 2.467 & 7,2 \\
\hline 455 & $-2,1$ & 4,5 & 2.112 & 7,7 \\
\hline 456 & $-2,1$ & 4,4 & 1.882 & 7,9 \\
\hline 456 & $-2,1$ & 4,2 & 1.610 & 8,4 \\
\hline 455 & $-2,0$ & 3,8 & 1.259 & 9,2 \\
\hline 455 & $-2,0$ & 3,6 & 930 & 9,7 \\
\hline 454 & $-2,0$ & 2,9 & 539 & 11,9 \\
\hline 453 & $-2,0$ & 2,0 & 434 & 17,8 \\
\hline 591 & 5,8 & 8,8 & 12.950 & 4,0 \\
\hline
\end{tabular}




\begin{tabular}{|c|c|c|c|c|}
\hline $\begin{array}{c}p_{\text {sat }} \\
(\boldsymbol{k P a})\end{array}$ & $\begin{array}{l}T_{\text {sat }} \\
\left({ }^{o} \mathrm{C}\right)\end{array}$ & $\begin{array}{c}\Delta T \\
\left({ }^{o} C\right)\end{array}$ & $\begin{array}{c}h \\
\left(k W / m^{2}\right)\end{array}$ & $\begin{array}{c}\text { incerteza } \\
(\%)\end{array}$ \\
\hline 589 & 5,6 & 8,5 & 11.448 & 4,1 \\
\hline 593 & 5,8 & 7,9 & 10.109 & 4,4 \\
\hline 595 & 5,9 & 7,5 & 8.801 & 4,6 \\
\hline 592 & 5,8 & 7,0 & 7.107 & 5,0 \\
\hline 590 & 5,7 & 6,1 & 5.439 & 5,7 \\
\hline 591 & 5,7 & 5,6 & 4.499 & 6,2 \\
\hline 590 & 5,7 & 5,1 & 3.745 & 6,8 \\
\hline 591 & 5,8 & 4,9 & 3.056 & 7,1 \\
\hline 590 & 5,7 & 4,5 & 2.822 & 7,8 \\
\hline 590 & 5,8 & 4,3 & 2.200 & 8,1 \\
\hline 591 & 5,8 & 4,2 & 2.010 & 8,2 \\
\hline 590 & 5,8 & 3,9 & 1.657 & 8,8 \\
\hline 589 & 5,8 & 3,6 & 1.339 & 9,6 \\
\hline 589 & 5,8 & 3,4 & 933 & 10,4 \\
\hline 586 & 5,7 & 2,6 & 620 & 13,3 \\
\hline 587 & 5,7 & 2,1 & 433 & 16,4 \\
\hline 593 & 5,7 & 9,1 & 12.568 & 3,8 \\
\hline 591 & 5,7 & 8,7 & 11.083 & 4,0 \\
\hline 592 & 5,7 & 8,3 & 9.717 & 4,2 \\
\hline 593 & 5,7 & 7,8 & 8.465 & 4,4 \\
\hline 592 & 5,7 & 7,0 & 6.747 & 4,9 \\
\hline 593 & 5,8 & 6,2 & 5.365 & 5,6 \\
\hline 593 & 5,8 & 5,6 & 4.448 & 6,2 \\
\hline 591 & 5,7 & 5,2 & 3.849 & 6,7 \\
\hline 591 & 5,7 & 4,9 & 3.451 & 7,1 \\
\hline 589 & 5,7 & 4,3 & 2.768 & 8,1 \\
\hline 590 & 5,7 & 4,1 & 2.446 & 8,5 \\
\hline 591 & 5,8 & 3,9 & 2.202 & 9,0 \\
\hline 590 & 5,7 & 3,6 & 1.819 & 9,7 \\
\hline 589 & 5,7 & 3,3 & 1.456 & 10,5 \\
\hline 588 & 5,7 & 3,1 & 1.077 & 11,2 \\
\hline 588 & 5,7 & 2,7 & 661 & 13,0 \\
\hline 587 & 5,8 & 1,9 & 426 & 18,3 \\
\hline 745 & 12,8 & 8,7 & 13.250 & 4,0 \\
\hline 745 & 12,9 & 8,3 & 11.858 & 4,2 \\
\hline 744 & 12,8 & 7,8 & 10.126 & 4,4 \\
\hline 742 & 12,8 & 7,4 & 9.044 & 4,7 \\
\hline 740 & 12,7 & 6,8 & 7.253 & 5,1 \\
\hline 742 & 12,8 & 6,2 & 6.370 & 5,6 \\
\hline 744 & 12,9 & 5,8 & 5.601 & 5,9 \\
\hline 743 & 12,9 & 5,2 & 4.670 & 6,6 \\
\hline 742 & 12,8 & 4,9 & 4.052 & 7,1 \\
\hline 744 & 12,9 & 4,6 & 3.668 & 7,6 \\
\hline 743 & 12,9 & 4,2 & 2.997 & 8,3 \\
\hline 746 & 13,0 & 3,9 & 2.554 & 8,9 \\
\hline 744 & 13,0 & 3,6 & 2.213 & 9,5 \\
\hline 744 & 13,0 & 3,4 & 1.854 & 10,1 \\
\hline 743 & 12,9 & 3,2 & 1.512 & 11,0 \\
\hline 742 & 12,9 & 2,9 & 1.075 & 11,8 \\
\hline 742 & 12,9 & 2,6 & 633 & 13,2 \\
\hline 741 & 12,9 & 2,3 & 379 & 15,6 \\
\hline 742 & 13,0 & 8,5 & 13.630 & 4,1 \\
\hline 739 & 12,9 & 8,2 & 12.089 & 4,3 \\
\hline 738 & 12,8 & 7,7 & 10.259 & 4,5 \\
\hline 743 & 13,0 & 7,3 & 8.954 & 4,8 \\
\hline 743 & 13,1 & 6,7 & 7.433 & 5,2 \\
\hline 738 & 12,9 & 5,8 & 5.536 & 6,0 \\
\hline 742 & 12,9 & 5,4 & 4.663 & 6,5 \\
\hline 742 & 13,0 & 4,8 & 4.096 & 7,3 \\
\hline 741 & 13,0 & 4,5 & 3.653 & 7,7 \\
\hline 740 & 13,0 & 4,0 & 3.020 & 8,6 \\
\hline 740 & 12,9 & 3,8 & 2.649 & 9,2 \\
\hline 739 & 12,9 & 3,5 & 2.256 & 9,9 \\
\hline
\end{tabular}

\begin{tabular}{|c|c|c|c|c|}
\hline $\begin{array}{c}p_{\text {sat }} \\
(\boldsymbol{k P a})\end{array}$ & $\begin{array}{l}T_{\text {sat }} \\
\left({ }^{o} \boldsymbol{C}\right)\end{array}$ & $\begin{array}{c}\Delta T \\
\left({ }^{o} C\right)\end{array}$ & $\begin{array}{c}h \\
\left(k W / m^{2}\right)\end{array}$ & $\begin{array}{c}\text { incerteza } \\
(\%)\end{array}$ \\
\hline 738 & 12,9 & 3,4 & 1.950 & 10,4 \\
\hline 737 & 12,9 & 3,1 & 1.543 & 11,2 \\
\hline 737 & 12,9 & 2,9 & 1.130 & 12,2 \\
\hline 736 & 12,9 & 2,4 & 682 & 14,3 \\
\hline 735 & 12,9 & 1,9 & 394 & 18,0 \\
\hline 877 & 186 & 79 & 14493 & 44 \\
\hline 880 & 18,7 & 7,6 & 13.127 & $\begin{array}{l}4,6 \\
4,6\end{array}$ \\
\hline 875 & 18,5 & 7,2 & 11.105 & 4,8 \\
\hline 876 & 18,6 & 6,8 & 9.379 & 5,1 \\
\hline 875 & 18,6 & 6,2 & 7.729 & 5,6 \\
\hline 875 & 18,6 & 5,9 & 6.875 & 5,9 \\
\hline 876 & 18,6 & 5,5 & 6.012 & 6,4 \\
\hline 877 & 18,6 & 5,0 & 4.879 & 7,0 \\
\hline 877 & 18,6 & 4,6 & 4.215 & 7,6 \\
\hline 875 & 18,6 & 4,3 & 3.814 & 8,1 \\
\hline 875 & 18,5 & 3,9 & 3.134 & 8,9 \\
\hline 876 & 18,6 & 3,7 & 2.669 & 9,5 \\
\hline 875 & 18,6 & 3,7 & 2.238 & 9,5 \\
\hline 874 & 18,6 & 3,5 & 1.838 & 9,9 \\
\hline 873 & 18,6 & 3,3 & 1.493 & 10,6 \\
\hline 872 & 18,6 & 3,0 & 964 & 11,8 \\
\hline 871 & 18,5 & 2,7 & 589 & 13,2 \\
\hline 871 & 18,5 & 2,4 & 314 & 14,9 \\
\hline 1.021 & 24,0 & 7,6 & 14.411 & 4,6 \\
\hline 1.022 & 24,1 & 7,3 & 13.107 & 4,7 \\
\hline 1.021 & 24,1 & 7,0 & 11.671 & 5,0 \\
\hline 1.019 & 24,0 & 6,5 & 9.729 & 5,3 \\
\hline 1.023 & 24,1 & 6,1 & 8.098 & 5,7 \\
\hline 1.018 & 24,0 & 5,7 & 7.164 & 6,1 \\
\hline 1.021 & 24,1 & 5,3 & 6.220 & 6,6 \\
\hline 1.018 & 24,0 & 4,8 & 5.111 & 7,2 \\
\hline 1.020 & 24,0 & 4,5 & 4.338 & 7,8 \\
\hline 1.019 & 24,0 & 4,2 & 3.924 & 8,2 \\
\hline 1.018 & 24,0 & 3,9 & 3.226 & 8,9 \\
\hline 1.020 & 24,0 & 3,6 & 2.755 & 9,6 \\
\hline 1.019 & 24,0 & 3,4 & 2.436 & 10,1 \\
\hline 1.018 & 24,0 & 3,2 & 2.052 & 10,7 \\
\hline 1.018 & 24,0 & 3,0 & 1.649 & 11,8 \\
\hline 1.016 & 23,9 & 2,7 & 1.222 & 12,9 \\
\hline 1.017 & 23,9 & 2,4 & 694 & 14,6 \\
\hline 1.016 & 23,9 & 2,1 & 399 & 16,3 \\
\hline
\end{tabular}

\begin{tabular}{|c|c|c|c|c|}
\hline \multicolumn{5}{|c|}{ Superfície de cobre ; Ra=2,6 $\pm 0,2 \mu \mathrm{m}$} \\
\hline 313 & $-13,1$ & 8,7 & 13.621 & 4,0 \\
\hline 311 & $-13,1$ & 8,2 & 12.003 & 4,2 \\
\hline 312 & $-13,0$ & 7,2 & 9.075 & 4,8 \\
\hline 312 & $-13,0$ & 6,6 & 7.557 & 5,2 \\
\hline 311 & $-13,1$ & 5,9 & 5.635 & 5,9 \\
\hline 310 & $-13,1$ & 5,3 & 4.710 & 6,5 \\
\hline 312 & $-13,0$ & 4,7 & 3.683 & 7,4 \\
\hline 312 & $-12,9$ & 4,0 & 3.086 & 8,7 \\
\hline 310 & $-13,0$ & 3,4 & 2.520 & 10,4 \\
\hline 311 & $-12,9$ & 3,1 & 2.213 & 11,4 \\
\hline 310 & $-12,9$ & 2,4 & 1.765 & 14,4 \\
\hline 309 & $-12,9$ & 1,6 & 1.041 & 21,2 \\
\hline 309 & $-12,9$ & 1,1 & 642 & 31,5 \\
\hline 453 & $-2,5$ & 7,9 & 14.548 & 4,4 \\
\hline 450 & $-2,7$ & 7,2 & 13.588 & 4,8 \\
\hline 450 & $-2,7$ & 6,7 & 12.041 & 5,2 \\
\hline 449 & $-2,7$ & 6,3 & 10.444 & 5,5 \\
\hline 449 & $-2,7$ & 5,7 & 8.766 & 6,0 \\
\hline 448 & $-2,7$ & 5,0 & 6.541 & 6,9 \\
\hline 449 & $-2,7$ & 4,6 & 5.493 & 7,5 \\
\hline
\end{tabular}




\begin{tabular}{|c|c|c|c|c|}
\hline $\begin{array}{c}p_{\text {sat }} \\
(\boldsymbol{k P a})\end{array}$ & $\begin{array}{l}T_{\text {sat }} \\
\left({ }^{\circ} \mathrm{C}\right)\end{array}$ & $\begin{array}{c}\Delta T \\
\left({ }^{o} C\right)\end{array}$ & $\begin{array}{c}h \\
\left(k W / m^{2}\right)\end{array}$ & $\begin{array}{c}\text { incerteza } \\
(\%)\end{array}$ \\
\hline 446 & $-2,8$ & 3,8 & 4.238 & 9,0 \\
\hline 447 & $-2,8$ & 3,0 & 2.879 & 11,7 \\
\hline 446 & $-2,7$ & 2,6 & 2.557 & 13,4 \\
\hline 445 & $-2,8$ & 2,2 & 2.068 & 16,1 \\
\hline 445 & $-2,7$ & 1,5 & 1.210 & 22,5 \\
\hline 444 & $-2,7$ & 1,0 & 743 & 34,7 \\
\hline 596 & 5,8 & 6,8 & 16.977 & 5,1 \\
\hline 596 & 5,8 & 6,5 & 15.106 & 5,4 \\
\hline 595 & 5,8 & 6,1 & 13.485 & 5,7 \\
\hline 595 & 5,8 & 5,7 & 11.676 & 6,1 \\
\hline 593 & 5,7 & 5,3 & 9.682 & 6,6 \\
\hline 594 & 5,7 & 4,7 & 7.169 & 7,4 \\
\hline 593 & 5,7 & 4,2 & 5.986 & 8,3 \\
\hline 594 & 5,8 & 3,6 & 4.616 & 9,6 \\
\hline 595 & 5,8 & 3,2 & 3.798 & 10,9 \\
\hline 594 & 5,8 & 2,7 & 3.063 & 12,7 \\
\hline 596 & 5,9 & 2,5 & 2.673 & 13,7 \\
\hline 595 & 5,9 & 2,1 & 2.120 & 16,8 \\
\hline 594 & 5,9 & 1,3 & 1.228 & 27,3 \\
\hline 593 & 5,9 & 1,0 & 899 & 34,9 \\
\hline 740 & 12,7 & 6,5 & 17.599 & 5,4 \\
\hline 741 & 12,8 & 6,2 & 16.084 & 5,6 \\
\hline 738 & 12,6 & 5,9 & 14.079 & 5,9 \\
\hline 742 & 12,8 & 5,5 & 12.118 & 6,3 \\
\hline 741 & 12,8 & 5,1 & 9.715 & 6,8 \\
\hline 737 & 12,6 & 4,4 & 7.418 & 7,8 \\
\hline 739 & 12,7 & 4,0 & 6.161 & 8,7 \\
\hline 740 & 12,8 & 3,5 & 4.904 & 10,0 \\
\hline 741 & 12,8 & 3,1 & 4.050 & 11,1 \\
\hline 739 & 12,7 & 2,7 & 3.223 & 12,9 \\
\hline 738 & 12,7 & 2,5 & 2.739 & 14,1 \\
\hline 740 & 12,8 & 2,1 & 2.100 & 16,7 \\
\hline 738 & 12,8 & 1,4 & 1.153 & 25,4 \\
\hline 738 & 12,8 & 1,1 & 744 & 31,7 \\
\hline 881 & 18,8 & 6,0 & 19.550 & 5,8 \\
\hline 884 & 18,9 & 5,7 & 17.228 & 6,1 \\
\hline 880 & 18,7 & 5,4 & 14.973 & 6,5 \\
\hline 878 & 18,6 & 5,1 & 13.116 & 6,8 \\
\hline 881 & 18,7 & 4,8 & 10.218 & 7,3 \\
\hline 879 & 18,8 & 4,1 & 7.995 & 8,4 \\
\hline 877 & 18,7 & 3,7 & 6.676 & 9,3 \\
\hline 879 & 18,7 & 3,3 & 5.350 & 10,6 \\
\hline 880 & 18,8 & 2,8 & 4.345 & 12,3 \\
\hline 880 & 18,8 & 2,5 & 3.499 & 14,1 \\
\hline 882 & 18,8 & 2,2 & 2.954 & 15,5 \\
\hline 881 & 18,8 & 1,9 & 2.267 & 18,4 \\
\hline 879 & 18,8 & 1,3 & 1.301 & 26,9 \\
\hline 879 & 18,8 & 1,1 & 841 & 32,8 \\
\hline 1.020 & 23,9 & 5,4 & 21.834 & 6,4 \\
\hline 1.022 & 24,0 & 5,1 & 19.471 & 6,7 \\
\hline 1.017 & 23,9 & 4,9 & 16.902 & 7,1 \\
\hline 1.022 & 24,0 & 4,6 & 14.440 & 7,5 \\
\hline 1.018 & 23,9 & 4,3 & 11.719 & 8,0 \\
\hline 1.016 & 23,8 & 3,8 & 8.460 & 9,2 \\
\hline 1.014 & 23,8 & 3,5 & 7.183 & 10,0 \\
\hline 1.019 & 23,9 & 3,1 & 5.556 & 11,3 \\
\hline 1.024 & 24,1 & 2,7 & 4.345 & 12,9 \\
\hline 1.021 & 24,0 & 2,4 & 3.581 & 14,7 \\
\hline 1.021 & 24,0 & 2,2 & 3.050 & 16,0 \\
\hline 1.019 & 24,0 & 1,9 & 2.267 & 18,2 \\
\hline 1.018 & 23,9 & 1,3 & 1.195 & 26,4 \\
\hline 1.018 & 23,9 & 1,1 & 803 & 30,6 \\
\hline
\end{tabular}

\begin{tabular}{|c|c|c|c|c|}
\hline $\begin{array}{c}p_{\text {sat }} \\
(\boldsymbol{k P a})\end{array}$ & $\begin{array}{r}T_{\text {sat }} \\
\left({ }^{o} \boldsymbol{C}\right)\end{array}$ & $\begin{array}{c}\Delta T \\
\left({ }^{o} C\right)\end{array}$ & $\begin{array}{c}h \\
\left(k W / m^{2}\right)\end{array}$ & $\begin{array}{c}\text { incerteza } \\
(\%)\end{array}$ \\
\hline \multicolumn{5}{|c|}{ Superfície de latão ; Ra=0,08 $\pm 0,01 \mu \mathrm{m}$} \\
\hline 314 & $-13,0$ & 11,8 & 6.434 & 3,0 \\
\hline 313 & $-13,0$ & 11,5 & 5.939 & 3,0 \\
\hline 312 & $-13,1$ & 11,2 & 5.340 & 3,1 \\
\hline 311 & $-13,1$ & 11,0 & 4.855 & 3,2 \\
\hline 311 & $-13,1$ & 10,6 & 4.315 & 3,3 \\
\hline 311 & $-13,0$ & 10,2 & 3.711 & 3,4 \\
\hline 311 & $-13,1$ & 9,7 & 3.143 & 3,6 \\
\hline 311 & $-13,0$ & 9,4 & 2.682 & 3,7 \\
\hline 311 & $-13,0$ & 9,2 & 2.463 & 3,8 \\
\hline 310 & $-13,1$ & 8,8 & 2.052 & 4,0 \\
\hline 312 & $-12,9$ & 8,6 & 1.806 & 4,1 \\
\hline 311 & $-12,9$ & 8,0 & 1.395 & 4,4 \\
\hline 310 & $-12,9$ & 7,8 & 1.164 & 4,5 \\
\hline 310 & $-13,0$ & 7,5 & 1.022 & 4,7 \\
\hline 309 & $-13,0$ & 7,0 & 858 & 5,0 \\
\hline 309 & $-13,0$ & 6,4 & 715 & 5,5 \\
\hline 309 & $-13,0$ & 5,0 & 558 & 7,0 \\
\hline 308 & $-13,0$ & 3,4 & 444 & 10,5 \\
\hline 308 & $-13,0$ & 2,0 & 383 & 17,4 \\
\hline 451 & $-2,6$ & 10,0 & 7.572 & 3,5 \\
\hline 451 & $-2,6$ & 9,7 & 6.997 & 3,6 \\
\hline 450 & $-2,6$ & 9,5 & 6.433 & 3,7 \\
\hline 450 & $-2,6$ & 9,2 & 5.729 & 3,8 \\
\hline 450 & $-2,6$ & 8,9 & 5.098 & 3,9 \\
\hline 451 & $-2,5$ & 8,5 & 4.499 & 4,1 \\
\hline 451 & $-2,5$ & 8,1 & 3.737 & 4,3 \\
\hline 452 & $-2,4$ & 7,5 & 3.009 & 4,6 \\
\hline 451 & $-2,5$ & 7,2 & 2.526 & 4,8 \\
\hline 449 & $-2,6$ & 6,9 & 2.181 & 5,0 \\
\hline 448 & $-2,6$ & 6,5 & 1.781 & 5,3 \\
\hline 449 & $-2,6$ & 6,1 & 1.498 & 5,7 \\
\hline 449 & $-2,5$ & 5,9 & 1.288 & 5,9 \\
\hline 449 & $-2,5$ & 5,7 & 1.095 & 6,1 \\
\hline 448 & $-2,5$ & 5,1 & 887 & 6,9 \\
\hline 447 & $-2,5$ & 4,6 & 661 & 7,6 \\
\hline 447 & $-2,5$ & 3,1 & 483 & 11,3 \\
\hline 447 & $-2,5$ & 2,0 & 364 & 18,0 \\
\hline 594 & 5,8 & 8,8 & 8.491 & 3,9 \\
\hline 593 & 5,7 & 8,7 & 7.804 & 4,0 \\
\hline 593 & 5,7 & 8,4 & 7.114 & 4,2 \\
\hline 594 & 5,8 & 8,1 & 6.536 & 4,3 \\
\hline 594 & 5,8 & 7,8 & 5.827 & 4,4 \\
\hline 593 & 5,7 & 7,5 & 5.254 & 4,6 \\
\hline 594 & 5,8 & 7,1 & 4.328 & 4,9 \\
\hline 592 & 5,8 & 6,7 & 3.696 & 5,2 \\
\hline 593 & 5,8 & 6,6 & 3.504 & 5,3 \\
\hline 591 & 5,7 & 6,1 & 2.858 & 5,7 \\
\hline 592 & 5,7 & 5,9 & 2.571 & 5,9 \\
\hline 593 & 5,8 & 5,6 & 2.030 & 6,2 \\
\hline 592 & 5,8 & 5,3 & 1.725 & 6,6 \\
\hline 591 & 5,8 & 5,1 & 1.487 & 6,9 \\
\hline 591 & 5,7 & 4,9 & 1.254 & 7,1 \\
\hline 590 & 5,7 & 4,6 & 983 & 7,6 \\
\hline 589 & 5,7 & 4,1 & 727 & 8,6 \\
\hline 589 & 5,7 & 3,2 & 493 & 11,1 \\
\hline 589 & 5,7 & 2,0 & 375 & 17,1 \\
\hline 738 & 12,7 & 7,8 & 9.684 & 4,5 \\
\hline 738 & 12,7 & 7,6 & 8.967 & 4,6 \\
\hline 738 & 12,7 & 7,4 & 8.161 & 4,7 \\
\hline 738 & 12,7 & 7,1 & 7.323 & 4,9 \\
\hline 741 & 12,8 & 6,9 & 6.663 & 5,0 \\
\hline
\end{tabular}




\begin{tabular}{|c|c|c|c|c|}
\hline $\begin{array}{c}p_{\text {sat }} \\
(\boldsymbol{k P a})\end{array}$ & $\begin{array}{l}T_{\text {sat }} \\
\left({ }^{\circ} \mathrm{C}\right)\end{array}$ & $\begin{array}{c}\Delta \boldsymbol{T} \\
\left({ }^{o} \mathrm{C}\right)\end{array}$ & $\begin{array}{c}h \\
\left(k W / m^{2}\right)\end{array}$ & $\begin{array}{c}\text { incerteza } \\
(\%)\end{array}$ \\
\hline 740 & 12,8 & 6,6 & 5.794 & 5,3 \\
\hline 737 & 12,7 & 6,2 & 4.780 & 5,6 \\
\hline 736 & 12,7 & 6,0 & 4.256 & 5,8 \\
\hline 736 & 12,7 & 5,8 & 3.950 & 6,0 \\
\hline 737 & 12,7 & 5,5 & 3.214 & 6,4 \\
\hline 738 & 12,8 & 5,3 & 2.888 & 6,6 \\
\hline 736 & 12,7 & 4,9 & 2.315 & 7,1 \\
\hline 735 & 12,7 & 4,6 & 1.936 & 7,6 \\
\hline 734 & 12,7 & 4,4 & 1.717 & 7,9 \\
\hline 738 & 12,8 & 8,1 & 9.475 & 4,3 \\
\hline 738 & 12,8 & 7,8 & 8.736 & 4,4 \\
\hline 736 & 12,7 & 7,6 & 7.937 & 4,6 \\
\hline 737 & 12,7 & 7,3 & 7.232 & 4,7 \\
\hline 735 & 12,7 & 7,0 & 6.522 & 5,0 \\
\hline 735 & 12,7 & 6,6 & 5.812 & 5,2 \\
\hline 735 & 12,7 & 6,3 & 4.777 & 5,5 \\
\hline 736 & 12,7 & 6,0 & 4.149 & 5,8 \\
\hline 737 & 12,7 & 5,9 & 3.841 & 5,9 \\
\hline 735 & 12,7 & 5,5 & 3.294 & 6,3 \\
\hline 735 & 12,7 & 5,3 & 2.910 & 6,5 \\
\hline 737 & 12,8 & 5,0 & 2.290 & 7,0 \\
\hline 735 & 12,7 & 4,7 & 1.933 & 7,4 \\
\hline 735 & 12,7 & 4,6 & 1.680 & 7,6 \\
\hline 734 & 12,7 & 4,3 & 1.462 & 8,1 \\
\hline 733 & 12,7 & 4,1 & 1.118 & 8,6 \\
\hline 733 & 12,7 & 3,7 & 814 & 9,5 \\
\hline 733 & 12,7 & 2,9 & 513 & 12,0 \\
\hline 733 & 12,7 & 2,2 & 355 & 16,1 \\
\hline 881 & 18,8 & 7,1 & 10.697 & 4,9 \\
\hline 880 & 18,7 & 6,9 & 9.948 & 5,0 \\
\hline 881 & 18,8 & 6,6 & 9.040 & 5,2 \\
\hline 879 & 18,7 & 6,4 & 8.089 & 5,4 \\
\hline 876 & 18,6 & 6,2 & 7.425 & 5,6 \\
\hline 876 & 18,6 & 5,9 & 6.467 & 5,9 \\
\hline 878 & 18,7 & 5,6 & 5.471 & 6,2 \\
\hline 877 & 18,6 & 5,3 & 4.687 & 6,6 \\
\hline 879 & 18,8 & 5,1 & 4.353 & 6,8 \\
\hline 878 & 18,7 & 4,9 & 3.652 & 7,1 \\
\hline 877 & 18,7 & 4,7 & 3.288 & 7,4 \\
\hline 878 & 18,7 & 4,4 & 2.563 & 8,0 \\
\hline 878 & 18,7 & 4,1 & 2.196 & 8,4 \\
\hline 877 & 18,7 & 4,0 & 1.926 & 8,8 \\
\hline 876 & 18,7 & 3,8 & 1.604 & 9,2 \\
\hline 876 & 18,7 & 3,6 & 1.288 & 9,8 \\
\hline 875 & 18,7 & 3,3 & 929 & 10,7 \\
\hline 874 & 18,7 & 2,6 & 535 & 13,3 \\
\hline 873 & 18,6 & 2,0 & 355 & 17,8 \\
\hline 1.020 & 24,0 & 6,7 & 11.484 & 5,2 \\
\hline 1.017 & 23,9 & 6,4 & 10.625 & 5,4 \\
\hline 1.020 & 24,0 & 6,2 & 9.699 & 5,6 \\
\hline 1.020 & 24,0 & 6,0 & 8.826 & 5,8 \\
\hline 1.020 & 24,0 & 5,8 & 8.074 & 6,0 \\
\hline 1.019 & 24,0 & 5,5 & 6.844 & 6,4 \\
\hline 1.019 & 23,9 & 5,2 & 5.852 & 6,7 \\
\hline 1.020 & 24,0 & 4,9 & 4.942 & 7,1 \\
\hline 1.021 & 24,0 & 4,7 & 4.681 & 7,4 \\
\hline 1.019 & 24,0 & 4,5 & 4.063 & 7,8 \\
\hline 1.017 & 23,9 & 4,3 & 3.492 & 8,1 \\
\hline 1.016 & 23,9 & 4,0 & 2.749 & 8,6 \\
\hline 1.021 & 24,0 & 3,8 & 2.377 & 9,1 \\
\hline 1.021 & 24,0 & 3,7 & 2.103 & 9,5 \\
\hline 1.019 & 24,0 & 3,4 & 1.767 & 10,1 \\
\hline 1.019 & 24,0 & 3,3 & 1.347 & 10,7 \\
\hline
\end{tabular}

\begin{tabular}{|c|c|c|c|c|}
\hline $\begin{array}{c}\boldsymbol{p}_{\text {sat }} \\
(\boldsymbol{k P a})\end{array}$ & $\begin{array}{c}\boldsymbol{T}_{\text {sat }} \\
\left.\boldsymbol{(}^{\boldsymbol{}} \boldsymbol{C}\right)\end{array}$ & $\begin{array}{c}\Delta \boldsymbol{T} \\
\left.{ }^{\boldsymbol{o}} \boldsymbol{C}\right)\end{array}$ & $\begin{array}{c}\boldsymbol{h} \\
\left(\boldsymbol{k W / \boldsymbol { m } ^ { 2 } )}\right.\end{array}$ & $\begin{array}{c}\text { incerteza } \\
(\%)\end{array}$ \\
\hline 1.017 & 23,9 & 3,1 & 954 & 11,4 \\
\hline 1.017 & 23,9 & 2,6 & 1.151 & 13,3 \\
\hline 1.016 & 23,9 & 2,0 & 765 & 17,7 \\
\hline & & &
\end{tabular}




\section{v. Resultados para o $R-134 a$}

\begin{tabular}{|c|c|c|c|c|}
\hline $\begin{array}{c}p_{\text {sat }} \\
(\boldsymbol{k P a})\end{array}$ & $\begin{array}{l}T_{\text {sat }} \\
\left({ }^{\circ} \boldsymbol{C}\right)\end{array}$ & $\begin{array}{c}\Delta T \\
\left({ }^{o} C\right)\end{array}$ & $\begin{array}{c}h \\
\left(k W / m^{2}\right)\end{array}$ & $\begin{array}{c}\text { incerteza } \\
(\%)\end{array}$ \\
\hline \multicolumn{5}{|c|}{ Superfície de cobre; Ra=0,07 $\pm 0,02 \mu \mathrm{m}$} \\
\hline 203 & $-9,2$ & 16,4 & 6.965 & 2,2 \\
\hline 203 & $-9,1$ & 15,8 & 6.110 & 2,2 \\
\hline 204 & $-9,0$ & 15,4 & 5.435 & 2,3 \\
\hline 202 & $-9,2$ & 14,7 & 4.301 & 2,4 \\
\hline 204 & $-9,2$ & 16,3 & 6.949 & 2,1 \\
\hline 204 & $-9,2$ & 15,9 & 6.087 & 2,2 \\
\hline 204 & $-9,1$ & 15,4 & 5.312 & 2,3 \\
\hline 204 & $-9,1$ & 14,9 & 4.399 & 2,3 \\
\hline 203 & $-9,1$ & 14,1 & 3.427 & 2,5 \\
\hline 203 & $-9,2$ & 13,6 & 3.052 & 2,6 \\
\hline 203 & $-9,1$ & 13,0 & 2.533 & 2,7 \\
\hline 202 & $-9,2$ & 12,5 & 2.216 & 2,8 \\
\hline 202 & $-9,2$ & 12,1 & 2.010 & 2,9 \\
\hline 203 & $-9,1$ & 11,4 & 1.701 & 3,1 \\
\hline 203 & $-9,1$ & 11,1 & 1.457 & 3,2 \\
\hline 202 & $-9,1$ & 10,2 & 1.222 & 3,4 \\
\hline 202 & $-9,1$ & 9,6 & 998 & 3,7 \\
\hline 202 & $-9,1$ & 9,1 & 925 & 3,9 \\
\hline 201 & $-9,1$ & 8,4 & 775 & 4,2 \\
\hline 201 & $-9,1$ & 7,8 & 622 & 4,5 \\
\hline 200 & $-9,1$ & 6,4 & 492 & 5,6 \\
\hline 200 & $-9,1$ & 4,3 & 373 & 8,2 \\
\hline 200 & $-9,1$ & 2,2 & 367 & 15,9 \\
\hline 256 & $-3,2$ & 15,3 & 7.476 & 2,3 \\
\hline 257 & $-3,1$ & 14,8 & 6.615 & 2,4 \\
\hline 256 & $-3,2$ & 14,2 & 5.671 & 2,5 \\
\hline 255 & $-3,2$ & 13,7 & 4.764 & 2,5 \\
\hline 256 & $-3,2$ & 12,9 & 3.792 & 2,7 \\
\hline 256 & $-3,1$ & 12,4 & 3.289 & 2,8 \\
\hline 256 & $-3,1$ & 11,7 & 2.747 & 3,0 \\
\hline 255 & $-3,1$ & 11,3 & 2.431 & 3,1 \\
\hline 256 & $-3,1$ & 11,0 & 2.250 & 3,2 \\
\hline 254 & $-3,2$ & 10,2 & 1.880 & 3,4 \\
\hline 254 & $-3,3$ & 9,8 & 1.668 & 3,6 \\
\hline 254 & $-3,2$ & 9,1 & 1.285 & 3,9 \\
\hline 254 & $-3,2$ & 8,5 & 1.153 & 4,1 \\
\hline 253 & $-3,3$ & 7,9 & 984 & 4,5 \\
\hline 253 & $-3,3$ & 7,4 & 881 & 4,8 \\
\hline 253 & $-3,3$ & 6,9 & 691 & 5,2 \\
\hline 253 & $-3,2$ & 6,0 & 515 & 5,9 \\
\hline 253 & $-3,2$ & 4,2 & 389 & 8,5 \\
\hline
\end{tabular}

\begin{tabular}{|c|c|c|c|c|}
\hline $\begin{array}{c}p_{\text {sat }} \\
(\boldsymbol{k P a})\end{array}$ & $\begin{array}{c}T_{\text {sat }} \\
\left({ }^{o} \mathrm{C}\right)\end{array}$ & $\begin{array}{c}\Delta T \\
\left({ }^{o} C\right)\end{array}$ & $\begin{array}{c}h \\
\left(k W / m^{2}\right)\end{array}$ & $\begin{array}{c}\text { incerteza } \\
(\%)\end{array}$ \\
\hline 252 & $-3,2$ & 2,3 & 351 & 15,3 \\
\hline 375 & 7.1 & 13,9 & 8.133 & 2.5 \\
\hline 374 & 7,1 & 13,5 & 7.158 & 2,6 \\
\hline 373 & 6,9 & 13,1 & 6.309 & 2,7 \\
\hline 373 & 7,0 & 12,5 & 5.310 & 2,8 \\
\hline 374 & 7,0 & 11,7 & 4.263 & 3,0 \\
\hline 373 & 7,0 & 10,5 & 3.102 & 3,3 \\
\hline 374 & 7,1 & 9,8 & 2.643 & 3,5 \\
\hline 374 & 7,1 & 9,6 & 2.538 & 3,6 \\
\hline 373 & 7,1 & 9,0 & 2.141 & 3,9 \\
\hline 372 & 7,0 & 8,6 & 1.869 & 4,1 \\
\hline 372 & 7,0 & 7,9 & 1.536 & 4,4 \\
\hline 372 & 7,0 & 7,4 & 1.346 & 4,8 \\
\hline 372 & 7,0 & 6,9 & 1.181 & 5,1 \\
\hline 373 & 7,1 & 6,6 & 1.004 & 5,3 \\
\hline 373 & 7,1 & 5,9 & 823 & 5,9 \\
\hline 372 & 7,1 & 5,2 & 584 & 6,8 \\
\hline 371 & 7,1 & 4,0 & 379 & 8,8 \\
\hline 371 & 7,1 & 2,6 & 279 & 13,6 \\
\hline 486 & 14,8 & 12,6 & 8.945 & 2,8 \\
\hline 486 & 14,9 & 12,2 & 7.941 & 2,8 \\
\hline 487 & 14,9 & 11,8 & 6.926 & 3,0 \\
\hline 486 & 14,8 & 11,2 & 5.719 & 3,1 \\
\hline 485 & 14,8 & 10,6 & 4.630 & 3,3 \\
\hline 486 & 14,9 & 10,0 & 4.059 & 3,5 \\
\hline 485 & 14,9 & 9,3 & 3.439 & 3,7 \\
\hline 484 & 14,8 & 8,9 & 2.997 & 3,9 \\
\hline 484 & 14,8 & 8,7 & 2.845 & 4,0 \\
\hline 484 & 14,8 & 8,0 & 2.382 & 4,4 \\
\hline 484 & 14,8 & 7,6 & 2.144 & 4,6 \\
\hline 484 & 14,9 & 7,0 & 1.782 & 5,0 \\
\hline 485 & 14,9 & 6,5 & 1.520 & 5,4 \\
\hline 485 & 14,9 & 6,2 & 1.356 & 5,7 \\
\hline 485 & 14,9 & 5,8 & 1.189 & 6,1 \\
\hline 484 & 14,9 & 5,3 & 893 & 6,6 \\
\hline 484 & 14,9 & 4,8 & 708 & 7,4 \\
\hline 482 & 14,9 & 3,8 & 431 & 9,4 \\
\hline 484 & 14,9 & 2,9 & 258 & 12,2 \\
\hline 715 & 27,2 & 10,5 & 10.613 & 3,3 \\
\hline 716 & 27,3 & 10,2 & 9.465 & 3,4 \\
\hline
\end{tabular}




\begin{tabular}{|c|c|c|c|c|}
\hline $\begin{array}{c}p_{\text {sat }} \\
(\boldsymbol{k P a})\end{array}$ & $\begin{array}{c}T_{\text {sat }} \\
\left({ }^{o} \boldsymbol{C}\right)\end{array}$ & $\begin{array}{c}\Delta T \\
\left({ }^{o} C\right)\end{array}$ & $\begin{array}{c}h \\
\left(k W / m^{2}\right)\end{array}$ & $\begin{array}{c}\text { incerteza } \\
(\%)\end{array}$ \\
\hline 715 & 27,3 & 9,8 & 8.175 & 3,5 \\
\hline 711 & 27,1 & 9,4 & 6.953 & 3,7 \\
\hline 714 & 27,3 & 8,7 & 5.546 & 4,0 \\
\hline 713 & 27,2 & 8,4 & 4.894 & 4,2 \\
\hline 713 & 27,2 & 7,8 & 4.142 & 4,5 \\
\hline 712 & 27,2 & 7,4 & 3.652 & 4,7 \\
\hline 713 & 27,2 & 7,2 & 3.432 & 4,8 \\
\hline 714 & 27,3 & 6,6 & 2.910 & 5,3 \\
\hline 714 & 27,3 & 6,3 & 2.662 & 5,5 \\
\hline 713 & 27,3 & 5,7 & 2.129 & 6,1 \\
\hline 713 & 27,3 & 5,2 & 1.800 & 6,6 \\
\hline 712 & 27,2 & 5,0 & 1.648 & 6,9 \\
\hline 712 & 27,2 & 4,7 & 1.380 & 7,4 \\
\hline 712 & 27,2 & 4,4 & 1.125 & 7,9 \\
\hline 711 & 27,2 & 3,9 & 804 & 8,9 \\
\hline 710 & 27,1 & 3,3 & 480 & 10,7 \\
\hline 710 & 27,1 & 2,7 & 289 & 13,0 \\
\hline 833 & 32,5 & 9,8 & 11.656 & 3,6 \\
\hline 835 & 32,6 & 9,5 & 10.416 & 3,7 \\
\hline 832 & 32,5 & 9,1 & 8.958 & 3,8 \\
\hline 830 & 32,4 & 8,6 & 7.519 & 4,0 \\
\hline 832 & 32,5 & 8,0 & 6.249 & 4,4 \\
\hline 834 & 32,6 & 7,5 & 5.206 & 4,6 \\
\hline 832 & 32,5 & 7,1 & 4.568 & 4,9 \\
\hline 831 & 32,4 & 6,8 & 4.037 & 5,1 \\
\hline 832 & 32,5 & 6,5 & 3.747 & 5,4 \\
\hline 831 & 32,5 & 6,0 & 3.206 & 5,8 \\
\hline 832 & 32,5 & 5,7 & 2.899 & 6,1 \\
\hline 837 & 32,7 & 5,1 & 2.456 & 6,8 \\
\hline 837 & 32,7 & 4,8 & 2.081 & 7,2 \\
\hline 834 & 32,6 & 4,4 & 1.800 & 7,9 \\
\hline 837 & 32,7 & 4,0 & 1.598 & 8,6 \\
\hline 832 & 32,5 & 3,7 & 1.343 & 9,4 \\
\hline 831 & 32,5 & 3,4 & 983 & 10,3 \\
\hline 832 & 32,5 & 3,0 & 544 & 11,8 \\
\hline 832 & 32,4 & 2,5 & 313 & 13,9 \\
\hline 833 & 32,6 & 10,0 & 11.442 & 3,5 \\
\hline 834 & 32,6 & 9,7 & 10.194 & 3,6 \\
\hline 832 & 32,5 & 9,2 & 8.600 & 3,8 \\
\hline 831 & 32,5 & 8,9 & 7.612 & 3,9 \\
\hline 831 & 32,5 & 8,2 & 6.005 & 4,2 \\
\hline 832 & 32,5 & 7,9 & 5.196 & 4,4 \\
\hline 831 & 32,5 & 7,4 & 4.386 & 4,7 \\
\hline 832 & 32,5 & 6,9 & 3.768 & 5,0 \\
\hline 832 & 32,5 & 6,7 & 3.571 & 5,2 \\
\hline 832 & 32,6 & 6,2 & 3.036 & 5,6 \\
\hline 834 & 32,6 & 6,0 & 2.752 & 5,8 \\
\hline 834 & 32,6 & 5,4 & 2.264 & 6,4 \\
\hline 834 & 32,6 & 5,0 & 1.935 & 6,9 \\
\hline 833 & 32,6 & 4,8 & 1.732 & 7,3 \\
\hline 833 & 32,6 & 4,5 & 1.468 & 7,8 \\
\hline 832 & 32,6 & 4,2 & 1.192 & 8,4 \\
\hline 832 & 32,5 & 3,7 & 862 & 9,3 \\
\hline 832 & 32,5 & 3,3 & 487 & 10,7 \\
\hline 835 & 32,5 & 2,8 & 284 & 12,5 \\
\hline 1.070 & 41,5 & 8,5 & 13.718 & 4,1 \\
\hline 1.073 & 41,6 & 8,1 & 12.106 & 4,3 \\
\hline 1.070 & 41,6 & 7,7 & 10.614 & 4,5 \\
\hline 1.068 & 41,5 & 7,4 & 8.962 & 4,7 \\
\hline 1.073 & 41,6 & 6,9 & 7.300 & 5,1 \\
\hline 1.074 & 41,7 & 6,6 & 6.299 & 5,3 \\
\hline 1.070 & 41,5 & 6,1 & 5.396 & 5,6 \\
\hline 1.070 & 41,6 & 5,8 & 4.588 & 6,0 \\
\hline
\end{tabular}

\begin{tabular}{|c|c|c|c|c|}
\hline $\left.\begin{array}{c}p_{\text {sat }} \\
(\boldsymbol{k P a})\end{array}\right)$ & $\begin{array}{c}T_{\text {sat }} \\
\left({ }^{o} \boldsymbol{C}\right)\end{array}$ & $\begin{array}{c}\Delta T \\
\left({ }^{o} C\right)\end{array}$ & $\begin{array}{c}h \\
\left(k W / m^{2}\right)\end{array}$ & $\begin{array}{c}\text { incerteza } \\
(\%)\end{array}$ \\
\hline 1.069 & 41,5 & 5,6 & 4.281 & 6,2 \\
\hline 1.069 & 41,5 & 5,2 & 3.736 & 6,7 \\
\hline 1.068 & 41,5 & 4,9 & 3.337 & 7,1 \\
\hline 1.072 & 41,6 & 4,4 & 2.749 & 7,9 \\
\hline 1.071 & 41,6 & 4,1 & 2.416 & 8,5 \\
\hline 1.071 & 41,6 & 3,8 & 2.152 & 9,0 \\
\hline 1.069 & 41,5 & 3,5 & 1.803 & 9,9 \\
\hline 1.074 & 41,6 & 3,3 & 1.446 & 10,6 \\
\hline 1.070 & 41,6 & 3,0 & 1.090 & 11,7 \\
\hline 1.071 & 41,5 & 2,8 & 595 & 12,7 \\
\hline 1.065 & 41,2 & 2,4 & 335 & 14,4 \\
\hline
\end{tabular}

Superfície de cobre; $\mathrm{Ra}=0,50 \pm 0,05 \mu \mathrm{m}$

\begin{tabular}{|c|c|c|c|c|}
\hline 205 & $-9,1$ & 11,0 & 10.492 & 3,2 \\
\hline 204 & $-9,1$ & 10,7 & 9.319 & 3,2 \\
\hline 204 & $-9,1$ & 10,1 & 7.725 & 3,4 \\
\hline 205 & $-9,0$ & 9,7 & 6.625 & 3,6 \\
\hline 204 & $-9,1$ & 9,1 & 5.424 & 3,8 \\
\hline 203 & $-9,1$ & 8,8 & 4.524 & 4,0 \\
\hline 204 & $-8,9$ & 8,3 & 3.929 & 4,2 \\
\hline 204 & $-8,9$ & 7,8 & 3.259 & 4,5 \\
\hline 203 & $-9,0$ & 7,2 & 2.636 & 4,9 \\
\hline 203 & $-9,0$ & 6,9 & 2.405 & 5,0 \\
\hline 202 & $-9,1$ & 6,1 & 1.957 & 5,7 \\
\hline 202 & $-9,1$ & 5,8 & 1.686 & 6,0 \\
\hline 203 & $-9,1$ & 5,4 & 1.397 & 6,4 \\
\hline 203 & $-9,0$ & 5,1 & 1.252 & 6,8 \\
\hline 202 & $-9,0$ & 4,6 & 1.017 & 7,6 \\
\hline 202 & $-9,0$ & 4,1 & 822 & 8,6 \\
\hline 202 & $-8,9$ & 2,8 & 574 & 12,6 \\
\hline 202 & $-8,9$ & 2,0 & 414 & 17,6 \\
\hline 255 & $-3,2$ & 10,5 & 10.937 & 3,3 \\
\hline 256 & $-3,2$ & 10,2 & 9.557 & 3,4 \\
\hline 255 & $-3,2$ & 9,8 & 8.237 & 3,5 \\
\hline 255 & $-3,2$ & 9,4 & 6.983 & 3,7 \\
\hline 254 & $-3,2$ & 8,7 & 5.576 & 4,0 \\
\hline 255 & $-3,2$ & 8,4 & 4.882 & 4,2 \\
\hline 255 & $-3,2$ & 7,9 & 4.152 & 4,4 \\
\hline 253 & $-3,2$ & 7,2 & 3.341 & 4,8 \\
\hline 254 & $-3,2$ & 6,8 & 2.855 & 5,1 \\
\hline 254 & $-3,2$ & 6,5 & 2.563 & 5,4 \\
\hline 254 & $-3,2$ & 6,1 & 2.105 & 5,7 \\
\hline 254 & $-3,2$ & 5,6 & 1.742 & 6,2 \\
\hline 255 & $-3,2$ & 5,4 & 1.568 & 6,5 \\
\hline 254 & $-3,2$ & 4,9 & 1.316 & 7,1 \\
\hline 254 & $-3,2$ & 4,4 & 1.110 & 7,9 \\
\hline 253 & $-3,2$ & 3,9 & 869 & 8,9 \\
\hline 253 & $-3,2$ & 2,9 & 554 & 12,1 \\
\hline 252 & $-3,2$ & 2,2 & 393 & 16,2 \\
\hline 374 & 7,2 & 9,6 & 11.656 & 3,6 \\
\hline 373 & 7,2 & 9,3 & 10.564 & 3,7 \\
\hline 372 & 7,1 & 8,8 & 9.119 & 3,9 \\
\hline 373 & 7,2 & 8,5 & 7.878 & 4,1 \\
\hline 374 & 7,3 & 7,9 & 6.333 & 4,4 \\
\hline 373 & 7,2 & 7,4 & 5.469 & 4,7 \\
\hline 373 & 7,2 & 6,9 & 4.758 & 5,0 \\
\hline 373 & 7,2 & 6,3 & 3.825 & 5,5 \\
\hline 373 & 7,3 & 6,1 & 3.190 & 5,7 \\
\hline 372 & 7,3 & 5,8 & 2.794 & 6,0 \\
\hline 371 & 7,2 & 5,3 & 2.275 & 6,6 \\
\hline 371 & 7,1 & 4,8 & 2.080 & 7,3 \\
\hline 372 & 7,2 & 4,8 & 1.743 & 7,3 \\
\hline 371 & 7,2 & 4,4 & 1.485 & 7,9 \\
\hline 371 & 7,2 & 4,1 & 1.183 & 8,5 \\
\hline
\end{tabular}




\begin{tabular}{|c|c|c|c|c|}
\hline $\begin{array}{c}p_{\text {sat }} \\
(\boldsymbol{k P a})\end{array}$ & $\begin{array}{c}T_{\text {sat }} \\
\left({ }^{o} \mathrm{C}\right)\end{array}$ & $\begin{array}{c}\Delta \boldsymbol{T} \\
\left({ }^{o} \boldsymbol{C}\right)\end{array}$ & $\begin{array}{c}\boldsymbol{h} \\
\left(k W / m^{2}\right)\end{array}$ & $\begin{array}{c}\text { incerteza } \\
(\%)\end{array}$ \\
\hline 371 & 7,1 & 3,6 & 875 & 9,6 \\
\hline 371 & 7,2 & 3,0 & 555 & 11,9 \\
\hline 371 & 7,2 & 2,3 & 373 & 15,4 \\
\hline 491 & 15,2 & 9,5 & 12.178 & 3,7 \\
\hline 489 & 15,1 & 9,0 & 10.758 & 3,9 \\
\hline 490 & 15,2 & 8,6 & 9.393 & 4,0 \\
\hline 489 & 15,1 & 8,2 & 7.965 & 4,2 \\
\hline 489 & 15,1 & 7,6 & 6.492 & 4,6 \\
\hline 488 & 15,1 & 7,1 & 5.673 & 4,9 \\
\hline 490 & 15,2 & 6,6 & 4.852 & 5,2 \\
\hline 491 & 15,2 & 6,2 & 4.321 & 5,6 \\
\hline 490 & 15,2 & 6,0 & 4.023 & 5,8 \\
\hline 489 & 15,2 & 5,5 & 3.461 & 6,3 \\
\hline 488 & 15,1 & 5,2 & 3.131 & 6,7 \\
\hline 489 & 15,1 & 4,7 & 2.613 & 7,4 \\
\hline 488 & 15,1 & 4,4 & 2.271 & 7,9 \\
\hline 488 & 15,1 & 4,1 & 2.041 & 8,5 \\
\hline 488 & 15,2 & 4,1 & 1.658 & 8,5 \\
\hline 487 & 15,2 & 3,7 & 1.299 & 9,4 \\
\hline 487 & 15,1 & 3,3 & 988 & 10,5 \\
\hline 487 & 15,1 & 2,7 & 599 & 12,8 \\
\hline 486 & 15,1 & 2,2 & 374 & 15,9 \\
\hline 718 & 275 & 82 & 13958 & 13 \\
\hline 718 & $\begin{array}{l}21,0 \\
275\end{array}$ & $\frac{0,2}{79}$ & 10.000 & $\frac{4,0}{44}$ \\
\hline 719 & 27,6 & 7,5 & 10.906 & 4,6 \\
\hline 718 & 27,5 & 7,1 & 9.355 & 4,9 \\
\hline 716 & 27,4 & 6,5 & 7.535 & 5,4 \\
\hline 718 & 27,5 & 5,7 & 5.715 & 6,0 \\
\hline 717 & 27,5 & 5,2 & 4.763 & 6,7 \\
\hline 718 & 27,5 & 4,8 & 4.044 & 7,3 \\
\hline 718 & 27,5 & 4,5 & 3.598 & 7,7 \\
\hline 720 & 27,6 & 4,0 & 3.027 & 8,6 \\
\hline 719 & 27,6 & 4,0 & 2.482 & 8,6 \\
\hline 719 & 27,6 & 3,8 & 2.182 & 9,3 \\
\hline 718 & 27,6 & 3,5 & 1.846 & 10,0 \\
\hline 718 & 27,6 & 3,2 & 1.505 & 10,9 \\
\hline 717 & 27,6 & 2,9 & 1.104 & 12,1 \\
\hline 716 & 27,5 & 2,2 & 730 & 15,9 \\
\hline 716 & 27,5 & 1,8 & 452 & 19,2 \\
\hline 1.072 & 41,8 & 7,3 & 15.563 & 4,8 \\
\hline 1.071 & 41,7 & 7,0 & 13.810 & 5,0 \\
\hline 1.072 & 41,7 & 6,7 & 12.326 & 5,2 \\
\hline 1.072 & 41,7 & 6,3 & 10.075 & 5,5 \\
\hline 1.067 & 41,6 & 5,9 & 8.190 & 5,9 \\
\hline 1.070 & 41,6 & 5,3 & 6.173 & 6,5 \\
\hline 1.071 & 41,7 & 4,8 & 4.939 & 7,2 \\
\hline 1.068 & 41,6 & 4,0 & 4.085 & 8,7 \\
\hline 1.067 & 41,5 & 3,6 & 3.331 & 9,5 \\
\hline 1.070 & 41,6 & 3,2 & 2.596 & 10,8 \\
\hline 1.068 & 41,6 & 3,0 & 2.203 & 11,7 \\
\hline 1.070 & 41,6 & 2,7 & 1.645 & 12,9 \\
\hline 1.070 & 41,6 & 2,2 & 731 & 15,9 \\
\hline \multicolumn{5}{|c|}{ Superfície de cobre ; $R a=2,5 \pm 0,4 \mu \mathrm{m}$} \\
\hline 206 & $-9,0$ & 7,3 & 15.761 & 4,7 \\
\hline 206 & $-9,1$ & 7,1 & 14.498 & 4,9 \\
\hline 206 & $-9,2$ & 6,7 & 12.531 & 5,2 \\
\hline 206 & $-9,1$ & 6,2 & 10.791 & 5,6 \\
\hline 206 & $-9,0$ & 6,0 & 10.015 & 5,8 \\
\hline 206 & $-9,2$ & 5,7 & 8.705 & 6,1 \\
\hline 206 & $-9,1$ & 5,5 & 7.829 & 6,4 \\
\hline 206 & $-9,1$ & 5,1 & 6.583 & 6,9 \\
\hline 206 & $-9,1$ & 4,8 & 5.698 & 7,2 \\
\hline
\end{tabular}

\begin{tabular}{|c|c|c|c|c|}
\hline $\begin{array}{c}p_{\text {sat }} \\
(\boldsymbol{k P a})\end{array}$ & $\begin{array}{l}T_{\text {sat }} \\
\left({ }^{\circ} \boldsymbol{C}\right)\end{array}$ & $\begin{array}{c}\Delta T \\
\left({ }^{o} C\right)\end{array}$ & $\begin{array}{c}h \\
\left(k W / m^{2}\right)\end{array}$ & $\begin{array}{c}\text { incerteza } \\
(\%)\end{array}$ \\
\hline 206 & $-9,0$ & 4,6 & 5.365 & 7,5 \\
\hline 206 & $-9,1$ & 4,4 & 4.551 & 7,8 \\
\hline 206 & $-9,1$ & 4,2 & 4.111 & 8,2 \\
\hline 206 & $-9,1$ & 3,9 & 3.355 & 8,9 \\
\hline 206 & $-9,0$ & 3,6 & 2.817 & 9,8 \\
\hline 206 & $-9,0$ & 3,3 & 2.547 & 10,6 \\
\hline 206 & $-8,9$ & 3,1 & 2.260 & 11,1 \\
\hline 206 & $-8,9$ & 2,7 & 1.872 & 12,8 \\
\hline 206 & $-8,9$ & 2,4 & 1.493 & 14,5 \\
\hline 206 & $-9,0$ & 1,7 & 963 & 20,0 \\
\hline 205 & -9,1 & 7,5 & 15.459 & 4,6 \\
\hline 204 & $-9,1$ & 7,2 & 13.937 & 4,8 \\
\hline 204 & $-9,1$ & 6,8 & 12.416 & 5,1 \\
\hline 204 & $-9,0$ & 6,4 & 10.599 & 5,4 \\
\hline 204 & $-9,1$ & 5,9 & 8.679 & 5,9 \\
\hline 204 & $-9,0$ & 5,3 & 6.450 & 6,6 \\
\hline 204 & $-8,9$ & 4,8 & 5.142 & 7,2 \\
\hline 203 & $-9,0$ & 4,2 & 3.998 & 8,2 \\
\hline 203 & $-9,1$ & 3,8 & 3.370 & 9,2 \\
\hline 203 & $-9,0$ & 3,3 & 2.651 & 10,6 \\
\hline 203 & $-9,0$ & 2,9 & 2.311 & 12,2 \\
\hline 202 & $-8,9$ & 2,4 & 1.830 & 14,7 \\
\hline 201 & $-8,9$ & 1,6 & 1.064 & 21,8 \\
\hline 201 & $-8,9$ & 1,2 & 637 & 28,9 \\
\hline 255 & 25 & 60 & 16010 & 51 \\
\hline$\frac{250}{255}$ & $\begin{array}{l}-3,5 \\
-3,5\end{array}$ & $\begin{array}{l}0,9 \\
65\end{array}$ & $\begin{array}{l}10.919 \\
14942\end{array}$ & $\frac{5,1}{53}$ \\
\hline 256 & $-3,4$ & 6,2 & 13.555 & 5,6 \\
\hline 255 & $-3,4$ & 5,8 & 11.886 & 6,0 \\
\hline 255 & $-3,4$ & 5,6 & 10.608 & 6,2 \\
\hline 255 & $-3,4$ & 5,3 & 9.570 & 6,5 \\
\hline 254 & $-3,5$ & 5,1 & 8.265 & 6,9 \\
\hline 254 & $-3,5$ & 4,8 & 7.036 & 7,2 \\
\hline 254 & $-3,4$ & 4,6 & 6.132 & 7,6 \\
\hline 255 & $-3,4$ & 4,5 & 5.732 & 7,7 \\
\hline 254 & $-3,4$ & 4,2 & 4.766 & 8,3 \\
\hline 255 & $-3,4$ & 4,0 & 4.206 & 8,6 \\
\hline 255 & $-3,3$ & 3,6 & 3.438 & 9,7 \\
\hline 255 & $-3,4$ & 3,3 & 3.042 & 10,4 \\
\hline 255 & $-3,3$ & 3,1 & 2.621 & 11,1 \\
\hline 254 & $-3,3$ & 2,9 & 2.375 & 11,9 \\
\hline 254 & $-3,3$ & 2,6 & 1.969 & 13,4 \\
\hline 253 & $-3,3$ & 2,2 & 1.497 & 15,7 \\
\hline 253 & $-3,3$ & 1,8 & 938 & 18,9 \\
\hline 253 & $-3,3$ & 1,5 & 579 & 22,5 \\
\hline 256 & $-3,3$ & 7,0 & 16.298 & 5,0 \\
\hline 256 & $-3,3$ & 6,7 & 14.793 & 5,2 \\
\hline 254 & $-3,4$ & 6,4 & 13.131 & 5,5 \\
\hline 253 & $-3,5$ & 5,9 & 11.207 & 5,8 \\
\hline 254 & $-3,4$ & 5,5 & 9.008 & 6,3 \\
\hline 255 & $-3,3$ & 5,0 & 6.671 & 6,9 \\
\hline 255 & $-3,2$ & 4,6 & 5.463 & 7,6 \\
\hline 254 & $-3,3$ & 4,0 & 4.223 & 8,6 \\
\hline 254 & $-3,3$ & 3,6 & 3.488 & 9,7 \\
\hline 254 & $-3,2$ & 3,1 & 2.795 & 11,2 \\
\hline 254 & $-3,2$ & 2,7 & 2.441 & 12,6 \\
\hline 254 & $-3,2$ & 2,3 & 1.939 & 14,8 \\
\hline 254 & $-3,1$ & 1,7 & 1.037 & 20,6 \\
\hline 253 & $-3,1$ & 1,3 & 682 & 25,9 \\
\hline 373 & 7,0 & 6,3 & 18.991 & 5,6 \\
\hline 372 & 6,9 & 5,9 & 17.034 & 5,9 \\
\hline 371 & 6,9 & 5,5 & 15.027 & 6,3 \\
\hline 371 & 6,9 & 5,2 & 12.967 & 6,7 \\
\hline
\end{tabular}




\begin{tabular}{|c|c|c|c|c|}
\hline $\begin{array}{c}p_{\text {sat }} \\
(\boldsymbol{k P a})\end{array}$ & $\begin{array}{l}T_{\text {sat }} \\
\left({ }^{o} \mathrm{C}\right)\end{array}$ & $\begin{array}{c}\Delta \boldsymbol{T} \\
\left({ }^{o} \boldsymbol{C}\right)\end{array}$ & $\begin{array}{c}h \\
\left(k W / m^{2}\right)\end{array}$ & $\begin{array}{c}\text { incerteza } \\
(\%)\end{array}$ \\
\hline 371 & 6,9 & 4,7 & 10.817 & 7,3 \\
\hline 369 & 6,8 & 4,1 & 8.200 & 8,4 \\
\hline 372 & 7,0 & 3,9 & 6.474 & 8,9 \\
\hline 371 & 7,0 & 3,4 & 4.968 & 10,1 \\
\hline 372 & 7,0 & 3,1 & 4.037 & 11,2 \\
\hline 372 & 7,1 & 2,7 & 3.243 & 12,9 \\
\hline 371 & 7,1 & 2,4 & 2.820 & 14,4 \\
\hline 371 & 7,0 & 2,1 & 2.050 & 16,3 \\
\hline 371 & 7,1 & 1,6 & 1.119 & 22,3 \\
\hline 371 & 7,1 & 1,2 & 484 & 29,2 \\
\hline 486 & 15,0 & 5,7 & 20.139 & 6,0 \\
\hline 486 & 14,9 & 5,5 & 18.338 & 6,3 \\
\hline 485 & 14,9 & 5,2 & 16.027 & 6,7 \\
\hline 488 & 15,0 & 4,8 & 14.068 & 7,2 \\
\hline 486 & 14,9 & 4,4 & 11.417 & 7,9 \\
\hline 486 & 14,9 & 3,6 & 9.270 & 9,5 \\
\hline 487 & 15,0 & 3,6 & 6.761 & 9,8 \\
\hline 484 & 14,9 & 2,8 & 6.024 & 12,6 \\
\hline 487 & 15,0 & 2,9 & 4.431 & 12,1 \\
\hline 486 & 15,0 & 2,5 & 3.550 & 13,9 \\
\hline 485 & 15,0 & 2,2 & 2.932 & 15,9 \\
\hline 485 & 15,0 & 1,9 & 2.239 & 18,1 \\
\hline 484 & 15,0 & 1,4 & 1.130 & 24,6 \\
\hline 484 & 15,0 & 1,2 & 690 & 29,1 \\
\hline 720 & 27,5 & 5,3 & 22.314 & 6,6 \\
\hline 721 & 27,5 & 4,9 & 20.097 & 7,1 \\
\hline 721 & 27,6 & 4,6 & 18.028 & 7,5 \\
\hline 719 & 27,4 & 4,3 & 15.464 & 8,0 \\
\hline 724 & 27,7 & 4,0 & 12.506 & 8,6 \\
\hline 724 & 27,7 & 3,5 & 9.316 & 9,9 \\
\hline 722 & 27,6 & 3,2 & 7.690 & 10,7 \\
\hline 724 & 27,6 & 2,9 & 5.999 & 11,9 \\
\hline 723 & 27,5 & 2,7 & 4.705 & 13,0 \\
\hline 727 & 27,6 & 2,5 & 3.466 & 14,1 \\
\hline 728 & 27,7 & 2,3 & 2.971 & 15,0 \\
\hline 727 & 27,7 & 2,0 & 2.143 & 17,1 \\
\hline 730 & 27,8 & 1,7 & 1.051 & 20,6 \\
\hline 729 & 27,8 & 1,4 & 382 & 25,2 \\
\hline 840 & 32,7 & 5,0 & 23.163 & 7,0 \\
\hline 842 & 32,8 & 4,6 & 21.005 & 7,5 \\
\hline 839 & 32,7 & 4,4 & 19.122 & 7,9 \\
\hline 839 & 32,7 & 4,1 & 16.343 & 8,5 \\
\hline 838 & 32,7 & 3,7 & 13.449 & 9,4 \\
\hline 839 & 32,7 & 3,3 & 10.284 & 10,6 \\
\hline 838 & 32,7 & 3,0 & 8.415 & 11,7 \\
\hline 840 & 32,7 & 2,6 & 6.491 & 13,2 \\
\hline 841 & 32,8 & 2,4 & 5.272 & 14,4 \\
\hline 838 & 32,7 & 2,1 & 4.045 & 16,5 \\
\hline 840 & 32,8 & 2,1 & 3.160 & 16,2 \\
\hline 841 & 32,8 & 1,9 & 2.215 & 18,0 \\
\hline 840 & 32,8 & 1,5 & 1.100 & 22,5 \\
\hline 840 & 32,8 & 1,3 & 656 & 25,8 \\
\hline 1.071 & 41,6 & 4,7 & 24.378 & 7,4 \\
\hline 1.071 & 41,6 & 4,5 & 22.259 & 7,7 \\
\hline 1.074 & 41,7 & 4,2 & 19.355 & 8,3 \\
\hline 1.072 & 41,6 & 3,9 & 17.298 & 8,9 \\
\hline 1.075 & 41,7 & 3,5 & 13.958 & 9,8 \\
\hline 1.077 & 41,7 & 3,1 & 10.831 & 11,0 \\
\hline 1.077 & 41,8 & 2,8 & 8.761 & 12,2 \\
\hline 1.077 & 41,7 & 2,5 & 6.568 & 13,7 \\
\hline 1.075 & 41,7 & 2,3 & 5.310 & 14,9 \\
\hline 1.074 & 41,7 & 2,1 & 4.146 & 16,3 \\
\hline
\end{tabular}

\begin{tabular}{|c|c|c|c|c|}
\hline $\begin{array}{c}\boldsymbol{p}_{\text {sat }} \\
(\boldsymbol{k P a})\end{array}$ & $\begin{array}{c}\boldsymbol{T}_{\text {sat }} \\
\left({ }^{\circ} \boldsymbol{C}\right)\end{array}$ & $\begin{array}{c}\Delta \boldsymbol{T} \\
\left({ }^{\circ} \boldsymbol{C}\right)\end{array}$ & $\begin{array}{c}\boldsymbol{h} \\
\left(\boldsymbol{k W}^{2} \boldsymbol{m}^{2}\right)\end{array}$ & $\begin{array}{c}\text { incerteza } \\
(\boldsymbol{\%})\end{array}$ \\
\hline 1.073 & 41,6 & 2,0 & 3.318 & 17,5 \\
\hline 1.072 & 41,6 & 1,8 & 2.376 & 19,5 \\
\hline 1.071 & 41,6 & 1,5 & 1.093 & 23,7 \\
\hline 1.070 & 41,5 & 1,3 & 656 & 26,5 \\
\hline &
\end{tabular}

Superfície de latão; $R a=0,08 \pm 0,02 \mu \mathrm{m}$

\begin{tabular}{|c|c|c|c|c|}
\hline 204 & $-9,0$ & 11,8 & 6.367 & 3,0 \\
\hline 204 & $-9,0$ & 11,6 & 5.827 & 3,0 \\
\hline 204 & $-9,0$ & 11,4 & 5.239 & 3,1 \\
\hline 204 & $-9,0$ & 11,2 & 4.838 & 3,1 \\
\hline 204 & $-9,0$ & 10,8 & 4.209 & 3,2 \\
\hline 204 & $-8,9$ & 10,5 & 3.615 & 3,3 \\
\hline 204 & $-8,9$ & 10,0 & 2.964 & 3,5 \\
\hline 204 & $-8,9$ & 9,8 & 2.539 & 3,6 \\
\hline 204 & $-8,9$ & 9,6 & 2.357 & 3,6 \\
\hline 204 & $-8,9$ & 9,4 & 1.911 & 3,7 \\
\hline 204 & $-8,9$ & 9,3 & 1.663 & 3,8 \\
\hline 203 & $-8,9$ & 8,8 & 1.277 & 4,0 \\
\hline 202 & $-9,0$ & 8,3 & 1.091 & 4,2 \\
\hline 203 & $-8,9$ & 7,8 & 952 & 4,5 \\
\hline 202 & $-8,9$ & 7,3 & 820 & 4,8 \\
\hline 202 & $-8,9$ & 6,4 & 691 & 5,5 \\
\hline 202 & $-8,9$ & 5,2 & 569 & 6,8 \\
\hline 201 & $-8,9$ & 3,3 & 458 & 10,7 \\
\hline 201 & $-8,9$ & 2,3 & 364 & 15,5 \\
\hline & & & & \\
\hline 255 & $-3,3$ & 11,0 & 6.967 & 3,2 \\
\hline 254 & $-3,4$ & 10,7 & 6.274 & 3,3 \\
\hline 253 & $-3,4$ & 10,5 & 5.874 & 3,3 \\
\hline 255 & $-3,2$ & 10,2 & 5.235 & 3,4 \\
\hline 254 & $-3,4$ & 9,9 & 4.708 & 3,5 \\
\hline 253 & $-3,4$ & 9,5 & 3.945 & 3,7 \\
\hline 252 & $-3,4$ & 9,1 & 3.284 & 3,8 \\
\hline 253 & $-3,4$ & 8,7 & 2.594 & 4,0 \\
\hline 254 & $-3,3$ & 8,3 & 2.014 & 4,2 \\
\hline 253 & $-3,3$ & 8,1 & 1.853 & 4,3 \\
\hline 253 & $-3,3$ & 7,8 & 1.430 & 4,5 \\
\hline 253 & $-3,2$ & 7,2 & 1.096 & 4,9 \\
\hline 252 & $-3,3$ & 6,6 & 878 & 5,3 \\
\hline 252 & $-3,2$ & 6,2 & 735 & 5,7 \\
\hline 252 & $-3,2$ & 4,9 & 597 & 7,2 \\
\hline 252 & $-3,2$ & 3,4 & 497 & 10,4 \\
\hline 252 & $-3,2$ & 2,2 & 347 & 16,3 \\
\hline 373 & 7,0 & 9,5 & 8.059 & 3,7 \\
\hline 371 & 6,9 & 9,2 & 7.330 & 3,8 \\
\hline 373 & 7,0 & 9,0 & 6.701 & 3,9 \\
\hline 372 & 7,0 & 8,7 & 6.130 & 4,0 \\
\hline 371 & 7,0 & 8,4 & 5.462 & 4,1 \\
\hline 371 & 7,0 & 8,1 & 4.678 & 4,3 \\
\hline 370 & 6,9 & 7,8 & 4.030 & 4,5 \\
\hline 370 & 6,9 & 7,3 & 3.124 & 4,8 \\
\hline 369 & 6,8 & 6,9 & 2.559 & 5,1 \\
\hline 372 & 7,1 & 6,7 & 2.255 & 5,2 \\
\hline 371 & 7,0 & 6,3 & 1.812 & 5,6 \\
\hline 371 & 7,0 & 5,9 & 1.515 & 5,9 \\
\hline 370 & 7,0 & 5,6 & 1.135 & 6,2 \\
\hline 369 & 7,0 & 5,1 & 860 & 6,9 \\
\hline 369 & 7,0 & 4,4 & 650 & 7,9 \\
\hline 369 & 7,0 & 3,2 & 472 & 11,0 \\
\hline 369 & 7,0 & 2,3 & 356 & 15,1 \\
\hline 486 & 15,0 & 8,5 & 8.981 & 4,1 \\
\hline 486 & 15,0 & 8,3 & 8.217 & 4,2 \\
\hline 485 & 14,9 & 8,2 & 7.521 & 4,3 \\
\hline 486 & 15,0 & 7,9 & 6.705 & 4,4 \\
\hline
\end{tabular}




\begin{tabular}{|c|c|c|c|c|}
\hline $\begin{array}{c}p_{\text {sat }} \\
(\boldsymbol{k P a})\end{array}$ & $\begin{array}{l}T_{\text {sat }} \\
\left({ }^{\circ} \mathrm{C}\right)\end{array}$ & $\begin{array}{c}\Delta T \\
\left({ }^{o} C\right)\end{array}$ & $\begin{array}{c}h \\
\left(k W / m^{2}\right)\end{array}$ & $\begin{array}{c}\text { incerteza } \\
(\%)\end{array}$ \\
\hline 488 & 15,1 & 7,6 & 5.976 & 4,5 \\
\hline 484 & 14,9 & 7,2 & 5.161 & 4,8 \\
\hline 485 & 15,0 & 7,0 & 4.391 & 5,0 \\
\hline 484 & 14,9 & 6,7 & 3.781 & 5,2 \\
\hline 485 & 15,0 & 6,5 & 3.569 & 5,3 \\
\hline 484 & 14,9 & 6,2 & 2.943 & 5,6 \\
\hline 485 & 15,0 & 5,9 & 2.479 & 5,9 \\
\hline 483 & 14,9 & 5,6 & 2.063 & 6,3 \\
\hline 484 & 14,9 & 5,3 & 1.747 & 6,6 \\
\hline 486 & 15,0 & 5,1 & 1.555 & 6,8 \\
\hline 485 & 15,0 & 4,9 & 1.273 & 7,2 \\
\hline 485 & 15,0 & 4,5 & 973 & 7,7 \\
\hline 484 & 15,0 & 4,1 & 739 & 8,5 \\
\hline 484 & 15,0 & 3,2 & 493 & 10,9 \\
\hline 484 & 15,0 & 2,3 & 321 & 15,3 \\
\hline 718 & 27,5 & 6,9 & 10.966 & 5,0 \\
\hline 717 & 27,5 & 6,7 & 10.160 & 5,2 \\
\hline 719 & 27,6 & 6,6 & 9.206 & 5,3 \\
\hline 719 & 27,6 & 6,3 & 8.299 & 5,5 \\
\hline 717 & 27,5 & 6,1 & 7.462 & 5,7 \\
\hline 717 & 27,5 & 5,9 & 6.474 & 5,9 \\
\hline 716 & 27,5 & 5,6 & 5.477 & 6,2 \\
\hline 717 & 27,5 & 5,3 & 4.690 & 6,5 \\
\hline 717 & 27,5 & 5,2 & 4.335 & 6,7 \\
\hline 719 & 27,6 & 4,9 & 3.561 & 7,1 \\
\hline 719 & 27,6 & 4,8 & 3.182 & 7,3 \\
\hline 719 & 27,6 & 4,5 & 2.599 & 7,8 \\
\hline 718 & 27,6 & 4,3 & 2.172 & 8,2 \\
\hline 717 & 27,5 & 4,1 & 1.838 & 8,6 \\
\hline 717 & 27,5 & 3,9 & 1.569 & 8,9 \\
\hline 718 & 27,5 & 3,6 & 1.236 & 9,6 \\
\hline 718 & 27,5 & 3,3 & 942 & 10,7 \\
\hline 717 & 27,5 & 2,7 & 548 & 13,0 \\
\hline 716 & 27,5 & 2,0 & 309 & 17,8 \\
\hline 721 & 27,5 & 7,2 & 10.350 & 4,8 \\
\hline 721 & 27,6 & 7,0 & 9.635 & 4,9 \\
\hline 720 & 27,6 & 6,9 & 8.924 & 5,0 \\
\hline 720 & 27,6 & 6,6 & 7.896 & 5,2 \\
\hline 719 & 27,5 & 6,5 & 7.066 & 5,4 \\
\hline 719 & 27,5 & 6,2 & 6.016 & 5,6 \\
\hline 719 & 27,5 & 5,9 & 5.204 & 5,9 \\
\hline 719 & 27,6 & 5,7 & 4.618 & 6,1 \\
\hline 719 & 27,5 & 5,5 & 4.119 & 6,3 \\
\hline 718 & 27,5 & 5,4 & 3.628 & 6,5 \\
\hline 718 & 27,5 & 5,1 & 2.964 & 6,8 \\
\hline 718 & 27,5 & 4,8 & 2.282 & 7,3 \\
\hline 717 & 27,5 & 4,6 & 1.987 & 7,6 \\
\hline 717 & 27,5 & 4,4 & 1.701 & 7,9 \\
\hline 716 & 27,4 & 4,1 & 1.284 & 8,5 \\
\hline 718 & 27,6 & 3,9 & 1.116 & 8,9 \\
\hline 719 & 27,6 & 3,6 & 827 & 9,8 \\
\hline 718 & 27,5 & 2,9 & 498 & 12,1 \\
\hline 718 & 27,5 & 2,3 & 336 & 15,3 \\
\hline 838 & 32,7 & 6,5 & 11.337 & 5,3 \\
\hline 836 & 32,7 & 6,3 & 10.635 & 5,5 \\
\hline 839 & 32,8 & 6,1 & 9.708 & 5,6 \\
\hline 836 & 32,7 & 6,0 & 8.812 & 5,8 \\
\hline 837 & 32,7 & 5,8 & 7.896 & 6,0 \\
\hline 835 & 32,6 & 5,5 & 6.847 & 6,3 \\
\hline 836 & 32,6 & 5,3 & 5.767 & 6,6 \\
\hline 835 & 32,6 & 5,0 & 4.980 & 6,9 \\
\hline 837 & 32,7 & 4,9 & 4.679 & 7,1 \\
\hline 836 & 32,7 & 4,6 & 3.819 & 7,5 \\
\hline
\end{tabular}

\begin{tabular}{|c|c|c|c|c|}
\hline $\begin{array}{c}p_{\text {sat }} \\
(\boldsymbol{k P a})\end{array}$ & $\begin{array}{r}T_{\text {sat }} \\
\left({ }^{o} \boldsymbol{C}\right)\end{array}$ & $\begin{array}{c}\Delta T \\
\left({ }^{o} C\right)\end{array}$ & $\begin{array}{c}h \\
\left(k W / m^{2}\right)\end{array}$ & $\begin{array}{c}\text { incerteza } \\
(\%)\end{array}$ \\
\hline 838 & 32,8 & 4,4 & 3.410 & 7,8 \\
\hline 837 & 32,7 & 4,2 & 2.751 & 8,4 \\
\hline 836 & 32,7 & 3,9 & 2.287 & 8,8 \\
\hline 836 & 32,7 & 3,8 & 1.995 & 9,2 \\
\hline 836 & 32,7 & 3,6 & 1.683 & 9,7 \\
\hline 835 & 32,7 & 3,4 & 1.329 & 10,3 \\
\hline 831 & 32,6 & 3,0 & 1.012 & 11,5 \\
\hline 833 & 32,5 & 2,6 & 585 & 13,3 \\
\hline 837 & 32,6 & 2,2 & 354 & 16,1 \\
\hline 835 & 32,7 & 6,7 & 11.504 & 5,2 \\
\hline 836 & 32,7 & 6,4 & 10.454 & 5,4 \\
\hline 835 & 32,7 & 6,3 & 9.574 & 5,5 \\
\hline 836 & 32,7 & 6,1 & 8.582 & 5,7 \\
\hline 834 & 32,7 & 6,0 & 7.689 & 5,8 \\
\hline 833 & 32,6 & 5,7 & 6.544 & 6,1 \\
\hline 835 & 32,7 & 5,4 & 5.646 & 6,4 \\
\hline 833 & 32,6 & 5,1 & 4.442 & 6,8 \\
\hline 832 & 32,6 & 4,9 & 3.647 & 7,1 \\
\hline 830 & 32,5 & 4,7 & 3.175 & 7,4 \\
\hline 829 & 32,5 & 4,5 & 2.579 & 7,8 \\
\hline 829 & 32,5 & 4,3 & 2.188 & 8,2 \\
\hline 830 & 32,5 & 4,1 & 1.851 & 8,6 \\
\hline 831 & 32,5 & 3,9 & 1.571 & 8,8 \\
\hline 830 & 32,5 & 3,7 & 1.158 & 9,5 \\
\hline 828 & 32,5 & 3,4 & 856 & 10,4 \\
\hline 830 & 32,5 & 2,9 & 534 & 12,1 \\
\hline 826 & 32,4 & 2,3 & 330 & 15,0 \\
\hline 1.069 & 41,5 & 5,7 & 13.209 & 6,1 \\
\hline 1.072 & 41,7 & 5,5 & 12.278 & 6,3 \\
\hline 1.069 & 41,6 & 5,4 & 10.848 & 6,5 \\
\hline 1.066 & 41,5 & 5,2 & 10.103 & 6,7 \\
\hline 1.074 & 41,7 & 5,0 & 9.014 & 6,9 \\
\hline 1.068 & 41,5 & 4,8 & 7.806 & 7,2 \\
\hline 1.068 & 41,5 & 4,6 & 6.697 & 7,5 \\
\hline 1.070 & 41,6 & 4,4 & 5.728 & 7,9 \\
\hline 1.071 & 41,6 & 4,3 & 5.188 & 8,1 \\
\hline 1.070 & 41,6 & 4,1 & 4.356 & 8,6 \\
\hline 1.069 & 41,6 & 3,9 & 3.930 & 8,9 \\
\hline 1.069 & 41,6 & 3,7 & 3.105 & 9,4 \\
\hline 1.066 & 41,5 & 3,3 & 2.259 & 10,5 \\
\hline 1.067 & 41,5 & 3,2 & 1.873 & 10,9 \\
\hline 1.071 & 41,6 & 3,0 & 1.463 & 11,6 \\
\hline 1.071 & 41,6 & 2,8 & 1.164 & 12,5 \\
\hline 1.074 & 41,6 & 2,5 & 626 & 14,1 \\
\hline 1.069 & 41,4 & 2,1 & 358 & 16,9 \\
\hline
\end{tabular}

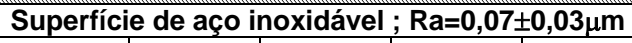

\begin{tabular}{|c|c|c|c|c|}
\hline 205 & $-8,9$ & 19,2 & 3.207 & 1,5 \\
\hline 205 & $-8,9$ & 17,5 & 2.809 & 1,6 \\
\hline 204 & $-9,0$ & 16,0 & 2.585 & 1,8 \\
\hline 204 & $-9,0$ & 14,4 & 2.327 & 2,0 \\
\hline 204 & $-9,0$ & 13,0 & 2.124 & 2,2 \\
\hline 203 & $-9,0$ & 12,5 & 2.014 & 2,3 \\
\hline 203 & $-9,0$ & 10,9 & 1.738 & 2,6 \\
\hline 203 & $-9,0$ & 10,3 & 1.633 & 2,8 \\
\hline 203 & $-9,0$ & 8,8 & 1.391 & 3,3 \\
\hline 203 & $-9,0$ & 8,2 & 1.256 & 3,5 \\
\hline 203 & $-9,0$ & 7,8 & 1.091 & 3,7 \\
\hline 202 & $-9,0$ & 7,2 & 922 & 4,1 \\
\hline 201 & $-9,0$ & 6,7 & 753 & 4,4 \\
\hline 202 & $-8,9$ & 6,5 & 551 & 4,5 \\
\hline 201 & $-8,9$ & 4,1 & 399 & 7,1 \\
\hline 200 & $-8,9$ & 1,2 & 431 & 24,5 \\
\hline
\end{tabular}




\begin{tabular}{|c|c|c|c|c|}
\hline $\begin{array}{c}p_{\text {sat }} \\
(\boldsymbol{k P a})\end{array}$ & $\begin{array}{l}T_{\text {sat }} \\
\left({ }^{\circ} \mathrm{C}\right)\end{array}$ & $\begin{array}{c}\Delta T \\
\left({ }^{o} C\right)\end{array}$ & $\begin{array}{c}h \\
\left(k W / m^{2}\right)\end{array}$ & $\begin{array}{c}\text { incerteza } \\
(\%)\end{array}$ \\
\hline 254 & $-3,3$ & 17,7 & 3.317 & 2,0 \\
\hline 254 & $-3,4$ & 16,5 & 3.068 & 2,1 \\
\hline 252 & $-3,5$ & 15,1 & 2.709 & 2,3 \\
\hline 253 & $-3,4$ & 13,5 & 2.474 & 2,6 \\
\hline 253 & $-3,4$ & 12,2 & 2.264 & 2,9 \\
\hline 253 & $-3,4$ & 11,7 & 2.199 & 3,0 \\
\hline 254 & $-3,4$ & 10,3 & 1.920 & 3,4 \\
\hline 255 & $-3,3$ & 9,6 & 1.791 & 3,7 \\
\hline 253 & $-3,4$ & 8,5 & 1.512 & 4,1 \\
\hline 253 & $-3,4$ & 7,7 & 1.322 & 4,6 \\
\hline 253 & $-3,4$ & 7,2 & 1.184 & 4,9 \\
\hline 254 & $-3,3$ & 6,8 & 1.025 & 5,2 \\
\hline 254 & $-3,4$ & 6,2 & 842 & 5,7 \\
\hline 253 & $-3,4$ & 5,3 & 643 & 6,7 \\
\hline 253 & $-3,5$ & 2,9 & 557 & 11,9 \\
\hline 253 & $-3,5$ & 1,2 & 692 & 28,4 \\
\hline 254 & $-3,3$ & 17,9 & 3.387 & 2,0 \\
\hline 252 & $-3,5$ & 16,5 & 3.090 & 2,1 \\
\hline 253 & $-3,4$ & 15,2 & 2.834 & 2,3 \\
\hline 252 & $-3,4$ & 13,6 & 2.552 & 2,6 \\
\hline 253 & $-3,4$ & 12,1 & 2.260 & 2,9 \\
\hline 254 & $-3,3$ & 11,6 & 2.220 & 3,0 \\
\hline 253 & $-3,4$ & 10,1 & 1.949 & 3,5 \\
\hline 252 & $-3,4$ & 9,5 & 1.797 & 3,7 \\
\hline 253 & $-3,4$ & 8,3 & 1.532 & 4,2 \\
\hline 252 & $-3,4$ & 7,4 & 1.353 & 4,7 \\
\hline 253 & $-3,3$ & 7,0 & 1.209 & 5,0 \\
\hline 252 & $-3,3$ & 6,5 & 1.073 & 5,4 \\
\hline 252 & $-3,3$ & 5,9 & 864 & 6,0 \\
\hline 251 & $-3,3$ & 5,4 & 613 & 6,6 \\
\hline 251 & $-3,3$ & 4,5 & 353 & 7,9 \\
\hline 250 & $-3,3$ & 2,7 & 294 & 12,9 \\
\hline 373 & 7,0 & 16,0 & 3.851 & 2,2 \\
\hline 373 & 7,0 & 14,5 & 3.442 & 2,4 \\
\hline 372 & 7,0 & 13,1 & 3.157 & 2,7 \\
\hline 371 & 6,9 & 11,8 & 2.869 & 3,0 \\
\hline 370 & 6,9 & 10,5 & 2.639 & 3,3 \\
\hline 371 & 6,9 & 10,0 & 2.526 & 3,5 \\
\hline 369 & 6,8 & 8,7 & 2.265 & 4,0 \\
\hline 369 & 6,8 & 8,0 & 2.118 & 4,3 \\
\hline 368 & 6,8 & 7,0 & 1.813 & 5,0 \\
\hline 370 & 6,9 & 6,3 & 1.616 & 5,6 \\
\hline 370 & 6,9 & 5,8 & 1.492 & 6,1 \\
\hline 369 & 6,9 & 5,2 & 1.342 & 6,7 \\
\hline 369 & 6,9 & 4,8 & 1.090 & 7,3 \\
\hline 370 & 7,0 & 4,1 & 842 & 8,4 \\
\hline 370 & 7,0 & 3,6 & 479 & 9,9 \\
\hline 370 & 7,1 & 2,6 & 332 & 13,5 \\
\hline 488 & 15,1 & 14,6 & 4.036 & 2,4 \\
\hline 486 & 14,9 & 13,7 & 3.733 & 2,6 \\
\hline 487 & 15,0 & 12,3 & 3.468 & 2,8 \\
\hline 486 & 15,0 & 11,0 & 3.175 & 3,2 \\
\hline 486 & 15,0 & 9,7 & 2.906 & 3,6 \\
\hline 486 & 15,0 & 9,0 & 2.794 & 3,9 \\
\hline 486 & 15,0 & 7,9 & 2.539 & 4,4 \\
\hline 487 & 15,0 & 7,3 & 2.378 & 4,8 \\
\hline 485 & 14,9 & 6,2 & 2.051 & 5,6 \\
\hline 485 & 14,9 & 5,5 & 1.809 & 6,3 \\
\hline 486 & 15,0 & 5,1 & 1.663 & 6,8 \\
\hline 486 & 15,0 & 4,6 & 1.461 & 7,6 \\
\hline 486 & 15,0 & 4,2 & 1.214 & 8,4 \\
\hline 486 & 15,0 & 3,5 & 925 & 9,9 \\
\hline 485 & 15,0 & 2,8 & 572 & 12,4 \\
\hline
\end{tabular}

\begin{tabular}{|c|c|c|c|c|}
\hline $\begin{array}{c}p_{\text {sat }} \\
(\boldsymbol{k P a})\end{array}$ & $\begin{array}{r}T_{\text {sat }} \\
\left({ }^{o} C\right)\end{array}$ & $\begin{array}{c}\Delta T \\
\left({ }^{o} C\right)\end{array}$ & $\begin{array}{c}h \\
\left(k W / m^{2}\right)\end{array}$ & $\begin{array}{c}\text { incerteza } \\
(\%)\end{array}$ \\
\hline 485 & 15,1 & 2,3 & 400 & 15,0 \\
\hline 721 & 27,6 & 13.0 & 4.458 & 2.7 \\
\hline 721 & 27,6 & 12,1 & 4.214 & 2,9 \\
\hline 718 & 27,4 & 11,1 & 3.842 & 3,1 \\
\hline 718 & 27,5 & 9,7 & 3.501 & 3,6 \\
\hline 719 & 27,5 & 8,6 & 3.261 & 4,1 \\
\hline 719 & 27,5 & 8,0 & 3.061 & 4,4 \\
\hline 718 & 27,5 & 7,1 & 2.854 & 4,9 \\
\hline 720 & 27,6 & 6.4 & 2.676 & 5,4 \\
\hline 720 & 27,6 & 5,4 & 2.320 & 6,4 \\
\hline 721 & 27,6 & 4,9 & 2.099 & 7,1 \\
\hline 720 & 27,6 & 4,5 & 1.900 & 7,8 \\
\hline 720 & 27,6 & 4,0 & 1.674 & 8,7 \\
\hline 722 & 27,6 & 3,6 & 1.411 & 9,7 \\
\hline 721 & 27,6 & 3,1 & 1.072 & 11,3 \\
\hline 722 & 27,7 & 2,6 & 674 & 13,6 \\
\hline 722 & 27,7 & 2,2 & 429 & 16,2 \\
\hline 838 & 32,7 & 12,7 & 4.614 & 2,8 \\
\hline 838 & 32,7 & 11,6 & 4.268 & 3,0 \\
\hline 838 & 32,7 & 10,5 & 3.926 & 3,3 \\
\hline 838 & 32,7 & 9,2 & 3.611 & 3,8 \\
\hline 837 & 32,7 & 8,4 & 3.386 & 4,1 \\
\hline 838 & 32,7 & 7,8 & 3.215 & 4,5 \\
\hline 841 & 32,8 & 7,1 & 2.991 & 4,9 \\
\hline 839 & 32,8 & 6,2 & 2.710 & 5,6 \\
\hline 839 & 32,8 & 5,2 & 2.352 & 6,6 \\
\hline 838 & 32,7 & 4,7 & 2.097 & 7,4 \\
\hline 838 & 32,7 & 4,4 & 1.979 & 7,9 \\
\hline 836 & 32,7 & 4,0 & 1.667 & 8,7 \\
\hline 838 & 32,7 & 3,5 & 1.411 & 10,1 \\
\hline 838 & 32,7 & 3,1 & 1.125 & 11,3 \\
\hline 837 & 32,7 & 2,5 & 694 & 14,2 \\
\hline 837 & 32,7 & 1,8 & 236 & 19,4 \\
\hline 1.072 & 41,6 & 11,7 & 5.138 & 3,0 \\
\hline 1.074 & 41,7 & 10,8 & 4.724 & 3,2 \\
\hline 1.071 & 41,6 & 9,7 & 4.310 & 3,6 \\
\hline 1.073 & 41,7 & 8,6 & 3.902 & 4,0 \\
\hline 1.075 & 41,7 & 7,8 & 3.667 & 4,4 \\
\hline 1.074 & 41,7 & 7,2 & 3.511 & 4,9 \\
\hline 1.073 & 41,7 & 6,5 & 3.297 & 5,3 \\
\hline 1.073 & 41,7 & 5,7 & 2.984 & 6,1 \\
\hline 1.073 & 41,7 & 4,8 & 2.595 & 7,3 \\
\hline 1.068 & 41,5 & 4,3 & 2.341 & 8,2 \\
\hline 1.076 & 41,7 & 3,9 & 2.158 & 8,8 \\
\hline 1.079 & 41,9 & 3,5 & 1.923 & 9,8 \\
\hline 1.079 & 41,9 & 3,1 & 1.619 & 11,4 \\
\hline 1.078 & 41,8 & 2,7 & 1.268 & 13,0 \\
\hline 1.078 & 41,8 & 2,2 & 767 & 16,1 \\
\hline 1.077 & 41,8 & 1,8 & 450 & 19,0 \\
\hline
\end{tabular}




\section{i. Correlações Levantadas}

Com base nos procedimentos apresentados no Capítulo 7 foram levantadas distintas correlações, cujas constantes multiplicativas e expoentes, ajustados através dos resultados experimentais encontram-se na Tabela 2. Com o objetivo de facilitar a apresentação desses resultados adotou-se os códigos ilustrados na Tabela 1, relacionando um caracter a cada forma utilizada na correlação de determinado efeito. Os desvios médios verificados para cada correlação encontram-se listados na Tabela 3. É interessante ressaltar, que cada desvio médio apresentado, envolve todos os resultados experimentais para a correspondente condição especificada.

Tabela 1 Relação entre a forma de correlação de cada efeito e um caracter

\begin{tabular}{|c|c|c|c|c|c|}
\hline \multicolumn{2}{|c|}{ efeitos de $\phi$} & \multicolumn{2}{|c|}{ efeitos de $p_{r}$} & \multicolumn{2}{|c|}{ efeitos de Ra } \\
\hline \multirow[t]{2}{*}{ A } & \multirow[t]{2}{*}{$\phi^{m_{1}-m_{2} \cdot p_{r}^{m_{3}}}$} & \multirow[t]{2}{*}{1} & \multirow{2}{*}{$p_{r}^{c_{1}} \cdot T_{r}^{c_{2}}$} & $\overline{\mathrm{G}}$ & $\overline{(R a / 5})^{p_{1} \cdot\left[-\log \left(p_{r}\right)\right]}$ \\
\hline & & & & $\mathrm{H}$ & $R a^{b_{1}}$ \\
\hline B & $\phi^{m_{1}-m_{2} \cdot p_{r}}$ & 2 & $p_{r}^{c_{1}} \cdot\left(1-T_{r}\right)^{c_{2}}$ & $\mathrm{E}$ & $(R a / 5)^{b_{1}-b_{2} \cdot p_{r}}$ \\
\hline \multirow[t]{2}{*}{$\mathrm{C}$} & \multirow{2}{*}{$\phi^{m_{I}}$} & \multirow[t]{2}{*}{3} & \multirow{2}{*}{$p_{r}^{c_{1}} \cdot\left(-\log p_{r}\right)^{c_{2}}$} & $\mathrm{~F}$ & $(R a / 5)^{b_{I} \cdot\left(1-p_{r}\right)}$ \\
\hline & & & & I & $p_{r}{ }^{b_{1}+b_{2} \cdot[-\log (R a)]}$ \\
\hline
\end{tabular}


Tabela 2 Constantes multiplicativas e expoentes das correlações levantadas

\begin{tabular}{|c|c|c|c|c|c|c|c|c|c|c|c|}
\hline & \multirow[b]{2}{*}{$m_{1}$} & \multirow[b]{2}{*}{$m_{2}$} & \multirow[b]{2}{*}{$m_{3}$} & \multirow[b]{2}{*}{$b_{1}$} & \multirow[b]{2}{*}{$b_{2}$} & \multirow[b]{2}{*}{$c_{1}$} & \multirow[b]{2}{*}{$c_{2}$} & \multirow[b]{2}{*}{$d_{1}$} & \multicolumn{3}{|c|}{ constantes } \\
\hline & & & & & & & & & \begin{tabular}{|l} 
cobre \\
\end{tabular} & latão & $\begin{array}{c}\text { aço } \\
\text { inoxidáve }\end{array}$ \\
\hline$\overline{\mathrm{A} 1 \mathrm{G}}$ & \multirow{15}{*}{0,9} & \multirow{15}{*}{0,3} & \multirow{15}{*}{0,2} & 0,13 & $\overline{----}$ & \multirow{5}{*}{0,46} & \multirow{5}{*}{2,7} & $\overline{-0,1}$ & 51 & 51 & 40 \\
\hline A1H & & & & 0,18 & --- & & & $-0,5$ & 210 & 220 & 160 \\
\hline A1E & & & & 0,20 & 0,15 & & & $-0,4$ & 200 & 220 & 160 \\
\hline A1F & & & & 0,20 & --- & & & 0,3 & 1,1 & 1,1 & 0,94 \\
\hline A1I & & & & $-0,06$ & 0,16 & & & 0,3 & 0,67 & 0,70 & 0,62 \\
\hline $\mathrm{A} 2 \mathrm{G}$ & & & & 0,13 & --- & \multirow{5}{*}{0,54} & \multirow{5}{*}{$-0,8$} & --- & 4,9 & 4,8 & 3,8 \\
\hline A2H & & & & 0,22 & --- & & & $-0,5$ & 45 & 50 & 38 \\
\hline $\mathrm{A} 2 \mathrm{E}$ & & & & 0,18 & $-0,3$ & & & $-0,6$ & 120 & 140 & 100 \\
\hline $\mathrm{A} 2 \mathrm{~F}$ & & & & 0,24 & --- & & & $-0,4$ & 34 & 37 & 29 \\
\hline A2I & & & & $-0,18$ & 0,2 & & & 0,1 & 2,6 & 2,9 & 2,2 \\
\hline A3G & & & & 0,13 & --- & \multirow{5}{*}{0,45} & \multirow{5}{*}{$-0,8$} & 0,0 & 12 & 12 & 9,5 \\
\hline A3H & & & & 0,20 & --- & & & $-0,5$ & 100 & 110 & 85 \\
\hline A3E & & & & 0,19 & $-0,12$ & & & $-0,6$ & 190 & 210 & 160 \\
\hline A3F & & & & 0,22 & --- & & & $-0,4$ & 80 & 84 & 66 \\
\hline A3I & & & & $-0,13$ & 0,18 & & & 0,2 & 3,2 & 3,4 & 2,5 \\
\hline B1G & \multirow{15}{*}{0,76} & & & 0,12 & --- & & & 0,0 & 19 & 19 & 15 \\
\hline B1H & & & & 0,17 & --- & & & $-0,5$ & 130 & 150 & 110 \\
\hline B1E & & & & 0,21 & 0,27 & 0,15 & 4,5 & $-0,3$ & 98 & 110 & 80 \\
\hline B1F & & & & 0,20 & --- & & & $-0,4$ & 120 & 130 & 95 \\
\hline B1I & & & & $-0,06$ & 0,16 & & & $-0,3$ & 68 & 74 & 57 \\
\hline B2G & & & & 0,12 & --- & & & 0,0 & 0,62 & 0,63 & 0,48 \\
\hline B2H & & & & 0,18 & --- & & & $-0,4$ & 3,9 & 4,3 & 3,1 \\
\hline B2E & & 0,3 & --- & 0,19 & 0,12 & 0.20 & -16 & $-0,4$ & 3,7 & 4,0 & 2,9 \\
\hline B2F & & & & 0,20 & --- & & & $-0,3$ & 3,0 & 3,3 & 2,4 \\
\hline B2I & & & & $-0,06$ & 0,16 & & & $-0,3$ & 2,0 & 2,2 & 1,7 \\
\hline B3G & & & & 0,13 & --- & & & $-0,1$ & 0,090 & 0,093 & 0,070 \\
\hline B3H & & & & 0,18 & --- & & & $-0,5$ & \begin{tabular}{|l|}
0,76 \\
\end{tabular} & 0,85 & 0,60 \\
\hline B3E & & & & 0,19 & 0,08 & 0,03 & $-1,8$ & $-0,5$ & 0,84 & 0,95 & 0,67 \\
\hline B3F & & & & 0,21 & -- & & & $-0,4$ & 0,66 & 0,73 & 0,53 \\
\hline B3I & & & & $-0,07$ & 0,17 & & & $-0,4$ & \begin{tabular}{|l|}
0,42 \\
\end{tabular} & 0,47 & 0,35 \\
\hline $\mathrm{C} 1 \mathrm{G}$ & & & & 0,13 & --- & & & 0,0 & 11,5 & 11,5 & 8,9 \\
\hline $\mathrm{C} 1 \mathrm{H}$ & & & & 0,18 & --- & & & $-0,5$ & 92 & 99 & 73 \\
\hline $\mathrm{C} 1 \mathrm{E}$ & & & & 0,19 & 0,10 & 0,08 & 3,7 & $-0,4$ & 97 & 100 & 78 \\
\hline $\mathrm{C} 1 \mathrm{~F}$ & & & & 0,20 & --- & & & $\begin{array}{c}-0,4 \\
\end{array}$ & 76 & 81 & 61 \\
\hline C1I & & & & $-0,06$ & 0,16 & & & $-0,3$ & 40 & 43 & 33 \\
\hline $\mathrm{C} 2 \mathrm{G}$ & & & & 0,13 & --- & & & 0,0 & 2,6 & 2,6 & 2,1 \\
\hline $\mathrm{C} 2 \mathrm{H}$ & & & & 0,18 & --- & & & $-0,5$ & 19 & 20 & 15 \\
\hline $\mathrm{C} 2 \mathrm{E}$ & 0,72 & -- & -- & 0,19 & 0,04 & 0,20 & $-0,65$ & $-0,4$ & 17 & 18 & 13 \\
\hline $\mathrm{C} 2 \mathrm{~F}$ & & & & 0,20 & --- & & & 0,0 & 2,9 & 3,0 & 2,2 \\
\hline C2I & & & & $-0,06$ & 0,17 & & & $-0,4$ & 10 & 11 & 8,4 \\
\hline $\mathrm{C} 3 \mathrm{G}$ & & & & 0,13 & --- & & & $-0,4$ & 29 & 29 & 24 \\
\hline $\mathrm{C} 3 \mathrm{H}$ & & & & 0,18 & --- & & & $\begin{array}{l}-0,4 \\
\end{array}$ & 16 & 16 & 12 \\
\hline $\mathrm{C} 3 \mathrm{E}$ & & & & 0,19 & 0,08 & 0,3 & $-0,35$ & $-0,4$ & 21 & 22 & 16 \\
\hline C3F & & & & 0,21 & --- & & & $-0,1$ & 3,8 & 4,0 & 3,0 \\
\hline C3I & & & & $-0,06$ & 0,17 & & & $\begin{array}{l}-0,4 \\
\end{array}$ & 2,4 & 2,5 & 1,9 \\
\hline
\end{tabular}

* Os expoentes e as constantes multiplicativas da Eq. (7.23), que consiste na correlação proposta pela presente pesquisa, estão indicados em negrito. 
Tabela 3 Desvios médios em relação aos resultados experimentais das correlações

\begin{tabular}{|c|c|c|c|c|c|c|c|c|c|c|c|c|c|c|c|}
\hline & $\begin{array}{l}A 1 G \\
(\%)\end{array}$ & $\begin{array}{l}A 1 H \\
(\%)\end{array}$ & $\begin{array}{l}A 1 E \\
(\%)\end{array}$ & $\begin{array}{l}A 1 F \\
(\%)\end{array}$ & $\begin{array}{l}A 1 I \\
\text { (\%) } \\
\end{array}$ & $\begin{array}{c}\text { A2G } \\
(\%)\end{array}$ & $\begin{array}{l}A 2 H \\
(\%)\end{array}$ & $\begin{array}{l}A 2 E \\
(\%)\end{array}$ & $\begin{array}{l}A 2 F \\
(\%)\end{array}$ & $\begin{array}{l}A 2 I \\
(\%)\end{array}$ & $\begin{array}{c}A 3 G \\
(\%)\end{array}$ & $\begin{array}{c}A 3 H \\
(\%)\end{array}$ & $\begin{array}{c}A 3 E \\
(\%) \\
\end{array}$ & $\begin{array}{l}A 3 F \\
(\%)\end{array}$ & $\begin{array}{l}A 3 I \\
(\%)\end{array}$ \\
\hline R-11/Cu & 27,9 & 13,6 & 14,2 & 33,8 & 31,4 & 20,3 & 10,0 & 10,8 & 11,1 & 14,8 & 20,2 & 11,5 & 10,7 & 11,6 & 16,2 \\
\hline $\begin{array}{l}R-11 / C u / \\
R a=0,17 \mu m\end{array}$ & 23,9 & 12,7 & 12,4 & 41,4 & 42,4 & 25,6 & 8,8 & 8,0 & 10,6 & 14,3 & 26,7 & 9,2 & 10,8 & 12,5 & 21,1 \\
\hline $\begin{array}{l}R-11 / C u / \\
R a=0,45 \mu m\end{array}$ & 26,8 & 5,5 & 7,1 & 29,9 & 28,1 & 12,3 & 4,1 & 4,1 & 5,5 & 13,0 & 12,3 & 4,9 & 3,1 & 4,8 & 15,6 \\
\hline $\begin{array}{l}R-11 / C u / \\
R a=2,3 \mu m\end{array}$ & 33,3 & 24,5 & 24,7 & 30,7 & 24,3 & 24,7 & 18,3 & 21,8 & 18,3 & 17,4 & 23,4 & 22,0 & 19,8 & 18,9 & 11,9 \\
\hline R-11/latão & 34,0 & 7,8 & 8,8 & 31,7 & 33,7 & 18,6 & 6,4 & 7,8 & 8,6 & 8,7 & 18,9 & 6,4 & 6,4 & 8,4 & 10,7 \\
\hline$R-11 / a c ̧ o$ & 32,1 & 11,9 & 12,5 & 39,3 & 47,0 & 26,9 & 10,4 & 8,8 & 12,6 & 16,3 & 28,7 & 10,4 & 10,6 & 12,5 & 17,4 \\
\hline $\begin{array}{l}R-11 / a c ̧ o / \\
R a=0,02 \mu m\end{array}$ & 36,5 & 11,4 & 12,2 & 41,8 & 54,1 & 33,8 & 9,4 & 7,3 & 12,5 & 18,3 & 36,0 & 9,1 & 8,9 & 12,2 & 21,0 \\
\hline $\begin{array}{l}R-11 / a c ̧ o / \\
R a=0,16 \mu m\end{array}$ & 28,3 & 12,3 & 12,8 & 37,1 & 40,9 & 20,9 & 11,2 & 10,2 & 12,7 & 14,5 & 22,3 & 11,5 & 12,0 & 12,8 & 14,3 \\
\hline$R-123 / C u$ & 12,1 & 11,2 & 10,6 & 39,5 & 36,5 & 17,9 & 10,2 & 7,2 & 11,8 & 33,0 & 16,1 & 6,0 & 7,0 & 9,3 & 32,7 \\
\hline $\begin{array}{l}R-123 / C u / \\
R a=0,16 \mu m\end{array}$ & 19,5 & 12,9 & 11,3 & 38,3 & 38,9 & 24,7 & 6,9 & 6,6 & 9,2 & 20,1 & 22,9 & 6,0 & 6,5 & 8,9 & 24,5 \\
\hline $\begin{array}{l}R-123 / C u / \\
R a=0,47 \mu m\end{array}$ & 10,2 & 13,3 & 12,1 & 35,6 & 33,8 & 19,3 & 11,1 & 8,5 & 11,8 & 34,4 & 17,0 & 6,0 & 7,9 & 9,8 & 35,0 \\
\hline $\begin{array}{l}R-123 / C u / \\
R a=3,3 \mu m\end{array}$ & 7,4 & 7,6 & 8,3 & 44,7 & 37,1 & 10,2 & 12,2 & 6,4 & 14,3 & 43,3 & 8,9 & 6,0 & 6,4 & 8,9 & 37,6 \\
\hline R-123 / latão & 21,2 & 12,8 & 15,2 & 34,7 & 36,3 & 19,5 & 12,4 & 17,4 & 11,3 & 27,4 & 19,2 & 9,5 & 11,6 & 9,4 & 26,0 \\
\hline R-123 / aço & 20,0 & 16,4 & 14,8 & 53,0 & 59,1 & 29,6 & 14,6 & 11,6 & 17,3 & 28,3 & 29,3 & 12,4 & 13,0 & 14,7 & 23,9 \\
\hline$R-134 a / C u$ & 16,5 & 11,9 & 11,3 & 30,9 & 27,9 & 22,3 & 10,5 & 10,5 & 12,7 & 6,9 & 20,9 & 8,6 & 9,0 & 12,0 & 9,7 \\
\hline $\begin{array}{l}R-134 a / C u / \\
R a=0,07 \mu m\end{array}$ & 14,9 & 12,3 & 10,7 & 32,9 & 33,6 & 28,4 & 6,5 & 9,6 & 10,6 & 3,6 & 23,5 & 3,4 & 5,5 & 9,4 & 4,5 \\
\hline $\begin{array}{l}R-134 a / C u / \\
R a=0,50 \mu m\end{array}$ & 10,5 & 15,1 & 13,6 & 36,2 & 29,8 & 18,9 & 18,1 & 15,3 & 18,4 & 4,0 & \begin{tabular}{|l|}
16,4 \\
\end{tabular} & 10,2 & 11,8 & \begin{tabular}{|l|}
14,4 \\
\end{tabular} & 4,3 \\
\hline $\begin{array}{l}R-134 a / C u / \\
R a=2,5 \mu m\end{array}$ & 23,3 & 8,6 & 10,0 & 24,2 & 20,3 & 3,7 & 8,4 & 7,5 & 10,1 & 12,9 & 2,0 & 13,1 & 10,5 & 12,8 & 20,0 \\
\hline$R-134 a$ /latão & 28,9 & 8,9 & 7,2 & 16,7 & 17,9 & 11,7 & 7,4 & 10,5 & 7,9 & 9,3 & 11,2 & 9,3 & 9,1 & 9,2 & 13,1 \\
\hline$R-134 a / a c ̧ o$ & 28,8 & 14,1 & 14,9 & 35,0 & 38,2 & 21,9 & 14,9 & 14,5 & 17,5 & 16,6 & 21,6 & 12,2 & 14,6 & 17,5 & 20,4 \\
\hline $\mathrm{R}-22 / \mathrm{Cu}$ & 17,1 & 10,3 & 7,9 & 23,7 & 21,8 & 9,9 & 11,8 & 13,4 & 10,3 & 10,6 & 10,1 & 8,9 & 11,9 & 10,2 & 10,7 \\
\hline $\begin{array}{l}R-22 / C u / \\
R a=0,07 \mu m\end{array}$ & 23,0 & 6,0 & 3,8 & 20,9 & 21,5 & 12,7 & 2,9 & 6,3 & 4,0 & 13,1 & 13,0 & 2,8 & 4,1 & 4,8 & 11,4 \\
\hline $\begin{array}{l}R-22 / C u / \\
R a=0,47 \mu m\end{array}$ & 13,0 & 14,2 & 11,3 & 24,2 & 21,3 & 7,8 & 16,6 & 16,8 & 13,8 & 7,1 & 8,1 & 12,6 & 16,9 & 14,1 & 8,0 \\
\hline $\begin{array}{l}R-22 / C u / \\
R a=2,6 \mu m\end{array}$ & 11,7 & 12,5 & 10,4 & 28,6 & 3,3 & 7,9 & 22,1 & 2,1 & 7,5 & 11,4 & 7,8 & 15,2 & 19,8 & 15,0 & 13,6 \\
\hline$R$-22 / latão & 30,6 & 7,0 & 5,8 & 12,0 & 12,3 & 5,9 & 5,9 & 11,0 & 4,8 & 12,2 & 5,5 & 5,6 & 7,4 & 4,8 & 15,2 \\
\hline$R-12 / C u$ & 24,6 & 12,2 & 10,4 & 27,8 & 26,9 & 15,4 & 10,3 & 14,7 & 8,1 & 10,7 & 17,3 & \begin{tabular}{|l|}
14,4 \\
\end{tabular} & 13,1 & 12,9 & 11,2 \\
\hline $\begin{array}{l}R-12 / C u / \\
R a=0,06 \mu m\end{array}$ & 22,2 & 10,9 & 7,4 & 28,6 & 29,4 & 18,6 & 7,8 & 13,1 & 4,7 & 5,9 & 17,0 & 11,5 & 10,4 & 9,8 & 7,6 \\
\hline $\begin{array}{l}R-12 / C u / \\
R a=0,51 \mu m\end{array}$ & 27,5 & 13,9 & 14,0 & 26,7 & 23,8 & 11,4 & \begin{tabular}{|l|}
13,4 \\
\end{tabular} & \begin{tabular}{|l|}
16,8 \\
\end{tabular} & \begin{tabular}{|l|}
12,2 \\
\end{tabular} & 16,5 & 17,6 & \begin{tabular}{|l|}
18,1 \\
\end{tabular} & \begin{tabular}{|l|}
16,4 \\
\end{tabular} & 16,6 & 15,7 \\
\hline R-12 / latão & 21,3 & 24,8 & 22,7 & 27,4 & 28,8 & 18,5 & 20,7 & 28,4 & 15,9 & 19,7 & \begin{tabular}{|l|}
25,7 \\
\end{tabular} & 7,4 & 9,3 & 10,5 & 12,0 \\
\hline$R-11$ & 30,2 & 11,9 & 12,6 & 34,4 & 35,0 & 21,2 & 9,2 & 9,7 & 10,8 & 13,6 & 21,6 & \begin{tabular}{|l|}
10,1 \\
\end{tabular} & 9,6 & 11,0 & 15,1 \\
\hline$R-123$ & 15,7 & 12,7 & 12,5 & 41,6 & 41,6 & 20,9 & 11,7 & 10,3 & 13,0 & 30,8 & 19,7 & 8,2 & 9,3 & 10,5 & 29,3 \\
\hline$R-134 a$ & 21,6 & 11,5 & 11,0 & 28,3 & 27,4 & 19,8 & 10,5 & 11,2 & 12,4 & 9,1 & 18,8 & 10,0 & 10,0 & 12,3 & 12,4 \\
\hline$R-22$ & 20,4 & 9,5 & 7,3 & 20,8 & 19,4 & 8,9 & 10,4 & 12,8 & 8,9 & 11,0 & 9,0 & 8,1 & 10,8 & 8,9 & 11,8 \\
\hline$R-12$ & 23,5 & 16,2 & 14,3 & 27,7 & 27,5 & 16,4 & 13,6 & 19,1 & 10,6 & 13,5 & 19,9 & 12,2 & 11,9 & 12,1 & 11,5 \\
\hline cobre & 19,8 & 11,9 & 11,0 & 31,1 & 28,8 & 17,4 & 10,6 & 11,3 & 10,9 & 14,8 & 17,1 & 9,8 & 10,3 & 11,2 & 15,8 \\
\hline latão & 27,8 & 12,0 & 11,6 & 24,7 & 26,1 & 15,0 & 10,2 & 14,5 & 9,6 & 14,5 & 16,3 & 7,6 & 8,6 & 8,5 & \begin{tabular}{|l}
14,7 \\
\end{tabular} \\
\hline aço & 27,2 & 14,0 & 14,0 & \begin{tabular}{|l|}
42,4 \\
\end{tabular} & 48,3 & 26,3 & 13,1 & 11,4 & 15,6 & 20,3 & 26,8 & 12,5 & 12,5 & 14,7 & 20,4 \\
\hline$p_{r} \approx 0,011$ & 46,0 & 13,8 & 15,7 & 39,6 & 39,3 & 26,6 & 11,0 & 10,1 & 13,4 & 25,8 & 25,8 & 11,2 & 9,2 & \begin{tabular}{|l|}
12,4 \\
\end{tabular} & 20,8 \\
\hline$p_{r} \approx 0,023$ & 33,0 & 9,7 & 9,8 & 19,8 & 20,4 & 13,4 & 8,0 & 10,3 & 9,0 & 22,9 & 12,2 & 8,0 & 8,5 & 8,1 & 20,3 \\
\hline$p_{r} \approx 0,035$ & 24,8 & 11,3 & 10,4 & 16,2 & 16,3 & 11,0 & 9,3 & 11,5 & 9,0 & 21,2 & 9,6 & 8,6 & 9,5 & 8,1 & 20,6 \\
\hline$p_{r} \approx 0,050$ & 30,0 & 12,3 & 11,4 & 18,1 & 17,7 & 13,9 & 9,3 & 12,7 & 10,1 & 8,6 & 16,4 & 12,9 & 11,4 & 13,2 & 13,3 \\
\hline$p_{r} \approx 0,064$ & 20,6 & 14,2 & 12,3 & 23,9 & 24,3 & 15,3 & 10,4 & 13,3 & 9,6 & 14,0 & 14,7 & 10,3 & 11,7 & \begin{tabular}{|l|}
10,4 \\
\end{tabular} & 17,0 \\
\hline$p_{r} \approx 0,092$ & 16,6 & 12,7 & 11,8 & 34,6 & 35,1 & 18,5 & \begin{tabular}{|l|}
10,7 \\
\end{tabular} & 11,2 & 11,0 & 14,7 & 17,6 & 9,5 & 10,6 & 10,6 & 17,3 \\
\hline$p_{r} \approx 0,120$ & 14,9 & 11,7 & 11,7 & 44,3 & 44,5 & 21,9 & 10,9 & 10,1 & 12,2 & 15,1 & 21,5 & 9,5 & 10,1 & 11,5 & 17,7 \\
\hline$p_{r} \approx 0,150$ & 19,6 & 8,2 & 6,6 & 20,4 & 19,3 & 8,0 & 9,5 & 9,6 & 8,2 & 11,4 & 8,1 & 7,4 & 9,2 & 8,7 & 12,2 \\
\hline$p_{r} \approx 0,180$ & 19,0 & 10,2 & 9,4 & 29,2 & 28,4 & 15,6 & 11,6 & \begin{tabular}{|l|}
12,4 \\
\end{tabular} & 10,8 & 11,6 & 16,2 & 9,3 & 9,9 & 9,7 & 11,3 \\
\hline$p_{r} \approx 0,200$ & 18,3 & 12,3 & 11,2 & 33,3 & 31,9 & 20,6 & 13,2 & 14,7 & 13,8 & 11,5 & 23,1 & 9,3 & 9,8 & 12,8 & 10,4 \\
\hline$p_{r} \approx 0,260$ & 19,4 & 15,2 & 12,4 & 41,6 & 37,0 & 24,9 & 16,8 & 22,4 & 16,5 & 13,9 & 31,7 & 9,2 & 11,0 & 16,8 & 10,8 \\
\hline Total & 22,8 & 12,2 & 11,6 & 31,1 & 30,8 & 18,0 & 10,8 & \begin{tabular}{|l|}
12,1 \\
\end{tabular} & 11,2 & 15,5 & \begin{tabular}{|l|}
18,2 \\
\end{tabular} & 9,6 & 10,2 & 11,0 & 16,1 \\
\hline
\end{tabular}


Tabela 3 (continuação) Desvios médios em relação aos resultados experimentais das correlações

\begin{tabular}{|c|c|c|c|c|c|c|c|c|c|c|c|c|c|c|c|}
\hline & $\begin{array}{c}\text { B1G } \\
(\%)\end{array}$ & $\begin{array}{c}\text { B1H } \\
(\%)\end{array}$ & $\begin{array}{l}\text { B1E } \\
\text { (\%) } \\
\end{array}$ & $\begin{array}{l}\text { B1F } \\
\text { (\%) }\end{array}$ & $\begin{array}{l}\text { B1I } \\
\text { (\%) } \\
\end{array}$ & $\begin{array}{c}\text { B2G } \\
(\%)\end{array}$ & $\begin{array}{l}\mathrm{B2H} \\
(\%)\end{array}$ & $\begin{array}{l}\text { B2E } \\
(\%) \\
\end{array}$ & $\begin{array}{l}\text { B2F } \\
(\%) \\
\end{array}$ & $\begin{array}{l}\text { B2I } \\
(\%) \\
\end{array}$ & $\begin{array}{l}\text { B3G } \\
(\%)\end{array}$ & $\begin{array}{c}\text { B3H } \\
(\%)\end{array}$ & $\begin{array}{l}B 3 E \\
(\%) \\
\end{array}$ & $\begin{array}{l}B 3 F \\
(\%)\end{array}$ & $\begin{array}{l}\text { B3I } \\
\text { (\%) } \\
\end{array}$ \\
\hline$R-11 / C u$ & 24,8 & 18,1 & 17,6 & 17,1 & 15,7 & 21,7 & 13,6 & 14,0 & 15,0 & 12,6 & 19,1 & 13,0 & 13,1 & 13,3 & 10,2 \\
\hline $\begin{array}{l}R-11 / C u / \\
R a=0,17 \mu m\end{array}$ & 30,1 & 14,1 & 17,2 & 17,5 & 18,8 & 24,5 & 10,8 & 11,4 & 11,0 & 13,3 & 20,0 & 6,3 & 6,0 & 6,8 & 8,6 \\
\hline $\begin{array}{l}R-11 / \mathrm{Cu} / \\
R a=0,45 \mu \mathrm{m}\end{array}$ & 16,8 & 11,1 & 11,0 & 10,1 & 8,9 & 13,2 & 6,3 & 7,1 & 8,9 & 6,6 & 11,3 & 7,4 & 7,9 & 8,2 & 6,3 \\
\hline $\begin{array}{l}R-11 / C u / \\
R a=2,3 \mu m\end{array}$ & 29,1 & 30,6 & 26,0 & 25,2 & 20,8 & 29,0 & 25,2 & 25,2 & 26,5 & 19,4 & 27,7 & 26,6 & 26,4 & 26,3 & 16,7 \\
\hline$R$-11/latão &, 8 & 10,5 & 3,0 & 1,9 & 4,2 & 18,6 & 6,7 & 7,6 & 8,4 & 10,5 & 16,2 & 4,7 & 4,9 & 5,9 & 8,0 \\
\hline$R-11 /$ aço & 31,6 & 15,1 & 16,9 & 16,1 & 22,5 & 26,3 & 10,8 & 12,1 & 13,1 & 18,7 & 22,8 & 9,6 & 10,2 & 11,1 & 15,7 \\
\hline $\begin{array}{l}R-11 / a c ̧ o / \\
R a=0,02 \mu m\end{array}$ & 39,3 & 15,4 & 17,6 & 16,4 & 27,6 & 33,0 & 9,7 & 11,4 & 12,9 & 23,4 & 28,1 & 8,3 & 9,3 & 10,6 & 19,4 \\
\hline $\begin{array}{l}R-11 / a c ̧ o / \\
R a=0,16 \mu \mathrm{m}\end{array}$ & 24,9 & 14,9 & 16,3 & 15,8 & 18,1 & 20,6 & 11,8 & 12,7 & 13,3 & 14,7 & 18,3 & 10,7 & 11,0 & 11,5 & 12,4 \\
\hline$R-123 / C u$ & 23,7 & 12,3 & 16,4 & 17,4 & 17,2 & 18,9 & 12,7 & 13,2 & 11,8 & 13,7 & 18,2 & 10,7 & 10,7 & 11,2 & 15,0 \\
\hline $\begin{array}{l}R-123 / C u / \\
R a=0,16 \mu m\end{array}$ & 31,6 & 14,4 & 17,1 & 18,5 & 17,9 & 26,4 & 14,2 & 14,6 & 12,8 & 13,9 & 23,9 & 12,5 & 11,8 & \begin{tabular}{|l|}
12,2 \\
\end{tabular} & 11,7 \\
\hline $\begin{array}{l}R-123 / C u / \\
R a=0,47 \mu m\end{array}$ & 26,0 & 13,6 & 18,0 & 19,4 & 18,7 & 20,4 & 14,6 & 14,9 & 12,9 & 14,9 & 20,4 & 13,5 & 13,3 & 13,6 & 16,7 \\
\hline $\begin{array}{l}R-123 / \mathrm{Cu} / \\
\mathrm{Ra}=3,3 \mu \mathrm{m}\end{array}$ & 14,2 & 9,1 & 14,2 & 14,3 & 15,0 & 10,7 & 9,5 & 10,1 & 9,7 & 12,2 & 10,6 & 6,0 & 6,8 & 7,7 & 16,3 \\
\hline R-123 / latão & 26,9 & 23,0 & 22,7 & 20,9 & 19,9 & 23,4 & 19,0 & 17,2 & 16,6 & 17,0 & 22,3 & 19,7 & 20,2 & \begin{tabular}{|l|}
17,8 \\
\end{tabular} & 17,3 \\
\hline$R-123$ / aço & 37,1 & 21,6 & 22,4 & 21,0 & 25,7 & 30,7 & 16,0 & 16,0 & 16,3 & 22,3 & 27,5 & 13,0 & 13,6 & 15,0 & 17,9 \\
\hline$R-134 a / C u$ & 20,5 & 13,0 & 12,8 & 13,9 & 13,8 & 23,6 & 15,2 & 15,9 & 14,9 & 15,4 & 22,3 & 14,4 & 14,4 & 15,9 & 15,1 \\
\hline $\begin{array}{l}R-134 a / C u / \\
R a=0,07 \mu m\end{array}$ & 27,4 & 15,1 & 14,8 & 17,1 & 16,5 & 32,0 & 17,0 & 18,4 & 16,4 & 19,1 & 30,4 & 16,3 & 16,2 & 19,0 & 19,9 \\
\hline $\begin{array}{l}R-134 a / C u / \\
R a=0,50 \mu m\end{array}$ & 14,7 & 12,8 & 16,6 & 18,8 & 13,1 & 19,4 & 20,5 & 20,1 & 17,9 & 14,5 & 19,4 & 19,7 & 19,3 & 20,2 & 17,3 \\
\hline $\begin{array}{l}R-134 a / C u / \\
R a=2,5 \mu m\end{array}$ & 17,8 & 0 & 7,4 & 6,1 & 5 & ,0 & 7 & 9,6 & $\overline{, 9}$ & 2,3 & 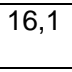 & 7,8 & 8,3 & 9,0 & 0 \\
\hline R-134a / latão & 7,8 & 12,6 & 8,6 & 8,7 & 8,5 & 13,4 & 7,7 & 6,8 & 7,2 & 9,0 & 13,7 & 8,6 & 8,8 & 8,9 & 10,9 \\
\hline$R-134 a$ / aço & 17,7 & 15,8 & 15,5 & 15,2 & 16,1 & 21,7 & 15,5 & 16,3 & 17,1 & 18,7 & 21,5 & 15,3 & 15,7 & 17,0 & 18,2 \\
\hline$R-22 / C u$ & 9,1 & 8,0 & 7,9 & 10,2 & 7,7 & 9,7 & 9,4 & 8,2 & 6,4 & 6,3 & 7,9 & 7,5 & 6,8 & 6,8 & 6,1 \\
\hline $\begin{array}{l}R-22 / C u / \\
R a=0,07 \mu m\end{array}$ & 11,4 & 6,5 & 4,5 & 6,7 & 6,6 & 11,6 & 5,0 & 4,7 & 3,5 & 5,5 & 7,6 & 4,0 & 3,4 & 3,7 & 4,5 \\
\hline $\begin{array}{l}R-22 / \mathrm{Cu} / \\
R a=0,47 \mu m\end{array}$ & 5,5 & 9,3 & 10,9 & 13,8 & 7,7 & 6,6 & 12,8 & 11,1 & 8,4 & 6,5 & 5,9 & 10,1 & 9,0 & 9,0 & 6,9 \\
\hline $\begin{array}{l}R-22 / C u / \\
R a=2,6 \mu m\end{array}$ & 10,6 & 9 , & 9,8 & 11,4 & 9 & 10,9 & 12,7 & 10,8 & 8,9 & 7,6 & 12,1 & 10,6 & 10,0 & 9,2 & 7,8 \\
\hline atão & 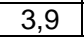 &, 1 & y & 7,1 & 7,0 & 7 & 4 & 1 & 3,5 & 4,5 & 4,4 & 6,2 & 5,4 & 3,8 & 4,9 \\
\hline$R-12 / C u$ & 21,0 & 20,3 & 15,7 & 17,2 & 17,7 & 19,1 & 16,6 & 15,0 & 14,0 & 15,4 & 20,4 & 20,8 & 19,5 & 17,9 & 18,4 \\
\hline $\begin{array}{l}R-12 / C u / \\
R a=0,06 \mu m\end{array}$ & 27,9 & 22,4 & 16,7 & 19,5 & 18,2 & 24,9 & 17,9 & 15,6 & 13,3 & 14,4 & 25,8 & 23,2 & 21,2 & 19,1 & 18,6 \\
\hline $\begin{array}{l}R-12 / C u / \\
R a=0,51 \mu m\end{array}$ & 12,6 & 17,8 & 14,5 & 14,4 & 17,2 & 12,0 & 14,9 & 14,2 & 14,9 & 16,6 & 13,7 & 17,8 & 17,4 & \begin{tabular}{|l|}
16,3 \\
\end{tabular} & 18,2 \\
\hline$R-12$ / latão & 37,2 & 44,5 & 38,7 & 39,5 & 39,1 & 35,4 & 41,1 & 38,1 & 36,3 & 37,2 & 44,3 & 49,6 & 48,6 & 45,9 & 46,4 \\
\hline$R-11$ & 25,4 & 15,6 & 16,3 & 15,6 & 16,7 & 21,8 & 11,4 & 12,1 & 13,0 & 13,3 & 13,0 & 10,3 & 10,5 & 11,1 & 10,7 \\
\hline$R-123$ & 27,4 & 16,6 & 19,1 & 18,9 & 19,7 & 22,5 & 14,7 & 14,6 & 13,8 & 16,3 & 21,1 & 13,0 & 13,3 & 13,4 & 16,1 \\
\hline$R-1$ & 17,0 & 13,4 & 12,3 & 12,9 & 13,0 & 20,9 & 13,5 & 13,9 & 13,5 & 14,5 & 20,2 & 13,2 & 13,3 & 14,5 & 14,7 \\
\hline$R-22$ & 7,8 & 8,8 & 7,6 & 9,4 & 7,5 & 8,2 & 8,7 & 7,2 & 5,7 & 5,9 & 7,1 & 7,2 & 6,4 & 6,0 & 5,8 \\
\hline$R-12$ & 26,2 & 28,0 & 23,1 & 24,3 & 24,5 & 24,3 & 24,4 & 22,4 & 21,1 & 22,3 & 28,0 & 30,0 & 28,8 & 26,8 & 27,3 \\
\hline cobre & 19,8 & 14,2 & 14,0 & 15,0 & 14,3 & 18,7 & 13,4 & 13,3 & 12,5 & 12,6 & 17,6 & 13,0 & 12,7 & 12,9 & 12,6 \\
\hline latão & 19,5 & 19,6 & 17,5 & 17,2 & 17,4 & 18,9 & 15,5 & 14,3 & 14,0 & 15,3 & 20,0 & 16,9 & 16,7 & 15,8 & 17,0 \\
\hline aço & 29,2 & 17,4 & 18,3 & 17,4 & 21,6 & 26,4 & 13,9 & 14,6 & 15,3 & 19,9 & 24,0 & 12,4 & 12,9 & 14,1 & 17,1 \\
\hline$p_{r} \approx 0$ & 31,8 & 19,3 & 21,1 & 20,3 & 22,4 & 26,9 & 13,1 & 14,4 & 15,9 & 16,6 & 22,7 & 12,9 & 13,0 & 13,4 & 14,9 \\
\hline$p_{r} \approx 0$, & 15,7 & 12,1 & 12,3 & 11,8 & 13,3 & 14,9 & 10,0 & 10,2 & 11,1 & 11,3 & 14,6 & 10,8 & 10,7 & 10,8 & 12,2 \\
\hline$p_{r} \approx 0,035$ & 14,1 & 13,6 & 12,4 & 12,6 & 12,3 & 12,2 & 11,6 & 11,0 & 10,5 & 10,6 & 13,1 & 12,0 & 11,7 & 11,5 & 11,3 \\
\hline$p_{r} \approx 0,050$ & 16,0 & 18,4 & 14,0 & 15,3 & 13,1 & 14,8 & 14,3 & 13,0 & 12,4 & 11,2 & 15,0 & 16,6 & 15,5 & 14,2 & 12,4 \\
\hline$p_{r} \approx 0,064$ & 22,2 & 20,1 & 17,5 & 18,8 & 18,2 & 18,2 & 16,0 & 14,6 & 13,0 & 14,0 & 18,6 & 16,5 & 15,6 & 14,6 & 14,7 \\
\hline$p_{r} \approx 0,092$ & 25,1 & 17,4 & 17,5 & 18,1 & 18,3 & 20,9 & 14,7 & 14,0 & 13,1 & 15,1 & 19,7 & 13,5 & 13,3 & 13,2 & 14,2 \\
\hline$p_{r} \approx 0,1$ & 26,9 & 15,0 & 17,4 & 17,3 & 17,4 & 24,6 & 14,2 & 14,3 & 13,8 & 15,9 & 22,5 & 12,1 & 12,4 & 13,1 & 14,3 \\
\hline$p_{r} \approx 0,150$ & 7,4 & 5,9 & 7,2 & 8,5 & 6,1 & 7,3 & 7,4 & 6,7 & 5,2 & 5,5 & 5,5 & 5,5 & 5,3 & 5,3 & 5,1 \\
\hline$p_{r} \approx 0,180$ & 14,7 & 10,4 & 10,4 & 10,5 & 10,5 & 18,0 & 12,0 & 11,8 & 11,4 & 12,4 & 17,4 & 12,8 & 12,8 & 13,0 & 13,4 \\
\hline$p_{r} \approx 0,200$ & 16,7 & 13,0 & 12,3 & 13,0 & 13,4 & 22,3 & 15,4 & 15,9 & 15,5 & 16,9 & 22,8 & 16,7 & 16,8 & 18,1 & 18,8 \\
\hline$p_{r} \approx 0,260$ & 16,6 & 24,7 & 17,1 & 18,2 & 20,4 & 24,4 & 22,6 & 22,4 & 22,2 & 22,1 & 26,6 & 24,6 & 24,7 & 25,9 & 25,6 \\
\hline Total & 21,0 & 16,0 & 15,5 & 15,9 & 16,0 & 19,8 & 14,0 & 13,7 & 13,2 & 14,3 & 19,0 & 13,9 & 13,7 & 13,8 & 14,3 \\
\hline
\end{tabular}


Tabela 3 (continuação) Desvios médios em relação aos resultados experimentais das correlações

\begin{tabular}{|c|c|c|c|c|c|c|c|c|c|c|c|c|c|c|c|}
\hline & $\begin{array}{c}\text { C1G } \\
(\%)\end{array}$ & $\begin{array}{c}\text { C1H } \\
\text { (\%) }\end{array}$ & $\begin{array}{l}\text { C1E } \\
(\%) \\
\end{array}$ & $\begin{array}{l}\text { C1F } \\
\text { (\%) }\end{array}$ & $\begin{array}{l}\text { C1I } \\
\text { (\%) } \\
\end{array}$ & $\begin{array}{c}C 2 G \\
(\%) \\
\end{array}$ & $\begin{array}{c}\mathrm{C2H} \\
(\%)\end{array}$ & $\begin{array}{l}\text { C2E } \\
(\%) \\
\end{array}$ & $\begin{array}{l}\text { C2F } \\
(\%) \\
\end{array}$ & $\begin{array}{l}\text { C2I } \\
\text { (\%) } \\
\end{array}$ & $\begin{array}{c}\text { C3G } \\
(\%) \\
\end{array}$ & $\begin{array}{c}\mathrm{C3H} \\
(\%)\end{array}$ & $\begin{array}{l}\text { C3E } \\
\text { (\%) }\end{array}$ & $\begin{array}{l}\text { C3F } \\
\text { (\%) }\end{array}$ & $\begin{array}{l}C 31 \\
(\%) \\
\end{array}$ \\
\hline$\overline{R-11 / C u}$ & 21,3 & 13,8 & 13,8 & 1414,2 & 12,1 & 19,2 & 413,0 & 12,3 & $\mid 13,0$ & 10,6 & 19,8 & 13,2 & $\bar{~} 12,3$ & 12,3 & 111,6 \\
\hline $\begin{array}{l}R-11 / C u / \\
R a=0,17 \mu m\end{array}$ & 21,9 & 9,5 & 9,6 & 10,2 & 12,1 & 23,1 & 10,8 & 12,4 & 17,7 & 11,8 & 20,8 & 17,8 & 14,5 & 17,1 & 18,0 \\
\hline $\begin{array}{l}R-11 / C u / \\
R a=0,45 \mu m\end{array}$ & 13,5 & 7,2 & 7,5 & 8,0 & 6,6 & 11,0 & 5,7 & 4,9 & 5,9 & 5,4 & 11,7 & 5,4 & 4,6 & 6,0 & 7,9 \\
\hline $\begin{array}{l}R-11 / C u / \\
R a=2,3 \mu m\end{array}$ & 30,1 & 26,2 & 25,8 & 25,9 & 18,8 & 25,3 & 23,9 & 21,1 & 16,9 & 15,6 & \begin{tabular}{|l}
28,7 \\
\end{tabular} & 17,8 & 19,6 & 15,3 & 9,7 \\
\hline R-11/latão & 18,5 & 6,7 & 8,7 & 8,4 & 10,2 & 17,4 & 6,3 & 6,4 & 7,8 & 9,2 & 16,9 & 6,2 & 6,5 & 8,0 & 9,4 \\
\hline$R-11 / a c ̧ o$ & 25,3 & 9,3 & 9,9 & 11,1 & 16,5 & 25,9 & 8,5 & 9,1 & \begin{tabular}{|l|}
10,2 \\
\end{tabular} & 16,3 & 24,6 & 8,5 & 8,9 & 10,7 & 17,1 \\
\hline $\begin{array}{l}R-11 / a c ̧ o / \\
R a=0,02 \mu m\end{array}$ & 31,7 & 8,4 & 9,3 & 10,9 & 21,0 & 33,1 & 7,7 & 8,5 & 10,2 & 21,0 & 31,3 & 7,9 & 8,3 & 10,5 & 21,7 \\
\hline $\begin{array}{l}R-11 / a c ̧ o / \\
R a=0,16 \mu m\end{array}$ & 19,7 & 10,0 & 10,4 & 11,2 & 12,6 & 19,8 & 9,2 & 9,7 & 10,3 & 12,2 & 18,8 & 9,1 & 9,5 & 10,9 & 13,1 \\
\hline$R-123 / C u$ & 4,8 & $\overline{0,1}$ & 0,5 & 0,7 & 13,6 & 15,7 & 8,5 & 11,0 & 20,8 & 11,0 & 10,7 & 14,8 & 11,9 & 20,3 & 24,6 \\
\hline $\begin{array}{l}R-123 / C u / \\
R a=0,16 \mu m\end{array}$ & 21,2 & 12,0 & 12,1 & 12,3 & 13,2 & 22,1 & 10,1 & 12,2 & 21,7 & 11,1 & 16,9 & 16,9 & 13,4 & 19,7 & 20,1 \\
\hline $\begin{array}{l}R-123 / C u / \\
R a=0,47 \mu m\end{array}$ & 16,3 & 12,4 & 2,7 & 12,8 & 15,4 & 17,2 & 9,8 & 13,1 & 23,5 & 11,7 & 9,7 & 17,9 & 14,5 & 2,8 & 6,8 \\
\hline $\begin{array}{l}R-123 / C u / \\
R a=3,3 \mu m\end{array}$ & 7,4 & 5,8 & 6,6 & 7,1 & 12,0 & 8,5 & 5,6 & 7,7 & 17,2 & 10,3 & 6,2 & 9,5 & 7,7 & 18,2 & 26,3 \\
\hline$R-123$ / latão & 17,6 & 14,9 & 11,6 & 13,8 & 14,8 & 18,6 & 11,4 & 13,4 & 20,4 & 13,6 & 13,6 & 13,0 & 13,7 & 20,3 & 19,5 \\
\hline R-123 / aço & 27,9 & 12,8 & 14,2 & 14,3 & 17,8 & 28,3 & 10,4 & 10,3 & 18,5 & 16,5 & 22,8 & 12,1 & 10,8 & 20,6 & 21,5 \\
\hline$R-134 a / C u$ & 19,9 & 12,4 & 12,7 & 13,8 & 14,1 & 22,4 & 12,6 & 12,7 & 13,9 & 14,1 & 22,5 & 11,7 & 11,2 & 10,7 & 11,5 \\
\hline $\begin{array}{l}R-134 a / C u / \\
R a=0,07 \mu m\end{array}$ & 22,5 & 12,5 & 13,0 & 14,8 & 16,3 & 26,7 & 10,6 & 10,6 & 11,6 & 15,4 & 30,2 & 10,6 & 9,2 & 6,1 & 9,1 \\
\hline $\begin{array}{l}R-134 a / C u / \\
R a=0,50 \mu m\end{array}$ & 14,8 & 15,7 & 15,6 & 15,9 & 11,6 & 18,7 & 14,2 & 14,9 & 14,4 & 11,5 & 19,3 & 13,7 & 12,4 & 10,7 & 7,0 \\
\hline $\begin{array}{l}R-134 a / C u / \\
R a=2,5 \mu m\end{array}$ & 21,6 & 9,6 & 10,1 & 11,0 & 13,9 & 21,0 & 13,4 & 13,1 & 16,0 & 14,9 & 16,9 & 11,2 & 12,5 & 15,9 & 17,9 \\
\hline$R$-134a / latão & 8, & 6,4 & 6,8 & 5,5 & 5,9 & 12,3 & 6,6 & 6,3 & 8,0 & 8,0 & 11,8 & 10,2 & 7,6 & 10,1 & 8,9 \\
\hline$R-134 a$ / aço & 20,7 & 15,3 & 15,8 & 16,8 & 17,3 & 23,6 & 16,6 & 17,6 & 20,3 & 19,1 & 23,8 & 16,8 & 17,4 & 19,5 & 19,1 \\
\hline$R-22 / C u$ & 8,7 & 9,1 & 8,3 & 8,0 & 6,5 & 10,2 & 9,2 & 8,5 & 6,6 & 7,4 & 20,0 & 9,4 & 8,1 & 6,8 & 5,9 \\
\hline $\begin{array}{l}R-22 / C u / \\
R a=0,07 \mu m\end{array}$ & 7,8 & 5,0 & 4,5 & 4,9 & 6,2 & 11,8 & 5,0 & 4,2 & 6,4 & 7,2 & 26,1 & 5,3 & 4,3 & 8,1 & 5,6 \\
\hline $\begin{array}{l}R-22 / C u / \\
R a=0,47 \mu m\end{array}$ & 6,9 & 12,4 & 11,3 & 10,5 & 6,7 & 8,2 & 12,4 & 11,4 & 6,1 & 8,1 & 19,1 & 12,8 & 10,9 & 5,2 & 4,2 \\
\hline $\begin{array}{l}R-22 / C u / \\
R a=2,6 \mu m\end{array}$ & 13,2 & 12,3 & 11,4 & 10,3 & 6,9 & 10,0 & 12,8 & 12,6 & 7,9 & 6,9 & 9,2 & 12,5 & 11,2 & 7,1 & 9,5 \\
\hline R-22 / latão & 7,1 & 4,9 & 4,1 & 3,5 & 3,3 & 5,1 & 4,5 & 4,6 & 10,9 & 5,2 & 11,8 & 7,5 & 5,4 & 12,6 & 10,3 \\
\hline$R-12 / C u$ & 15,5 & 12,9 & 11,6 & 10,3 & 11,8 & 15,7 & 9,8 & 8,7 & 8,9 & 10,7 & \begin{tabular}{|l|}
14,3 \\
\end{tabular} & 8,4 & 8,6 & 9,0 & 9,7 \\
\hline $\begin{array}{l}R-12 / C u / \\
R a=0,06 \mu m\end{array}$ & 17,4 & 11,9 & 10,1 & 8,2 & 9,2 & 16,4 & 4,6 & 3,7 & 5,3 & 5,5 & 13,3 & 4,1 & 3,2 & 4,1 & 5,1 \\
\hline $\begin{array}{l}R-12 / \mathrm{Cu} / \\
R a=0,51 \mu \mathrm{m}\end{array}$ & 13,1 & 14,0 & 13,5 & 12,9 & 15,1 & 14,9 & 16,1 & 14,7 & 13,3 & 16,9 & 15,6 & 13,7 & 15,2 & 14,9 & 15,2 \\
\hline R-12 / latão &, 5 & 29,4 & 26,1 & 25,0 & 5,5 & 8,0 & \begin{tabular}{|l|}
16,2 \\
\end{tabular} & \begin{tabular}{|l|}
15,6 \\
\end{tabular} & \begin{tabular}{|l|}
13,4 \\
\end{tabular} & 14,7 & 16,7 & 12,8 & 11,8 & 9,9 & 10,7 \\
\hline$R-11$ & 21,4 & 11,2 & 11,8 & 12,2 & 12,5 & 20,1 & 10,4 & \begin{tabular}{|l|}
10,2 \\
\end{tabular} & 11,2 & 11,4 & 20,0 & 10,5 & 10,2 & 11,0 & 12,2 \\
\hline$R-123$ & 18,3 & 11,7 & 11,6 & 12,2 & 14,8 & 19,2 & 9,5 & 11,3 & 20,2 & 12,8 & 14,0 & 13,8 & 12,0 & 20,4 & 22,9 \\
\hline$R-134$ & 17,4 & 11,5 & 11,9 & 12,4 & 12,7 & 20,3 & 11,9 & 12,1 & 13,6 & 13,5 & 20,2 & 12,2 & 11,5 & 12,1 & 12,2 \\
\hline$R-22$ & 8,3 & 8,1 & 7,3 & 6,9 & 5,7 & 8,9 & 8,1 & 7,5 & 7,7 & 6,9 & 18,0 & 9,0 & 7,4 & 8,3 & 7,0 \\
\hline$R-12$ & 17,4 & 18,1 & 16,2 & 15,0 & 16,2 & 16,5 & 11,8 & 10,9 & 10,3 & 12,0 & 15,1 & 9,8 & 9,6 & 9,3 & 10,0 \\
\hline cobre & 16,3 & 11,7 & 11,5 & 11,6 & 11,6 & 16,9 & 10,8 & 10,8 & 12,6 & 10,8 & 17,9 & 11,6 & 10,5 & 11,7 & 12,4 \\
\hline latão & 14,8 & 12,0 & 11,3 & 11,0 & 11,8 & 14,5 & 8,8 & 9,0 & 11,5 & 10,0 & 14,3 & 9,6 & 8,7 & 11,6 & 11,3 \\
\hline aço & 24,8 & 12,2 & 13,1 & 13,8 & 17,2 & 26,0 & 11,5 & 12,0 & 15,9 & 17,2 & 23,8 & 12,1 & 12,0 & 16,5 & 19,1 \\
\hline$p_{r} \approx 0$ & 26,5 & 14,2 & 14,9 & 15,3 & 16,7 & 23,2 & 12,0 & 12,1 & 13,0 & 14,3 & 27,5 & 11,9 & 11,8 & 12,6 & 16,1 \\
\hline$p_{r} \approx 0,023$ & 16,8 & 11,0 & 11,2 & 11,4 & 12,6 & 13,5 & 9,9 & 9,9 & 11,9 & 10,5 & 16,4 & 11,2 & 10,0 & 12,0 & 13,5 \\
\hline$p_{r} \approx 0$ & 13,3 & 11,5 & 11,4 & 11,2 & 11,4 & 11,0 & 10,1 & 9,9 & 12,9 & 9,4 & 11,8 & 11,9 & 10,4 & 13,4 & 14,3 \\
\hline$p_{r} \approx 0,050$ & 15,2 & 13,0 & 11,7 & 11,8 & 10,8 & 15,5 & 11,7 & 11,5 & 13,1 & 11,7 & 13,2 & 10,8 & 11,2 & 13,4 & 11,9 \\
\hline$p_{r} \approx 0,064$ & 15,5 & 12,8 & 11,8 & 11,5 & 12,0 & 14,6 & 9,9 & \begin{tabular}{|l|}
10,2 \\
\end{tabular} & 13,3 & 9,9 & 11,3 & 12,0 & 10,7 & 13,4 & 13,5 \\
\hline$p_{r} \approx 0,092$ & 17,0 & 11,3 & 10,9 & 11,1 & 12,4 & 17,2 & 9,7 & 10,1 & 14,1 & 11,0 & 14,3 & 11,3 & 10,5 & 14,0 & 14,8 \\
\hline & 19,3 & 10,5 & 10,6 & 11,4 & 12,8 & 21,0 & 9,7 & 10,4 & 15,2 & 12,2 & 18,0 & 10,9 & 10,4 & 14,7 & 15,5 \\
\hline$p_{r} \approx 0,150$ & 6,1 & 7,0 & 6,7 & 6,5 & 5,2 & 7,0 & 7,4 & 7,1 & 7,0 & 6,5 & 19,4 & 8,5 & 6,9 & 8,6 & 6,6 \\
\hline$p_{r} \approx 0,180$ & 13,3 & 10,5 & 10,5 & 10,3 & 10,6 & 15,6 & 9,6 & 9,4 & 9,1 & 10,5 & 20,7 & 9,8 & 8,8 & 8,8 & 9,0 \\
\hline$p_{r} \approx 0,200$ & 17,2 & 13,3 & 13,7 & 13,6 & 13,7 & 21,1 & 12,1 & 11,6 & 10,8 & 13,9 & \begin{tabular}{|l|}
25,4 \\
\end{tabular} & 11,4 & 10,1 & 8,4 & 9,7 \\
\hline$p_{r} \approx 0,260$ & 19,5 & 15,9 & 16,0 & 14,8 & 15,2 & 28,4 & 14,1 & 13,5 & 14,4 & 15,8 & 27,0 & 12,1 & 10,4 & 9,6 & 11,2 \\
\hline Total & 17,1 & 11,9 & 11,7 & 11,8 & 12,4 & 17,5 & 10,4 & 10,5 & 12,8 & 11,5 & 17,8 & 11,2 & 10,3 & 12,3 & 13,1 \\
\hline
\end{tabular}

